


kefi C. DU M E R'I L'S, DOCTORS UND PROFESSORS AN DER MEDICINISCHEN SCILLE
ZU PARIS,

\section{INALYTISCHE ZOOLOGIE.}

AUS DEM FRANZÖSISCHEN, MIT ZUS Z̈TZEN

$\operatorname{VON}$

L. F. F R O R I E P,

TROFESSOR ZU HALLE.

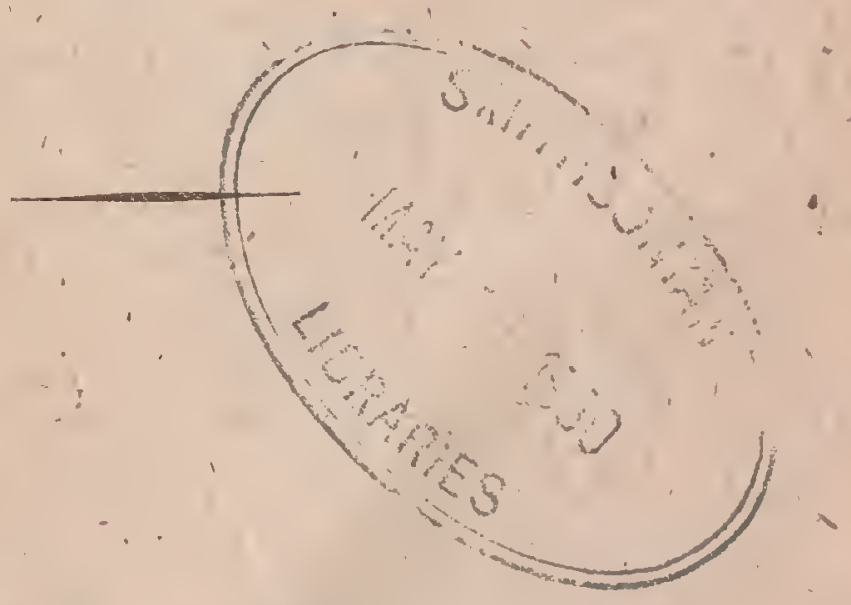

Parva $\int e d a p t a$.

\section{W E I M A R}

IN VERIAGIE DES LANDES-INDUSTRIE-COMPTOIRS 1806. 

 \\ crnofal Mil.}

\section{Vorrede.}

Das Werk, wovon ich hier dem Publiko eine deutche Bearbcitung übergebe, ift erft zu Anfange diefes Jahrs zu Paris unter folgendem, ausführlichen Titel erfchienen: Zoologie analytique, ou méthode naturellé de Claffification: des animaux rendue plus facile a l'aide de tableaux Jyrioptiques; par A. Conlt. Dumeril D. et Profeffeur a l'ecole de médecine à Paris etc.

Gleich bey der erften Durchlicht des Buches gefiel mir die Einrichtung deflelben fo fehr, es fchien mir fowohl zur Grundlage hey Vor]efungen über Zoographie als auch als. Hälfsmittel für Anfänger - um fich in dem fo Cehr fchwierigen Beftimmen der Thiére fortzuhelfen - fo zweckmäfsig, dals ich mich entfchlofs eine deütche Ausgabe davon zu veranftalten. Die genauere Bekanntchaft, die ich während meinex Arbeit felbft nnd bey meinen diesjährigen Vorlefungen, (wo ich die einzèn erfcheinenden Bogen gleich als Leitfaden benutzte) nit dem Werke machen'mufste, haben dio günftige Meinung', welche ich von ihm hegte, eher verftärkt als vermindert, fo dafs ich hoffe, es werde anch das dabey intereflirte Publikum, wenn es díes Buch genauer kennen lernt, mein Unternehmen nicht milsbilligen. - 'Dem was ich dem Werke hier voranzufchicken für nöthig finde, er]aube ich mir nur das für uns Wefentliche von dem, was der Verfaffer in feinex von mir weggelaffenen Vorrede fagt, heyzufügen.

Die Methode, die der Vf. (welcherdas Glick hatte, bey feiner Arbeit alle Gegenftände nach der $N$ atur befchreiben und vergteichen zu können) befolgt hat, und die er die analytifche nernt, ift in der Botanik fchon mehreremale -mit Nutzen gebraucht worden, z. B. in der Botanographie belgique von $L$ e $t i$ boudo is, in der Flore francaife von Lamark in der Dispofitio generum plantarum Europre von Batfch und wohl in andern 
Werken, die ich nicht kenne. Auch in der Zoologie hat man diefe Methode wohl vcrficht z. B. in Brunich fundanenta entomologiae, abex in dem Umfange und mit dem Glizck als fre hier von dem Verfaffer angewendet ift, war es bisher nicht gefchehon.

Es ift bey diefer Analyfis nicht immer der Charakter dex Claffe, Ordńung und Gattung von einem und demfelben Theile hergenommen; dies ift bey den Pflanzen lehr gut, bey den Thieren nicht wohl thunlich. Man ṇuls aber darum nicht glauben, dafs die Charaktere, welche von fcheinbai unwichtigeren Theilen hergenommen find, deswegen eincn geringcren Werth hätlen. Die geringften Modifikationen äufserer Theile ż. B. der Bewegnngsorgane eines Thieres find aufs innigfte mit der inneren Organifation, Lebensart u. f. w. verknüplt! So fcheint es auf dem erften Blick fehr gleichgültig zu feyn, ob der Schwanz einer Eidechfe rund oder platt ift: man wird aber aufhören dies fiir unwefentlich zu halten, 'wchn man bedenkt, dafs die Eidechlen mit zufammengedrïckiem, plattem Schwanze beftändig im Waffer und in feuchten Orien leben, gut fchwimmen, ihre Beute leicht, exhafchen, daher gröfser und ftärker werden können als die mit rundem Schwanze, welche aile diefe Eigcnfchaften nicht haben. Wenn man bey dor Charakteriftick immer un auf die Eigenthümlichkeit eines Orgàns fieht; fo ift es fehr fchwer oft die einzelnen Gattungen z.u unterfcheiden und man ift gezwungen, fich faft ängftich. nach den allergeringften Únterfchieden um zu fehen, dahingegen man, wenn man auch auf mehrere anderé Dinge Rücklicht nimmt, die weit auffallenderen Unterfchiede hervorheben kann. Sieht der Entonologé z. B. blos auf die Frefswerkzeuge, wie wenig verfchieden find dann die Gattungen bronte, trichius, bruchus, die doch in andern Rückfichten fehr von einander abw cichen.

Vorzinglich brauchhar ift das Buch um danach Thiere, die man nieht kennt, der' Gattung nach zu beftímmen. 'Will man z. B. gern wiflen zu welcher Gattung der fo genannte $\mathbb{Z} a n$. der oder Sandart gehört, fo verfährt er folgcndermafsen. Man weifs durch die Berückfichtigung der crften Tabelle, dafs dex 
Zander als ein rückgrathiges Thier, ohne Lungen aber mit Riemen zu der Klafje der.Fifche gehört; die allgemeine Tabelle diefer Klaffe pag. 96 zeigt, dals es ein Knochenfijch mit Kiemenàeckel und Kiemenhaut ift, dafs er alfo zur Ordnung der Holobranchion gehört; diefe Ordnung (Tábelle p. I10) zerfällt nach: der Stellung der Floflempaare in vicr Unterordnungen und der Fifch, den man unterfucht, ift ein fogenanntér Briffflofjer; Nach der 74 Tabelle pag. II 8 hilden diejenigen Eruftfloffer, die, wie der Zander, einen an der Seite zufammengedrückten Körper und einen gezähnelten oder ğeftachelten Kicmendeckel haben, die Familie der Acanthopoinen: diefe fucht man auf! Vergleicht man nun noch einmal den Zaríler mit den auf der 85 Tabelle p. 132 angegebenen Gegenfätzen, lo fieht man fchion aus dem Kiemendeckel, der zugleich geftachèlt und gezähnelt ift, und aus der doppelten Riickenflofje, dafs der' 'Zander zu der Gattung Barfch (percə) gehört. Hier hat man allo 6 Tabellen zu vergoleichen úm die Gattung zu beftimmen, es giebt aber Gattungen, zu deren 'Befimmung man nur zwey Tabellen nachzufehè braucht.

Allein obgleich dás Werk für Anfänger' ganz vorzüglich branchbar ift, fo werden doch fclbft diejenigen Naturforfcher, die fich mit der Naturgefchichte der Thiere fchon lange beCchäftigt haben und mit ihrem Gegenftande vertraut gewor-; den find, "dás Broch nicht unhefriedigt aus der Hand legen. Sie finden darin dic neueften Fortlchritte, die die Franzoleri in der Kenntnifs der Thiere gemacht haben, fo angegeben, dafs auch die ganz nequerdings erft entdeckten oder békanntgewordenèn Thiergattungen z. E. Wombat, Beuteldachs p. If, Phaskotom p. 19, Vielfoffer p; 149, Pneumoderm p. 159 u. f. w. hiex fchon aufgeführt find und zugleich ftoffon fie oft auf die intereffanteften nèuen Beinerkungen über den ïnern Bau mancher Thiere, wo ichnur z. B. auf S. 2I. 95. III. I6I. verweifen will.

Der erfte Entwurf des, von dem Vf. in feinem Buche analytifch bchandelten; Sylteins findet fich zu Ende des erften Bandes der leçons d'anatomie comparée de Curvier récueillies par Dumeril. - Nach und nach wandte Dumexil feine analytifche Methode auf alle Claffen an, indem er für jede 
dic Arbeisender ncueften Naturforfcher zum Grunde legte. Die Süngthiere find nach Cuviers, und Geoffroys Arbeiten alugetheilt, mit einigen Modificationen von dem VF.; bey den Cetacen ift La ce pedes neueftes Werk berick fichtigt. - In der Claffe der Vögel ilt $C$ uniers tableau clemontaire d'hift. nat. des animaux befolgt; die Veränderungen, die der Vf. in der Anordnung der Gattungen vorgenommen hat, haben blos den $Z$ weck die Charaktere derfelben beffer hevauszuheben. Die Reptilien find nach Al. Brongniarts Vorfchlage in vier Hauptordnungen agetheilt, doch find auch die Arbeiten von Labrenti, Schneider, Lacepede, Daudin, Latreille u. I. w. henutzt und diefer Theil überhaupt vollftündiger als. bisher behandelt. In Hinficht auf die zweyfüfsigen Reptilien aber fcheint der Vf. doch nicht den beften Weg eingefchlagen zu haben. - Die Fifche find ganz nach'Lace pede bearbeiter, nur ift diele Clafle, wo Conft alle Lacepedifchen Gattungen beybchalton find, hier in eine ungezwrincenere Anordnung gchracht. - Die Mollusken lind ganz nach $C_{u}$ viers Arbeiten und Anordnungen abgetheilt.' Da der VF. nur die Thiere und nicht die Conchylien zum Gegenftand feiner Bearbeitung gewählt hat, fo hat er von Lanarks Arbeitẹn wenig Gebrauch machen kümen. Doch muls man fich wundern, warum Poli nicht mehr zu Rathe gezogen, ift. Sollte z. B. nicht die arca auf der rob Tabelle aufgeführt feyn, da Pali eine fo Cchöne Zergliedrung 'von ihr geliefert hat? Ueberhaupt fcheint mir die Idee des Verfáffers ( $\mathrm{p}$. I $7 \mathrm{I}$ ), die Conchylien gar nicht zu berückfichtigen, keinesweges zu billigen. If t es auch wahr, dafs main bisher manchmal den Conchylien zu viel Auf. merkfamkeit gewidmet hat, fo mufs man fie jetzt.auch nicht ganz veráchten wolleh!. Kann man nicht oft einen bedeutenden Schlufs rom Aeufsern aufs Innere machen? Ift nicht eine eigenthimliche Bildung der Schaale meiftens mit einer eignen Organifation des Thiors verbunden? - Diefe und andere Rübkfichten haben'mich beftimmt, die hier von dem Vf. übriggelaffene Lïcke durch einen. Auszug des Lamarkfchen Syftêne des animaux fäns vertebres, (welches in Beziehung auf Conchyliologie wohl das befte ift, was wir haben) anszuful- 
Ien. Diefor Auszug, der auf etwa zwey Bogen nächftens erfcheinen foll und als ein Supplement zu diefer Zoologie angefehen werden kann, wird zugleich alle diejenigen neuen Conchyliengattungen enthalten, welche in den Annales du mufeum national d'hiftoire natsirelle bisjetzt bekannt gemacht find.

Die'Wümer find überhaupt noch wenig bekannt, dach find die bekannteren hier, nach Cuvier und Lamark, anf eine fehr leicht zu überfehende Weife zufammengeftellt. Die Cruftaceen find durchaus nach Latreille's und Lamark's Arbeiten behandelt. - Die Infekten aber find nach einem ganz neuen, dem Vf. cignen, Syfteme aufgefübxt und der Entomologifche: Theil ift ohnftreitig in dem ganzen Werke am befton bearbeitet, da. Du neril fich über zwölf Jahre befonders Heifsig mit den Infekien befchaftigt und eine der gröfsten Sammlungen über diele Claffe zufammengebracht hat., - Die Claflé der Zoophyten ift ebenfalls nach den $\mathrm{Ab}$ theilungen der geachtetften Naturforfcher bearbeitet; ganz befonders liegt ihr auch Lamark's Syftême des animaux fans vertébres zum Grunde. - Die fchwächfte Parthie ift wohl die, die von den Eingeveide - Wiïmern handelt und dies ift bey der Unkenutnifs der Franzofen in der deufchen Literatur auch fehr bégrciflich. Hätte dex Vf. die neuern vortrefflichen Arbeiten von $R$ udolphi, Zeder i. C. W. gekannt, fo 'würde diefer' Theil wohl ganz anders ausgefallen feyn. Ueberhaupt if man aber mit den Eingeweidewürmern in dem Falle, dafs man mit einer allgemeinern Kenntnifs derfelben gar nicht weit reicht, fondern, wenn man fie kennen. lernen will, gezwungen ift, fich gleich in détails einzulaffen. Man wird allo ohnehin bald feine Zuflucht zu den Werken obenerwähńter Männer nehmen müllen.

Was nun aber ins befondere die gegenwärtige deutfche Ueberfetzung ánlangt, fo habe ich gefucht ihr dadurch einige Vorzïge vor dem Originale zu geben, dals ich bey den verCchiedenen charakterifirten Gattungen immer eine Art (Ipecies) als Beylpiel genannt habe. Dies hat zwar bey ganz neis entdeckien Gattungen, keinen, aber bey, aus bekannten Arten, neu zufanmen geftellter Gattungen einen nicht unbedeutenden 
Werth. Wer z. R. das Original braucht, weifs nicht, wenh er mancheilnm neue Gattungen und Namen liefst und charakterifirt findet, ob fie aus neuentdeckten Arten gebildet, alfo ganz neu, oder aus alten hekannten Arten neu zufammengeftelit find. Durch meinen Zufatz lieht er dies im-erften Augenblick, da ich, wo.ich konnte, die bekannten Arten nach der Izten von $G$ mel in heforgten Ausgabe des Linneifchen Naturfyftems citirt liabe. So fteht z. B. bey cheiromys z. B. Sciurus madagascarienfis, bey Phalacrocorax z. B. Pelecanus carbo L. u. f. w. Diefe Zufätze waren oft fchwieriger, als fie manchem fcheinen mögrn, do fie genaue Verglëichungen und den. Gebranch mancher in Deutfchland eben nicht häufigen Werke erforderten; weswegen ich auch bey einem allenfalfigen Irrthume um Entfchuldigung bitte. Wer das Original forgfältig mit diefer Ausgabe vergleichen kann, wird auch hie und da einen Irrthim des Vf. berichtigt finden ohne dafs es befonders angemerkt wäre.

Von Vielen wérden wohl die neuen Namen der Familien getadelt und gemifsbilliget werden und es ift auch nicht zu Jeugnen, dafs manche von ihnen fehr hart klingen. DerVf. Jegt auch auf fie keinen befondern Werth, keinen andern als dea der Kürze, und den muls man doch auch gelten laffën; denn ift es nicht kürzer den Ausdruck Adelobranchien zu brauchen als zu Cagen: die zwerte Familie der dritten Ordinung der Klafje der Mollusken? ift das Wort Stenopteren nicht küuzer als: die zwölfte Familie, der zweyten Unterordnung der erften Ordnung der Klafje der Infekten? Wenn an manchen Namen die deutfchen Endungen hart klingen, fo ift das mehr Fehler von mir als ron dem Vf; allein wer fich die, Müüe geben will, folche Namengebungen felbft zu verfuchen, wird finden dafs auch hier das Tadeln etwas leichter ift als das beffer machen.

Halle arn i 8 . Sept.

Froriep. x.806. 


\section{ANALYTISCHE ZOOLOGIE.}




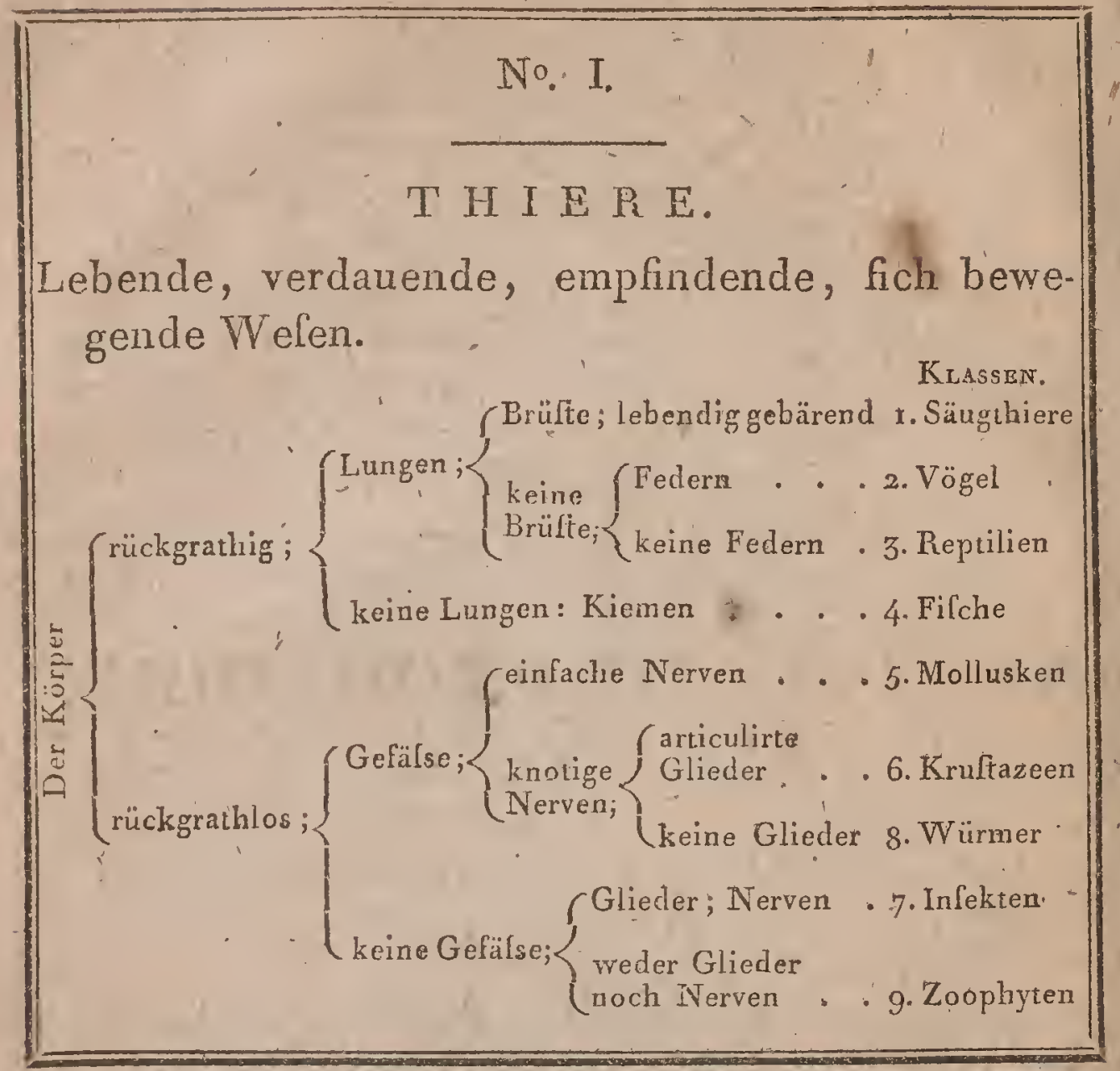

\section{BEMERKUNGEN ZUR I. TABELLE.}

Lebend ift ein Welen, wenn es, vermittellt belonderer Organe, èine Folge von Verrichrungen bewerkftelligt, den beftändigen (äufseren) Naturkräften entgegenwirkt, hie verändert oder modificirt, wo andere Körper diefen Kräften unterworfen find und daher auch unorganifch oder todt go: nannt werden.

Ferdauen heilst, Fremde Subltanzen in eine Höle des Körpers aufnehmen, und lie zur völligen Aufnahme in die eigentliche Körpermafle vorbereiten.

Enzpfnden heifst, Eindrücke durch die Sinnes-VVerkzeuge, welche die Verbindung. mit der Aufsenwelt vermitteln, empfangen Alle Thiere Icheinen die Gegenwart (äufserer). Körper durch die Berührung zu emplinden; aber meiftens verbindet der Taftefinn lich noch mit dem Gelchmack, dem Geruch, lem Gelicht und dem Gehör.

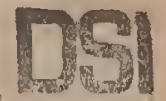


Sich bewegen ift hier in dem Sinn, willkürlich, mit, dem ganzen Körper oder einzelnen Theilen, den Ort zu veränderr,, genommen.

Die Vermögen, zu verdauen, zu empfinden und fich zu bewegen, finden fich nie in einer Pflanze zugleich vereinigt.

Dur Rückgrathift die Säule, welche vorn immer mit dem Kopfe endigt, hinten meiftens in einen Schwamz übergeht. Die Knochen, woraus er befteht, bewegen fich an einander und find lo ausgehöhlt, dafs fie einen feften Kanal bilden, in welchem das Rückenmark liegr, was eine Fortletzung des in einer Höle des Kopfes enthaleven Gehirns ift.

Lungen find zum Relpirationsgefchäft in der Juft beftimmt. Gawöbnlich find es Säcke oder blafige fchrvammige Malfen, (auf deren Wänden'fich die Blutgefälse zerälteln, ) in welche die Luft durch eine fogenannte Luftröhre eindringt, woran der obere Theil der Larynx und die untere Theilung die Bronchien geñannt vird.

Kiemen find die Lungen der im Waffer lebenden Thiere. Sie beltehen aus Blattern, die firls wieder in kleinere Blätter theilen, (auf wêlchen fich die Blutgefäfse verzweigen,) lo dals fie dem Waffer, was durch die Höle, worị die'Kiemen liegen, getrieben wird, die grölste Oberläche darbieten.

Unter Gefäfsen werden. hier die Canäle zự Circulation des rothen oder weifsen Blutes verftanden. Alle T'hiere, wo fich diefe Gefälse finden, haben auch ein Herz d. h. ein Organ, "wodurch das Blut in die Gefalse getrieben, wird.

Die Nerven fcheinen das Leben aller Theile des Körpers zu vermitm teln und lo wohl die Empfindung als den Willen zu leiten und fortzu* pllanzen; einfach find die Nerven, wenn die weilsen Fäden fich mehroder weniger gerade zu einem dicken Ganglion oder Auftreibung begeben, die ïber dem Munde liegt und die Stelle des Hirns verfiebt; in Gegentheil nennt man fie knotige Nerven, wenn fie eine Reihe von Gauglien bildein, die faft 'von derfelben Dicke find wie das Hirn, aber unter den Eingeweiden liegen.

Wegen der übrigen Dinge fehe man die allgemeinen Tabellen jeder einzelnen Clafle:

Diefe Tabelle hat dem Anfchein nach mehr Schwierigkeiten als die folgenden, weil die dalelbft angegebone Charakteriftik von den innerm Theilen genommen ift, derẹn Beobachtung nicht ganzleicht, ift; allein derjetzige Zultand der Zoologie lälst dies nicht anders zu. Eine fyftematilche Ueberficht der. Thiete erfordert, dafs.man die wichtigften Organe kennen lerne, weil an diefe fehr viele Veränderungen der Form und der Lebensart gebunden find; und hiedurch werden doch die Thiere am natüfliellften vereinigt. - Uebrigens wird 'mán, durch die Beobachtung, léhe bald in den Stand geletzt, die Klafle zu beftimmen, zu welcher ein Thier gehört, ohne yafs man gerade nörhig hat, anatomifche Unrerfuchungen anzuftellen; obgleich der wahre Naturforlcher zoै ihnen allein feine ZuAucht nehmer wird, wenn er in der Claflification auf Schwierigkeiten ftöfst. 
Säugthiere überhaupt.

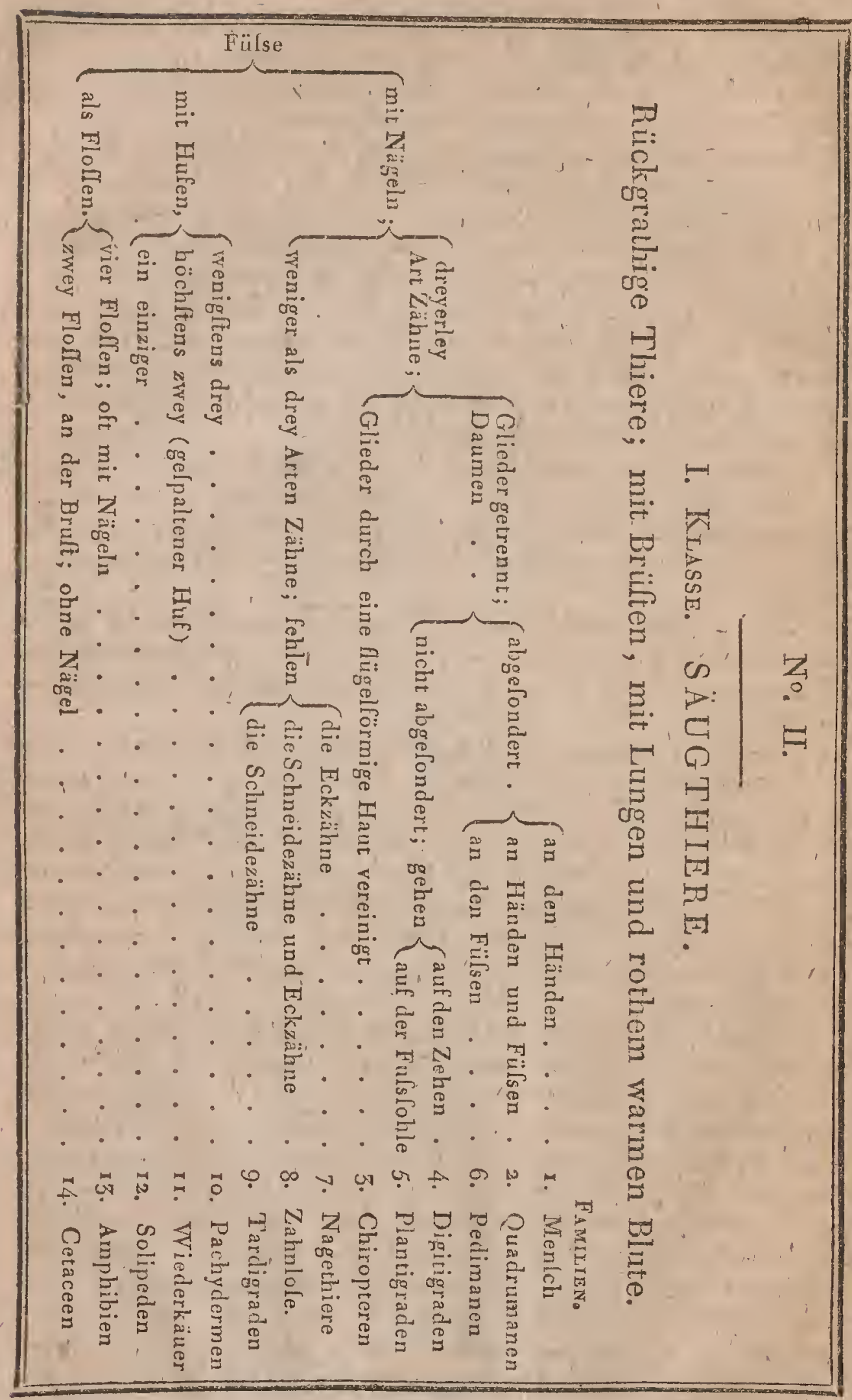




\section{BEMERKUNGEN ZUR II. TABELLE.}

Die Sürtgithiere (Mammalia) werden alle, wenn fie eben geboren find, mit'Milch gefäugt, die in den Brïften der Weibchen abgefondert wird. Die Zahl der Brüfte variirt zwilchen zwey und zwölf; fie fitzen an der Bruft oder an dem Bauche; auch bey den Männchen aller Säugthierarten finden fich Spuren von Säugwarzen: nur bey, drey Arten, die einftweilen in die Familie der Zahnlolen gebracht find, hat man fie noch nicht entdeckt.

Die Wärme des Blutes Icheint von der Art der Circulation und ReIpiratiou bey den Säugthieren abzuhängen. Die ganze Mafle ihres B́lutes wird (nach und nach) von dem Herzen durch die Lungen getrieben, und der Einwirkung der'Luft ausgeletzt; ihre Relpiration wird (im Leben) mie ganz unterbrochen. Herz und Lungen liegen' bey allen Säugthieren ohne Ausnahme in der Brufthöle und find von den übrigen Eingewaiden durch eine fleifchige Scheidewand, das Zwvergfell, gecreunt.

Nägel und Hufe find hornartige Ueberzïge zum Schutz des äulserIten Endes der Zehen oder Finger; der Nagel ift Ichneidend, oft lpitz oder glatt und umlchlielst niemals das letzte Zehenglied ganz; der Hu aber ift abgerundet und bedeckt das Zehenglied ganz und gar,

Der Daumen ift derjenige der fünt Finger, welcher (dem Körper am nächlten) nach innen fteht, wenn die Hand - oder Fufsfäche auf den Boden geftütat ift. Wenv das Thier ihn für fich allein bevegen, von den übrigen Fingern entfernen oder nähern kann: fo nemnt man ihn abgefondert. Man findet diefe Bildung auch noch bey den meiften Chiropteren und einigen Nagethieren. Eine Art von Quadrumanen und etliche Pedimanen haben den Daumen fehr kurz und nur als einen Höcker unter der Haut. Floffer find hier kurze, platte ruderförnige Glied̉er, wovon die Finger an einander liegend und bis an ihre Spitze von der Haut bedeckt find.

Man erkennt ein Säugthier für einen Ferlengeher (Plautigrada), wenn die ganze untere Fläche desFulses, von derFerfe bis zu den Zehen, harlos und von einer lo fchwieligen Haut, wie bey dem Menfchen, bedeckt ift.

Die Schneidezïhne dienen zum Zerscheiden, fitzen vorn-inı Munde und find meift leharf zugelfhliffè. Die Eck -, oder Hunds - oder Augeruzühne find meift in èinen langen fp̣izen Kegel verlätgert und dienen zum Zerreifsen. Die Backenzülune fitzen hịten und dienen zum Zermalmen der Nahrungsmittel. Ihre Form ift lehr verlchieden, bey den fleifchfrelfenden Thieren find lie mit mehreren fchneidenden fHervorragungen, bey den Pflanzenfreflenden find lie platt und gefurcht oder mit Liumpfen Höckèrn verlehen. 


\section{No. III.}

\section{FAMILIE. BIMANEN.}

Säugthiere mit getrennten, Nägel tragenden, Glièdern; wo blos an den Händen der Daumen den übrigen Fingern entgegengeletzt werden kann; mit allen drey Arten von Zähnen.

Der Menfcle.

\section{BEMEPKUNGEN ZUR III. TABELLE.}

Die Familie der Bimaner oder der Säugthiere mit zwey Händen (an den Bruftgliedern) begreift nur die Gattung Menfch. Er ilt das erfte unter den belebsen Welen, lo wohl durch Vollkommenheit leiner Organe, als durch leine geiftigen Fähigkeiten fo wie durch die Sprache. Die allgemeine Bildung leines Körpers nähert ihn'aber den Säugthieren, von welchen er alles Wefentlirhe hat. Es werden hier nur einige Punkte Ceiner Naturgelchichte angefïhrt, um in dem Werke keine Lücke zu laffen.

Die Form der Hände des Menlchen ift eigenthünlich; der Daumen ift lang und kann den übrigen Fingern entgegengeletzt werden, was man bey den zwey folgenden Familien nicht fo wahr nimmt. Der Menlch ift allein unter den Säugthieren fähig, fiç blos auf der Fläche der Hinterfülse aufrecht zu halten; bey ihm allein lieben auch die in der, mit hervorragendem Kinne verlehenen, Kinnlade fitzenden Zäline ganz vertika!,

Der Meuích zeichnet fich auch durch eine allgemeine Schwäche feiner Organe, in der erlten Periode des Lebens gleich nach cler Geburt, und durch die lange Zeit aus, die zu leiner ertien phyfilchen Erziehung erforderlich ift. Kein anderes Säugthier bedarf lo lange wie er der Sorgfalt 'und des Schutzes feiner, Aéltern und ies fcheint, dals yon diefen nothwendigen beftändigen $\Lambda$ ffmerkfamkeiten, die das Kind immer verlangt und bedarf, dafs bievon auch der gefellfchaftliche Verein und vorzüglich die Ehe begründet verde, welche natürlich gleiche Dauer mit dem Leben beyder Gatten haben muls.

Der Menfch allein bat unter den Säugthieren den Vorzug, artikulirte Töne hervorgubringen, lie mit einander zu verbinden, um feine Ideen, feine Wünfche, feine Abneigung, Ceine Freude und feinen Schmerz ause zudrücken. 
Das Vermögen, fich yergangener Dinge zu erinnern, Ceine Gedanken zulammenzuftellen, etwas zu vergleichen, zu beurtheilen, gewifle Umftände durch Erfahrung geleitet vorherzulehen, 〔eine Gefühle andern mitzutheilen, Ceine' erften Empfindungen zu vervollkommnen - Dies Vermögen hat nur dor Menfch." Nur er hat ein fo vollkommnes Gedächtnils; nur er ift mit vergleichendem Scharflinn, Urtheilskraft, nur er mit eigentlicher Intelligenz begabt.

Das menlchliche Gefchlecht (genus und Ipecies), was utter allen Climaten der Erde, die Pole ausgenommen, lebt, zeigt in der allgemeinen Mafle der Individuen in gewiflen Gegenden einige Verfchicdenbeiten der Hautfarbe, des Haarwuchles und des Hartes, der Kopf-und Gefichtsform und der ganzen Statur des Körpers. Bey der Beobachtung der conftantelten Verfchiedenheiten diefer Art hat man geglaubt, fie unter lechs Racen bringen zu mülfen.

'x. Die kaukafifche oder arabifch-europäifche Race, wovon dio Haut weils, die Haare lang und fchlicht, das Geficht oval, und gerade und die Nafe länglicht ift; bewohnt vorzüglich Europa und einige Theile von Afrika und Alien.

2. Die hyperboreifche (oder Polarrace), mit brauner Haut, fchwatzen Chlichten kurzen Haaren, plattem Gefichtiund Nafe, finclet fich im Norden der alten und neuen Welt, in der Nähe der Polarcirkel, und fcheint eine Milchuug der mongolifchen und kaukafilchen Race zu feyn.

3. Die mongolifche Race, deren Haut rolhbraun oder gelb, Haar Schwarz, Gelicht rund, mit vorftehenden WVangen und ftrahlenartigen. Runzeln um die Augen, Nale kurz und gériückt, der Hirnlchädel kegelförnig verlängert ilt, bewohnt das füdliche Alien, China und die Tartarey.

4. Die amerikanifche Race, mit röthlicher kupfriger Haut, langex, ftarken dunkelbraunen Haaren, mit langem breiten bartolen Gefichte und etwas breitgedrückter $\mathrm{Na}$ a, lebt bolonders im mittäglichen Amerika.

5. Die malaifclue Race, hat gelbbraune Haut, dicke, fchwarze, weiche, leicht gekräufelte Haare, Lchräges fchmales Geficht mit vorftehendem Kinne, eine gevölbte Stirn, dicke vorragende Nale, weiten Mund, wenig vorragende Lippen; diefe Race, die an diekaukafifche und äthio. pifche gränzt, bewohnt die Infeln des fiillen Meers, die Plilippinen, die Molucken und die Halbinlel Malacka.

6. Die äthiopifche Race, mit (chwarzer Haut, mit fchwarzen kurzen kraulen (wolligen) Haaren, runden Geficht, vorltehendem Munde und aufgeworfenen Lippen, - kurzer lehr breiter N'ale, platter Stirn und kleinem Hirnfcbädel, bildet die am beftimmtelten unterfcbiedene Race, die falt eine befondere Art der Gattung ausmacht. 
Säugthiere mit Nägeln.

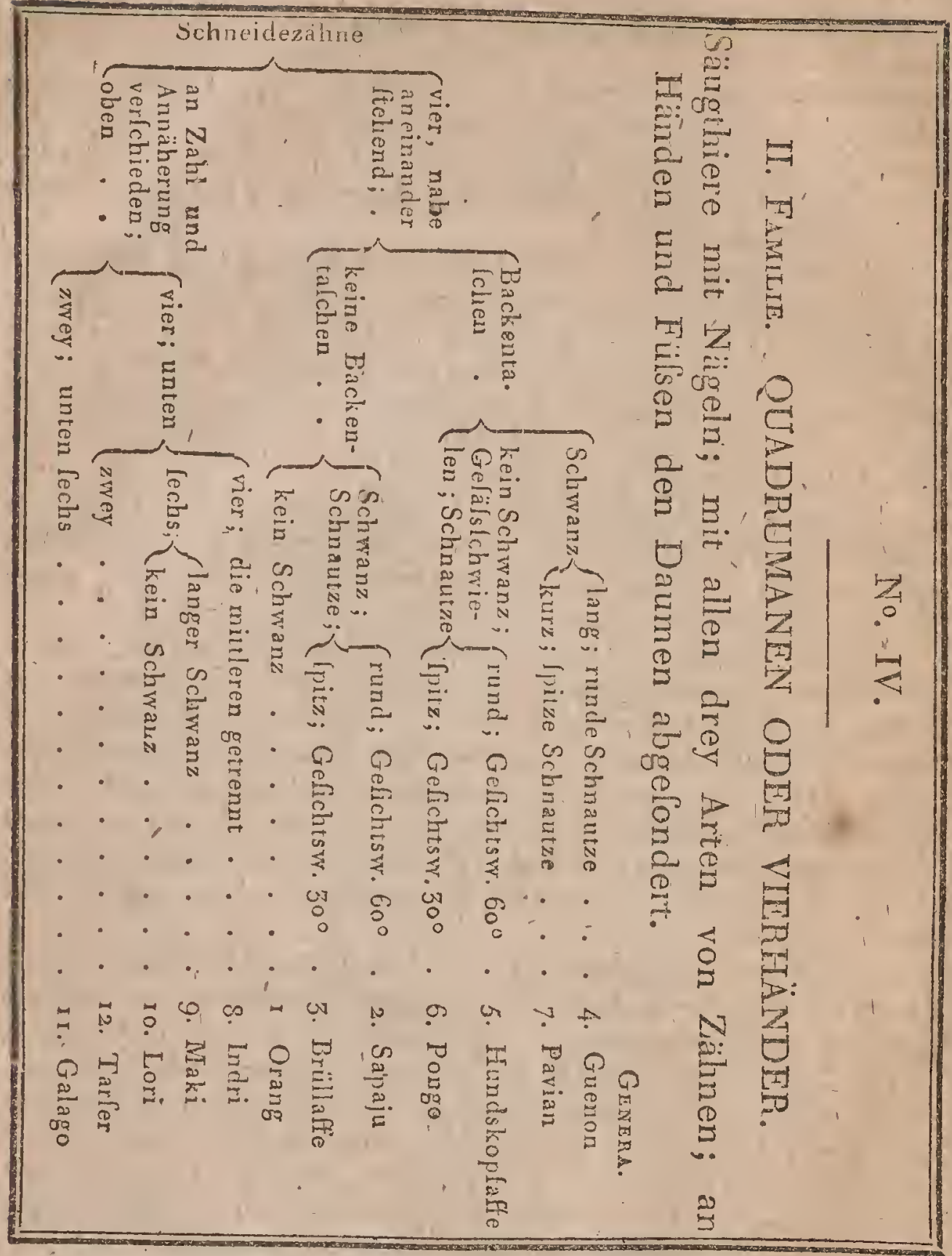

\section{BEMERKUNGEN ZUR TV. TABELLE.}

Der Name Quadrumanen oder Vierhänder wird im Gegenfatze zu eigentlichen Vierfüisern gebrancht.

Diefe Familic vereinigt diejenigen Säugthiere, wo an allen vier Gliedern der Daumen abgefondert ift: fo dals diefe Thiere fehr leicht frey oder vorftehende Körper umfaflen, fich daran feft halten und folglich mit Leichtigkeit klottern können. 
Die Zahl und Stellung der Schreidezähe ift hier zur Eintheilung diefer Fanilie fehr geeignet; die fechs erften Gatungen kagnn man (als dic eine Abtheilung diefer Familie) mit dem gemeinfchafilichem Namen Affen belegen; Lie haben vier an einander fichenóe Schueilezähne in beyden Kinnladen; wahrend die Stellúts diefer Zabre in der andern Abtheilung fehr variirt, dic man Halbaffen nennen könnte..

Backentafoken find häutige Säcke oder Talckon, die fich in den Mund offnen und in welchen das Thier leine Nahrungsmitten aufbewahrt; da', wo fie fich finden, find die Backen, wenn die Tafchen leer find, Cchlaff und hängend.

Gef üfsfluwielen fund nackte Stellen, wo die Haut verdickt und oft gefärbt ilt, worauf das Thier lich beym Sitzen ftützt.

Die Hervonagung, welche die Schnautze vor dern Kopf bildet, kamn durch einen Winkel ausgedrückt werden, der durch awvey gnade Linien gebildet wird, wovon die eine horizontal an der untern Fläche der Gaumendecke länt und durch eine andexe fchräge von der Stirn nach dem hervorragendiften Theil der Schnautze gezogene durchlchnitten wird; die Vereinigung diefer Linien ift der Gefichiswinkel, fon welchem die'ge. ringere Zahl der Grade die grösere Jervorragung der Schnaitze anzeigt.

I, Das genus Orang (pithecus) begreift die Affenarten, die tem Menlchen am nächften kommen; alle fïnf bekannte Arten haben lange Arme" und find Bewohner der alten Welt. Z. B. Sim. fatyrus L. 2. Die Sapajus (callitrix) habep faft die Schnautze der Orangs. Mre Nafenlöçer lteluen von einander entfernt. Man findet fie nur in Amerika; alle haben einen langen Schwanz; die, bey donen diefer Schwanz kein Wickelfchwanz ift, fund von einigen Natutorfchern Sakis und Saguins genannt. Z. B. Sim. paniscus, puhecia, midas. L. 3. Die Drüllaffen (cebus) unterlcheiden fich von denSapajus noch durchibren pyramicialifch crhabenen Kopf und durch fehr grolse Lnterkinnladen. Man ketit uur zwey Arten aus Amerika. 2. B. Sim. Cemiculus. L. 4. Die Guenons (cercopithecus) und alle folgende Affen find Bewohner der alten Welt; dis Nalenlöcher ftehen lehr nahe an einander; einge haben den Schwanz länger, andere kürzer, als den Körper; letztere heilsen auch Meerkatzen. Z. B. Sim. nictitans, cynomolgos.'L. 5. Von den Hilndslioplaffen (cynocephalus) kennt ìnan nur eine Art. Z. B.Sim. inuus. L. b. Der $7^{*}$ ongo (pongo), auch nur eine lpecies, ilt aufder Infel Borneogefunden. 7 . Vor den Pavianen (papio) giebt es lechs Arten. Zs. B. Sin. fphinx. L. o. Indriz. B Lem. -indri L., Lori z. B. Lem, tardigradus und Galago heilsen lateinilch eben fo, und find wie die Maki (lemur) und Tarfer (Tarfius) Bewolnner dar alten Welt. Die meiften haben den Namen : Affen mit Echslchnautzen; fie fcheinen wirklich den natürlichen Uebergang von den Allesfreflenden, d. h. die fich eber fo gut von Fleifch als, von Früchten, nähren, zu den Tleifchfreffenden zu machen, die fich blos von thierifchen Subltanzon nähren und noch das nit ihnea gemein haben, dals fie aucli mehr als «wey Junge zugleich haben. 


\section{No. V.}

III. Famile, CHIROPTÉREN ODER ALIPEDEN. Säugthiere mit allen drey Zähnarten; zwifchen den Füfsen und meiftens zwilchen den (verlängerten) Fingern, häutige Ausbreitungen.

fnicht verlängert; keine obern Schneidezähne; lehr kúrzer'Schwanz. . . . . . . . 1. Galeopitheke

$\left\{\begin{array}{l}\text { fehr verlän- } \\ \text { gert; Nale }\end{array}\right.$ $\left\{\begin{array}{l}\text { mit einem Blatt } \\ \text { oder Häuten be- } \\ \text { letzt; Eckzähne }\end{array}\left\{\begin{array}{l}\text { fon einauder } \\ \text { ftellend - . 5. Rhinolophe } \\ \text { ftehend . . 6. Phylloftom }\end{array}\right.\right.$ $\left\{\begin{array}{l}\text { am Ende } \\ \text { frey . 3. Noctilion } \\ \text { in der } \\ \text { ohne Haut S Schwanz } \\ \text { oder Blatt }\end{array}\right.$ Ooder Blatt; $\left\{\begin{array}{l}\text { Membran } \\ \text { unterwärts }\end{array}\right.$ gebogen-. 4. Fledermaus kein Schwanz . 2. Vampyr

\section{BEMERIUNGEN ZUR V. TABELLE.}

Der Name Chiropteren (chiroptera) bedeutet die Hände in Flügel verwandelt. Dies ift auch bey den meiften wirklich der Fall; aber ihr welenticher Charalkter belteht r. in der Vereinigung aller drey Arten von Zähnen, wodurch fie fich von dem Ratternden Eichhörnchen (polatouche), einem Nagethiere, unterfrheiden; 2. in dem Mangel eines abgelonderten Daumen au den Hinterfülsen, den man bey dem flatternden Beutelthiere bemerkt; 3. in der Ausbreitung der Haut an der Seite des Körpers, wel. che die Vorder - und Hinterfulse verbindet und wodurch das Thier in der Luft:erhalten wird, wenn es die.Fülse von dem Körper entfernt; dies wird durch die Benennung Alipeden, die Fürse als Flügel, ausgerirückt.

Diele "Thiere nähern fich den Quadrumanen durch die Zahl und Vertheilung der Brülte und, durch dẹ bey den meiften abógelonderten Daumen an den Fündea. Sie kommen auch den Plantigradea nabé, fo- 
wohl dałurch, dals fie die Ferfe heym Gehen auf den Boden fützen als durch ihre fchneidenden und fpitzeckigen Backzähne.

r. Die Arien, welche keine verlängerte. Finger haben, fliegen weniger gut, aber fie können defto beller, den Kopf nach oben, klettern; lie erbalten fich nur flatternd durch die Seitenhaut in der Luft wie durch einen Fallchirm. Der Name Galeopitheken (galeopithecus), den man ihnen beylëgt, bedeutet Katzenafte. Sie hinder lich nur auf dén: Mollukilchen Inleln. Z. B. Lemur volans. L.

Bey allen andern Gattungen find die Finger der Vorderfülse aulseroro dentlich lang und, mit Ausnahme der Daumen, in eine haarlole Hant eingelchloflen, deren Feltigkeit fie verltärken. Alle diele Thirre leben gelellig; fie ziehen fich in dunkle Orte zurïck und kommen blos des Nachts zum Vorlchein. Die Weibchen haben gewölulich nur zwey Jumge, die fie an den Brülten hängend mit fich tragen. Alle Arten fallen im Vinter in einen betäubten Ichlafenden Zultand, - Winterlchlaf; beym Klettern haben fie den Kop, nach unten gerichtet.

2. Die Fampyre (Pteropns): find die grölsten bekannten Arten und leben in den warmen Theilen von Afrika und Afen. Z. B. Vespertilio vampyrus $L$.

3. Die Noctilionen oder Nachllöwen lind lo genaunt worden, weil das. Ende des Schwanzes frey und umgebogen und die Schnantze rund und der eines Löwen ähnlich ift; die hieher gehörigen Arten find wenig bekanntmol leben 'nur, in den heifselten Zonen. Z. B. Vespert. leporinus I.

4. Die Fledermüufe (veśpertilio) unterfcheiden fich von -der vorigen Gattung nur dadurch, dals fie den'Schwanz ganz in der Flughaut verborgen und nach unten gefchlagen haben; fe halten lich unter gemäIsigten Himmelsftrichen vorzüglich in Europa auf. Z. B. Vespertilio murinus $L$,

5. und 6. Die Nafenblätter oder ausgebreitete Membranen oberhalboder unterhalb der Nafenlöcher fcheinen beltimmt zu feyn, dem damit verfehenen Thiere eine lebhaftere Empfindung der Gerüche, vidleicht felbl Empfindung von den' in der Atmolphäre fchwimmenden Lö̈rpern zu verfchaffen. Die Rhinolophen (d. h. Blattaafe) z. B. Vespért. ferrum equiHum L. und Phylioftomen (d. h. Blattmaul z. B. Vespert. haftutus L.) haben ihren Namen von dieler Bildung.

Wohl mit Un'recht hat man den Thieren disler Familie einen fechs. ten Sinn zugelchrieben; der Taftion ift bey ihnen, durch die nackron. Flughäute und die vielen unter der Haut weglaufenden Nerven, fo fehr entrickelt, dals höchft wahrlcheinlich die grolse Emplindlichkeit diefer Theile ibnen andere Organe (nämlich Áge ader Nale) erletat, weil fie fich eben fo frey und ficher bevegen könmen, wenn fie a der letztern Osgane auch beraubr find. 


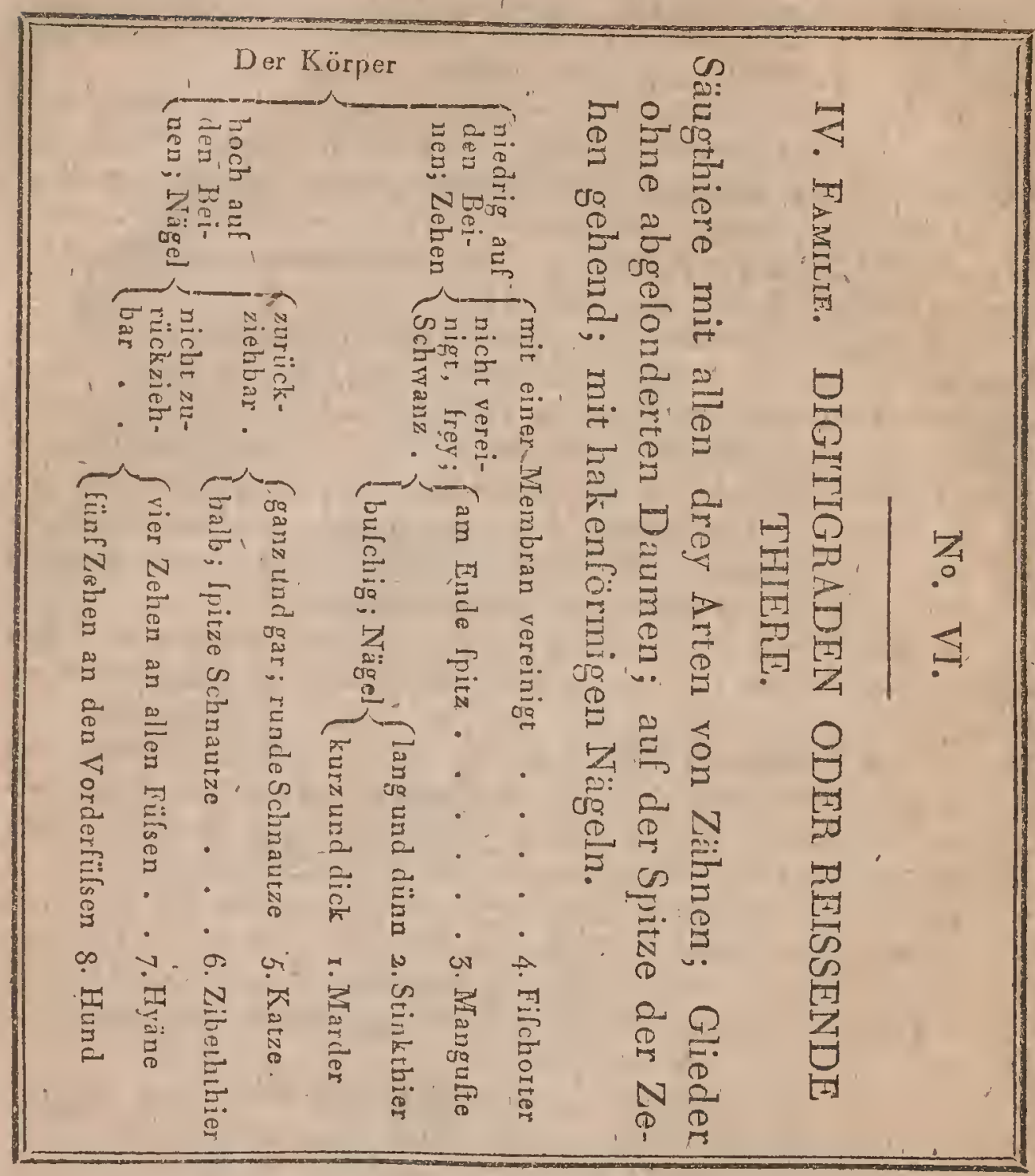

\section{BEMERKUNGEN 'ZUR VI. TABELLE.}

Der Name Digitigraden ärückt das Vermögen aus, auf den Zehen zu gehen, was lehr vielen Thimes eigen ilt; Hier ift das Wort in einem engern Sinne genommen, im Gegenlatze der Plantigraden, Pedimanen und Chiropteren, die ungefähr wie die Säugthiere dieler Familie gebildet find; wovon aber kęine Art auf den Zehenfpitzen geht.

Alle hieher gehörigen Thiere lind fleifchireffend; fie find mit fehr vollkommnen Sinneswerkzeugen varlehen und haben überhaupt eine Bildung, welche die ltarken, Ichnellen und gewandten Bewegungen begür- ftigt, die lie, urn auf den Raub auszugehen, nöthig hatten.

Die eine Abtheilung hat den Körper wenig erhoben; diefe. Find im Ganzen fchwächer; lie 'wenden daher mehr Lift an; fie fchleichen, fo- 
zu Iagen, nur des Nachts hervor und verbergen lich in Löcher unter der Eride.

Die andern haben den Körper hoch auf den Beinen; diefe können fchnell laufen; find färker und kühner. Die meiften haben belonders einen Sinn, entweder das Geficht, das Gehör oder den Geruch, felur entwickelt.

Die Gatrungen, welche die Nägel zurücksiehen oder beym Gehen in die Höhe richten können, können lehr leicht klettern, aber abwärts können lie nur rückwärts herabgleiten. Die andern kơnen nicht kléttern; die meiften graben in die Erde.

I. Die Marder (multela) haben fünf freye Zehen an jedem Fufse; den Körper langgeftreckt, gewölbt; den Schwanz kurz zylindrifch. Sie nähren fich von Eyern und dem Bîtute anderer Thiere. Z. B. mult. martes L.

2. Die Stinkthiere (mephitis) haben ihren Namen von dem ibbeln Geruch, den lie verbreiten; îhr Körper ift hinten dicker, der Schwanz fehr haarig und wie geftutzt. Z. B. Viverra mephitis, putorius L.

3. Die Manguften (ichneumon) haben einen an der Bafis dicken, aber am Ende fpitzen Schwanz, der beynahe fo langr als der Körper ift. In den heifsen Gegenden von Afien und Afrika find fie zu Haule. Z. B. Viverra mungo, ichneumon L.

4. Die Fifchotkern (lutris) haben die fünf Zehen jedes Fulses durch eine Schwimmhaut vereinigt und fcheinen die Camivoren mit den Amphibien nuter den Säugthieren zu verbinden. Die Schnautze if rund und der Schwanz' an der Bafis dick; ihe Geficht ilt frhwach, aber der Geruch fehr fcharf. Sie nübren fich vorzüglich von Fifchen, die fie tauchend aus dem Wafler holen. Z. B. Multela lutris L.

5. Die Katzen (felis) haben die Zunge mit hornartigen rückwärss. gerichteten Stacheln befetzt und dâher rauh wie eine grabe Feile. Einige, z. B. Karakals und Luchfe, haben einen Haarbüfchel an der Spitze des äulsern Ohrs und einen kurzen Schwanz; chie andern haben einen langen Schwanz und das Ende der Ohren nackt. Man theilt fie ein : 'a. in Iolche mit einfärbigem Pel\%, z. B. Puma und Caguar; b. in folche mit geftreiftem Pelz, z. B. Katze, Tiger u. I. w.; c. in die gefleckten, z. B. Leopard, Panther, Unze u. f. w. Diele Gattung ift fehr zahlreich und die Arten derfelben find in der alten und neuen Welt zu Haufe.

6. Die Zibeththiere (civetta), welche mit der Geftalt der Marder, Aie Nägel der Katzen und die Schnautze der Hunde verbinden, haben unter dem After einen Sack oder eine Spalte, worin fich eine riechendo molchusähliche Materic ableizt, Z: B. Viverra civetra, Zibetha L.

7. Die Hyänen (hyaena) find deu Hunden fehr nahe verwandto Thiere, haben aber eine Art von Mähne und den hintern Theil des Rückgraths viel weniger erhaben als denvordern. Z. P. Canis hyaena L.

8. Die Hunde (canis) vereinigen in diefer Gattung zugleich Wolf, Fuchs und viele andere Arten. 
Säugthiere mit Nägeln.

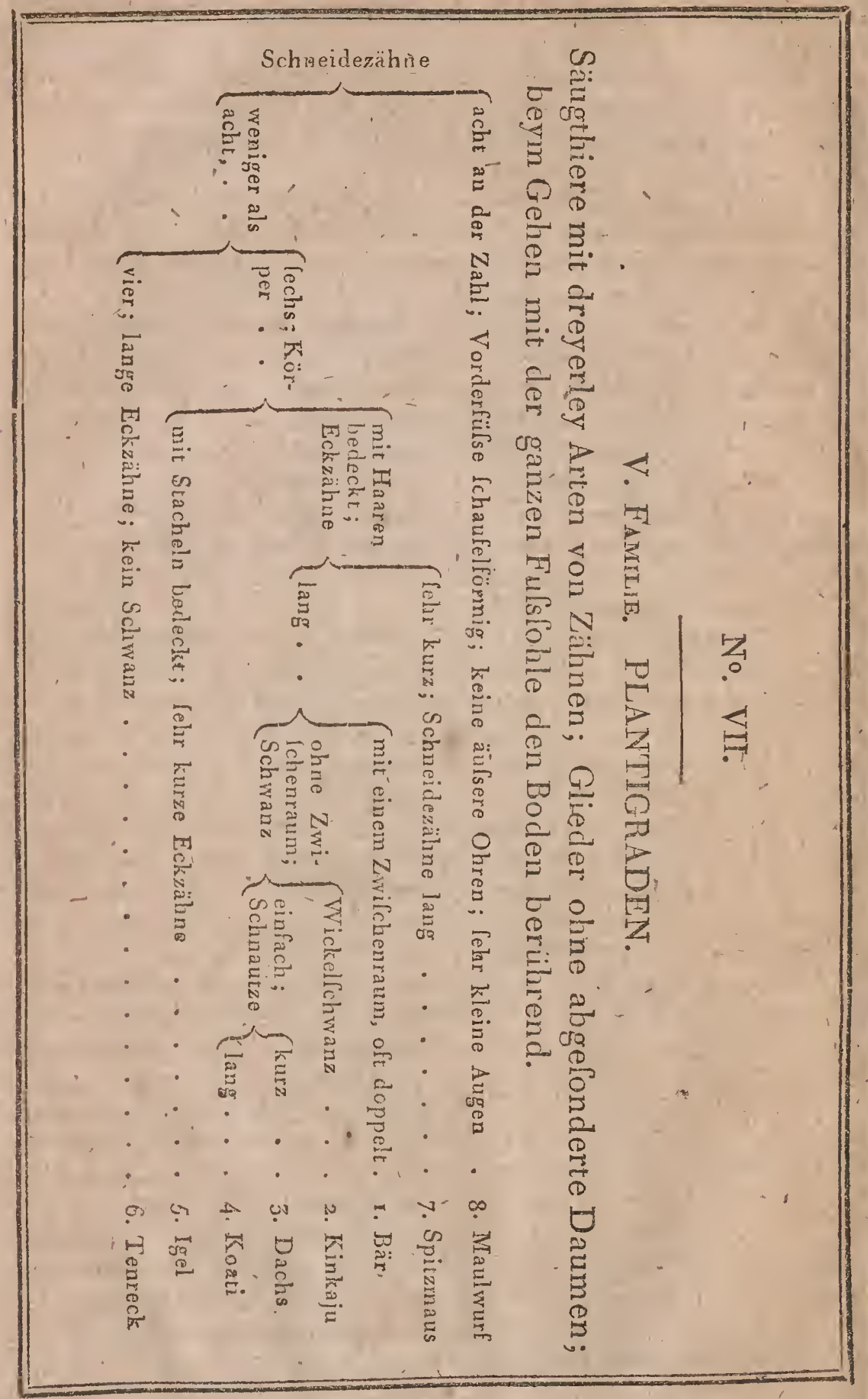




\section{BEMERKUNGEN ZUR VII. TABELLE.}

Die Säugthiere dieler Familie ftützen die ganze Fulslohle der Hinterfüfse beym Gehen auf die Erde; die Form ihrer Vorderfülse ilt in den verfchiedenen Gattungen fehr verfchieden; die hieher gehörigen Thiere find von állen derien Säugthierehn, die keine abgefonderten Daumen haben, die am wenigften Fleifchfreffenden; diemeiften lieben Früchte und fülse Wurzeln. Sie gehen und laufen. Ichlecht; kommen-gewöhnlich blos des Abends bervor; und in kalten Ländern halten fie einige Monate lang eine Art von Winterlchlak.

Die Form und Zahl der Zähne giebs eine leicht zu merkende Abtheilung an.

I. Die Bären (urfus) find an ilıren langen Eckzäbnen lejcht zu erkennen, hinter welchen mañ einen kleinern und dảhinter eine Lücke wahrnimmt. Z. B: Urfus arctos

2. Die Kinkaju (caudivolvulus) find die einzigen Thiere dicfer Familie, welche einen Wickellchwanz haben, der viel länger ift als der Körper; finden fich nur in Amerika. Z. B. Fiverra caudivolvula L.

3. Die Dachfe (raxus) find dem Bär etwas älnlich, aber ihre Eckzähne-ftecen dicht an den Backzähneu. Man vereinigt unter diele Gattung Thiere aus der alten und neuen Welt, z. B: den Vielfrafs, den Packum (Walchbär) u,. .w. Z,B. Urlusmeles L., Viverra mellivora L.

4. Die Koaci (nafua) haben die Nale beweglich und in einen Rüfel verlängert, langen Schwanz; finden lich in Amerika. Z. B. Urfus naía L.

5. Die Igel (Erinaceus europaeus L.) und 6. die Tenreck (fetifer) z. B. Erinaceus letolus L. haben den Körper mit Stacheln oder Borften bedeckt. Wie die Stachellebweine und Echidnas können die Igel fich bey drohender Gefahr zufammen rollen und fo Kopf und Fülse völlig verbergen. Die hiezudieñenden Hautmuskeln laben eine ganz befandere Einrichtung.

7. Die Spitzmäufe (forex) 'haben gewöhnlich die Schnautze über dieUnterkinnlade hinaus verlängert z. B. Sorex fodiens L.;-die Arten, welche die Hinterfülse mit einer Schwimmhaut haben, nennt man Desmaz. Z. B. Sorex mofchatus I. Die meilten dieler Thiere ähneln den Maulwürfen durch ihre Schnautze und Zähne, - den Mäulen aber durch ihre Haar und Fülse.

8. Die Maulwürfe (ta]pa). Da auch einige Spitzmäule, z. B. chryTochloris, ähnliche Tchaufelförmige Vorderfüfse mit lchneidenden Nägrgeln haben: To muls man hier eine belonders genaue Zählung und Betrachtung der Zähne zur Unterlcheidung benutzen. Z. B. Talpa europaea L. 


\section{No. VIII.}

VI.FAMILIE. PEDIMANEN ODER BEUTELTHIERE,

Säugthiere mit Nägeln und den drey Zahnarten; den Daumen an den Hinterfuifsen abgelondert; unter dem Bauche ein Sack oder eine Hautfalte.

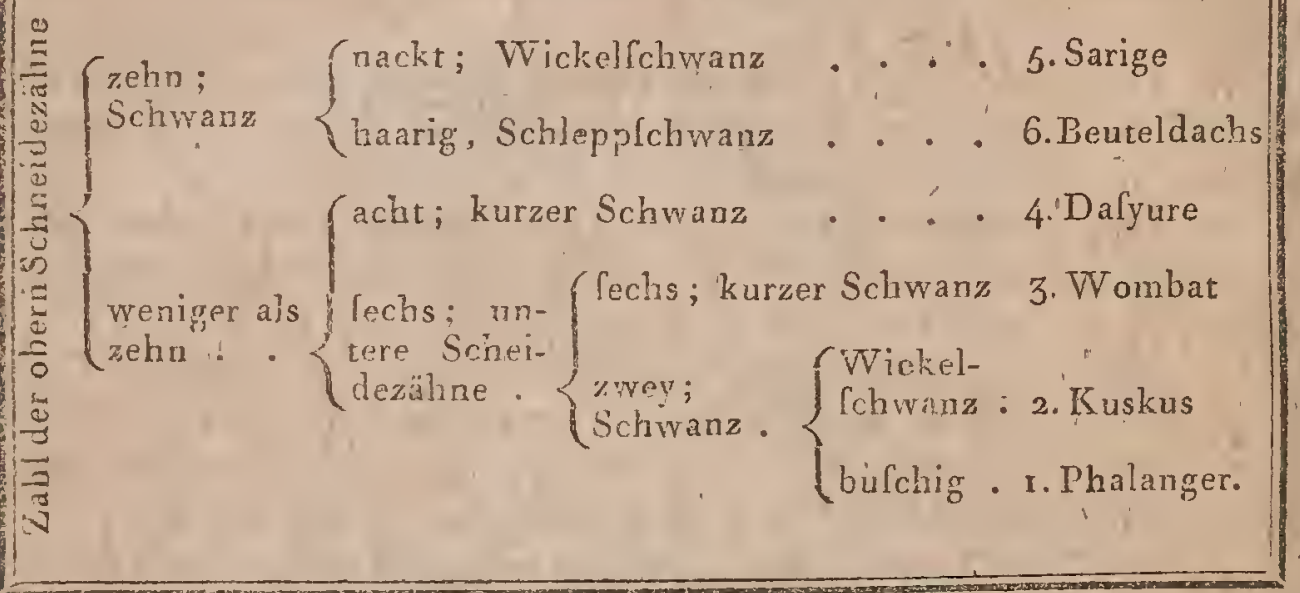

\section{BEMERKUNGEN ZUR VIII. TABELLE.}

Der abgefonderte und nagellofe Damen an den Hinterfülsen hat den Namen jedimanen veranlafst; allein diefe Beftimmung 'palst doch micht auf alle Gattungen, vorzinglich nicht aut den Benteldachs (perameles). Dic zweyre Benennung Bentelliter ift befler, weil fie fich auf ein conftanteres Kennzeichen, auf die Gegenwart eines Beutels oder einer Falte der Bauchhaut, wo fich die Saugwarzen finden, gründet; aber die Kanguruhs und thaskolomen, Thiere der folgenden Ordnung, zeigen diefelbe Bildung. Man muls daher nothwendig die drey Eigenthümlichkeiter zuIammen zur Beftimmung benutzen. aber mit zween derfelben lich beguïgen, wenn man fe vereinigt antrifft.

Die Thiere diefer Familie zeigen eine befoudere Eigenthümlichkeit in den Gemeracionsorganen. Die Weibchen abortiren nämlich, ehe noch die Jungen für fich allein lebenslähig find; aber Iogleich kommen diefe Jungen in den Beuțel unter dem Bauch, wo fie fich an die Sáugwarzen hängen, und daran wie bey dert Chiropteren fo lange bleiben, bis fie gauz ausgelildet find. Alle kommen aus Amprika oder Auftralien; es ift merkwürdig, dals überhaupt die meiften Säugthiere, die Aultralien 
befitat, zu diefer Familie der Beutelthiere gehören. Cuvier hat in den Gypslagera von Montmartre bey Paris auch ein foffiles Skelet eines Beuted. thiers gefunden.

I. Die Phalanger (phalangifta) haben die Glieder 'durch eine Ausbreitung ihrer mit Haar bedeckten Seitenhaut vereinigt, und natuern fick dadurch den fatternden Eichhörnchen aus der Ordnung der Nagethiere, und den Galeopitheken aus der. Familie der Chiropteren; allein die fechs obern und zwey untern Schneidezähne, der frey abgelonderte Daumen an den Baurhgliedern und der Beutel unter dem Leibe unterlcheidet fie deutlich. Man kennt zwey Arten. Z. B. Didelphis volans L.

2. Die Gatiung Kuskus (coescoes), die von Lacepede aufgeftellt ift, unterfcheidet fich von dem Phalanger durb den Mangel der Seitemmembran und durch" den Wickellchwanz; fie findet lich in Indien. Z. B. Dideiphis orientalis $\mathrm{L}$.

3. Der Wombat aus Neuholland ift norh wenig bekannt. Z. B. Wonbatus folfor.

4. Dafyurus bedeutet wolligter Schwanz; der Name ift von Geoffroy angegeben, und wirklich ift, nächlt der Zahl der Schneidezähne, aclit oben und fechs unten, der mit langen Haaren befetzte Schwanz die auffallendite Eigenlchaft. Man kennt fechs in Aultralien einheimilche Arten. Z. B. Didelphis viverrina (Shaw.)

5. Den Namen Sarige (Didelphis, doppelte Gebärmutter) habęa die, zuerft bekant gewordenen Arten dieferFamilie erh lfen. Alle baben im Oberkiefer zehn, im Unterkiefer acht Schneidezähne, vorftehende Schnautze und einen Wickellchwanz. Sie treten mit der ganzen Fulslohle beym Gehen auf den Boden; man kennt mehr als zehn Arten, Z. B. Did. marfupialis L.

6. Geoffroy hat das genus Beuceldachs, (perameles,) anfgeftellt, um durch dielen Namen die Aehnlichkeit, die die Geftalt des Thíeres mit der des Dachles hat, anzudeuten. Man findet kaum noch eine Spur von einem freyen Daumen an dem Hinterfulse Z. B. Peram. naluta G.

Diefe Familie der Beutelthiere enthielt als Cuvier und Geoffroy fie guerlt aufführten nur, wenige bekannte' Arten. "Es ift merkwürdig dals die meiften der feit zehn Jahren neu entdeckten Saugthiere diefelbe Bildung der Generationsorgane zeigen; woher kann wolil der londerbare Abortus kommen, den alle Thiere aus Neuholland zu erleiden Ccheinen? Diele Frage if noch unbeantwortet. Man weils felbit n ch sicht genau, ob die Embryonen, die die Mutter zur.Welt bringt, von ihr felbit in den Zitzenlack gebracht werden, oder ob, lie durch eine Art 1 effnun: dahin kommen, die in diefer Periode fich vieltuch ian den farchdecken bil. det. 


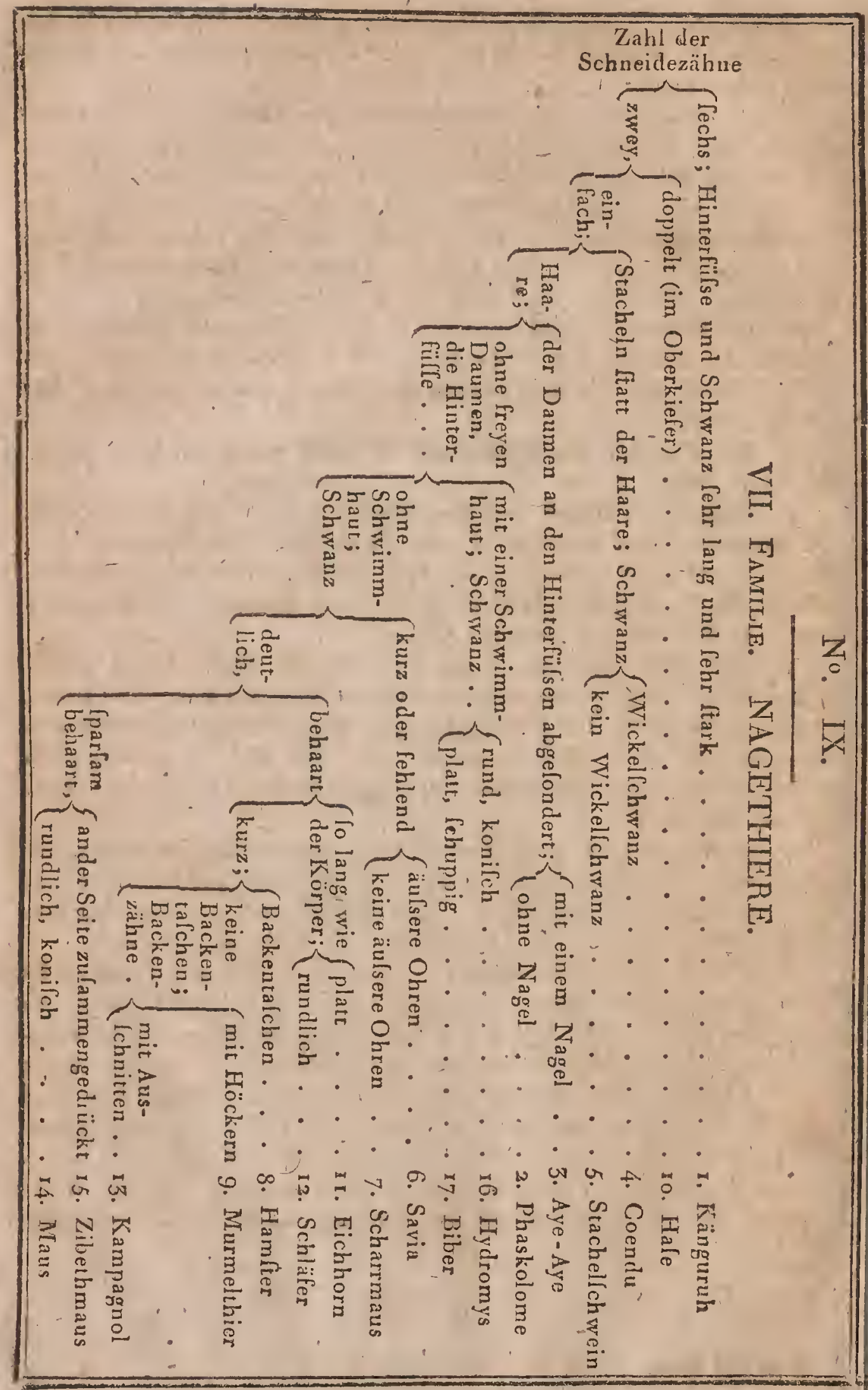




\section{BEMERKUNGEN ZUR IX. TABELLE.}

Die Nagethiere (rofores) die deswegen fo genannt find, weil fie ihre Nahrungsmittel nicht anders zerkleinern können als wenn fie fie wie mit einer Feile benagen, baben immer nur zwey Schneidezähne im Unterkiefer, und alle aulser dem Känguruh und dem Hafen haben auch nicht mehrim Oberkiefer. Sie bilden eine natürliche Familie, die mit den Beutelthie ren durch das Känguruh, den Phaskolome und das Aye-ayé zufámmenhängt; mit der Plantigradén durch das Stachelfchwein und den Coendu; mit den Chiropteren durch die Polatulche. (Sciur. vol.) Alle nähren fich von feften Subfianzen, harten Kräutern, Holz und Wurzeln. Sie haben melır als zwey Säugwarzen und bringen mehrere Junge I. Die Känguruk (kangurus) haben lehr lange Hinterfülse, kurze Vorderfülse, hakenförmige Nägel; Jie bedicnen fich auch des Schwanzes zum Gehen. Z. B. Kang. Giganteus (Geoftr.) 2. Die Phaskolomen (phascolomys) oder Beutelmäufe, find die einzigen Nagethiere, welche zugleich eiuen Zitzenfack und den Daumen an den Hinterfülsen abgefondert und Nagellos haben man hat fie wie die Arten der vorigen Gattungen nur in Aufiralien gefunden. 3. Das Aye-Aye, (cheiromys) oder Handmaus ilt ein von Sonnerat auf Madagaskar entdecktes Thier. Z. B. Sciur, madagalcarienlis L. - 4. u. 5. Die Goendus (coendus) (Hyltrix preherfilis L.) und Stachelfchweine (hyltrix) (Hylt. criflata L.) gränzen fehr nahe an einander. 6. Die Savia (cavia) find amerikanilche Thiere, die oft an den Hinterfüfsen hufenähnliche Nägel haben. Einige haben gar keinen Schwanz und aus diefen hat man ein eignes Genus hydrochoerus, z. B. Cavia capybara L., machen wollen; die übrigen mit einem kuren 5 chwanze hat man Agutz genannt. Z. B Cavia paca L. 7. Die Scharmäule (Sphalax) haben den Kopf lo breit als den Körper, der kurzbeinig. ift und keinen Śchwanz; man fieht bey ihnen (äulserlich) keine Augen, die lie, bey ihrer unterirdilchen Lebensart nicht brauchen. Z. B. mus typhlus L. 8. Die Hámfter (cricetus), (mus cricetus L.) unterfcheiden fich wefentlich von den 9. Mur. melchieren (arctomys) (arctom. alpinus L.) welche keine eigentlichen Backentalchen haben. 10. Die Hafen (lepus) Z. B. lepus timidus L. Find in zwèy Untergatiungen getheilt wovon das zweyte die Alperhafen (pica, lagomys) (lepus alpinus L.) leicht an rlen kurzen Ohren und mangelnden Schwanze zu erkennen ift. ז. Das Eichhörnchen (Iciuru's) 'Z. B. Iciur. vulgaris L. und 12. die Schläfer (myoxus) (m. glis. L.) kommen in Geftalt, Gewohnteit und Lebensart eiriander lehr nabe. 13. und 14. Dite Kampagnols, Feldmäufe (arvicola) 2. B. mus arvicola L. unterfcheiden lich von den Mäufen (mus), z. B. mus rattus L. durch die Geftalt ihrer Bachenzähne, die bey erfteren nicht ausgefchnitren lind, und durch den beharten Schwanz. I5. Die Zibethmazs (ondatra) natent fich den Kampagnols durch die Zähne, und den Mäulen durch den Schwanz. Z B. Nus zibethicus L. 16. Der Hydromys und 7. die Biber (Gber) (Caltor liber) L. find auf ter Tabelle hinreichend untercheidend charaktexilint. 


\section{No. X.}

\section{Familie. ZAHNLOSE.}

\section{Nägeltragende Säugthiere. Ohne Schneide - und} Eckzähne.

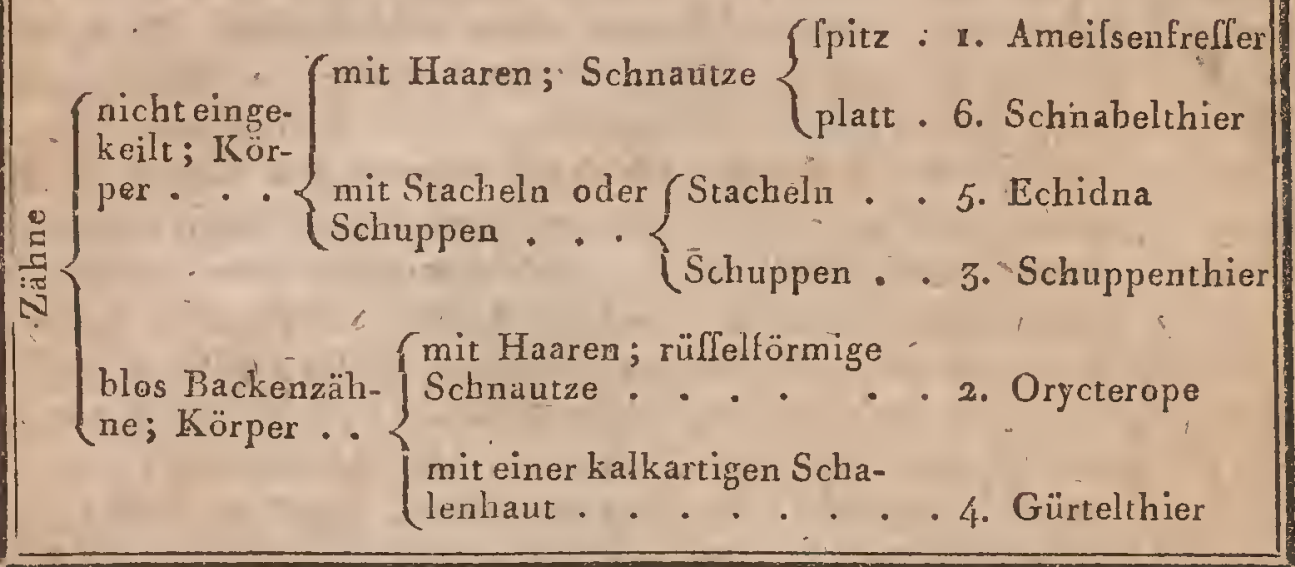

\section{BENERKUNGEN. ZUR X. TABELLE.}

Der gänzliche Mangel an Schneide- und Eckzähnen hat diefen Thieren den Namen Zahnlose (edentati) verCchafft. Ihre Lebensweile ift noch wenig bekannt, fie bewohnen die wärmften Theile der Erde, Afrika, Amerika und Auftralien. Alle, mit Ausnahme des Ornithorynchus, haben eine mehr oder weniger verlängerte Schnautze, alle können eine cylindrifche, lange, klebrige Zunge hervorftrecken, welche beftimmt ift die fich daran felthängenden Infekten in den Mund zu ziehen.

MIan beobachtec bey den hier zufammengeftellten Säugthieren eine fehr grofse Verfchiedenheit der'Bedeckungen, wovon bey den andern Thier-Familien fich nichts ähniiches vorfindet. Einige hàben Haare auf dem Körper, allein dies Haar ift von ganz befonderer Art, es ift ên langes plattes Mälnenhaar, wie trocknes Gras; andere haben ein dickes, bufchiges Seidenhaar. Bey einigen ift der Körpèr und Schwanz mit ftarken, an den Rändern Icharfen, dachziegelartig liegenden Schuppen bedeckt; bey noch andern finden fich Stacheln wie bey dem Igel, und wiederum andere haben den Körper in eine Art von knochigem Harnifch gehüllt, der irı Gürtel und regelmälsige Abtheilungen getheilt ift, die die nöthige Berregung zulaffen und doch eine Lehr felte Vertheidigungswaffe abgebèn. 
Eine andere merkwürdige Eigenheit diefer Familie ift die gïnzliche Abwelenheit voń Săugewarzen bey den Gattungen 5 u. 6-, die überhaupt aus Thieren beftehen, deren Organilation to fehr von der alle andern Süugthiere abweicht, dafs die Naturforlcher falt ungewils find, ob fie nicht aus ihwen eine eigne Klafle machen follen. Geoffroy hat fie wenigftens als monotrémes (monotremata) als eine eigne Ordnung aufgegeführt.

1. Ameifenfrefer (myrmecophaga) Myrm. didactyla L. find noch nicht in Europa wahrgenornmen ; einige haben Wickelfcliwänze, andere nicht,

2. Man kennt nur eine Art von Orycteropen (orycteropus) was Grabefuls bedeutet; das Thier ift in Afrika zu Haule und wegen feiner platten Nägel merkwürdig. Z. B. Myrmeçopl. capenfis Li.

3. Auch die Schuppenthiere (manis) finden fich in Afrika, der bierher gehörige Phatagin (M. tetradactyla) hat unter allen Säugthieren die meiften Schwanzwirbel.

4. Die Gürtelthiere (dafypus) find mur in Amerika gefunden. Es fcheint, als wenn die Zâhl der Gürtel nach-den Jahren verfchieden ift, wodurch_die Beftimmung der Arten Cehr fchwierig wirk.

5. Von den in Neuholland einbeimifchen Echidnas (ẹchidna) \&. B. Myrmecophaga aculeatus (Shaiv) find zwey Arten bekannt.

6. Eben fo ift es mit den SGhnalelthicren (ornithoxynchis), denen man dielen Namen gegeben hat, weil ihre platte haarlofe Schnautze einem Entenfchnabel fehr ähnlich ift. Z. B. Ornith. paradoxus. (Blumenb.)

Die heyden letzten Gattungen find nur einftweilen hier placirt, bis fich'ein ${ }^{1}$ Cchicklicher Ort für fie findet. Sie unterfcheiden fich von allen Säugthieren übrigerss durch folgendes: keine Süugewarzen; eine Kloake oder eine gemeinf'chafliche Oeftnung für dic Gefchlechtsorgave, den Urin und den Koth; , keine einigekeilten Zähne; keine fleifchigen Lippen; knöcherner Gaumen, init abgefonderten Zwifchenkieferbeinen; zwey Schlüffelbeinknochen, wovon eins dem Gabelknochen der Vügrel ähnlich ift. - Die Arme in einem Charniergelenk mit den beyden Schulterknochen artikulirend; das Wadenbein viel länger als das Schienbein; die Zehenglieder fehr kurz mit doppelten Gelenkrollen und lechs Zehen an den HinterfüIsen II. $\lceil$. w.- Alle diefe Eigengeiten Icheinen fie von derOrdnung der Säugthiere auszufchlieísen; dagegen beobachtet man ähnliche Bildungen bey mohreren Vögels: und befonder bey vielen Rep. tilien. 


\section{No. XI.}

IX. Familie. TARDigradeN.

Säugthiere mit Nägeln, denen blos die Schneidezähne fehlen.

Faullhier.

\section{No. XII.}

\section{$\mathrm{X}$. Familie. PACHYDERMEN.}

Säugthiere mit Hufen und mehr als zwey Zehen.

$$
\begin{aligned}
& \left\{\begin{array}{l}
\text { fünf; die Nale in einem muskulölen } \\
\text { beweglichen Rüllel verlängert . . . . 5: Elephant }
\end{array}\right. \\
& =\text { Fan allen vier }\left\{\begin{array}{l}
\text { alle vier Zehen den Bo- } \\
\text { Fülsen berührend . . . 6. Hippopotamus }
\end{array}\right. \\
& \approx \text { vier }\left\{\begin{array}{l}
\text { Fulsen } \\
\approx
\end{array}\right. \\
& =\text { an den Vorder . drey an den Hin. frechs 3. Tapir } \\
& \text { ter Fülsen; obere Schneidezähne. }\left\{\begin{array}{l}
\text { zwey r. Daman } \\
\text { zwa }
\end{array}\right.
\end{aligned}
$$

\section{BEMERKUNGEN ZUR XI. TABELLE.}

Die Tardigraden haben, was die Bildung ihres Gefichtes und den Sitz der Säugwarzen auf der Bruft anlangt, einige Aehnlichkeit mit der orlten Ordnung der Säugthiere, aber durch die Bildung des Magens kommen fie den folgenden Thieren nahe (von den Affen u. I. w. unterlcheiden fie fich vorzüglich dureh ihre Sichelklauen). Man kennt nur zwey in Amerika einheimifche Arten die man in das Genus Bradypus (Langlamfuls) Faulthier gebracht hat. Die eine Art zeigt das bey den Säugthieien einzige Beylpiel von neun Halwirbelbeinen. Z. B. Brad. tridactylus. L. 


\section{BEMEKUNGEN ZÚR XII. TABELLE.}

Die Pachydermen (craflipelles I. pachyderma) Thiere mit dicker Haut, find durch eine mehr künftliche als natürliche Weife zufammengeftellt; bilden aber demohngeachtet eine von andern fehr unterlchiedene Familie. Es.find die einzigen Thiere die zugleich meiftentheils alle drey Zahnarten und mehr als zwey Hufe haben. Die meilten find nur fparfam behaart; fie ruminiren nicht. Der Elephant allein hat keine Eck: zahne und nähert fich gewiffermalsen den Nagethieren, da feine Hauer an der Stelle der Schneidezühne litzen. Der Daman hat dichtes Haar und nähert fich durch die Form der Fülse den Savias und Stachellchweinen. Alle mit Ausnahme des Damans fuchen feuchte Orte zu ihren Aufenthalt.

I. Die Daman (hyrax) die Linné zu dep Nagethieren-zählte, unterfcheiden fich von diefen lehr durch ihre vier untern Schneidezähne; man kennt zwey in Afrika einlieimilche Arten. Z. B. Hyrax capenfis.

2. Die Schweine (Ius) bilden eine wegen der Bildung des Fufses lehr merkwürdige Gattung, indem obgleich vier Zehen da find, nur die zwey mittelften den Boslen berühren; lo dals der Fuls, wie bey den Wiederkäuern gelpalten zu 〔eyn fcheint. Die Eckzähne ragen of aus dem Munde hervor und lind wie Hauer umgebogen. Alle haben einen Rüfel, 'mit' dem lie in der Erde nach den Wurzeln wühlen, wovon fie fich nähren. Z. B. Sus fcropha L.

3. Die Tapire (tapirus) Wafler-Schwein, find amerikanifche Säugthiere mit einem kúrzen'Rülel, der dem des Elephanten iähnelt. Z. B. Tap. americanus. Cưvier hat in den Steinbrüchen von Montmartne bey Paris von zwey andern Arten dief́er Gattung, die jetzt nicht mehr lebend vorzukommen (cheinen, die folfilen Skelete gefunden.

4. Die Rhinozeros (rhinoceros) Nashorn, haben keine Eckzâhne, oft fehlen ihnen fogar'die Schneidezähne ganz und gar. Man kennt nuri zwey lebend vorkommende Arten, das Afratilche einhörnige, und das Afrikanifche zweyhörnige. Diele Hörner fitzen lenkrecht auf der Nafe und fcheinen aus vereinigten Haaren gebildet zu leyn. Z. B. Rhin bicornis.

5. Die Elephanten (elephas) unterfcheiden fich von allen Thieren dien fer Familie durch die Zahl der den Fuls begränzenden Hufe, wodurch alle Zehen in einen. Stump£ vereinigt find, und durch den langen Rüffel in welchen die Schnauze ausgeht und deflen das. Thier fich wie einet. Hand bedienen kann, z. B. Elephas indicus I.

7. Die Flufspferde (hippopotamus) haben allein in dieler Familie, vier den Boden berührende Hufe. Man kennt nur eine lebende. Art, die in Afrika einheimifch ift, aber auch lelten zu werden fcheint. Z.B. Hipa pop. amphibius L.

Cuvier hat, hey leinen Unterfuchungen über die: folfilen Knochen, auch welche entdeckt, die zwey zu diefer Familie;zu zählenden Gattungen angehört $z$ hahen fcheinen. Das eine ment er Paleotherium, das! andere Anoplotherium. 


\section{No. XIII.}

\section{Familie: WIEDERKÄUER.}

Säugthiere mit zwèy Zehen und nur zwey Hufen.

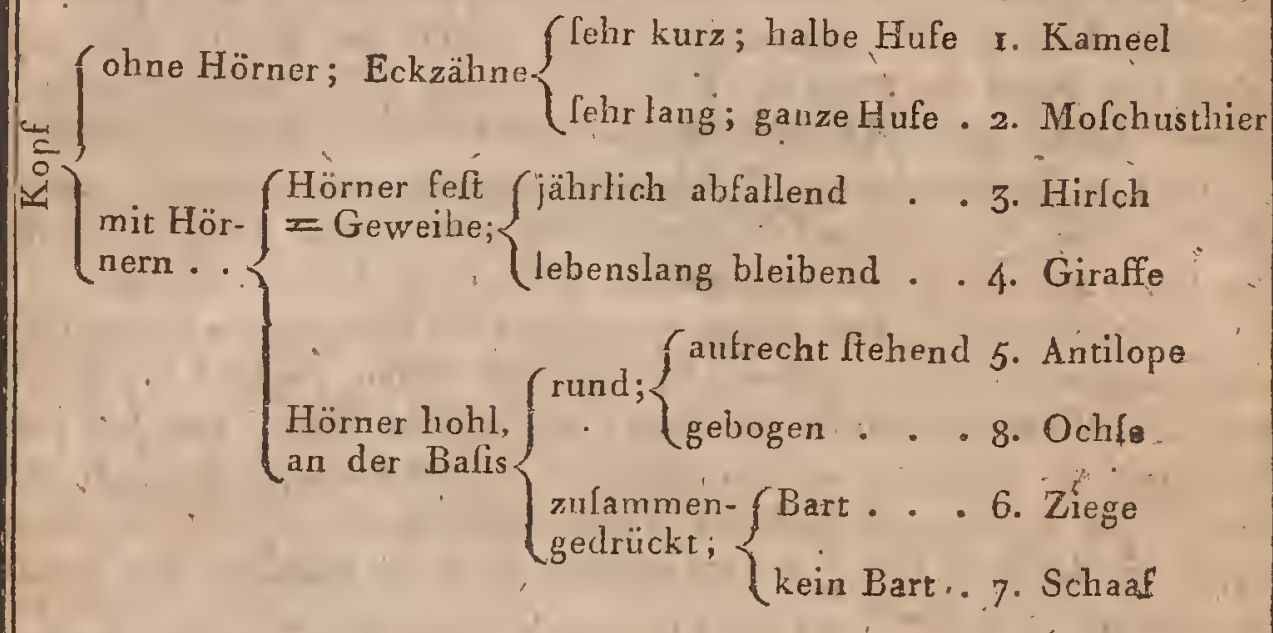

\section{BEMERKUNGEN ZUR XIII. TABELEE.}

Die Wiederkäuer (ruminantia, bifcula, pecora) find eine fowohl durch äufsere Geftalt als Organifation und Lebensart fehr natürlich verbundene Familie. Wiederkäuer heilsen fie, weil fie die Kräuter, wovon fie fich nähren, wenn fie eine Zeitlang im Magen gewefen lind; wieder in den Mund zurückgehen laflen und da zum zweytenmale kauen; es lteht dies mit einer befondern Einrichtung des Magens in Verbindung, der in vier Säcke getheilt ift, in den Panzen, die Haube, den Pfalcer, und den Laabmagen.

1. Man nennt fie auch Thiere mit gefpaltenen Klauer, Bifulca, weil der Fuls wirklich ausfieht als wäre er gelpalten; die zwey dreyeckigen Hufe, laffen wenn fie den Boden berühren einen gabelförmigen Eindruck zurück. - Sie find die vorzüglichften Hausthiere, die man Heerdenweis hält. Z. E. Schaafe, Rennthiere, Kühe, Kamele, Ziegen u. I. w. $\because$ Die meiften hieher gehörigen Thiere haben keine Eckzähne, welche ihnen bey ihrer Pflanzennahrung unnütz feyn würden. Selblit die Schneidezähine finclen fich meiftens'nur in Unterkiefer, dann find fie breit und achit an der Zahl: Die Oberkinnlade ift mit einer feften Widerhand. leiftenden Subftanz bedeckt, gegen welche die Schreidezühre argedrückt 
werden, die dann Zangenartig das Gras faffén, um es mehr abzureitsen als abzubeilsen. - Die zwey erften Gattungen entfernén fich von den übrigen etwas durch das Dafeyn aller drey Zahnarten, und durch die, $A b$. welenheit der Hörner oder Geweihe.

r. Die Kanecle (camelus) machen gleichlam den Uebergang von diefer Familie zu den Solipeden; lie haben alle drey Arten von Zahnen und die Zehen find in eine wenig gefpaltene [chwielige Sohle eirgefchlolfen, fo dafs man nur vorn zwey kleine Hufe wahrnimmt. "Man theilt diefe Gattung in eigentiche Kameele, die einen oder zwey Höcker auf dem fiücen haben z. B. Camelus bactrianus und L. in Lamas welche lzeinen Höckér auf dem Rücken und weniger Schnoidezähne haben. Z. B. Cam. lacma L.

2. Mofchusthier, Mofchúshirfch (mofchus) fondern (in einem Béuł tel am Nabel) den bekannten Molchus ab. Haben keine obern Schnei= dezähne, aber an Ober-Kiefer litzen zwey lange unterwärts gebogene Sckzähne. In dieler'Gasturg finden "fich die allerkleinften Arten diefer Tamilie. Z. B. Molch molchiferus L.

3. Zu den Hirfchen (cervus) gehören alle die Thiere, wovon entweder ein, oder beyde Gefchlechter auf dem Kòpfe, Geweibe (oft âtige), tragen, die von keiner Haut bedeckt find und jährlich, réugebildet werden. Z. B. Cervus elaphus L.

4. Die Girafien (camelo-pardalis) find die einzige Art dieler Gattung, und in Afrika einheimifche Thiere, deren mit Haut bedeckte nud an der Spitze Haarbülchel tragende Hörner lebenslänglich dauern. Z. B. Camelo - pardalis giraffa $L$.

5. Die Gattung der Antilopen (antilope) begreift eine grofse Menge fehr von einander verfchiedener Thiere, die die alte Welt bewohnen, und deren runde mit hervorragenden Ringen oder fpiralformigen Leifien verfehene Hörner, knöchorne, inwendig nicht hohle, grolse Fortätze des Schädels bedecken. Z, B. Antil cervicapra .

6. Dié Ziegen' (capra) kommen in etwas mit deñ Antilopen über. ein. Ihr Hauptrharakıer befteht in dem Bülchel langer Haare, was fie unter dem Kinne haben. Z. B. Capra a egagrus L.

7. Die Schaafe (ovis) haben zufammergedrückte, eckige Hörner, die an ihrer Bafis rückwärts und nachher wieder vorwärts gebogen lind. Z. B. Ovis aries L.

8. Die Ochfen (bos) haben auch einige Aehnlichkeit mit einigen, Antilopenarten; aber ihre Hörner, find nie an der 3 alis gerade nufrecht fiehend fondern ganz leitwärts oder hinterwärts gebogen. (Auch haben lie Antilopen nicht die hängende Kehlhaur, die Wanne, der Ochfen. R. B. Bós taurus L. 


\section{No. XIV.}

\section{FAMilite. SOLIPEDEN.}

Säugthiere mit einer Zehe und einem einzigen Hufe.

$$
\text { Pferd. }
$$

\section{No. $\mathrm{XV}$.}

\section{FAMILIE. AMPHIBIEN.}

Vier Füfse flof̂enförmig; die Zehen meiftens nägeltragend.

$\left\{\begin{array}{l}\text { alle drey Arten; obere Schneide- } \begin{array}{l}\text { lechs au der Zahl I. Seehund } \\ \text { zähne }\end{array} \\ \text { nicht alle drey Arten; }\left\{\begin{array}{l}\text { Eckzähne . . . . . 3. Dugong } \\ \text { keine Eckzähne . . . . 4. Manati }\end{array}\right.\end{array}\right.$

\section{BEMERKUNGEN ZUR XIV. TABELLE.}

Obgleirh die Familie der Solipeden (Colipedes) nur eine Gattung, von vier Arten, in fich begreift, fo ift fie demohngeachtet doch eine der natiirlichlten unter den Säugthieren, ja man könnte fagen unter den rückgrathigen Thieren; es find durchaus die einzigen Thiere die nur auf einer Zehe gehen. Ferner haben fie einen einfachen Magen, und die drey Zahn Arten; ' ihre S̈̈̈口gwarzen, nur zwey an der Zahl, fitzen nicht an der Brult, fondern in den Weichen.

Die Gattung Pferd (equus) enthält vier Artén, die alle in der Alten Welc zu Haule find. Z. B. equ. caballus L. 


\section{BEMERKUNGEN ZUP. XV. TABELLE.}

In diefer Familie find auch unter dem Namen Amphibien (amphibia) Thiere zufammengeftellt, dic is Organifation und Nahrung feht von einander abweichen. Ihr Namen giebt die Gewohnheit diefer Thiere an, die, gewöhrlich im Waffer leben, obgleich fie wvie andere Säugthiere das Bedürfnifs haben Luft zu athmen und obgleich fie lange aufser dem Waffer leben können.

Alle hiehergehörigen Thiere haben eine ilure Lebensart andeutende Körperform. Ihre Bruftglieder find deutlich, aber kurz; die Zehen durch flie Haut in eine Art Ruder vereinigt.

Die Bauchglieder find meift ganz nach hinten gerichtet und bilden oft mit dem Schwanze zulammen eine einzige Flofle, die ihnen als Steuerruder dient, wenn fie die Bruftglieder als Ruder brauchen.

I. Die Seehunde (phoca). leben im Meere, find eigentlich nock wenig bekannt, fcheinen aber in Hinficht auf Lebensart, Form der Schnautze und Zahl und Vertheilung der Zähne in einigen Verbindung mit den Fifchotter zu ftehen. Z. B. Phoca vitulina L.

2. Wallroffe (trichecus) baben wie die Elephanten in dem Ober: Kiefer, zwey grolse Stolszähne, die hier aber die Eckzähne zu feyn fchèinen; fie zeigen durch Lebensweile und innere Organilation mit den $\mathrm{Pa}_{\mathrm{a}}$ chydermen einige Beziẹhungen. Z. B. Trich. rosmarús L.

3; Der Dügong (Dugong) ilt noch wenig bebannt, nur in den indifchen Meeren beobachtet; hat im Unterkiefer weder Schneide - noch Eckzähne, hat aber Conft einige Aehnlichkeit mit der vorigen Gattung: $\mathrm{Z}$. B. Triche c. dugong $\mathrm{L}$.

4. Die Manatis (manatus) haben faft die Zähne' der Faulthiere, und áuch wie es fcheint die invere Organifation, wenigftens in dem was die Verdauungsorgane betrifft. Sie find planzenfreflend. Z. B. Triche. cus manatus, L. 


\section{No. XVI.}

\section{Famrle. CETACEEN.}

Floflen ohne Nägel; Keine Hinterfüfse; Spritzlöcher.

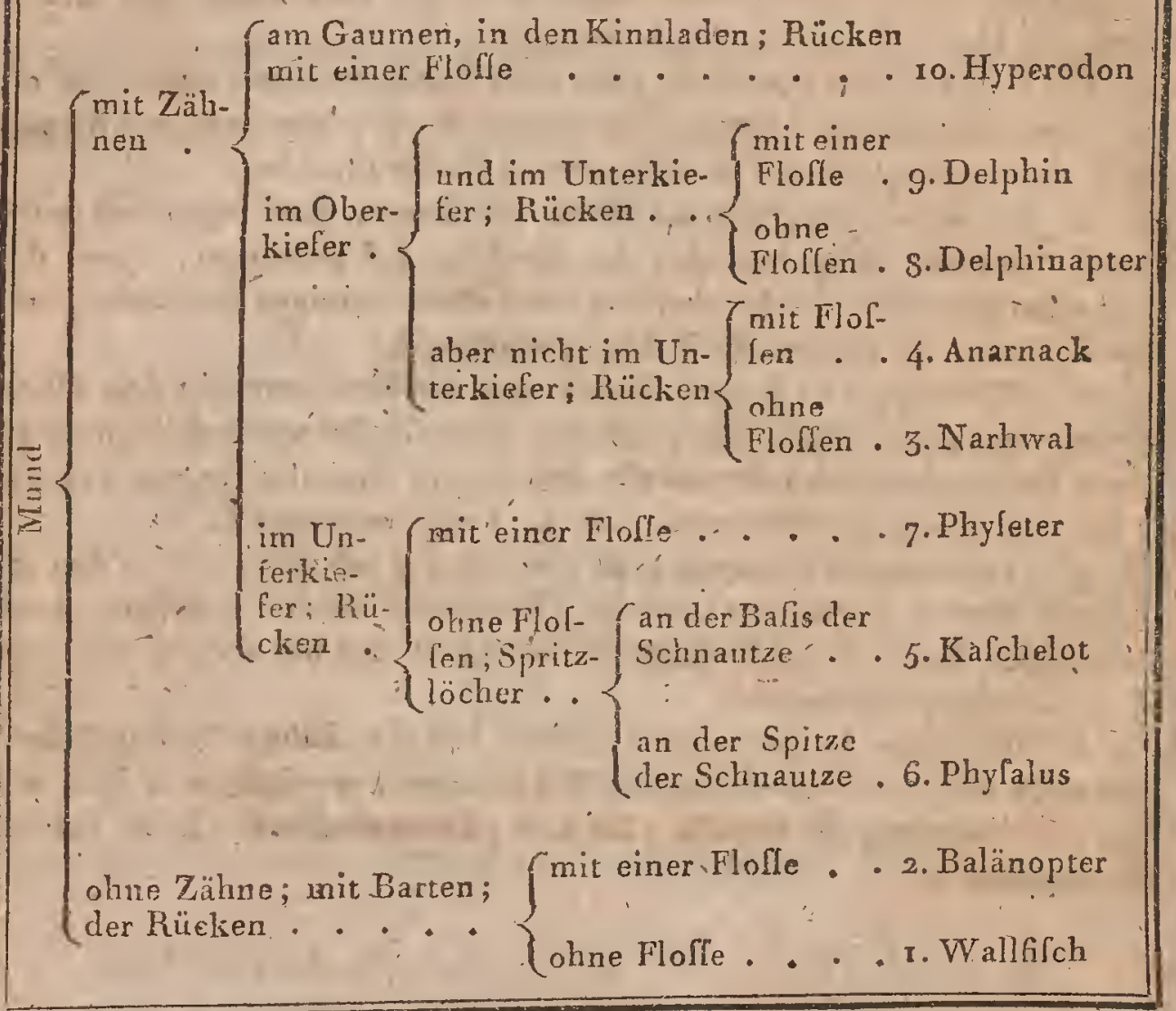

\section{BEMERKUNGEN ZUR XVI. TABELLE.}

Die Cetaceen (cete) haben eine von den übrigen Säugthieren fo abweichende Form, dals man lie lange Zeit für Fifche gehalten und mancher geglaubt hat, eine eigene Claffe von ihneu bilden zu müffen; und doch ilt ihre Organifation ganz die der übrigen Säugthiere. Sie athmen durch Lungen, "bringen lebendige Junge, die lie durch die Mibch ihrer Brüfte ernähren; aber die Hinterfülse folten ihnen wirklich gänzlich. lhre Haut ift glatt, obne Schuppen oder Haare; der Körper hat eine konilche Form urd endet fich in eine borizontal lingende Flofle; äulsere 
Ohren Find gar nicht vorhanden; die Nafenlücher üfnen lich oben auf dem Kopfe und find mit Muskelfäcken verfehen, die das in die Kehle gekommene Waffer mit Gewalt wieder ausfprützen. Alle leben im. Meere und könne es nicht verlaflen. Sie nähren fich von Fifchen und anderen Seethieren.

Die hier aufgeftellten Gattungen find die, die Lacepede in feiner Hiftoire naturelle des cétacés bekannt gemacht hat; obgleich fie auf lauter künfliche Abtheilungen gegründet find, lo geben fie doch ein fehr bequemes Hülfsmittel zur Kenntnils dèr Arten ab, wás doch der einzige Zweck der naturbiftorifchen Sylteme ift.

r. und 2. Die Wallffiche (balaena) z. B. Balaena myfticetus und die Balüncpteren (balenoptera) (z. B. Balaena gibbola.) find unter allen bekannten Thieren die welche die beträchtlichfte Grölse und das gröfte Gewicht erreichen; fie fieben, fo zu lageil, das Meerwaffer durch, was fie zwilchen den Blättern ihrer Barten durchtreiben, wie die Enter wennfie in dem Schlamm Ichlappern

3. Die Gattung Narhwal (narwhalus) (z. B. Monodon monoceros L.) wwurde lehr uneigentlich monodon genannt, weil der Narhwal häufig zwey lange. Hauer im Oberkieler trügt; es gehören hieher drey Arten, die von der folgenden Gattung 4. Anarnack (anarcus) z. B. Monod. Ipurius Oth. Fabric.) nur durch die Abwefenheit der Ruckenflolle unterIchieden find.

5. Die Kafohelots (catodon z. B. Plyyfeter macrocephaius L. ) 6. der Phyfalus.(Phyfalus) z. B. Ph. zylindricus und 7. der Ply feter (phyfeterus) z. B. Pbylet. microps L. geben eine fehr natüliche Abtlseilung in diefer Familie, vermöge des Sitzes der Zähne, die nur an der Unterkinlade deutlich find.

8. und 9. Die Delphine (Delphinuss, z. B. Delph. vulgaris L. und die Delphinapteren (Delphinapterus) z. B. Delphinus beluga L., bilden auch eine ganz natürliche Abtheilung ir der grofsen Familie, und begreifen eine grolse Menge Arten, die meiltens in Vergleich zu denen der vorigen Gáttungen, tnur eine geringe Grölse erreichen.

ro. Die Hyperodons (hyperodon) z. B. Delphinus orca L. lind fonderbare Thiere. Von dewn Defphin, mit dein fie fonfi übereinkommen, unterfcheiden fie fich durch die auf dem Gaumen fitzenden Zälıne und durch die geringe Zahl der Zähne im Unterkiefer. Es Jcheint als wenn der Hyperoden in einiger Hinficht dem Ornithorynchus, der einftweiler unter den cihnlofen aufgefühst ifl, nahe kümmt.

Ende der Clafre der Süughthiere. 


\section{No. XVII.}

\section{KLASSE. VÜGEL.}

Pückgrathige, Eyerlegende Thiere; mit Lungen und rothem Blute; der Körper mit Federn bedeckt und die Vorderfüfse in Flügel verwandelt.

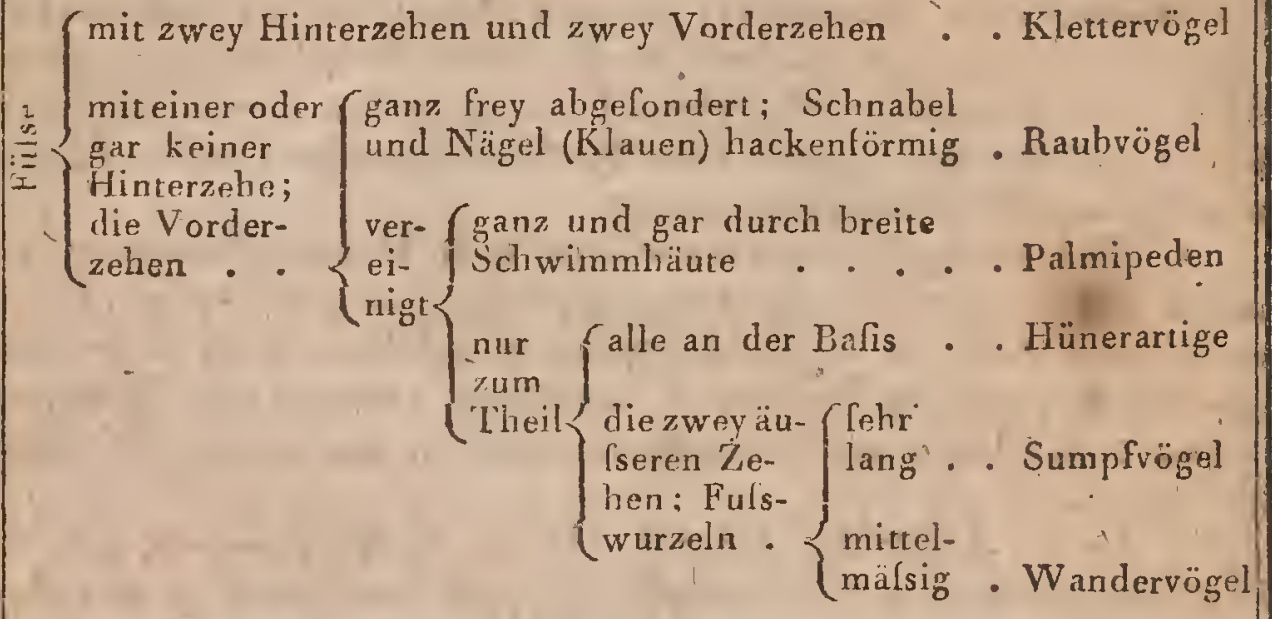

\section{BEMERKUNGEN ZUR XVII. TABELLE.}

Die Claffe der Vügel (aves) begreift T'hierarten in fich, die lo deutlich durch Geftalt, aulsere Bedeckung und Organifation unterlchieden find, dafs es uninöglich ift fie mit Thieren der anderen Claflen zu verwechloln.

Ihr hornartiger Sclinabel, ohne fleilchige Lippen, entfernt fie von den meiften Säugthieren und nähert fie dem Schnabelthiere und den. zahnlofen Cetaceen weiche die Form der Fifche haben.

Sie lind die erften Thiere, bey denen die Keime zur Fortpflanzung der Árt, in einer mit einer Kalkartigen Schaale umgebenen lekundären Gebär* mutter - dem Eye - enthalten, fich eher von der Mutter tremnen ehe fie ganz entwickelt find, und in der Luft einer Wärme von 30 Grad Reaumür bedürfen um ganz entwickelt zu werden. Deswegen heilsen Cie Eyerleger de. Die Federn dér Vögel find eine diefer Clafle ganz eigne Bedeckung; es find hornartige Kiele die, je zu fïnf́ in einem Q.idrat (in quincunce) in der Haut fitzen und mit dicht an eiriander liegenden, durch kleine Häk- 
chen vereinigten, Bärten verfehen die auf den Seiten lo angebracht find, dals fie leichte und lehr elaftî́che B'ätter bilden. Man giebt den auf den Flügeln und dem Schwanze fitzenden'Federn den Namen Schzung federn (pennae); die Flügeltedern bat man auch Ruderfedern (remiges) und die Schwanzfedern Steuerfedern (rectrices) genanut. Form und Länge variiren fehr. Man benutzt lie zur Charakterilitk der Gattunga

In der Bildung der Fülse zeigt eine Familie der Vögel eine be. foudere Eigenheit, deren'man fich zur Charakteriltik bedient hat, nämlich die Bildung der Zehen wo fie zangenartig einander entgegenftehen. Andere Vögel haben, zwar auch das Vermögen, willkülırlich eine Zehe auch etwas nach hinten bewégen zu können; aberidie, dic man Klettervögel genannt hat; können die Hinterzehen nicht vorwärts bewegen, und auf die ganze Organifation fcheint diefe Art lich zu bewegen einigen Einflufs-gehabt zu haben.

Alle anderń Vögel haben nur eine oder gar keine Hinterzehe. Von diefen haben einige die Fülse mit fcharfen hakenförmigen Klauen verfehen, die Zehen ganz frey abgelondert, und den Schnabel gekrümmt und mit einer hakenförmigen Spitze endigend

Bey den, übrigen lind die Zehen mehr oder weniger durch Membranen unter einander vereinigt, bald find fie es nur an ihrer Baffs, bald bilden die drey oder vier Zelıen eine Art von Ruder. Dies ift bey, allen- auf der Oberfläche des Waffers Schwimmenden Vögeln der Fall.-

Die Vögel, deren Zehen nur unvollkommen an ibrer Bafis vereinigt 'find, zeigen aulser den auf der Tabelle angegebenen Eigenthümlichkeiten, noch eine grofse Menge andere in ihrer Organifation und

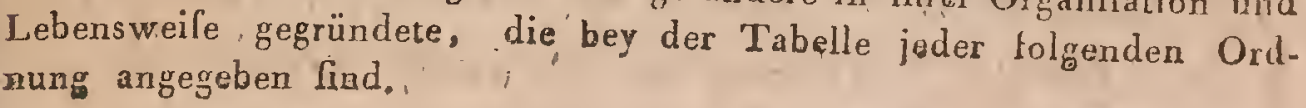




\section{No. XVIII.}

I. Ordnung. PiaubVügel.

Rine einzige Zehe hinten; die Vorderzehen'ganz frey; Schnabel und Klauen hakenförmig.

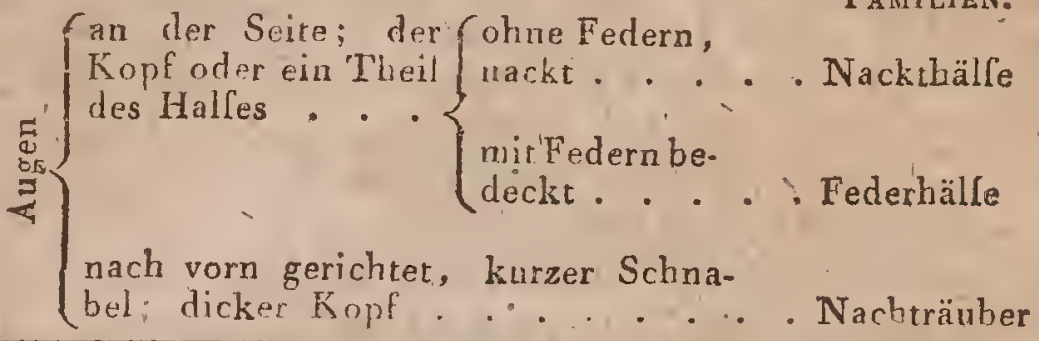

I. Familie. DIE NACKTHÄLSE ODER PTILODÉREN. *)

Der Untertheil des Halles mit kraufen Federn, wie mit einem Kragen umgeben, der Obertheil mit einen leichten Flaum bedeckt; der Schnabel anfangs an der Bafis gerade, an der Spitze hakenförmig.

$$
\text { Kopf oder Hals }\left\{\begin{array}{l}
\text { mit Warzen . . Sarkorampf } \\
\text { ohne Warzen . . 2. Gcyer }
\end{array}\right.
$$

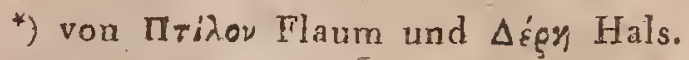

\section{BEMERIUNGEN ZUR XVIII. TABELLE.}

Więes der Namo fchon angiebt leben die Raubvögel. (accipirres, sapaces) nur von Rauhen und Beatemachen. Die Fülse lind im Ganzen fohr kurz, mit fpizers, bakenförmigen, fiarken und [chneiảenden 
Nägeln an? ftarken Zehen bewaffnet, deren Vereinigung man mit dem Namen Klauen bezeichnet. Ihr meiltens kurzer' Schnabel ift an der Spitze in feinem Oberthéile gekrümmt. Bie Flügel find lang und geben dem Vogel, wenn er fliegt, einen beträchtlichen Umfang in die Breite. Alle leben paarweile, legen nur wenig Eyer in ein, an einem erhabenen Orte angebrachtes, nucht künftlicies Neft. Die Mannchen find kleiner als die Weibchen. Thre Farben haben eiren dunkeln Anftrich und zeigen meift eine Mifchung von Schwarz und Weirs.

Einige Arten Icheinen diefe Ordnung mit einigen der folgenden zu verbinden; fo fteht $z$. E. der Sekretair mit langen nackten Fuiswurzeln in Verbindung mit einicen Sumpfrögeln, von denen er fich lonft durch den Schnabel unterlcheidet. Da einige Nachtvögel aurh die äufsere Zehe hinterwärts bewegen kömnen, lo könnten fie diefer Eigenlueit wegen mit den Klettervögeln, verwech felt werden; wenu urcht die Lage der Augen fie wieder davon unterfchiede.

Diefe vorwärts liegenden Augen find hier als ein Hauptcharakter der Nachtvögel benutzt; auch ift es eine Bildung die man lonft bey keiner Gat tung diefer Ordnung antrifft; die hier zu den Nachtvögeln gehörigen Arten find, nebli den Nachtichwalben aus der Ordnung der Sperlingsartigevvögel. die einzigen, die bey $\mathbb{N a c h t}$ und in völliger Dunkelheit fliegen können.

Die Bezeichnung nackter Hals inuls man nicht im firenglten Sin. ne nehmen, es foll dadurch nur angezeigt werden, dafs der Hals nur mit einem fpárlichen Flaum bedeckt ift, durch weichen man die nur $2 n$ einigen Stellen ganz nackte Haut durchfehen, kann; es ift diele Bezeichnung nur vergleichend und dem entgegengefetzt, was man bey den' Federhälfen hemerkt, deren Hals gewöhnich ganz mit Dachziegelartig übereinander liegenden Federn bedeckt.ift.

\section{BEMERKUNGEN ZUR XIX. TABELLE.}

Die zwey Gattungen der Familie der Nackthälfe find leicht zu unterfcheiden, weil ihr Charakter blofs in'dem Dafeyn oder der Abwefenheit von Fleilchwarzen am Kopfe oder Halfe liegt. Einige andere Vögel, aus fehr verfchiedenen. Ordnungen zeigen eine gleiche Bildung, aber lie unterfcheiden fich durch die wichtigften anderen Eigenheiten.

Die Gattung Sarkoramph (Sarcoramphus) 'd. h. Fleifchlch abel', hegreift diejenigen Geyer-Gattungen, die fleifchige Carunkeln oder Erbabenheiten auf dem Kopfe oder um den Schnabel herum haben z $\boldsymbol{E}$ der Geyerkönig (vultur papa L.), der Condor, der Ariku, u. I. w:

Die Geyer (vultur) find die übrigen Arten von Raubvögeln mit ganz, öder zum Theil nackten Halle. Diefe Vögel, find, obgleich lie fehr ftark find, meift nur wenig muthig. Es find, fehr geträlsige Thiere, die belonders dem Aafe nachgehen, von deffen Witterung fie aus fehr weiter Entfernung berbeygezogen werden; fie fliegen in zahlreichen Haufen. Z. B. Vult. fulvus L.

Dumeril 'Zool. 


\section{No. XX.}

II. FAMILIF. FEDERHÄLSE ODER KRYPHODEREN. *)

Augen feitwärts am Kopfe; Hals und Kopf mit Federn; die Bafis des Schnabels mit einer farbigen fleifchigen Erhabenheit, (Wachshaut), verfehen.

$\overrightarrow{\mathrm{D}}$ (mit einem Pinfel von Haaren oder Federn befetat x. Bartigeyer

) ohne Pin- (ltufenförmig, lang: Federbufch im Na-

$\left\{\begin{array}{l}\text { fel; der } \\ \text { Schwanz }\end{array}\right\}$ cken; Cehr lange Fulswurzeln. . . 5. Sekretairvogel

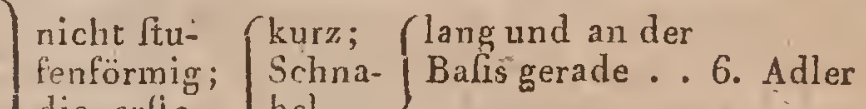

die erfie
Schurufe bel. $\begin{cases}\text { Bebo- } & \text { 2. Weite }\end{cases}$

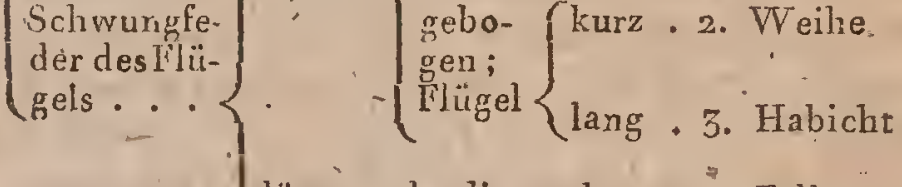

länger als die andere. 4. Falke

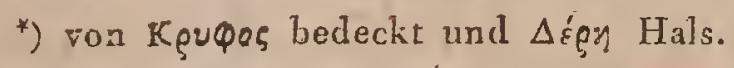

\section{No. XXI.}

\section{FAMilie. NACHTVÖGEL.}

Augen fehr grois, an dem fehr dicken.Kopfe nach vorn zu fitzend; der Schnabel kurz, hakenförmig, und an der Bafis fo, wie an den Nalenlöchern mit fteifen Borften befetzt.

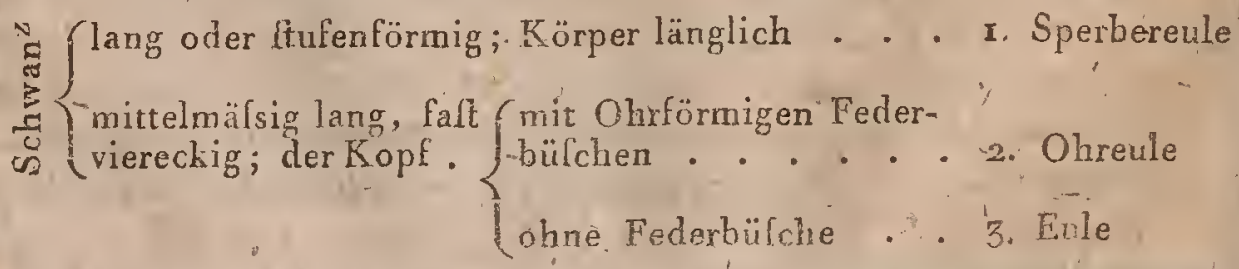




\section{BEMER KUNGEN ZUR XX. TABE:LE.}

Der Name Federhalfe ift hier hlols im Gegenfatz zu der vorigen Familie genommen. Die Lage der Angen entfern die hierler gehörioen Vogel von den Nachtvögeln, welche überdem die. Bafis des Srtínahols von Haartedern verfieckt haben, die hier yon einer farbi en nackten Warhshaut bedeckt ift. Alle diefe Vögel thesen hey Tage, näbren Gch meilt, von lebenden Thieren, aut welclie lie mit aufserordentlirher Srinelligkeit, wie aus' der luft herunterfallen: fif kreilen und teigen fo hock 1 dafs man fie aus dem, Gelicht verliert, und fliegen nie truppwrile. Männ chen und Weibchen bleiben nur die Brütezeit beylammen. 1. Dia Bartgeyer (gyptus) unterlcheiden fich lehr.Jeicht von.allen übrigen Arten durch die Pinfel von Borftenhaaren am Sehnabel; es guhörn hichar der Lämmergeyer z. B. Vult. barbaus L. die Harpie u. f. w. . deren L art mit der der Geyer ubereinkömmt. 2. Dir Weihen (buteo die maa nach Anleitung der Tabelle leicht erkennen kann, find auch Vögel deren Muth nicht ihrer Stäke entiprirbt; fie gresfen keine Thiere an, die ihnen Widertaun leiston. Z. B. Lalco butéo I. 3. Die Habichte (altur) z, B. falco palumbarius L.' (wohin auch die sperber gehöreri, deren riüuel, wenn fie an den Rücken gelegt find, an Länge dem Sckwanze nichi gleich kommen), haben lehr lange Fulswurzeln undden Schrabel von der Bafis an gekrümmt. 4.ZZu dèn Falken (falco) rechner man nur die Arten, die recht lange Flügel haben, deren Käper aber aufBeinen mit kurzen Fulswurzeln ruht. Z, B. F. communis L. 5. Der Sekrecür (fecretarius) ift ein afrikailfcher Vogel, fein Schwanz ift doppelt fo lang als die Flïgel, an denen die zwey mittelften Scbwungfedern eine beträchtliche Länge haben Dinbeträchlliche Länge der nackten Fulswirzeln giebt ihm ein befonderes Anlehen. F. Cerpentarius L. 6. Die Adler (aquila) haben einige Aehulichkeit, mis den Bartgeyern. Die meiften haben die Fülse bis an die Zehen befiedert; die Flügel aber bald länger bald kürzer als den Schwanz. Z B. F. chrylaetos L.

\section{BEMEPRUNGEN ZUR XXI. TABELLE.}

Die Nachrvögel (nocturni), in der Grölse und Richtung der Angenin etwas dem Katzen ähnlich, Cehen in der Dunkelheit (Dämmerung) gut und bey Tage (chlecht; die meiften haben am vordern Theil des Kopfes einen Kreis von feinen (teifen federlolen Haaren, der die: Sulle der äufsern Ohren verfieht. I. Die Gattnng Sperbereulé (furnia) begreift die Eulen mit langen Schwanze z. B. Strix hudlonia L. 2. Die Ohreulen (bubo), lind diefelben die Linné fchon lo genannt hat. Z. B. Strix bubo L. 3. $\mathrm{Zu}$ den Eulen (Strix) gehören alle übrigaArten, die nicht in die zwey vorigen Gattungen paflen. Z. B. Strix aluco L. Alle nähren fich von kleinen Thieren; die fie wie die Kalmen fangen; die meiften habon die Fülse mit einem zarten Flaum bedeckt und ihre Schwungfedern find to weich, dafs das Geräılch was fie im fliegen machen, kaum hörbar ilt. Thre Stimine ift rauh und unaugenehm und ihre Farbe dunkel. 


\section{No. XXII.}

\section{- II. Ordnung. WANDERVÖGEL.}

Eine einzige Hinterzehe; die zwey äufseren Vorderzehen vereinigt. Fufswurzeln von mittlerer Höhe.

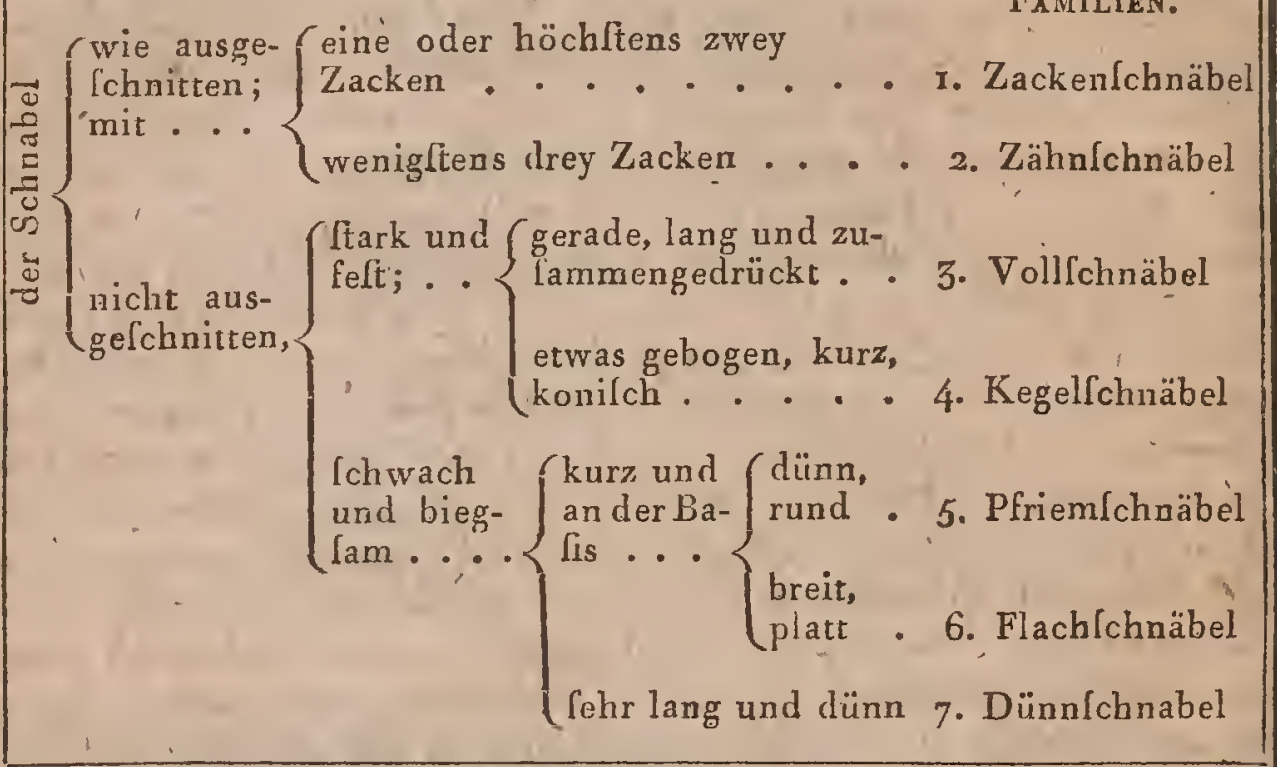

\section{BEMERKUNGEN ZUP XXII. TABELLE.}

Die Wander - oder Singvügel (pađleres) ftehen durch einige Arten von Aneifendroffeln mit dem Sumpfrögeln und dnrch die Tauben mit den Hünerartigen in Verbindung; aber zu den in der Tabelle angeführten Eigenheiten kommen noch andere die Lebensweile und Gewohnheiten betrefenden hinzu, die beweifen wie notbwendig es war; fie von der andern abzufondern. - So vereinigen fich die meiften Paarweile zur Begattungszeit, leben alsdann abgefondert, bauen gemeinlchaftlich das Neft, was fehr künftlich verfertigt wird und Mänchen und Weibchen beforgen gemeinIchaftlich die Bebrütung der Eyer und die erfte Erziehung der Jungen. Auf dem Boden fpringen fie mehr, mit beyden Fülsen zugleich, als dals fie gehen, wovon nur einige Gattungen z. B. Raben', Lerchen, a usgenommen find; die Weibchen haben gewöhnlich weniger fchöne und glänzende Farben als die Mänchen. Die Jungen find, wenn lie aus dem Eye kommen blind und ohne Federn; fie müffen von ihren Eltern erzogen 
und aus dem Kropfe geätzt werden. Nachher nähren fie fich von Inlekten und Körnern.

Aufser den, wie man fie wohl mit Recht nennen kann, natürlichen Charakteren, wodurch die hieher gehörigen Vögel mit einander übereinfirmmen, find fie auch durch eine Menge negativer, Eigenheiten von den: übrigen Ordnungen unterfchieden. So haben fie z. B: 1. niemals wie die Klettervögel żwey Zehen nach hinten und zwey nach vorn. 2. Niemals die vorderften Zehenglieder ganz mit einander vereinigt, wie das bey den Palmipeden oder Schwimmvögeln der Fall ift. 3. Die vorderlten Zehen find lelbft nicht einmal durch eine kurze $\mathrm{Mlembran}$ an ihrer $\mathrm{Bafis}$ vereinigt, wie bey den Hïnervögeln. 4. Ihre Fulswurzeln find kurz und felten, wie, bey den Sumpfüögeln, federlos. 5. Niemals find Klauen und Sclunábel gekrümmt, Cchneidend oder bakenförmig wie bey den Raubvögeln. Man konnte alfo füglich fie in eine eigne Ordnung bringen. Der Name Wandervögel pafferes, den ihnẹ Linné gegeben hat, giebt zwar keinen allgemein pallenden und beltändigen Namen an, aber er eriunert doch daran, dafs die meiften hieher gehörigen Vögel Zugvögel lind, die in grolsen' Haufen zu gewiflen Jahirszeiten auswandern. Man nennt fie auch Iperlingsartige Vöğel.

Die Zacken und Aus Tchnitte am Schnabel erleìchtern zwar fehr die Eeftimmung der Gattungen, aber lie geben nicht beftimmt die Nahrungsweile an, obgleich die meiften von denen, die nur ein oder zwey Zacken haben fleilchfreflend find. Vielmehr zeigen die zu ganz andern Familien gehörigen, die Schwalben, Meifen u. f. w. diefelbe Lèbensart und.Sitten. Man mufs daher diefe Abtheilungen in Familien nur als eine zur Auffindung der verfchiedenen Gattung bequeme Anordnung anfehen. Uebri-, gens werden wir bey jeder diefer Familie wahruehmen, dals fie, in dem fie die einander am meiften verwandten Vögel vereinigen, fich von den andern Familien immer durch eine Eigenheit unterlcheiden. 


\section{N. XXIII.}

I. FAMILIE. ZACKENGUANABL ODER GLYPHI RAVIPLN. *)

Wandervögel mit hönftens einen oder zwey Aus lchniten an der Spitze des Schnabels.

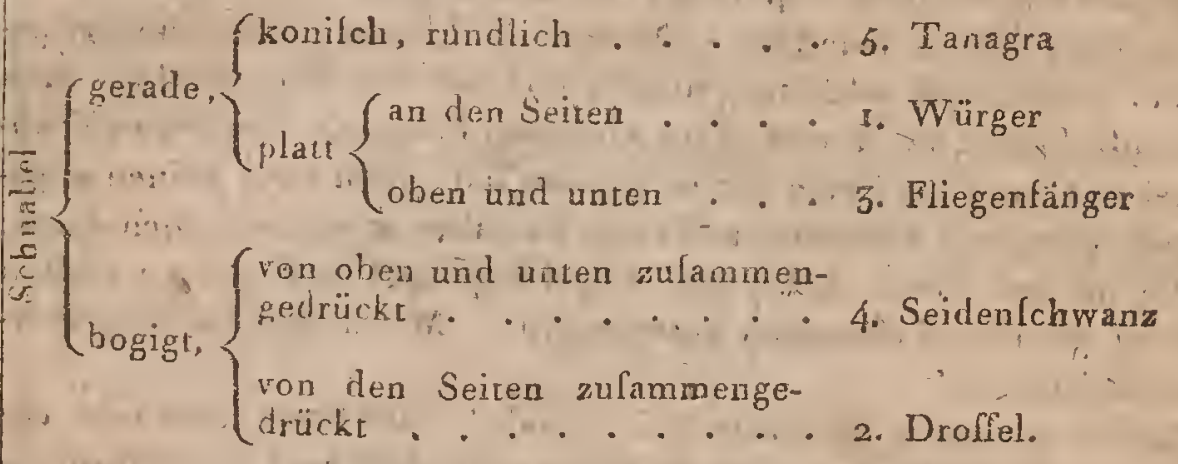

*) von $\gamma \lambda u \varphi_{b \xi}$ Sägęarken und exuфos Schrabel.

\section{BEMERKUNGEN ZUR XXII. TABELLE.}

Die Zackenfchräbel (emarginatiroftres Linn.) find meiftens klaine Vögel die fich eben lo gut von weichen. Früchten als von Inlekten nahren; ' lo dals die in gemälsigten Gegenden einheimilchen Arten gar nicht. zum Wandern gezwungen find, weil entweder die eine oder die andere Nỉhrung finh zu jeder Zeit des Jalıres vorfirder.

Obgleich die Familie der Zarkenlchnäbel nur wenige Gattungen in fich fasst, lo gehören doch lehr viele Arten hieher, die lo wohl in der alten als der neuen Welt vorkommen, und es ilt nicht zu leuguen dals dip durch die angegehenen Charaktere bier vereinigten Individuen eine grolse Manniglaltigkeit der Form wahrnehınen laflen.

Die Würger verbinden offenbar die Wandervögel mit den Raubvögeln; und die Ameifenvögel unter den Drolleln machen den Uphérgang zu den Sumpfrögeln; die Fliegenvögel und Taragras haben lange Flïgel und haben viel Ausdauer inı Fluge; lagegen die Droffeln. Seidenfcluwänze und Würger wit ihren kúrzen Flügein nur mühlam liegen können.

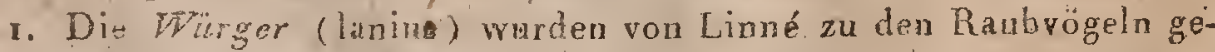
säbli, unterlcheiden fich aber. a) durch den kleinen und von leinen UrCpruage geraden Schnabel b) durcb die Yereinigung der äulsern Zehen, 
welche bis an das letzte Zehengelenk genau'verbunden fud. Mebrere Arten dieler Gattung greifen zwar kleine Vügel an, tödten lie auch und verzehren ihr Hirn; aber meiftens befteht ihre Nahrung doch in Infekten. Man kenut mehr als lechzig in beyden Veltheilen einheinilche Arten. Z. B. Lars. excubitor L.

2. Die Droffeln (turdus) 2. B. Turdus muficus, bilden eine an Aiten noch weit zahleichere Gattung als die vorhergehende. Es ift fehr fchwer in diefer Gattung lolche Unterabtheilunger zu machen, die für das Sïudium vollkommen bequem find; die bisher verfuchten find wenigftens noch nicht genügend. Diejenigen Arten, welche lehr hohe Fulswurzeln, und einen kurzen Schwanz haben und den Rallen unter den Sumplvögeln nahe kommen, hat man Ameifenvögel (formicivori) r. B. Turd.formicivora L. genannt; Krammetsügel (baccivori) heilsen die Arten, die ein gefprènkeltes Gefieder zeigen; eigentliche Drolfeln heifsen die, deren Gefieder einfarbig ift.

3. Die Fliegenfünger (imuscicapa) könnén fehr leicht an den fteifen Borfter erkannt werden, the aufsen un die Nafenlöcher herum litzen. Die zahlreicher in Amerika und Indien einheimilchen Arten nähren fich von Infekten, wie ihr Name es auch [chon angiebt. Z. B. Muscicapa. atricapilla $\mathrm{L}$.

4. Die Seidenfchwänze (ampelis) fiud fehr (chöne Vögel mit lebz lıaft-glänzenden Gefieder und meiftens-in Amerika zu Haule; auch hier find die Nalenlöcher mit Borften bedeckt die aber nicht fo ausgebreitet find; der Seidenlchwanz, z. B. ampelis garrulus, Pompadur, amp. pdmpadora u. I. w. gehören hieber.

5. Die Tanagras oder Merlen (tanagra) haben den Schuabel rundlich, wie unfere Sperrlinge, aber an der Spitze mit einem kleinen AusIchnitt verfehen; die meiliten zeigen ein lehr lchönes Gefieder und lind in Amerika zu Haufe. Z. B. Tanagra talao. 


\section{N. XXIV.}

II. Familie. ZÄHNSHNÄBEL ODER ODONTORAMPHEN. *)

Wandervögel mit wenigftens drey zahnartigen Ausl'chnitten.

$\vec{\Xi}$ Cehr lang, mit einem hornartigen Helm beletzt 3. Hornvogel

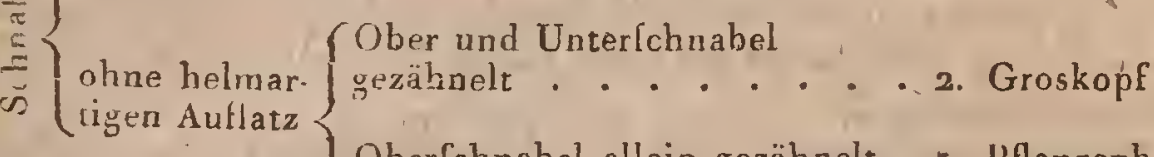
Oberfchnabel allein gezähnelt . r. Pflanzenbeifser

*, von odous Zahn und pauфos Schinabel.

\section{No. XXV.}

III. Familie. VOLLSCHNÄBEL ODER PLEREORAMPFEN. *) $\equiv \begin{aligned} & \text { mit nackten Stellen oder federlofen Fleilch- } \\ & \text { warzen .. . . . . . . . . . . . Atzel }\end{aligned}$

Whne nackte (lehr lang; Stirnfedern lammt-

$\left.\approx \begin{array}{l}\text { Stellen; Sei } \\ \text { ten-oder Rü- } \\ \text { kenfedern }\end{array}\right)$ arrig........

2. Paradiesviogel

kurz; (nackt; Spitze des Schna.

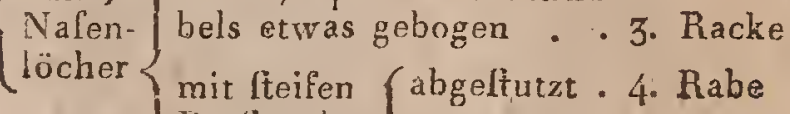

Borlten be. lang und

deckt; der litufenför-

Schwanz. $\left\{\begin{array}{l}\text { ftutenfor- } \\ \mathrm{mig} . .4 \text {. Aelfter }\end{array}\right.$

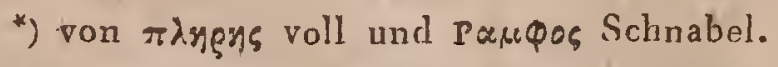

\section{BEMERKUNGEN ZUR XXIV. TABELLE.}

Die Familie dor Zähnfchnäbel (Dentiroftres) begreift nur wenige soch dazu nicht fehr bekannte Gatungen in fich, die fich von Früch 
ten und vegetabilifchen Suhftanzen ernähren, in Europa gar nicht vorkommen und fich von den Vögeln der andern Familie lebr unterfcheiden.

1. Die Pflanzenbeifser (phytotoma) find Vögel die jen Kernbeilser. gleichen, die Ränder des Oberlchnabels aber gezähnelt hajen; man kennt nur zwey in dem füdlichften Theil der Erde einheimilche Arten. Z. B. phytoioma rara $L$.

2. Groskopf (momotus B riffon.) Z. B. rbamphaltos momota L. ilt ein amerikanilcher Vógel von dem man eräählt, dals er unter der Erde nilte und fich von Fleilch nähre, obgleich leine Zunge wie die der Pfefferfrafse getheilt ift, mit welchen man ihn fonft aucli zu den Klettervögeln zäblte.

3. Die Hornvögel (buceros) bewohnen die wärmften Gegenden der alten Welt. Ihr lehr langer Schnabel trägt an Ceiner Bafis eine küucherne Hervorraguug, deflen Form fehr, verfchieden ift und hinter welchen fich die Nafenlöcher öffuen. Z. B. buceros rhinoceros L.

\section{BEMERKUNGEN ZUR XXV. TABELLE.}

Unter dem Namen Pleniroftres lind in dieler Familie die Arten von W'andervögel vereinigt, die, den ftärkften und feftelten Schnabel ohne Krümmang und zahnartige Einfchnitre haben; deren Fulswurzeln mit Schuppen oder ringförmigen Schildern bedeckt find und die ihr Neft auf den Gipfel hoher Bäume oder anderer hoher Gegenftände machen.

I. Die Atzeln (gracula) baben viele Aehnlichkeit mit den Raben und den grolsen Droflelarten. Man kann fie Cehr leicht an den nackien Stellen oder gefärbten Fleilch. Warzen am Kopfé oder Halfe erkennén. Alle find in Indien einheimil'ch; fie näbren fich von Inlecter, vorzïglich von Heulchrecken und Käferlarven; der Kehllappenvogel glaucopis ift mic diefer Gattung verwandt. Z. B. gracula religiofa.

2. Die Paradiesvögel find in Indien zu Haule; übrigenstauf der Tabelle hinlänglich charakterifirt. ' Z. B. paradilea regia $L$.

3. Die Racken (coracias) find der Art Raben, die man Häher nennt, sahe verwandt, unterfcheiden fich aber durch ilure ganz blolsen Nafenlöcher. Z. B. coracias garrula L.

4. In die Gattung der Ráben (corvus) hat man eine grofse Anzahl Vögel gebracht deren Hauptcharakter von der Bildung des Schnabels; von den mit vorwärts gerichteten Borfien bedeckten Nalenlöchern, von den langen Fulswurzeln und von dem kurzen wie geftutzien Schwanz grenommen ift. Man zählt lieher Dohlen, Häher, Krähen u. 1. w. Z. B. corvis corax, monedula L.

5. Die Aelfern (picae) unterfcheiden fich von dem Pialsen einzig durch den längeren Scliwanz, (deflen ffufenfömigfitzende Federn lich im Fluge nicht ausbreiten,) und dadurch dafs fie auf Erde melar (pringen als gehen. Corv, pica I. 
Wandervögel.

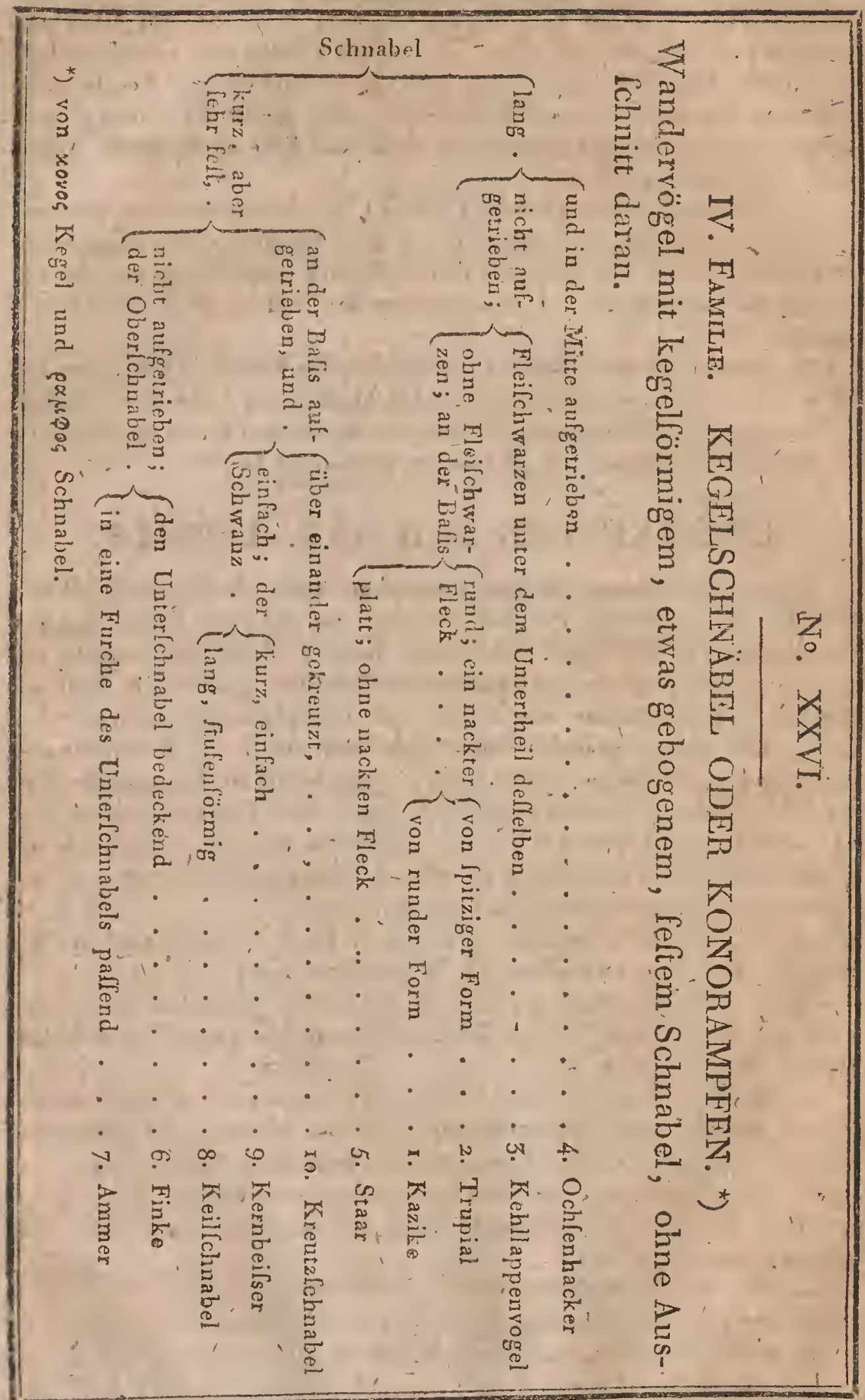




\section{BEMERKUNGEN ZUR XXVI. TABELLE.}

Die Wandervögel bilden unter fich fellbft eine fo natüliche Ordnung, und die dahingehörënden Gattungen kommen fo nit einander überein, dals man lie lér leicht dun Allgemeinen wäh würde kennen lernèn dsönnen, wenn ihrer nur nicht eine lo grolse Zabl wäre; aber es giebt eine lo aufserordentliche Menge von Arten, dals man wegen der Vrahl der Charakicriftik lehr in Verlegenheit kommt, weil gerade die lür gewifle Gattungen. ganz cbarakterifilchen Eigenthümlichkeiten allmählig zu verfchwinden und den Uehergang zu der folgersen Gattung zu má chen Icheinen. Von den Kegelfchnäbeln gilt dies ganz befonders, und, man muls geftehen dals diele Ordnung durchaus küuftlich ift.

x. Die Kaziken (cacicus) oriolus perficus L. unterfcheiden fich von den Triupialen oder Pirol (oriolus) $z$. B. oriolus viricits L. nur durch den federlòlen Theil der Stirn, der, ftatt fpirz ausgelchnitien zu feyn, eînen runden Fleck darftellt. Die hieher gehöıgen Vögel leben meilt in zahlreichen Gefellfchaften und näbren lich von Körnern oder Früchren; ihre Nefter hängen fie auf eime Lehr künftliche Weife an die äulserften Enden der Zweige der Bänme.

3. Der Kehllappenuagel (glancopis, callaeas Lath. 7. B. G. cinerea, hat wegen del unter dem Schnabel fitzenden runllicher. Warze einige Aehnlichkeit mit den Atzeln Es ift diefer Vogel in Neufeeland beobachtet, aber eigentlich wenig bekannt.

4. Der Ochfenlcacker (buphaga) ift ein afrikanifcher Vogel, der auf fler Haut der Wiederkäuer die Oeltruslarven und die anderen diefe Säugrhiere plagenden Infekten lucht. Z. B. Buph. africanus Lath.

5. Die Strare (fturnus) haben ihre Nafenlöcher darch eine Art von Eleifchiaut halb verlohlolfen; einge Arten naheren fich den Drolfelı, andere mehr den Atzeln aus den vorhergehenden Ordntingen. 2. P. Sturnus vulgaris $L$.

6. In der zahlreichen Gattung der Finken (Aingilla) finden fich über hundert Arten z. B. Kanarienvơgel, Stieglitz, Hänlling u. f. w., die fich alle von Körnern und kleinen Infecten nähren.

7. Die Ammern (emberiza) haben den Unterfchnabel breiter als den Oberfchnabel fo dafs letaterer z. L. emb. nivalis L. von crfterer aufgenommen wird; gerade das Gegentheil wird bey, den meiften übrigen Vögelı bemerkt.

S. 9. го. Die Keilfchnäbel (colius) z. B. col. capenfis L., Kernlecfsay (ioxia) z. B. loxia coccothrauftes $I$. und Kreatafchriabel (curviroftra) z. L. Loxia curviroltraL. find einander in vieler Hinlicht fehr rahe; alle haben einen ftarken feften Schnabel, der leichi in die hartlchaligon Exüchte z. B. Nülse und andere Kerne hinein dringen kann. 


\section{No. XXVII.}

V. Familie. PFRIEMENSCHNÄBEL ODER RA-

\section{PHIORAMPEEN. *)}

Schnabel kurz, , fchwach, biegfam, ohne Ausfchnitt daran, mit runder dünner Bafis.

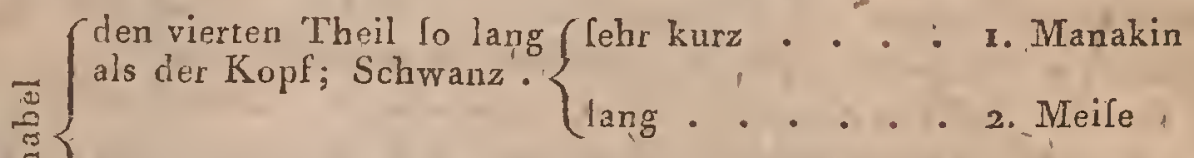

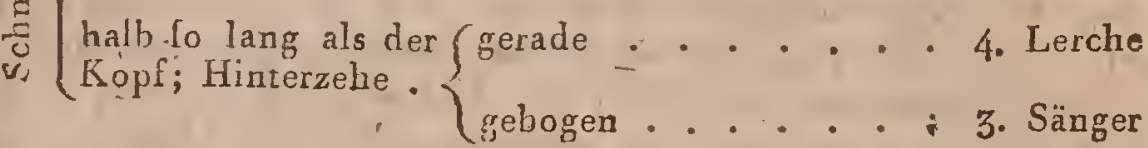

\section{No. XXVIII.}

VI. Familie. FLACHSCHNÄBEL ODER OMALORAMPHEN. *)

Wandervögel mit kurzem Ichwachen Schnabel, ohne Ausfchnitt daran, aber mit breiter platter Bafis.

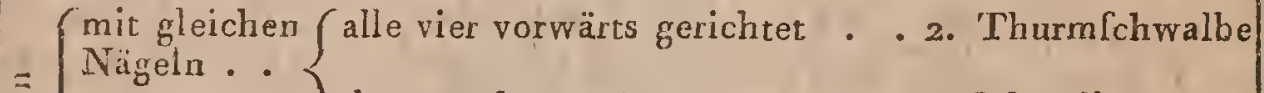
drey nach vorwärts . . . I. Schwalbe.

woran der mittelfte $\mathrm{Nagel}$ an einer Seite gezähnelt . . . . . . . . . . 3. Nachtlchwalbe

*) opadio's flach, und $\xi x \mu \varphi \circ$ s Schnabel.

\section{BEMERKUNGEN ZUR XXVI. TABELLE.}

Die Vögel der einen Gattung, welche die kleine Familie der Pfriemenfchnäbel ([ubuliroltres) bilden, kommen allerdings was die Form des Sclonabels anlangt lehr mit einander überein. Allein was die Form des 
Körpers und der Fülse anlangt und in Beziehung auf die Lebensweile find fie lehr von einander abweichend (allo nur. künflich hier vexeinigt.)

1. Die Manakins (pipra) zeichnen fich durch die Lebhafrigkeit er Farben an dem Gefieder der meiften Arten und durch die Kürze des Schwanzes aus. Sie bewohnen Amerika und einige haben einen äulserft fchönen Gelang. Z. B. pipra pareola.

2. Die Meifen (parus) haben die äufseren Zeben nicht, wie die vorige Gattung, vereinigt; lie klettern und halten fich mit der grölsteu Gefchicklichkeit allenthalben feft: Beftändig find lie in Bewegung, lie find fehr muthig; nähren fich vorzüglich von Infeckten; fie greifen aber auch kleinere Vögel an, deren Gehirn fie verzehren, und von denen fie auch Blut auslaugen (?) Sie haben einen wenig angenehmen Gelang. Z. B. Parus maior L.

3. Die Sünger (motacilla) begreifen die Vögel unferes Vaterlandes, die die angenehmlte Stimme hảben; alle nähren fich von weichen Inleckten ader kleinen Saamen. Die meiften verlallen uns den. Winter hindurch. Sie legen nicht fo viel Eyer wie die Meifen, aber fie machen ihre Nelter mit grölserer Sorgfalt, Z. B. moiacilla luscinia, rubecula L'.

4.-Die Lerchen (alauda) find die Arten diefer Familie, welche den längften Schnabel haben, der ganz gerade und an der Bafis etwas vorra. génd ift; auch der Nagel der Hinterzehe ift gerade und oft lehr lang. Einige niften 'auf dem Erdboden; alle fingen ganz angenehm. Z. B. Alauda arvenfis.

\section{BEMERKUNGEN ZUR XXVIII. TABELLE.}

Die Wandervögel mit plattem und breitem Sclınabel, Flachechnübel (planiroltres) nähren fich allein von Infeckten die fie im Fluge in der Luft fangen; fie bilden eine der natürlichften und und unterlchiedenften Familien diefer Ordnung.

r. Die Schwalben (hirundo) flegen bey Tage; fie wandern alle Jahr zu der Zeit aus, wo die Inleckten mangeln. Z. B. hirundo rultica L.

2. Die Thurmfchwalben' (apus) háben ganz kurze Füfse, gar keine Hinterzehe, fondern alle vier hakenförmige Nägel find vorwärts gerichtet, " und fie halten fich damit an dern Eingange ihres von Erde u. 1. w. gebaueten Neftes felt. Z. B. Hirundo apus L.

3. Die Nachifchwalbien oder Ziegenmelker (caprimulgus) fliegen felten während des Tages, wo das helle Licht fie blendet; alle haben den Schnabel fehr'weit gelpalten, an der Bafis mit fteifen Borften beletzt, weite Ohrlücher und runden Schwanz. Sie nähren fich vorzüglich von Schmetterlingen und Nachtinleckten. Z. B. caprim. europaeus L. 


\section{No. XXIX.}

VII. FamLIE. DÜNNSCHNABEL ODER, LEPTO RAMPHEN. *)

Wandervögel mit langem, dünnem oft biegfamen Schnabel, ohne Auslchnitr.

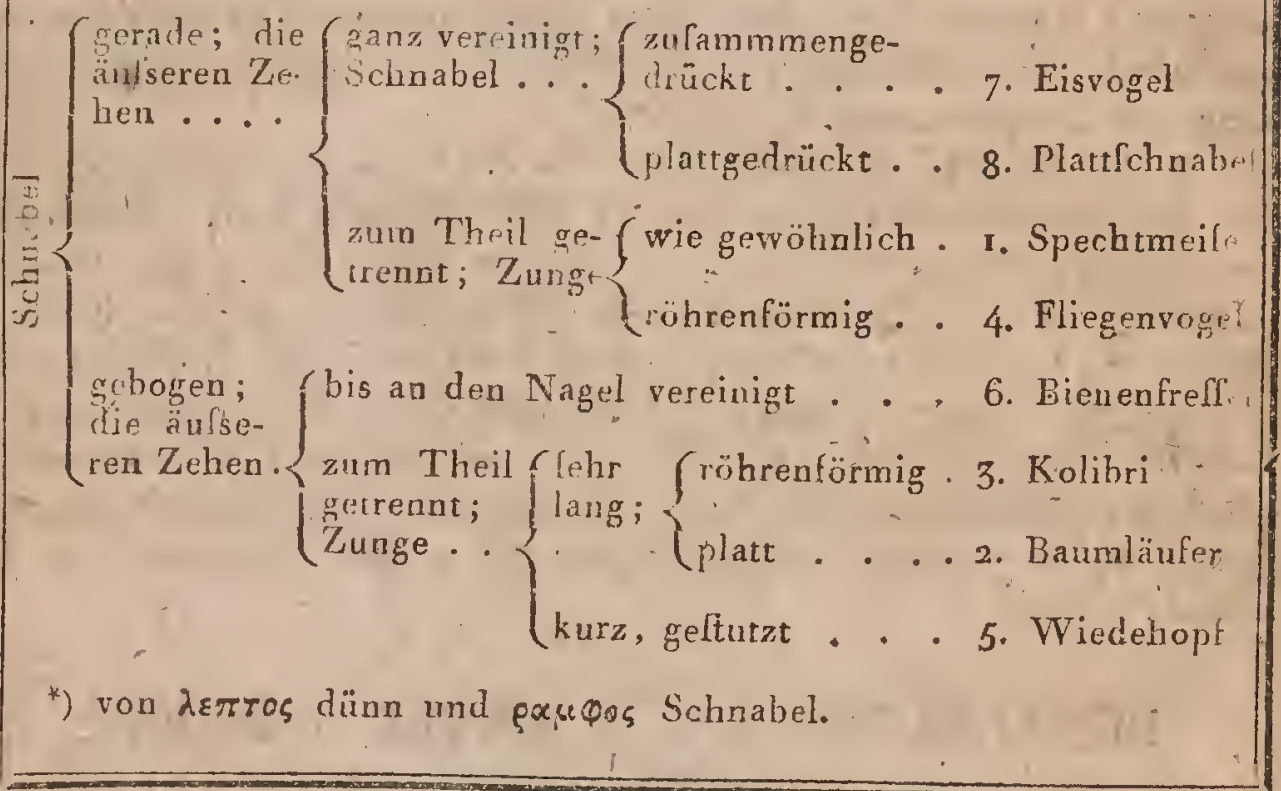

\section{BEMERKUNGEN ZUR XXIX. TABELLE.}

Die Dünnfchnäbel (Tenuiroftres) haben alle den Schnabel wenigftens noch einmal fo laing als den Kopf; allein die hier zulammengeftellten Vögel find lonft ganæ wilkührlirh vereinigt; Geftalt und Sitten find bey den aufgeführten Gattungen höchlt verfchieden.

r. Die Spechtmeifen (Sitta) klettern wie die Meilen, kommen aber auch fonft in Lebensart und Gewohnheit mit den Spechten unter den Klettervögelñ überein. Z. B. Sitta europaea. L.

2. Die Baumlïufer (cerhia) nühren fich vorzüglich von Infeckten wie die Meifen, hahen eine äufserft ftarke lange Hinterzehe; die Nägel find hakenförmig. Z. B. certhia familiaris.

3. Die Kolibris (Trochilus) find kleine Vögel, gefchmückt mit den reichlten und glänzenften Metallfarben; fie laugen fliegend den Honig aus den Blumen; fangen abur-auch im Fluge Inleckten. Nur in Amerika 
hat man fie gefunden. Sie brüten nur zwey Eyer auf einmal, in cinem Nefte, was fie lehr künftlich aus flockigen Maflen verffrigen. 7. J. Trochilus pella $\mathrm{L}$.

4. Die Fliegenvëgel, (orthorynchus) find die allerkJeinlten Vögel die es giebt. Sie unterfcheiden fich von den Kolibris uur durch die Form des Schnabels. Z. B. T'rochilus minimus, mosquitus L.

5. Die Wiedehopfe (upupa) haben falt den Schnabel der Brachvögel (im Kleinen) und sähren lich von Infekten. Z. B. Upupa epops 1..

6. Die Bienenfreffer, (merops) haben mit den vorigen talt glciche Lebensweife, unterfcheiden fich aber durch ihren winklichen Schnabel. Faft alle haben fehr lange Federn auf dem Kople, Halle oder Schwanze? Merops apiafter. L. *

7. Die Eisuögel (alcedo) leben am Waffer; Sie fangen im Fluge die kleinen Fifche die an der Oberfläche des Waffers fchwimmen, verfchlingen fie ganz und gar und brechen nachher die Gräthen wieder aus. Der Form des Schnabels und den Jebhaften Farben des Gefieriers nach, haben fie viel Aehnliches von den Spechten. Z. B. alcedo ispida L.

8. Die Plattfchnäbel ('Todus) haben den Schnabel flach, platt, wie die Flachfchnäbel aber er ift dabey lang. Nur im füdlichen Amerika kommen fre vor, wo lie fich von weichen Infecktenlarven nähren. $Z, B$. Todus viridis. 


\section{No. XXX.}

Dritte Ordnung. KLETTERVÖGEL.

Fülse woran zwey Zehen vorwärts und zwey hinterwärts ftehen.

Famitren.

Schnabel. $\left\{\begin{array}{l}\text { dünn an der Bafis, nicht gezähnelt } \\ \text { fehr dick an der Bafis, oder gezähnelt 2. Leichtfchnäbe }\end{array}\right.$

\section{No. XXXI.}

I. Famile. KEILSCHNABEL ODER SPHENO. RAMPHEN. *)

Der Sćchnabel Cpitz, dünn an der Bafis, keilförmig und nicht gezähnelt.

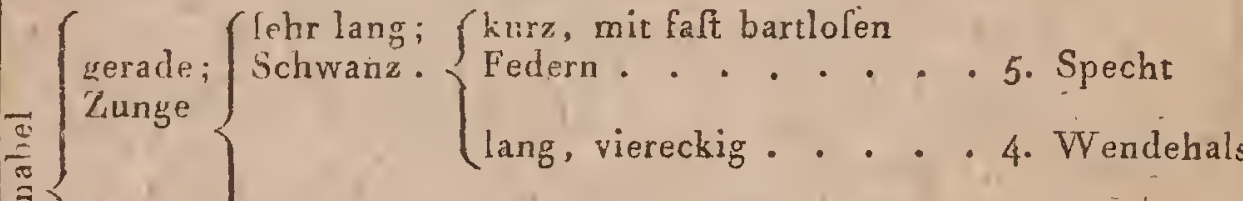

$$
\begin{aligned}
& \text { kurz . . . . . . . 2. Jakamar }
\end{aligned}
$$

von $\sigma \varphi$ Y Keil und gakpos Schnabel.

\section{BEMERKUNGEN. ZUR XXX. TABELLE.}

Die Stellung der Zehen, zwey nach vorn und zwey nach hinten, wodurch eine Art Zange gebildet wird, vereinigt die logenannten Kletter 
vögel (fcanfores) aul eine fehr natürliche Weife. Man kennt überhaupt bsy den rückgrathigen Thieren keins, wenn man etwa das Chamäleon ausnimmt, was eine ähnliche Bildung zeigte.

Diefe Ordnung theilt fich fehr bequém in zwey Familien. Die zu der einen gehörigen Vögel nähren fich von Infekten, die lie auf den Bäumen und lelblt unter den Rinden derfelben fuchen; diefe haben einen keilförmigen und felten beträchitlich dicken Schnabel. Die zur ándern $\mathrm{Fa}$ milie gehörigen freflen nur Früchte und Saamen. Ihr Schnabel ift, Io grols er auch ilt, lehr leicht, weil er inwendig hohl und leer ift.

\section{BEMERKUNGEN ZUR XXXI. TABELLE.}

Die Keilfchnäbel (cuneiroftres) und überhaupt die Klettervögel können aut der Erde und allen Flächen, die ihre Zehen nicht umfallen, nur fchlecht gehen.

. '. Die Kuckucke (cuculus) von ihrem Gefchrey lo genannt, zeigen die Eigenthümlichkeit, dafs fre ihre Eyer in die Nefter andêrer Vügel legen und ausbriiten laflen, fo dals die Eltern weder Nelter bauen noch für die Ernährung der Jungen forgen. Z B. cucul. canorus L:

2. Die Jakamars (galbula) in Amerika zu'Haufe, find lange zu derr Eisvögeln gezählt. Durch ihre Lebensart und Schnabelbildung kommen Ife den Spechten nabe, haben aber weder den Schwanz noch 'die 'Zunge'. derfelben. Z. B. Alcedo galbula L.

3. Die Anis (crotophaga) haben die Gewohnheit der Ochfenhacker in Hinficht auf die Art ihren Frals zu luchen; fie find, aber bis jetzt nur in Amerika angetroffen. Sie lehen den Raben ziemlich ähnlich. Zur Brütezeit vereinigen fich eine Menge Weibchen, bauen ein gemeinfchaftliches Neft, legen dann ihre Eyer und bebrüten alle zulammen nebeneinander litzend. Z Z. B. Crotophaga ani.

4. Der Name Wendelials (yınx) zeigt die gewöhnliche Bewegung des damit belegten Vogels an. Gewohnheiten und Lebensart bringt die Wendehälfe den Spechten nahe. Z. B. Funx torquilla L:

5. Die Steuerfedern des Schwanzes der Spechte (picus) z. B. picus viridis $L$. Find fteif und am Ende wie abgenutzt und dienen dem Vogel um lich auf, die Baumftärmme damit aufzuffützen, wo er fich anhält und mittelft der langen am Ende mit rückwärts gerichteten Stacheln befetzten Zunge, In lekten fuchen kann. 


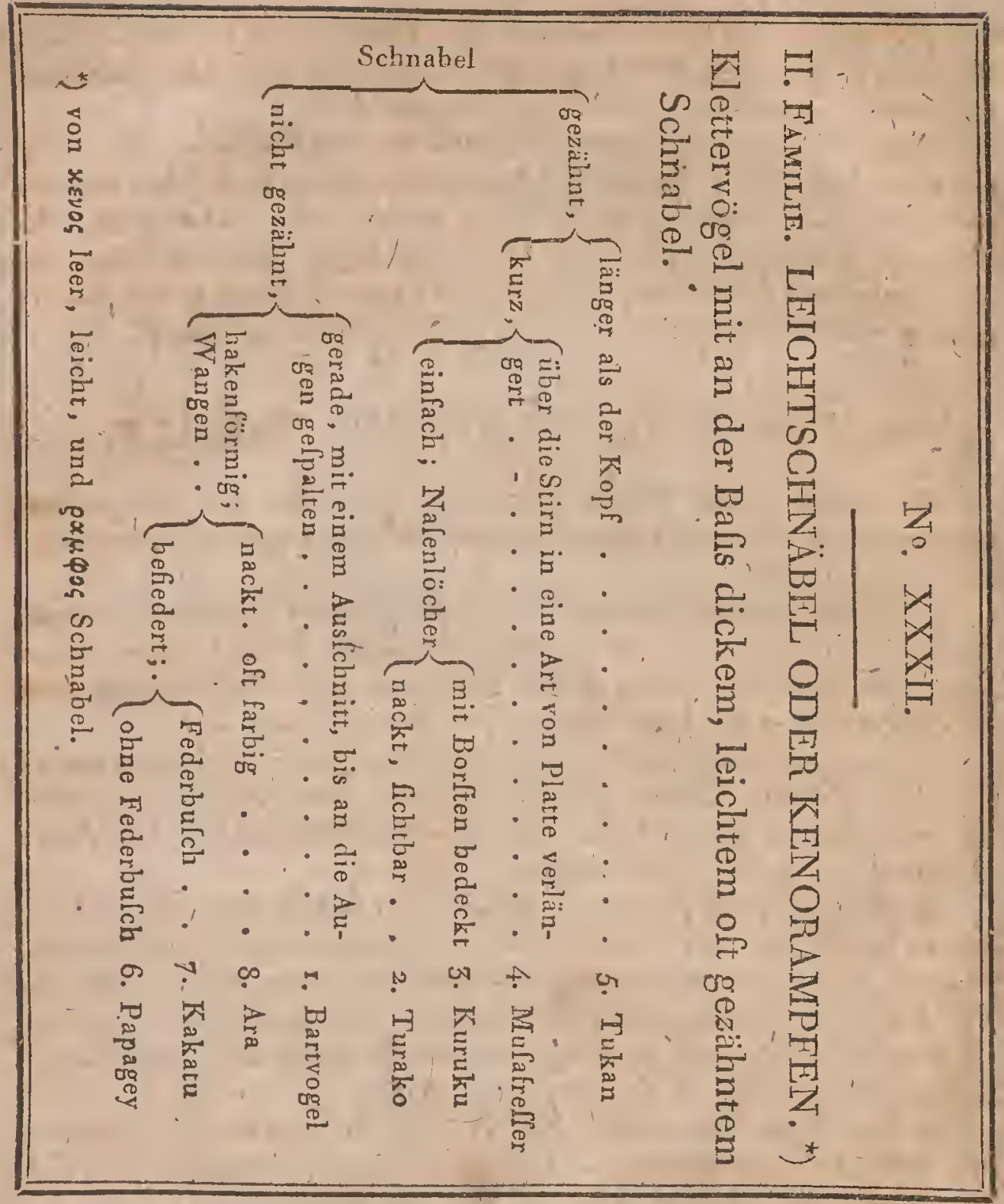

\section{BEMERKUNGEN ZUR XXXIT. TABELLE.}

Die meiftẹn zu diefer Familie gehörigen Vögel hahen einen Io grofsen und zur Grölse des Kopfes unproportionirten Schnabel, dafs, er ilven zur Laft werden mülste, wenn er nicht inwendig hohl und daher Cehr leicht wäre. Daher der Name Leichtfinabel. (Leviroftres) Die meilten legen nur zwey Eyer, wie die Tauben, mit welchen fie in diefer Hinficht überein kommen. In Europa find fie einheimifch nicht beobachiet. 
1. Die Bartvógel (bucco), z. B. Bucco philipinenlis, fcheinen diele Fa. milie, mit der vorhergehenden zu verbinden; fie nähren fich gern von Infekten, die fie wie die Bienenfreffer im Fluge fangen. Die amerikanilchen Tamaitas und die afrikanilchen Barbikais gehören hieher.

2. 3. u. 4. Die Kurukus (trogon) z. B. trogon viridis, die Turakos (turaco) cuculus perla, L. und die Mufaftrefer (mulophaga) M. violacea-L. find Vögel mit glänzendem Gefieder, deren Lebensart noch wenig hekant ilt, die man in den heilselten Zonen angetroffen hat.

5. Die Tukans (rhamphaftos) haben einen bemerkungswerthen grofsen Schnabel, fo dals man auf dem erfen Anblick glauben follte, er gehürte einem rehnmal gröfseren Vogel; alle find in den heifseften Zonen einheinifch und nähren fich von Palmfrüchten. Sichaben fchönes lebhaft * gefirbtes Gefieder. Ihr Gefieder wird , Sehr gefucht und inacht einen Gegenftand des. Pelzhandels aus.

6. 7. 8. DielPapageys (pfitracus) pfitt. elychacus und die Aras (ara) pfittac. macao L. fo wie die Kakatus (cacatoes) plittac. criltatus L. Laben einen in Form und Beweglichkeit merkwürtigen Schnabel. Sie zeichnen fich durch ibre fleifchige Zunge und belonders die Papageys durch ihre Stimme, die die Stimmen aller Thiere nachahmen, fehr aus; es find die einzigen Vögel die fich ihrer Fülse bedienen um die Nahrungsmittel damit zum Munde zu fübren.

Aulser der Abtbeilung ia Kakatus oder gelıubte Papageyen und in Aras oder Papageyen mit'nackten. Wangen, haben die Franzolen die verfchiedenen Arter der Gattung Papagey, wach der Vertheilung der Farben und der Lïnge des Schwanzes, verlchieden abgetheilt und benannt. x. Perrucites oder perriques nennen fie die, wolche einen fiufenartigen oder fehr langen Schwanz haben. 2. Die welche am Ende der Flïgel keine Flecke haben, heilsen Papegais. 3. Wenn fich ein rother Fleck dafelblt vorfinden baben fie den Namen Amazones. 4. Crics heifsen lie wenn der Fleck von anderer Farbe ift. Die Papageyen deren Gefieder grofse Parthien von Roth zeigen, heifsen Loris u. f. w. Diele Gattung enthält mehr als hundert und funfaig verfchiedene bekannte Spezies. 


\section{No. XXXIII.}

\section{ORDnung. HÜNERARTIGE VÖGEL.}

Die Vorderzehen an der Bafis durch eine kurze Membran vereinigt.

\section{FAMILIEN.}

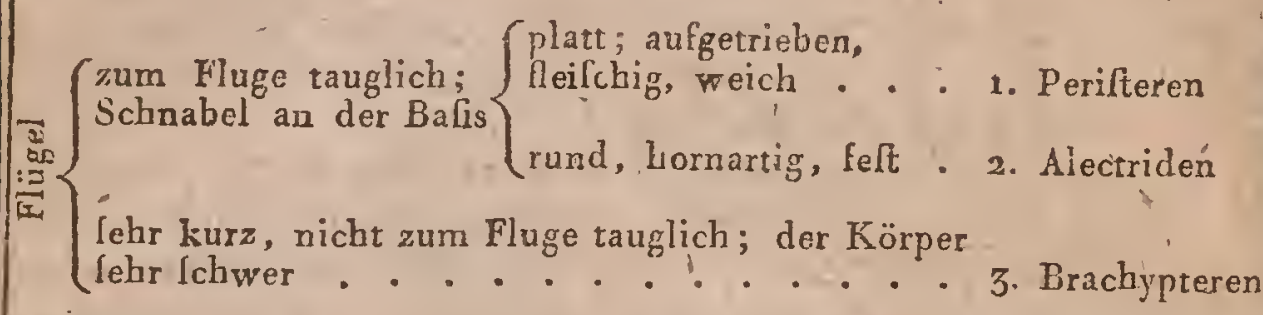

\section{No. XXXIV.}

I. Famile. TAUBENARTIGE ODER PERISTÉREN. *)

Flügel zum Fluge tauglich; Schnabel an der Bafis gerade; Nafenlöcher von einer weichen Haut bedeckt; Körper niedrig auf den Beinen.

\section{Taube.}

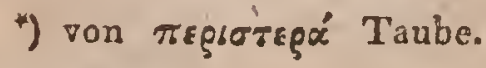

\section{BEMERKUNGEN ZUR XXXII. TABELLE.}

Die Hïnervügel (gallinae) kommen darin überein, dafs zwifchen den. Vorderzehen fich eine kurze Membran findet, und dais entweder gar keine oder nur eine Hinterzehe da ift. Dieler Charakter dient dazu, um fie fowohl vón den Raubvögeln zu unter(cheiden, deren Zehen bis 
2n die Bafis frey lfind, als von den Schwimmvögeln, wo fie im Gegentheil ganz und gar vereinigt find und auch von den Klettervögeln, wro zwey Zehen nach hinten ftehen. Die. Wandervögel haben zwar wohl die äulseren zwey nie-aber alle drey vereinigt. Von den Sumplrögeln unterfcheiden fie lich durch ihre Fulow zrzeln; obgleich einige Arten ibnen auch felir nahe kommen.

Alle Hünervögel nähren fich von Körnern, die fie verfchlingen ohne fie vorher zu verkleinern. Alle mit Ausnalime der erften Familie legen eine grofse Zabl Eyer in ein Neft, was dio Weibchen allein auf dem Boden zubereiten und wo fie auch olme Hülfe der Männchen brüten. Die Kleinen kriechen nach einer langen Bebrütung:aus und Iuchen gleich für fich allein die Nahrung, wozu dic Mutter fie anleitet.

Die meiften haben einen feften, kurzen, etwas gekrümmten Schaabel wo der Oberlchnabel den Uuterfchnabel bedeckt. Die Männchen haben gewöhnlich ein Ichöneres Gefieder und fchönore Formen als die Weibchen. Ihr Gefang ift nicht ambaltend, unangenebm und bey den Weibehen gẹöhnlich ganz unbedeutend.

\section{BEMERKUNGEN ZUR XXXVI. TABELLE.}

Die Taubenartigen ('columbini) zeigen lo viele die Lebensart betreffende Abweichungen von den ïbrigen Hïnervögeln, dafs einige $\mathrm{Na}$ turforfcher geglaubi haben, fie in eine belondere Ordnung bringen zu nüfen. Sie find die einzigen Hünervögel die einen weichen bieglamen Schnabel haben, die in einén Zuge fort triaken faft wie die Pferde, dié parweife und nicht in Polygamie leben: die gemeinfchaftlich und zwar mehreremal des Jabres küren, die nur zwey Eyer in ein hohes Neft legen; deren Junge wenn fie mur Welt kommen lehr fchwach find and die Shre Jungen ätzen d. h. ihnen die erfe Nahrung 'zubereitet in den Schnabel bringen. Man theilt die Arten ab in lolche mit langem und in folche mic mittelrälfigem Schwánz; letztere künner wieder abgetheilt werden in folche mit Fleifchwarzen um die Augen und in folche mit gewöhnlichen Augenliederin; auch kann die Länge und Pichtung des fehr kurzan und an feinem Urfprunge gekrümmten Schabels zur Unterfcheidung diefer Vügel benutzt werden, wovon es mehr als 60 Arten giebt, die bey zahmén Vögeln fo zalilroiche Varietäten' ungereclnnet. Z. B. Columba domelica. 
Hünerartige Vögel.

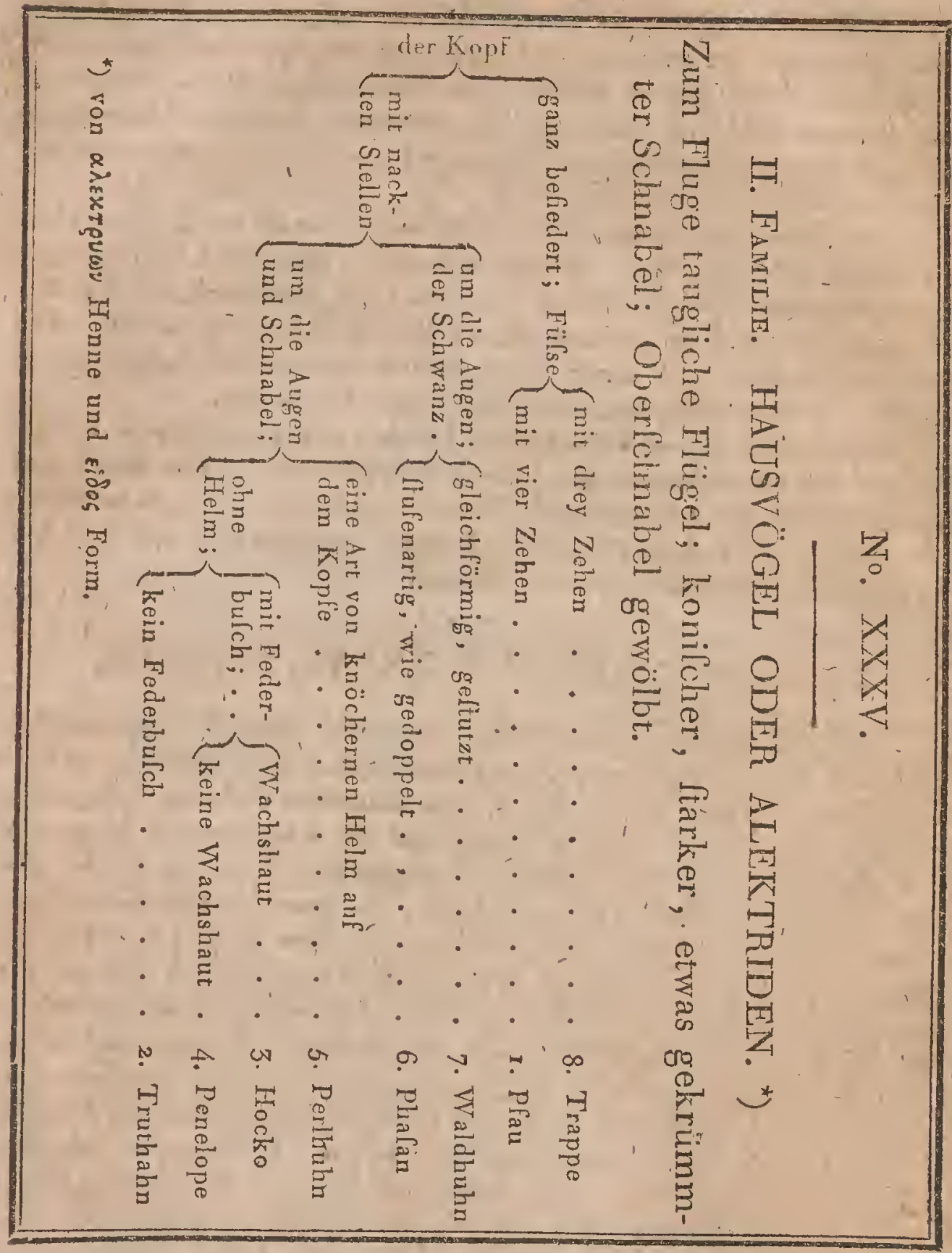

\section{BEMERKUNGEN ZUR XXXV. TABELLE.}

Die Vögel die der Menfch zu zähmen gewifst hat, hat man insbefondere mit, \{lem Namen Hausvügel, Hï̈ner, oder Federvieh belegt (alectrides.) Alle gleichen fich in der Form des Schnabels fowoh] als auch der Füfse, die wie mit Schuppen bedeckt und unten mit harten Warzen befetzl find; 'fie kommen ferner überein in der'Form der Flügel 
die zwar nur mittelmärsig aber doch noch' hingechend find um den'Körper über dem Boden, zu erheben und fort zu tragen, und in ihrer ganzen Lebensart.

1. Die Gattung der Pfauen (pavo) unterlcheidet fich noch von allen andern diefer Fanilie durch die Stellung gewiffer Federn auf dem Srheitel, die an ihrer Bafis nicht nahe aneinander fitzen und mit ilirer Spitze fich wie ein. Federbulch ausbreiten; eben fo durch die Federn auf dem Steilsbein, die fehr lang, oft mit augenförmigen Flecken gezeichnet lind und von den Thiere willkührlich erhoben ued in einem halben Zirckel oder Ràd ausgebreitet werden. Z. B. Pavo criftatus.

2. Die Truthühne (meleagris) find in Amerika einheimifch, und. macben nur eine Art aus; das Männchen hat 18 Steuerfedern.im Schwanze und einen Haarbüfchel auf der Bruft. Z. B. Mel. gallopavo L.

3. u. 4. Die Hockos (crax) z. B. Cr. alector L. und die Penelopen (penelope) z. B. Penel. marail L. find ebentalls amerikanilche Vögel, diofich von den Truthähnen dadurch unterfcheiden, dals ihnen die von der Stirn herabhängende Fleifchwarzen feblen, dals fie dagegen einen Federbufch auf dem Kopfe laben der willkührlich aufgerichtet werden kann, und dals die längeren Flügel über den Schrvanz hinạs ragen.

5. Die in Afrika einheimilchen Perlhühner (numida) zeichnen fich von alleń andern Vögeln diefer Familie durch iłren knöchernen Helm. aus, wovan der Scheitel ihres Kopfes bedeckt ili. Am Halfe haben fie Fleilchwarzen wie die Truthähne. Man kennt drey Arten. Z. B. Numida meleagris $\mathbf{L}$.

6. Die Wraldhühner (tetrao) bilden eine fehr zahlreiche Gattung, die Cchon Linné in drey Abtheilungèn gebracht hat; a) die Arten, welche befiederte Fulswurzeln und drey bis vier Zehen haben, wohin z. B. das Hafelhuhn, Birkliuhn, und dio eigentlichen Waldhühner gehören' 2. B. Tetrao urogallus L.; b) die Arten wo die Füfse unbefiedert und die Fufswuraeln bey den Männchen mit Spornen verfehen find z. B. Rebhuhn und Frankolin; Tetr.perdix L. c) die Wachteln. (z. B. Tetrao coturnix) wo die Fufswurzeln nie mit Sporen verlehen lind und wo fich bald vier bald drey Zehen finden.

7. Die Fafanen (phafianus) haben itn Schwanz fiufenartig und die mittellten Steuerfedern' fehr lang; aufser diefem Hauptcharakter haben die meiften auch noch Spornen oder konifclie Nägel an den Fulswurzeln. Der Halın und die Henne, wovon man mehr als 20 bey der Fortplanzung fortdauernde Variationen kennt, gehören "hieher. Z. B. Phafian, colchicus L.

8. Die Trappen (otis) lcheinen den Uebergang zu den zwey folgenden Farrilien zu machen; die Fufswurzeln lo wie überhaupt das Untertheil des Fulses find unbefiedert; in Hinficht der Körperform kommen fie dem Strauls und Caloar nalie. Z. B. otis tarda. 


\section{No. XXXVI.}

\section{FAMIIIE. KURZFLÜGEL ODER BRA- CHYPTEREN. *)}

Flügel wegen ihrer Kürze zum Fluge untauglich; fchwerfälliger Körper; Beine oberhalb der Ferle nackt.

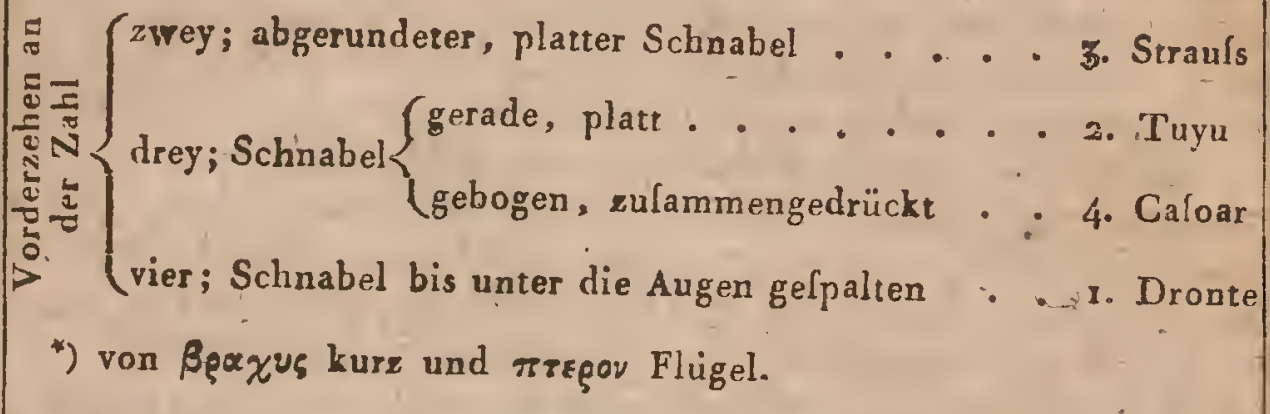

\section{BEMERKUNGEN ZUR XXXVI. TABELLE.}

Der von der Kürze der Flügel hergenommene Charakter ift allerdings hinreichend um die zu den Hünerartigen gehörige Reihe von Vögeln ron den Kurzflïgeln zu unterfcheiden; aber da diefer Umftand auch anzeigt dafs der Vogel nicht Alegen kann, und da die Bildung der Fülse auch nicht erlaubt dafs er lchwimmen kann, fo darf man auch noch daraus fchlielsen, dals alle fchnell gehen, dals fie ferner aúf gewifle Gegenden eingefchränkt find, auf trockne Orte, vorzüglich auf flache Gegendén. Hierin 'o.mmen auch alle diele Vögel überein, aber die Form ihres Srhnabels, fo wie die Lebensark die fie führen, if nach den Gattungen ganz verfchieden.

Keine einzige Art diefer Familie nährt fich von Fruchtkörnesn; die Form ihres Schnabels und die Bildung ihrer Zunge Ccheint dazu nicht geeignet zu feyn. Die meilten lieben Früchte und kleine Thiere, und fie verfchlurken ihre Nahrungsmittel ohne fie zu verkleinern.

Alle diefe Vögel find nur in den mittäglichen Gegenden der E:de einteimifch, wo fie cinlam leben. bey einigen Gattungen bebrïten dịe Weibchen ihre Eyer mit der grölsten Sorgfalt bey anderat begnügen fre fich, Lie aut den Sand oder in Löcher die fie in. den 
Saude machen, zu legen, wo fie dann durch' die Somnenhitze ausgebrütet werden,

Nur die beträchtliche Grölse des Körpers und die Kürze der Flügel vereinigt diefe vier Gattungen, die lonft eben nicht weiter mit einander übereinftimmen. Die Gattung Caloar hat zwey Arten, die übrigen alle nur eine

Es ilt zu vermuthen, dals, wenn einige Arten von Vögeln auf der Erde untergegangen find (wie dies doch durch geolegifche Unterluchungen bewiefen zu werden fcheint) vorzüglich auf die mit diefer Familie verwandten Vögel der Untergang lich erltreckte, wie er unter die Säugthiere vorzüglich die Familie der Pachydermen getroffen zu haben Icheint, welche am wenigften im, Stande waren der grolsen Cataftrophe zu entfliehen, wovon die Spuren allen Theilen 'der Erde Io deutlich eingedrückt find. .

x. Die Drontes (didus) find werig bekannte Vögel, welche fonit auf Isle de france rind I. Bourbon gelebt haben follen, jetz: aber dafelbft nicht mehr gefunder werden; ihr langer Schnabel gleicht dem des Pelikan, bat aber einen Endhaken wie bey der Scbarbe.- Z. B. didus ineptus. L.

2. Die in Ghili einheimilchen Tujus (rhea) fteben der Geftalt nach, etwa in der Mitte zwilchen Strauls und Caloar. Z. B. Struthio americanus $\mathrm{L}$..

3. Die Cafoars (caluarius) haben faft den Schnabel der Hünervögel; aber Federn mit ganz befonderer Eigenheit. Bey dem Indilchen Caloar find 'lie ganz haarartig; bey der in Südindien cinheimifchen Art, die keinen knöchemen Helm hat, ift. der Kiel jeder Foder in zwey Zweige getheilt, deron jeder leinen befondern und am Ende bieglamen Bart hat. Z. D. Struthio cafuarius. L.

4. Die Straufse (ftruthio) find die cinzigen bekannten Vögel, dis nur zwey Zehen haben; es fcheint dies auch die grölste Art von Vü. geln zu feyn und die einzige (?) welche ibre Eyer nicht bebrütet und welche in diefer Hinficht der Reptilien nake kommt. Z, B. Struthio camelus. L. 


\section{No. XXXVII.}

\section{OrDnUNG. SUMPFVÖGEL.}

Sehr lange, bis an das Bein unbefiederte, Fuiswurzeln; die äulseren Zehen an ihrer Bafis vereinigt.

$$
\begin{aligned}
& \text { FAMLLLEN. }
\end{aligned}
$$

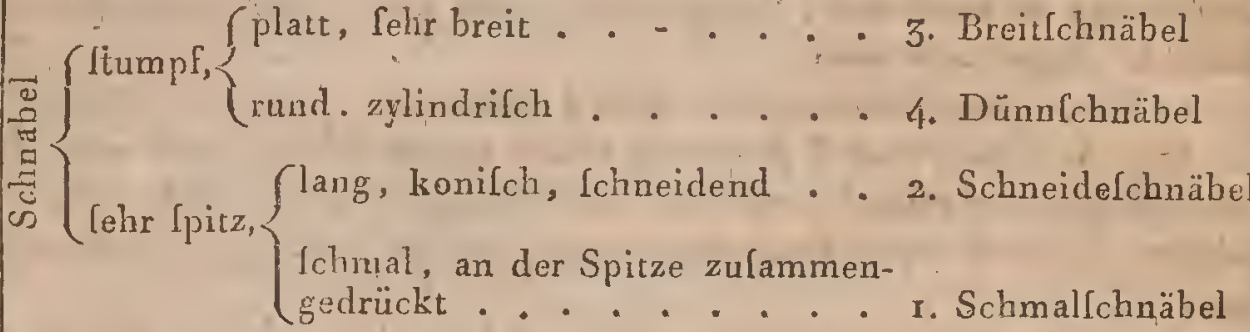

\section{BEMERKUNGEN ZUR 'XXXVII. TABELLE.}

Die Beine der Sumpfrögel, an dem untern Theile obne Federn, mit langén Fulswurzeln und langen Zehen, fcheinen beftimmt zu feyn, das Gehen am Ufer des Walfers zu erleichtern, wo fie, wie auf Stelzen gekend, ihren Körper gar nicht nals machen; man hat fie auch Ufervögel (Grallae) genannt. Diele Lebensart Icheint aber noch viele andere Eigenheiten nąch fich gezogen zu haben. So haben die meiften einen kurzen Schwanz, damit dieler nicht im Waffer nachfchleppe, wenn der Vogel auf Sumpfboden wadet: die Länge der Zehen. verhindert das Einfinken und da es bey allen (?) rückgrathigen Thieren etwas allgemeines ift, dafs der Mund den den Körper ftützenden Boden. berühren und die Nahrungsmittel ergreifen kann, fo mulste der Hals in Proportion zu den Fülsen verlängert werden. Daher denn die ganze Bildung; welche die Sumpfrögel zeigen, und befonders ilure ihnen eigne, Nahrung, die in Sumpt-oder WValferthieren befteht.

Die Vägel diefer Ordnung find ohnltreitig die, welche am beften und am meilten ohne ermüdet zu werden, gehen. Die beträchtliche Länge ihrer Fulswurzeln, und die befondere Belchaffenheit ihrer Artikulationen, welche durch eine Art von mechanifcher Feder unbeweglich (wie manche Tafchenmeffer) werden, erleichtern das Stehen, felbft af ei- 
nem Fulse. Die meiften halten beym Fliegen die "Fülse ganz hinter den Körper ausgeftreckt, lo dals fie dem Gewichte des vorwärís gerichteten Halles dadurch das Gleichgewicht halten. Die Sumpfrögel fiegen im Ganzen genommen mit grofser Leichtigkeit, belonders wenn lie; fich erlt bis zu einer gewiffen Hohe erhoben haben. Meiftens legt das Weibchen viele Eyer, welche fie ausbrütet indem fie fich rittlings über das (von deni Boden "etwas erhabene) Neft fetzt. Die Jungen find wenn fie aus dem Eye kommen, bey deh aut der Erde niftenden Arten, gleich ziemlich flink, und diele werclen von den Aeltern auch nicht befonders ernährt.

Allein die Ordnung der Sumpirögel ift doch nicht lo zulammengeftellt, dafs nicht der Naturforfcher zuweilen verlezen oder ungewils wäre', 'wohin er einige Arten briggen foll. So fteht der Sokratärvogel bey den Raubvögeln; lo ftehen von den Droffeln die Cogenannten Ameilenvögel bey, den Wandervögeln. Wir haben auch gefehn, daf's die Trappen und Straulse einige Achnlichkeit, mit diefer Ordnung haben. So finden fich auch unter den Schwimuvögeln der Flaningo, die Säbellchnäbler, die Waflerhühner, u. . w., welche, da fie Stelzenfüfse haben, in beyde Ordnung gebrackt werden können. Nur bey dẹn Klettervögeln findet gar kein $Z_{\text {weifél }}$ ftatt.

Die Abrheilung dieler Ordnung in vier. Familien, nach der Form des Schnabels giebt fehr natürliche Abfchnitte. Die Arten mit fumpfen Schnabel verfchlingen ihre, Beute ohne fie zu zerkleinern, die andern aber durchbohren oder zerlchneiden fie, ehe fie fie verfchlin. gen. Ein Theil nährt fich von weichen Würmern, Ider andere greift Kruftazeen und hartfchalige Thiere an. 


\section{No. XXXVIII.}

I. FAMILIE. SCHMALSGHNÄBEL ODER RAMPHOSTENEN. *)

Mit fpitzigem, fchmalem, befonders an der Spitze zufammen gedrücktem, mehr hohem als breitem Schnabel.

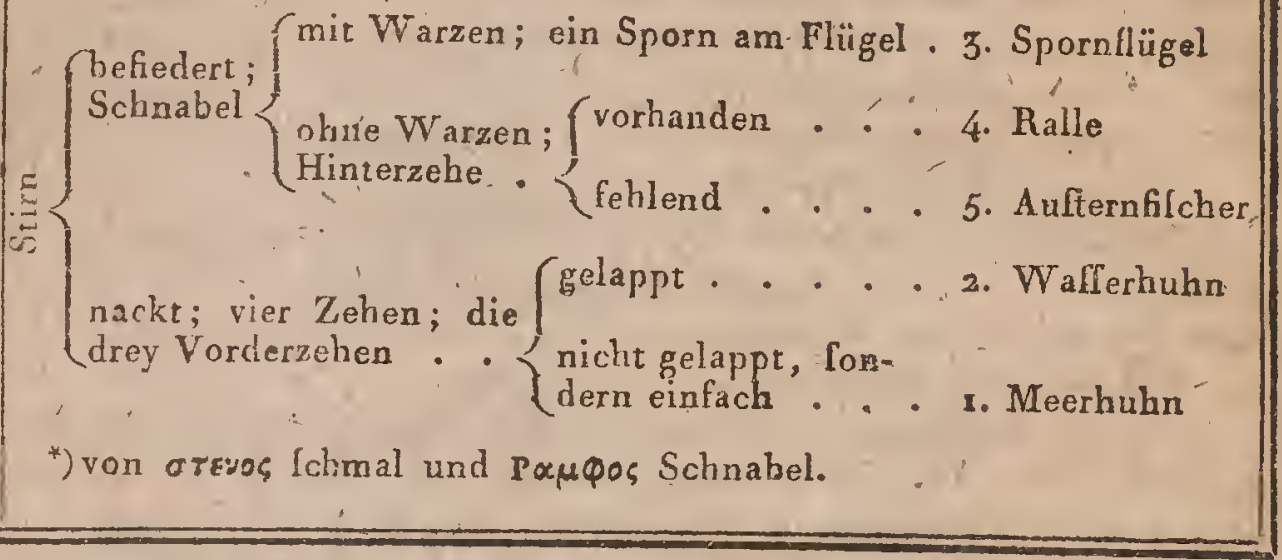

\section{BEMERKUNGEN ZUR' XXXVIII. TABELLE.}

Die Ufervögel mit von den Seiten zufanmengedrücktem Schnabel, haben überhaupt don Ober - und Unterlchnabel ltark genug um fich derfelben als Scheerenblätter, oder Meilsel zu bedienen, mit degen 'fie Würmer und Infektenlarven zerlchneiden, dio Gehäule' der Bauchfchleiclier zerbrechen und zwifchen die Valveln der kopflofen Mollusken fich hineindrängen um ihr Fleifch zu verzehren.

'т. Die Meerhühner (porphyrio) baben einiges Uebereinftimmende mit den Rallen, fie leben paarweile und laufen fehr fchnell im Schilf, fliggen aber fchlecht, mit unter dem Körper hängenden Fülsen; fie tauchen gut und lange $z, B$, fulica porpbyrio. L.

2. Die Wafferhühner (Fulica) gleichen einigen Arten der vorigen Gattung fehir und haben auch diefelbe Lebensart, aber fie fchwimmen noch belfer, klettern leichter an den Rohrltengeln in die Höhe, unt laufen an der Oberfläche des Waflers wie rnit breiten Schlittfchuhen ohne rinzulinken. Z. B. Fulica atra.

3. Die Spornflügel (parra) find amerikanifche Vögel, die lich beConders durch zwey Arten von fpitzigen Hörnern auszeichnen, welche 
an dem Anfange des Flügels, den man den Afterflügel zennt, fizen und deren fie fich zum Angriff bedienen. Die Hinterzehe ifi, wie die der Lerchen, mit einem langen Nagel verfehen. Z. B. Parra jacana L.

4. Die Rallen (crex) find in Europat das Analogon der vorigen Gattung. Es lind Vögel die in flachen Gegenden und am Ufer von Sümpfen fich taufhalten, einen kurzen Schwanz und leichtgebogerieu Schnabel haben, ihr Neft auf dem Boden baúen, und wenn der Winter herannaht zach füdlichen Gegenden zielien.' Z. B: Rallus aquaticus.

5. Die Aufternfreffer (haematopus) bilden eine Gattung von einer einzigen Art, die an der Form des Schnabels und an der rothen Farbe des, létatern wie der Fülse leiclut erkannt werklen kann. Diele Vögel bewohnen allenthalben in boyrlen Veltheilen die Ufer des Meeres, wo lie fich von Würmern und kleinen Schalthieren nähren, die fie an den Schaalen finden, welche fie fo wie fie fie am Ufer fehen nach aller Richtung drebera und välzen. Z, B. (Haematopus oftralegus) 


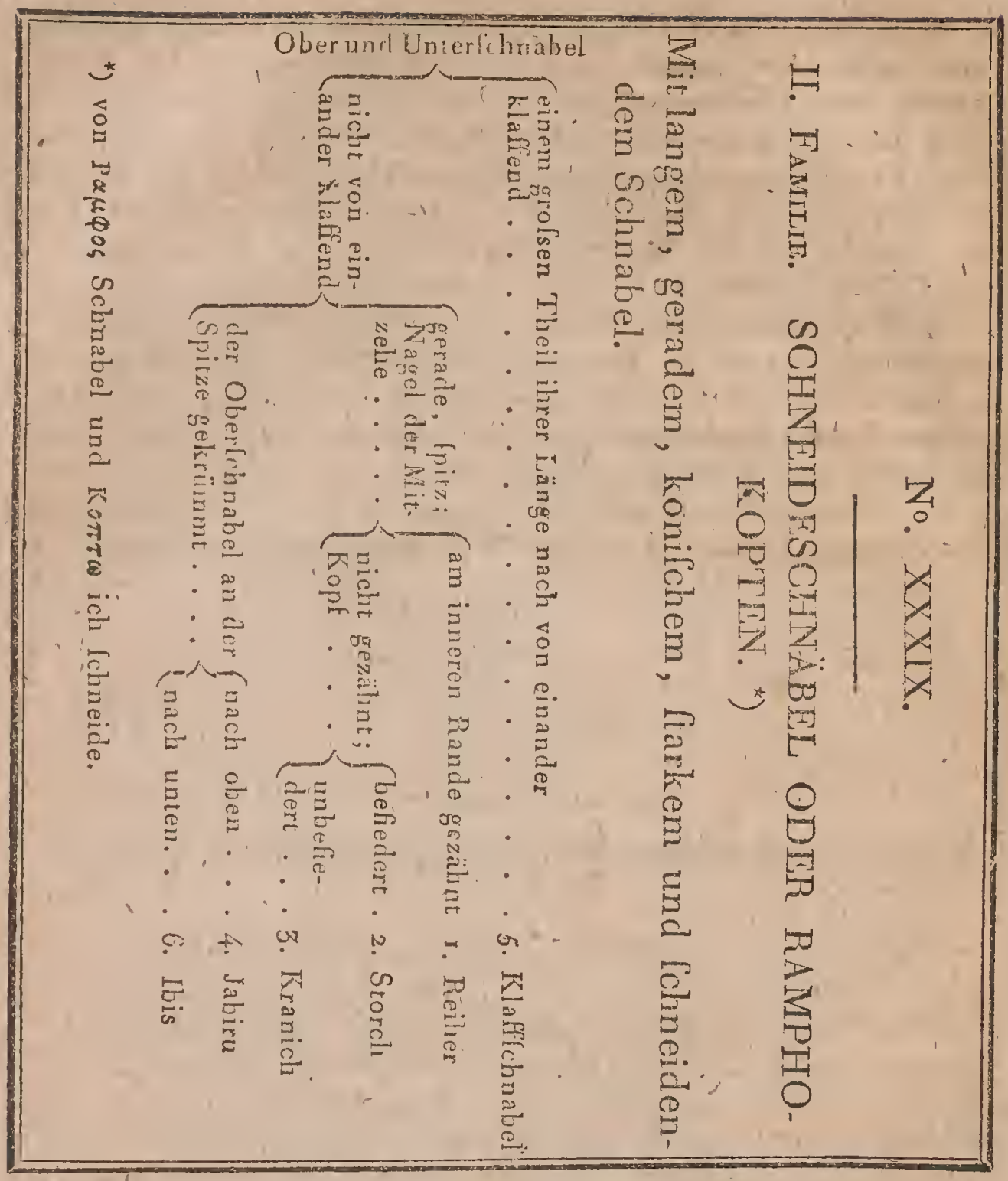

\section{BEMERKUNGEN ZUR XXXIX. TABELLE.}

Die Benennung cultriroftres ift mehr dazu paffend um den Gegenlatz in der Schnabefform der folgenden Familie anzugeben, als der eigentlichen Charakter der unter diefem $\mathbb{N}$ amen vereinigten Sumpfvöge? auszudrücken. Diele fehr natürliche Familie bat keine meflerförmigen Schnäbel; fondern die fehr langen Schnäbel haten blols vorftehende an den Rändern fchneidende Seiten. Die meiften nähren fich von Reptilien und befonders von Frölchen, Kröten und Schlangen.

r. Die Gattung Reiher (ardea) und die drey folgenden find einathder in fehr viel Stiicken äbnlich. Alle haben einen langen, fehr fpit- 
zen faft vierfeitigen Schnabel. Die Nafenlöcher find durch eine faft ganz an der. Spitze des Schnabels anfangende Furche angezeigt.

Man hat diefe Gattung in zwey Abtheilungen gebracht. Zu der erlten zählt man die Arten, die einen Federbufch auf dem Kopfe ha. ben, z, B. ardea garzetta, cinerea L. Buifchreiher. In die zweyte kommen die, welche nicht mit langen Federn auf dem Kopfe gefchmückt find, dies find dann die eigentlichen Reiher. Z. B. Ard. butor.

2. Die Stürche (ciconia) haben nackte Augenlieder und den Nagel der Mittelzehe nicht gezahnt. Z. B. arclea alba. X.

3. Die Kraniche (grus) haben den Kopf ganz ohne Federn oder höchlfens mit einem leichten Flaum bedeckt, unier welchem man die gewöhnlich gefärbte Haut deutlich fieht. Z. B. ardea grus, pavonina. L.

4. Die Jabirus (mycteria) felsen den Kranuichen fehr ähnlich, unterf́cheiden fich nur von ihnen durch die Krümmung der Spitze"des (fehr ftarken) Schnabels nach oben. Es find dies mit die gröfsten amerikanifchen Vügel; fie nähren fich von Fifchen.' Z. B. Mycter. americana..

5. Die Klafffchnabel (hyans) wurden fonft zu der Gattung Reiher gezählt von der fie aber durch den nicht gezähnelten Nagel der Mittelzehe und durch die Form des Schnabels abweichen, welcher wenn die Kinnladen an einander gelegt find, zwilchen der Bafis und der Spitze einen freyen Raum hat.

6. Die Tantalus -Arten (tantalus) find durch die Krümmung des Schnabels hinlänglich in diefer Familie unterlchieden.

Nach Cuviers Unterluchungen Icheint man mit Unrecht einige Arten ' diefer Gattung für den wahren von den Eyyptiern verehrten "Ibis gehalten żu habea. Die bey - Theben gefundenen Ibis-Mumien gehören beftimmt $z u$ einer Art Brachvögel aus der Familie der dünnIchräbeligen Sumpfrögel, da man den ganzen Schnabel und felbft die Farbe der Federn erkennt. Man hat aus einer Mumie ein vollfiündiges Skelet entwickelt, was man zu'Paris in dem Cabinet für vergleichende Anatomie aufbewahrt. (vergl. A. L. Z, 1805. das Titelkupfer zum 3ten Bande und No, 229.) 


\section{No. XL.}

III. FAMiLIE. BREITSCHNÄBEL ODER RAMPHASTOPLATEN. *)

Mit abgerundetem, ftumpfem, plattem, fehr breitem Schnabel.

- in der Mitte fchare gebogen; Oherfchnabel platt;

Enrerlchnabel convex . . . . . . . . 3. Flamingo

E) (länger als der Kopf, Ipatelförmig'breit

werdend . . . . . . . . 2. Spatelreiher

kitrzer als der Fopl; der Obertbeil kiel-

fömig ............. 1. Hobllchnabel

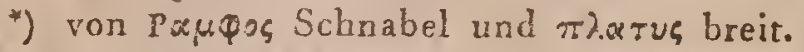

\section{N. XLI.}

IV. FAMILIE. DÜNNSCHNÄBEL ODER RHAMPHOLITEN. *)

Mit weichem, dünnem, -ftumpfem, zylindrifchen oder rundlichen Schnabel.

(lehr gebogen; dreymahl fo lang fnach oben. I. Säbelfchnäbler $\bar{c}$ als der Kopf; gekrümmt.

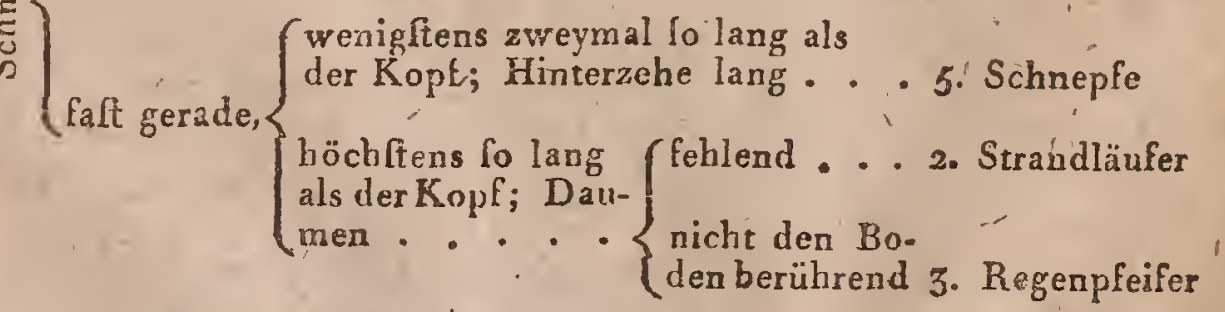

*) Von Pauфos Schnabel und $\lambda_{6 r o c}$ dünn. 


\section{BEMERKUNGEN ZUR XL. TABELLE.}

Man kennt von den Sumpfiogeln mil breftem vorn rnnden Schnabel (latiroltres) nur fechs Arten, die von einauder fehr durch Lebensart u. f. w. abweichen; aber alle am Ufer der Fli:lle oder des Meeres leben. 1. Die Hohlfchmäbel (cancroma) oder Lüffelfchnübel (corhlearius) find amerikanikhe Vögel, deren kurzer und breiter Schnabel nach oben einen Kiel bildet; ihre Nahrung find vorzüglich Filche und Krabben, Z. B. Cancroma cochlearia L. 2. Spatél-Reiher (platalea) háben den Schnabel ganz wie das Inftrument gebillet, wovon fie den Namen haben. Ihre Füfse find zur Hälfte mit Scliwimmhäuten verfehęn; fie klettern auf Bäume und nilten allda. Z. B. Flatalea lencorodia L. 3. Die Flamingos (plioenicopterus) verbinden durch ihre Fülse die Schwimmvögel mit den Sumpf. vögeln; auch nähern fie fich noch den Sägelchnäbeln, z. B. den Enterh durch ihre Schnabelbilduug. -Aber die aufserordentliche Länge ihrer Fulswurzeln, die Nacktheit des Uutertheils der Beine und ibre ganze Lebensweile machen liè zu Ufervögeln. Sie leben in warmen Ländern, Cuchen in dem Uferfchlamm von Flülfen und dem Meere, Vürmer, kleine Filche, und dahingelegte Eyer, wobey fie den Schnabel fo drehen, dal's der platte Obertheil des Schnabels nach unten kommit und der Un' terlchnabel fich bewegt, um den Schlamm wie durch zu lieben. Z. B. Phoenicopt. ruber. L.

\section{BEMERKUNGEN ZUR XLI. TABELLE.}

Die Sumpfyögel mii dïnnem Schnabel (tenuiroltres) näbrẹn, fich von Würmern und kleinen Infekten. Sie bedienen lich ihres ftumpfen, duinnen und oft langen Schnabels als eines Stockes, um das Terrain zu unterfuchen, Einige, wie die Srhneplen und Brachvögel, gehen des Nachts ihrer Nalrung nach und diele verlaffen auch woll die feuchten Gegenden, die andern leben immer an Sümpten.oder am Meerufer.' 1. Die Säbelfchnübel (recurviroftra) find Sumplvögel mit Schwimmfülsen, wo: vonidie Hinterzehe nicht den Boden berührt und wo der lehr din- ne Schnabel an leiner vordern Hälfre platt ift. $Z$. B. recurv. avoçetta $L$. 2. lund 3. Sirandläufer (tringa) z. B. tringa vanellus L. und die Regenpfeiffer (charadrius) z. B. Char. pluvialis L. haben faft gleiche.Lebensart und Schnabelforix; lie laufen fchnell und fliegen gleich gut. Sie gehen of tief ins Land, belonders zur Regenzeit. 4. Die Brachoügel (numenius) unterfcheiden lich fehr leicht von den; verwandten. Gattungen durch ihren Schuabel, In.Lẻbensart kommen lie der folgenden Gattung gleich. Z. B. Scolopax arquata L. 5. Die Schnepfen (l'colopax) haben ihren dünnen zylindrilchen Schnabel gewöhnlich gerade und nur in einigen Gattungen, am Ende aufwärts gebogen; man zählt hieher Waldichnepfen, Heerlchnepten und viele andere Vögel nuit ähnlichem Sclonabel. 2. B. Icol. rufticola I.

Dumeril Zool. 


\section{No. XLII.}

\section{VI.' Ordnung. SCHWIMIMVÖGEL.}

Zehen durch breite Häute vereinigt; kurze Fufswirzeln.

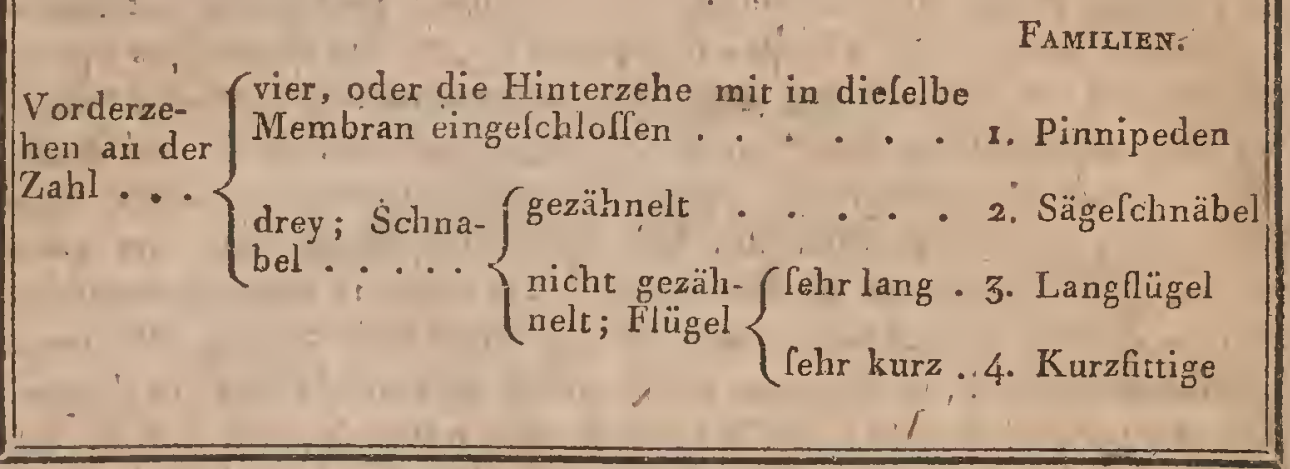

\section{BEMERKUNGEN ZUR ' LXII. TABELLE.}

Die Vügel mit Schwimmfüfsen, Palmipeden, Schwimmvögel (anferes) leber eigentlich auf dem Waffer. Ihre durch die Haut vereinigte Zehen bilden eine Art von Schaufel, wvelche derFlülfigkeit gegen die fie andrückt eine breite Fläche darbietet, wenn der Vogel den Fufs wie beym Gehen nach hinten bewegt. Mehrere $\int_{c h}$ wimmende Säugthiere zeigen eine ähnliche Bildung: die Ottern unter den reilsenden, die Biber und Hydromys unter den Nagethieren und alle Arten derAmphibien. Die Fifche belonders und mehrere Reptilien tragen an ihren Gliedern ebenfalls das Gepräge ihrer Hauptgewohnheiten. Diefe Vügel gehen auf dem Lande fehr fchlecht und unbehülffich, weil ihre Beine zu kurz und zù weit nach hinten angebracht find. Alle haben einen langen Hals um auf dem Boden des Waffers die Nahrung zu fuchen, die für fie palst.

Einige leben in Polygamie; aber bey den meilten Arten leben Männ chen und Weibchen paarweife, wenigftens für die Brütezeit. Im Winter vereinigen fie fich (befonders unter gemälsigten Himmelftrichen), in mehr oder weniger zahlreichen Trupps.

Das Weibchen legt vicle Eyer, die fie faft immer ganz allein in einem mit ihręm fehr zarten Flaum ausgepolfterten Nefte bebrütet. Die Jungen kommen ganz beweglich aus dem Ey und können felblt ihre Nahrung falfen; ja einige fuchen fie gleich im Walfer, wo fie gleich mint der 
grölsten Fertigkeit nach ihrem Inftinkt fchwimmen. Einige nähren fich von Kräutern, die fie am-Ufer wie abgralen; die meilten aber fuchen Wafferchiere, Infekten - larven, Würmer und Fifche.

Diefe Ordnung der Palmipeden fcheint, in der' Oekonomie der Natur eine grofse Rolle zu fpielen. Die Arten mit langen Flügeln vernichten die Kadaver von; ertrunkenen und durch die Wiellen ans Ufer getworfenen Thieren, fo wie die Nackthälle die zuf dem Lande faulenden Körper verzehren. Alle diele Arten haben ein hartes. Ichwarzes, zähes Fleilch. Von andern Thiéren werden fie nicht verrehrt.

Man darf vermuthen, dafs die Sägefohnäbel diefer Ordnung die Eyer gewwifler Filche, im Innern ihres. Körpers fehr weit forttragen und verpllanzcn: es fcheinen diefe Eyer wenigliens nicht verdaut zu werden, wenn ihre Oberfläche nicht angegriffen ift; ungefäbr wie die Körner die fich im Pferdemilt oder in dem Kothe der Drofleln entwickeln. So kann man etwa erklären, wie gewifle Landfeen Filche hervorbringen, obgleich fie weder mit Flüflen noch mit dem Meere zufammenhängerr.

Die vier diefe Ordnung bildende Familien kann man natürliche nennen; denn fje vereinigen Vögel, welche unter einander aufs deut-, lichfte durch die Form des Schnabels und Lebensart verivandt find. 


\section{No.' XLIII.}

I. FAMmLie. SÄGESCHNÄBEL ODER PRIONORAMPFEN. *)

Die drey Vorderzehen in der Schwimmhaut fteckend; lange Flügel; gezähnter Schnabel.

Chochbeinig; Schnabel wio geknickt, gebogen;

Gatiungen.

J der Oberfchnabel platt und gezähnt .. . . . I. Flamingo

14 kurzbeinig; der Schna- dreymal lo lang als

kbel gerade und ... als breit..... 2. Ente

Lünfmal to lang als breit 3. Tauchente

*) von IIglov Süge und Papழos Schnabel.

No. XLIV.

II. Familie. PINNIPEDEN, ODER PODOPTEREN. *)

Die vier Zehen in eine Membran vereinigt.

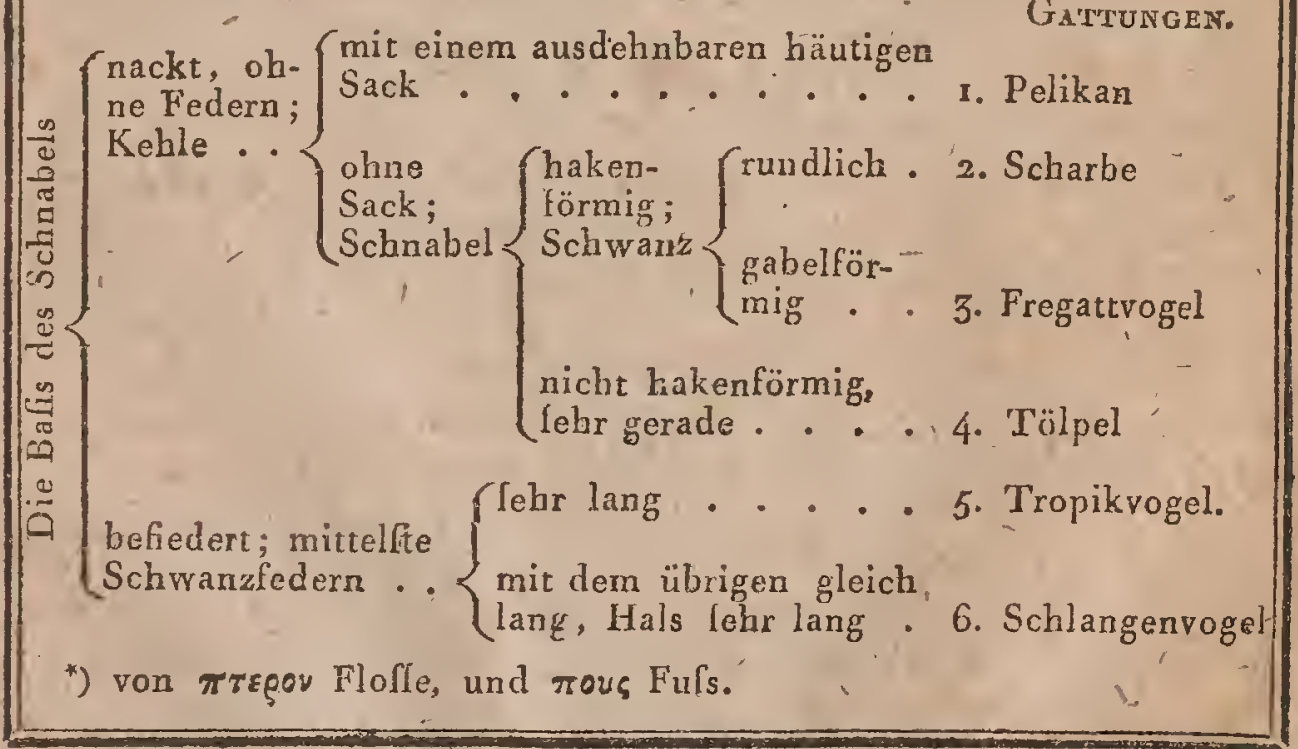




\section{BEMERKUNGEN ZUR XLIII. TABELLE.}

Die Sägefchnübel (Seriroltres) haben den Rand des Schnabels gezäbnelt und fcheinen vermüge dieler Bildung das Wafler, worin ficl ihre Nahrung findet, gleichlam durchzulieben. Alle nähren fich von kleinen Thieren oder Wiefenkräutern, die fie wie die Wiederkäuer abweiden d. h. "mehr abreilsen als abbeilsen. 1. Die fchon bey den Sumpfrögeln p. 64 erwähnten Flamingo find hier nur aufgeführt um auf dielem analytifchen Wege gar keine Lüicke zu laflein. 2. Die Énten (anas) habeu. den Schnabel mit einer weichen Haut bedeckt und die Zunge an den Seiten gefranzt. Man hat die fo fehr zahlreiche Cattung in zwey Abrlieilungen gebracht. In dié erfte gebören die, welche eine W Urlprunge des Schnabels haben. Z. B. anas, cygnus L. In die zweyte, die, deren Schnabel ganz einfach ift $z:$ B. anas bolchas L. 3. Die Tauchenten (mergus) haben einen Ichmäleren Schnabel als die Enten und nähren fich nícht von vegetabilifchen Subltanzen, londern ftellen kleinern Filchen und vorzüglich ihrem Laich oder Eyern nach. Z. B. merg. mergailer.

\section{BEMERKUNGEN ZUR XLIV. TABELLE.}

Die Schwimmoügel deren vier Zehen alle in einer Haut verborgen find, find wirkliche Raubvögel, lie näkren fich von Fi fchen flie fie aúf eine gefchickte Weife fangen oder von Thierkadavern die das Meer auswirft. Ihr Name Pinnipeden bedeutet Floflenfüfse und zeigt beltimmter. das Ruder an, deffen Gröfse noch durch den Daumen oder die Hinterzehe vermehrt wird, wovon keine andere Gattung ein Beylpiel zeigt. I. Die Pelikans (pelecanus) find fehr leicht an dem ausdehnbar häutigen Sack. unter dem Scknabel zu erkennen, diele Vïgelitauchen vortrefflich und zähren fich vón lebenden Filchen, Frölchen z. B. Pel. onocrotalus L. 2. Die Scluarlen. (phalacrocorax) deren Eigenhümlichkeiten leicht aufzufaflen find, machen thr Nell an hohen Orten wie die Raben, mit denen fie auch in ler Lebensart übereinkommen. Z. B. Pelecan. carbo L. 3. Die Fregactvögel (fregata) haben forrohl in Lebensart'als Geftalt Aohnlichkeit mit den Adlern; abé fie nähren fich nur von Fifchon und: entfernen lich oft unglaublich weitvom feften Lande. Z. B. Pelecanus aquilus L. 4. Die Tülpel (fula) kommen in der Lebensart ganz init den vier letzten Gattungen überein und unterfcheiden fich nur durch die Form des Schnabels. Z. B. Pelecan. ba fTanusL. 5. Die Tropikvögel (Phaetón) find nur im Südineer zwilchen den Wendekreilen angetroffen, haben einen geraden, Ichneidenden, weit gefpaltenen Schnabel, falt wie die Reiher. Z. B. Phaeton, aethereus. 6. Die Schlangenvögel (plotus) find den Sumpfvögeln mic fchneidenden Schnâbeln noch mehr ähnlich, belonders durch die lo beträcbtliche Länge ihres HLalfes. Z. B. plotus ankinga. 


\section{No. XLV.}

III. Familie. LANGFLÜGEL ODER MACROPTEREN.* *)

Drey Zehen mit einer Membran vereinigt; fehr lange Flügel; nicht gezähnter Schnabel.

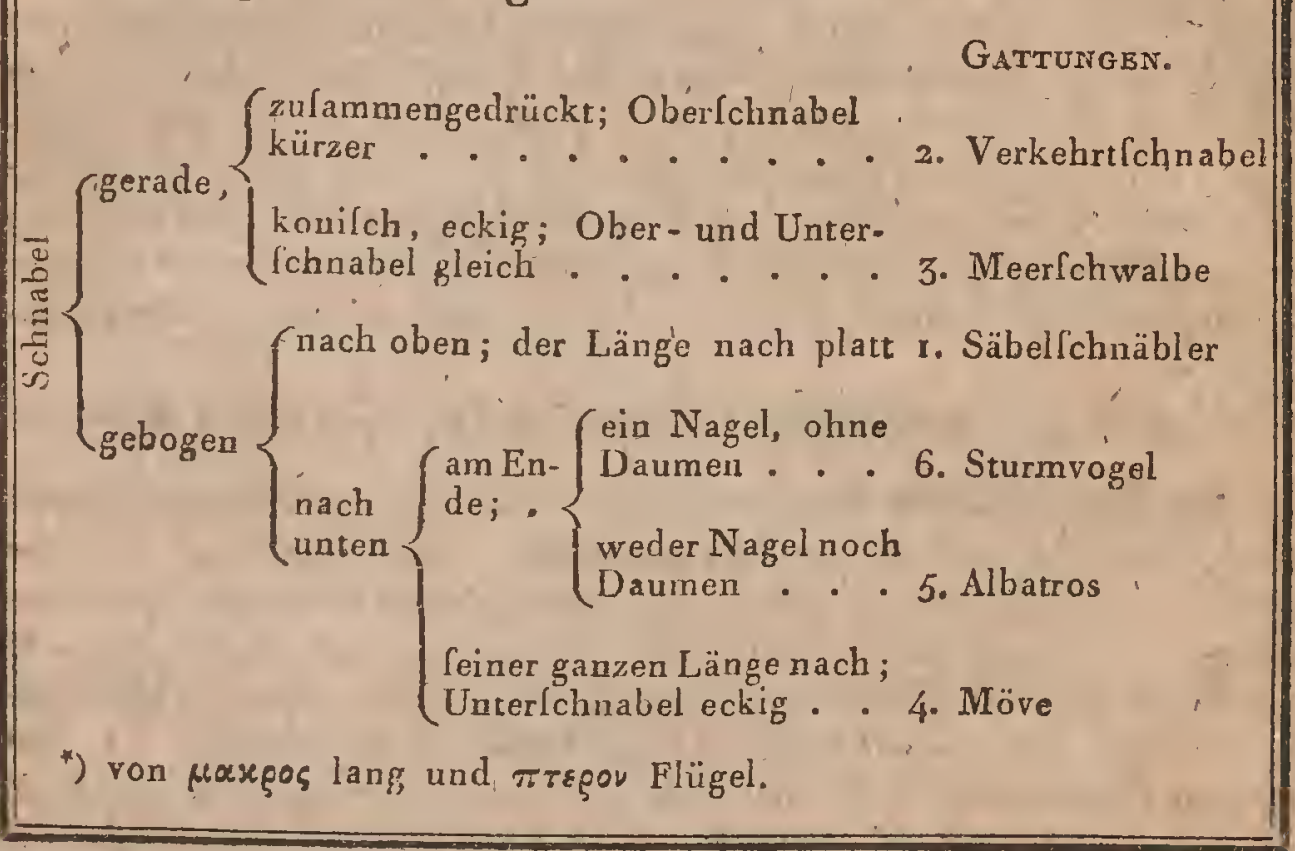

\section{BEMERKUNGEN ZUR XLV. TABELLE.}

Der Name Langflügler der einer kleinen Familie hier vereinigter Vögel gegeben ift, déutet mehr eine relative als ablolute Eigenheit an. Die Länge der Flügel ift hier nur als Gegenfatz zu einer Eigenheit angeführt, die bey den andern Schwimmvögeln mit nicht gezähneltem Schnabel und freyer nicht in die Membran vereinigter Hinterzehe wahrgenommen wird.

I. Der Sübelfchnübler (recurviroftra) den wir lchon bey den dünnfchnäbligen Sumpfrögeln aufgeführt haben, ift wirklich ein Ufervogel mit Schwimmfüfsen. Er hat eine für feine Lebensart höchlt brauchbare Bildung; indem er feine Nahrung im Meerfande luchen muls und zu dielem Behul fich an den Küften-und Infelufern; aufhält. Während der Ebbe und Fluth wadet er lo lange am Ufer als fein Schnabel noch den' Boden erreichen kann. Die Wellen würden, ihn aber oft überralchen, 
wenn er fich dann nicht gleich dem Schwimmea überlaffen könnte. Hat er fich zu weit vom Ufer entfernt, fo erhebt er fich nittels feiner langen Flügel und fliegt mit Leichtigkeit davon. Z. B. Recurv. avocetta $\mathrm{L}$.

2. Diê Jerkehrtfchnübel (rhinchops) find die einzigen Vögel, wo der Ichmale, blattähnliche, hohe Oberlchnabel vertikal auf den Unterfchnabel fällt. Der Oberfchnabel ift dabey noch kürzer als der UnterIchnábel. Man kennt núr eine Art; den die Matrolen wegén feiner Lebensart Wallerlchneider nennen. Er gleitet bey feinem Fluge auf dem Meere mit feinen Schnabel fo dicht an der Oberfäche des. Waffers weg, dals er die kleinen Filche leicht bemerkt. So wie er einen wahrnimmt, fenkt er Teinen fchmalen Unterfchnabel ins Waffer, und ergreift feine Beute mit dem zangenartig wirkenden Oberlchnabel. Z. B. Rhynch. nigra.

3. Die Meerfchwalben (fterna) haben ihren Namen von ihren lan. gen Flügeln und ihrem Gabellchwanz erhalten. Sie leben nur in der Nähe des Meeres oder am Ufer. Z. B. Sterna hirundo L.

4. Die Müven (larus) fchwimmen auf dem 'Meere aber nur nicht weit vom Ufer, fie freflen Würmer, kleine Filche, und todte Thiere ungefähr wie die Raben. Z. B. Larus maximus $L$.

5. Die Albatrofs (diomedea) find grofse Vögel, die man in mehren Gewällern antrifft, vorzüglich bey Kamțchatka nnd dem Vorgebürge der guten Hoffnung. Z. B. Diomedea exulans L..

6. Die Sturmvögel (procellaria) Gind, wie die Fregattvögel, die Vügel die am weitelten fliegen, und fich am meilten vom felten Laude entfernen. Wenn fie müde lind, laflen fie lich auf die Obernäche des Walfers nieder, wo fie fehr gut fchwimmen. Man fieht fie logar auf der Fläche delfelben gehen. Z. B.'Procellaria pelagica L. 
No. XLVI:

IV. FAMULIE. KURZFITTIGE ODER 'UROPO. DEN. *)

Der Daumen frey oder fehlend; Schnabel nicht 'gezähnelt; lehr kurze Flügel; die Fülse ganz am Hintertheile des Körpers.

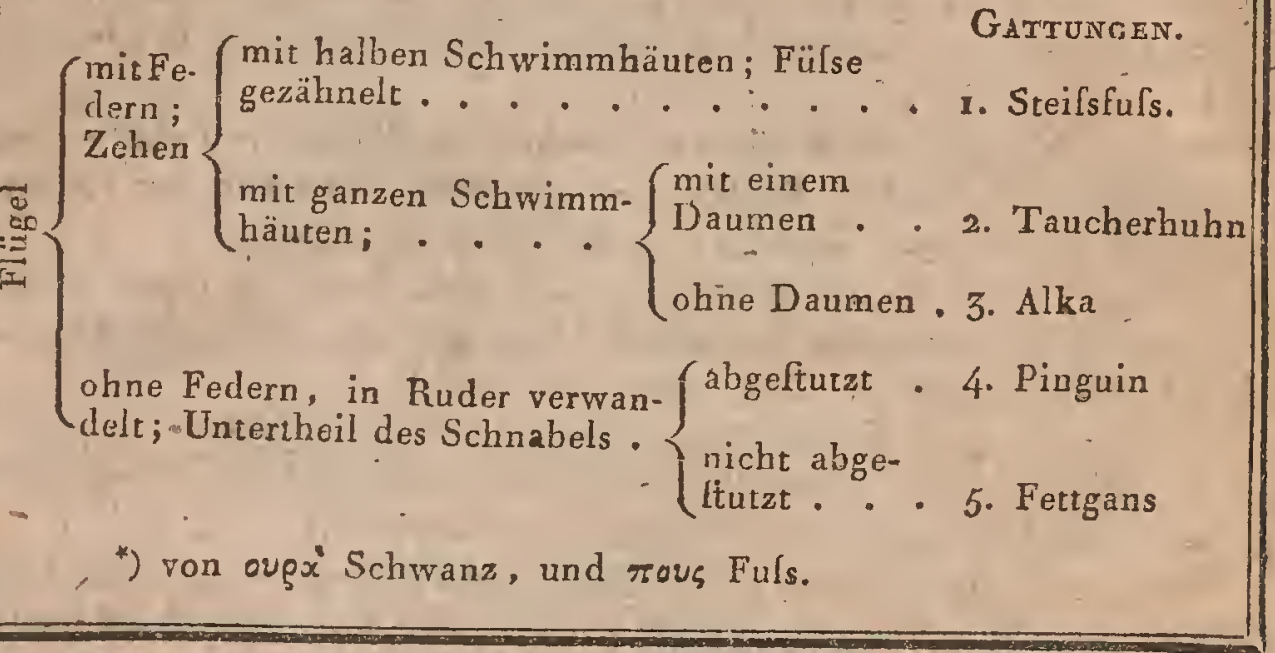

\section{BEMERKUNGEN ZUR XLVL, TABELLE.}

Kurzfiltige nennt man die Schwimmvögel, die bey kurzen Flügẹn die Fülse lo weit hinten haben, dals fie, wenn fie auf dem Landegehen wollen, fich ganz aufracht, den Körper vertikal, baltan müffen. Diefe Bildung, die beym Tauchen dem Vogel fehr zu ftatten kömmi, ift ihm auf dem Lande lehr hinderlich. Finige Arten können gar nicht fliègen. Aber wenn fie fo der Haupteigenheit ihrer Klaffe beraubt find, fich in die Lüfte zu erheben, fołfind fie dafür entfchädigt, durch das Vermögen mit der grölsten Leichtigkeit zu tauchen und lange unter Wafler zu bleiben ohne Athem zu Ichöpfen.

Die Knochen ihrer Beine zeigen eine lehr bemerkenswerthe Eigenthümlichkeit. Bey den meiften Vögeln, ragt der (dünuere) Knochen des Beines, das Wadenbein, über die Tibia hinaus und legt fich in eine Rinne an dem äufseren Gelenkkopf des Schenkelknochens hinein, Lo dafs fie faft wie eine Feder einlchnappt und das Bein unterftützt wẹnn es ganz geftreckt iff. Hier ift diefer Mechanismus noch deutlichor 
und die-Theile weit fefter. Da überdem die Füfse hier auch die Flü-. gel, deren Muskeln wenig entwickelt find, erfetzen, fo fclicint es faft als wäre alles Fleifch (d, h, Muskeln) hieher gelegt. Die Tibia geht. noch weit über die Artikulation in die "Höhel, und bildeti l'o eine mit. dem Körper des Knochens verwachlene Kniefcheibe, wodurch denn dieler Knochen eine aufserordentliche Stärke erhält, um den Widerftand zu überwinden, den (beym, Tauchen) das $W$ affer der Ppezifilchen Leichtigkeit des Vogels leiftet.

r. Die Steifsfiufse (colymbus) find auch Taucher genannt. - Ihr Schwanz ift lehr kurz und ihr Schnabel fpitz. Sie fliegen fchlecht und nicht weit. Thre Zehen find of gelappt. Z. B Colymb. criltatus L.

2. Die Taucherhïhncr (uria) z. B. alca lomvia L. unterlcheiden fich von den 3. Alken (alca) z. B. alca arctica nur durch ihre Hinterzehe; Sie niften und brüten unter der Erde in Lüchern, dio fio an dem Ufer fich bereiten.

4. Die Pinguins (torda) haben gar keine Felern an den Flügeln. Es lind dies den Norden bewohnende Vögel. Z. B. alca torda L.

5. Die Fetrgänse (aptenodytes d. h. Taucher ohne Flügel) haber (tat, der Hinterzehe nur einen Nagel. Diefe find Vögel der füdlichea Mleore. Z. B. apten. patagonica.

Ende der Clafle der Vögel. 


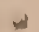

\section{Nó. XLVII.}

\section{KLASSE. REPTILIEN.}

Rückgrathige Thiere mit Lungen und kaltem Blute; ohne Haare, ohne Federn, ohne Brüfte.

Ordnungen.

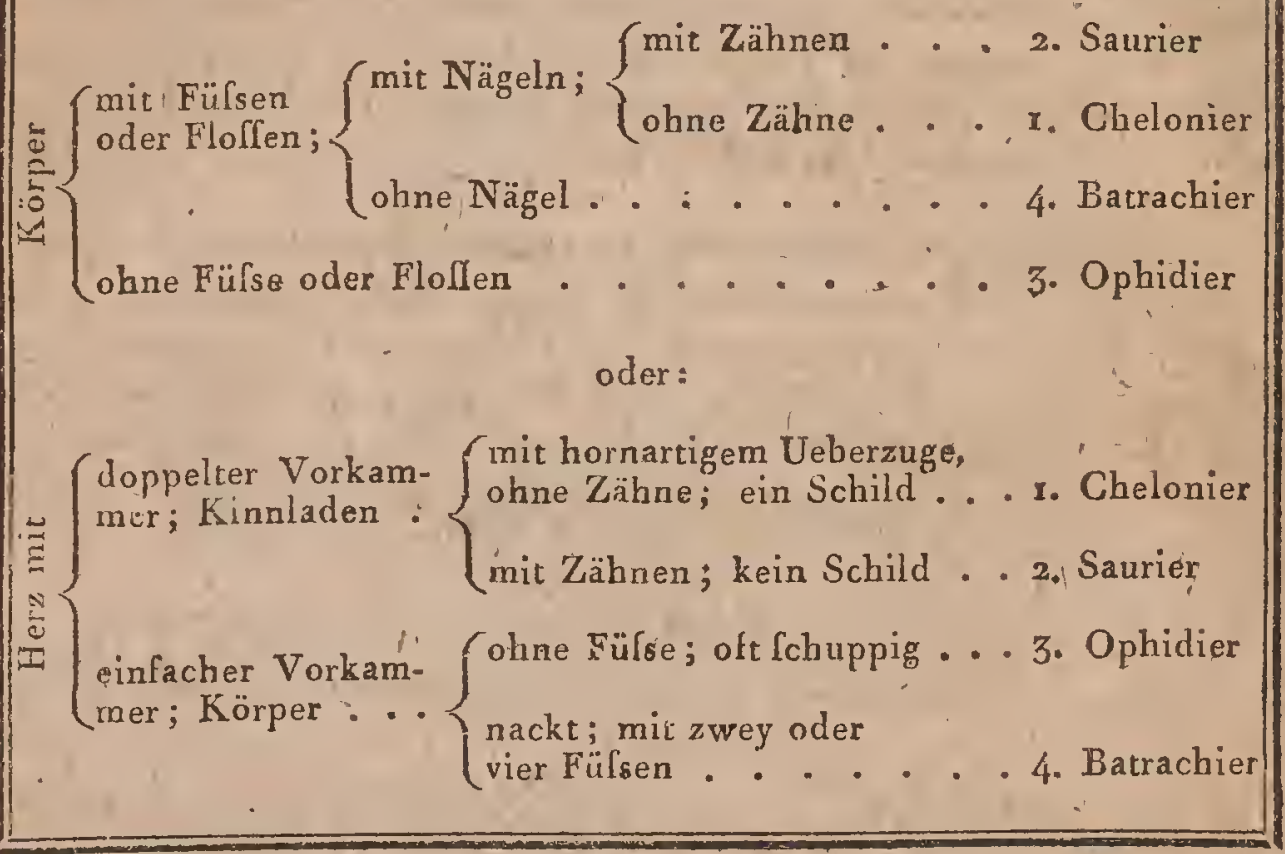

\section{BEMERKUNGEN ZUR XLVII. TABELLE.}

Die Reptilien (reptilia), die man lonft in zwey grofse Abtheilungen brachte, in Schlangen und vierfülsige Eyerlegende Thiere, haben keinen äulseren Charakter gemeinlchaftlich, als den negativen der fehlenden Haare und Brüfte. Alle haben zwar Lungen wie die Säugthiere und Vögel, da aber nicht ịhe ganze Blutmaffe mit der Luft in Berührung kommt, fo bleibt diefe Flifffigkeit, fo wie der ganze Körper, in der 'Temperatur des Mediums, worin die Reptilien fich befinden. Deswegen lagt man von ihnen, fie haben kalres Blut. Sie unterfcheiden fich von den Fifchen, bey denen' lich auch kaltes Blut findet, dadurch, dals letztere niemals Lungen zum Luft athmen, londern nur (Waffer athmende) Kiemen haben.

In keiner andern Klafle des Thierreichs zeigen die Gattungen 1o merkliche Unterlchiede und lo befondere Eigenheiten, als die welche 
die Abtheilung der Reptilien in vier Ordnungen'begründet haben- So ift z. B., obgleich die meiften aus einem Eye kommen, das Ly bald durch eine Begattung in Mutterleibe befruchtet, wie z. B. in den drey erften Ordnungen, bald im Gegentheil wird es ohne eigentliche Begattung befruchtet und oft gefchieht dies erft aufser dem Körper. So zeigt fich fetnex bey den erften das Jurge, wenn es aus dern Eye kommt, gleich in der Form die es das "ganze Leben behalten loll; oder, wie man es bey den Batrachiern beobachtet, das geborne Thier ift anfanga ein wirklicher Filcb, bey welchem fich die Langen nur bey erfolgenden Wachsthume entwickeln. Man nennt dies unvollkơmmne Thier Quappe oder Larve.

So verhält es fich auch mit der übrigen Organifatiou. Z. B. die Ophidier d. h. Schlangen haben niemals Fülse; bey den andern foden Go fich immer. Bey den Batrachiern endigen die Fülse nie mit Nägeln, da bey den übrigen Łdie Zehen allemál damit verfehen find. Einige können nur fchwimmen; andere gehen, Springen oder kriechen; eiue kleine ZahL kann auch flattern.

Alle, die Chelonier ausgenommen, nähren lich irn ausgewachfenep Zultande von animalichen Subftanze., die von keiner Gattung eigentlich gekäuet werden. Sie lieben lebende Thiere; todté Thiere Icheinen' ihnen zuwider zu leyn.

Kein einziges Reptil hat eine Ohrmu[chel oder ein bowegliches äufseres Ohr. Alle haben für die Ausleerung der Nahrungsmittel - Ueberbleibfel, für den Urin und für die Gefchlechtstheile nur eine Oeffnung die man Cloake nennt.

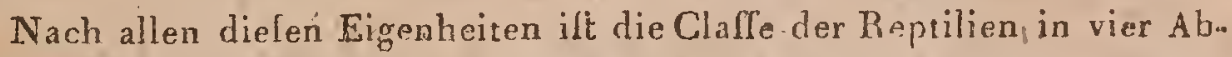
theilungen gebracht, wie die vorhergegangenen Tabellen lehren, wovon eine die äulsern Formen, die andere die Organifationen jeder Ordnung angiebt. 


\section{No. XLVIII.}

\section{Orennung. CHELONIER. *)}

Körper kurz, oval, gewölbt, bedeckt von einem Rücken-und Bauchfchilde; keiné Zähne.

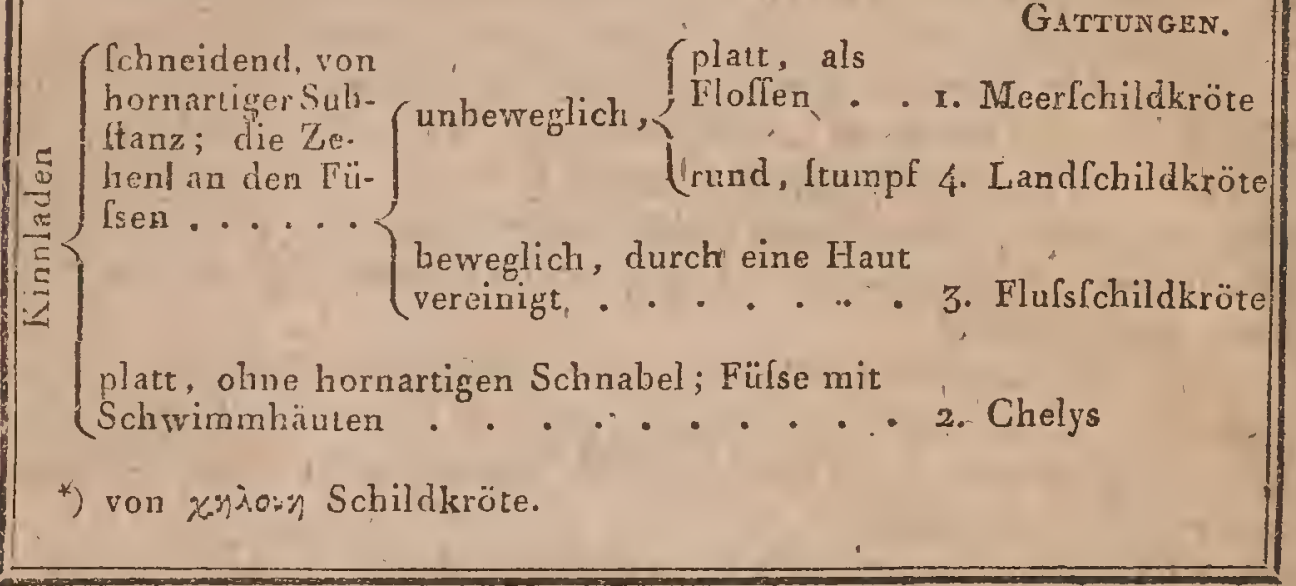

\section{BEMERKUNGEN ZUR XLVIII. TABELLE.}

Der Name Chelonier (chelonii) den die erfte Abtheilung der_Clafle der Reptilien erhalten hat, zeigt an; dafs die darin begriffenen Thiere Aehnlichkeit mit den Soe-Schildkröten haben, die man für die merkwerkwürdigften und nützlichftes häl. Aufser den in der Tabelle angegebenen Eigenthümlichkeiten zeichnen fie fich durch gar manches in der Organilation, Forn und Lebensart aus, was hier angegeben werden loll.

Sie find die einzigen Reptilien, welche einen deutlich unterfchiedenen Hals haben; dic Rippen, der Rückgrath und das Bruftbein liegen faft an der Oberfläche des Körpers und bilden eine Art von Schaale oder doppeltem Schilde, welche alle Eingeweide und bey einigen Arten lelbfr den Kopf, die Fülse und den Schwanz Cchützend bedeckt., Alle haben kurze, weit von einanderltehende Fülse, lo dals, wenn fie auf dem Lande find, der Körper den Boden herührt. Ihr Gang ift lo langlam dals er in den meiften Sprachen zum Sprichwort geworden if. Ihre Hüftheine find an der Wirbelfänle beweglich; die mit einander verwachlenen Schulterknochen find wie umgekehrt und nach innen zwifchen die Rippen und das Brultbein gebracht.

Allo Chelonier haben drey Augenlieder und Londern eine zur Anfeuch tung des Augapfels beftimmte Thränenfeuchtigkeit ab. Ihre Nafenlöcher 
fiad lelten röhresartig verlängert, meiftens find fie einfach und nicht grofs. Die Zunge ift fleifchig (weich) mit Warzen bedeckt und tritt nicht aus dem Munde hervor, fie fcheint dem Thiere beträchtliche Gefchmackrennpfindung zu verlchaffen. Meiltens ift ihr Trommelfell unier hornartigen Schuppen verborgen, aber demohngeachtet ift bey vielen das Gehör fein.

Bey allen - muls zur Fortpllanzung eine wirkliche Begattung ftatt finden. Die äufseren Gefchlechistheile des Münnchens Cind einfach. Die Begattung dauert fehr lang of mehrere Tage. Lie Eyer, welche das Weibchen in den Sand legt und der Sonnenwärme überlürst, find ron einer kalkartigen Schaale eingefchloflen.

I. Die Gattung der Meerfchildkrüten (chelonia) begreift alle dis Arten, die fich im falzigen Meerwafler aufhalten und deren ungleich lange Zehen, mit platten Nägeln endèn und in eine Flofle vereinigt find. Man kennt nur vier Arten diefer Gattung genau; die andern die man als andere Arten befchrieben hat, lind vielleicht nur Varietäten, Z. B. Teltudo mydas $L$.

2. Die Gattung Chelys (chelus) enthält nur eine Art, nemlich die Matamatafchildkrüte (teltudo fimbriata), Schoepf t. 21. die in Guiana lebt und einen Kopf wie die Pipa hat. Ihr Hals und Kopf find mit Franzen oder fleilchigen Anbünglelı beletzt.

3. Die Flufsfchildkrüten (einys) bilden eine zahlreiche Gattung. Sie leben in Flülfen, kkleinen Bächen, Sülswafferfeen und deren Ufern. Ihre Füfse find Schwimmfülse mit Häuten, mit deutliclien, beweglichen, hackenförmigen, sıägeltragenden Zeher. Mar theilt fie in folche' mit weichem Rückenfchilde, dereu wenige find. (Z. B. tefiudo (erox) und in folche mit knöchernen hartem Schilde, wovon es an dreilsig verlchiedene giebt. Z. B. teltudo lutaria L.

4. Die Landfchildkrüten (teltudo) find folche, die nie im Wafler leben. Ihre Füfse mit nicht dètlich uvterlchiedenen Zehen bilden rundliche Stumpfen, die im Kleinen Elephantenfülsen ähnlich fehen. An den Räıdérn find lie mit platten fchneidenden hufeähıliçhen Nägeln verfehen, auf welche das 'Thiè fich im Gehen fo ftützet, als ein Wagenrad auf die die Reife haltenden Nïgel. Z. B. teftudo graeca L. 
No. XLIX.

\section{ORDNUNG. ' SAURIER. *)}

Körper ohne Schild; mit (meift) vier, hakenförmige Nägel tragenden, Füfsen. Kinnladen mit eingekeilten Zähnen.

FAMILIEN.

Der, oft lehr foben oder an den Seiten platt. Platrlchwänze lange, Schwanz) konilch, rund ....... Rundlchwänze

*) von $\Sigma$ aupos Eidechle.

\section{BEMEPKUNGEN ZेUR XLIX. TABELLE.}

Die Ordnung der Saurier (Saurii) unterlcheidet fich welentlich von den Batrachiern, welche niemals Nägel haben und Metamorpholen erleiden; wefentlich von den Ophidiern, die weder Fülse noch Bruftbein haben; endlich auch von den Cheloniern, deren Kinnladen nie mit eigentlichen Zähnen londern nur mit einem hornartigen Schnabel verlelıen find und deren Körper durch ein Rücken-und Brultlchild bedeckt ift.

Alle Saurier haben den Körper von einer Schuppenhaut bedeckt in deren Dicke man einige Knochenpunkte entdeckt. Ibre Bewegungen find im Ganzen lebhatter und leichter als die der Thiere der andern Ordnungen diefer Clafle. Ihre Fülse find kurz, faft von gleicher Lünge und fehr entfernt vom Mittelpunkte des Kürpers, lo dals bey dem meiften während des Gehens der Leib den Boden berüht. Alle haben die in der Mitte verwach-: fenen Kinnladen mit mehr oder weuiger vorragenden, oft konifchen, felten

' chneidenden oder hökerigen Zähnen beletzt. Sie nähren fich von lebenden Thieren. Ihre Stimme ilt Ichwach. Die Generationsorgane find bey beyden Gelchlechtern doppelt; und es findet eine wirkliche Begattung ftatt. Die Jungen haben, wenn fie aus dem Eye kriechen, die Geftalt, die fie behalten follen.

Die Ordnung der Saurier weicht von den andera noch durch man. che Eigenthümlichkeit der Organilation ab. So haben fie nie einen deutlich unterfchiedenen $H$ Hals, wie die Chelonier; ihre Zähne lind eingekeilt und konilch. was nur (?) noch bey den Ophidiern vorkommt ; Ge haben, und darin unterfcheiden fie fich von allen übrigen Reptilien, oft 
noch freie blos mit dem Brultbein verbundene Rippen. Die Gefchlechtstheile find, wie oben bemerkt, bey den meiften doppelt, was fich auch nur noch bey den Ophidiern findet. Sie find, nebft eiver Art der Ophidier, die einzigen welche eine äulsern Gehörgang haben.

Die Saurier verbinden fehr natürlich die Chelonier mit den Ophidiern. Die Arten Flufsfchildkröten mit weichem Schilde oder einer hornartigen'Scheibe, näbern fich den Krokodilen und den exften Arten der Ophidier; wievon den letzteren alle die mit verwachfenen Kinnladen und belonders die Ophifaure den allmähligen Uebergangıvous der gegenwärtigen Ordnung zur künftigen machen.

Merkwürdig ift, dals diefe ganze Ordnung welche mehr als zweyhundert Arten enthält, auf die heifsen. Gegenden belchränkt zu Ceyn Icheint. In den nördlichen Gegenden von Frankreich (und Deutfchland) kennt man nur einige Arten der Gattung Lacerta. Alle andere Reptilien dieler. Ordnung kommen bey uns nicht vor.

Zwey Familien theilen ziemlich naturlich die Ordnung der Saurier. In der einen werden alle grolsen Arten begriffen, die an feuchten Orten leben und mittels ihres platten und meift zufammengedrückten Schwanzes gut Lchwimmen könṇen. In der andern Fanlite find die Arten vereinigt, die gewöhnlich nicht lehr grols werden, die trocknen, dürren Gegenden vorziehen und felten ins, Waffer gehen, wo fie nicht Ichwimmen könnten, indem ihr Schwanz zylindrifch ift und mit einer Spitze endiget. 


\section{No. L.}

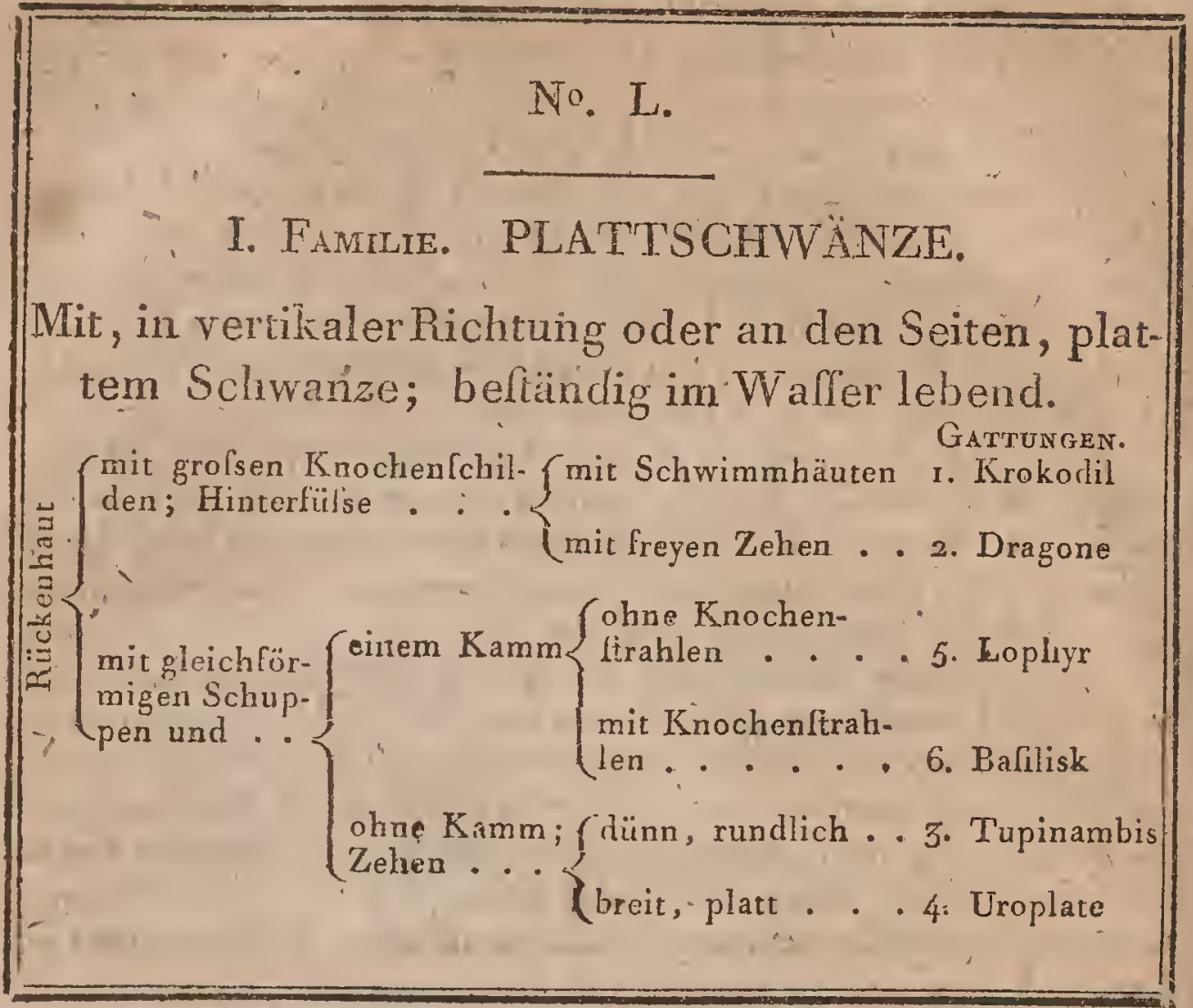

\section{BEMERKUNGEN ZUR L. TABELLE.}

Die Plattcharänze (planicaudati) haben ihren Namen von ihrer Eildung erhalten; indem alle, mit Ausnahme einer einzigen Gatturig, den Schwanz von den Seite' zufanmengeedrückt haben, fo dals er mehr hoch als breit ilt.

Knochenfchilder nennt man grolse fchilóförmige Schuppen,: die einzeln in der Haut fitzen. Diefe Schilder Icheinen, wie gefagt, die erfte Gattung von Sauriern zu verbinden, init den Flulslchildkröten, befonders mit denjenigen, welche eine weiche Haut haben, So hat z. B. das Krokodilmännchen auch die Gefchlechtstheile einfach, verlälst felten das Wafler'und hat auf dem Laide einen belchwerlichen und lang. famen Gang.

I. Die Krokodile (crocGdylus) find die grölsten bekanntén Arten von Sauriern. Ihre Zunge kann nicht hervorgeltreckt werden. Sie al. lein baben die Hinterfülse mit Schwinmbäuten verfehen. Einige Arten baben die ¿Schnautze fol̆mal, falt zylindrifch. Z. B. Lacerta crocodylus gangeticus L. Andere breit und platt, Z. B. Lac. crocod. niloticus L.

2. 'Die Dragone (Dracoena) ift' cine Gattung von einer einzigen Art. Man kännte fie für cin Krokodil halten venn die Hinterfülse Sohwimm. 
häute hätten, wenn die Zähne konilch und nịcht platt wäı en, und' wenn' der Kopf keine viereckig konifche Form hätte. Die Zähne find zahlreich, rund urd haben platte Kronen. Diefe Eigenheit, die bey keiner andèrn Art vorkommt, Ceheint hier eine belondere Lebensart anzudeuten, Z. B. Lacertus indicus Wormii.

3. Die Tupinambis (rupinambis) würden den Eidechlen gleichen, wenn nicht alle Rückenfchuppen einander gleich und wenn nicht ihr Schwanz zufammengedrückt wäre. Diele Gattung enthält viele Arten, aber alle aus warmen Ländern. Man hat fie eingetheilt in folche mit einem Kamm auf dem Schwanze ( $z$. B. Lacerta exanthematica,) und in folche mit einfachem Schwanze. Z. B. Lacerta monitor $L$.

4. Die Gattung der Uroplaten (uroplatus) enthält nur einige Arten die man fonft Geckos mit plattem Schwanze nannte. Die Form ihres Schwanzes entfernt fie yon allen bisher bekannten Sauriern; ilure Zehen find gelappt und unten mit dachziegelartig liegenden Lamellen verféhen Z. B. Gecko fimbriatus Daud.

5. Die Lophyren (lophyrus) find von einigen Naturhiftorikern zu den Agamen gezählt worden; ihré Haut ift mit dichten Körnern befeter; chagrinartig. Man keunt ihre Lebensart nicht. Z. B. Lacerta fuperciliola $L$.

6. Die Bafilisken (Bafiliscus) haben die Form der Tupinambis und in etwas auch die der Legrkans; Aber der Kamn auf dem Rücken unterfcheidet fie von den exften und die Geftalt des Schwanzes trennt Gie von den letztera. Z. B. Lac, bafiliscus L. 
Şaurier.

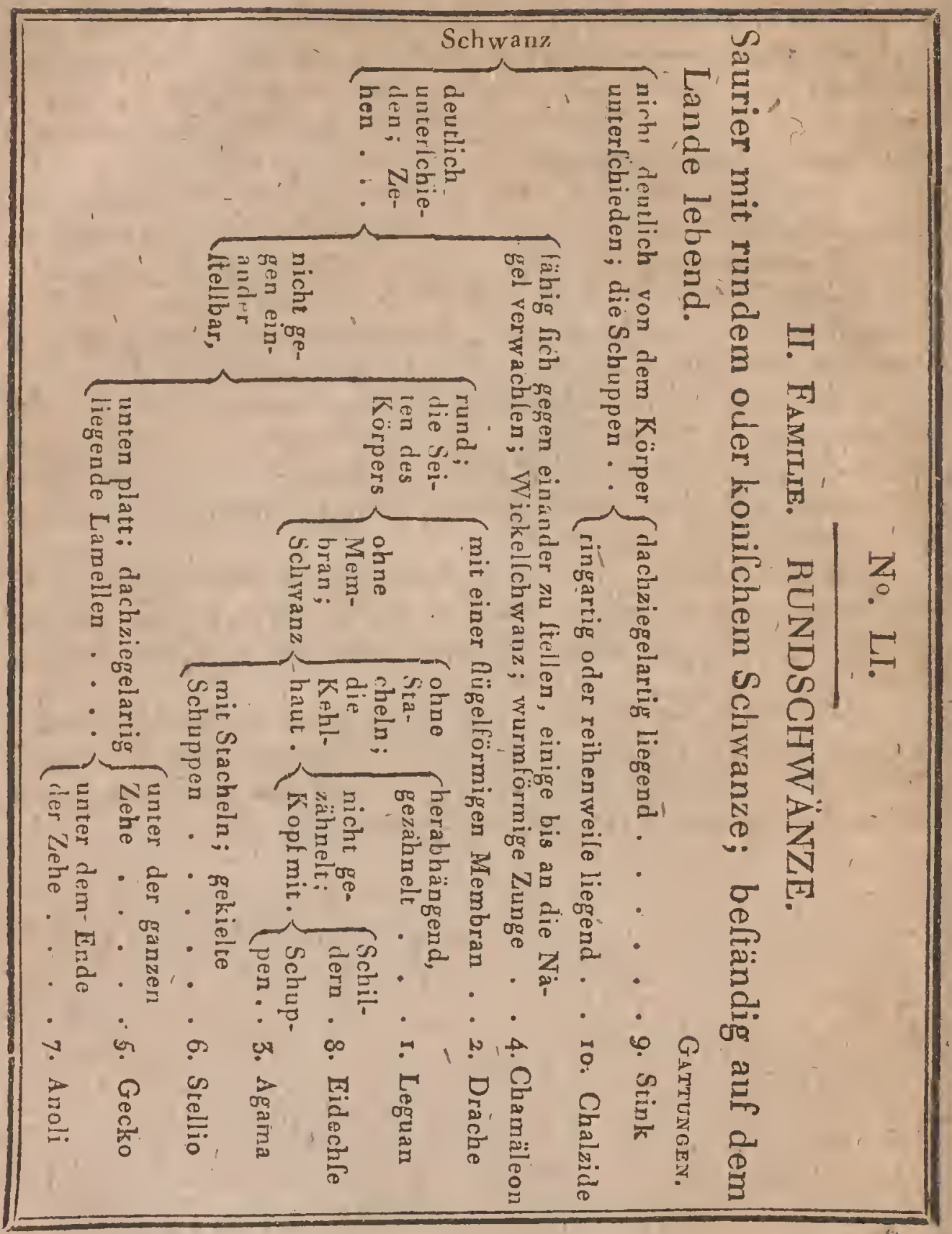

\section{BEMERKUNGEN ZUR LI. TABELLE.}

Die rundrchwänzigen Saurier, (tereticaudati) haben im Ganzen dexi' Schwanz fohr lang und blols nachlchleppend. Diele Bildung in Verbindung mit der Kïrze, oder oft mit der gänzlichen Abwelenheit, der Vorder-oder Hinterfüfse, fcheint den Uebergang zu der. Ordnung der Ophidier anzudeuten. 
r. Die Legruans (iguana) find grofse Eidechfen die auf dem Rücken einen gezähnelten, von Spitzen Schuppen gebildeter, Kamm und auf ders Wangen einen runden Fleck hahen. 'Z. B. Lacerta iguana L.

2. Die Drachen (draco) lind kleine in Indien einheimifche Saurier, die die Seitenhaut ihres Körpers über Knochènftrahlen gefpannt habea und fich damit, wie mittelft eius Fallfchirms, in der Luft erhalten. $Z$. B. Draco volans L.

3. Agama's (agama) nent man in den heifseften Gegenden beyder Welttheile einige Eidechfen, deren Charakter in den den Kopf bedeckenden Schuppen und in der kurzen Zunge lingt; fie halten fich an feuchten Orten auf und kommen nur res Abends hervor. Z

4. Die an ihren hohen Füisen fchou erkennbaren Chamäleoñs, (Cha. maeleon) können $z$ wey verwachfene Zehen gegen die drey andern ebenfalls verwachlenen, zangenartig, bewegen. Sie haben ihre lange Zunge in einen klebrigen Kuopf geendigt; den Körper von der Seite zufammengedrïckt und den Wickellchwanz unterwärts gebogen. Z. B. Lac, charnaeleon L.

5. Die Geckos, (gecko) kommen, ihren runden Schwanz ausgenommen, ganz mit den Uroplaten überein; die Lamellen unter den Zehen fondern einen giftigen Saft áus. Z. B. Lac. gecko L.

6. Die Stellionen (ftellio) die man auch Stachelfchwänze nennt, haben den Körper mit kleinen Schuppen, den Schwanz aber mit knochigen, Spirzen, ltachlichen Schuppenringen bedeckt. Z.B. Lac. cordylus L.

7. Die Anolis, (anolis) umlarlcheiden lich von den Leguans durch nichts als die Zehen. Z. B. Lac. himaculata L.

8. Die Eydechfen (lacerta) begreifen alle Arten, die in den vorher. gegangenen Gattungen keinen Platz finden. Ihr Unterleib ift wie bey den Krokodillen mit viereckigen Schildein, eben fo der viereckige Kopf mit Schild-Schuppen bedeckt. Es gehören hieher über vierzig Arten wovon man die, deren Schwanz dreymal fo lang als der übrige Körper ift, Tackydromen (Z.B. tachydromus' lexlineatus Daud), und die welche kein Halsband von gröfsern Schuppen haben Ameivas ("⿱中⿰㇀丶㇀ ta ameiva L. ) genannt hat.

9. Die Stincke (fincus) haben den Körper ganz lo wie die Fifche mit Schuppen bedeckt ( $Z, B$. Lac. fincis, L.); die Arten mit vier kurzen von einanderftehenden of nagellofen Zehen hat man Seps genannt $(\%$. B. Lacerta leps"L. ); die aber, wo fich blos Hinterfürse finden, heifsen Bipeden (z. B. Lac. apoda Pallas.)

10. Die Chalziden (chalcides) verhalten fich faft wie die Stincke; aber ihr Körper ift mit viereckigen, reihenweile oder ringarig liegenden Schuppen bedeckt, die nicht fchuppenartig liegen. Man unterlcheidet auch hier Vierfilfsige z. B. Chalcid. tridactylus Lácep, und Zweyfïfsige Z. B. Bipes cabaliculatus Lacep. 


\section{No. LII.}

\section{Ordnung. OPHIDIER. *)}

Körper lang, dünn, ohne Fülse, ohne Flolfen; Kinnladen mit Zähnen verlehen.

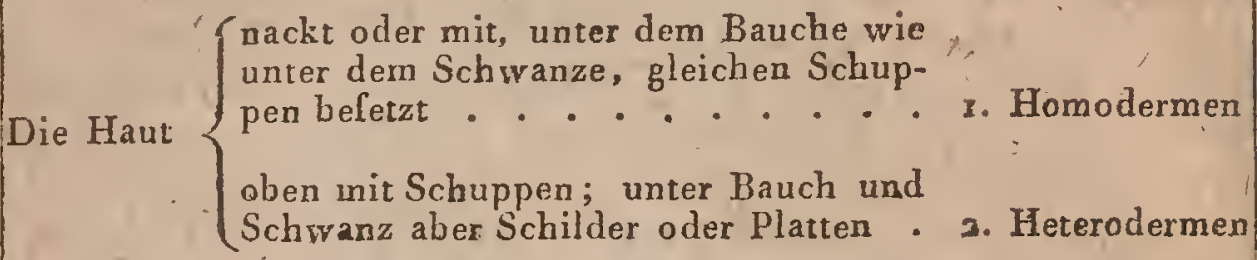

*) von oQis Schlange und eldos Form.

\section{BEMERKUNGEN ZUR LII. TABELLE.}

Die Ordnung der Schlangen oder Ophidier (Lerpentes) ift unter den. rückgrathigen Thieren am leichteften zu unterlcheiden. Der gänzliche Mangel von Gliedern. Flollen und Kiemen und das Vermögen dieler Thiere durch Lungen Luft zu athmen, find keinel zweydeutige Eigenfchafien. Alle kommen noch untereinander in gewillen Eigenheiten ihrer Bildung und Lebensart überein. Sie find die einzigen mit Lungen verfeheлen rückgrathigen Thiere ohne Augenlieder und eigentliches Brufitbein. Thre Gefchlechtsorgane kommen lebr mit denen derSaurier überein. Bey Sehr vielen Arten find die Weibchen aus Eyern lebendig gebärend d. h. die im Körper des Weibchens befruchteten Eyer werden dafelbft ausgebrütet und die Jungen kommengleich mit dem Vermögen fich zu bewegen zur Welt. In Ganzen behalten die Schlangen die Bildung uad Organe, mit dencn fie zur W elt kommen, 'auch ihr übriges Leben durch.

Die Abtheilung dicler Ordnung in zwey grofse Familien, gründet fich ganz auf die in der Natur vorhandenen Verfchiedenheiten der Form, der Organifation und der Lebensart.

So haben die Homodermen deren Haut von gleicher Befchaffenheit unter dem Bauche wre auf dem Rücken ift, die Unterkinnlade nie-; mals aus zwey ausdehnbaren Stücken beftehend. Die Oberkieferknóchen zeigen einen vollkommenen nicht unterbrochenen Bogen; Alle ohne Ausnahme habon tinen kleinen durch keine Zulammenfchnü- 
rung rom Körper getrennten Kopf. Bey keinem einzigen finden fich swifchen den Kinnladen noch Knochen mit beweglichen Giftzähnen; Nie find lie im Stande grölsere Thiere als fie lelblt find zu verfchlingen. Alle zu diefer Abtheilung gehörigen find unlchädliche Thiere von fanftem friedlichem Charakter; die fich von Infekten und kleinen Thieren gähren.

Bey den Heterodermen (Ungleichhäutern) aber, deren Haut oben. mit gleichen Schuppen," unten am Bauche und Schwanze aber mit grölseren logenannten Schildfchuppen bereckt. ift, beobachtet man die Unterkinnlade ftets aus zwey getrennten Stücken beftehend. Die Oberkieferknochen zeigen einen doppolten Bogen, oder vielmehr der Obeskiefer befteht aus vier länglichten Knochen, die vorn nicht vereinigt lind, die fich nicht allein ein- und auswärts, fondern auch vor-und rückwärts bewegen können. Die meiften.haben einen dickén platten Kopf, gegen den Hals $z u$ wic ausgefchnitten. Thre Kinnladen machen einen beträchtlichen Vorlprung vor den Schedel. Alle diefe Schlangen haben zwey der Länge nach ftehende Reihen Zähus (auf jeder Seite), die eine am Gaumen, die andere am Rande des Kiefers. Bey vielen Arten ift das Maul vorn mit befondern. wie durch einen Schwengel, beweglichen Knochen verfehen, auf welchen fpitzige inwendig boble Zähne fitzen, deren Canal in eiuer Blale anfängt, wo ficb ein fehr leftiges in Drüfen abgelondertes Gift befindet. Alle können Thiere verfchlingen, die sörser find als ihre Körper. Hieher gehören alle Giftfchlangen.

Noch' eine Bewerkung, die aus dem Ángegebenen gewiffermalsen. folgt, ift dals die Homodermen in der Regel nur von unbedeutender Grölse find, weil lie; (da fie fich von lebenden, die Gröfse ihres Körpers nicht ïberfteigenden Thieren nähren und keine eigentlichen Mittel befitzen fie zu zerkleinern) gewiflermalsen gezwungen gewelen wären, in einem fort zu freflen um den Verluft deu ihr Körper erleidet, dor natürlich um fo beträchtlicher ilt jo grölser das Volumen des Körpers, zu erletzen. 


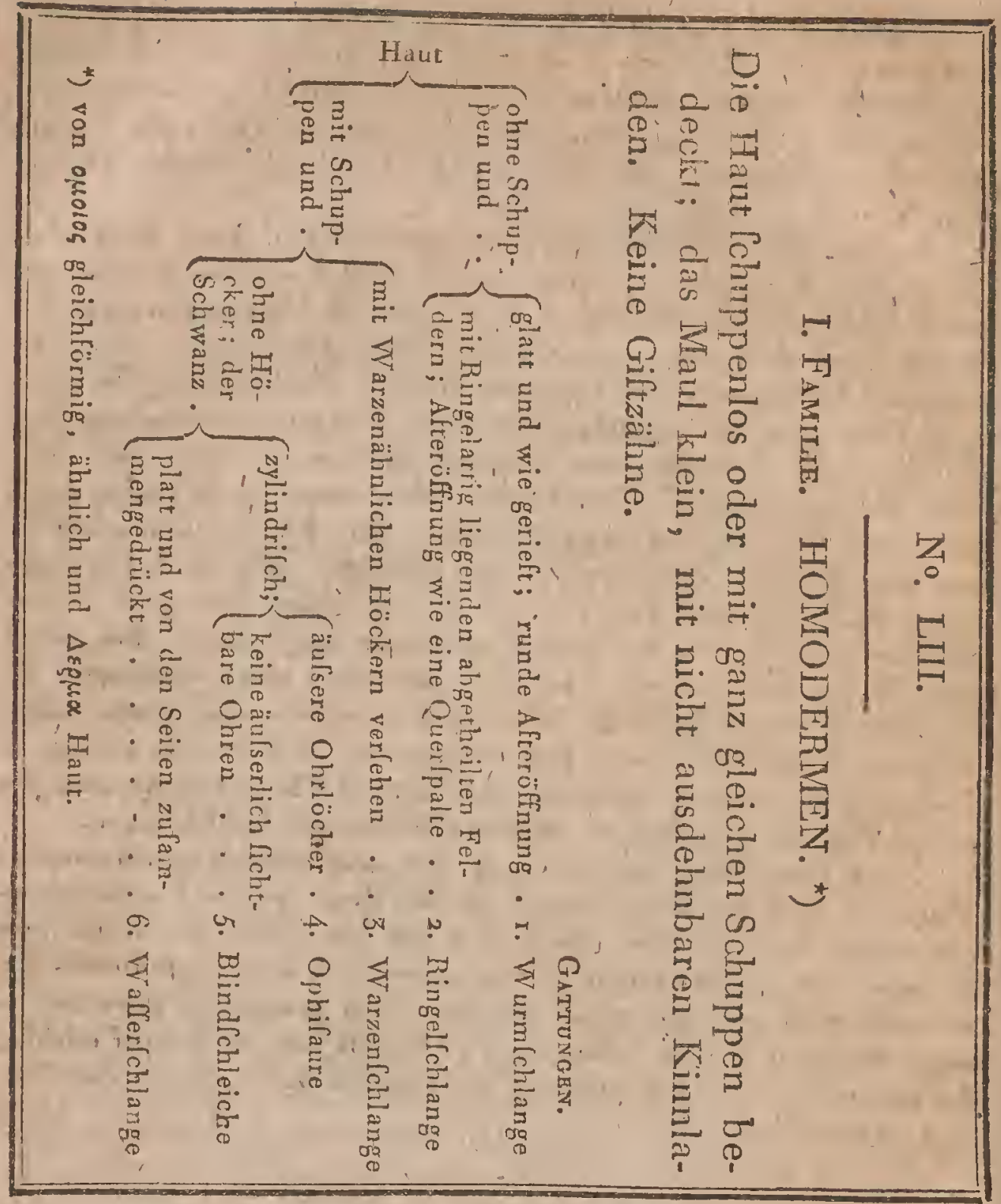

\section{BEMERKUNGEN ZUR LIIT. TABELLE.}

Die Tabelle giebt wirklich alles unterlcheidend Eigenthümliche der Gattungen diefer Familie von Gleichhäutern (Homodermi) an.

r. Die Wurm/chlangen (caecilia) find die einzigen Schlangen, deren Ichuppen - und Ichildlole Haut ganz nackt wie bey den Batrachiern ift. Ihr Körper kommt lehr den Regenwürmern nahe; fie find, die einzigen Schlangen, wo die für die Gelchlechtsorgane und die Exkremente gemeinfchafliche Oeffaung rund ilt. Alle diefe Schlangen Icheinen in unteridifchen Löchern zu leben; lie kriechen nie am hel- 
lem Tage umber und luchen feuchte Orte. Die meiften haben kein fichtbares Auge, indem das Gefichtsorgan ihnen bey ihrer Lebensart ziemlich unnitzilt Die Unterkinnlade ift meift kürzer als der Oberkiefer, und die Mundöffnung fcheint nur eine Spalre zu leyn. Nur in heilsen Klimaten hat man die Arten diefer Gattung gefunden. Z.B. caecilia glutinofa L.

2 Die Ringelfchlangen, Amphisbänen (amphisbaena) was im Grie-. chilchen Doppelgeher bedeutet, unterlcheiden lich von allen andern Schlangen durch die kleinen viereckigen ringartig liegenden Abtheilungen der Haut.' Sie find die einzigen Schlangen, doren als eine Queerfpalte fichtbarer After mit vertieften Purcten, Oefnungen, befetzt ift, wie die an den Schenkeln vieler Saurier. Alle bekannten Arten find in Amerika eiuheimifrh. Z. B Amphisb. fuliginola L.

3. Die TWarzenfchlangen (acrochordus) ein Name der warzig oder hö krig ausdrückt, find noch nicht hinlänglich unterfucbt- Die müir lten lind nur nach trocknen Schlangenbäuten abgebildet, die zu ftark ausgeftopft waren, und wo die Schuppen allo zu fehr hervorragten. Z. B. Acroch. javenfis 'Hornfte $\bar{d}$.

4. Die Ophifauren (Ophifaurus) d. b. Eidechfen-Schlangen heifsen. fo, weil der Kopf der einzigen bekannten Art, irn Hintergrunde eives wahren äufseren Gehörganges ein ordentliches Trommelfell (wie bey dex Eidech(en) zeigt, der Körper überdem zwey vom Halle bis zum After der Länge nach laufende Falten hat. Z. B. Anguis ventralis L.

5. Die Blindfchleichen, (anguis) haben wie die Ophilauren den ganzen Körper mit oben und unten gleichen Schuppen bedeckt. Dicfe Schlangen gränzen. durch Lebensart und Körperform lehr nahe an die Eidechlen und koinmen belonders den Chalziden nabe. Z. B. anguis fragilis $\mathbf{L}$.

6. Die Wafferfchlangen (hydrophis) nähern fich ihrer Form nach. in etwas den Boas und Plaruren (der folgenden Familie.). Sie unrerIcheiden fich von ihnen durch die Gleichförmigkeit der Schuppen fowohl um den Mund herum als unter dem Leibe. Ihre Zunge ift kurz, und mit einem Auslchnitt verlehen; ihre Kinnladen verwachfén und ihr von der Seite zufaminengerlrückter Schwanz endet firh in einen breit abgeruadeten Tbeil. Z. B. Hydr. cloris, Shoucur Jeen RuSfel. 


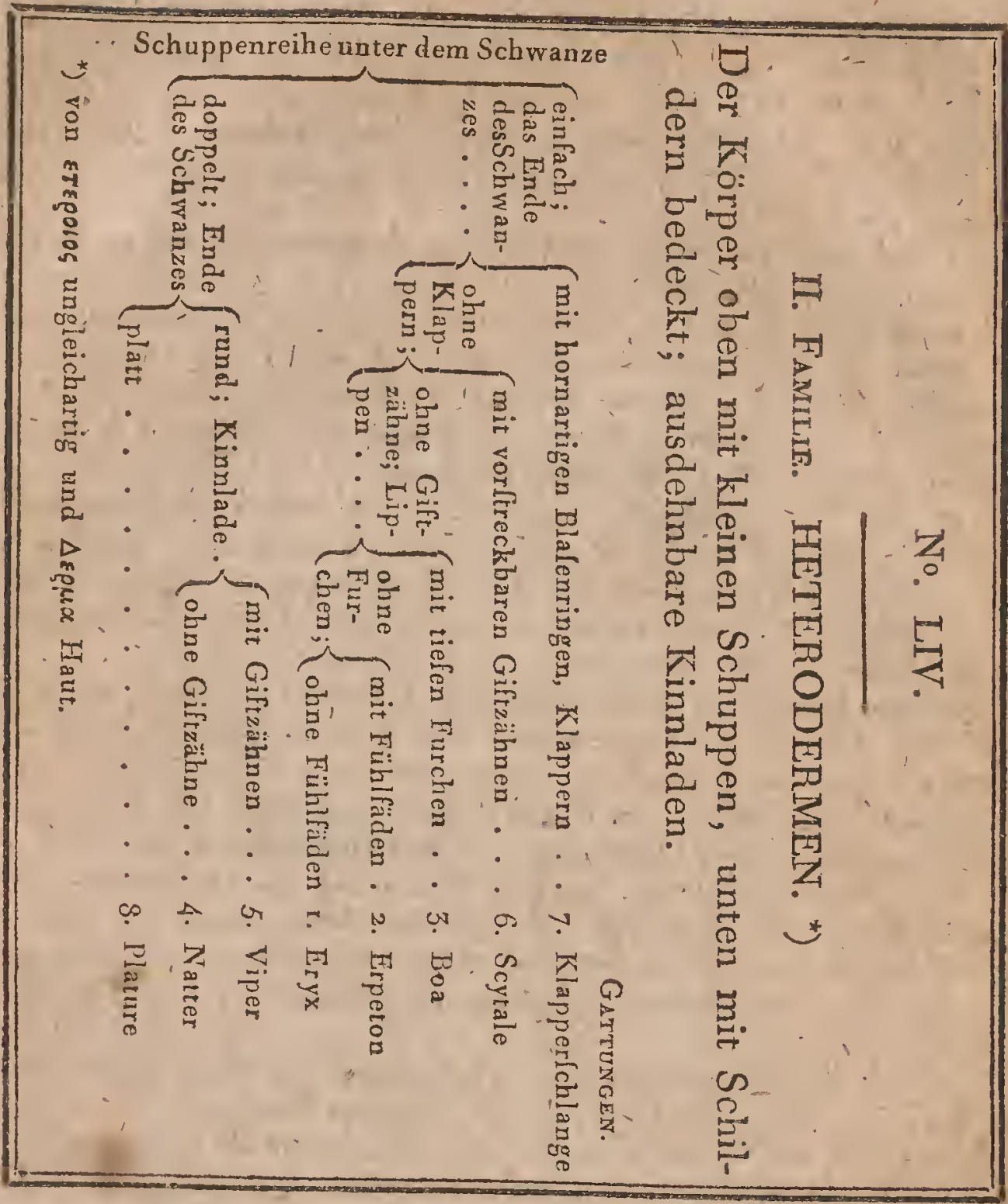

BEMERKUNGEN ZUR LIV. TABELLE.

Die ungleichhäutigen Schlangen (hederodermi) haben, (nach pag. 85) viele Eigerheiten gemeinlchaftlich. r. Die Gattung Eryx (erix) lcheint den Uebergang dieler Familie zu den Bliudfchleichen zumachen, wozu fie auch von einigen Naturforlchern gerechnet wurden. Der Kopf ift klein; die Kinnladen können nur wenig von einander entfernt werden. Die Schuppenlchilder unter dem Leibe find fchmal, und meiftens regelmälsig fechs oder achteckig. Unter dem Schwanze liegen ähnliche die nach der Spitze zu allmählig kleiner werden. Z. B. anguis iaculus, colubrinus L: 2. Der Erpeton (Erpeton) ilt, wegen Leinermit Schuppen bedeckten Fühlbörner vor den Maule, eine lebr fonderbare Scblange. Nur unter dém Leibe find Schilderfchuppen, unter dem Schwanze liegen Schuppen wie auf dem Rücken. Lacepede hat diefe Gattung zuerft belchrieben und in dén Anna. 
Les du Mufee d'hifioire naturelle abgebildet. Z. B. Erpeton tentaculatus Lac. 3. Die Loas (Boa) haben den Banch fchmäler als den Rücken; fie erreichen unter den Schlangen und überhaupt unter den Reptilien, die beträchtlichlte Grörse. Die meilien haben die Lippen mit wink. ligen Furchen und den Kopf, mit ungleichen Schildarlchuppen bedeckt. Daudin hat diele zablreiche Gattung folgendermafsen noch abgetheilt:

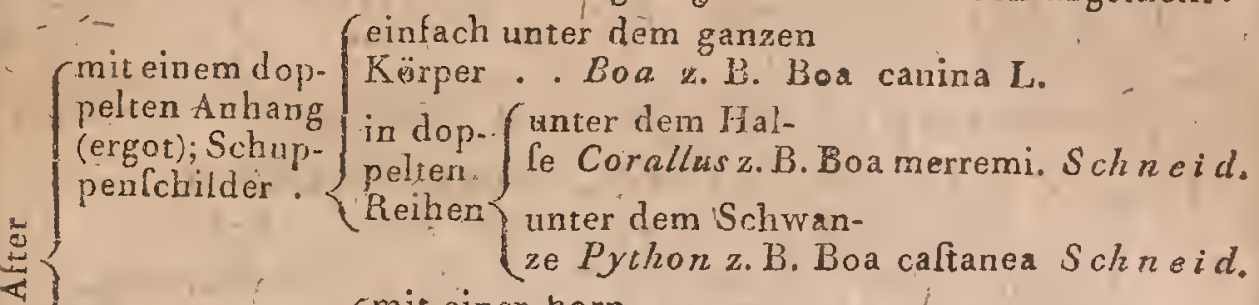

$$
\begin{aligned}
& \text { obne hornarti- } \begin{array}{l}
\text { mit einer horn- } \\
\text { artigen Spitze ...Acanthophis ceraltinus }
\end{array} \\
& \text { gen Anhang; } \text { Schwanz : } \\
& \text { Spitze....... Hurria pleudoboiga. }
\end{aligned}
$$

4. Die Gattung der Nattern (coluber) begreift alle ungleichhäutigen Schlangen, deren zylindrilcher Schwanz unten mit einer doppeltés Reihe von Schuppenfchildern verlehen ift und deren Kopf mit Schildern, niche mit dachziegelartig liegenden Schuppen, bedeckt ift und keine Giftzähnt. hat. Es giebt eine lebr grofse Zahl von Arten, die man abér noch auf keine leichte und natürliche Weife eingetheilt hat. 'Dievon der Zahl der Schuppenlchilder hergenommenen Merkmahle können variiren, find daher fehr ungewils. Z. B. Coluber natrix L. 5. Die Fipern (vipera) find Natzern mit Giftzähnen; unterlcheiden lich nur durch diele, wenn fie den Kopf mir Schuppenfchildern bedeckt hahen. Aber die meilten haben, doch einea platten, ftumpfen Kopf mit dachziegelich liegenden Schuppen. Der Name Viper fcheint eine Zufammenziehung von vivipara,zu feyn; ili aber nichts diefer Gattung ausfchliefslich eignes, da andere Gattungen auch lebendige Junge bringen. Z, B. Coluberberus, naja L. 6. Die Scyialcn (lcytale) unterfcheiden fich von den Nattern nur durch die einfachén Schuppenfchilder unter dem Schwanze, und durch die vorhandenen Giftzähne. Z. B, pleudoboa carinata Schneid. 7. Die Klapperfihlangen (crotalus) wovon der Name den Hauptcharackter angiebt, fehen den Vipern lehr ähnlich, aber ihr letztes Schwanzwirbelbein ift von allen Seiten von einer einzigen Schuppe umgeben. Bey jeder neuén Häutung umfchlielst die Schuppe die daruntar befindliche, und hält fo feft, obgleich fie beweglich bleibt, Da nun alle diefe Sohuppen der vorhergegangenen Jahre lich felt halten, fo enifteht dadurch eine Artvon Rolenkranz, derjedesmal klappert wenin das Thier fich bewegt. Alle diele Klapperfchlangen find'mit Giftzähnesi verfehen, Z. B. crotalus horridus L. 8. Die Platuren (platurus) kommen den Wrafferfchlangen der vorigen Familie nabe, aber fie haben wutor dem Leibe nur eine Reihe von Schuppen und zwey Reihon nuter dem Sclowan. ze, welche platt von der Seite zulammengedrickt find. Anneruti hat lie Breitlchwäkze laticauda genannt. 


\section{No. LV.}

\section{OrDinung. BATRACHIER. *)}

Körper nackt, ohne Schuppen und Schilde; Füfse ohrie Nägel. Keine eigentliche Begattung.

Familién.

Ckurz und dick, ohne Schwanz; Vorderfülse

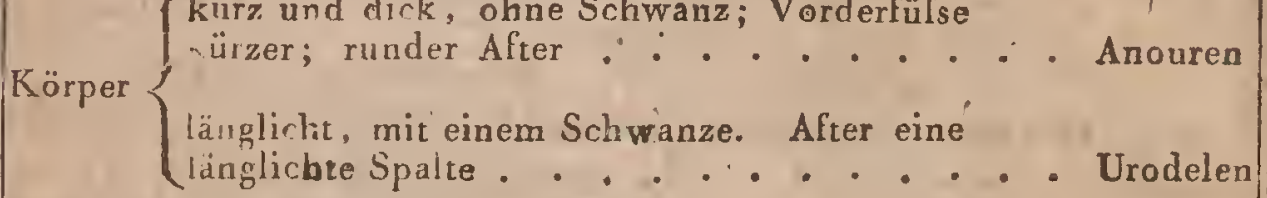

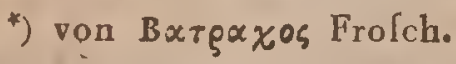

\section{BEMERKUNGEN ZUR LV. TABELLE.}

Die Batrachier (Batracii) fcheinen den Uebergang von den Reptilien zu den Fifchen zu machen. Alle Arten diefer Ordnung kommen den Fifchen, wenigftens in der erlten Periode ihres Lebens, in Lebensart und Refpiration nahe Diele Ordnung unterfcheidet fich durchaus von allen übrigen diefer Clafle 1. durch die vorhandenen Glieder, die man nie bey den Schlangen findet; 2. durrh die Abwelenbeit der Nagel an den Fülsen; 3. durch die nackte Haut; 4. durch ibre Fortpflanzung, ohne eigentliche Begattung; 5. durch die Metamorphofe, die die jungen Individuen erleiden.

Diele Thiere haben gar keine der (gewöhnlich) unempfindlichen Bedeckungen auf ihrem Körper; die Haut ift nackr, fehr porös, und nur bey einigen Arten mit Wárzen bedeckt, aus welchen eine mehr oder weniger klehrige, gefärbte oder riechende Feuchrigkeit ausgefondert wird. Weun die Batrachier die Metamorphoíe erlitten haben und ausgebildet find, näbren fie fich nur von lebenden Thieren und ihre Därme find lehr kurz; in ihrem erften Zuftande find lie aber um defto langer. Der Mund jlt weit. mit nicht ausdehnbaren Kinnladen und ohne Lippen. Ihr Athmen wird durch die Halsmuskeln, (die ihnen die Luft ordentlich verfclulucken helfen) begünltiget. Sehr lelten wird ihre eigentiche Stimme 
hörbar. Die ausgeathmete, und bey itarem Durchgange durch den obern Kehlkopf in Bewegung gefetzte, Luft dringt mit Geräufch in Säcke am. Anfange der Kehle; dies ift das fogenannte Quacken.

$\mathrm{Zu}$ den von dem Dafeyn oder der Abwelenheit des Schwanzes hergenommenen Eigenheiten kommen noch mehrere andere, die die Trennung der Ordnung in zwey natürliche Familien rechtferigen.

Die allgemeine Körperform, die in diefer Ordnung Lehr verfchiedèn ift, (cheint die Art der Bewegung beftimmt zu haben. So findet man Arten, die langfam gehen (kriechen) andere die fpringen, einige klettern und die meiften können fchwimmen. Alle Batrachier haben übrigens die Füfse an der Seite des Körpers, in ziemlicher Entfernung von einander. Alle Arten, wo fich Vorderfülse finden, haben ein lehr groIses Bruftbein, was zugleich die Refpirationsbewegungen unterftützt. Die Hinterfüfse find durch ein bewegliches Becken mit dem Rückgrath in Verbindung. Die Arten welche Ppringen, haben die Fülse in der Mitte des Körpers dicht nebeneinander artikulirend, fo dafs fie fich auf den Schenkeln fchleppen, deren Muskeln fehr entwickelt find, fo wie dies auch mit den Muskeln des Beins der Fall ift, wo fie ordentliche Waden bilden, wovon unter denSäugthieren der Menfch allein ein Beyโpiel zeigt. 


\section{No. LVI.}

1. FAMIJIE. UNGESCHWÄNZTE ODER ANOUREN

Der Körper kurz, breit, ungefchwänzt. VorderfüIse kürzer als Hinterfülse.

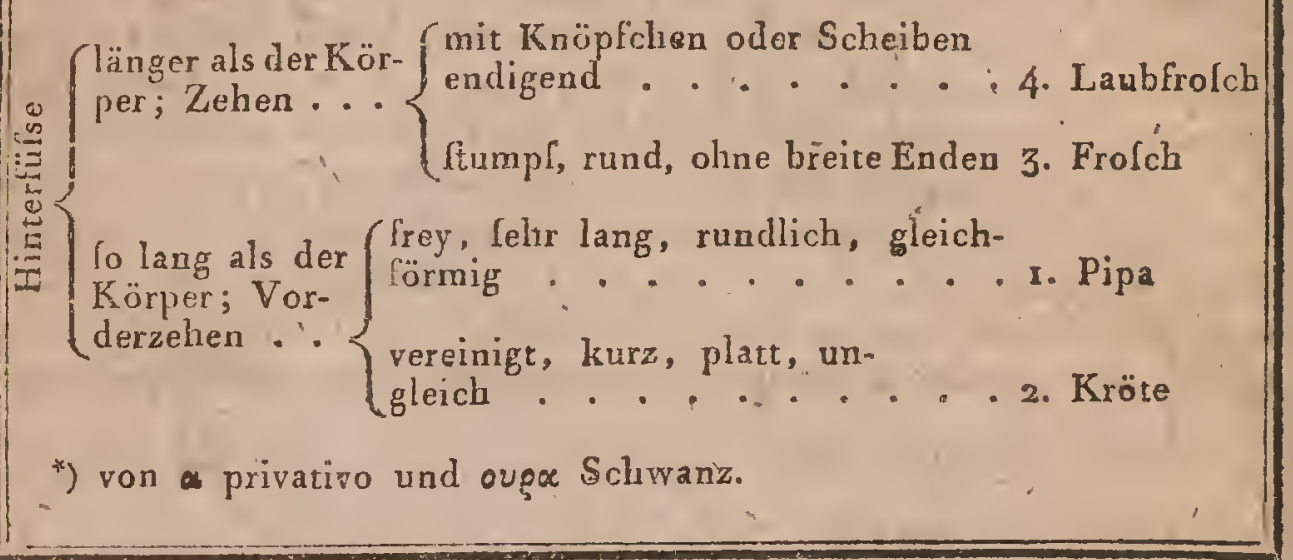

\section{BEMEPKUNGEN ZUR LVI. TABELLE.}

Dic ungelchwänzten Batraclier' (ecaudati) kommen durch ihre BilJung im Welentlichen mit einander überein. Alle haben die Haut nur vrenig mit dem Körper zufammenhängend, fo dafs diefer darin wie in oinem Sack lteckt. Ihre vierzehigen Vorderfülse find immer kürzer als ihre Hinterfülse, worall immer fünt Zehen vorkommen. Die Zunge ilt frey beweglich und vorn an der Aushöhlung der Unterkinnlade felt gewachlen (lo dals fie heraus und zurück geklappt wird). Die Befruchtung der Eyer der Weibchen findet aufserhalb des Körpers derlelben ftatt, wo das Männchen lie in dem Augenblick mit dem Saamen befruchtet wo fie gelegt werden; das Männchen lilft auch wohl, die Weibchen davon zubefreien.

1. Die Gattung Pipa (pipa) enthält nur zwey Arten. Der Körper iff platt ohne Warzen nnd Parotiden. Die Vorderfülse mit konilchen, runden, dẹutlich von einander getrennten gleich langen Zehen: Dië Hinterfülse, mit Schwimmbäuteŕ, kürzer als der Körper. Die Jungen. Icheinen ihre Metamorpkofe, in den Eyern, auf der Rückenhaut der Mutter zu erleiden, wohin fie durch das: Männchen, fo wie fie aus den GeIchlechtstheilen des Weibchens zum Vorfchein kommen, gebracht warden. 2. B. Rana pipa Li 


\section{Batrachier.}

2. Di̛e Kräcen (bufo) haben die Hinterfülse kaum lo lang vie den Körper, die Zehen find konilch, platt, ungleich; der Körper breit, dick, warzig, mit zwey grofsen Drülen aufdem Halle, die man Parotiden nennt. Die vielen in diele/Gattung gehörigen Arten find in drey Unterabtheilungen gebracht: 1. folche, deren Hinterfülse falt ohne Schwimmbaut lind 3. B. Ràn ventricola L.; 2. folche, wo einehalbeSchwimmliaut an den Hinterfülsen vorkommı z. B. Rana bombina L.; 3. folche, wo man diefelbe Bildung an den Vorderfüsen bemerkt. Z: B. Rana bufo L. Diefe Form ihrer Fülse [cheint auf die Wahl ihrer Aufenthaltsorte einigen Einflufs zu haben. Einige leben gewöhnlich im Wafler, andere an feuchten und wieder andere gauz an trocknen Orten. Alle fiehen das Licht und kommen nur des Nachts zum Vorfchein; in nicht ganz.warmen Climaten halten Cie einige Monate einen Winterfchlaf; gewöhnlich vereinigen fie fich gegen den Winter in Gefellfchaft an enge Oèrter, oft unter dem Schlamm, wie die Frölche.

3. Die Fröfche (rana) unterfcheiden fich von den Kröten nur durch die Länge ihrer Hinterfüfse und durch die Abwefenheit-der Parotiden. Sie pllegen nicht wie die Kröten zu kriechen auch nicht wie die Laubfröfche zu klettern, londern fie fpringen. Z. B. Rana esculenta L.

4. Die Laubfrösche (hyla) haben in der Bildung ihrer Zehen einen zu unterfcheidenden Charackter, als dafs man fie mit den tben erwähnten Gattungen verwechíln könnte. Man uxierfcheidet die Laubfrölche noch in Colche, wo die Zehen der Hinterfïfse ganz getrenut Z. B, rana arborea L. und in folche wo fie durch eine Schwimmhaut vereinigt find. Z. B. rana boans $I_{1}$. 


\section{No. LVII.}

II. FAMrLIF. GESCHWÄNZTE ODER URODELEN.*)

Körper von länglichter Form, mit einem Schwanze; die vier Fülse von gleicher Länge. Anliegende (unbewegliche) Zunge.

Gatumaen.

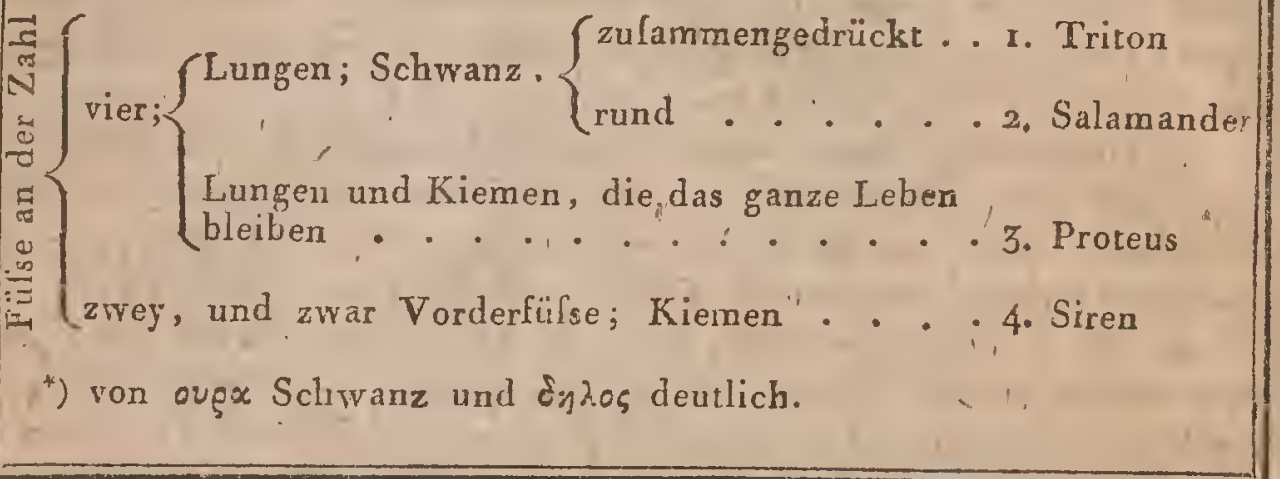

\section{BEMERKUNGEN ZUTR LVII. TABELLE.}

Nicht blofs der vorhandene Schwanz charakterifirt diefe Ordnung der. Urodelen (caudati), lie, kommen vielmehr auch noch durch andere Eigenheiten überein, die man bey den Anouren noch nicht bemerkt hat. Bey allen ift $2 . R$. die Haut feftanliegend; wenn fich vier Füfse finden, fo find lie fehr kurz, einander gleich und lo weit von einatuder entfernr, dals fie die Lalt des Körpers nicht tragen können. Ihre Zunge ilt feft anliegend in der Höhlung der Kinnlade und mit ihrer breiten Bafis hin: terwärts gerichtet. Bey den meiften ift die Stimme fchwach und die aus den Lungen herausgetriebene Luft bringt nur ein leichres Gurgeln hervor. Obgleich keine vollkommne Begattung d. h. kein Einbringen eines männlichen Gliedes in die weiblichen Gelchlechstheile, fiatt fin. det, fo werclen doch die Eier in dem Körper der Mutrer befruchtet. Es fcheint als wenn der Sanme des Männchens, voll den in dieler, Zeit felsr angefchwollenen weiblichen Gefchlechtstheilen ablorbirt würde. Die Eyer werden, in Zwilchenräumen, gelegt und kommen einige Tage bachher aus. Bey einigen; kommen die Jungen fchon im Innern des mütterlichen Kürpers aus dem Eye, und werdea in der Geftalt geboren, die fie behalten follen. 
Die Arten welche im Wafler leben, haben den Schwanz von dex Seiten zulammengedrückt, und die Fläche deflethen oft durch eine vo:ı der verlängerten Haut gebildete Fett-Flofle vẹrgröfserı, und bedienen lich deflelben gerade wie die Filrhe. Audere haben den Schwanz rund oder konilcur, leben gewöhnlich auf dem Lande aber an feach-' I' ten Orten.

I. Die Gattung Triton (triton) begreift alle Iogenannten Wafferfalamander. Sie legen Eyer und leben, wexigliens zur Zeit der Fortphanzung, im Wafler. Es gehören hieher lehr viele Arten, wovon eigenllich wenige genau belchrieben find. Man hat lie abgetheilt a. in folche, deren Hinterfülse ohne Schwimmhaut und die Zehen ganz getrennt find. Z. B. Salamandra alpeltris $S c h n e i d e r . b$ in folche, wo die Zchen mit einer getrennten gelappten Haut verlehen find. Z. B Salainandra elegans Daudin c. in folche wo fich ordentliche Schwimmbäute finden. Z. B. Salamandra palmata Schneid.

2. Die Salamander (lalamandra) find der vorigen Gattung ähnlich; lehen aber immer auf dem Lasde, ihr Schwanz ift rund, konilch; niemals haben fie Schwimmfülse. Sie legen keine Eyer, die Eyer kommen in Muterleihe aus und die Jungen werden in der Geftalt geboren, die fie ihr Laben hindurch behalten follen. Dar Körper der hieher gehörigen Arten ift mit Warzen oder Queerfalten verfehen. Die. Begattungsweife kennt man noch nicht recht. Z. B. Lacerta falamandra L.

3. Der Proteus (proteus) gleicht vóllkommen den Larven der Trió tonen (Wafferfalamander) die ibre Kiemen noch nicht abgelegt haben. Bey der zuerft beobachteten Art, z. B. Proteus ánguineus, ilt der Körper Ichleimig, der 'Knochen weich und die Farbe fehwach., Bey einer andern in Peru beobachteten und von Humboldt mitgebrachten Art, ift Haut und Glieder ganz wie bey den Salamandern; man weis aber, dals die Kiemen lebenslang bleiben follen, da fie, wie bey den Fifchen durch bellondere Kuochen geltützt find.

4. Die Siren (firen) find nur wenig beobachtet. Man kennt nur eine Art, 'die in Amerika gefunden ift, und die man für eine Salamanderlarve halten könnte, wenn man nicht bemerkte, dalș die HinterfüIse bey der Larve eber erlcheinen als die Vorderfülse, und hier blof Vorderfülse find, Z. B. Siren lacertina.

Ende der Klafle dex Reptilien. 


\section{No. LVIII.}

\section{Klassè. FISCHE.}

Rückgrathige Thiere, mit Kiemen und kaltem Blute, ohne Lungen, ohne Haare, ohne Federn und ohne Brüfte.

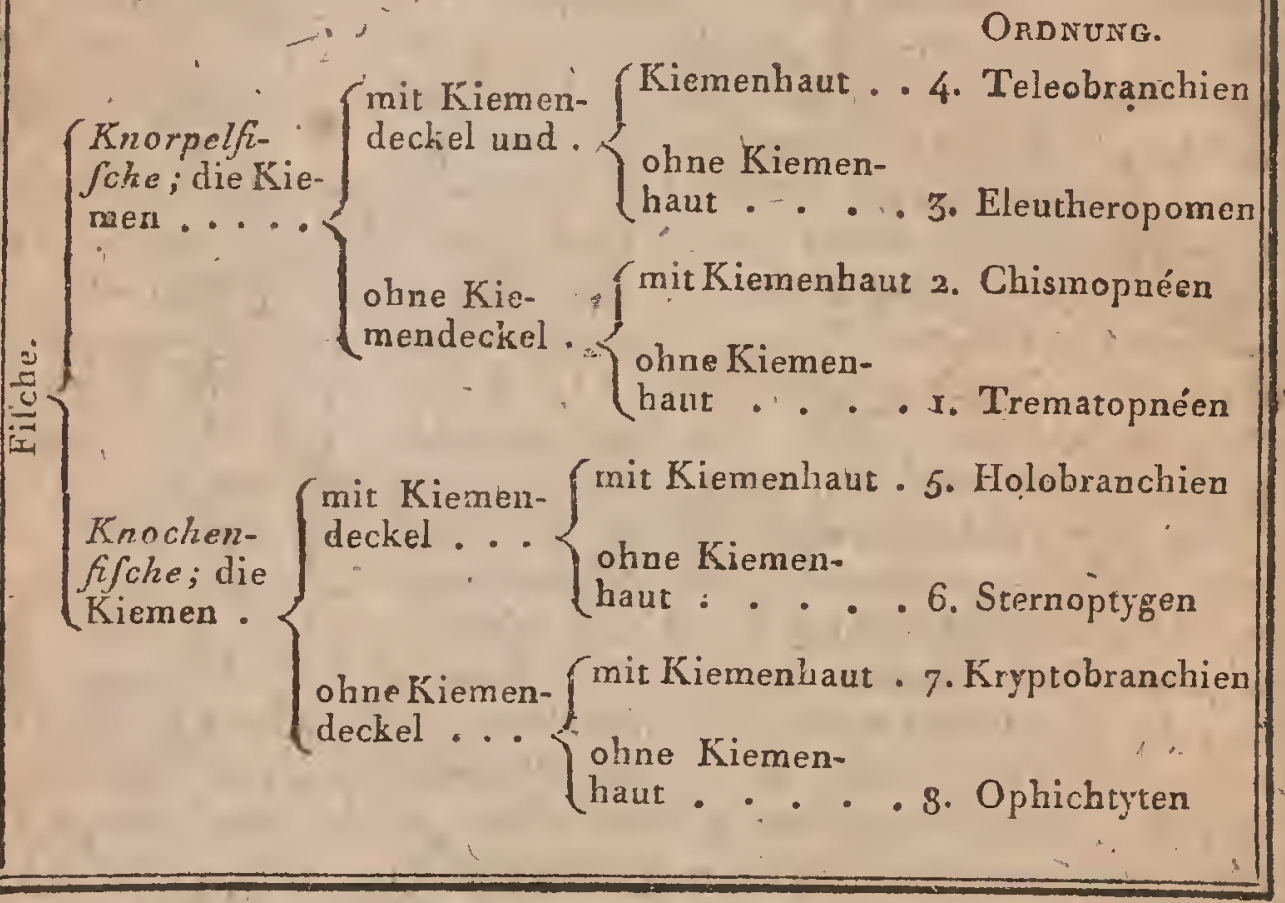

\section{BEMERKUNGEN ZUR LVIII. TABELLE.}

Die Klafle der Fifche e(pisces) begreift die letzten rückgrathigen 'Thiere, deren Organifation am wenigften complicirt ift. Der ihnen nothwendige Aufenthalt im Wafler, die Art ihrer Refpiration u. f. w. Ccheint ihr ganzés Welen modificirt zu haben. Obgleich die äulsere Geltalt fehr verCchieden ift, [o ift doch im Ganzen der Körper lang und hat vorn den Kopl, der das Gehirn in fich Ichliefst. Das andere Ende zeigt meift ejnen langen Schwanz, der mit einer vertikal ftehenden, durch Knochenftrablen unterftützten (Flollen) Membran endigt. Die Wirbelbeine ihres Rückgraths zeigen eine eigne merkwürdige Artikulation; durch Falerreiche Knorpel, die in konirchen Aushöhlungen am Vorder - und'Hin- 
tertheil des Körpers jedes Wirbelbeines aufígenommen werden. Die grölsere ocer geringere. Fefligkeit des Rückgraths hat die Abtheilung in Filche mit knorpligem und in Filche mit knochigen Skelet veranlalst:

Die Fifche haben nie eine eigentliche Bruft; die Knochen welche man ihre Rippen nennt, find nie zur Unterftiitzung' der Refpirationsbewegung, Condern zum Schutz der Eingeweide des Unterleibes, beItimmt.

Die Kiemen, häutige Blätter, die man fehr uneigentlich arich Filchohren genannt hat, erfetzen ihnen die Lungen; diefe Orgaue fcheineu beftimnt zu leyn, ron dem Waller, was beftändig ihre Oberfläche befpühlt, die demlelben, beygemifchte oder beygemengte kleiné Quantität Luft auszulcheiden. Kein Filch hat feine Kiemen, äulserlich. fichtbar, wie die Larven der Batrachier und mehrere Würmer und Mullusken. Immer find diele am Halle gelegenen Organe bedéckt; bald liegen fie unter eirein nach Willkühr von dem Thierd beweghichen Schuppenftücke, was man Kiemendeckel genannt hat und was in dieler Verrichtung noch von einer darunter gelegenen befondern Haut, in deren Duplikatur man gewöhnlich einige Knochenftrablen wahrnimt, und die man Kiemenhaut nennt, unterliütat wird; tald tehlt diefer Kiemendeckel und diefe Haut. Nach dem Daleyn und der Abwefen. heit dieler Theile hat man die Ordnungen dex Filche abgetheilt und wir werden lehen, dals diele, mit der Refpiration in genauer Verbindung ftehenden, Eigenbeiten, wirklich lehr natürliche Zufammenftellungen geben.

Der Kopf der Filche if im Ganzen lehr dick, was aber mehr von den Schling - und Relpirationswerkzeugen als von 'dem Schädel abbängt, der eigentlich klein und deflen innere Höle nicht ganz von Gehirn ausgefïlt ift. Die meiften haben bewegliche Lippen, durch beforidere Knochen unterfützt; ihr Mund ift in der Queere geöfnot; oft kann. er fich vorwärts bewegen. Die Zähne variiren lehr in Zahl, Geftalt und Vertheilung an den verlchiedenen Knochen', des Munkles und dienen fehr gut zur. Charakteriftik.

Die Fifche haben immer eine einfache Cirkulation; alles Blut wird durch ein Herz mit einer eimfachen Kammer in die Kiemen getrieben. Aber die Kiemenarterie vereinigt fich, nachdem fie fich zertheile hat, in einen einzigen Venenftamm, der fich plötzlich in eine grolse Axterie verwandelt, an deren Balis, keine Kammer wahrgenommen wird.

Die meiften weiblichen Fifclse geben unbefruchtete Eyer von fich, welche die Männchen dadurch erft beleben, dals' lie ihre Samenfeuchtigkeit daran gehen laffen. Einige Arten aber begatten fich nicht allein, fondern oft behalten dann auch die Weibchen die Eyer fo lange bey lich, dals die Jungen im Körper der Mutter Ichon aus dem Eye kommen. wie'dies bey einigen Reptilien, Z. B. den Vipern, gelchieht. (Manfehe forner die Bemerkingen zur folgenden Tabelle.)

Dumeril Zool. 


\section{No. LIX.}

\section{T A B E L L E}

\section{ÜBER LACEPEDES ICHTHYOLOGISCHES SYSTEM.}

、 Unterklasshis.

OrdNungen. UNTERORDNUNGEN. - I. K3. Kahlbäuche

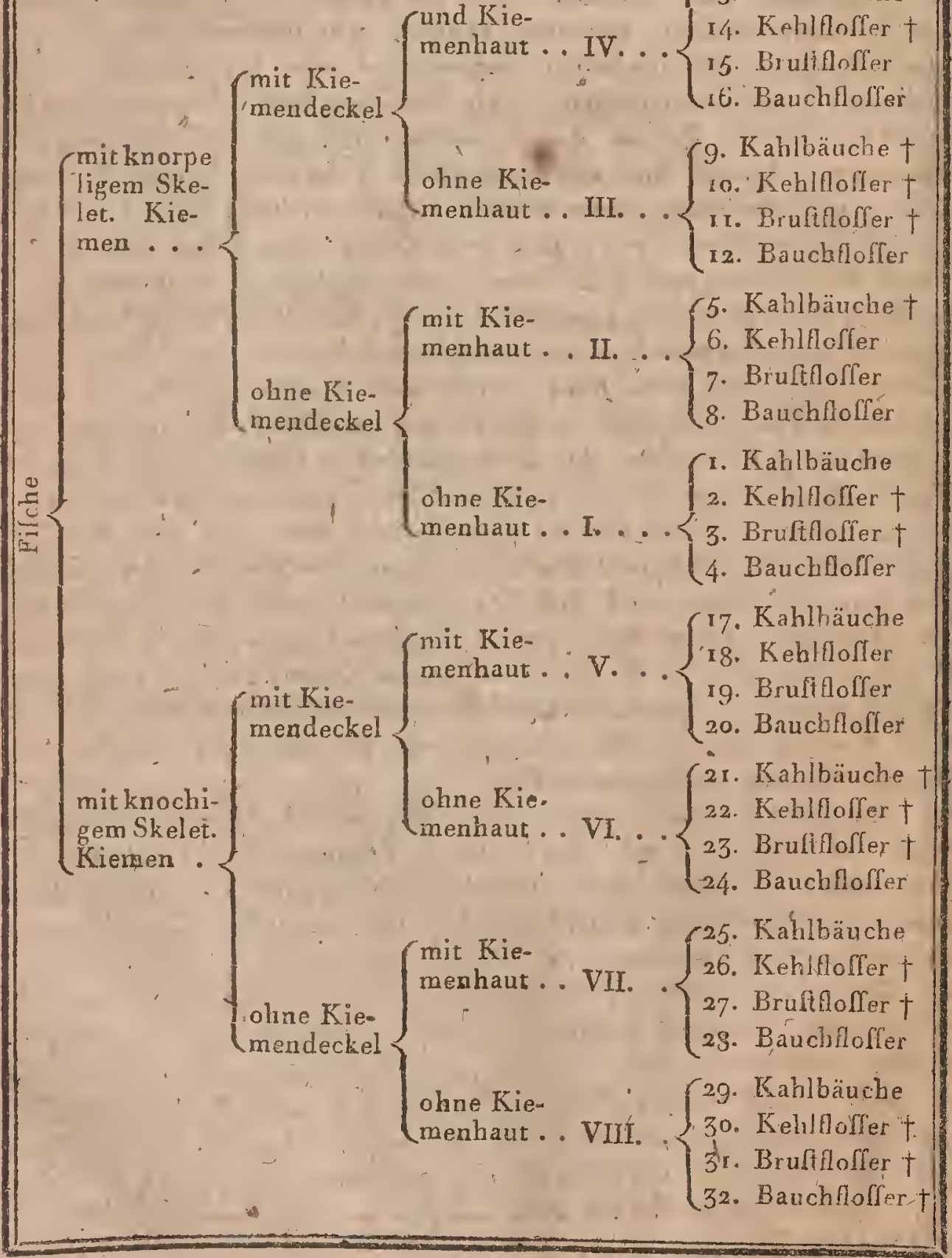




\section{BEMERKUNGEN ZUR .LIX. TABELLE.}

Die allgemeine Tabelle der Eintheilung der Fifche, die fich auf pag. $3^{6}$ finder, ift nur ein Auszug aus Lacepedes Syftem, worüber die gegenwärịge weit vollfändiger ift. Man kann fie als ein vorhér entworlenes Schema antehen, nach welchem man die Fifche ordven und die Gatungea auch hinzufiellen kann, die einige der in dea Unterorinungen angegebenen Eigenbeiten zeigen werden, obyleich man noch keine dahin gehörigen Arten kennt. Diele Unterordnungen find mit thezeichnet.

Wenn hier pag. 96 einige neue Ausdrüclse zur Bezeichnung der Lacepedifchen Ordnungen angegeben lind, lo gelchah das nur un nicht immer Umlchreibungen brauchen zu müffen; die lich nicht fo leicht wïrden imner auders geben laflen und daher mit einigen Unbequemlichkêten verbunden gewefen leyn würden.

Alus demlelben Grunde lind hier die Namen für die Unterordnungen angegeben, die von Lacepede blos angedeuret worden waren. Vielleicht wird das fonft hier beybehaltene Syftem diefes angefuleaen Naturforfchers durch den vergleichenden und analytifhen Weg, den wir hier gegangen find, und lurch einige $V$ erletzungen gewiffer Gattupgen, die ms nöbig fchienen, in leinem Gebrauche noch erleichtert.

Die Eintheilung in Knorpelfifche und Knochenfifctue ift wirklich eine fehr deutiche. Wenig Knorpelfifche haben eigentliche dacligiegelartig liegende Schuppen. Thre $\mathrm{Züh}_{\mathrm{a}}$ find gewöhalich uicht eingekeilt; lie haben keine Rippen oder Knochengräthon; đie meilten haben keine Schwimmblafen u. [. w. Alles dies liebt fall in Widerfpruch mit dem, was fich bey den Knochenfilchen vorfinder.

Die Bauchfloffen, die man vielleicht beffer mit dem Namen Kato. podend.b. Unterfüfse belegté, (odèr Allopteren, Flollen die ibren Onverändern, nensen körnte, ) find paarweife Floflen, unter den Leibe. BauchMollen find nur vorhanden wenn auch das andere Paar da ift. So nennt man alle Fifche floffenlole (apodes), Kriblbüuche, wo fich nur ein oder gar kein Paar Flollen finden. W'enn zwey Paur lolcher Floffen vorbanden fund, fo find die untern bald unter der Keble d. hi vor den Bruffloflon fitzend und diele Arten heifsen Kehlfloffer (jugulares.) bald lizt das aweyte Paar unter dem erften und die nemnt man'Brujtfloffer (thoracici) oder endlich, fie fitzen hinter den Brufffoflen wirklicb an Líache und dann heilsen Le Bauchfloffer (abdominales.) 


\section{No. LX.}

\section{ORDNUNG TREMATOPNÉEN. *)}

Knorpelfifche ohne Kiemendeckel und ohne Kiemenhaut; das Waffer durch runde Oeffnungen athmend.

Familien.

Bauchfloflen $\left\{\begin{array}{l}\text { feblend; der Mund zirkelförmig rund 1. Cykloftomen } \\ \text { deutlich vorhanden; der Mund als ei- } \\ \text { ne breite Queer-Oeffnung . . . 2. Plagioftomen }\end{array}\right.$

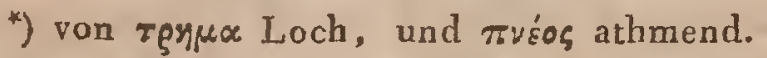

\section{No. LXI.}

\section{Familie. CYCLOSTOMEN. *)}

Knorpelfifche ohne Kiemendeckel, ohne Kiemenhaut, ohne Floflenpaare; der Mund zirkelrund ganz vorn an dem cylindrifchen, nackten, klebrigen Körper.

Gattungen.

Kiemenlöcher an Jer Zahl $\left\{\begin{array}{l}\text { fieben, auf den Seiten . r. Lamprete } \\ \text { zwey, unter der Bruft . 2. Bauchkieme }\end{array}\right.$

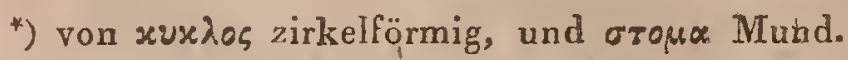

\section{BEMERKUNGEN ZUR LX. TABELLE.}

Die Ordnung der Tremacopnéen vereinigt, diejenigen Knorpelfifche, deren Kiemen durch gar keine feften Theile bedeckt find. Die rociften 
ben viele runde Löcher, dirch welche das verlchluckte Waffer wieder heraustreten kann, wenn es zur Refpiration gedient hat. Gerade bey diefen Fifchen,' findet man die meiften Arten mit Spritzlöchern, d. h. befonderen Oeffnungen, durch tvelche das Wafler aus der Mundhöle heraus und hinein (?) dringen kann, wenn die Mundöffnung verichlollen ift.

$\mathrm{Zu}$ diefer Ordnung gehören zwey fehr verfchiedene Familien; bey der, einen findet man niemals paarweile Floflen. Ihr zylindrifcher Körper ift vorn wie abgeftutzt, zeigt eine runce Oeffnung, an den Lippen herum mit Zähneu befetzt. Nalenlöcher oder Géruchöhlen hat man bey ihnem noch nicht gefunden. Sie begatten fich nicht; Gie legen (laichen) runde Eyer in einer fchleimigen Umgebung.

Die zurandern Familie gehörigen Filche haben grolse Bruft - und kleine Bauchlloflen. Die meiften haben einen breiten queer unter der Schnautze liegenden Mund. Sie begatten fich und die Eyer kommen in Mutterleibe aus oder kommen befruchtet zur Welt, von einer hornartigen, platten, viereckigen in langen Fäden ausgehenden Hülle, die man uneigentlich Seemäufe nennt, umfchlollen.

\section{BEMERKUNGEN ZUR LXI. TABELLE.}

Die Familie der Cykloftomen; weicht durch die Form ihres Mun. des von allen Thieren dieler Klafle, ja von allen rückgrathigen Thieren. $a b$ und nähert lich einigormalsen gewilfen Nereiden und Amphinomen.

I. Die Lampreten (Petronyzon) haben dielen Namen von ihrem Vermögen fich mittels ihres Mundes, der wie ein Schröpfkopf wirkt, an dio Steine fefi zu hängen (a lambendo petras). Jedes der lieben Kiemenlöcher führt in eine befondere Höle wo die Kieme liegt. Das Thier kann willkührlich durch diefelbe Oeftnung Wafler einnehmen und ausftoflen. Die Kiemen find nicht wie bey den andern Filchen blätterartig angebracht, londern nur eine gefaltete, gefälsreiche Haut. Man kennt 8 - ro Arten dieler Gattung. Z. B. Petromyzon marinus L.

2. Die Bauchkiemen (gaftrobranchus) haben die Oeffnung ihrer Kiemen, wie dies der Name anzeigt, unter dem Körper. Ber Mund ilt mit Bartfaden beletzt; man hat aber weder Augen noch Nalenlócher, wobl aber ein Spritzloch üher dem Munde gefuriden. 'Es ift noch nicht ganz entlchieden ob die beyden hieher gezäblten Arten wirkliche Filche fiad. Z. B. Gaftrobranch. coecus Bloch. Myxine glutinofa L. 


\section{No. LXII.}

\section{Famiute. PLAGIOSTOMEN. *)}

Knorpelffche olne Kiemendeckel und Kiemenhaut; vier Seitenfloflen; breiter queer unter der Schnautze liegender Mund.

Gatitunghen.

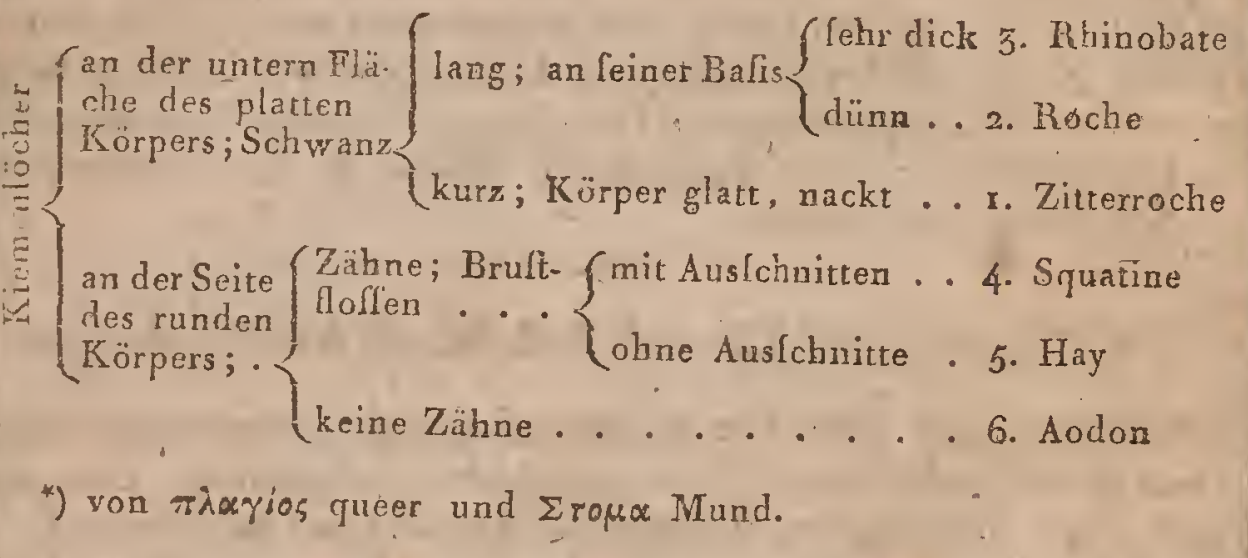

\section{BEMERKUNGEN ZUR LXII. TABELLE。}

Die Plagiofiomen, Queermäuler, entfprechen der vierten Unterordnung des Lacepedelchen Syltems. Sie find die einzigen Fifche, welche beftandig 4 bis 5 Paar Kiemenöfnungen haben. Ilure Bruftloflen lind immer lehr entwickelt und find von einer fuhr-grofsen: Zahl von fächerarig liegenden Kuorpelftrablen gebildet. Die Männchen haben zur Seite des Urfprungs des Schwanzes, zwey Anhänglel, deren Beftimmung ift; das Weibchen bey der Begatrung feft zu halten. Das Maul, was vimmer in die Queere und breit ift, hat gewöhnlich mehrere Reiben in Zahl und, Form höchft verfchiedener Zähne. Die übrigen Eigenbeiten find in der Frläuterung der (60.) Tabelle der Trematopneen angegeben.

I. Die Gattuhg der Zitcerrochen (corpedo) begreift nur drey Arten, ift aber von allen übrigen diafer Ordnung lehr leicht zu unterfcheiden: I. durch die ovale Form des Körpers; 2. durch die völlige Nacktheit deffelben; 3. durch die Dicke und Kürze des Schwanzes; 4. durch den um dic Kiemen herum liegenden eloktrilchen Apparat, der aus einez 
Menge vieleckiger Röhren befteht, "deren Ęnden durch die Haut Ichimmern. Z. B. raja torpedo L.'

2. Die Rochen (raja) haben einen meilt winklichen Körper, der fich in einen dühnen Schwanz endigr, auf der Rückenfeite mit Stacheln oder Höckern bedeckt ift und die Augen nachoben gerichtet trägt. Sie Ichwimmen, mit der Fläche, fehr fchnell, nähren fich von Krabben, Schaalthieren und Filchen. Einige Arten erreichen eine lehr-beträchtliche Gröfse, man hat fie bis von 200 'Pfund gefunden.' Man hat fie in Untergattungen abgetheilt, nach der Befchaffenheir der Schnautze, der Gefialt der Zähne, der Zahl der Rückenfloflen und nach der Gegenwart und Vertheilung der Stacheln des Körpers; es ift dies eine an Arten lehr reiche Gattung. Z. B. raja batis.

3. Die Rhinobaten (rhinobates) machen den. Uebergang von den, Rachen zu den Hayen. Ihr Körper ift lang wie-bey den letztern, aber Whre Kiemenlöcher find an der Unterfeite des Körpers. Man zählt nur drey Arten hieher. Z. B. raja rhinobates L.

4. Di๔ Squatinen (qquatina), gewöhnlich Meerengel genaint, machen nur eine einzige Art aus, deren Hauptcharakter von der Form der an ihrer Bafis ausgelchnittenen Flóllen und von der Lage des Mauls am Ende de rundlichen Kopfes hergenommen ift. Z. B. Squalus Iquatina L.

5. Die Hayffche (lqualus) haben einen taft kegelförmigen Körper. Es find Fifche die eine - tehri beträchtliche Grölse erreichen; man hat fie von 1500 Pfund und darüber gefangen. Die. Haut ilt gewöhnlick, ganz rauh; das Maul, unter der-Schnautze verborgen, ilt mit einer grolsen Zahl Ipitziger, fehneidender Z̈̈hne beletzt. Die Kiemenöffnungen liegen immer-an der Seite de Halles und bilden eine Reihe von Spalten. Man theilt die Arten ab nach dem Dafeyn und der Abwefenheit a. der Spritzlöchier hinten auf dem Kopfe b. der Afterllolle und nach der Form der $\mathrm{Nale}$ und des ganzen Kopfes. Z. B. SquaIus carcharias L

6. Die Aodons (aodon Lacep) unterlcheidet fich von den Hayfilehen aurch nichts als durch, was auch der Name ausdrückt, den gänzlichen Mangel der Zähne." Forskael hat zwey Arten unter dem Namen Maffafa und Kumal belchrieben, Squal. maltala L. Gm. 


\section{No. LXIII.}

it. Ordnung und III. Famile. Chismopnéen. *) Knorpelfifche ohne Kiemendeckel, mit der Kiemenhaut; Kiemenöffnung als Spalte an der Seite des Halles; zwey Paar Flollen.

Gattungen.

. C dem Halre vor den platt gedrückt .... . Frolchfifch

Brufflolfen; Körper $\left\{\begin{array}{l}\text { von der Seité zufammenge- } \\ \text { drückt }\end{array}\right.$

. . . 2. Seeteufel

den Brufthoffen . . . . . . . Hornfifch

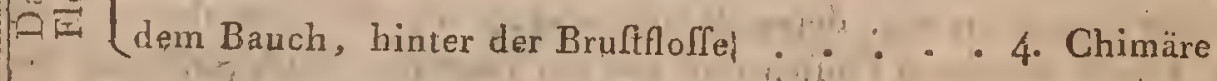

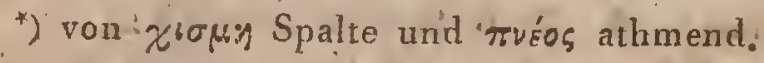

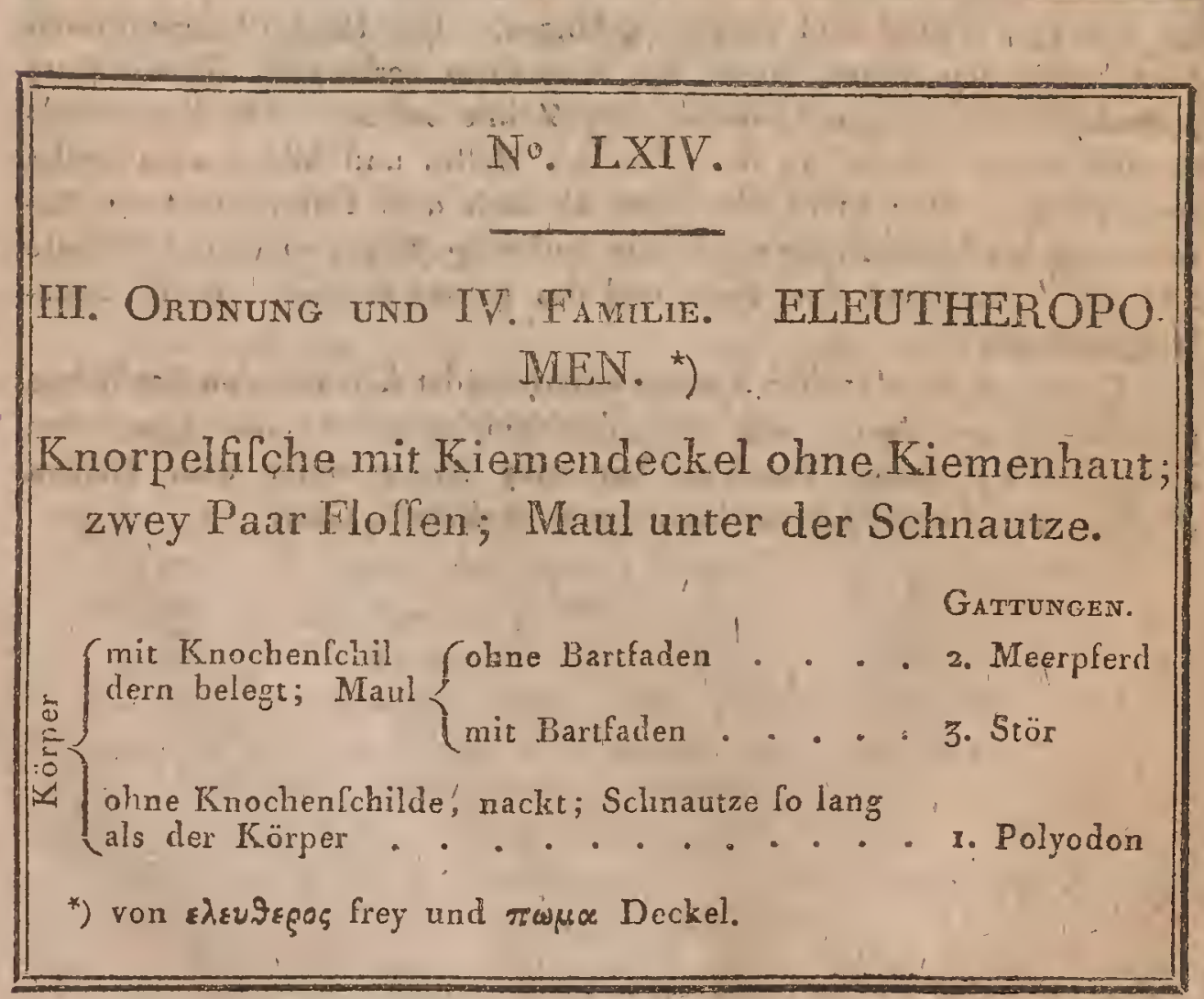




\section{BEMERKUNGEN ZUR LXII. TABELLE.}

Alle zu Lacepedes zweyter Ordnung gerechneten Fifche, haben ftatt des Kiemenlochs eine Kiemenfpalte. Alle haben vier Seitenfloffen, deren Sitz aber vérlchieden ilt; auch gehören lie deswegen zu drey verfchiedenen Unterordnungen: zu Kehlfoffern, Brultlolfern und BauchUlolfern. 1. Die Frofchfifche (Batrachus Klein) habon einen mebr breiten als hohen Körper, einen breiten Mund mit zahlreichen, Ipitzigen nicht dicht an einander ftehenden Zähnen. Der Kopt ilt fo grofs dal's er allein den dritten Theil des Filches ausmacht. Die Bauchloflen fcheinen am Urfprunge des Schwanzes zu Gitzen. Z. B Lophius vespertilin L. 2. Die Sec teufel (Lophius) haben einen dicken oft zufammengedrückten Körper. Ihr Mund ift klein und mit fleilchigen Fühlfäden, Anhängleln verlehen., Die Bauchfloflen lehen aus wie Füfse. Z. B. Lophius hiftrio L. 3. Die Hornfifche (Baliftes) haben einen' (ehr zulammengyedrückten Körper mit rauher, in kleine Felder abgetheitter, Haut. Der Mund ift klein und hat wenigftens acht nahe an einander ftehende hervorragende Zähne. Ihre unter den Bruftfloflen fitzenden Bauchfloffen lind oft in eine einzige vereinigt oder durch einen Stachel erfetzt. Diele Filche kommen einigermalsen mit den Klippfilchen (Chaetodon) überein, unterlcheiden fich aber von ihnen, durch den mangelnden Kiemendeckel, durch die Breite und Zahl der Zähne, und durch das Knochengerült. Man kenut mehr als 20, Arten, Z. B. Balistes vetula L. 4. Die Climü̈ren (chimaera, callorhincus Gouan) find Bauchflofler, über deren éngem Munde ein fleifchiger Anhängfel befindlich ift und die zwey S.hneidezähne in jeden Kiefer haben. Es find nur awey Arten bekannt. Z. B. Chi maera arctica.

\section{BEMERKUNGEN ZUR LXIV. TABELLE.}

Diele dritte Ordnung enthält nur eine Familie, wohin blofs BauchAlofler gehören. r. Die Polyodons (Ipatularia Shaww) bilden eine Gạttung von einer Art, die ihren Namen von ihren vielen Zähnen hat; fie find wegen ihrer aufserordentich langen, mit einem käutigen Blatte verfehenen, Schnautze merkwürdig. Z. B. Cpatul, folium. 2. Die Meerpferde (pezalus) haben die Bauchifoffen , durch einfache Filamente er'Setzt, die Bruftloflen aber'breit und grofs.' Z. B. pegal. Draconis L. 3. Die Störe (acipenfer) find grolse Fifche, die das Maul mit Bartfaden beletzt und eine fehr grofse Schwimmblafe haben. Es find Meerfifche dielin die Flüle fteigen, und wegen ihres Fleifches und ihrer Eyer fehr gelucht vierden, Z. B. Acipenfer fturio. L. 


\section{No. LXV.}

\section{ORdnung. TELEOBRANCHIEN. *)}

Knorpelffche mit vollkommenen Kiemen, d. h. mit folchen, wo fich auch ein Kiemendeckel und Kiemenhaut findet.

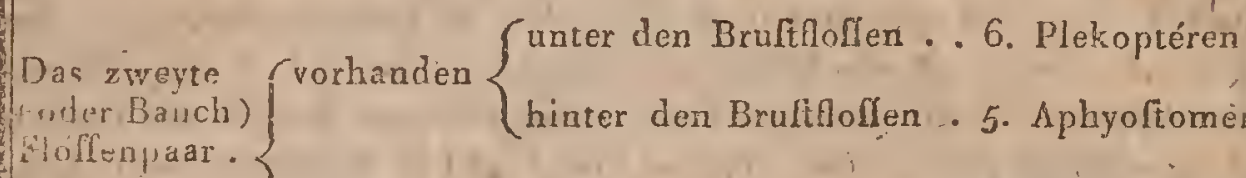
tehlend...... 7. Ofteodermen

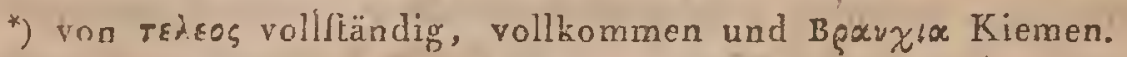

\section{N". LXVI.}

\section{Famile. APHYOSTOMEN. ${ }^{\star}$ )}

Knorpelfiche mit vollkommnen Kiemen, Bauchfloffen hinter den Bruffiloffen. Das Maul am Ende der Schnautze.

GitTungen.

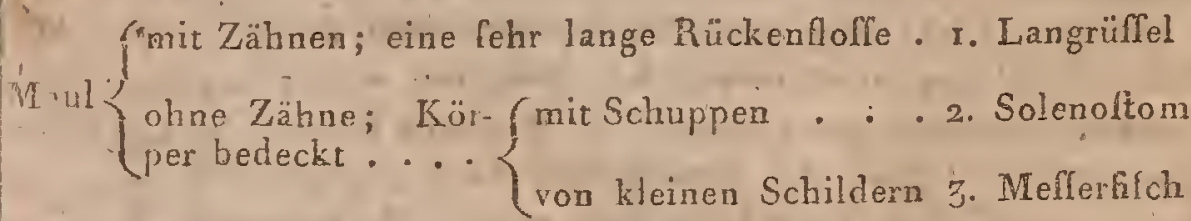

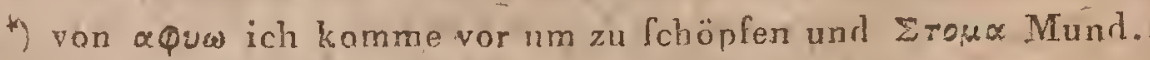

BFMERKUNGEN ZUR LXV. PABELLE

Die vierte und letzte Ordnung der Knorpeltilche befteht aus denen, decen Refpirationsorgane am komplicirteften find; fie.Icheinen den U⿴囗十 
bergang zwilchen den beyden Unterklaffen zu machen. Auch planzen fie fich auf diefelbe Waife fort, wie die Knochenfifche der folgenden Ordnung oder wie die Ofteopomen. Man kennt keine, wo das zweyte Floffenpaar zwilchen den Brufthoffen und der Kehle lälsen. Lacepede hat fle zu den Bruftiloflern, Bauchflofiern und Kahlbäuchen gezählt.

\section{BÉMERKUNGEN ZUR LXVI. TABELLE.}

Die mit Bauchfoffen vierfehenen Teleobranchien haben alle eine fehr verlängerte Schnautze an deren Ende das kleine Maul fitat, was wirverlucht haben durch das Wort Aphyoftomen auszudrücken.

Man kennt nur drey Gattungen dic hieher gehören, wovon jede nur wenige und"kleine Arten zählt.

I. Der Langriugfel (macrorynchus) ift ein kleiner chinefilcher Filch, deffen fchuppiger Körper mit einer Rückenfoffe verlehen ift, die fich vom Kopf bis zum Schwanz erftreckt.' Die Bauch hoflen hahen nur cinen Strahl; der Mund ift mit Zähnen befetzt. Z. B. Marror, argenteus $L$ a $c e p$.

2. Die Solenoftomen, Röhrenmundfffche (folenoftoma. Kl ein.) haben den Körpër mit Schuppen bedeckt und auf dem Rückeu zwey Foflen. Die Hauptart ift unter dem Namen Schnepfenfilch bekannt und, ift im mittelländifchen Neere an den italiänifchen Külten ziemlich häufig. Die fer Filch hat die gröfste Aehnlichkeit mit den Syphonoftomen unter den Holobranchien der Knochenfilche.' Z. B. Cehrisisc. Icolopax L.

3. Die Mefferffche (centriscus), haben einen zulammengedrückten 'von Schildern bedeckten und' durch Stacheln gelchü̈zten Körper. Sie haben keine Zähne. Ihre Unterkinnlarle ift länger als der'Oberkiefer. Z. B. Centriscus fcutalus.

Man muls-geftehen dals die zwey erften Gattungen diefer Familie durch ihren mit Schuppen bedeckten Körper lich felhr von den übrigen in diefer Unterklafle zulammengeftellten Filchen entfermen. Nur die Zergliederung kann den Naturforlcher über die Klaffifikation diefer beyden Gattungen aufklären. 


\section{NVo. LXVII.}

\section{Familie. PLEKOPTEREN. *)}

Kinorpelfifche mit vollftändigen Kiemen; die Bauchfloflen mit einander vereinigt, unter den BruftHoffen fitzénd.

\section{GATTUNGRN.}

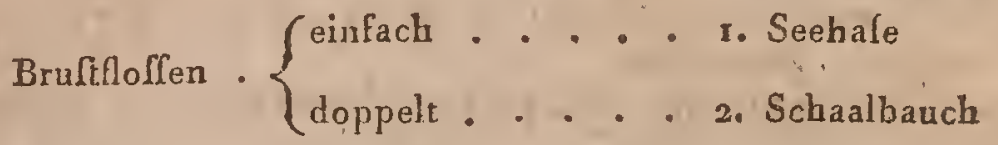

$\left.{ }^{*}\right)$ von $\pi \lambda \varepsilon s o \varepsilon$ vereinigt und $\pi r \varepsilon \rho \circ v$ Flolle.

\section{No. LXVIII.}

\section{FAMILIE. OSTEODERMEN. *)}

Knorpelfifche mit Kiemendeckel und Kiemenhaut; ohne Bauchfloflen; die Haut mit einer Cchaaligen Bedeckung oder Knochenpunkten verfehen.

GaTTUNGEN.

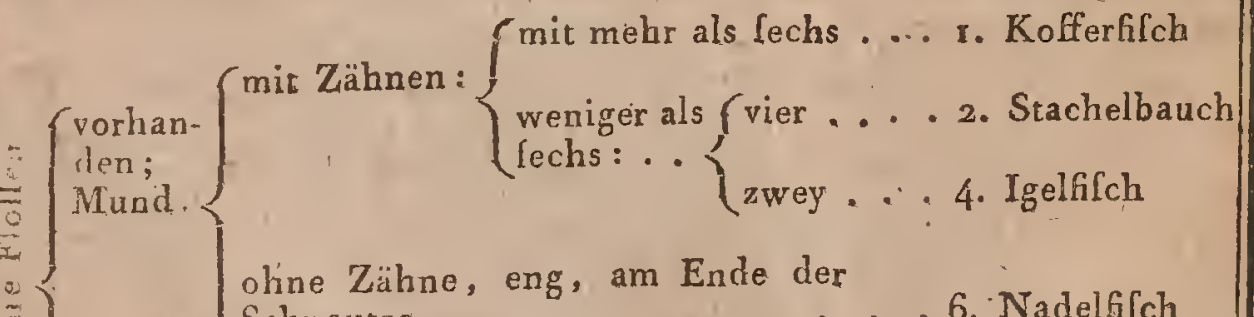

$$
\begin{aligned}
& \text { ohine Zähne, eng, am Ende der } \\
& \text { Schnautze . . . . . . 6. Nadelffch } \\
& \text { fehlend; Oberkief'er mit. }\left\{\begin{array}{l}
\text { zwey Zühnen } . \text { 3. Eyerfflch } \\
\text { vier Zähnen, . 5. Kugelfifch }
\end{array}\right.
\end{aligned}
$$




\section{BEMERKUNGEN ZUR LXVII. TABELLE.}

Die Familie der Plekopteren gehört in die Ordnung der Knorpelfsche mit Kiemendeckel und Kiemenhaut und, in die Unterordnung der Bruftfloffer. Ihre beyden Bauchfloflen find in eine einzige, runde unter den brulthofleu fitzende vereinigt.

I. Die Gattung der Seehafen (cyclopterus) hat einen kurzen, dicken, vorn abgeltumpften fchuppenlolen Kürper. Das Maul diefer Seefilche ifft mit Ipitzigen Zähnen befetzt.' Gronow hat eine Art diefer Gattung unter dem Namen Cyclogafter anfgeführt, nemlich cyclopt. liparis, wo die Rücken, Schwanz und Afterfloffen in einander übergeken.

2. Schaalbüuche (lepadogafter, $G$ o u a $n$ ) haben diefen Namen deswegen erfialten, weil fie doppelte Bruftloffen und diele in eine Art Schèibe vereinigt baben, welche man mit einem Barbierbecken, einer Schaale, verglichen hat.

\section{BEMERKUNGEN ZUR LXVIII. TABELLE.}

Die Ofteodermen find Knorpelfilche mit vollftändigen Kiemen aber oh. ne Bauchfloffen. Alle haben kleine Knochenfchilder in ihrer Haut ftecken.

I. Die Kofferfffche (oltracion) haben den Körper von einer knochigen Haut umgeben, die in kleine Felder abgetheilt ift. Der Mund ift klein und mit einer-Reihe Schneide-Zähne verfehen. Die unpaaren Floflen fitehen durch Ausichnitte aus der kalkerdigen Hülle hervor. Man hat fie nur in den Südmeeren beobachtet. Z.B. oftrac, triqueter L.

2. Die Stachelliäuche (terrodan d. h. Vierzahn) haben jeden Kiefer in zwey Zälıne abgetheilt. 'Z. B. tetr. hispidus L.. Die' Arten, wo der Körper gewaltig zulammengedrückt und hinten wie geltutzt ift, hat man Kopffifche (cephalus) genannt z. B. tetr. mola, wo der ganze Körper nichts als einen Kopf zu bilden fcheint.

3. Die Eyerfijche (ovoides Lacepede) unterlcheiden fich von den Diodons nur durch die mangelnden unpaaren Flofen; z. B. ovoid. fasciaius Lac.

4. Bey den Igelfffche ift der Kürper mit beweglichen Stacheln bedeckt; der Mund klein, die Zähne von den wwey knochigen nicht getheilten Kinnladen gebildet, und die unpaaren Floflen rophanden. "Sie kommen fonft lehr mit den Tetrodons überein. Z. B. Diodon hyftrix L.

-5. Die Kuggelfifche (orbis) find für die Tetrodons, was die Eyerfilche für die Diodons find. Z. B. orbis tuberculatus.

6. Die Nadelffche (fyngnatus) find kleine langgeftreckte Fifche, mit wirklichen, artikulirenden Schildern. Der Mund ift klein, ohne Zühne und wie mit einem Deckel verlehen. Sie haben ein oder zwey unpaarn Floflen und zwey, kleine Spritzlöcher auf dem Nacken. Sie tragen ibre Eyer unter einer Bauchlpalte und find nicht lebendig gebärend, wvie man fonft glaubie, $Z$ Z, B. Syngn, acus L. 


\section{No. LXIX.}

\section{Ordnung. HOLOBPaNCHIEN. * )}

Knochenfiche mit vollftündigen Kiemen, d. h., wo fich auch Kiemendeckel und Kiemenhaut finden.

UNTERORDNUNGEN,

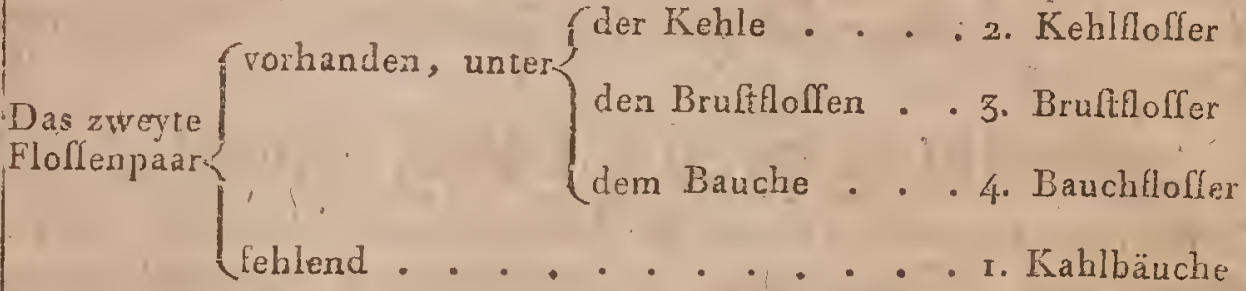

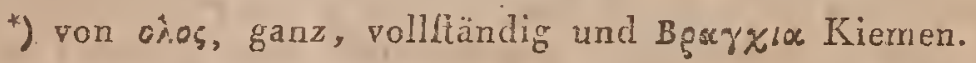

No. LXX.

I. UnTERORDNUNG. HOLOBRANCHIEN KAHLBÄUCHE.

Knochenfiche mit Kiemendeckeln und Kiemen haut; das hintere oder untere Floffenpaar fehlend.

FsMinteriv.

Die ibrigen Floflen $\left\{\begin{array}{l}\text { alle vorhanden . . 9. Pantopteren } \\ \text { zum Theil auch fehlend . 8. Peropteren }\end{array}\right.$

\section{BEMERKUNGEN ZUP LXIX. TABELLE.}

Die achte Ordnung der Fifche entbält allein viermal lo viel Gattum. gen und Arten, als die fieben andęrn Ordnungen zufammengenommen. 
Die hieher gehörigen Thiere bilden eine lehr natürliche Abtheilung, der man leicht eirre Menge von belonderen und auf Gégenfätzen beruhenden, von der Körperform und Organifation hergenommenien, Eigenthümlichkeiten beylegen kann; 'o haben die meiften den Körper mit Schuppen bedeckt, die in quiricunce firzen und dachriegelarrig über einander liegen. Beftändig findet man auf den Seitentheilen des Körpers eine vertiefte Linie, oder eine der Länge nach laufende Reihe von kleinen Oeffnungen oder vorftehenden Höckern, über welcher ein vom Halle bis zum Ende des Schwanzes laufender Nerv liegt. Die meilten haben deu Unterleib oder die Höle, wo die Digeftionsorgane liegen, von knöchernen, den Rippen der Süugthiere ähnlichen, Reifen beichürzt Bey den állermeifien ift die Fähigkeit zu fchwimmén und nach Willkühr fich in dieler oder jener Höhe des Waffers zu halien, durch eine hydroltatilche Blafe erleichtert, wrodurch die Filche eine mehr oder minder grofse Menge Wafler aus ibrer Stelle treiben können, ohne die abfolute Schwere ihres Körpers zu verändern. - Keire Art hat melir als \%wcy Kiemenöffnungen. Alle laichen rundtiche Eyer. Nur einige wenige find zugleich Eyer - nnd lebendig gebärend und diefe begatten fich auch allein vorher: es giebt aber, wie es fcheint, weit wenigger Männchon als Weibchen. Ihr Skelet ifiknöchesner Natur, aber doch auch fehr bieglan.

Die Gegenwart oder Abwefenheit der Bauchfloflen oder Katopoden, wie wir lie genannt haben, giebt ein lehr bequemes Mittel ab, diele Ordnung in vier Unterordnungen abzulbeilen, obgleirh diele Abfchnitte an der Zahl einander lehr ungleich find. Die Bauchjloffer find lehr zahlreich an Familien und Gattungen, die meilten find Flufs - und Sülswalferfilche. Die Brufteffer lind noch zahlreicher, aber es giebt unter ihnen weniger Flulsfilche. Die Kehlfloffer machen nur eine einzige Familie aus; deren fich zwey bey den Kahluäuchen finden.

\section{BEMERKUNGEN ZUR LXX. TABELLE.}

Die Knochenfilche mit vollfärdigen Kiemen aber ohne das hintere. (Bauch) Floffenpaar, kriechen gevoöhnlich im Schlamm oder aut dem Sande, da fie fich nicht gut im Gleichgewicht erhalten können. Bey den meiften ift der Körper lang geftreckt, zylindrifch. oder blattähnlich zufammengedrückt. Sie fchwimmen wie die Schlangen durcb ftarke Krümmungen und Biegungen ihres Körpers; deswegen find auch die unjiar, vorkommenden Floflen bey ihnen meiff fo grofs, z. B. die Rückentlofle, die Schtranz: und Afterfloflo. 


\section{No. LXXI.}

\section{Familie, :PEROPTÉPEN. *)}

Knochenfifche mit vollftändigen Kiemen; die Bauchfiolfen und eine oder die andere der übrigen Floffen fehlend.

'Gattungen.

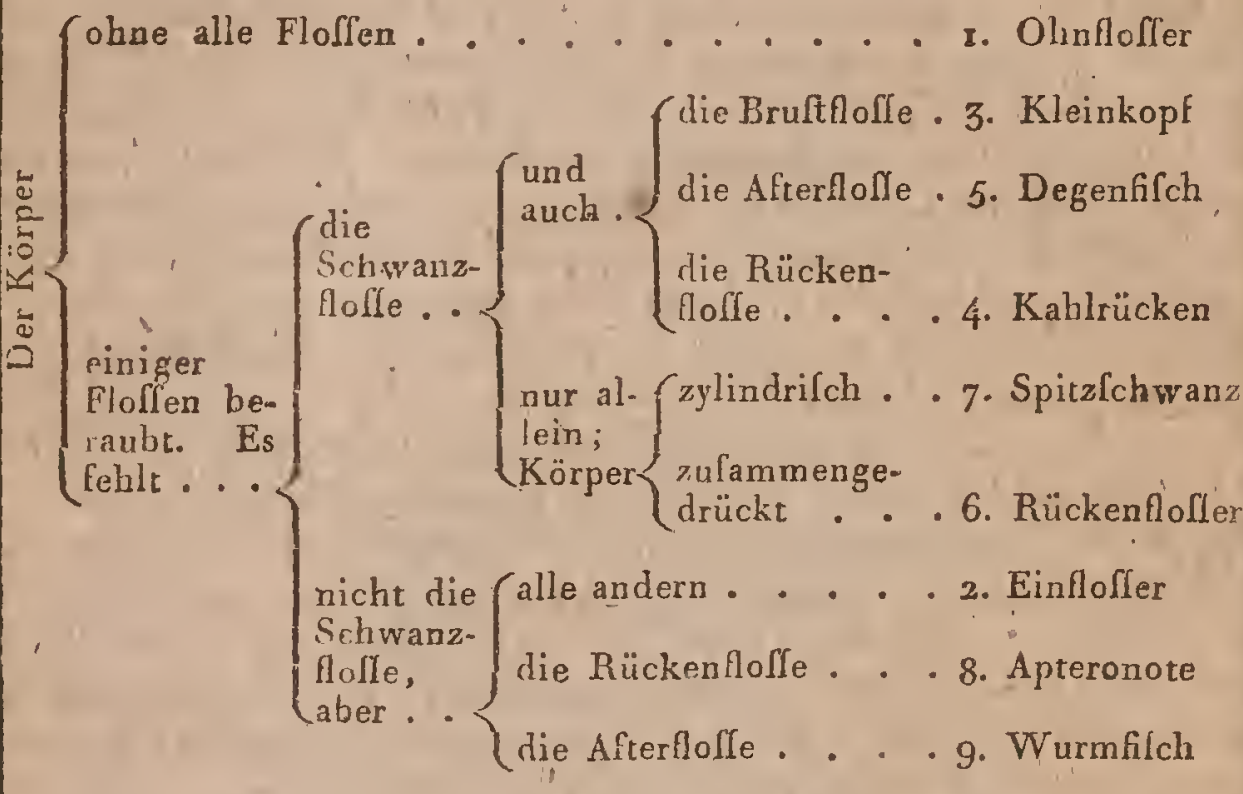

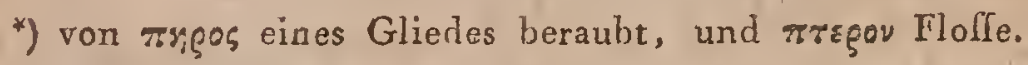

\section{BEMERKUNGEN ZUR LXXI. TABELLE.}

Die hier mit dem Namen der Peropteren belegten Filche, können, da ihnen die Bauchfloffen und einige der anderen Floflen fehleil, nur wie die Schlangen fchwimmen. Die meiften haben den Körper gewaltig lang und zulammengedrückt, andere haben ihn mehr zylindrifch und diefe halten fich am meiften anf dem Boden des Waflers auf. Sie machen eine ziemlich natürliche Fámilie aus, die zwar aus vielen Gattungen aber venigen Arten befteht.

I. Die Gattung der Ohnfloffer, (caecilia oder belfer, um nicht ein in der Klaffe der Reptilien gebrauchten Namen zum zweytenmal anzuswezden, Apterichthys) enthält nur nur eine von Branider an den Küften 
der Barbarey becibachtete Art, die wenig bekannt und noch nicht einmal gut abgebildet ift. Dies ift der einzige ganz floffenlofe Fifch, den es giebt. Z. B. Muraena coeca L.

2. Die Einflofier, (Monopterus) kennt man nur aus der von Commerfon hinterlaffenen Befchreibung einiger Fifche diefer Art, die in der Nähe von Java gefangen wurden. Z. B. Mon. javanicus. Lacepede.

3. Der Kleinkopf (Leptocephalus) ift auch eine Gattung von einer einzig̨en Art, wovon man einige Exemplare an den englifchen Küften gefangen hat, z. B., Leptoceph. Morrifii Lacep:

4. Die Gymnotus oder Kalulrücken (gymnotus), haben wirklich auf dem Rücken und dem Schwanze keine Flofle. Es gehört hieher der elektriIche Aal, gymnot. electricus I.. aus Surinam, der den Thieren, die ihn berühren, eine Erlchütterung, wie dusch die Entladung einer electrifchen Batterie, mittheilt. -- "Man zählt zu diefes Gáttung acht Arten, die man in Abtheilungen bringen kann, je nachdem der Körper zylindrifch oder zulammengedrücki ilt, und je nachdem die Ober oder Untcrkinnlade mehr hervorragt. Alle find Süfswafferlffehe und finden fich nur in heilsen Ländern,

5. Die Degenfffche, Spitufchwänze (trichiuruș), zeigen gerade das Gegentheil von dem, was bey den Gymnotus vorkommt; ihr ganzer Rücken ilt nemlich mit einer langen Floffe befetat, aber die Afterflofle fehlt; der Körper ift ganz platt zufammexıgedrückt. Man kennt nur zwey Arten. Trich. Lepturus und T. electricus. L.

6. Die Notopteren (notopterus Laceped.) find kleine den Gymnotusarten ähnliche Filche, die aber, wie ihr Name es angiebt, auf dem Rücken eine Flofle tragen. Z. B. Gymnot notopterus L.

7. Die Schlangenfchwänze (ophilurus Lacep.) mit einem zylindrifchen felur langen Körper, fehen den Aalen fehr ähnlich, haben aber keine Schwanzfofle z. B. muraena ophis $L$.

8. Die Apteronoten (apteronotus Lacep.) find Surinamilche Filche, die von dem Gymnotus, wozu fie auch lange gezühlt find, fich nur durch ihre Schwanzfloffe unterlcheiden, die jenem fehlt. Aulserdem giebt aber die londerbare Lage des Afters, zwifchen den Aeften res Unterkièfurs, ein Unterfcheidungszeichen ab. 'Z, B. Gymnot. albifrons L.

9. Die $W_{u r a m} f$ f che (Regalecus Ascanii) find Kahlbäuche, denen nur noch die Afterfloffe tehlt. Man kennt zwey Arten $R$ glesne und lanceolatus. Die erfte aber Icheint, nach $S / 2$ aws Meynung, ein Bruftlloffer zu leyn und zu der Gattung gymnerrus.zu gehören. 


\section{No. LXXII.}

\section{FAMILiE:- PANTOPTEREN. *)}

Knochenfifche mit vollftändigen Kiemen, ohnel Bauchfloffen; aber mit allen unpaaren Floflen ver Sehen.

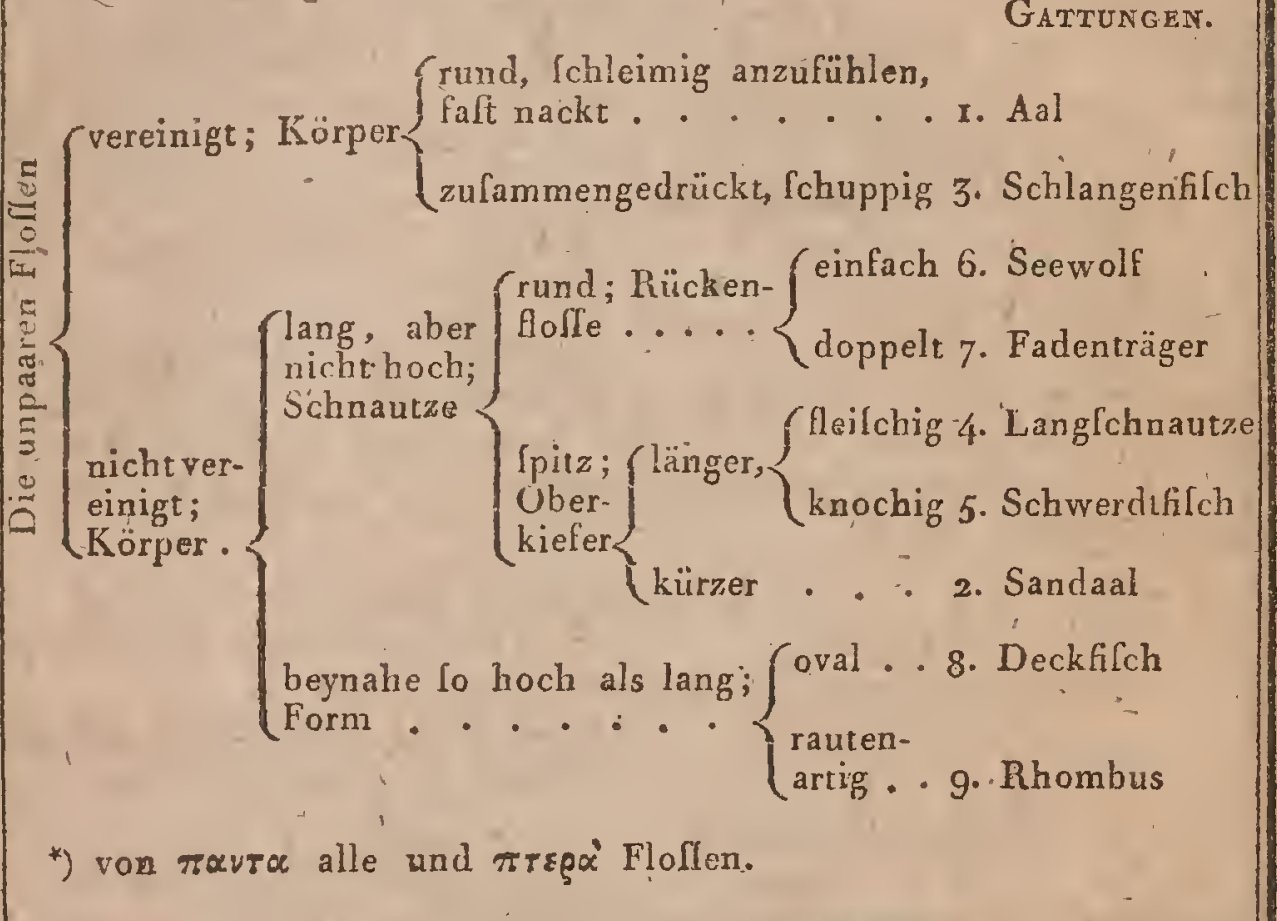

\section{BEMERKUNGEN ZUR LXXII. TABELLE.}

'Der Name Pantopteren iff hier blos als Gegenfatz des. Namens der vorhergegangenen Familie gebraucht. Die meiften der hierher gehörigen Filche, mit Ausnahine der zwey letzten Gattungen, haben einen lehr langen Körper, leben gewöhnlich auf dem Bodew des Waflers, aber lie können fich da mit der grölsten Leichtigkeit bewegen und mit den Brult. foflen das Gleichgewicht halten.

1. Die Muränen oder Aale haben eine fchlüpfrig glatte Haut, fo dafs man fie gar nicht feft lalten kann; übrigens find die auf der Tabelle angegebenen Eigenhoiten völlig hinreichend unterfcheidend. Z B. M. a aguilla L. 
2. Von den Sandaalen (ammodytes) kennt man nur eine Art. Diea ilt ein kleiner fehr langer zulammengedrückter Seefilch, deflen Untérkiefer länger als der Oberkieler ilt. Sie verbergen fich unter dem Sande. Z. B. Ammod. tobianus L.

3. Die Schlangenffrolue (ophidium Artedi) haben auch einen bandCörmigen Köper. Man kennt nur wenige Artell, eine mit, die andere ohne Bartäden am Unterkiefer. Z. B. Oph. barbatum L.

4. Die Langrïglel (nacrognathus Laceped.) find lange zu den Aalen gezählt, von denen fie fich durch die nicht vereinigten unparen Floflen unterlcheiden, fo wie durch die Verlängerung der Oberkinnlade in einen fleilchigen Rülfel, womit fie im Sande wüh!en und ihre Nabrung fuchen lollen. Z. B. Ophidium aculeatum L.

5. Die Schwerdiffche (Xiphiłs Kleim) bat feinen Namen von der Verlüngerung des Oberkiefers in 'eine knochige Spitze.' Sie haben keine Schuppen auf ibrem Körper. Man kennt zwey Arten; eine mit platter Ichneidender, die andere mit runder Schnautze. Z. B. Xiph. gladius $\mathrm{L}$.

6. Die zul der Gattung der Secwölfe oder Añarrhichas gehörigen Fi. fche haben einen ftumpfen Kopf; die übrigen Eigenlyeiten lind a uf der Tabelle angegeben. Die Secwölfe find äufserft gefrälsige Filche, ihr Mund ift mit konifchen und auch höckrigen Zähner befetzt, die auch wohl follil, unter dem Namen Bufoniten, vorkommen.

7. Die Fadentrïger (comephorus Laceped.) find in Afrika gefunden; ihren Namen haben fie von den langen Faden erhalten, die fie auf der zweyten Rückenfloffe tragen. Z: B. Callionymus baikalenlis L.

8, Die Deckfijche (ftromateus Aric di ) haben einen ovalen zulammengedrückten Körper mit einer einzigen und langen Rückenflofle. Z. B. Litromat. fiatola $\mathrm{L}$.

9. Der Rhombus (rhombus Lacepedo) hat (einen Namen von feiner Geftalt. Der Kö́per ilt fehr zulammengedrückt, die Rücken und After. foffen find mit Stacheln bewaftnet. Diele Gattung enthält nur einen in ¿üdlichen Amerika gefundenen Fifch. Z. B. Chaetodon alepidotus L: 
Holobranchien.

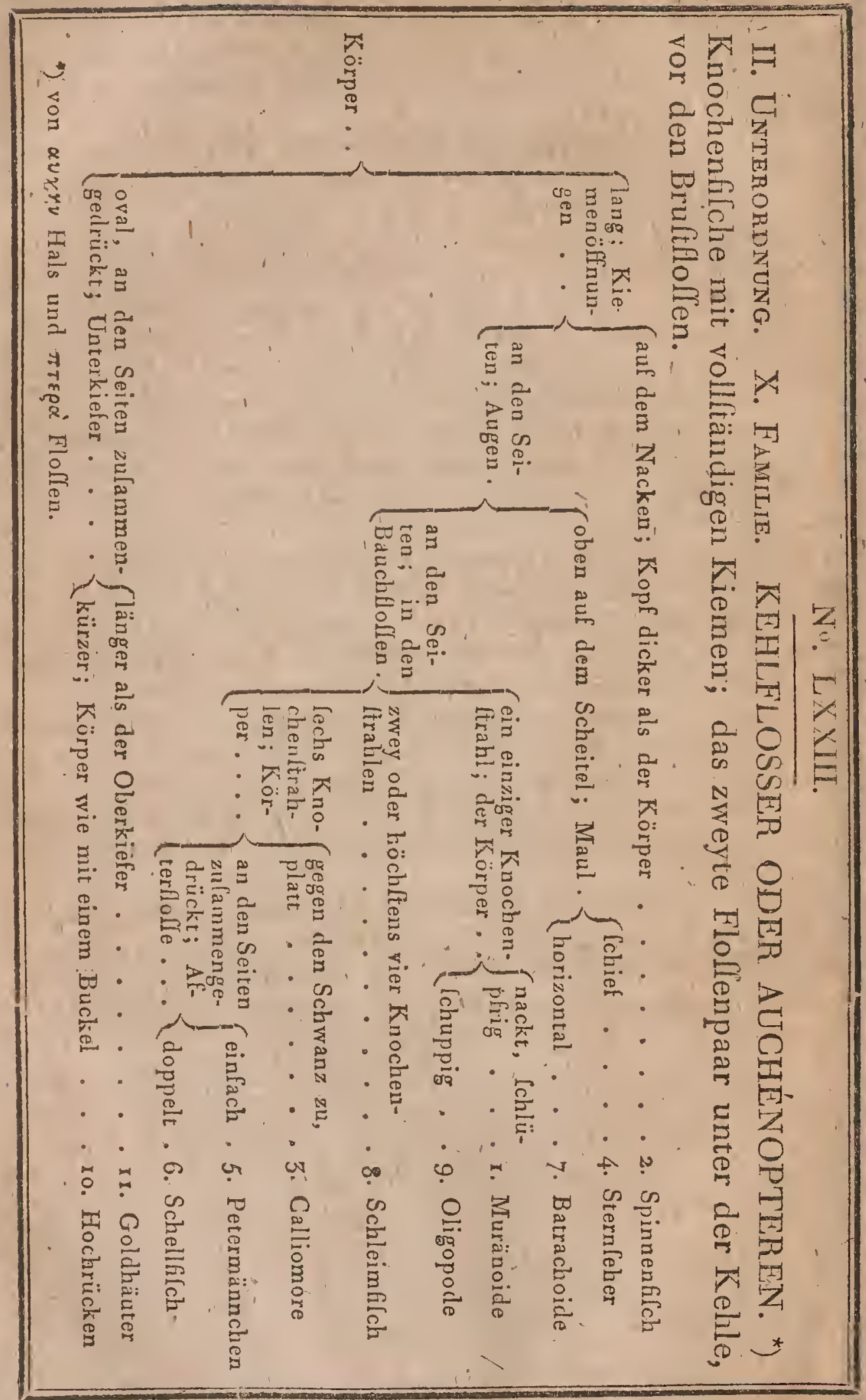




\section{BEMERKUNGEN ZUR LXXIII. TABELLE.}

Die Filche welche die Bauclufloflen unter der Kehle haben, brauchen lie nicht um im Wafier das Gleichgewicht zu balten, fondern fie fcheinen hier nicht viel mehr als die Relte derjenigen zu' feyn, die man in den zwey andern Unterordnungen fieht. Oft beftehen fie nur aus einem-einzigen Strahle, und wenn es anch der Strahlen mehrere giebt, to lïüzen fie wenigliens keine breite Haut. Auch lieben die 'meilten diofer Filche die Ufer, wo fie ihre Nahrung im Sande fuchen; faft alle find. Seefilche. I. Die Muränoidc (muraenoides Lacep.) ift ein kleiner Fifch, der lange zu den Schleimfifchen gezählt wurde,' lich aber durch den einzigen Knochenftrahlin dem untern Floflenpare unterfcheidet. Z. B. Blennius murenoides L. 2. Die Spinnenfifche (callionymus) baben einern falt nackten Körper mit fehr von einander abfiehenden Bauchfloflen, dickem Kopfe und doppelter Oberlippe; ihre Augen find wenig zu unterfcheiden und ihre faft verwachlenen Kiemendeckel haben ihre Oeffnum gen auf dem Nacken. Z B. Call. lyra. L. 3. Die Calliomoren (calliomorus) deren Namen die Verwandfchaft mit der vorigen Gattung anzeigt, unterlcheiden fich durch die an den Seiten liegenden Kiemenöfnuugen. Bloch hat diefe Fifche unter dem Namen Platycephalus Ipatula, aber unter den Bruftfloflern, aufgeführt. Callionymus indicus L. 4. Die Sternfelser (uranofcopus) haben einen dicken faft viereckigen Kopl, wo die Augen ganz und gar oben liegen, daher der Name Z B. Uranolc. fcaber. 5. Die Petermäncken (trachinus) find an der Rückenflofle und an dem Kiemendeckel mit Stacheln verfehen; fie gleichen den Wittlingen (gadus merlangus) haben aber ihre Augen nach oben zu und dem Munde nahe. Z. B. Trach, draco L. 6. Die Schellffche (gadius) haben cinen laugen glatten Körper mit kleinen Schuppen, die Augen an der Seite, das zweyte Flollenpar mit einer dicken Haut bedeckt, zwey Afterfloflen, die Bruftfloflpn fpitz und ihre Kiemendeckel ungexähnelt. Es ift dies eine fehr zahlreiche Gattung, die man abgetheilt hat a) nach der Zahl der Bauchfloflen, b) nach dem Daleyn oder Abwelenheit der Bartläden. Hieher gehört gadus morhua, merlangus, u. I. w. 7. Die Bacrachoiden (batrachoides Lac.) ftehen zwifchen Schellflche und Sohleimfilchen mitten inne. Z. B. Gadus tau L. blennius vaninus L. 8. Die Schlezinfifche (blennius) haben' wirklich einen Ichlïptrigen, langen, zufammenged:ückten Körper, deren Bruftloffe von zwey bis, zu vier Strahlen hat. Z. E. Bl. viviparus L. 9. Die Oligopoden (oligopodus) haben den Namen erhalten, weil die Kehlfloflen nur zwey Strahlen zeigen. Z. B. Coryphaena velifera L. 1o. Hochrücken (kurtus) hat B lo cle einen indifchen Filch genannt, deflen lehr zufammengedrückter Körper oben wie ein Schifskiel vorlteht und einen Buckel bildet. 'Z. B. Kurtus indicus loch. I , Mit dem Namen chryfoltroma Goldhüuter hat Lacepede einen kleinen Filch der bey Rom vorkommt, bezeichnet. Z. B. Chryf. fiatoloides Lacep, (fiatola Rond elet. 


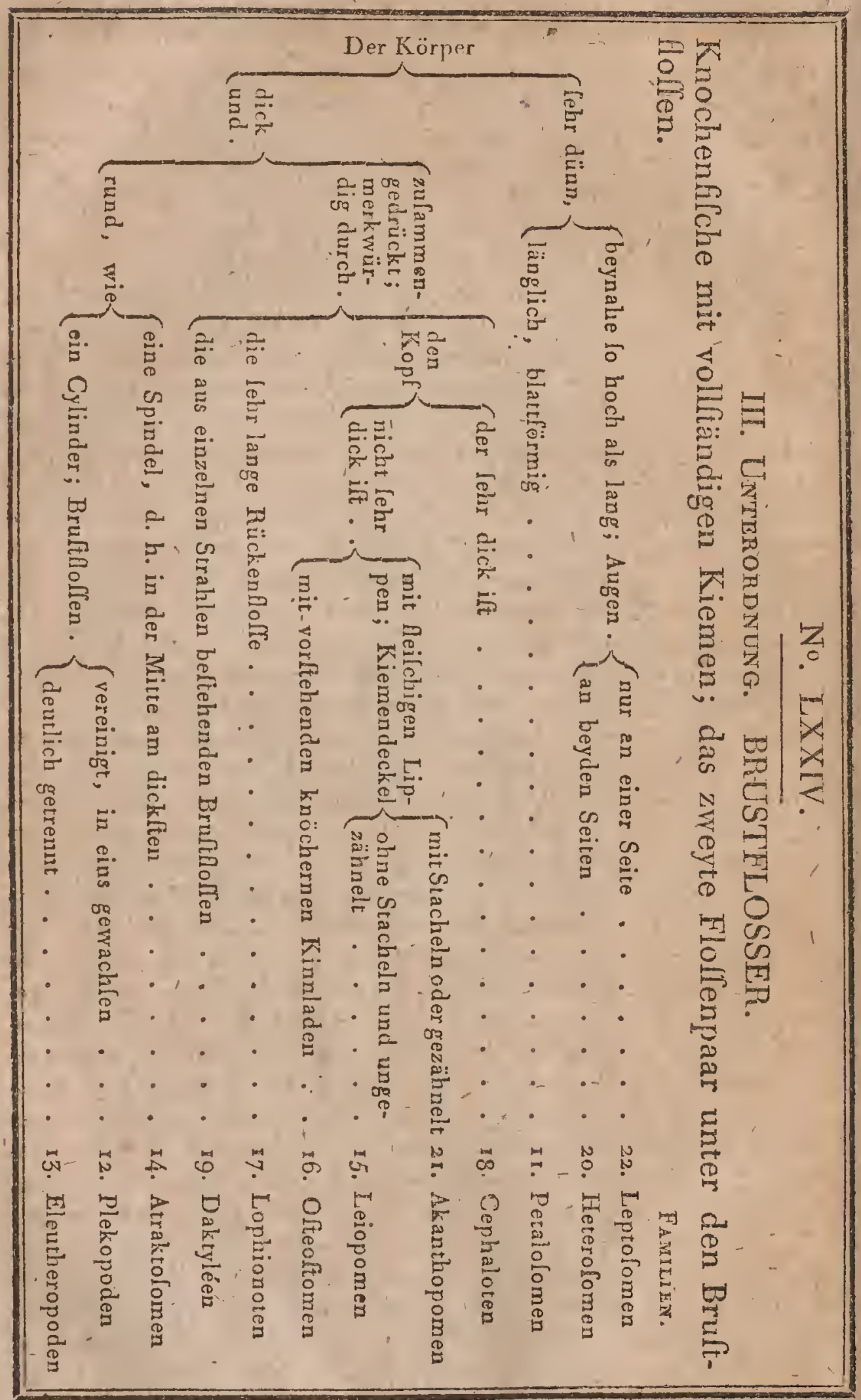




\section{BEMERKUNGEN ZUR LXXIV. TABELLE.}

In diefe zahlreiche Unterordnung gehören diejenigen Knochenfilche mit volltändigen Kiemen, dereñ zweytes Flođenpaar unter den Bruftlolfen fitzt; fie allein enthält mehr Arten als die ganze übrige Ordnung.

Es ift deswegen fehr f'chwer, diefe Unterordnung gut und ordentlich abzutheilen. Die Gattungen enthalten fehr viele Arten und die Eigenthümlichkeiten, wodurch diefe fich von einander unterfcheiden, fcheinen nach und nach zu verlchwinden; fo dafs der.Naturforfcher of in einer unangenehinen Ungewilsheit ift:

Die meiften Abtheilungen, die hier aufgefühtrt find, entfprechen den Gattungen, die von Linné und Artedi zu einer Zeit gebildet.wurder wo man wenig Arten nur kannte. Wir werden nachher ihre Verbindungen angeben. Die Filche find noch viel zu wenig bekannt'ais das man die hier vorläufig aufgeftellten Familien für beftändig geltend anfehen könnte. Es ift das hier nur ein Verfuch, der vervollkommnet werden viird.

Der Gefichtspunkt, von welchem aus die Abtheilung "gemacht iff, bringt, ob er gleich ganz künftlich ift, die Bruftloffer in zwey grofse Abtheilungen, deren Schwimmen ganz und gar verfchieden ift. Die Filche welche einen dünnen blattähnlichen Körper'haben, bedienen fich ihrer Bruft und Bauchflọllen fehr wenig; ihr ganzer Körper Icheint in einen Schwanz verwandelt zu feyn, deffen Windungen die Bewegungen luervorbringen. Die Artẻn in Gegentheil welche den dicken Körper fait . fo hoch als breit haben, haben auch grolse Bauchflofler und bedürfen ihrer auch, um das Gleichgewicht bey ihren Bewegungen bey zu behalten, welche vorzüglich -durch 'das Hintertheil des Körpers hervorgebracht werden.

Die meiften diefer Fifche leben im Meere; man findet aber auch einige in lüfsem oder Flulswafler. Die Námen die bier den Abtheilungen diefer Unterordnung beygelegt find, bezeichnen eine der Haupteigenheiten der Form; aber die meiften haber noch andere Eigentbümlichkeitea die bey jeder Famille insbelondere angeführt werden follen. 


\section{No. LXXV.}

1 XI. Familie. PETALOSOMEN. *)

Knochenfifche, Bruftflofler, mit vollftändigen Kiemen. Körper lang, dünn, blattähnlich.

Gattuncen.

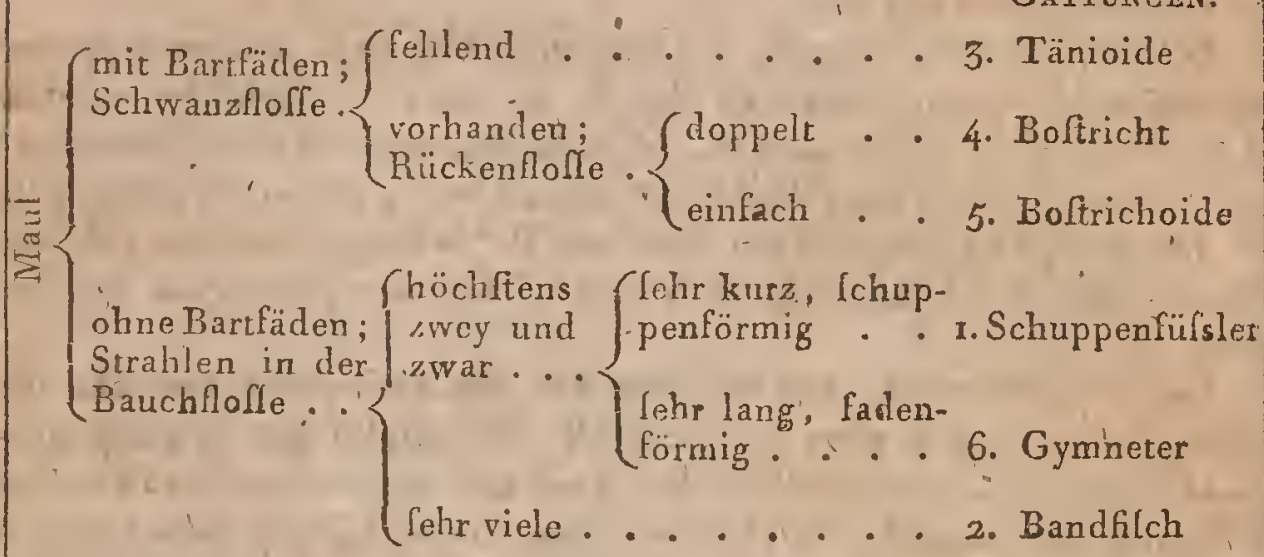

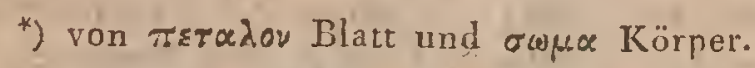

\section{BEMERKUNGEN ZUR LXXV. TABELLE.}

Die. Petalofomen haben, wie es ihriNamé ängiebt, einen blatt-oder bandförmigen Körper. Sie haben in diefer Hinficht grofse Aehnlichkeit mit den Bauchfloflenlofen Perópteren, nicht allein in Beziehung auf die Körperform londern auch in der Lebensart. Sie fchwimmen nur wie die Schlangen, indem fie mit ihrem ganzen Körper Windungen machen, lo wie die Aale. Demohngeachtet find ihre Bewregungen fehr Ichnell; fie durchlchneiden das VVaffer wie ein Pfeil; aber ihre Anltrengung ift dabey fo grofs, dal's fie es nicht lange aushalten können und fie bald auf den Boden in den Schlamm finken.

I. Die Schuppenfüslor (lepidopus) find kleine Fifche des mittelländilchen Meeres mit nacktem Körper, deren Bauch- und Afterflolle aus einem einzigen Floflenftrahle befteht, der aber ausfieht wie eine verlängerte Schuppe; daher der Name. Diefer Filch, Lepidopzs Gouania-. nus La cep. hat fehr grol'se Aehnlichkeit mit dem Trichiurus lepturus.

2. Die Bandffclue (cepola) haben den Körper nit kleinen Schuppén bedeckt, und mehrere Floflenfrahlen in den Bauchloffen. Ihr Körper 
ift fo dünn, dafs man einige Arten Seeband, Desen, Band u. I. w. genannt, hat. Alle diefe Fifche bewohnen das mittelländifche Meer. Z. B. cepola taenia L.

3. Die Tänioiden (taenioides) haben, wie die meifteñ Peropteren, keine Schwanzfloflen. Z. B. Taenioides Herrmanni Lacep.

4. Die Boftrichten (Boftrichthys) entfprechen der Gattung Boltrychus La.cepede. Wir haben geglaubt hier den Namen ändern zu müflen, weil fchon früher eine Gattung Käfer, von Geoffroy, damit belegt ift. Man kennt aus chinefifchen Zeichnungen zwey Arten. Z. B. Boftrychus finenfis $L a c e p$.

5. Die Boftrichoiden (Boftrychoides) Lacop. unterfcheiden fich von der vorigen „Gattung nur durch die einfache Rückenflofle. Z. B, Boftrych. oculatus Lacep.

6. Die Galtung Gymneter (gymnetrus Bloch.) enthält Fifche von Ionderbaren Formen, die keine Afterfloflen haben und deren Bauchfloffen fo eigenthümlich gebildet find, dafs man lange glaubte, fie fehlten ganz. So ift es belonders mit der von Ascanius unter dem Namen Regalecus'glesne befchriebenen Art. Man kennt jetzt fǘnf Arten, Za. D. Gymn. Hawkenii. 


\section{No. LXXVI.}

\section{XIr. Familie. PLECOPODEN. *)}

Knochenfifche, Bruftflolfer; mit vollftändigen Kiemen; runder Körper; das untere Floflenpaar vereinigt und wie verwachlen.

\section{Gattungen.}

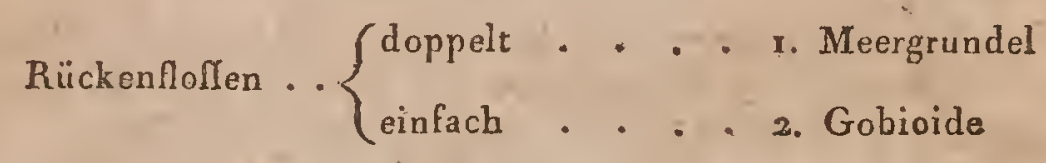

*) von $\pi \lambda_{\varepsilon x}$ ich vereinige und $\pi$ ous Fufs.

\section{No. LXXVII.}

\section{Familie. ELEUTHEROPODEN. *)}

Knochenfifche, Bruftlolfer, mit vollftändigen Kiemen; runder Körper; das untere Floflenpaar deutlich, nicht verwachlen.

\section{Gattungew.}

Kop $\{$ mit einem ovalen queergefurchtem Schilde.3. Schildfifch. $\left\{\right.$ oline ovales Schild; Rückenflolfe $\left\{\begin{array}{l}\text { einfach . 2. Gobiomoroide } \\ \text { doppelt .1. Gobiomore }\end{array}\right.$

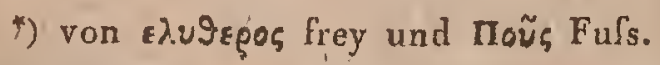

\section{BEMERKUNGEN ZUR LXXVI. TABELLE.}

- Die Plckopodon zeigen ungefähr die nemliche Eigenbeit als die Seehafen unter den Knorpelffchen. Ihr unteres Floffenparar ift in eine, 
Sclieibe oder Trichter vereinigt, wàs den Hauptcharakter abgiebt. Diefe Familie befteht bis jetzt aus 24 Arten, die man nach der Belchaffenheit der Rückenfoffe in zwey Gattungen gebracht hat.

Diele 'Filche halten fich gewöhnlich auf dem Sande auf; zuweilex verbergen fie fich logar ganz darin. Die meiften verlchaffen fich rlurch Lift ihre Náhrung. Ihren klehrigen Körper bedecken fie mit Schlamm und, Lo verfteckt, uähern fie fich ganz langlam den kleinen Thieren, die fie zu ihrer Beute auserfehen haben. Man behauptet, dals der durch die Vereinigung ibrer Bauchflofle entltandene Trichter, den Mcergrundela (Gobius) z. B. Gob. pectiniroltris L. und den 2. Gobioides z. B. Gobius anguillaris, als Saugnapf diene, womit he fich als fefte Körper auf dem Boden des Meeres felt legten.

\section{BEMERKUNGEN ZUR LXXỸII. TABELLE.}

Die Eleutheropoden find im Gegenlatze zu der Eigenlyeit der vorigen Familie lo genannt. Die Floflen des zweyten Pares find zwar nicht bey allen Arten ganzvon einander getreunt, aber lie find doch wenigltens niemals in fó einen trichtertörmigen Teller vereinigt, wie man ibn in der vorigen Familie findet.

r. und 2. Die Gobiomoren (Gobiomorus Lacep.) 7. B."Gobius ftrigatus L. und die Gobiomoroiden (Gobiomoroides Lacep.) z.: B. Gobius pifonis:L. find Fifche die mit den Meergrundeln fehr viel Aehnlichkeit zeigen, wie das auch der Name zeigt; lie unterfcheiden lich durch die getrennten Bauchfloflen.

3. Die Schiffshalter, Schildfifchc (echeneis haben einen langen konilchen Ichuppenlolen Kürper; auf dem Scheitel ein londerbares Infirument, wodurch fie fich mit dem Kopfe leicht an Cotaceen, Hayfifche, Schildkröten, Schiffe und überlaupt an alle im Meere fchwimmenden Körper fefthängen können. Es befteht dies Organ aus einer unbeltimmten Zahl kleiner horizóntalltehender Knochenlamellen, die fich einander lo bedecken, dals lie zwey Reihen bilden und fich auf einer queerliegende Scheibe fo bewegen wie die Bretter der Fenfterjaloulien! Der freye Rand jeder Lamelle ilt mit einer dreyfachen Reibe kleiner hinterwärts gerich teter Haken beletzt, die zum Eingreifen und Fefthatten an die Körper dienen, wo die Filche fich befeltigen wollen. An der Seire des Kopfes liegen die Muskeln, wodurch die verlchiedenen Lamellen um ihre Axe bewegt werden. Es find dies Filche aus warmen Himmelfriclien, die 'man aber doch zuweilen im atlandifchen Meere findet. Man kennt nur drey, Arten. Z. B. echeneis remora $L$. 


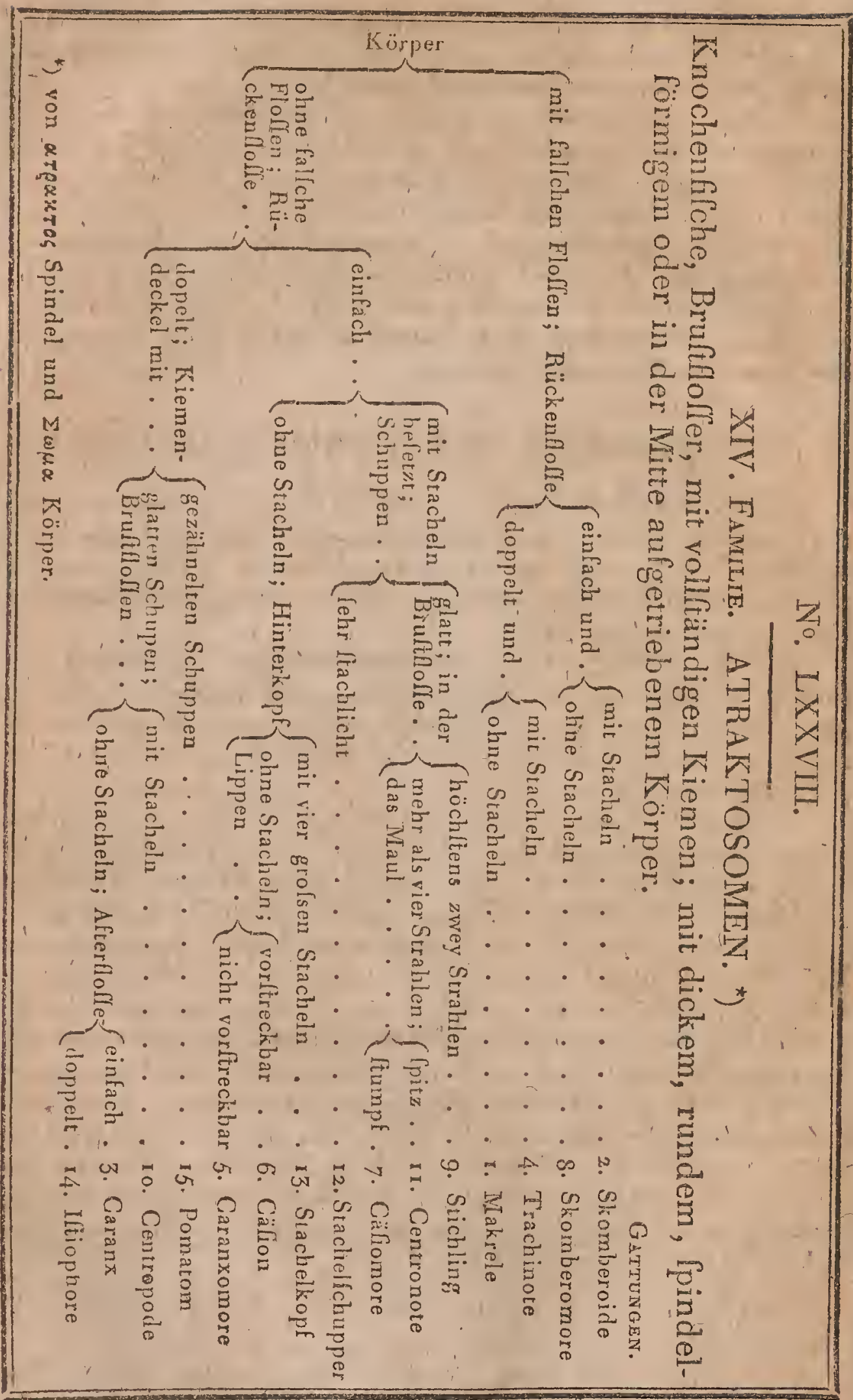




\section{BEMERKUNGEN ZUR LXXVIII. TABELLE.}

Diefe Familie der Alraktofomen entfpricht den Linneifchen Gattungen Scomber und gafterofteus, und enthält alle die mit vollftändigen Kiemen verlehenen Bruftloffer, deren Körper in der Nitte am dickften ift. Falfche Floffen nennt man die kleinen von Knochenftrahlen unterfiüzten Membranen, die man hinter der Rücken - unt Afterfloffe wahrnimmt.

x. Die Makrelen (Icomber Artedi) z. B. Scomb. thynnus, haben aulser den auf der Tabelle angegeberien Eigenheiten noch den Schwanz gekicht oder zwey Stacheln vor der Afterflofle.

2- Die Scomberoiden (Icomberoides Laceped.) haben nur eine einzige Rückenflolle, "unter velcher'fich melır oder weniger zahlreiche Stacheln linden. Z. B. Scomberoid. Laltator Lacep.

3. Die Caranx (caranx $C$ ommerfon) lind meiltens im indilchen Meere einheirailch. Z. B. Ccomber. fpeciolus L.

4. Die Trachinoten oder Stachelrücken (trachinotus Lacep.) haben ihren Namen von den Stacheln auf den, R̈̈cken; es gehört hieher nur der von Forskäl bef'chriebene Scomber falcatus L.

5. Die Caranxomor ift eine Art in einer Gattung (caranxomorus), nemlich der fcomber pelagicusi. I.

6. Die Cäfios (caefio) z. B. centrogafter equula L. und 7. die Cäfiomóren (caeflomorus) \%. B. caeliomor. Blochii La cep., find Filche die man nur in afiatifchen und afrikanifchen Meeren beobachtet hat und deren Namen auf die blaue Farbe hinweilet. 8. Der Scomberomore (lcomberomorus plumierii Lacep.) ift blos'aus einer Zeichnung des Pater PJumiers bekannt, der ihn auf Martinique beobachtete.

9. Die Stichlinge (galterofteus) d. h. Stachelbauch, heilsen fo, weil die Stacheln, die fie an der Stelle der Bruftlollen haben, nach Villkühr des Thieres bewegt und feftgeftellt werden können, indem fie durch einen belondern Haken mit einem knochigem Bruftbein artikuliren. Hieher gehören die allérkleinften Sülswafferfifche. Z. B. Galter. pungitius L.

ro. Die Centropoden (centropodus) z. B. centrogafter rhombeus L. und $\mathbf{r}$. die Centronoten (centronotus) ż. B. gafterofteus conductor I. fcheinen zwifchen den Stichlingen und Makrelen mitten inne zu ftehen.

12. Die Stachelfchupper (lepifacanthus) z. B. gafterofteus japonicus und 13. Stachelköpfe (cephalacanthia z. B. gafterofteus fpinarella L. find wegen ihrer in der Tahelle angegebenen Eigenthümlichlkeiten von der Gattung der Stichlinge getrennt.

14. Die Gattung der Segelträger (iftiophorus) enthält nur eine Art 2. B. Icomber gladius Bloch., die man, fehr mit. Unrecht zu den Schwerdtilchen, die doch Bauchflofler lind, gezühlt hat; da hingegen diefe offenbar in die gegenwärtige Familie gehören.

15. Die Pomatdmen (Pomatomus) zeichnen fich noch durch ibre fettige Afterflolle aus. Z. B. Pomat. Khib La cep. 


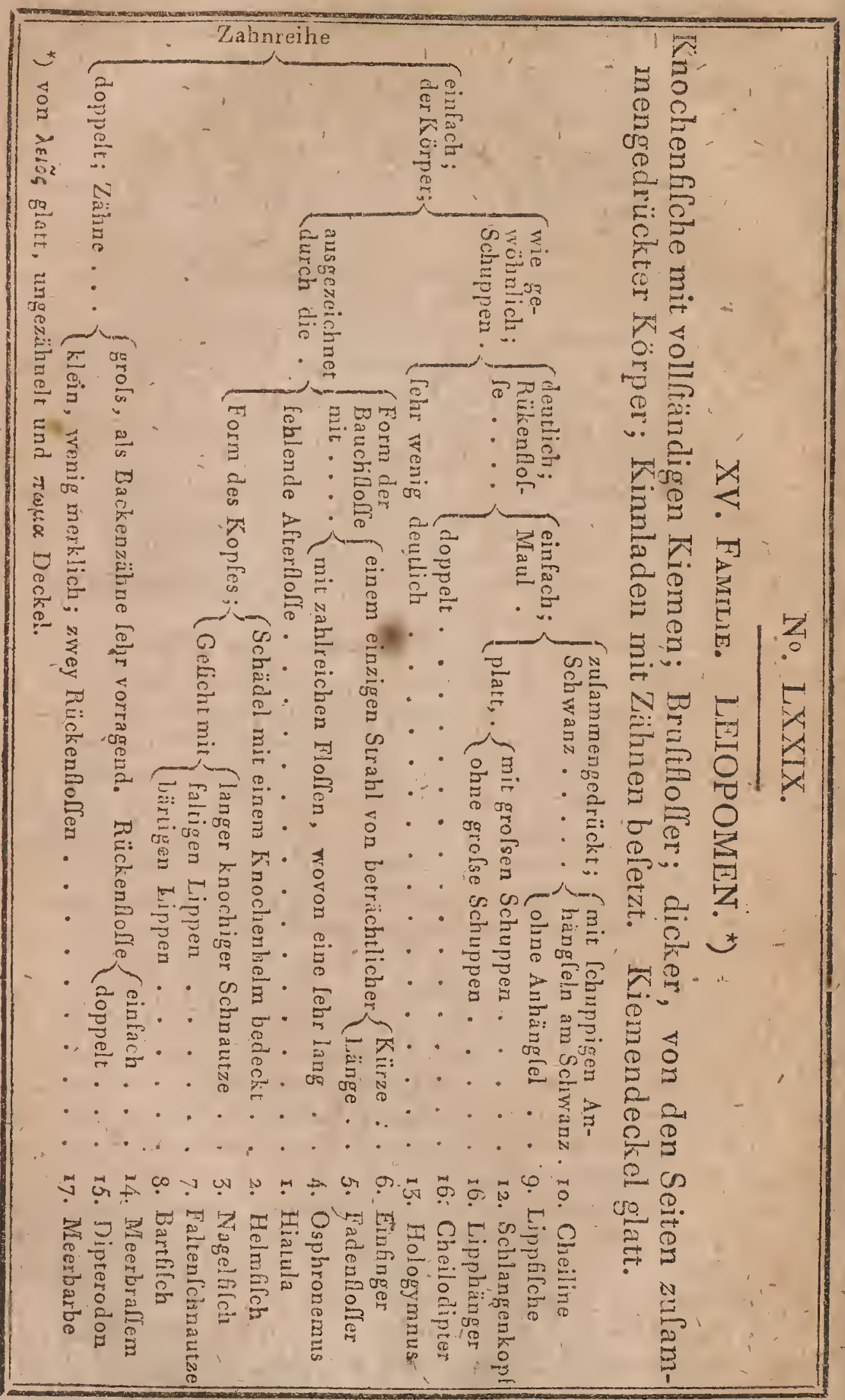




\section{BEMERIXUNGEN ZUR LXXIX. TABELLE.}

Die Leiopomen, Fifche mit glatten Kiemendeckeln, find vorzüglich im Gegenlatze zu den Akanthopomen (pag. i 32 ) lo genannt; fie entiprechen den Gattungen fparus und labrus anderer Ichthyologen. Alle finden fich sur in heifsen Wfeltgegenden. 1. Die Hiatula (hiritula) \%. B. labrus hia. rula L. lebt an den Külten von Carolina urd unterlcheidet fich von aller andern durch die mangelnde Afterlofle. 2. Der Helmfifch (coris) hat Leineu Namen von der Art Knochenhelm am Kopfe, und findet fich in den indifchen Meeren. Z. B. Coris aygula Lac. '3. Der Nagclfifch (gompholus) hat die Schnauze an ihrem Ende plötzlich aufgetrieben, wodurcl einige Aelinlichkeit mit einem Nagel entfteht. Z. B. Gomplh. coerulens Lacep. 4. Osphronemus ift eine oftindifche Art dieler Gattung von Cominerfon genanit, der hier ein Riechbein wie bey den'Säugthieren gefunden haben wollte. Z. B. osphronemus goramy Lacep. 5. Fadenfloffer (trichopodus Lacep:) Z. B. labr. trichopterus L. 6.' lo wie die Einfinger (monodactylus) z. B. falciformis $L$ a cep. find durch die Floffen genug charakterifirt. 7. und 8. Die durch die Lippen fehr londerbare Falienfchnauize (plectorynchus) z. B. pl. chietonoides'Lacep., Icheint doch mehr zu der Familie der Akanthopomen (p. 132) zu gehören. Die Bartffche (pogonias) z. B. fafciatus Lacep, aus Carolina, heilsen lo vor den vielen Bartfaden an dem Unterkiefer. 9. Die Lipplifche (labrus Artedi) Z. B. lahr. hepatus I. bilden eine an Arten lehr reichbaltige und verbreitete Cratiung, die man nach der Form der Schwanaloflen, wieder abgetheilt hat. 10. und I. Die Chcilinen (cheilinus) z. B. labrus fcarus L. und die Cheilodipteren (Cheilodipterus) z. B. Labr. boops I. haben ihren Tlamen von ihrer dicken Oberlippe, und unterfcheiden fich untereinander nur durch die Rückenflofen. 12. Die Schlargenkopfe (ophicephalus) Z. B: Oph. punctatus B $B / 0 \mathrm{ch}$. haben den Kopf platt, wie bey einér Blindlchleiche, und mit Schuppen bedeckt. '13. Der Hologymnus (hologymnolus z. B. Hol. fasciatus $L$ a c.) liat wenig fichtbare Schuppen und der Schwanz zeigt zwey an der Bafss aneinander gelegte Kegel. I4, und 5. Die Meerbraffeme (fparus Artedi) baben wenger ausdehnbare Lippen als die Lippfifche, viele Zähne und eine einzige Rückenfolfe. Z. B. fcá, auratus L., hierdurch unterlcheiden fie fich yon den Diplerodons (dipterodon Lacep.) a. B. Iparus notatus L. I6. Die Lipphängér (cheilio) find indifche blols von Commerfon beobachtete Fifche. Z. B. cheilio auratus Lacep. 17. Die Meerbnrben (mullus) habea den Körper mit grol'sen leicht losgehenden Schuppen bedeckt, urd den Unterkiefer unten meift mit Bartiaden beletzt. Z. B. Mull. barbatus L. Blochs Gatung Lonchiuris 3. B. L. barbatus und Laceped es Apogon Zo 'B. mull. imberbis L. Lind mit don Mérbarbon zaho verwandt. 


\section{No. LXXX,}

\section{FAMILI: OSTEOSTOMEN. *)}

Knochenfifche mit vollf:ändigen Kiemen; Bruftfloffer; mit dicken zufammengedrücktem Körper und ganz und gar knochigen Kinnladen.

Gattungent.

$\left\{\begin{array}{l}\text { mit Stacheln; glaţc Zähne.. 3. Glattkiefer } \\ \text { ohne Stacheln; gezähnelie Kinn- } \\ \text { laden . . . . . . . Papageyffch }\end{array}\right.$

4

\section{No. LXXXI.}

XVII. Familie. LOPhiOnOTEN. *)

Knochenfifche rnit vollkommnen Kiemen; Bruftflofler; mit dickem zufammengedrückten Körper; und fehr langen Ruickenfloffen.

Gattungen.

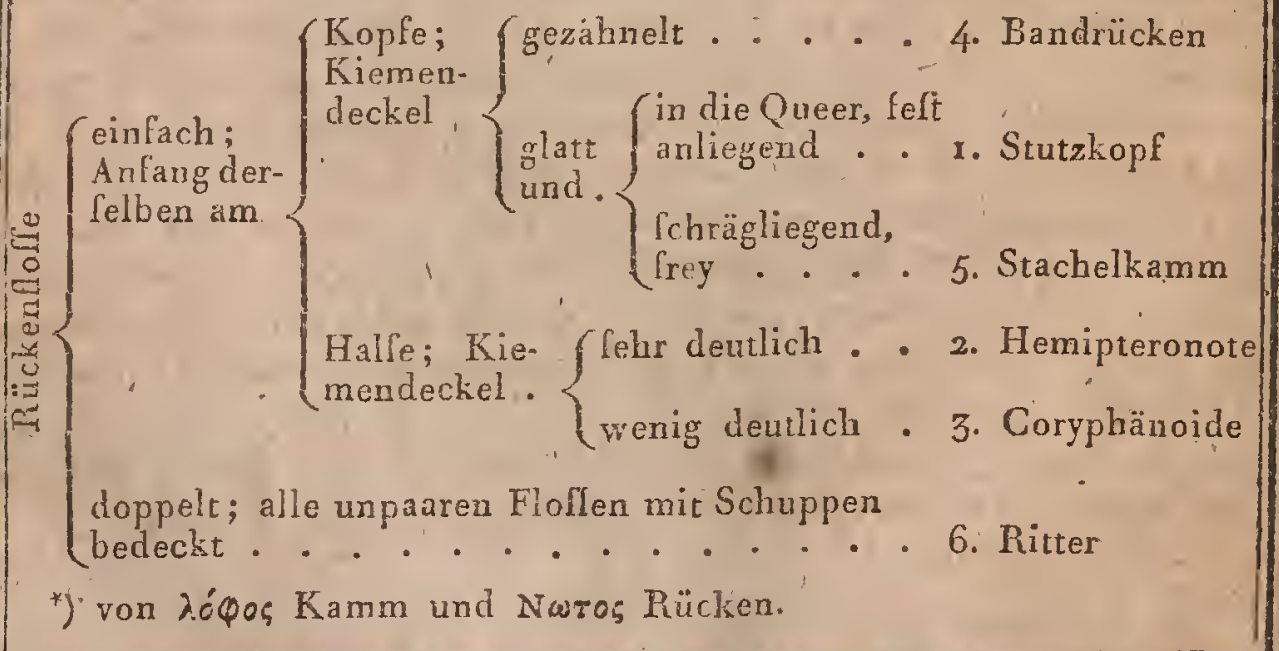




\section{Holobranchien.}

\section{BEMERKUNGEN ZUR LXXX. TABELLE.}

Die ofteofomen find unter den Knochenfilchen das, was die Diodons und Tetraodons unter der Familie der Ofteodermen p. 108 find; lonft haben fie in ihrer Körperform einige Aehnlichkeit mit den Lippfifchen und:Meerbraflemen. Sie nähren fich von Kruftazeen und kleinen Schaal Mollusken; obgleich man lange Zeit glaubte, dals. lie Meergräler fräfsen:

r. Die Papageyffche (Icarus) z. B. Icar. ferrugineus, unterfcheiden fich von den Knochenfchnäbeln (ofteorhincus) z. B. Oft. Heurieu La cep. nur durch die Rückenflolle. Die meiften diefer Filche haben eine grünliche Farbe und bewohnen die heifseften Meere Ibre Zähne lehen daJurch wie emaillirt aus, weil fie mit andern kleinen, aus ihrem Innezen hervorkommenden, Zähnchen mofaikartig beletzt find.

3. Die Glactkiefer (leiognathus Lacep.) unterlcheiden fich von den Papageyfilchen nur durch die ftachliche Rückenflofle. Jede Bruftund Bauchfloffe ift überdem durch ein Ichuppiges Anhänglel wie gefchützt. Man' kennt nur eine an den indilchẹn Küften gefangene Art, die man lange für eine zahnlofe Makrele anfah. Scomber edentulus Bloch.

\section{BEMERKUNGEN ZUR LXXXI. TABELLE.}

Die Lophionoten find, wie dies auch ihr Name anzeigt, wegen der Länge ihrer Rükenfloffe merkwürdig, zugleich aber auch dadurch, dals man bey ihnen keine einzige Eigenheit der vorigen Familie mehr findet. Deswegen haben wir auch den Segelträger bey den Atraktofomen aufgelührt, obgleich er vermöge der natürlichen Verwandlchaft in die gegeawärtige Familie gehört. So ift aber dagegen hier der Bandrücken mit hingeftellt, der mehr zu den Akanthopomen gehört. Alle diele Arten fchwimmer fehr fchnell, und nähren fich von andern Filchen, die fie deswegen verlolgen.

i. Die Stutzköpfe (coryphaena) haben den Kopf wie die Seewölfe vorn abgeltutat und ihre Kiemen offnen fich in eine Queerfpalte. Man hat fie nur in Meeren heifser. Weltgegenden gefunden. Z.B. Coryph. hippuris, L.

2. 3. und 4. Die Hemipteronoten (hemipteronotus) z. B. Coryph. hemiptera L. würden zur vorigen Gattung gehören, wenn fie nicht die Rückenflolle nur auf der Hälfte des Körpers hätten; dabey lind ihre Kiemenlöcher offenbar, erweiterungsfähig, wodurch lie fich von den Coryphaenoiden wo die Kiemenöffnungen eine eirifache Spalte bilden. Z. B. coryphaena branchioltega L. unterfcheiden. Da die Bandrücken (taenianotús) Stacheln auf dem Kiemendeckel haben, follen fie bey den Akanthopomen pag. 132 aufgeführt werden.

5. und 6. Die Siachelkïrmme (centrolophus) z. B. centr niger Lacep. haben ihre Rückenfolfe mit Stacheln bewaffnet, und die Rilter (eques) haben zwey Rückenloflen, wovon die erftere, fehr hoch und mit Fäden beferzt ift. Z. B. eques americanus. $B / 0 c h$.

Dumeril Zool. 


\section{No. LXXXII.}

XVIII. FAMILIE. DICKKÖPFE ODER CEPHALO TEN. *)

Knochenfifche, Bruftfloffer, mit vollftändigen Kiemen; der Körper dick und zufammengedrückt mit einem fehr dicken Kopfe.

Gattungen.

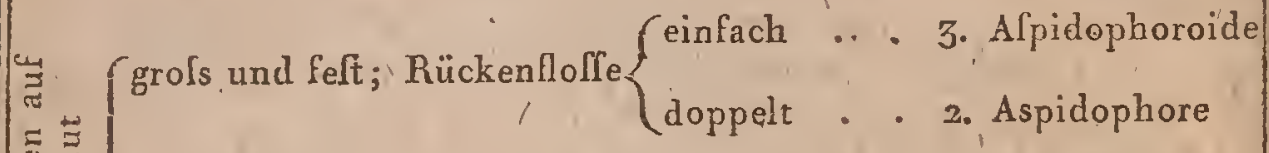
klein oder (einfach und. $\{$ lang . . 5. Drachenkopf fehlend;
Rücken- $\quad\left\{\begin{array}{l}\text { kurz, dicht neben } \\ \text { dem Schwanze. I }\end{array}\right.$ flolle.... doppelt; Kopf mit Stacheln . 4. Groppe.

$\left.{ }^{*}\right)$, von $x \varepsilon \varphi \propto \lambda$ wros dickköpfig.

No. LXXXIII.

XIX. FAMILIE. FINGERFLOSSER ODER DAGTYLEEN. *)

Knochenfifche, Bruftfloller mit vollftändigen Kiemen; der Körper dick, zulammengendrückt; die Bruftfloflen aus einzelnen nicht verbundnen Strahlen' beftehend. $\left\{\begin{array}{l}\text { nicht vereinigt; } \\ \text { Rückenflolle }\end{array}\left\{\begin{array}{l}\text { einfach; Körper gepanzert . 4. Periftedion } \\ \text { doppelt, da- } \\ z w i l c h e n\end{array} \cdot\left\{\begin{array}{l}\text { Stacheln . . 2, Sägerücken } \\ \text { keine Stacheln. 3. Seehahn }\end{array}\right.\right.\right.$ vereinigt' durch eine Haut, die eine zweyte Flofle bildet... . . . . . . . . I. Fingerllieger *) von $\Delta x x r u$ ros Finger. 
Die Dickköpfe, haben die Haut entweder faft nackt und shneSchuppen oder mit grolsen Schuppen befetzt und unterlcheiden lich lonft durch Zakl und Form der Rückenflofle.

I. Die Hechtgrúndeln (gobiefox) fcheinen wirklich die Geftalt der Meergrundeln und der Hechte zu vèreinigen. Es gellört hieher ein von Plumier befchriebeneramerikanilcher Flulsfilch, der nur nabe am chwanze eine kurze Rückenflolle hat. Z. B. gobielox cephalus L.

2. und 3. Die Afpidophoren (afpidophorus), 2. B. cottus cataphractus und die Afpidophoroiden (aspidophoroides) z. B. cottus monopierygius L. haben ihre NTamen von den Schildern womit ihr Körper bedeckt ift. Die Bauchfloflen haben weniger als vier Strahlen.

4. Die Groppen (cottus) find eigentliche Dickköpfe, es gehört dahin der Kaulkopf der kleinen Flülle. Cott. gobio. L.

Die Drachenköpfe (fcorpaena) find Filche von ganz befonderer Form. Ihr grolser fchuppenlofer Kopt ift mit vertieften turchen oder gewundenen Hervorragungen verlehen, und trägt meiftens Stacheln z. B. Scorp. horrida.

\section{BEMERKUNGEN ZUR LXXIII. TABELLE.}

Die Fingerfloffer fehen aus als wenn fie vor'ihren Bruftfoflen noch Finger fitzen hätten. Sie nähiern fich in diefer Hinficht den Fingerfilchen (polynemus) unter den Bauchfloffern. Linné hatte fie alle unter die Gattung der Seehäbne gebracht. Sie haben einen dicken faft viereckigen Kopf, die Augen oben, und leben im hohen Meere. Ihr Fleifch wird rehr gefchätzt.

1. Die Fingerflieger (daclylopterus Lacep.) haben eine kleine Flólfe vor der Bruftfolle, deren Strahlen durch eine Membran vereinigt find, $z$. B. trigla volitans $\mathbf{I}$.

2. und 3. Die Sägerücken (prionotus Lac.) z. B. trigla evolans, unterIcheiden fich von den (Seehähnen (trigla,) z. B. triglä lyra, durch nichts als durch die Stacheln, die fie zwifchen ihren zwey Rückenflolfen haben.

Die Periftedions (periftedion) haben ihren neuen Namen von einer Art Schild, welches die Knochenftücke um ihren Körper zu bilden fcheiner. Z. B. trigla cataphracta L. Sie finden fich im lüdlichen Mcere. 


\section{No. LXXXIV.}

\section{- XX. Famile. Heterosomen. *)}

Knochenfifche, Bruftflofer; mit dünnem, unregelmälsigem, nicht fymmetrifchén Körper. Beyde Augen auf einer Seite.

$$
\text { Bruitfloffen }\left\{\begin{array}{l}
\text { deutlich vorbander }, \ldots \text { x. Scholle } \\
\text { nicht fichtbar } \ldots . .2 \text {. Achir. }
\end{array}\right.
$$

*) von étręos ungleichartig und $\Sigma$ wika Leib.

\section{No. LXXXV.}

\section{FAMiLIE. AKANTHOPOMEN. *)}

Knochenfilche, Bruftllofler, mit vollkommnen Kiemen; Körper dick, zufammengedrückt; Kiemendeckel ftachlicht oder gezähnelt.

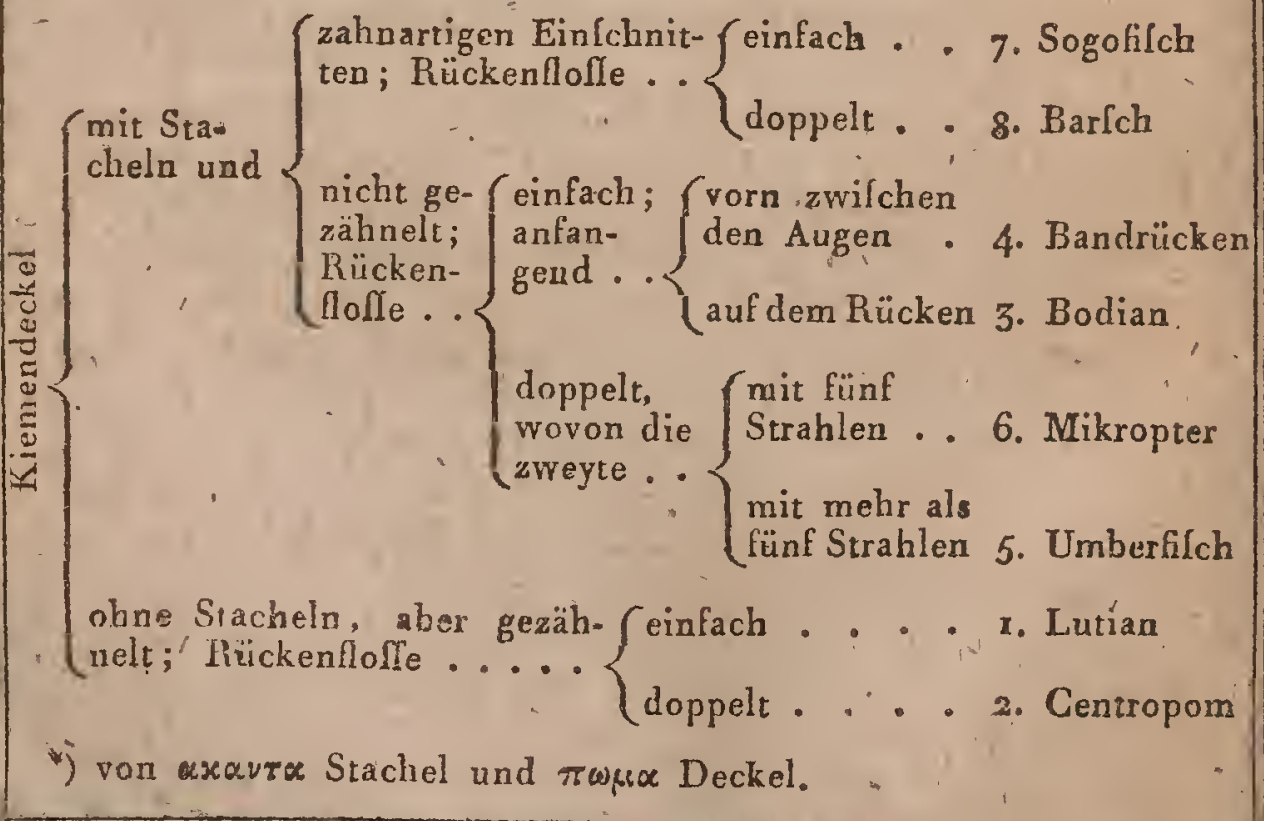




\section{BEMERKUNGEN ZUR LXXXIV. TABELLE.}

Der Name Heterofomen bezeichnet, dals die damit belegten Fifche einen Körper von ganz befonderer Form haben. Sie find wirklich die einzigen Thiere, deren Körper nicht fymmetrifch ift. Alle Organe des äufseren Lebens find unregelmälsig bey ihnen. Ihr Skelet ift in fich felbft gleichlam wie verbogen und die Muskeln Icheinen den Knochen, wo fie fich anfetzen, gefolgt zu Ceyn. 'Die Nafenlöcher, Augen, Mund und das innere Gehörorgan find alle auf eine Seite gedrängt. Die Bauchhöhle ift aulserordentlich verengt, lo dal's die Generationsorgane nicht darin ent-" balten find.

I. Die Schollen (pleuronectes $R a i$ ) fchwimmen auf der Seite. Die eine Seite ihres Körpers ift glatt und gare weifs, und ein Auge iff im mer kleiner als das andere. Beyde Augen liegen übrigens bald rechts, z. B. Pleur. folea L. bald links z. B. Pleuron. maximus L.

2. Die Achiren (achirus L a c ep.) unterfcheiden fich von den Schol. len, blos darch die fehlenden Bruftloffen. Z. B. Pleuron. achirus L.

\section{BEMERKUNGEN ZUR LXXXV. TABELLE.}

Die Akanthopomen entfprechen den Gattungen perca und lciaena dés Linné. Die meiften haben den Kiemendeckel mit Schuppen bedeck wie die Lepidopomen, und aúlserdem mit Stacheln oder Zähnen beletzt. 2. Die Lutians (lutianus) haben von Klock den chinefifchen Namen lut gang erhalten und die meiften Arten find in Indilchen Meeren zu Haús. Es ift eine an, meiftens 〔chöngefärbten, Arten zahlreiche Gattung. Die Rückenflofle ift meiftens mit Stacheln beletzt. 2. u. 3. Die Centropomen (centropomus Lacep.) unterlcheiden fich von den I,utjans durch die doppelte Rückenflofle, z. B. perca lucioperca L. Die Bodianfifclue (bodiaw $B(0, h)$ haben ihre Namen von einer Art dieler Gattung die in Portugal lo genannt wird; die meiften Arten find in den Indilchen Meeren oder in Japan zu Haule: Z. B. Iparus palpebratus L. perca louti L. 4. Die Bandrïcken (taenianotus Lacep.). Ichon bey den Lephionoten aufgeführt, zeigen falt diefelben Eigenheiten als die Bodianfifche, nur ift die Rückenfloffe lehr lang und fängt zwilchen den Augen an. Z. B. taenian. vittatus Lacep. 3. Die Gattung der Umberfifche (Iciaena) ilt lo zu Iagen der typus der gegenwärtigen Familie z. B. Sciaena fammara L. 6. Die Mikropteren (micropterus) bilden nur eine einzige Art, die den Umberfifchen ähnlich ift, aber die zweyte Rückenfofle klein und kurz hat, z. B. Micropt. Dolomieu Lacep. 7. Die Sogofilche (Holocentrus) find, wie der lateinilche (griechifche) Name angiebt, ganz mit Stacheln beletzt. Z. B. Labrus chanus L. Perca marina L. Die Arten, welche einen Ichuppenlolen Kopf baben, find helonders epinepleclus genamt worden. 8. Von den Barfcheh (perca. A r tedi), ift die bekanntefte Art (perca fluviatilis), mit fcliwarzen Fleckca verfehen, ein beliebter Filch. Man kennt otwa ir Arten. 
Holobranchien.

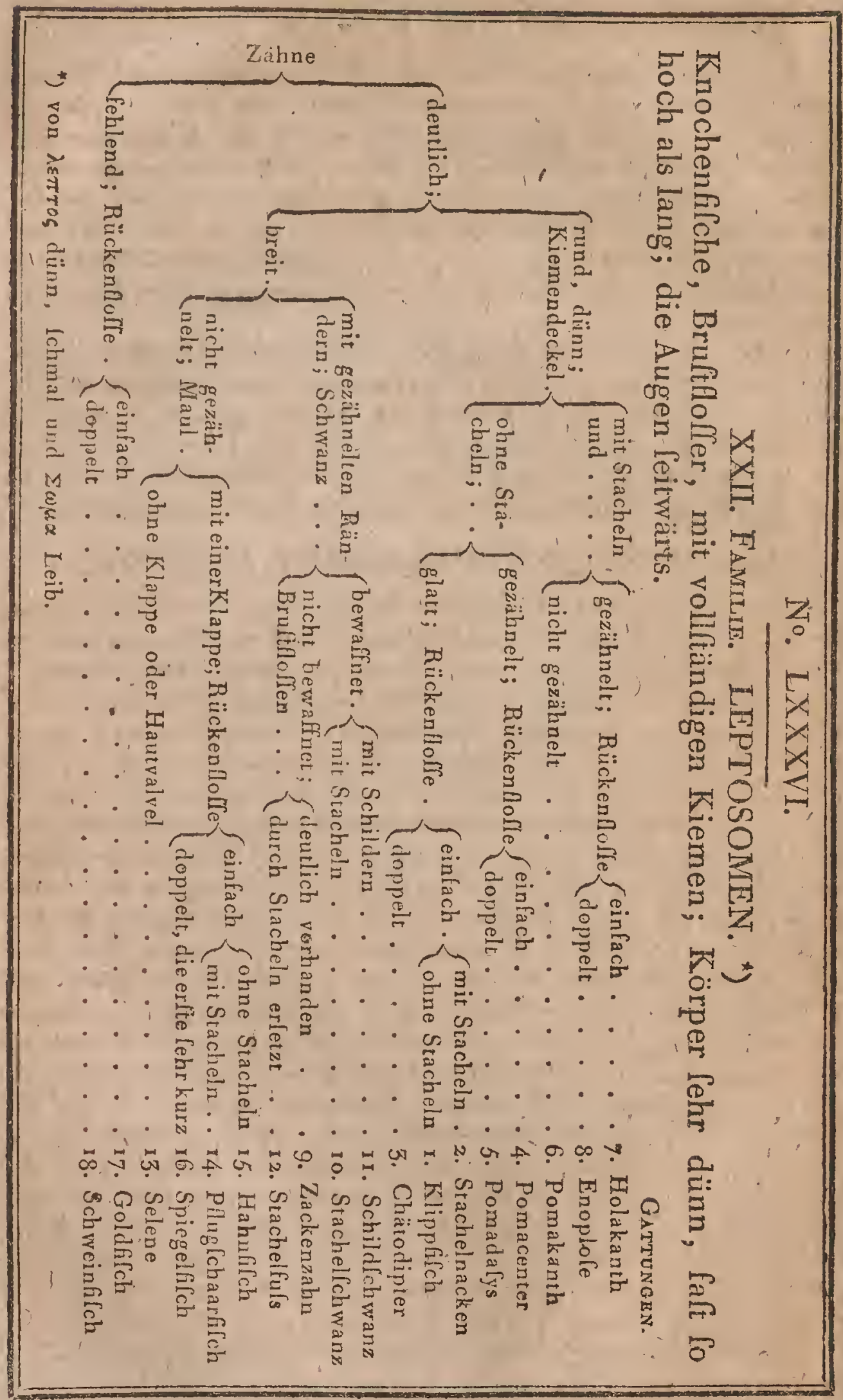




\section{BEMERIKUNGEN'ZUR LXXXVI. TABELLE:}

Die Leptofomen'(Schmalbäuche) haben einen von der Seire ganz zufammen gedrückten Körper, und entprechen den Gattungen Chaetodon and Zezs der bisherigen Naturhiftoriker. Die vorangelchickte Tabelle charakterifirt fie fo vollftändig, dals es unnöthig wäre hier noch fẹr ins Détail au gehen.

I. Der den Klippfifchen von Śb a gegebene Name: chaetodon, Arückt' die harborften-ähnliche Form der Zälne dieler Fifche aus. Es ift dies eine fehr zahlreiche Gattung, worin man die Arten nach der Form der Scbwanzllofle unterfcheidet. Chaet. curacao L.

2. U. 3. Die Stackelnacken (acanthinion) 2. B. Chaetod. rhomboides und die Chätodipteren Chaetodipterus z. B. Chaetadon Plumerii, find in der Tabelle unterlcheidend von' den Klippfifchen eharakterifirt.

4. Dievon Lacepede angegebenen Gattungen Pomacentrus z. B. Chae. rod. pavo L. 5. Pomadafis (Pomadalys), z. B. Sciaena argentea L. und 6. Pomakanth (Pomacanthus) z. B. Chaetod. cánescens L. haben die Kiemendeckel geftachelt wie die Akanthopomen p. 132, von denen fie aber ihre Körperform unterfcheidet."

7. Die Gattung holacanthus vereinigt mehrere fehr verlchiedene Ar-" ten z. B. fciaena rubra L, chaetadon bicolor. Von den 8. Erioplofen (enoplofus) kennt man nur eine Art. Z. B. En. White L a c ep.

9. Die Zackenzähne (glyphifodon) halsen, wie auch die drey folgenden Gattungen die Zähne gezähnelt, mufsten allo von den Klippfilchen getrennt werden. Z. B. Chaetod, Taxatilis $\mathrm{L}_{\text {o }}$

ro. U. I. Die Stachelfchwänze (acanthurus Lac.) gleichen den Za. ckenzảinen, haben aber als Hauptcharakter den Stachel oder Dornen am Schwanze z. B. Chaet. chirurgus L. bey den Schildfchwänzen (aspiurus Lac. Fndet fich ltatt des Stachels ein kleines Schildchen z. B. Chaet. foharL. 12. Die Stachelfïfse (acanthopodus) find Klippfiche, deren BauchIoffen in Stacheln verwandelt zu'feyn fcheinen, z. B. Chaet. argenteus $L_{\text {. }}$. 3. Die Gattung Selene (Lacep.) ift mit durch die verlängerte zweyte Rückenflolle unterfchieden; die hiehergehörigen Filcharten, haben Zähne und den Mund durch keine Klappe wie die folgenden 3 Gattungen verrehloffen. Z. B. Zeus quadratü.

14. 15. und 16. Die Pfugfchaarfifche (Argyreiofus Lncep.) z. B. Zeus vomer L. Die Halinfifche (Gallus Lac.) z. B. Zeus gallus L. und die Spiegelfifche (zeus). Z. B. Z. faber find äufserft fchönfärbige Filche. Eine Art der letztern Gattung, Z. infidiator, fpribt Wafler aus feinen Schnabel auf die an der.Oberfläche des Waflers flegenden Infekten, die er verzehrt; er lebt in 'den fülsen Gewällern von Malabar.

17. und 18. Goldfiche (chrylotos) find die (chönften Filche der europäilchen Meere \%. B. Zeus luna Li. dié an 5 Fuls lang wird und von Gold, Silber, und Blau glänat. Die Schweinfifche (capros) Z. B. Zeus aper, IaL len, wenh fle argriffen werden, eine Art von Grunzen horen. 


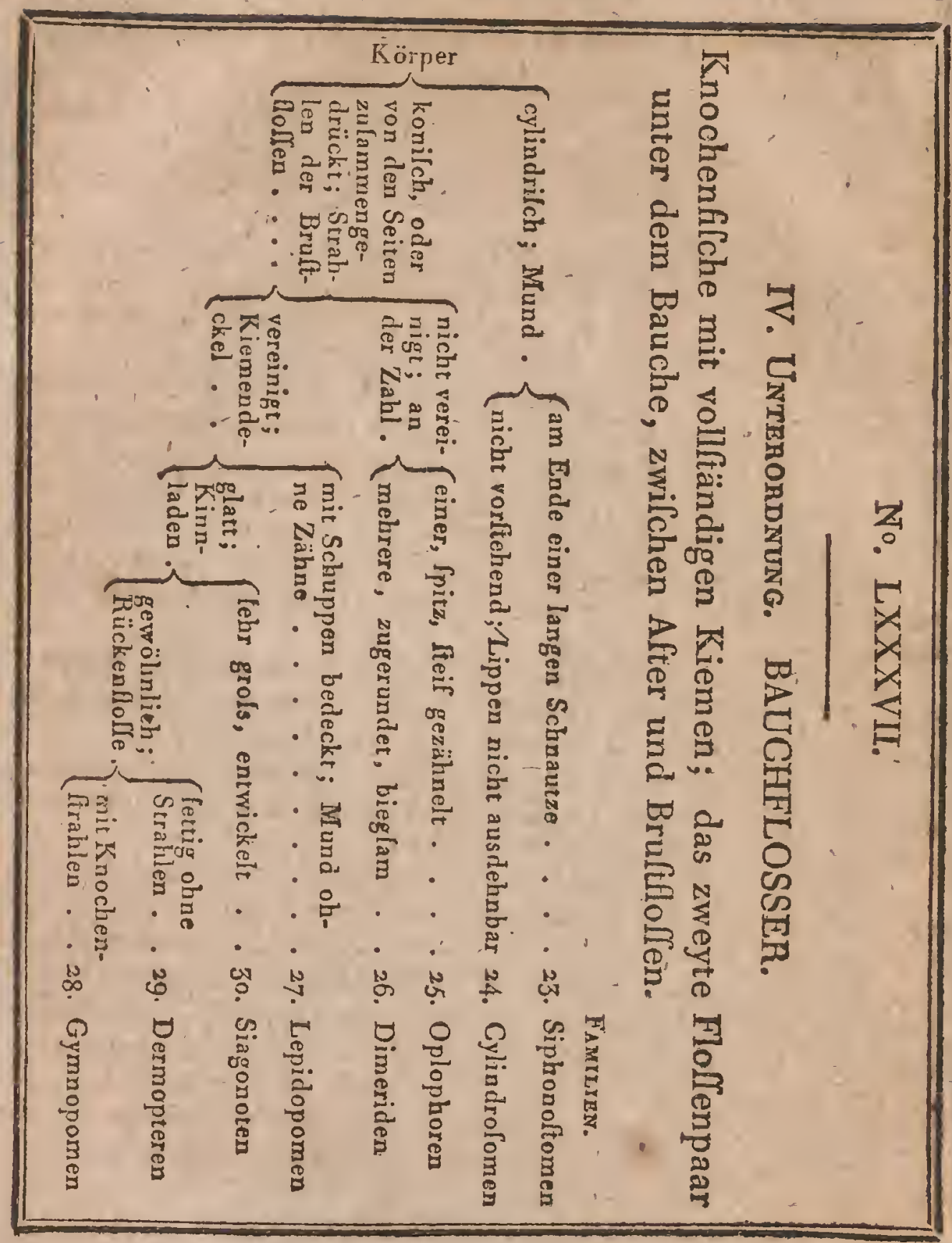

$\therefore$.

\section{BEMERKUNGEN ZUR LXXXVII, TABELLE.}

Die mit vollftändigen Kiemen verfehenen Knochenflche, deren zweytes Floflenpaar hinter den Bruftfloffen fitzt, find weniger zahlreich als die Bruftlloffer; enthalten aber doch mehr Gattungen als die zwey erftern Unterordnungen. 'Die meiften Fifche, von denen jetzt die Rede leyn wird, leben beltändig in lülsem und lielsendem Wafler. Es lçheint dals 
die Bauchfollen hier vorzüglich zur Erhaltung des Gleichgewichtes in der Mitte des Waflers dienen. Alle fchwimmen mit grolser Leicbrigkeit, Celbft gegen die hefrigften Waflerftöme an. 'Die Familien find hier un vieles unterfchiedener als bey den Bruftlolfern.

Die meiften hior erwähnten Abtheilungen ontfprechen Gattungen, die von Linné und Artedi aufgeftellt wares, aus welchen. die neuen Naturhiftoriker, insbelondore Lacepede, die abweichenden Arten ausgezogen und beftimmt bezeichnet haben.

Unter zylindrifchem Körper ift hier die Bildung verftanden, dafs der mittlere Theil des Körpers wenig dicker als der Kopf, und von einem bis zum andern Ende des Körpers der fenkrechte Durchmelleriungefähr fo gros ift, als der horizontale; dies ift hier vorzüglich im Gegenfatze von dem' genommen, was man bey den andern Filchen bemerkt.

Die zwwey Familien, die alsdann in der Ordnung der Tabellen folgen, find ebenfalls léhr leicht zu unterlcheiden; bey der einen ift der erfte Strahl der Bruftloffen Ipitz, und dient als Vertheidigungswaffe, indem er nach Willkühr des Thieres feft aufgeftellt werden kann; bey der andern Ifcheinen die Bruftloffen getheilt oder anf jeder Seite doppelt vorhanden zu feyn, Bald find die den Anhang bildenden Strahlen durch eine Membran vereinigt, bald find fie frey und eine von den andern getrennt.

Die neun und zwanzigfte und dreilsigfte Familie find jede fehr ausgezeichnet durch eine Bildung, die nur den hieher gehörigen Gattungen eigen ili. Die erfte, die den Salmen des Arcedi entlpricht, hat immer eine kleine Rückenflofle obine Strahl, obgleich die Brultfloflen keine fteifen oder fpitzen Strahlen habèn, wiẹ einige Gattungen der Oplophoren. Bey der andern, deren Arten der Gattung Hecht der meiften Ichthyologen entfpricht, find die Kinnladen lehr vorftehend und zeigen eine Menge vertiefter Punkte.

Endlich bleiben in den zwey letzten Familien nur die Arten übrig. welche in den vorhergehenden keinen Platz finden. Die zur einen gehörigen haben den Kiemendeckel mit grolsen deutlichen Schuppen bedeckt. und hievon giebt es nur wenige; die zar anderen gerechneten zahlreichen Arten haben keinen Kiemendeckel und Gind in dreyzebn Gattungen gen brachts 
No. LXXXVIII.

XXIII. Famile. SIPHONOSTOMEN. *)

Knochenfifche, Bauchflofler; mit vollfändigen Kiemen; der Körper rund, zylindrilch; der Mund am Ende einer langen Schnautze.

Stacheln vor ihr lizzend; Schwanzfofle Gatrumger.

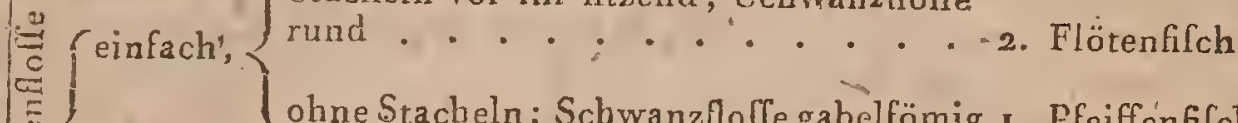
ohne Stacheln; Schwanzflofle gabelfömig r. Ffeiffénflch

doppelt; Körper mit vorragenden wellenförmigen

Linien . . . . . . . . . . . . Solenoftom

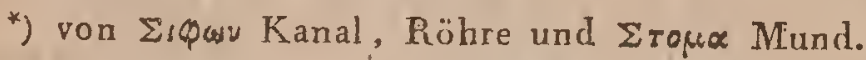

No. LXXXIX.

XXIV. Familie. CYLINDROSOMEN. *)

Knochenfifche, Bauchflofler, mit vollftändigen Kiemen; Körper rund, zylindrifch; Mund nicht vorftehend; Lefzen nicht ausdehnbar.

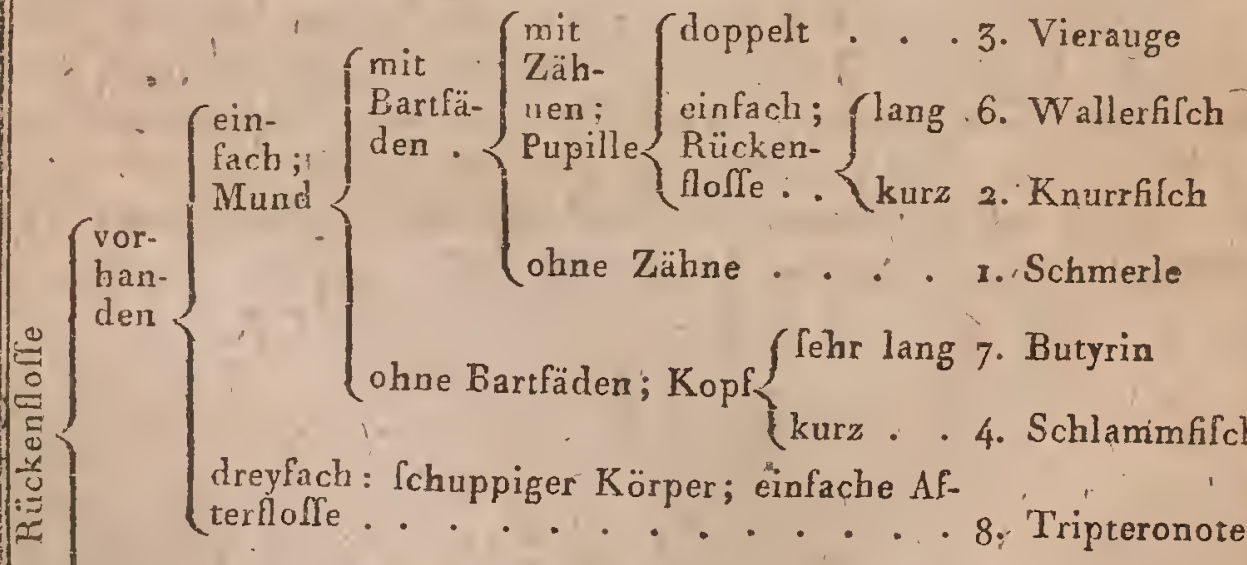

$$
\begin{aligned}
& \text { fehlend; Afterfoffe }\left\{\begin{array}{l}
\text { kurz, } \int_{\text {chmal }} \cdot \text {. . 5. Natterfifch } \\
\text { lagg, breit . . . 9. Ompock }
\end{array}\right.
\end{aligned}
$$

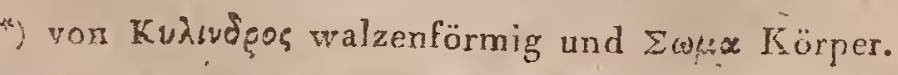




\section{BEMERKUNGEN ZUP LXXXVIII. TABELLE.}

Die Siphonoftomen, Röhrenmäuler, find Filche; deren Kopf, aulserordentlich lang, in eine Schnautze vorgeltreckt ift, die an ihrem Ende den Mund trägt. Der Unterkiefer ift gewöhnlich länger als der Oberkiefer und billet eine Art von Klappe, wie bey den meiften Aphyoftomen inter den Knorgelfifchen und bey den Nadelfifchen sus der Familie der Ofteodermen. Linne hatte die meiften' dieler Fifche in der folgenden erfien Gattung vereinigt.

1. Der Pfeiffenfifch (fltularia L.) wird in den weltindifchen Gewäffern beoachtet; der Körper endigt fich in einen langen hornartigen Faden, 'der in dem Gabelausfchnitt der Schwanzfoflen fitzt. Z. B. Giftularia tabacaria.

2. Der Flütenfifch (auloftoma $C o m m e r \int o n$ ) unterlcheidet fich von dem pfeiffenfilch nur durch das auf der Tabelle angegebene. Z. B. fiftul. chinemfis $L$.

3. Die Solenoftomen (Lolenoltoma Gronow) d. h. Röhreamund, hat einen Körper von mehreren Flächen und gleicht den Nadelfifchen und Mefferfifchen. Z. B. Fift. paradoxa L. (Tabelle 66.)

\section{BEMERKUNGEN ZUR LXXXIX. TABELLE.}

Die Cylindrofomen (Walzenkörper) entfprechen den von Linné und. Artedi aufgeltellten Gattungeı cobitis und amia.

x. Die Schmerlen (cobitis) find länglichte Filche, die gewöhnlich unter dem Schlamm bleiben. Ihr Förper ift lchleimig, ilir Fleifch geIchätzt. Z. B. der Steinpitzger (cobitis taenia L.)

2. Der Knurfffch (misgurnus La cep.) Schlampitzger, unterlcheidet fich von der vorigen Gattung, zu welcher er immer gezïhlt wird, nur durch die auf der Tabelle angegebenen Eigenthümlichkeiten. Z. B. cobitis folfilis.,

3. Das Vierange (auablebs) hat den Namen von der fonderbaren Bildung des Auges, was doppelt zu feyn fcheint, weil es zwey Pupillen hat. - Das einzige Beylpiel unter den rückgrathigen Thieren. ,Z. B. cobitis anablebs $\mathrm{L}$.

4. Die Schlammfifche (Fundulus) find Schlammpitzgeriohne Bartfaden. Z. B. cobitis heteroclita.

5. 6. und 7. Die Natterffecle (colubrina, z. B. col. chinenfis ' $I$, $a$. cepede) Wallerffche (amia) z. B. am. calva L. und der Bucyrin (Butyrinus) z. B. But. bananus Lacep., haben alle einen langen, platten, und, wie bey den Schlangen mit Schildern bedeckten Kopf.

8. Der Tripteronote ' (Tripteronotus) ift der einzige Fifch dieler Fa. milie, wo fich drey Rückenfloflen finden. Z.B. Tr. hautin Lacep.

9. Der Ompock hat einige Aehnlichkeit mit den Kahlrücken, voxi dénen er fich aber durch die Gegenwart der Bauchflollen unterlcheider. Z. B. Omp. Ciluroides La cep. 


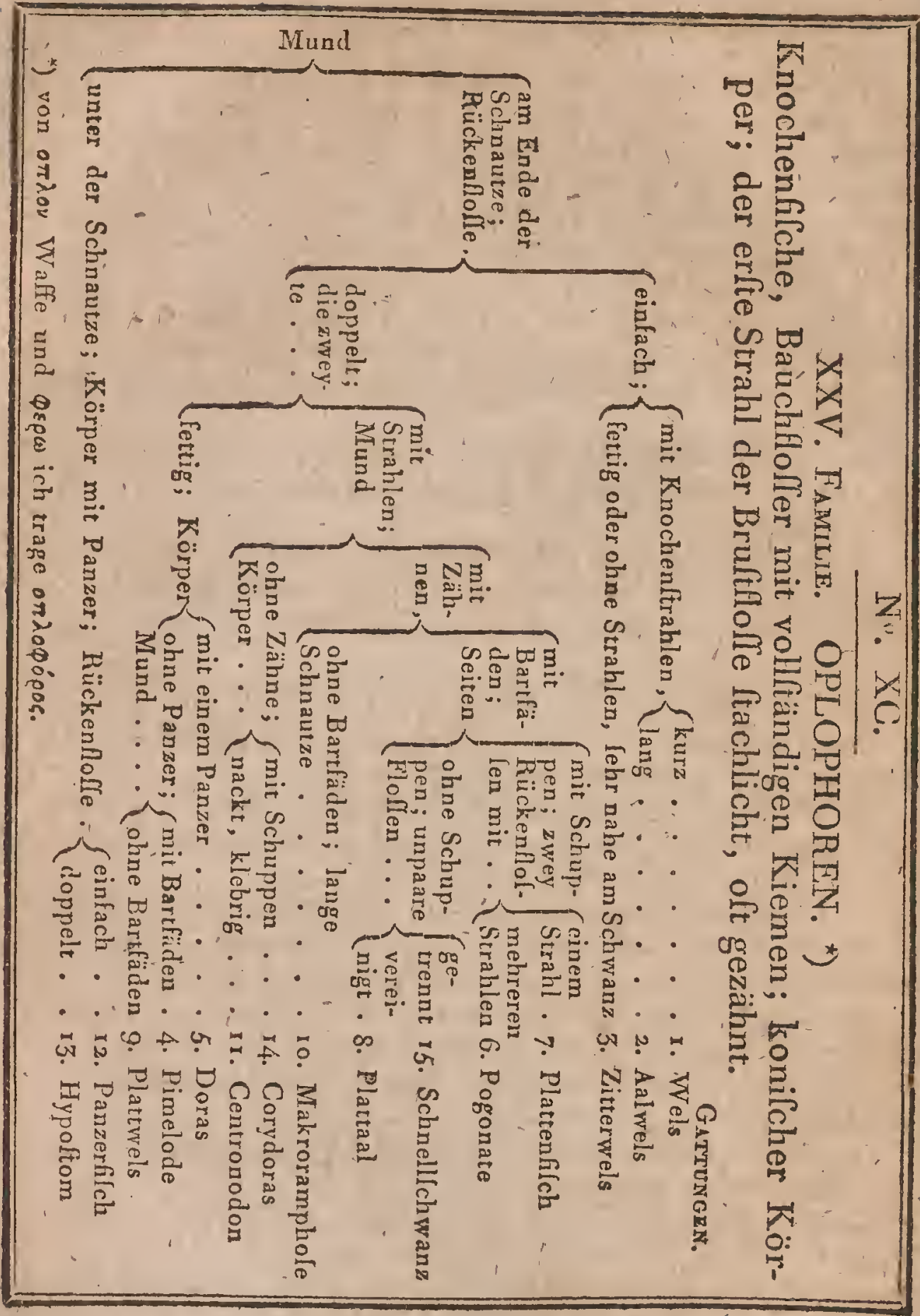

\section{BEMERKUNGEN ZUR XC. TABELLE.}

Die Oplophoren find mehr mit Vertheidigungs als mit Angriffswaffen perlehen. Der erfte Strahl ihrer Bruftloden ift ihre Schutzwaffe, und diés 
durch einen fonderbaren, fehr einfachen Mechanismus. Er kann, wenn er aufgerichtet und in einen rechten, Winkel mit dem Körper gebracht ilt, felt und unbeweglich in feiner Artikulationshöhle auf dem Brultbein werden. Oft ift béy den erften Strahlen derRückenflofle diefelbe Vorrichtung.

1. Die! Welfe (filúrus) haben einen fchlüpfrigen, Ichuppenlolen Körper, mit einem dicken, platten, feft-knochigen Kopf; es find Sülswaf ferfilche. Z. B. Sil. glanis L.

2. 3. Diè Lalwelfe (macropteronotus) z. B. Silur. anguillaris L. und die Zitterwelfe (malapterurus) z. B. filur. electricus $L$. lind von $L a c$ epede aufgeftellte Gattungen. Zu der erften zählt man die Velle mit lehr langen Rückenflofle, zu der zweyten die Arten, die nur eine kleine Fettflofle ohne- Strahlen auf dem Rücken mahe am Schwanze, wie die Dermopteren, haben.

4. Die Pimeloden (pimelodus Lacep.) kommen den Wellen nahe aber die erfte Rückenfolfe hat Knocbenftrahlen. Z. B. Silurus felis, bagne L. Auch die Fifche, welche nacb Humboldt von den Peruanifchen Vulkanen ausgeworfen werden, gehören hieher. Z. B. Pim. cyclopum Humboldt .

5. und 6. Die Doras (doras) z. B. Silur. carinatus L. und Pogonathen (pogonathus z. B. Pog. auratus $L$ a cep.) haben an den Seiten grofse Schuppen; - übrigens find lie auf der Tabelle charakterifirt.

7. Der Harnifchflech (cataphractus $B l o c h$.) bat auch" den Kör-, per durch grolse Schilder bedeckt, die wie an einem Panzerhemde über einander liegen. Z. B. Silurus callichthys L.

8. und 9. Die Plaitaale (plotolus Lac.) z. B. platyftacus anguillaris Bloch, und die Plattwelfe (ageneiolus Lac.) z. B. Silurus militaris L. haben einen ganz nackten Körper mit zwey Rückentloflen.

10. Der Name Makroramphofe (macrorampholus) bedeutet ein Filch mit langer Schnautze. Wirklich findet man diefe Bildung bey einen kleinen Welsähnlichen von Forskael belchriebenen, auch im mittelländilchen Meere gefangenen, Filch. Z. B. Silur. cornutus L.

Ir. Die Centranodons (centronodon Lac.) haben Stacheln an Kie. mendeckel und Rückenflofle aber keine Zühne. Z. B. Silur. imberbis L.

12. und 13. Die Gattungen, Panzerffch (loricaria'Lin.) z. B. L. cataphracta und Hypoftom (hypoftomus Lac.) z. B. Loricaria plecoftomus L, haben falt trleiche Bildung: der Körper ift von einem vielfeitigen Panzer umgeben und der Mund unter der Schnautze.

14. und 15: Die Corydoras (corydoras $L$ a c.) haben den Körper mit grolsen Schuppen, den Kopf mit breiten Schildern bedeckt. Z. B. corydoras Geoffroy. Der Körper der Schnellfchwänze (Tachyfurus La c e p.) ift nackt, und man kennt nur eine Art nach einer in China verfertigten Zeichnung. Z. B. Täch. Lineafis. 


\section{No. XCI.}

\section{Famile. DIMERIDEN. *)}

Knochenfifche, Bauchfloffer mit vollfändigen Kiemen; konifcher Körper; Brufflloflen mit mehreren einzeln. ftehenden nicht vereinigten Strahlen.

Gat'Tungen.

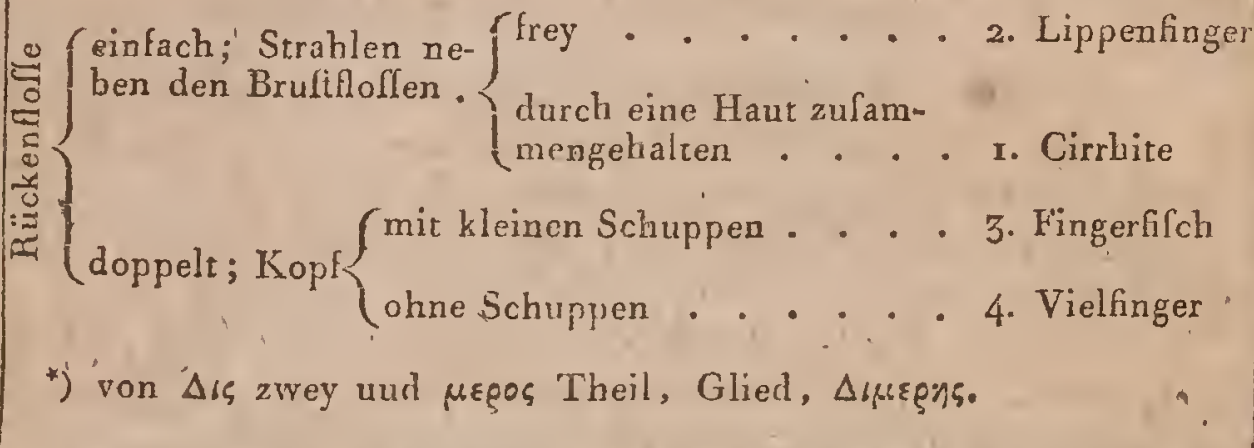

\section{No. XCII.}

\section{FAMiLIE. LEPIDOPOMFN. ,}

Knochenfifche, Bauchfloffer mit vollftändigen Kiemen; konifcher Körper; Kiemendeckel mit S.chuppen bedeckt; Mund ohne Zähne.

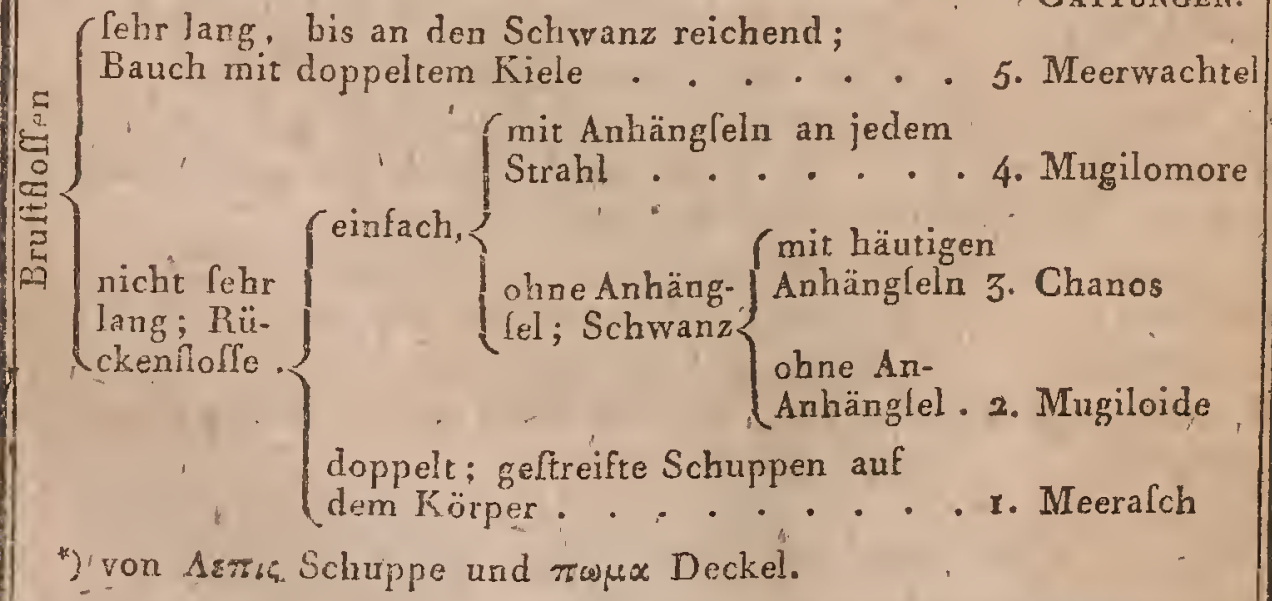

Gattungen. 


\section{BEMERKUNGEN ZUR XCI. TABELLE.}

Die Familie der Dimeriden ift für die Bauchflofler derHolobranchien das was die Floflenfinger No. 83. für die Bruftlofler waren. Nan fieht noch nicht hell über diele fonderbare Bildung der freyen Strahlen, die gewils nicht zufällig ift.

r. Die 'Gattung Cirrhite (cirrbitus Commerfon) enthält oftindifche Fifche, 'die einen fchuppigen Körper haben und wo die Stralılen vor den Bruftloflen fo durch die Haut vereinigt lind, dafs fie ein zweytes Floffenpaar zu bilden fcheinen. Z. B. C. maculatus Lacep.

2. Die Lippenfinger (cheilodactylus Lącep.) haben weit vor den BBruftfloffen freye Strahlen; aulserdem ift die Oberlippe fehr ausdehnbar. Z B. Ch. fasciatus Lacep.

3. Die Fingerfifche (polynemus Lin.) find Fifche aus Südamerika, mit fünt freyen Strahlen neben den Bruftlollen, und einem mit Schuppen bedeckten Kopf. Z. B. P. plebeius.

4. Die Vielfinger (polydactylus Lace p.) unterlcheidet fich von den vorigen bJos durch den (c.huppenlofen Kopf. Z. B. Pol. plumierii,

\section{BEMERKUNGEN ZUR XCII. TABELLE.}

Die Lepidopomen entfprechen den Linneilchen Gattungen mugil und exocoetus... Obgleich ihr Name Tchuppige Kiemendeckel anzeigt, lo ift doch diefer Charakter nur im Gegenfatz zu der Eigenthümlichkeit der folgenden Familie aufgeftellt. Das welentliche iff, dafs mit jener Bildung auch ein gänzlicher $\mathrm{Z}$ ahnmangel eintritt.

A. Der Name mugil den Apitenr den Aefchon gegeben hat, foll aus den zulammengezogenen Worten multum agilis gemacht leyn und allo, die Schnelligkeit anzeigen. Der Körper ift zulammengedrückt, von geftreiften oder. leicht gefurchten Schuppen.bedeckt und die Kinnlade nach.innen zu kielförmig erhaben. Z. B. Mugil cephalus.

2. 3. und 4. Die Mugiloide (mugiloides Lacep.) z. B. mugil chilenfis L, Die Mugilomore (mugilomorus La c e p.) z. B. Mugilom. annacarolina ünd Aer Chanos (chanos Lacep.) z. B. mugil chanos L. machen immer Gattungen von einer /Art aus und find auf der Tabelle genugfam charakterifirt.

5. Meerwachteln (exocoetus Artedi) find die Logenannten liegenden Fịlche; fie haben aufserordentlich lange Bruftloffen, vermöge weelcher fie fich einige Zeit in der Luft halten, indem, fie von ihnen, wenn fie fich aus dem Waffer gefchnellt haben, wie von einem Fallfchirm getragen werden. Alle finden fich unter der Linie. Z. B. Ex. volitans L. 
Holobranchien.

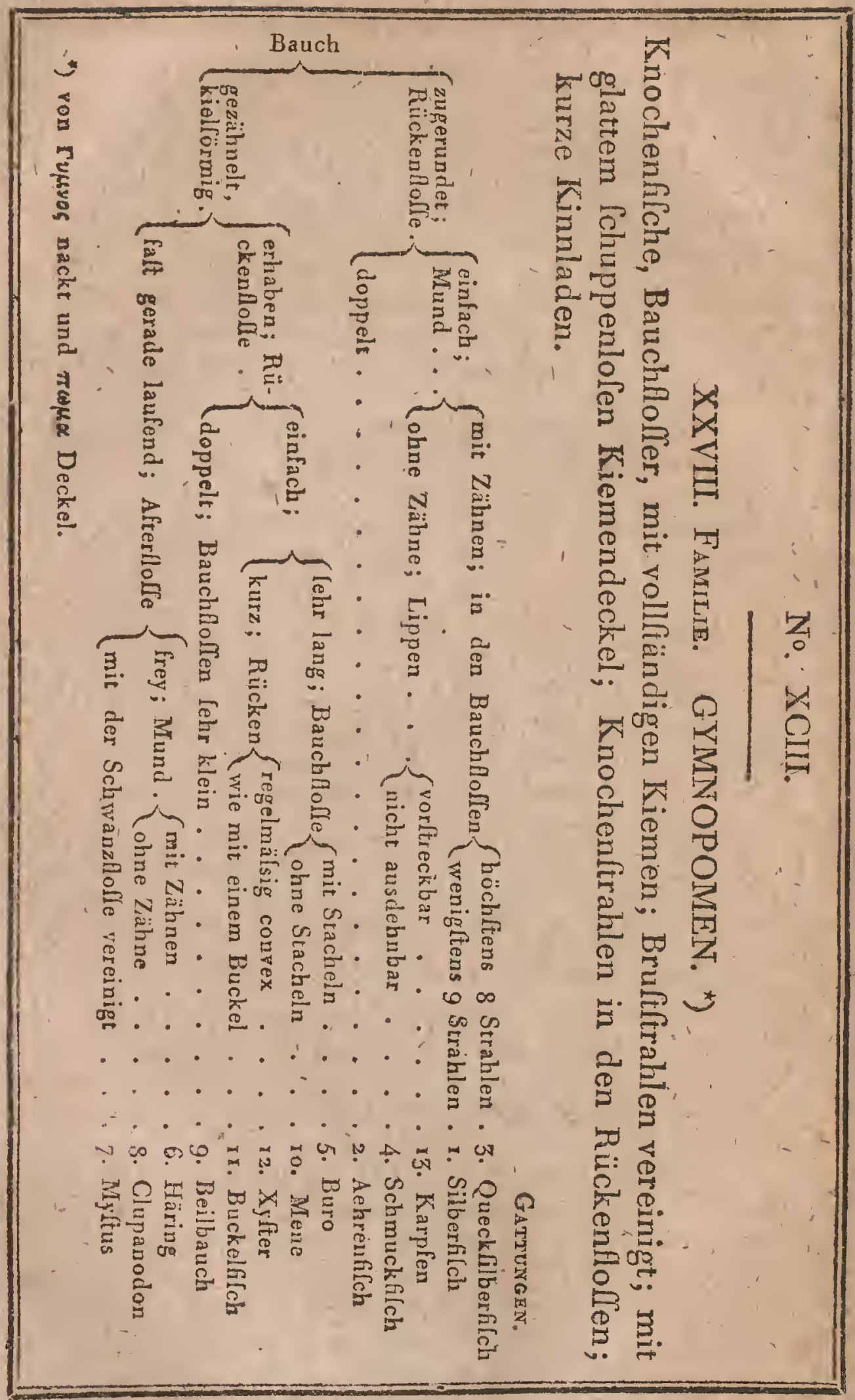




\section{BEMERKUNGEN ZUR XCII. TABELLE.}

Die Familie der Gymnopomen ift, wie \{chon p. 137. angegeben, diejenige, wo die Beftimmung der Arten mit den grölsten Schwierigkeiten verknüpt ift. Es find der Arten Cehr viele, und es hält fehr fchwer fie unter Gattungen zu bringen, deren Characktere feft und unterlcbeidend lind.

ห. und 2. Die Aehrenfische (atberina Lin.) 2. B. ather. hepletus und die Silberfffche (argentina Lin.) $z$. B. argentina Iphyraena, unterlcheiden fich yon den Häringen durch ihren zugerundeten Buach; eine von der andern unterfcheiden fie fich durch die Zahl ihrer Rückenflolfen.

3. und 4. Die Queckfilberfyfche (hydrargyra Lacep. z. B. H. Iwampina) und die Schmukfifche (ftolephorus L a cep. z. B. Stol. japonicus) find aut der Tabelle wélentlich unterfchieder.

5. Die Gattung Buro (Buro Commerfon z. B. Buro brunness Lacep.) shefteht aus einer in den indilchen Meeren einheimilchen Art, bey der fich zwilchen den Bauchfloflen doppelte Stacheln finden.

6. Die Häringe (clupeà Artedi) haben einen gekielten, gezähnelten Bauch, den Körper filberfarben, den Mund voll Zähne, einé einzige Rückenflofle und die Afterfolle von der Schwanzflofle getreait." 2 . B. clup. harengus, Iprattus, alo「a u. l. w.

7. und 8. Die Gattung Myftus (myltus Lacep.) z. B. clupea myltus L. unterfcheidet fich von den. Häringen nur durch die von der Schwanzfolfe nicht getrennte Afterllolle, - fo wie vón den Clupanodóns (clupanodon Lac. 2. B. Clupea thrifla), nur durch die zahnlofen Kinnladen.

9. u. ro. Die Gattung Beilhauch (Gafteropelecus $B l o c h$ ) z. B. falmo gafteropelecust L. gleicht fehr den Hätingen, "hat aber der Bauch Lehr convex; die Bauchloflen find fehr kleis und die Rückenfloflen dop. pelt. Die Menes (mene) z. B. mene anna-carolina Laćp. hat die Körperform der Beilbäuche aber die Rückenflofte ift einfach und léhr lang. und es finden fich keine Stacheln zwilchen den Bauchflollen wie bey den Buros.

Ir. und; 12. Die Buckelfffche (dorfuarius Comimerfon)'z. B. Dorf. nigrescens Lacep. und die Xyfteren (Xyfter Commerfon) z. B. Xylt. fuscus $L$ acep. Findén fich unter dem Aequator und find den vorhergehenden Gattungen nahe verwandt.

13. Der Karpfen (cypripus Artedi) haben den Körper mit Schuppen bedeckt, den Mund zahílos, die Lippen vorftreckbar, und eine einzige Rï̈ckenflofle. Sie find Süfstvaflerfiche. Man theilt fie ab a) in folche mit vier Bartfäden, $\dot{z}$. B. cypr. carpio L. b) in folche mit zwey Bartfäder צ. B. Cypr. tinca L. c) in folche ohne Bartfäden, mit nicht ausgefchnittener Schwanzflofe z. B. cypr. cephalus L. und d) in Bartfadenlole mit ausgefchnittener Schwanzlofle. Z. B. Cyprin, auratus, leuciscus, phoxiม מง L. U. I. W.

Dumeril Zool. 


\section{No. XCIV.}

\section{FamiLIE. DERMOPTEREN. *)}

Knochenfilche, Bauchfloffer mit vollftändigen Kiemen; Brufttrahlen vereinigt; glatte Kiemende. ckel; die eine der Rückenflollen ohne Knochen ftrahlen.

Gattungen.

kielförmig und lägeartig gezähnelt; Körper

lehr hoch . . ... • . . . . • . . 5. Serrafalm

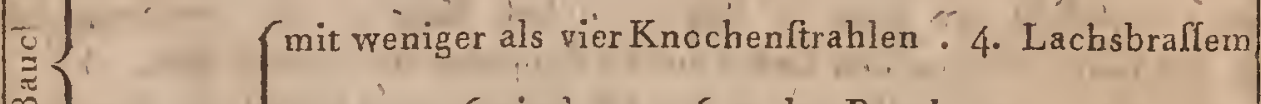

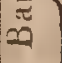

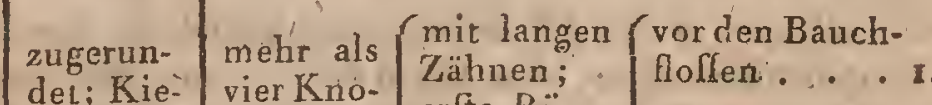

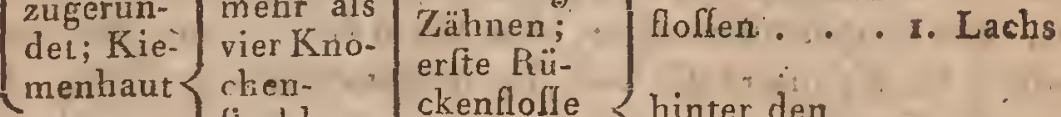

menhaut $\left\{\begin{array}{l}\text { chen- } \\ \text { litrahlen; }\end{array}\right.$ ckenflolle $\{$ hinter den Mund. $\{$ Bauchfloílen . 2. Sint

ohne Zähne, oder mit lebr

kleinen Zähnen, •. . . 3. Alch

*) von $\Delta$ egpex Haut und тrspor Floffe.

BEMERKUNGEN ZUR XCIV. TABELLE:

Die kleine Rückenflofle, ohne Knochenftrahlen, ift der wefentliche Charakter der Familie der Dermopteren; aber um diele Filche von den Gattungen Zitterwels, Doras, Pimelode und Plattwelle der Familie der Oplophoren zu unterlcheiden, mufs man noch die zweyte Bedingung in Anfchlag bringen: dafs der erfte Bruffloflenftrahl keine fteife Stachel bildet, auch nicht in die Hühé gerichtet werden kann. Die méiften FiIche diefer Familie wurden bisher unter Ider Gattung Salmo begriffen. Alle leben vorzüglich in füfsem Waffer, Ichwimmen mit grolser Schnel. ligkeit felbft gegen den ftärkften Strom an. Sie können fich aus dem Waffer in die Höhe fchnellen und fich durch ungehevre Sprünge, in der Luft oder felblt in dem Waffer, lo erheben, dals,fie logar über Wafler-1 fälle in die Höhe gelangen. Ihr Fleilch ift wohlfchmeckend und allenthalben beliebt. 


\section{Holobranchiea.}

1. Die Lachfe oder Lackusforellen, (Lalmo) baben den Körper mit kleinen, oft kaum fichtbaren, immer aber zarten, glatten Schuppen bedeckt; aber weder Stacheln noch Bartfäden. Ihr Mund am Ende ihrer'Schnautze ift mit ftarken Zähnen vèrfehen. Die erfte Rückenfloffe, oder die wo fich Knochenftrahlen finden, fängt allemal vor den Bauchfloflen an und litzt allo dem Kopfe näher als diefe. Es gehören hieher über zwanzig Arten. Z. B. Salmo lalar, trutta, umbla u. $\int$. w.

2. Die Stinte (osmerus Artedi) unterfcheiden fich von den Lachlen nur dadurch, dals ibre Rückenfloffe weiter vom Kopfe entfernt ift als die Bauchfloflen. Z, B. Salmo eperlanus, Yaurus etc. L.

3. Die Aefche (corregonus Artedi) haben als Hauptcharackter febr kleine kaum fichtbare Zähne, z. B., Salmo lavaretus, thymallus etc. L. Leben in Landieen und Flüflen.

4. Die Lachsbrafeme (characinus Gronöw) unterfcheiden fich durch einen nicht leicht aufzufindenden Charakter, nemlich durch die kleine Zahl der Strahlen in der Kiemenhaut. Alle hieher gehörigen Arten find in indilchen oder amerikanifchen Meeren einheimilch. Z. B. Salmo argentinus, dentex, L. etc.

5. Die Serrafalmen (ferralalmo $L a c e p$.) find Surinamilche Fifche, die von den Lachfen nur durch die auf der Tabelle angregebenen Eigenthünlichkeiten abweichen. Z. B. Salmo rhombeus L. 


\section{No. XCV.}

\section{FAmilie. SIAGONOTEN. *)}

Knochenfifche, Bruftfloller mit vollftändigen Kiemen; glatte Kiemendeckel; Brufftrahlen vereinigt; lange vorftehende gefurchte Kinnladen.

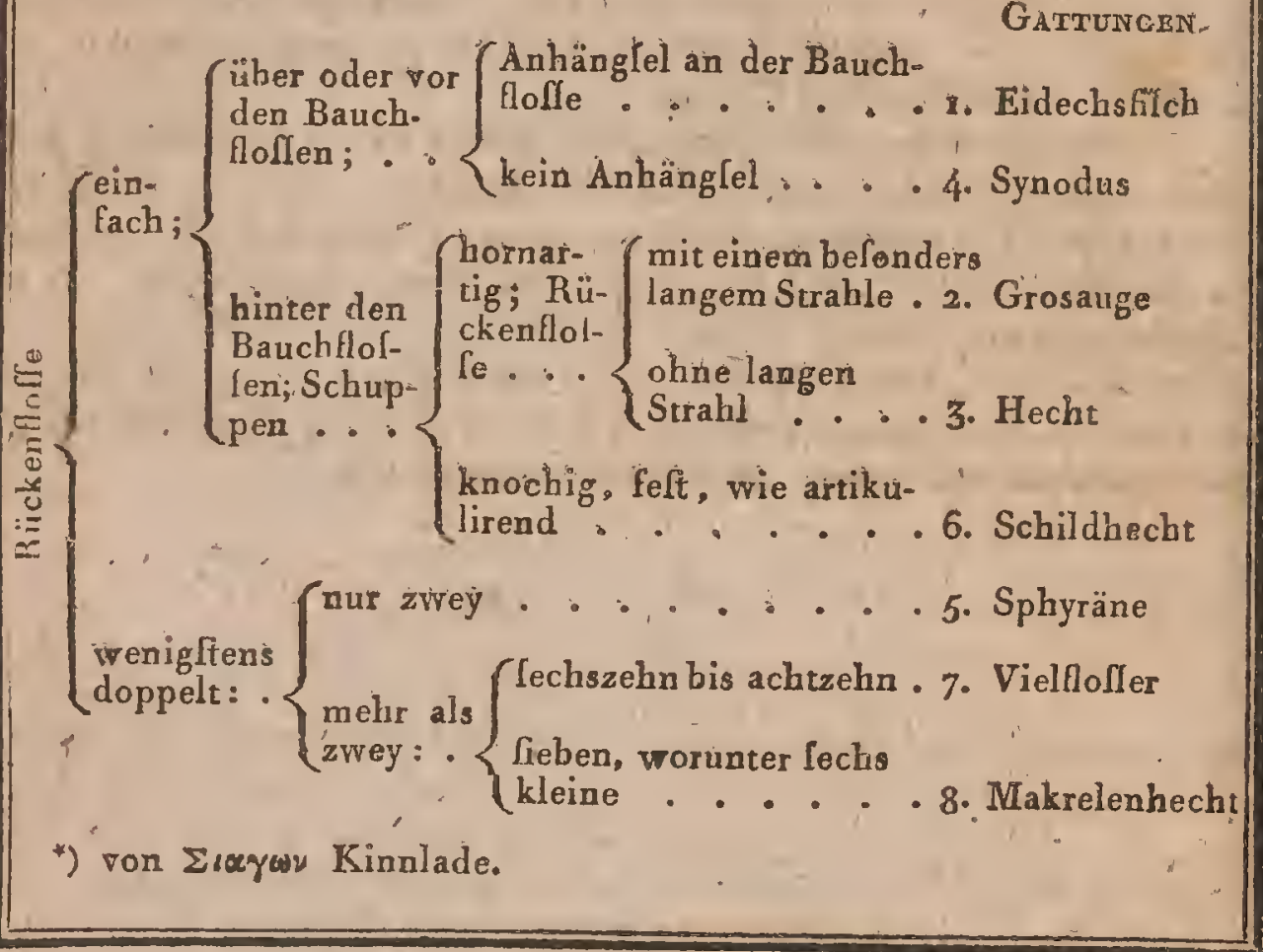

\section{BEMERKUNGEN ZUR XCV. TABELLE.}

Die Siagonoten haben den Kopf in lange Kinnladen verlängert und diefe mit lebr. ftarken fpitzen Zähnen bewaffnet, womit lie die andegn FiIche, wovon fie fich nähren, tödtern.

r. Die Gattung Eidechfis $\int c h$ (elops $t_{i}$ in.) enthält nur eine einzige Art, welche Sloane in feiner Gelchichte von Jamaika befchrieben hat.' Der Körper diefes Filches ift zugerundet, mit Schuppen bedeckt, die Rückenflofle einfach. Aber der Hauptcharakter befteht in Ichuppigen Anhängfeln, die die Bafis der Bauchfloflen bedecken, und in den vielen Strahlen der Kiemenhaut, dèren man auf joder Seite an 30 gezählt hat. Z. B. elops faurus Liñ. 
2. Das Grosauge (inegalops $C o m m$ erfo $n$ ) bat einige Aehnlichkeit mit den Häringeń; ihre Rückenflole zeigt binten einen Iehr langen Faden. Z. B. meg. filamentolus $L$ a c.

3. Die Hechte (efox) follen ihren lateinifchen Namen daher haben. weil lie immer Hunger zu haben fcheinen. Ihr Körper ift leicht zulamnerigedrückt, mit harten hornartigen Schuppen bedeckt, die fehr feft in der Haut litzen. Sie haben nur eine Rücken und eine Afterflófle die kurz find und einander gegen über fitzen. Z. B, elox lucius, belone L.

4. Die Gattung Synodus (fynodus) (die man nicht mit den, zu den Meerbraflemen gehörigen, Synodons der Alten verwechleln mufs,) unterlcheidet fich von den Hechten nur durch das Verhältnils der Bauch und Rückenflolfe. Z. B. élox fynodus, vulpes L:

5. Die Sphyrünen (fphyraena Lac.) haben zwoy Rückenfloffen. Man kennt fünf Arten, die meift zu den Hechten gezählt wurden, Z. B. elox fphyraena L.

6. Die Schildhechce (lepilolteus La cep.) find grolse Hechtähnliche Fifche, deren'Körper mit grolsen Knochenlchuppen gepanzert ift, die feft an einander liegen und fo hart find, dafs fie einer Flintenkugel widexftehen. Z. B. elox offeus L.

7. Der Vielfloffer (polypterus) ift ein Egyptifcher Filch, von Geoffroy wegen Leiner vielen Rückenflollen fo genannt; lonft kommt or mit den Schildhechtén überein. Z. B. Polypt. bichir Geoffroy.

8. Endlich der Makrelenheche (Icomberelox Lacep.) zeigt eine Menge logenannter fallcher Floffèn, über und unter dem Schwanze zwiIchen der Rücken - und Schwanz - und zwifchen der After - und Schwanz:Allfe. Z. B. Scomberefox camperii La cep. ilt im mittelländifchen Meere zu Haufe, und wird einen Fuls lang. 


\section{No. XCVI.}

\section{ORDNUNG. STERNOPTYGEN. *)}

Knochenfifche mit, von einem Kiemendeckel bedeckten, Kiemen ohne Kiemenhaut.

$$
\text { Sternoptyx. }
$$

*) von $\Sigma \tau \varepsilon$ gुov Brult und $\pi r \nu \xi$ Falte.

\section{No. XGVII.}

\section{Ordnung. KRYPTOBRANCHIEN. *)}

Knochenfifche mit Kiemen ohne Kiemendeckel aber mit Kiemenhaut.

Gattringen.

Bauchfloflen $\left\{\begin{array}{l}\text { vorhanden }=\text { Bauchflofier } . \text { Stieltriger }^{\prime} \\ \text { fehlend }=\text { Kahlbauch } . . . \text { Murmelffch }\end{array}\right.$

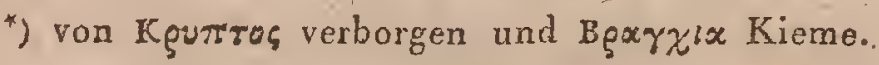

\section{BEMERKUNGEN ZUR XCVI. 'TABELLE.}

Es fchien überflüflg hier noch durch einen befonderen Namen die Ordnung su, bezeichnen, zu welcher, nach dem Lacepedofchen Syltem, der einzige Knochenfich gehört, der keine Kiemenhaut aber einen Kiemendeckel hat. 'Es ilt daher lieber der Name Sternopiyx beybehalten, der augleich Ordnung, Familie, Gatzung und Art bezeichnet. Weil aber 
nur dieler Filch allein eine folche Bildung zeigt, fo werden einige ausführlichere Notizen nicht unzweckmälsig feyn.

Der verftorbene Profelfor Hermann in Strasburg ift der erfte chriftJeller, der diefe Art befchrieben und von ihr eine Abbildung geliefert hat, die nachher in den meifter fyltematilchen Werken über Filchkunde copirt ift. Es ift diefer Fifch von Jamaika' gekommen. Der Körper ift filberfarben, Cehr zufammengedrückt, vorzüglich an dem unteren 'Theile, welcher fo dünn wird, dals man dürchfehen kann. Der Kopfilt abgeltutzt, der ganz fenkrecht ftehende Mund mit. kleinen Zähnen verfehen. Bauchfloflen und Seitenlinien fehlen. Der Schwanz ift gabelförmig. Die Bruft hat aufjeder Seite zehn bis zwölf Falten, und bildet unten einen durchfich. tigen Kiel, Sternoptyx diaphana L.

\section{BEMERKUNGEN ZUR XGVII. TABELLE.}

Die Krypiobranchien entiprechén einige malsen den Chismopnéen. unter den Knorpelfifchen, Allein die Zahl dieler Knochenfifche, mit Kiemenhaut aber ohne Kiemendeckel ift viel geringer.

I. Der eine diefer Fifche; der eine der wunderbarfen Formen bat, hat gar keine Bauchfloflen; der Mund fteht nach dem Hintertheile des Körpers und die Augen fitzenguf rundlichen Stielen; der Körper ift fil-. berfarben und obne Schuppen, lehr lang, zulammengedrückt und hinten in einen fehr langen Faden endigend. Diefer londerbare Filch ift im hohen Meere zwilchen Kuba und Martinique gefangeil; er ilt von Shaw unter dem Namen Stylephorus (Stielträger) belchrieben. Z. B. Styl. cordatus Shaw.

2. Die Murmelffiche (mormyrus) wurden fönte den Knorpelffehen beygelellt. Es find diefe von Forskacl befchriebenen Filche im Nil zu Haule und fcheinen keinen Kiemendeckel zu Kałen. Der Körper if mit Schuppen bedeckt, lang und ihr Mund mit Zähnen befetzt; fie haben nur cine Rückenflofle und lcheinen den Hornfilchien (baliftes) in etwas mahe zu kommen. Man hat noch keire Abbildung vou ihnen. Profelfor Geoffroy in Paris wird aber, wenn er ihre Naturbelchreibung liefert, auch fehr fchöne von Redoucẻ in Egypten verfertigte Zeichnungen dazu ftechen lallen. Z, B. Mormyrus cyprinoides $L_{\text {, }}$ 


\section{No. XCVIII.}

\section{Ordnung. Ophichthyten. *)}

Knochenfilche ohne Kiemendeckel, ohne Kiemenhaut und ohne Bauchflollen.

Gattumgen.

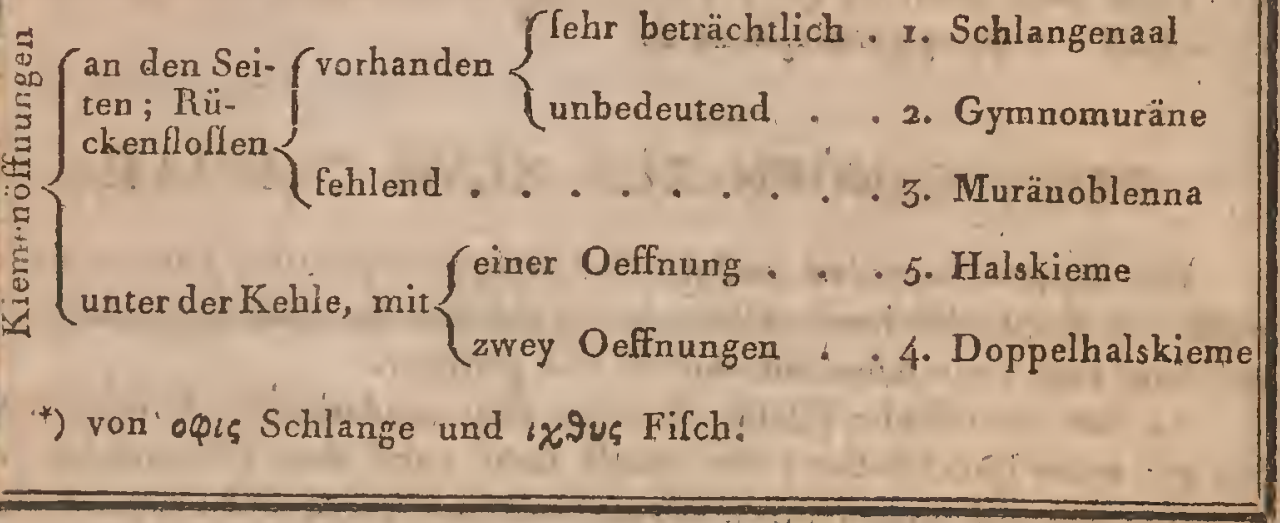

\section{BEMERKUNGEN ZUR XCVIII. TABELLE.}

Die in diefe letzte Ordnung zufammengeftellten Filche haben keine Bauchfloffen, 'ihr Körper ift rund, lang und fchlangenähnlich; deswegen heifsen fie auch Ophichthyken. Die meiften diefer Filche waren Ionft zu den Aalen gezählt, yon denen fie fich nur durch den fehlenden Kiemendeckel unterfcheidon, denn ihre übrige Organilation ift der der Aale fehr ähnlich. Die meiften der hier genännten Gattungen find von Lreepede angegeben.

x. Die Schlangeñale (Muraenophis), wovon Blochleinige unter dem Namen gymnothorax belchrieben hat, haben einen zylindrifchen Körper und die unparen Floflen alle mit einander vereinigt, Die Kiemenöfnurgen liegen an der Seite des Halfes. Zu diefer Gattung géhören die Muränen (der Alten), deren Fleilch fo beliebt war. Z, B. Muraena helena L. Die meiften anderen in heifsen Himmelftrichen vorkommenden Arten fnd mit lchönen Farben geziert, die lehr segelmälsig vertbeilt find.

2. Die Gymnomuränen (gymnomuraena) find von Commerfon ent deckt und von Lacepede fo genannt, weỉ ihre Floflen fo klein find und fo wenig vorltehox, dals lie ganz zu fehlen Icheizen und dafs max 


\section{Ophichthyten.}

die Filche zergliédern muls um die Gräthen zu finden, die eigentlich die Flofle ftützen follen. Z. B. Gymnom, doliata Lacep.

3. Man kennt nur eine Art der Gattung Muraenoblenna und dielo nur aus der von Commerlon hinterlaflenen Befchreibung, der den Fifch in der Magellanilchen Stralse zu beobachten Gelegenheit batte. Z B. M. olivacea.' Es ift dies vielleicht der auf der 5 I Tabelle aufgeführte Ohnflorfer, worüber man noch lo wenig Nachrichten hat.

4. Der Doppelkalskieme ( phagebranchus $B l \dot{o} \mathrm{c} k$.) if ein oftindifcher Filch, ohne Schuppen und Floffen. Auf jeder Seite hat er vier Kiemen und die Déffnungen zu den Kiemenhöhlen liegen als zwey deutliche Spalten an der Seite des Halles, Z. B. Sph. roftratus Bloch.

5. Die Halskiemer (unibranchaperturá Lac. Synbranchus $B l o c h$ ) haben nur eine einzige in die Kiemeahöhlen führende Oeffaung unter der Kehle. Z. B. Synbr. marmoratus Bloch.

Die Fifche aus diefer Ordnung finden fich nur in den Mecren beifser Zonen.

Ende der Klalle der Fifche. 


\section{No. XCIX.}

\section{KLasse. MOLLUSKEN.}

Weiche rückgrathslole Thiere; ohne artikulirte Glieder, mit Gefälsen, Refpirationswerkzeugen und einfachen nicht knotigen Nerven.

OrDNUNG.

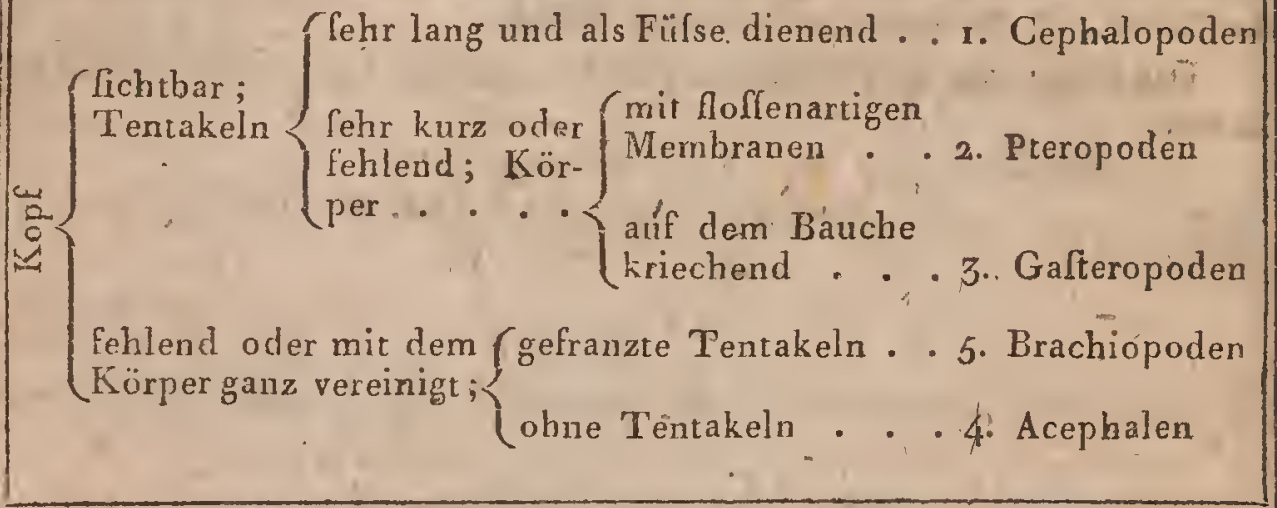

\section{BEMERKUNGEN ZUR XCIX. TABELLE.}

Die Klafie der Mollusken (mollusca) und die Abtheilungen derfelben find leit 9 Jahren von Cuvier zuerft aufgeftellt. Er ift der erfte Naturíorfcher, der fich mit dem genauen Studio dieler Thiere befchäftigt und fie an der Spitze der rückgrathlolen Thiere geftellt bat; da ihre innere Organilation viel komplizirter ift als die der ándern.

Alle Arten haben ein 'zur Cirkulation befimmtes Gefälsfyftem', an deffen Anfange (Mittelpunkte) fich eine oder mehrere muskulöle, zulammenziehungsfähige Höhlen finden, welche die in fie gelangende Flüfrigkeit forrbewegen und in einen Relpirationsapparat treiben, wo eben diefe Gefäl'se' fich endlich auf mehr oder minder grofsen Flächen verbreiten, die man alsdann Kiemen nennt.

Die Organe der Emplindung beftehen bey den Mollusken aus einem Hirn oder einer an der Seite des Mundes auf dem Schlunde (allo im Kopfe, wenn diefer da ift) befindlichen, beträchtichen Auftreibung. Es gehen von da fehr viele Faden ab, um fich zu den Tentakeln, den Augen und den benachbarten Theilen zu begeben; aber die zwey Hauptfränge umfallen die Speileröhre oder den Anfang des Nahrungskanales wie ein Halsband. 
Sie'vereinigen fich bald von neuem, fchicken viele Faden an die benachbarten Theile, die zwey grölsten aber erftrecken fich bis in die Bauchhöh. le, um die Organe der Bewegung, der Verdaung, der Fortpllanzung zu verforgen, ohne dafs fich eihe gröfsere Zahl von Ganglien bildete, wie dies in den folgehden Klaflen gefchieht.

Die Organe der äulseren Sinne Lind bey den Mollusken fehr verlchieden; die meiften, die Kopflolen ausgenommen, haben in der NachbarIchaft des Mundes fleilchige Hörmer loder Lappen, zwey oder vier oder mehr. Man nennt fie Tentakcln, (tentacula) und, hält fie für T'aftorgane.

Bey den Cephalopoden, Kopfürslern, find die Augen falt wie bey den Fifchen gebildé, aber bey den Gafteropoden, und einigen Pteropo. der find fie viel einfacher. Die Acephalen und Bracliopodonthaben gar keine.

Die Käuwerkzeuge bilden bey den Cephalopoden einen aus zwey Stücken beftehenden Schnabel, der einem Papageylchnabel fehr ähnlich ilt. Bey einigen Gafteropoden ift das Maul mit verfolieden geltalteten gezähnelten Stückèn befetzr. Die meilten anderen Molksken haben aber nur eine einfache Oeffnung, eineSpalte die mehroder weniger (als Rülfel) vorgeltreckt, werden kann.

Der Körper der Mollusken ift gewöbnlich fehr weich und daher, haben lie auch ihren Namen. Unterdeflen ift ihrKörper doch meiftens von einer kalkartigen Hülle umgeben; die au der äulseren Haut des 'Thieres ausfchwitat und deren Geftalt nach deu Ordnungen und Gattungen verIchieden ift. Man nennt diele äulsere Haut des Kürpers der. Molluskeu den Mantel; bald ift er auf der eilen Seite leiner gauzen Länge nach gefpalten, bald bildet er um den Körper eine Art von Rühre; manchmal ift er an der einen oft an beyden Seiten offer.

Vorzüglich find es die Bewegungswerkzenge der Mollusken, woran man Verfchiedenheiten bemerkt und fie geben auch die deutlichlten Eigenthümlichkeiten zur Begründung der Claffifkation an. So find die meiften Acephaten und Brachiopoden feft fitzend und unheweglich. Nur einige können den Ort verändern und langlam fich mittels eines muskulölen Anhanges, den man den Fufs nennt, fortbewegen; dieler Fuls dient dem Thiere lich feft zu halten, oder aus einer eignen Drüe Faden hervorzuziehn, die im Wafler unauflöslich find und das Thier am Fellen befeftigen. Die Bewegungswerkzenge der übrigen Ordnung geben ihren Hauptv charakter ab.

Die Geñerations-Organe find nảch den verfchiedenein Familien Cehr verlchieden; wir werden ihrer beyoden einzelnen Familien erwäbnen. 


\section{No. C. .}

I. Ordnung und I. Familie. CepHalopoden. *) Mollusken mit deutlichem Kepfe, 'Augen' an den Seiten; Kinnladen wie ein Papageyfchnabél geformt. Armförmige nicht gegliederte Tentakeln, die mit Saugwarzen oder Saugnäpfchen befetzt " find.

Gatrungen.

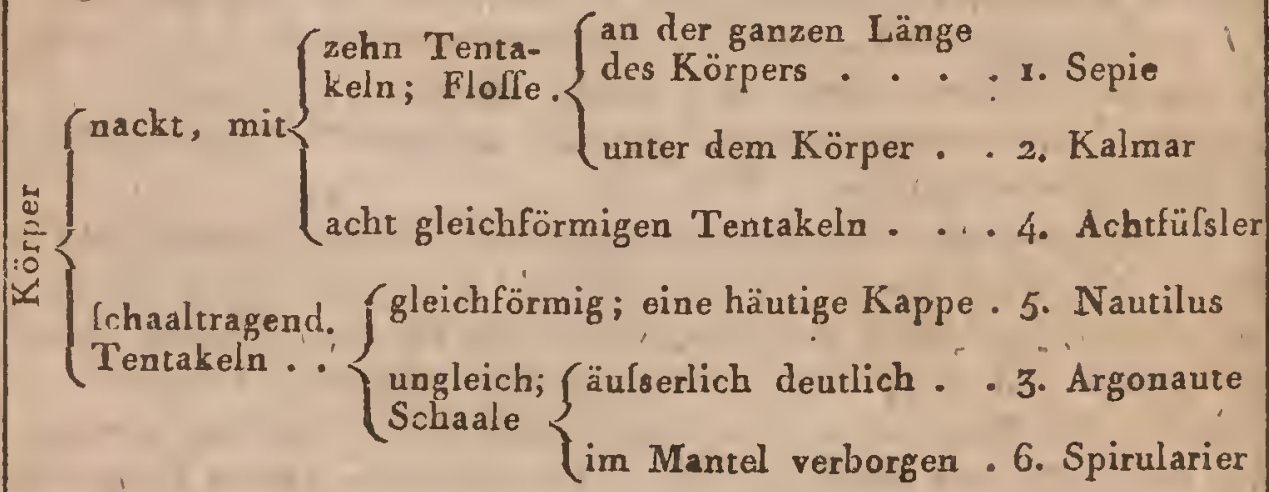

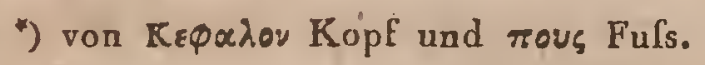

\section{BEMERKUNGEN ZUR C. TABELLE.}

Die Ordnung der Kopfülsler (mollusca cephalopoda) 'unterfcheidet. fich, was die Organifation betrifft, von den übrigen Mollusken lehr. Bey allen ift der Kapf deutlich zu unterlcheiden und trägt zwey grolse nicht geltielte Augen. (Die Firolen allein (eine Molluskenart der folgenden Ordnung) find noch in demfelben Falle.) Ihr Mund ift oben auf. dem Kopfe, in der Mitte der zehn Tentakelm; er ift mit Papageyfchnabelartigen Kinnladen verfehen, wenigftens bey den bisher unterfuchten Arten.

Der Körper ift in einem von den Mantel gebildeten Sacke eingelchlo[fen, deffen Form nach den Gattungen verfchieden ift. Bey einigen ift er beftändig nackt und enthält nur einen fefteren Körper in fich.'- Bey andern kann er fuch in eine im Leben dee Thieres immer fichibare Schaale zurückziehen. 
Die Refpirationsorgane find immer innerhalb des Mantels verborgen an welchem man immer Oeffnungen für den Eintritt und Austritt des Waflers findet; denn alle fcheinen beftimmt zu' feyn im Meere zu leben.

Die Gelchlechter find getrennt, in zwey Individuen vertheilt. Die Eyer kommen oft im Eyerftock der Mutter aus.

1. und 2. Die Sepiers (Iepia) z. B. fep. officinalis L. unterlcheidek, fich von den Kalmars (loligo) z. B. lep. loligo L. uur durch die Natur der feften Subftanz, welchefunter dem Mantel ihren Körper befchützt und die man fehr unpaflend Knochen nennt. Bey denSepien ift dieler Körper dick, kalkartig, zerreiblich und befteht aus mehreren horizontalen Lagen, die wechlelsweile durch kleine hohle Säulen geftützt werden; man nennt ihn wei/ses Fifchbein, in Holland Meefrchaum. Bey den Kalmars im Gegentheil ift dieler Körper dünn, knorplich, durchfichtig, lang und in die Queere gebogen. Ueberdem erftreckt fich bey der erften Gattung die Flofle um die ganze Länge des Mantels; bey der zweyten nur um das Untertheil.

3. Der Argonaute (Argonautus) würde eine Sepie oder ein Kalmar leyn, wenn die beyden Arıne, welche bey letzteren länger find, hier nicht, einen Theil ihrer Länge nach; in eine ovale Membran ausgedebnt wären; das Thier kann diele Haut willkührlich ausbreiten und zulammenrollen, und bedient fich derlelben als eines Seegels. Ueberdern kommt die Schaale in Anfchlag. Z. B. Nautilus papyraceus L.

4. Die Achifiufsler (octopus) z. B. fep. octopus L. haben, wie der Name angiebt nur 8 Füfse. Ihr Mantel hat keine Floffenhaut an der Seite. Einige Arten erreichen eine lehr beträchtliche Grölse; es giebt welche, deren Arme an drey Fufs lang find, was einen Umfang von wenigftens achitzebn Fuls vorausfeizt, indem alle diefe Tentakeln einann der gleich und in die Runde angebracht find.

5. Der Nautilus (nautarius) hat eine den Sepien äbnliche Bilduńg, aber der Körper fitzt in einer mit Abtheilungen verlehenen, fpiralförnig urn fich felbft gewundenen Schaale- Die Rückenhaut verlängert fich hinter dem Kopfe in eine Art von Kappe die dem Thier als Seegel dient, und um den Mund firzen mehrere conzentrifche Kreife von vielen kurzen, an den Rändern gezackten Tentakeln. Z. B. Nautilus pompileus L.

6. Die Spirularier ('pirularius) fehen im Kleinen den Sepien und Kalmars ähnlich. Die Haut ihres Körpers aber endigt fich hinten mit $z$ wey Lappen, welche zum Theil sino kleine vielkammerige Schaale beaecken. Zo B. Nautilus Ipirula I. 


\section{No. CI.}

\section{Ordnung̀. PTEROPODEN. *)}

Mollusken mit deutlichem Kopfe, ohne lange Ten takeln; der Körper frey, mit keinen anderen Gliedern, als eine oder zwey Floflen verfehen.

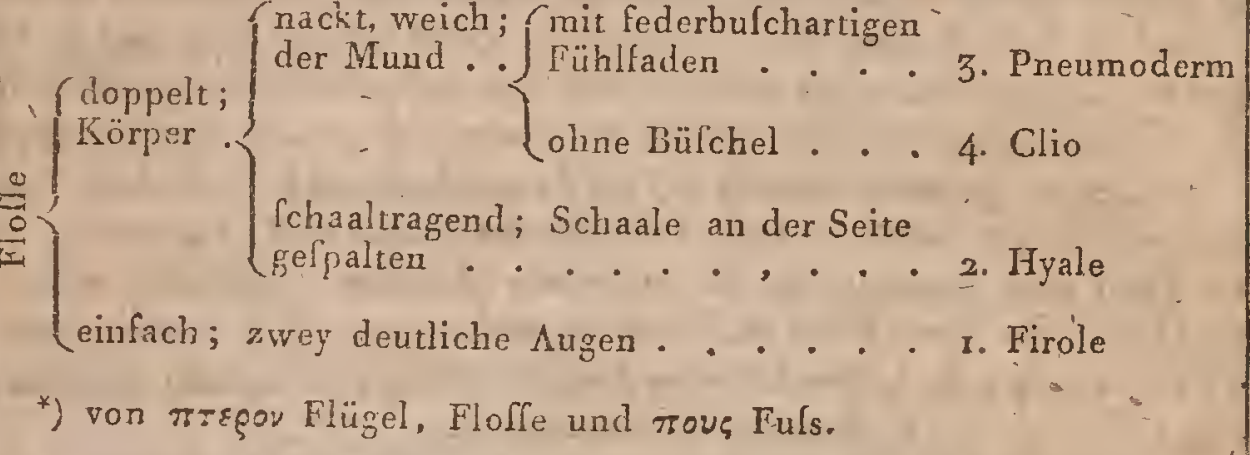

\section{BEMERKUNGEN ZUR CI. TABELLE.}

Die Ordnung der Ptèropoden (mollusca pteropoda, pinnata) ift erft ganz neuerdings von, $C$ u vier aufgeftellt (annales du Muf. d' hift. nat. No. XXI. p. 223.) um einige lonft zu den Acephalen gezählte Molluskengattungen dahin zin bringen.

Sie unterfcheiden lich a. von den Cephalopoden dadurch, dafs fie nic armförmige Tentakeln haben 2. von den Acephalen und Brachiopoden durch ihren allzeit deutlichen Kopf 3 . von den Galteropoden dadurch, dafs fie keine muskulüfe Bauchfcheiben haben. Sie zeigen einige Uebereinftimmung mit der erften Ordnung, vermöge des Körperbaues überhaupt, der mit Häuten oder Floflen an den Seiten verfehen ift, verm'ige eles deutlich getrennten Kopfes und der Lebensart.' Die 'erfte Gattung diefer Ordnung fcheint den Uebergang von der vorigen Ordnung abzugeben. Doch zeigten die bisher unterfuchten Individuen, wie die GaIteropoden, beyde Gefchlechter vereinigt, und batten in d’m Cirkulationslyfteme keine drey Herzen, wie das bey den Cephalopoden der Fall ift.

Von den zu disler Ordnung gezählten Arten baben einige den Körper durch eine kalkartige Scháale gefchützt, die anderen lind ganz nackt. 
1. Die Firolen (pterotrachea Forskael) find die einzigen Pteropoden mit ganz deutlichen Augen. Der Körper ilt weich, durchfichtig und mit einer einzigen in der Mitte oder am Ende. des Körpers fitzenden Flofle verfehen. Die zu diefer Gattung gerechneten Arten find nur von Forskael beobachtet, und waren im mitländifchen Meere gefilcht. Z. B. Pterotrach. coronata L.

2. Die attung Hyale (byalaea) enthäl die einzigen lchaaltragenden Arten diefer Órdiung. Der Kopt hat zwey Floffen zur Seite des Mundes und die Kiemen diefes Mollusks find innerhalb" einer von dem Mantel bedeckten Schaale enthalten, 'durch, deren Seitenlpalte das Wafler hineindringen kann. Z.B. clio pyramidata L.

3. Die Pneumodermen (Pneumoderma Cuvier) háben ihre Kiemen auIserhalb, unter der Haut des Hintertheiles ihres Körpers. Auf dem Kopfe fitzen zwey Bülchel kleiner. Tentakeln und an der Seit des Halles beob: achtet man zwey Kiemell. Hr. Peron hat dies Thierl in grolser Menge im Atlantifchen. Ocean gefunden. $Z$. B. Pneumoderma Cuvierii.

4. Die Clios (clio Brown) haben, als wefentlichen Charakter, die Kiemen an der Oberfläche der Floflen. Der Kopf ift von zwey Höckern gebildet, deren jeder ein Loch zeigt, aus welchen zwey kleine Tentakeln hervorkommen. Der" Mund ift eine einfache dreywinkliche Spalte zw:fchen den zwey Höckern, und ift mit zwey häutigen Lefzen verfeben. Die Arten diefer Gattung lind vorzüglich in dem nordifchen Meere gefunden und daleibft in 10 rolser Menge vorhanden, dals die Wallfifche fich hauptlächlich von ihnen nähren. z. B. clio borealis L.

Wahrfcheinlich werden in diefe Ordnung noch eine Menge anderer Thiere kommen, die die Naturforfcher bisher genau zu beobachren vernachläfigt haben. Cusiers Unterfuchungen und der Weg den er vorgezeichnet hat, verfprechen auch diefen Theil der Naturgefchichte vorwärts au bringen. 


\section{No. CII.}

\section{OrdNung. GASTEROPODEN. *)}

Mollusken mit deutlichem Kopfe; mit einer muskulölen Scheibe unter dem Bauche zur Fortbewe gung.

Familien.

Cäu「serlich, als Blätter oder Fadenbülchel

๕.) fichtbar .. . . . . . . - I. Dermobranchien

innerlich; die äuisere als eine Röhre . 3. Siphonobranchien

Refpirationsöffnung . lals ein einfaches

3. Adelobrarchien

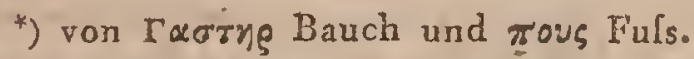

\section{BEMERKUNGEN ZUR CII. TABELLE.}

Die Gafteropoden (gafteropoda Cuvicr) find fehr leicht an dem, durch ihren Namen bezeichneten, Charakter zu erkennen," alle kriecher auf einer fleilchigen Scheibe, die unterhalb der Unterfeite ihres Körpers befindlich ift. Alle haben einen Kopf, der meiftens mit zurückziehbaren Tentakeln verfehen ift, die das Thier vorwärts ftreckt, wenn es fich bewegt; die Zahl diefer Fühlhörner, wenn lihrer, überhaupt vorhanden find, ift wenigftens zwey; die meiften von den aufserhalb dem Waffer am Ufer lebenden haben aber deren vier.

Die gröfte Zahl der hieher gehörigen Thiere hat den Körper von einet aus einem Stücke beltehenden Schaale bedeckt. Einige luaben deren mehrére mit einander artikulirende Stücke, kein einziges bieher gehöriges Thier aber hat zwey gleiche Schaalen. Sie können fich lo zufammen ziehen, dafs fie fich bis auf die Hälfte ihrer Länge verkürzen und auch um das doppelte verlängern.

Falt alle find Hermaphroditen; aber ihre Befruchtung kann nur als Folge einer Begattung ftatt finden, "wo jedes der zwey Individuen die Samenfeuchtigkeit dem, andern giebt und von dem andern orbält. 
Die Relpiration der Gafteropoden kann auf dreyerley verlchiedeneWei. fe ftart finden, die von dem Aufentbalte des Thieres abhängig ift. Die Verfchiedenheiten, welche Vie Rélpirationsorsane darbieten, fud hier benutat, um die Ordnung in drey Familien abzubeilen, die um fo natülicher zu Leyn Icheinen, da fie Thiere mit einander vereinigen, deren Form und Lebensart wirklich einander fehr gleichen.

I. Die Dermobranchien (demobranchiata) haben ihre Kiemen auIserhalb und, wie es der TYane angiebt, in derDicke cler Haut. Die meiften leben im Meere und bleiben beftändig unter lem Viller, wenn fiè zricht, wie dies bey einigen Gartungen der Fall ilt, clen Mantel mit einerFurche oder einer Schale verfehen haben, unter welcher lich erwas Wiffer anfammelt, was aufbewahrt und mit der Luft bewegt und.wie gefclrwangert wexden kann; un zur Refpiration zu dienen.

2. Die Adelobranchicn (adelobranchiata) müllers aber lämtlich die Luft. felhft athmen, welche durch eine Spalte oder Loch in eine Höhlekommt, auf deren grolser Oberläche die blutälnliche. Fenchrigkeit in zahtreichen Gefälsen fichverbreitet. Faft alle Arten leben auf dem Lande, an feuchton Oren oder in'fachen füfsen Gewäfern, kommen aber an die Oberflitche um zu athmen. Einige Gattungen bewohnen dié Meorufer.

3. Die Siphonobranchien (mbilpirantia) find aber genöthigt befän. dig im unl unter Waffer zu leben, wovon lie eine kleine Quantität mittels einer belondern Röhre abforbiren; "diefe Röhre macht gewöbnlich in der kalkartigen Hülle, wovon alle Arten umgeben find, "einen Canal oder eine Furche, woran man den Laulderfelben erkennen kann. Alie Arten "haben nur zwey. Tentakeln, auf' wolchen die Augen fitzen. Die meiften leben im Meere und haben den Körpervon einer felten Schaalc, deren Farben mannigfaltig abweclufeln, bedeckt. 


\section{NNo. CIIT.}

\section{TAMLIX. DEMORRANCHIEN: ")}

Mollusken, Gafteropoden; athmen durch äufserlidho, Lamellen-Faden- oder Büfchelförmigè, Kiemen.

GatTungen,

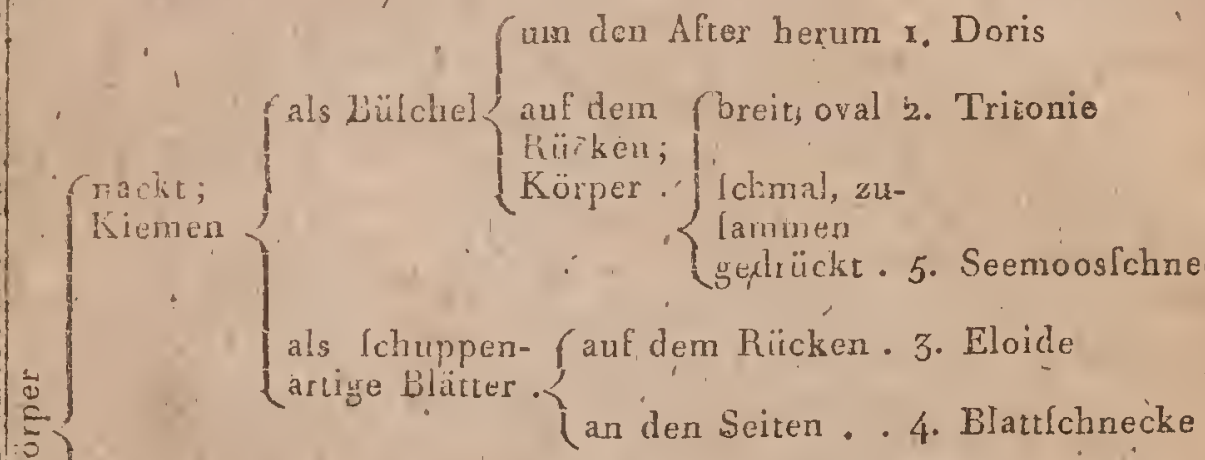

$$
\begin{aligned}
& \text { mit einer (aus einem einzi- }\left\{\begin{array}{l}
\text { mit zwey Ten- } \\
\text { takeln . . . Patelle }
\end{array}\right.
\end{aligned}
$$

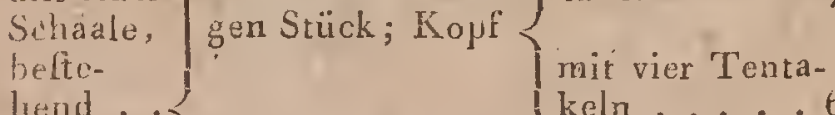

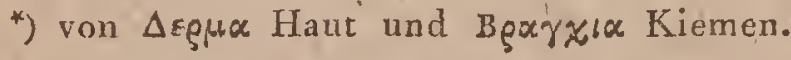

\section{BEMERKUNGEN ZUR CIII. TABELLE.}

Die, Gafteropoden welche zur Familie der Dermabranchien gehören, find meift ganz, nackt und leben ain Ufer des Neeres. Das Allgeninein über diefe Fainilie findet lich auf der roz Tabelle.

1. Die Doris (doris) hat den ganzen Körper von ihrem Mantel bedeckts der lich logar über den Kopf ausbreitet. Der After ift mit, von den Kiemen gebildeten, Bülcheln umgeben, wodurch fie den Holothurien ähnlick werden. Cuvier theilt 13 von ilm belchriebene Arten (Annales du Muf: d'hilt. nat. No 24.) a) in flache, mit ovalem, plattem Körper mit fternförmig litzenden Kiemen z. B. D. argo und b) in prismatilche oder dreyeckige, deren Kiemen einer Krone gleichen z.'B. D. lacera; alle haben den Mund rüluliornig, obne Zähne. 
2. Die Tritonien (tritonia) haben die Kiemen in zwey Reihen längs des Rückens fitzen. Ihre zwey Tentakeln Lehen Bülcheln oder ausgezackten Blättern'ähnlich und ihre Kinnladen fehen aus wie eine Schaaflcheere. Sie nähren fich vorzüglich von Meergras. Z. B. Doris clavigera L.

3. Die Eoliden (aèolidia) würden Tritonien levn, wenn die Kiemen nicht wie platte ziegelartig liegende Blätter oder wie über einander liegende Häute auslähen. Z B. Doris fasciculata, papillola.

4. Die Blattfchnecken, (Phyllidia Cury i r: Bullein des fcienc. No. 51) haben, wie die Napffchnecken, die (blattförmigen) Kiemen in einer Furche des Mantelrandes, aber fie háben keine Schaale; die einzige bekannte Art ift von isle de Reunion gekommen.

5. Die Scylläen, Seemosfchnecken (Scyllaea Linn.) haben einen langen dünnen zufammengedrückten oder zylindrilchen Körper. Dns Hintertheil der Körperhaut bildet eine Art von Cpitzem Schwanz und man firht auf ihrem Rücken drey Paar Kiemen. Die Scheibe unterhalb ihres Körpors zaigt immer eine Furche, womit fie aie Stiele der-Seegewächle umfaflen, von denen'fie fich näluren. Z. B. Scyll. margaritacea.

6. Die Organilation der Haliotiden, Seeohrfchnecken (haliotis) ilt Jehr wenig bekannt. Man weils blols, dals lie-vier Tentakeln haḅen, wovon die beyden kürzeften an ihrer Spitze Augen tragen. Ihre Schale - ift platt mit fehr nierírigem Gewinde, auf dem linken Rande ift fie mit einer unbeflimmen $Z$ abl runder Löcher, in einer Reihe, verfehen. $O b$ die Faden, welche den Rand des Mantels einfaffen, Kiemen fiud, oder ob eine belondere Relpirationshöhle da ilt, ift noch nicht entfchieden. Deswegen ftehen fie hier noch unter den Adelobranchien. Z. B. haliotis tuberculara L.

7. Die Patellen, Napffchnecken (patellarius) haben eine aus einem. Stück beftehende, nicht gewundene, unten hohle Schale. Sie Laben nur zwey Fühlhörner, die die Augen, bey den wahrén Patellen, z. B. Patella vulgata L., auswärts, bey den von Geoffroy mit dem Namerl ancylus belegten Süfswafler-Patellen, z. B. patella lacusltris L., aber einwärts, an der Bafis tragen. Die Fiffurellen (fiflurella Brugieres) z. B. pat. puftulata L. haben den After an der durchlöcherten Spitze der Schaale. Die Emarginula $L$ a m arkz. B. patella fillura L. hat den Rand der Schaale mit einem Auslchnitt verfehen und die Spitze derfelben abwärts geneigt. Die auch von Lainark aufgeftellten Gathungen crepidnla $\mathrm{z}_{\text {. }} \mathbf{B}_{i}$ patella porcellana L. und calyptraea $z$. B. patella equeftris, haben in der Höhle "der Schale eine Scheidewand, die bey erlterer horizontal, bey den źweyten mehr vertikal ift.

8. Die Chitons Küferfchnecken (chiton) gleichen den Blattfchnecken, aber ihr Körper ift mit einer Reilıe kleiner, dachriegelartig liegtnder Schup pēn verfehen, die durch den lederartigen, (mit körnigen Hervorragurgenn ? Haaren oder Stachein befeizten) Rand des Mantels in ihrer Lage gehalien werden, Z. B. 'Chiton aculeatus $L$. 
Gafteropoden.

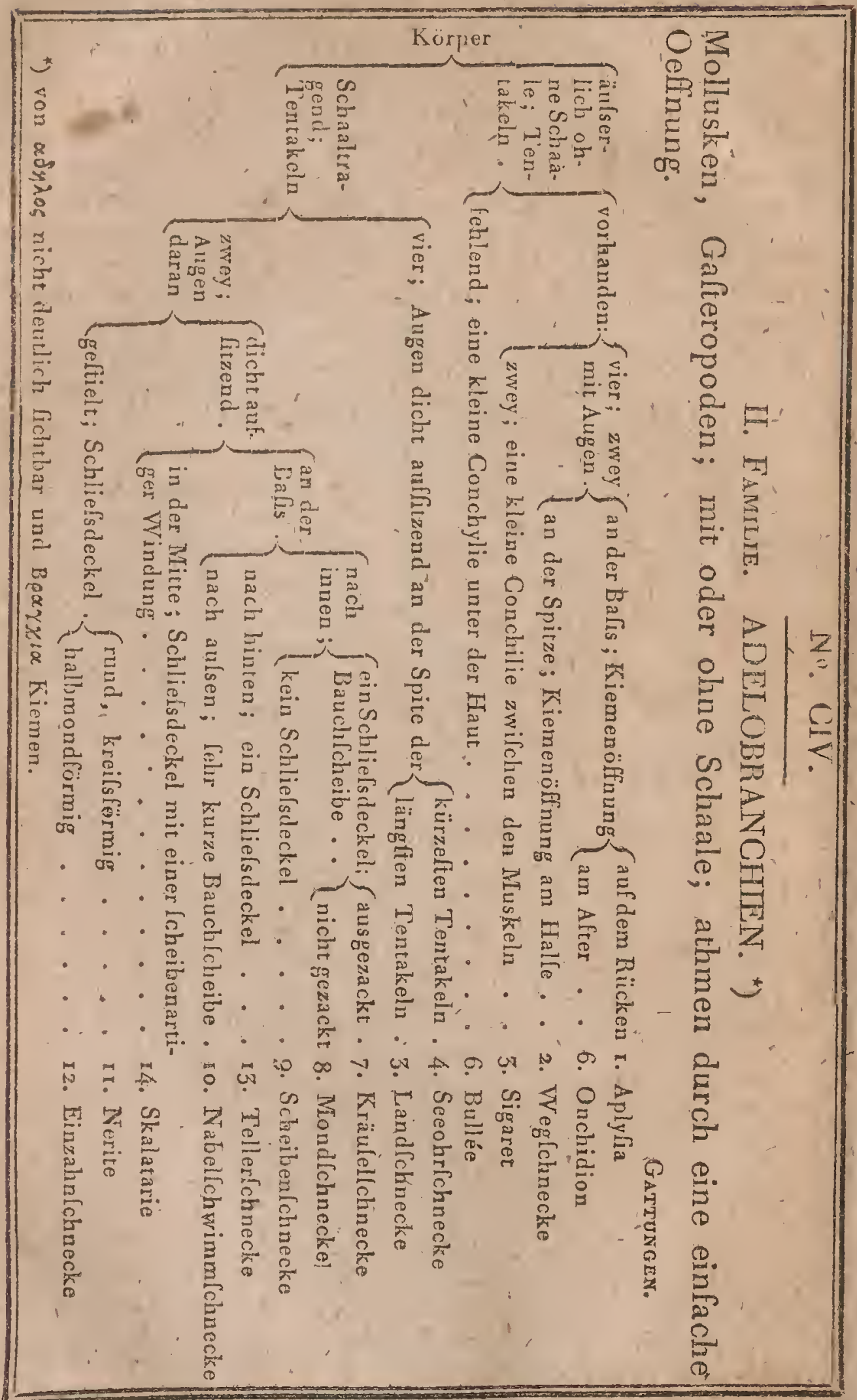




\section{BEMERKUNGEN ZÜR CIV. TABELLE.}

Das Allgemeine der Familie der Adelobranchien ilt p. 16r beygebxacht. Die Arten mit einem Mantel chue äulserlich fichtbare Schale, Icheiren fich-'den Dermobranchien zu nühern. x. Die Aplyfien (aplyfia fiondelet) z. B. apl. depilans L. haben in I inern des MTantels, uber den Kiemen, eine kleine hornartige Schaale verborgen. Der After ift oben am Ende des. Köspers. 2. u. 3.: Die W Werg/chneckeri. (limax) find meiftens Landthiere, haben auch eine kleine (lecterartige) Schaale unter dom logenannten Schilde ihres Mànels. Z. B. limax atex L. Ilire Organifation gleicht der der Landfchnecken (helix) deren Körper von einer fpiralartig gewundenen-Scbale, mit halbmondförmiger mehr breicer als langer Oeffnung, bedeckt ift. Z. B. belix pomatia L.; der Munc' beyder Gattungen ift mit einer halbmondformigen gezihnelten Kinnlade verfehen, womit fie die Blätter abreilsen. Der Af̌ter liezt neben der Kiemenöffnuug. Es gehören hieher auch die neugofuluffenen Gattungen, die Fleifchfreffende ieftacella Z.B. teft. europaea Draprirnaud; Iymnaca z. B. helix Itagnatis; bulimustz. B. helix denudatus L. u. ' . w. 4. Die Seeohrfchnecke fteht ichon als No. 6, auf der vorigen Tabelle. 5. Der Signret (figaretarius) trägt im Innern Ceines äufserlich glatcen Mantels eine kleine platte Schaale mir wenig erhabener Windung, die einigo Achnlichkeit mit dem Seeohr hat. (Vergleiche Bullet des Ccienc. No. 3r.) 6. Die Bulléen (bullearius) z. B. Bulla aperta L. kommen in der Organifation der Aplyfia nabe, Dè Magen ilt mickalkartigen Stücken beletzt, die man als belondere Schnecken (chaalen, z. B. die gioenia von Brugieres; anlah. 7. Die Kräufelfchnecken (trachiarius) baben einen rundlichen, irwendig convexen, und aufsen mit Cirkelftreifen vertetrenten Schliefsdeckel (operculum) Z. B. trochus magus L. 8, Die Mondfinnecken (Turbinaritrs) z. B. turbo littoreus L. und andere ihm ähnliche Thiere bildea Conchytien, wowon man dis Gattungen delphinula z. B. turba delphinus L. iurritclla z. B. turbo terebra L. folarium z. B. trochus perfpectivus. Pupa z. B. turbo uva u. I. w. gemacht hat. Sie leben am Uter des Meeres. 9. Die Scheilemfchnecken (planorbarius) unterfcheiden fich (die Schaale mberücklichtiget) von den vorigen nur durch den mangelnden Schlielsdeckel. Es find dies Flulsichnechen. Z B. helix cornea. 10.' Die Nabelfohwimmfchnecken (naticarius) haben einen zylindrifchen Ichmalen Kopfo 2. B. Nerita canrena L. Ir. u. r2. Die Neriten (Schwimmfohmecken) z. B. nerita fluviatilis L. und Einzahnfchnecten (Monodontarius) z. B. trochus pharaonius find a a der Tabelle charakterilirt. 13. 4. 14. Die Tale vearien (valvèarius) find Sülswaller-Mollusken. z. B. Valvatá criffata Muller. Die Skalatarien '(́calatarius) ż.B. turbo. clathrus L. haben'eine zungenförmige zurückzishbaretRöhre und find in: eine Schale eingefchloffen, deren runde Ränder nach aufsen aufgeworfen find und fo eine Reihe von Queerrippen bilden. 
Gafteropoden.

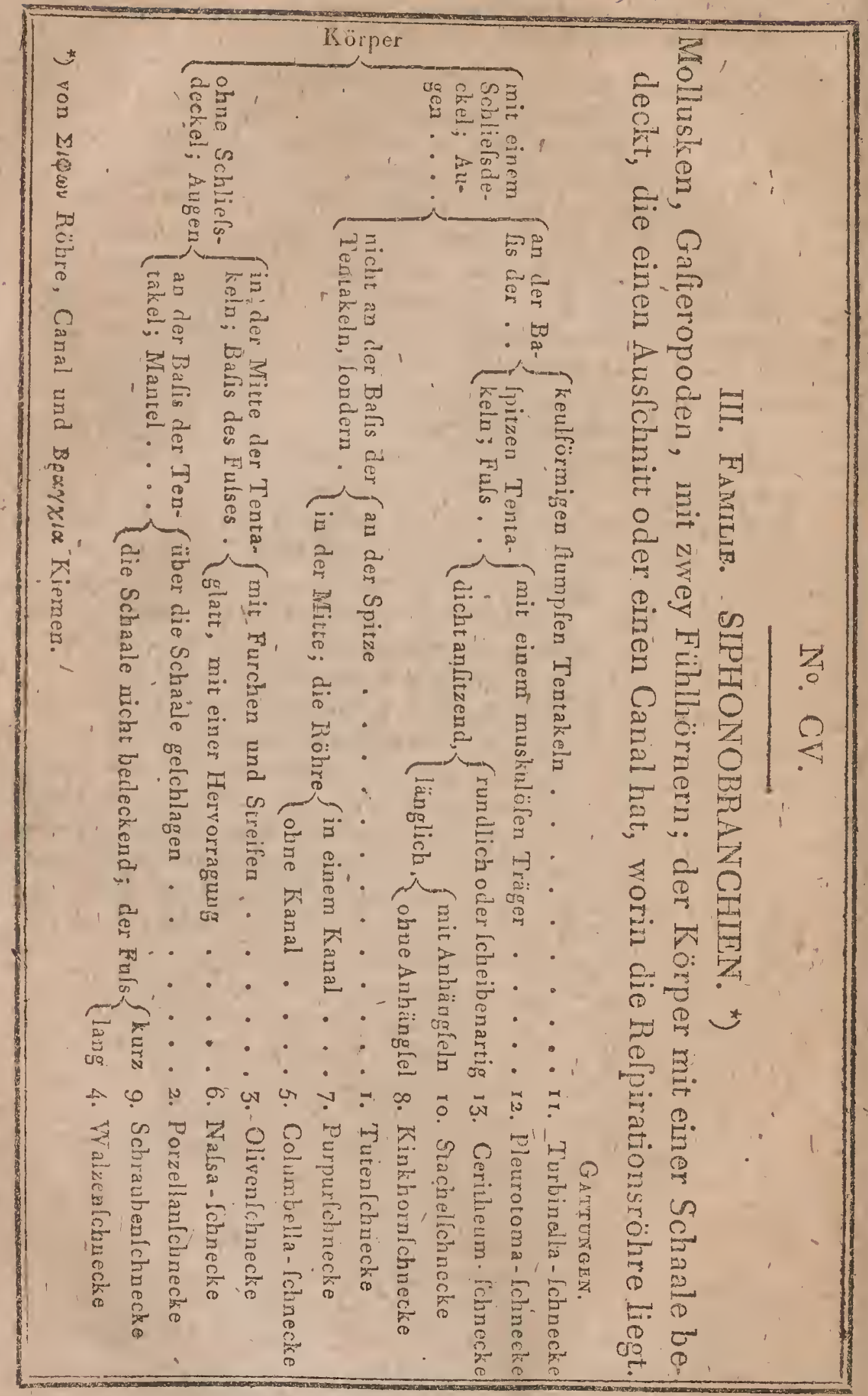




\section{BEMERKUNGEN ZUR CV. TABELLE.}

Alle zu der Familie der Siphonobranchien gebörenden Gafteropoden leben nur in der See. Allé find in eine Conchylie eingefchloffen, deren Oeffnung, der logenanute Mund, mit einem Auslchinitt oder einem Kanal zur Aufnalıme der Relpirationsröbre verleben ift. I. Die, in den unter dem Namen conus bekannten Conchilien lebenden, Tuten/chnecken (conarius) habon aulser der auf der Tabelle angegebenen Charakterifik eimen fchmalen Fufs mit einem kleinen oft bicgfamen Schlielsdeckel. Z. B. conus marmoreus L. 2. Die Porzellanfchnecken (cypraearius) bilden die Gehäule, welche man unter dem Namen Cypraea aufbwahrt, deren Oberfäche inmer von dem. Thiere dalusch glatt: erhalten wird, dafs es fie ganz mit den zwey Lappen feines. Mantels einhüllt. Z. B. cypraea arous L. 3. u. 4. Die Olivenfchnecken (olivarius) z B. voluta oliva und die Watzenfchnecker (volutarius) \& B. Voluta mufica I. haben Gehaule, die einander in einer Rückficht ähnlich find, dafs fie nemlich ron keinen Obertsäuchen bedeckt find. Alle Arten dieler Gatmog finct nur in den Meeren heifser Zonen zu Hanle. 5. Dié vón La mark aufreltelicon Gattungen Columbella z. B. voluta mercatoria L. und Marginelle z. B. voluta glabella $L$. find lange Zeit bey den Wralzenlchnecken aufyefinht, wegen mebrerer den 'Thieren' und den Gehäulen zukomnenden Wigenheiten. 6. Die Naffafchnccke (nalfarius) bewirken durch dic bervolragende Bafis ilures um die Spindel des Geläules bewegten Fulses. eine Vertiefung, der der Hauptcharatser der Schale ift. Der breite Fuls ilt vorn wie geftutzt, ragt aber weiter als der Kopf hervor. Z. B.,

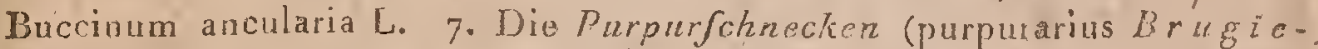
res) haben eines kleinén runden Kopf; ihre Augen fitzen lall auf der äulserften Spitze der langen Tentakeln. Der Fuls ift kurz, trefurcht oder geftreif. Hier Lcheinen getrennte Gefchlechter vorhanden zu feyn. Z. B. huccinum perficum L. S. und 9. Die Kinkhornfchnecken buccinarius) z. B Buccin. undatum, haben den Kopflang, mit Ausfclinitten verfeben, fehr lange Tentakeln, und die Rölire noch weiter als diele rorragend. Die Schraubenfchnecken (terebraius) z. B. Buccinum maculatum. haben zwar faft diefelbe Geftalt, aher das Gebäufe und dic Organilation ift doch fohr abweichend. 10. Die Stachelfchrecken (muricarins) murex brandaris, haben viel Aebnlichkeit mit den Mollysken, deren Schate die Conchylinlogen unter harpa, Dolizm, crlfis zularimengeftellt haben. I. und Is. Die Turbinellafoluecken (subinellarius) z. B. Voluta pyrum L. und die Plezrolomafirneckén (plourotomarius) z. B. Murex babylonius L. haben falt ähuliche Schalen; aber ihre Orgarilation unterlcheidet fie. 
Acephalen.

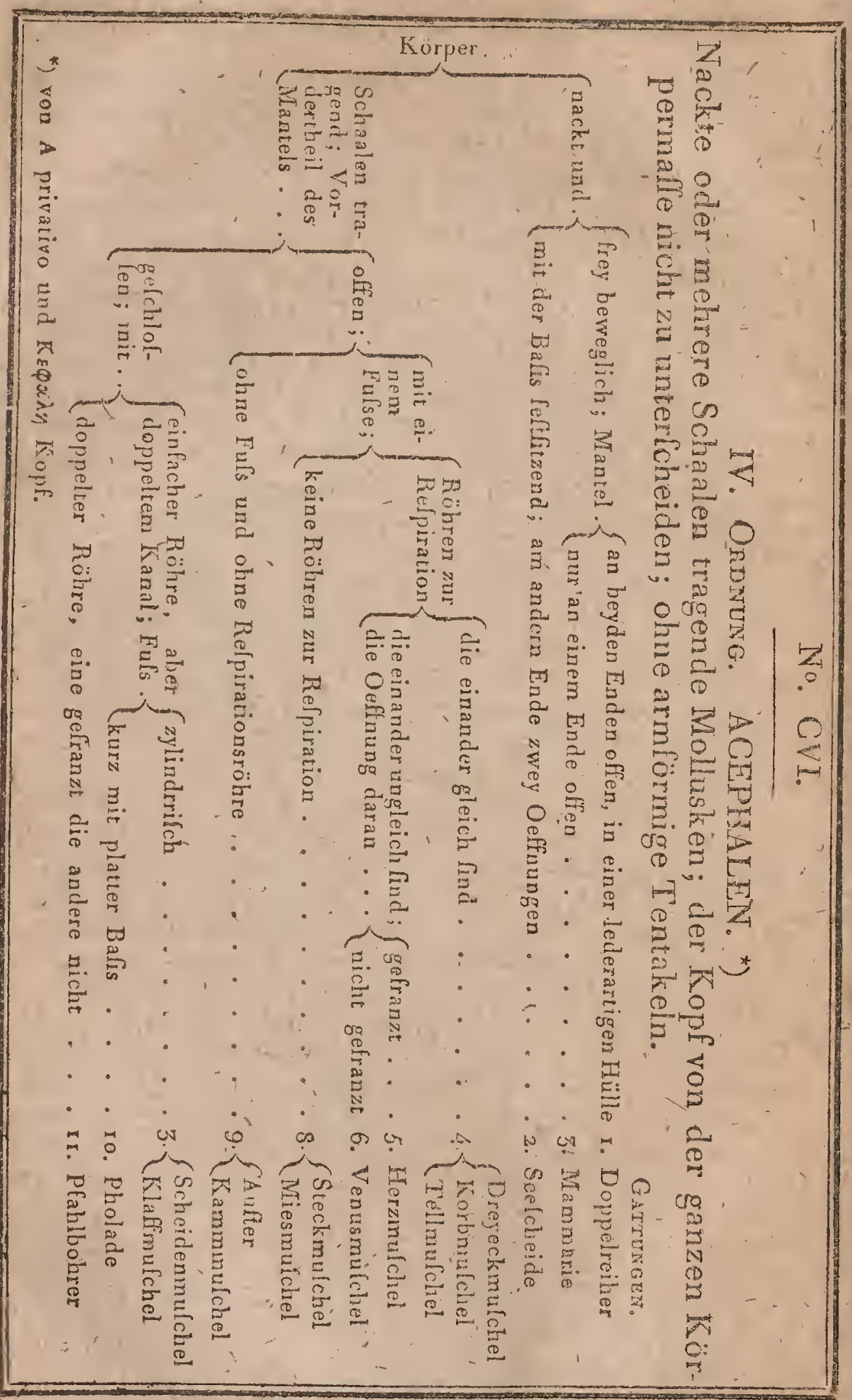




\section{BEMERKUNGEN ZUR CVI. TABELLE.}

Die zil den Acephalen, kopflofen Mollusken, (aceplata $C$ uvier) gezählien Thiere find im Ganzen nur noch lehr wenig unterlucht. Cuvier und Poli fip̧d die einzigen Naturforleher, die Cirs für die Kenntnifs der die zweylchaaligen Conchylien bewohnenden Thiere intereffirt haben. x. Die Doppelreiker (lalpa Forskael, thalia Brotvn; Annales du Múleum d'bift. nat. No. 23.) find erft durch die Unterfuchungen'. welche Cuvier an fechs Arten angeftellt hat, genauer bekannt. Z. B. Salpa criftata Cuv. 2. Die Seefcheiden (ascidia) find in eine Art hornartiger ŝcheide eingefchlollen, die auf dem Boden des Meeres fefifitzt. Z. B. ascidia intelitiralis. 3. Die Manmarien (mammaria) find noch wenig bekannt, fie háben ei en kugelförmigen Körper. Z B. mammaria mammilla L, 4. Die, Mollusken, welche die unter dem Gattungs - Namen donax z.B. don. ru-1 gola L., meretrix z. B. Venus mexètrix, tellina z. B. Tell. radiata mactra z. B. mactr. ftultorum u. โ. w. bekannten Conchylien bewohnen, fcheinen untereinander lehr viel ähnliches zu haben. 5. Und die in den Conchylien cardium z. B. card, edule, ifócardium z. B. chama cor $\mathrm{h}$. und cardita befindlichen Thiere find taft in derntelben Falle. 6. Die Venusmufcheln (venufarius) unterfcheiden fich von den übrigen No. 4 auf der Tabelle angeführten Gattungen riur durch die errährue Eigenheit. der Organifation. "Z. B. venus verrucola. Die hler erwähnten Thiere leben gewöhnlich unter dem Sande oder Schlamme. Zuweilen kommen fie an die Oberläche des Wafters, wo fie auf der einen Valvel fchwimmen, wahrend ihnen die andere als Seegel dient. (?) 7. Die SchcidennulScheln (folenarius), die dic Logenannten Mefferfcheirlon zu Schaalen haben, gleichen den Ascidièn; fie halten fich im Sande auf, wo fie vertikale Lücher haben, aus denen fie fetır felten herauskommen. Z. B. Sólen vagina Die Klaffmufcheln (niyarius) z. 3. mya truncata, unterlcheiden lich blols durch die Form der Schaale g. Die Schinkenmufoheln (pinnarius) z. B. pinna rudis und die Miesmufcheln (mytilarias) z. B. mytilus edulis L. find immer durch einen von dem Thier gefponnenen Seidenbülchel (byffus) an den Fellen befeftiget. Diele Mollusken find Hermaphroditen und itre Eyer entwickeln lich in ibrem Körper. Von einer Art Miesmulchel (mytilus marğaritiferus L.), kommen die Perlen. 9. Die Aufterń (oliracarius und Kammmufcheln haben einen gefranzten Mántel welcher dio blätterartig übereinander liegenden Kiemen bedeckt. Sie haben anch ùm ihren Mund vier häutige Lappen. Thre Jingen komnen ganzausgebildet und mit den Schaalen zur Welt. ro. Die Pholaden, die die Schaalengattung Pholas bewohnen, und die man gewohntich im Innern der von ibnen ausgebohlten Kalkfelfentindet, haben wie die Scheidenmu. fcheln den Mantel gefchloflen. Z. B. pholas dactyla L. II. Die P far bohrer (teredo) haben auch den Körper ganz von einer Röhre eingelchlolJen, die von dem Mantel gebildet ift. Sie durrhbohren gewöhnlich das Hola mittels ein paar kleiner Schaalen, die die Stelle von Feilen verfehen. Z, R. teredo savalis $L$. 


\section{No. GVII.}

\section{Ordnung. BRACHIOPODEN'. *)}

Schaalentragende, Kopflofe Mollusken, mit gefranzten, in das Innere der feftfitzenden Conchylie zurückziehbaren, Tentakeln.

Gattunenan.

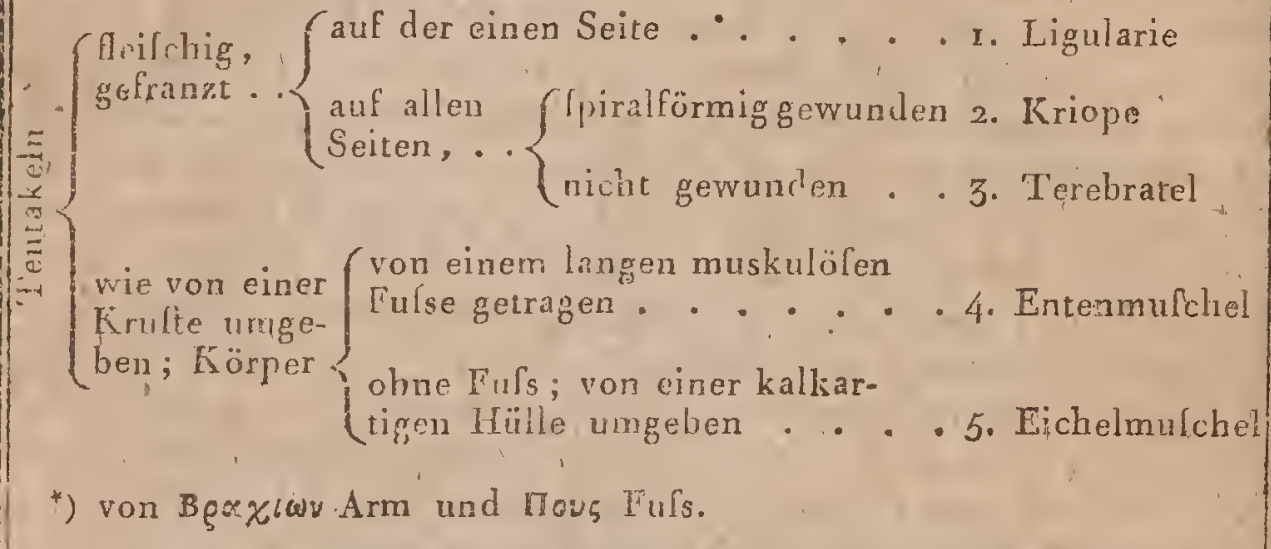

BEMERKUNGEN ZUR CVII. TABELLE.

Die Brachiopoden, Armfülster, (Mollusca Brachiopoda) haben durch die in der Nachhatchaft des Mundes fuzenden Tentakeln einige Aehulichkeit mit den Cephalopoden; aher fie unterfcheiden fich durch den gänzlichen Mangel eines Kopfes und folglich auch durch den Mangel der Augen und andèrér mit jenem Theil verbundéner Organe. Sie hahen auch etwas Aehnliches von den Acephalen und felbft von den Krultazeen, den rückgrathlolen Thieren' der folgenden Klaffe. - Es gehört in diefe Ordnung nur eine kleine Anzahl Thiere und alle diefe haben den Kürper von. mehr odur weniger zahlreichen, kalkartigen Schaalenftücken bedeckt und. immer au felte Gegenftäride belefingt.

x. Cuvier iit der einzige Naturforlcher, der die Orgunifation des Thieres der lingula belchrieben hat, oblchon Seba es in leinem TheSaurus á. I. w. abbildete. Dás Mollusk trägt zwey Schaalen am Ende einer langen Röhre. Die Tentakeln welche fich in die Schalen zurückbiegen können, lind etwa um ein drittel längूer. Z. B. Patella unguis L.

2. Das Thier der orbicula (orbicularius) ift, noch wenig bekannt. Po fi bat es unter dem Namen Kriope und Muller als patella anoinala 
befchrieben. Nach dielen Befchreibungen und Abbildungen gehört das Thier in die gegenwärtige Ordnung. Der Körper if röthlich mit zwey blauen, gelbgefranzien Tentakeln. Vou den Schalen ift die eíne gewölbt die andere platt und diefe immer auf einen felten Körper fitzend.

3. Die Terebrateln (terebratularius) find nur durch Befchreibungen bekannt; fie fehen den Lingularien ähnlich, haben zwey Arme die länger find als der. Körper, womit fie lich bey fillem Wetter an die Oberfläche des Waflérs heben. Sie lïhren den Namen Terebrateln, weil die grölste ihrer Valveln an der vorftehenden umgebogenen Spize durchlöcliert ift.

4. Dio' Entenmufcheln (anatifarius) bilden mit der folgenden Gattung' den natürlichen Uebergang von den Mollusken zu den Kruftazeen, und befonders zu den logenannten Einaugen; die, aus füıf oder fechs Hauptfchaalenftücken zufammengefetzte, Conclyylie fitzt am Ende einer Reilchigen Röhre, die an unter der Oberfäclie des'Waffers befindlichen Körpern fefthängt. Der mit der Bafis an der Röhre' feftitzende Körper hat dafelbft auch die vorwärts gerichtete Mundöffnung, und oben find auf jeder Seite fünf Höcker, deren jeder doppelte Tèntakeln trägt, welche aus fehr vielen kleinen feften, wie gegliederten, gefranzten, heweglichen Stückchen zulammengeletzt find; Sie billen zufammen zwey gefärbte, bewegliche, vorwärts gerichtete Bülchel. Die Kiemen fitzen an der Bafis der Tentakeln und können folglich wie diele in die Schialen zurückgezogen werden; hieher gehört die der Aehulichkeit vegen fogenannte Fuiszehe. anatifa pollicipes $L$.

5. Die Eichelmufcheln (balanarius) gleichen den Enteumufcheln, haben aber keine Röhre; fie befeltigen fich of: an Wallfiche, deren lateinifcher Name auf fie übergetragen zu feyn f'cheint. Die Geftalt ihrer Schaale variirt fehr; deswegen hat man die Gattungen noch befonders in: tubicinella, coronula und balanus abgetheilt, wovon befonders die zweyte Gattung nach $D$ ufresne's Beobachtungen in der Haut der Cetazeen leben foll.

Obgleich die meiftęn Naturforfcher die Conchylien befchrieben und fie in gewifle Gattungen gebracht haben; fo fcheint es doch nicht als, wena man fchon im Stande wäro, aus der Form der Schaale Folgerungen auf die Form der Thiere zu uachen. Dies ift die Urfache warum fie in diefe' analytifche Zoologie, wo blols die organifirten Wefen nicht aber iltre Ueberbleibfel beirachtet werden, nicht aufgenommen find.

Ende der Klaffe der Mollusken. 


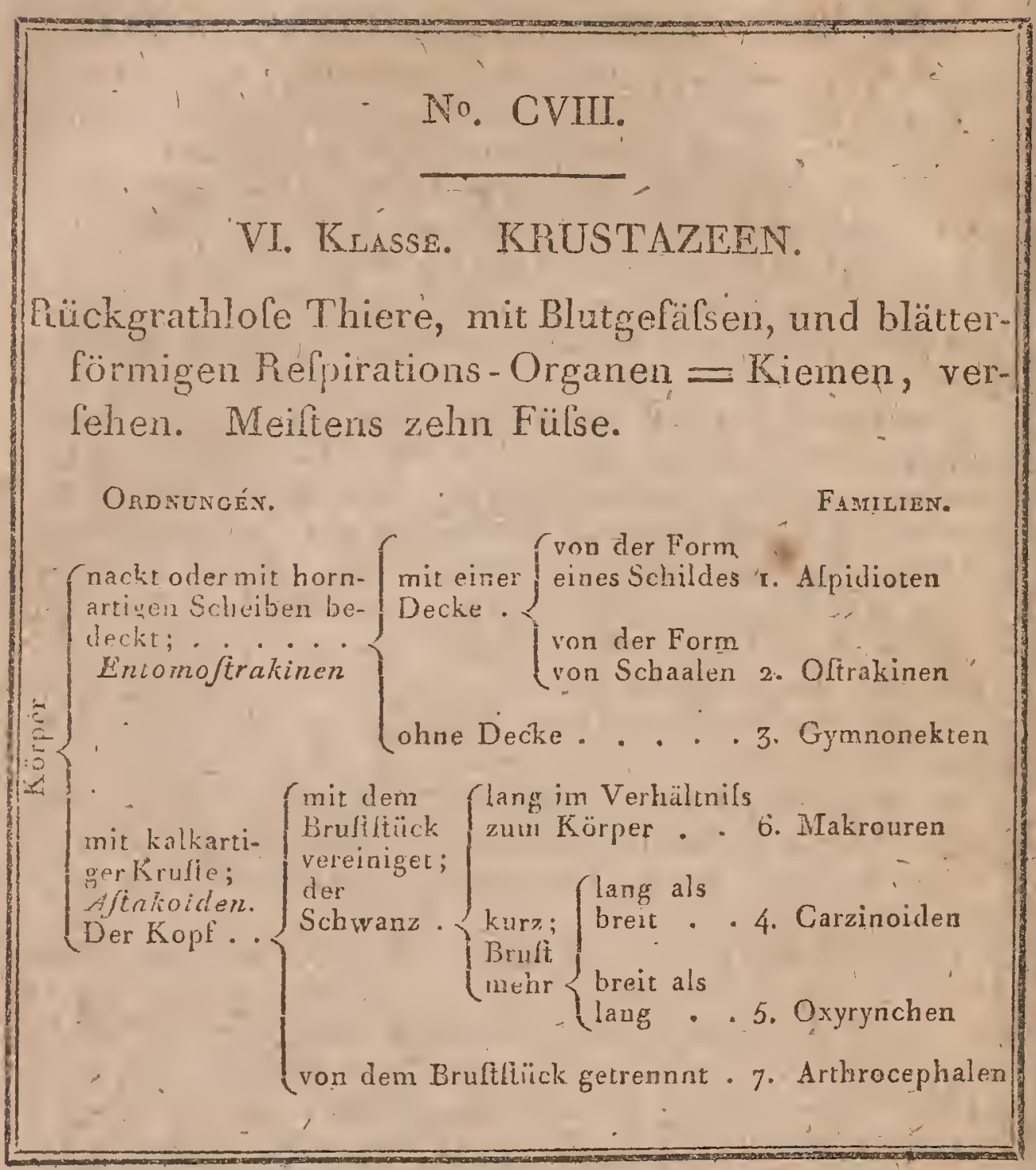

\section{BEMERKUNGEN ZUR CVII. TABELLE.}

Die zu dieler Klaffe gehörigen Thiere haben den etwas unbeltimmten Namen Krajtazeen. Krullenthiere, (cruftacea) erhalien, weil diemeiften oder vielmehr diejenigen von ihnen, welche zuerft bekannt geworden lind, den Körper und meift auch die Gliedermit eines kalkartigen Krulte be kleidet haben, die fie jährlich ablegen. Sie unterfcheiden fich von allen rükgrath ofen Thierendurch fehr viele Eigenbeiten, wovon die wichtigften fchion in des Generaltabelle der Abtheilung der Thiere angegeben find. Hier werden nur diejenigen angefüht, wodurch man diefe Thiere von den Mollusken und Inlekten unterlcheiden kann, mit denen fie-fonlt. durch einige Gattungen ganz natürlich verbunden zu feyn Icheiren. 
Die Infekten haben in ihrem vollkommnen Zuftande niemals Kiemen und alle haben alsdana, mit Ausnahme einiger fligellolen, -mir lechs gegliederte Fülse. Aber die Afleln fcheineu den natürlichen Uebergang von einer Klaffe zur andern zu machen. Die Mollusken find beynahe in demfelben Falle. Die meiften, (mit Ausnahme der Brachiopoden, die die lerzte Familie bilden) haben keine gegliederten Ful'se. Auch hat de Lamark ganz neuedings geglaubt, die Balanen zu den Kruftazeen zählen zu müllen.

Befonders aber fieht man die Nothwendigkeit ein, die Krultazeen als eine befondere Klaffe aufzuführen, wenn man, aufser clem über de: Tabelle angefïhrten, noch folgendes beherziget.

Die Krultazeen haben im Ganzen genommen vier Antennen, youd den Mund mit vialen; einander bedeckend augebrachiten, Kinnladen verSohen, welche fih horizontal gegoncinander betwegen und deren jede an ihrer nicht fchneidenden Seve eine Frelsfuicze, trägr. Die Mandibeln.lelhft tragen in der ainen ganzen Ordnung émen gegliederten Faden eine wahre Frelslpitze, deren Theile in Zahl, Gefialt und Lage variiren. Die meifien haben den Kopf mit dem Bruftilicke vereinigt, zwey dicht auffitzende oder geftichte Augen; und ihre Fül'se, die oft den Kiemen entprechen, find wenigftens zehn an der Zahl.

Die innere Organifation lbezeichnet, auf eine noch beftimmtere WeiLe, die wahre Klafle diefer Thiere. Da lie Kiemen haben, fo'muf́ste iir Blut nothwendig in Kanälen fortbeweyt werden: deswegen baben fie Herz und Gefülse, was mán xicht in den Infekten findet, wo die Lult durch belondere liöhrew - Tracheen, - injon Körper dringt, die man bey den 'Kruftazeen nie findet. - Eben lo ift das Nervenlyllem, was hey den Mollusken eiufach if und kein Ganglion als in einer géwiflen Entfernung von dem Gehirn zeigt', bey den Kruftazeen knotig, d. h. die beyden. Fáden, wẹlche den Schlund uageben, vereinigen fich gleich von neuem, um ein Ganglion zu bilden, von wo viele Fäden ausgehen, deren zwey gröfste. fich (immer wieder) in ciniger Entfernung vereinigen; hieraus entfteht eine Reihe von 8 - iq. Nervenknoten, die in dem Unterleibe fortläuft.

Auch die Begattung der Kruftazeen bietet Conderbare Eigenheiten dar, die in der Tolgè erwähnt werden follen; die Weibchen tragen gewöhnlich ihre Eyer als ein Paquet uater den Scbwanze oder in der Nachbar¿chaft. 


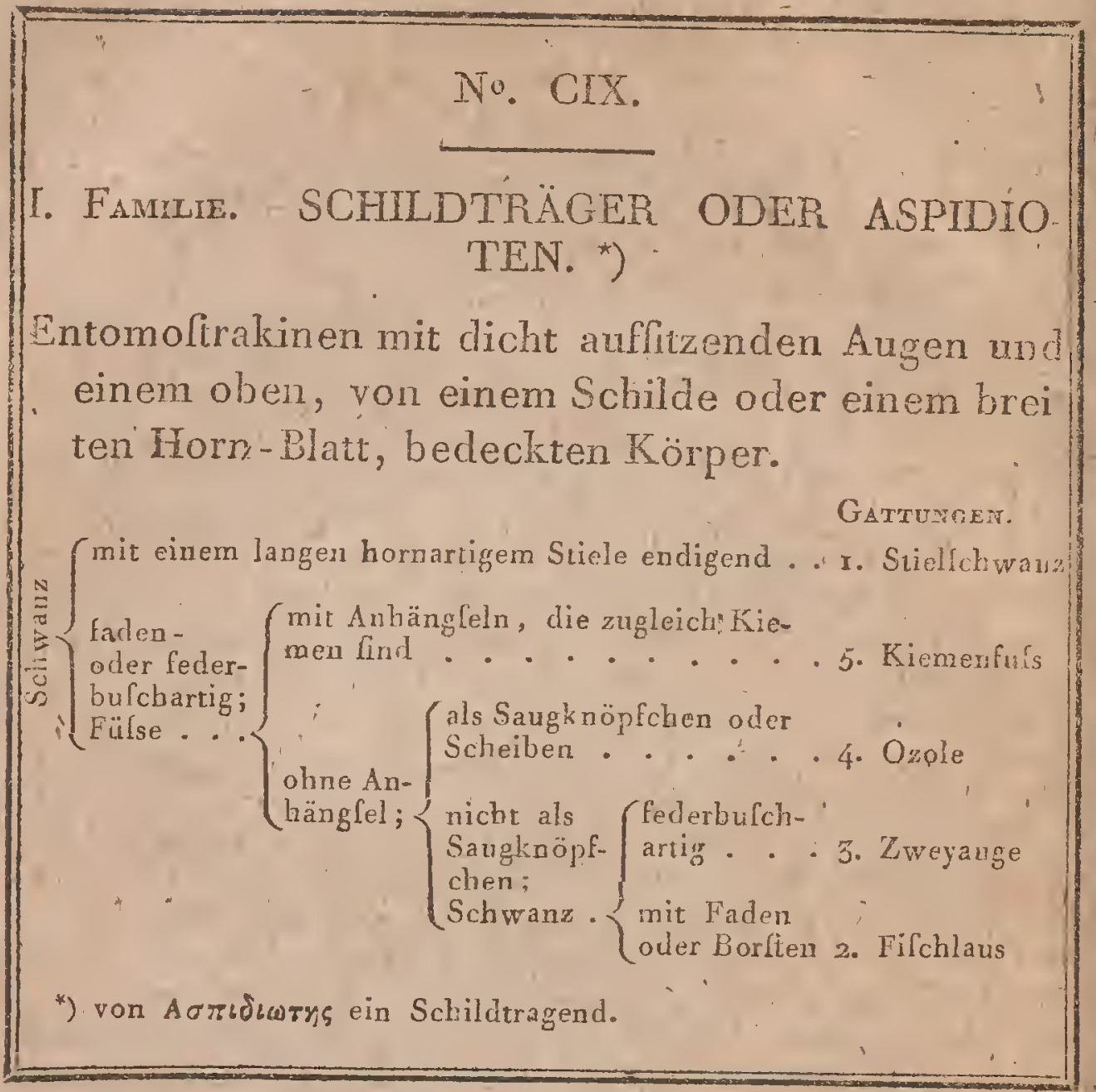

\section{BEMERKUNGEN ZUR CIX. TABELLE.}

Die drey erften Familien der Thiere der gegenwärtigen Klafle, find noch befonders Entomoftrakineiz genanint, d. h. Infekten mit Schalen. Sie kommen einander wirklich in verfchiedenen Punkten ihręr Organifation fehr nahe. So ift z. B. ihr Körper niemals ganz von kalkartigen Kruften bedeckt. Wenn dergleichen vorlanden find, fo find es mebr bieglamo hornartige Platten, als eigne Hüllen für allè Glieder. Meiltens find die Antermen in Floffen verwandelt; iht Mund hat wie einen fo zufammengefetzten Käu-Apparat als bey den Altakoiden. Sie haben nie mehr als zwey Kinnladen und ihre Mandibeln, wenn fie vorhanden find, tragen nie Frefsfpitzen. Ihre Augen' find meiltens dicht auffitzend, klein und oft in eine einzige Scheibe vereinigt; diefer Eigentbümlichkeiten wegen hat man fie auch wohl Sufflioculata genannt; Ibre Füfse endigen nur felten in Zangen oder Klauen und viele diefer Thiere find nur unter dem Mikroskope zu unterfuchen. Alle leben in Waffer. 


\section{Entomoftrakinen.}

Bey den Aspidioten 'indet man die a]lergrörsten Arten. Thre Lebensart iftenoch wenig bekannt. Einige leben al's Schmarotzer auf anderen Thieren. Andere Ichwimmen trey im Meere oder fülsén VValfer.

"r. Die Stielfchwänze (limulus Fabr.) fund lehr grofse' in den indiSchen und-amerikanifchen Meeren lebende Arten. Ihr Köper ift von eiriem grolsen hornartigen, aus zwey Stücken zufammen geletzten, Schilde bedeckt, welches in einen langen Anhang endigr, der von derfelben Belchaffenheit, aberbeweglich und artikulirt ift. Das Thier hat keine Antennen; feine Augen find klein und wie viereckig, z. B. Monoculus polyphemus L.

Die Fifchlürse (calygus Mïller) find Schmarotzer, dic man norh nirgends als auf Fifchen beobachtet hat. Sie haben mit den Stielfchwänzen einiges die Körperform überhaupt betreffendes gemein; aber iL'r Mund ift etwas fchrabelfömig; ihr Schwanziendiget, wenigltens bey einem von beyden Gefchlechtern, in zwey fehr lange Farten, z. B. Monoc. pisicinus L.

3. Die Zweyaugen (Binoculus Geoffroy) Lind, auch Schmarotzer Thiere. Man hat fie bey mehrern in Flïflen lwenden Bauchloflern gefunden. Sie halpen ihr Schild aus einem einzigen Stück beftehend und die Röhrer ilires Schwanzes mit Büfcheln befetzl. Auch hat fie Geoffroy Binocle $a$ quelle en plumet genannt, z. B. Monoc. argul. Fabr.

4. Die Ozolen (ozolus Latreille) unterfeheiden fich von den Zweyaugen nur durch die Sangiknöpfe, an der Bafis der Fühlhörner oder der vorderen Fülse. Es ilt dies dalfelhe Thier, was Geoffroy Binocle de lepinoche genannt hat, ozolus galterollei L a ireille.

5. Die Kiemenfülse (apus Frifch) lind Sülswalferkrultazeen, die man in Sümpfen leicht beobachten kann. Ihre Fïlse lind kiemenartige Organe, die die Thiere befïndig bewegen um das Wafler durcliaufiebea, und um diekleinen Thierchen zu bekommen wovan lie fich nähren. Ihr Schwanz iff weich, aber mit horbartigen diunen, artikulirende Kreifera verfehen und bildet eine Art ron 'Kegel welcher in zwey Faden endiger, 3. B. monoculus apus Lo. 
No. CX.

II. Famile. ZWEYSCFAALEN ODER OSTRAKINEN. *)

Entomofirakinen mit dicht auffitzènden Augen; der Körper von zwey kalkartigen oder hornartigen, conchilienförmigen, Schaalen bedeckt.

Gatumaen.

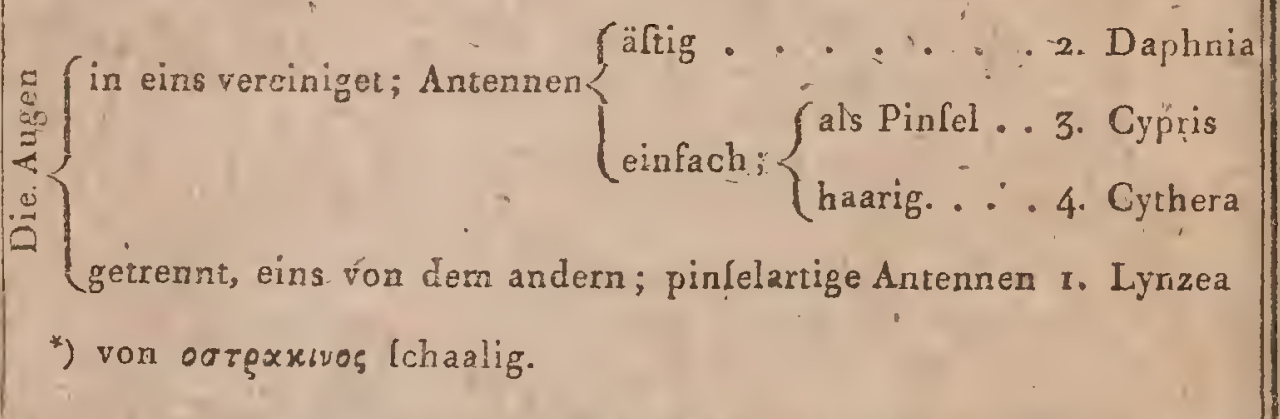

\section{No. CXI.}

III. FAMILIE. NACKT - SCHWIMMER ODER GTMNONECTEN. *)

Entomoftrakinen, deren ganz nackter Körper deutliche. Artikulationen zeigt.

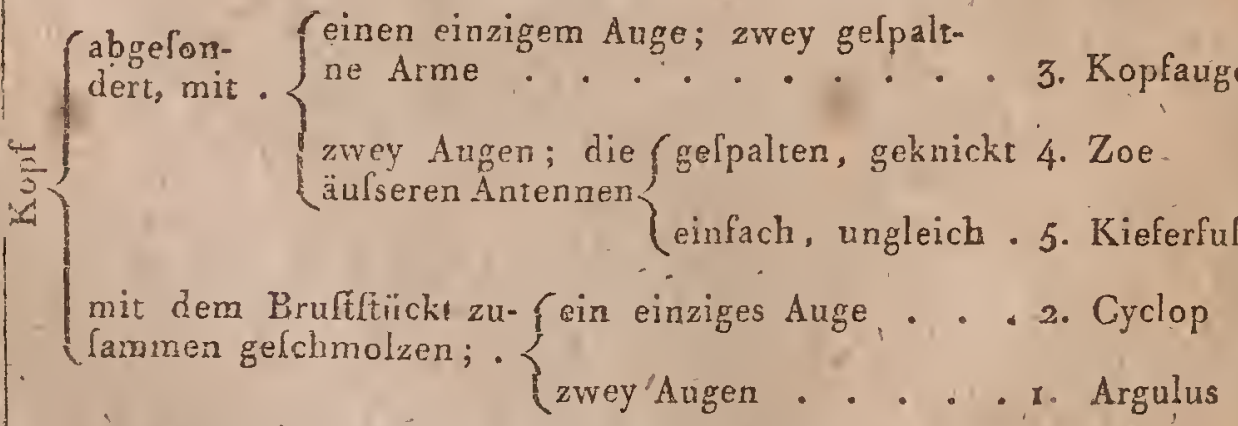

*) von Tuнros nackt, blols und Nyุxtos Schwimmer. 


\section{BEMERKUNGEN ZUR CX. TABELLE.}

Diejenigen Krulłazeen, deren Körper, wie die Kopflofen Mollusken, zwilchen zwey Schaalen eingelihloflen ift, haben den Namen Oftrakinen (oftracoda Latr.) erhalten. Es ift dies ih- Hauptcharakter; wobey aber die Formen fels modifizirt werden. x. Die Haupteigenheit der Lynzéen (lyncaeus $M \ddot{a} l l$ er) liegt in den auf einem fchnabelförmigen Kopfe fitzenden getrennten Augen. Ihre vier Antennen fcheinen nur zum Schwimmen tauglich zu feyn. Sie find in fillftehendem Waller lehr häufg. Z. B. Nonoculus brachyurus Fabr. 2. Die Daphnien (Daphnia M ï Li er) haben nur ein Auge und zwey Antennen. IhreSchaden fcheinen an der RückenCeite verwachfen zu leyn. DieAntennen oder Anhänglel, welche aus dem. Vordertheil hervorkommen, dienen vorzüglich zur Bewegung des Schwimmens; eben lo auch der Schwanz am entgegengefetzten Ende, der in zwey lange feifeSpitzen übergeht, zwilchen welchen man den Aftor lieht. Z.B. Mónoculus pulex L. 3. Die Cypris (cypris Müller) haben eine aus zwey artikulierenden Klappen beftehende Schale, aus welcherfievier Fülse, einen Schwanz und zwey Anhänglel vorftrecken, die man Antennen nennt, und deren fie lich-als Ruder zum Scbwimmen bedienen. Sie leben in ltebendem Wafler. Z. B. Monoc. conchaceus I. 4. Die Cytheren (cythere Müller) gleichen den Ar:en der vorigen Gattung felur; aber man hat fie nur in lalzigem Waller gefunden. Sie haben keinen Schwanz, aber ächt Füse. 2. B. Monoc. viridis Fa $L$ r.

\section{BEMERKUNGEN ZUR CXI. TABELLE.}

Dié Arten von Entomoftrakinen, welrhe gar keine Schaale haben, die Gymnoncklen (gymnota $L a c r$.) bikden fünf deütliche Gatrungen. I. Die Argulusarten find kleine eyertörmige Thierchen, die zwey Augen, vier bis acht Fürse, keinen schwanz und haaförmige Antennep haben. Lacr eille glaubt, dals die hieher gezählten Arten wohl junge L,ynzéen leyn könnten. Z. B. Argul. charon Müller. 2. Die Cyklopen (cyclops Müller) bilden eine fehr natürliche Gattung. Sie haben nur ein rundes Auge und zwey oder vier Artennen, daş diele fich von der Bafis an fpalten. Der Körper endigt in einen langen gabelförmigen Schwanz z. B. monocul. quadricornis; nach den Beobachtungen von Jurine in Genf find die kleinen Cyklopen, die ganz anders ausfehen als wenn fie ausgewachlen find, von Mïller unter den Gattungsnamen nauplia und amymome be(chrieben. (Bülletin des Sc. tom. I. p. I16.) 3. Die Kopfaugen (polyphemus $M$ üll ler; cephaloculus $L_{1}$ a mark) heilsen 10 , weil fie nur ein Auge haben, was lo grols ift, dal's es für fich allein den ganzen Kopf bildet. Z. B. Mónocul. oculus. 4. Die Zwoes (zoea) find eine von Bosc. gebildete Gactung, wohin ein kleines, im hohen. Neere 500 Meilen von Europa gefundenes Thierchen gehört. Z. B. Z. pelagica. 5. Die Kieferfiifse (branchiopoda $L a m a r k$ ) leben in ftehenden Gewälfern," find die einzigen Entomoftrakiner mit geftielten Augen. Z. B. cancer ftagnalis. 


\section{No. CXII.}

\section{FAMIII. SPITZSCHNAUTZEN ODER OXY- RYNCHEN. *)}

Kruftazeen mit zehn Fülsen; Kiemen verborgen; Schwanz kürzer als der Rumpf und am Ende einfach; Brufttück mehr lang als breit.

Gattungen.

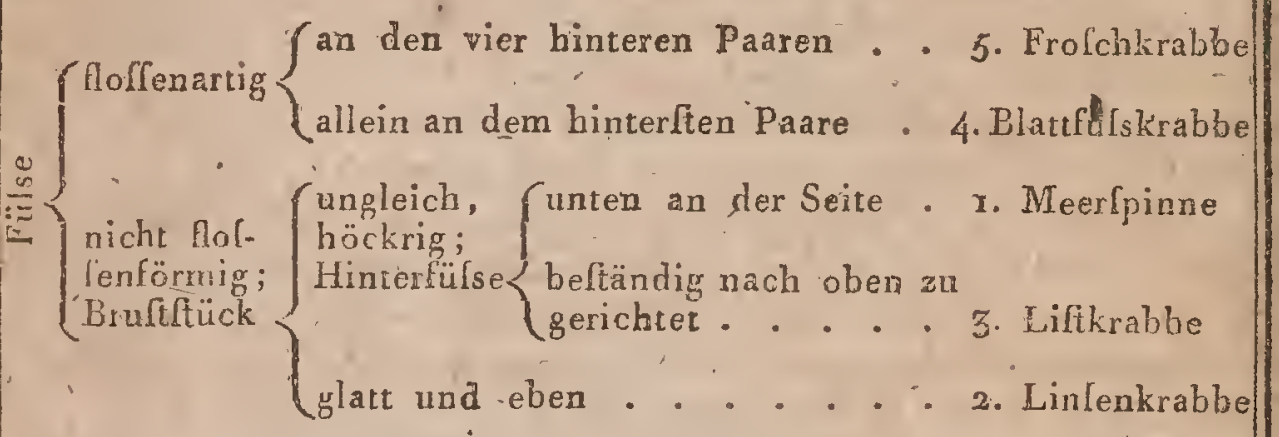

*) von Oçus fpitzig und Pugxos Nafe, Schnautze.

\section{BEMERKUNGEN ZUR CXII. TABELIE.}

Die von Latreille logenannten Spitzfchnautzen oder Oxyrynchess haben das Bruftechild mehr lang als breit, oder in der Queere viel Ichmäler und vorn in eine oder mehrere Spizzen endigend. Die mittellten Antennen find immer fichebar und vorftehend.

I. Die Seefpinnen (maia $L a m a r k$ ) Iind leicht zu unterIcheiden. Sie entiprechen der Fabriziusfchen Gattung Inachus und Parthenope. Die Oberfläche diefer Kruftazeen if mit İcharfen Hökern geftachelt und of ganz haarig. Diefe Meerfpinnen find im mittelländifchen Meere belondérs häufig. Z. B. Cancer araneus L., parthenope longimana Fatr. Inachus cornutus $F a b r$.

3. Die Linfenkrabben (Leucolia Fabr.). Find gewöhnlich glatt und wie polirt an ihrer Oberfläche, wodurch fie fich unter einander felir äbnlich fehen; aber die von den verlchiedenen Naturhiltorikern ihnen zugefchriebenen Eigenbeiten fcheinen Tehr unbeftimmít zu feyn. Die meiltes dex bey uns foffil gefundener Krabben mögen wohl zu diefer Gattung ge- 
hören z. B. cancer craniolaris L., was vorzüglieh deswegen merkwürdig ift, weil die lebenden Arten die man jerat kennt; mit Ausnahme einer einzigen (cancer nucleus L.) alle aus afiatifch-oder amerikanilchen Meere find. Z. B. Leucol. Ccabriuscula, pila Fahr. u. C. w.

3. Die Liftkrabben (Doriṕpe $F a b r$ ) haben die zwey hinterften FüIse befländig auf dem Rücken, die beliimmt zu ltyn Icheinen, fremde Körper, z. B. Seekork, oder Corallen damit zu halten, unter welchen das Thier verfteckt oder gefichert liegtwie unter einem tragbaren Dach. Die meiften befchriebenen Arien gehören in beilse Meere. Z. B. cancer lanatus L., Dorippe aftura $F a b r .$, Dor. callida fin $b r$.

4. Blaufufskrabbe (orithyia $F a b r$.) heilst die eine und einzige Art diefer Gattung, die aus China kommt, deren Hinterfülse platt an den Rändern ausgelchnitten und blattähnlich find und dereu Brultfchild kuglich ift. 2 Z, B. O. mammillaris.

5. La mark hat die Gatung der Frofchkrabben (Ránina) nach einem aus Ambonia fiammenden Krultenthiere gemacht, was von $R$ i $m$. phius und Linn é̉ unterähnlichem Namen, cancer rnninus, belchrieben wurde. Es ift dies Thier wirklich wégen der Form 'leiner Vorderpfoten merkwürdig, dié haarlos find und, wie bey den Schaufelkrehlen, in einen langen, und anf der gegen dås Bein lirgenden Seite, gezähn wten Nagel endigen. Die andern Fiilse find ganz behaart; am Ende platt und fo in eine Art Flodle verwandelt. 


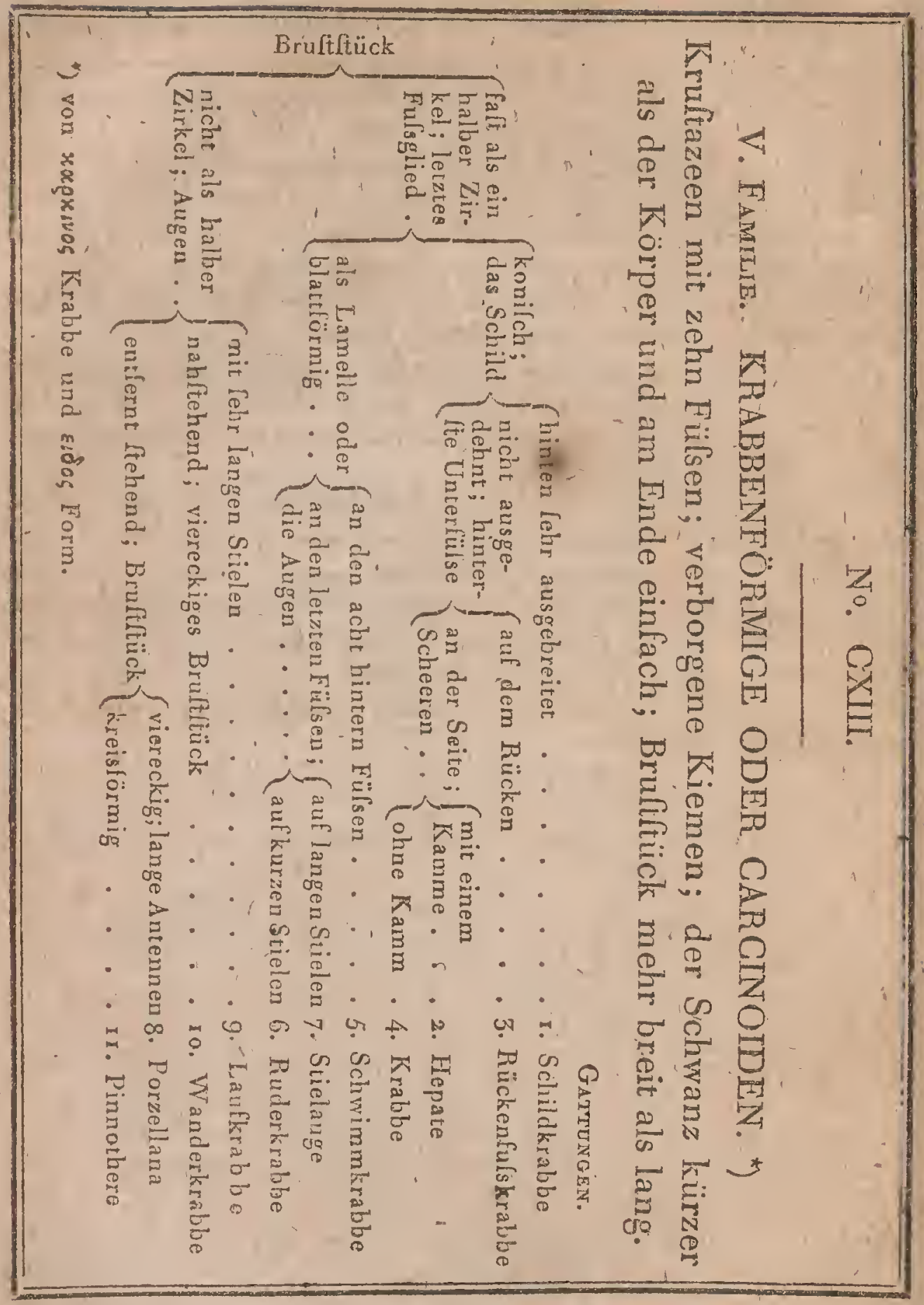

\section{BEMERKUNGEN ZUR CXIII. TABELLE.}

Diefe Kruftazenfamilie entfpricht gan den von Latreille aufgefiellten Canceristen. Sie unterfcheiden fich ron denea der vorigen Fa- 
milie drirch die, Geftalt ihres Bruftchildes, welches mehr breit als lang Ift und durch die Lage ibrer mittlern Antennen, welche in einer'belonderm Höhle wie zufammengelegt und wie verborgen find.

1." Die Schildkrabben (calappa Fabr.) unterfcheiden fich von dea eigentichen Krabben nur durch die Form des. Brulilchildes, was hinten ausgefchweift ilt und durch die vordern grofsen zufammengedrückten Scheere, welche dèn Mund und das, Bruftchild ftützen. Z. B. Cancer calappa L.

2. Die Gattung Hepat (hepatus $L$ atreille) ift den Schildkrabben fehr ähnlich. Z. B. Calappa angultata Fabr.

3. Die Rückenfufsirabben (dromia $F a b r$.) find ganz den Liftkrabben in der'Bildung der Hinterfülse ähnlich, aber die Form ihres BruftCchildes ilt fehr verfchieden. Z. B. cancer dromia L.

4. Die Gatung der Krabben (cancer) enthält nur noch einige Arten von denen, die Linné mit diefem Namen belegte und zwar nur folche, welche von den Syftem - liebenden Naturforfchern durch keine belondere Eigenheit divon getrennt werden konnten. Z. B. Cancer pagurus.

5. und 6. Die Schwimmkrabben (matuta Fabr.) z. B. mat. victor, und die Ruderkrabben (portúnus Fabr.) a. B. port. pelagicus lind wenig von einander verfchieden. Sie lchwimmen fehr gut, kommen felten ans Uter; halten fich gern aut einigen Fucus Artea auf. Thr Wleifch ift fehrigchichätzt.

7. und 8. Der Name Stielauge (podophtalmus) bezeichnet die Haupteigenfchaft dieler von Lamark anfgeftellten Gattung der dabin eine, Art zählt (portun. vigil), die übrigens von den Laufkrabben (Ocypoda $F a b r$.) z. B. Canc. ruricola, fich durch nichts, als noch durch die viereckige Form des Bruftchildes untericheidet. Alle Arten mit geftielten Augen leben in warmen Ländern, entfernen fich oft ziemlich weit vom Meere und können felr fchnell urid anlialtend laufen.

9. Die auch von Lamark als Gattung anfgeftellten Porzellanén (porcellana) enthalten Arten, deren, glattes Bruftichild etwas Aehnliches von den 'Linfenkrabben zeigt, von denen fie fich aber durch die Form und Stellung der, an der äufseren Seite der Augen bofindlichen, Antennep, Z. B. Cancer hexapus, unterlchidet.

ra. Die, Wanderarabben (graplus Lamark) \%. B. Cancer graplus L. unterfcheiden fich von den übrigen 'Gattungen diefer Familie kaum noch durch-etwas anderes als durch das auf der, Tabelle angegebene. Alle hieher gehörigen Arten kornmen aus fïdlichen Méeren.

r. Die Pinnoheren (pinnotheres Latreille) haben diefen Namen von einer Art ertalten, vou der fchon Ariftoteles, angab, dals fie in den Tweylchaaligen Conchylien wohne: daher ihr Name, der, im Griechilchen, Jäger oder Verfolger der Steckmufchel bedeutet. Man findet wirklich diefe kleinen Krabben in den Steckmulchela, wo fie hinein kriechen, nicht um die VVächter oder Verfolger diefer Mollusken zu, Ceyn, wie man es den Alten nacherzählte, Condern um fich dafelblt in Sicherheit zu bxingen. Ihre Bedeckung ift immer fehr weich. Z. B. Cancer pilum L. 
Entomoftrakinen.

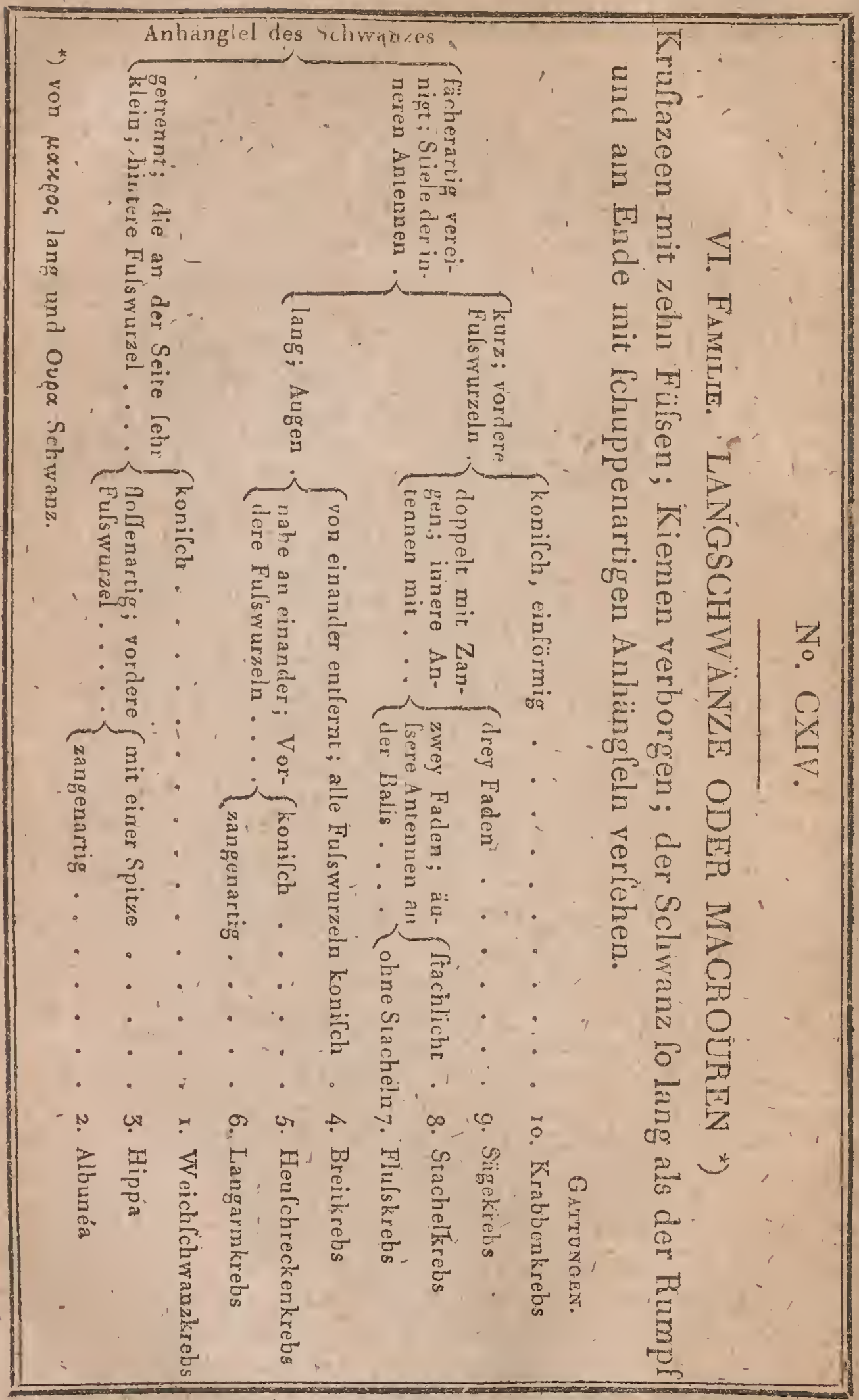




\section{BEMERKUNGEN ZUP CXIV. TABELLE.}

Die bier unter dem Namen Makrouren' den Kreblen durch den langen Schwanz ähnlich, der ihnen zum Schwin men dient, da lie nur mit. Mïhe auf dem Lande gehen.

1. Die. Wheichfortranzkrable (pagurus Fabr.) find'wegen ihres weichen Schwanzes merkwürdig, den fie in leere Conchylien oder in Isöchex von Steinen zu ftecken pflegen, um ihn zu belchürzen. Die Körper, die ihnen lo zur WVohnung dienen, ichleppen fie mit lich herum. Auch hat man éinige Artęn Eremit, Dio enes u. l. w. genannt z. B. Cancer bernhardus." Gewöbnlich ift eine ihrer Scheeren gröfser'als clie andere.

2. Die Albunéen (atbunaea Fabr.) Scheinen die Krabben mit der Krebfen zu verbinden; ihr kurzer Schwanz nemlich, dei fre mir den Krabben gemein haben, ift, wie bey den Kreblen, nicht unter den Leib gefchlagen. Z. B. Cancer lymunilia.

3. Die Hippas (hippa F $F_{b} r_{\text {. }}$ ) haben die mittlern Anrennen gabelföre mig' und die Vorderfüfse mit kọnifchen Nägelı endigend; die meiften kommen aus indifchen Meeren. "Z. B. Cancer emeritus L.

4. Die Breitkrebje (fcyllarus Fabr.), würden den Schaufelkreblen ganz ähnlich feyn, wenn ihr Kopf nicbt mit dem Bruftchilce verwachfen wäre. $\mathrm{Z} i . \mathbf{B}$. Cancer arckus $\mathrm{L}$.

5. Die Heufchreckęnkrebje (palinurus Fabr.) hahen keine Zange an den Vorderfülsen. Durch die allgemeiné Körperform gleichen fie den Krebfen lehr. Man hat fie nur im Mittelländifchen Méere und in der Südfee gelunden. Z. B. Palinurus qquadričrnis.

6. Die Langarmkrebje (galatea Fabr.) nühern fich noch mehr dea Kreblen; aber das Brulifchild ift hier mit Queerfurchen verlehen, welche den Artikulationen des Schwanzes enifprechen. Z, B. Cancer ftrigolus L.

7. Die Krebfe (aftacus $F_{a}$ b $r_{\text {. }}$ ) baben dis Anterinen in einer Reihe; die minlern find kurz, his an die Bafis getheilt, und die äulseren find fehr lang uad ohne Seitenlchuppen. Thr Brufiftiick endiget voru in eine zwifchen den Augen vorragenden Spize. Z, B, aftac. fluviatilis.

8. Die Stachelkrebfe (penaeus Fab.r. Z. B. P. monodon) find in Indien zu Haufe und haben immer ein liachliches Anlänglel an der Bafis der äulseręn Antennen.

9. Die Sügekirebse (palaemon $F a b r$ ) haben die. Spitze des Brufto ftückes fehr vorragend und gezähnelt und die mitteren Antenneñ dreqfach gelpalten. Hieher gehört die Garneele cancer fquilla.

ro: Die Krabibenkrebje (crago, Fabr.) unterfcheiden fich von den Sägekreblen wenig, ihr Bruftlticck ragt aber nicht als eine gezähnelte Spi în ze vor, Z. B. Cancer crangon $L_{19}$ 


\section{No. CXV.}

VII. FAMILE. GLIEDERKÖPFE ODER ARTHROCEPHALEN. *)

Kruftazeen mit meiftens vierzehn Füfsen; Kiemen an dem Schwanze fichtbar; und der Kopf an dem, Brufftück beweglich artikulirt.

Gattungen.

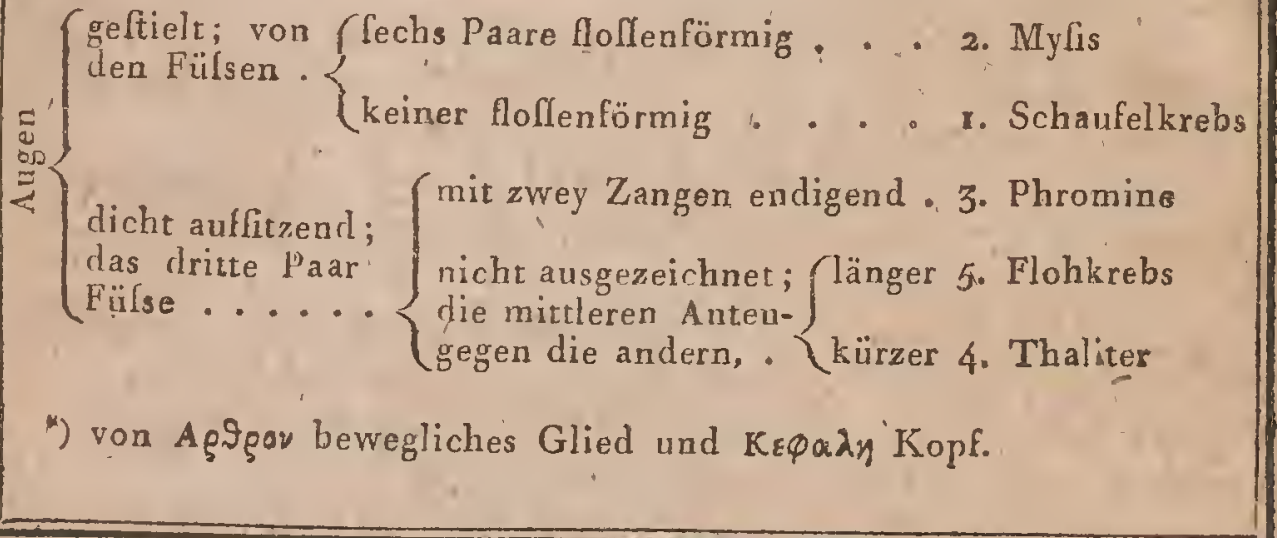

\section{BEMERKUNGEN ZUR CXV. TABELLE.}

Die Arten, welche bier Arthrocephalen benannt find, weil fie allein in dieler Ordriung einen von dem Bruchftück getrennten und beweglichen Kopf zeigen, find von Latreille als feine letzten Ordnung der Unterklaffe: malaroftraca; aufgeführt und haben von ihm den Namen Branchiogaftra erhalten. Zu der auf der Tabelle erwähnten Eigenheit der Bildung kommen noch mehrere andere fehr merkwürdige. So find gewöhn lich mehr als zehn Füfse vorhanden; die Kiemen ftatt unter dem Bruftfchilde verborgen und an den Urfprung der Fülse befeftigt zu leyn. Find hier fichtbar, getrennt und beweglich; die Augen, welche bey den andern Kruftazeén beweglich lind, und auf einem mehroder weniger langen Stiele fitzen, find bier meiftens dichtauffitzend und unbeweglich: Das Bruftftück, was allein bey den Oxyrinchen und Carzinoiden $z$ wey Drittel und bey den Makrouren die Hällte des Körpers beträgt, macht hier höchftens eis Drittheil der gauzen Länge aus. Alle diele Eigenheiten konnten al- 
lerdings hinreichen um, wie Latreille gethan hat, aus ihner eine eigne Ordinung zu machen.

1. Die Gattung Schanfelkrebs ('quilla $F a b r$.)'z. B. Cancer mantis L. zéichnet fich aus durch ihre fechzehn Füfse, wøvon die vorderften lang und arnförmig lind und mit einem beweglichen mit fcharfen Spitzen beletzten Nagel endigen.

2. Die Gattung Myfis (Mylis Latreille) hat zum Unterfchiede von den Schaufelkrebfen nur vierzehn' Füfse und zwifchen diefen, nicht unter dem Schwanze, die Kiemen und kurze Vorderfüfse.

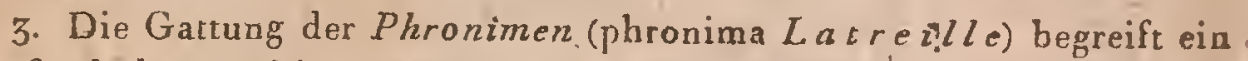
lehr fonderbares.Thier, was man in einem gallertartigem durchlichtigem Körper, (vielleicht in einer todten Qualle,) beobachret hat. Es hat nur zwey Antennen und zehn Fülse, von denen das dritte Paar länger als die übrigen und mit zwey Zangen bewaffnet ift. 'Der Körper endigt fich in mehrere gabelartige Faden. Z. B. Cancer fedentarius Forskael.

4. Die Gattung der Thalitern (thalitrus Latreille) gleicht in vie. ler Hinficht den Flohkrebfen. Z. B. Cancer locufta.

5. Die Flohkrebje (gammarus $F a b r$.) z. B. Cancèr pulex L. unterlchei den fich von alien andern Altakoiden a) durch die Form ihres zweyten Körperabfchnittes, welcher nicht länger als die gleich darauf folgendes ift, b) durch die gabelförmigen Anhänglel diè man am Ende und zur Sei. te des Schwanzes beobachtet und c) durch ihre unbeweglichen Augen, die beynahe fo find wie die der Afleln und Wafierafleln, Infekten mit de nen die Flohkreble verwandt zu feyn fcheinen. Diefe Kruftazeen 'leben im fülsem und falzigem WalTer; Ichwimmen fehr. fchnell und zwar immer auf der Seite.

Ende der Klaffe der Kruftazeen. 
Eintheilung der Infekten.

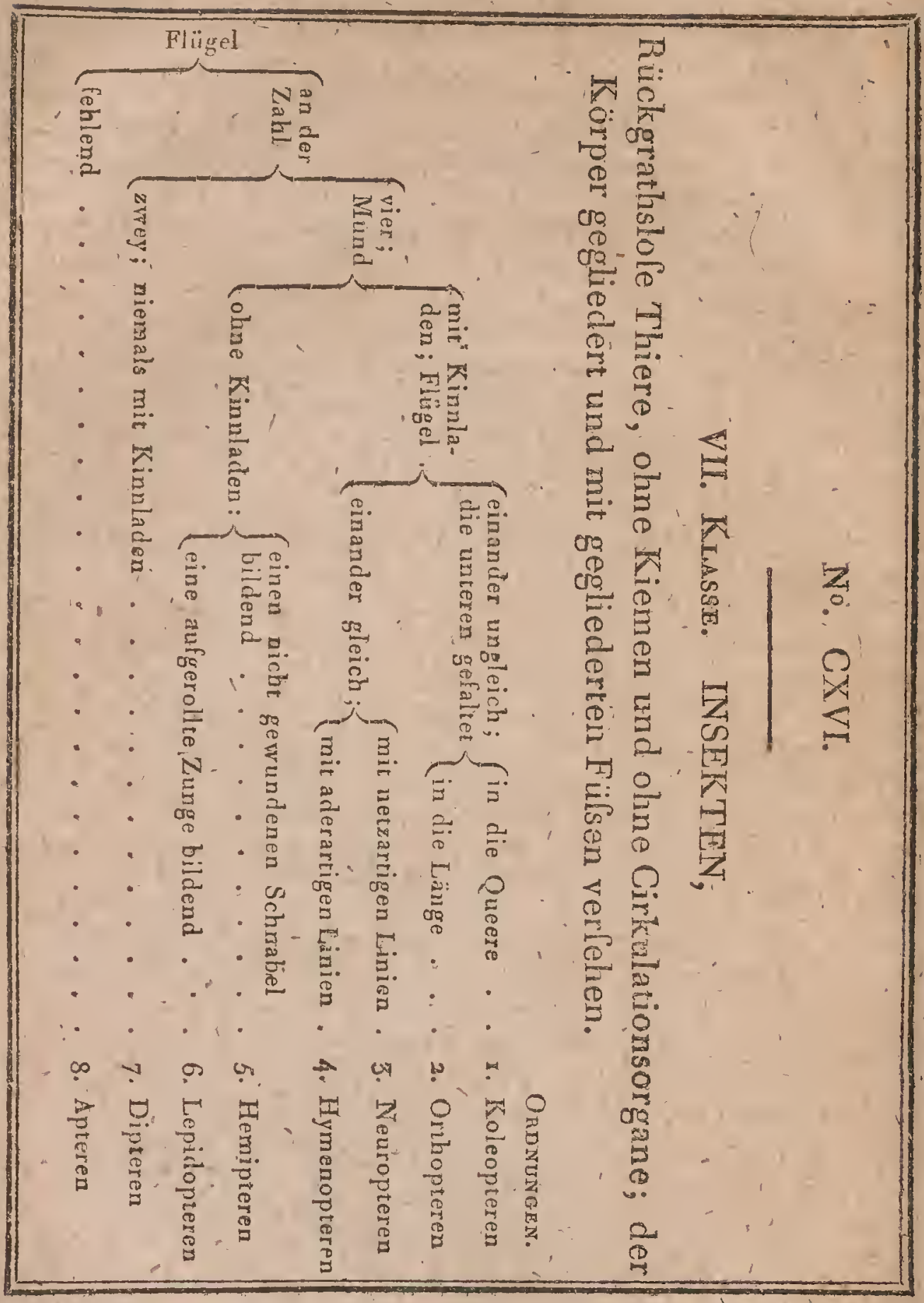

\section{BEMERKUNGEN ZUR CXVI. TABELLE.}

Die Klafle dex Infekten 'ift unter den rückgrathslofén Thieren điø;"; wrelche am leichteften zin ftudieren ift, obgleich fie allein mebr völlig bokannte Arten in fich fchlielst, als die vier andera zufanmengenommar. 
Thre gegliederten Fuifse, ihr faft beftändig deutlicher und unterfchieAdener Kopt, enternen fie von den Mollusken, Würmern und Zoophyren und ihre liefpiration, die nicht yermittelft der Kiemen ftatt findet, reicht hin, urn fie von den Krultazeen zu unterfcheiden. Ihre Bildungen, ihre inneren Grgane und iłre Entwickelung erfordern, dafs die Naturlorlcher fie für fich belonders ltudieren.

Mit Ausnahme einer einzigen Familie, hảben alle Infektan einen artikulirten Kopf; der mit zwey unbeweglirben Augen und mit zwey mehr oder weniger langen und beweglichen Hörnern verfehen ift, welche $A n$ teñ̄eñ oder Fürilhörnen genannt werden. Der Theil des Körpers welcher aif den Kopf folgi und das erfte Fufspaar trägt lreilst das Halsfchild, óder Halsftück, der Theil wo die andern Fulspaare und die Flügel fitzen, abér Bruftftïck, oder Brultfchild, dann folgt der Hinterleib oder Abdomen. So ift es bey den geflügelten Inlekten.

Die Flïgel variiren 'is Zahl und Textur. Eine ganze Ordnung ift derfelben ganz und gar beraubt; undildele Modifikation der Bildang lcheint eine Menge anderer Verändernngen nach fich zu ziehe». In einer andern Ordnung find inmer nur zwey dünnbäutige vorhanden. Die meiften aber haben ihrer vier, deren Textur lechs Háuptveffliedentueiten zeigt, aach welchen fich die Benemung der Orcinungen richtet.

Die Nalrung und Lebensweife ift in den verfchiedenen Ordnungen fehr verfchieden. Die Nahrung aber, welche die Infekten vorzüglich lie. ben, kann nach der Bildung des Mundes leicht beftimmt und daraus erkannt werden. So können die Arten, bey denen fich Kinubacken und Kinnladen finden, fefte Nahrungsmittel zcrtheilen, die im Gegentheil, welché nur eine Röhre, eiren Rüffel ader eine zufammengerolle Zunge baben. müflen fich von Säften rähren, die fie von der Oberfläche oder aus der Subftanz gewiffer Körper aufnehmen.

Die innere Struktur der Infekten ift, was die Muskeln únd Nerven anlangt, der der Altakoiden aus der vorigen Klafle ähnlich. Die-Nutritionsorgane variiren lehr in den verfchiedenen Klalfen. Die Relpirationsorgane find ihnen aber ganz eigenthümlich; nemlich Trackéen, Rühren, welchefich, nach Art der Blutgefäfse bey höheren Thirren, immer zeräftela und die Luft in alle Theile aes Körpers hinführen.

Dis Gelchlechter find bey den Infekten immer getrennt. Alle kommen aus Eyern, welche aber oft im Korper áer Mutter auskommen. Die meiften werden untér einer ganz andrrn Form às die if geborén, die fie in der Folge haben follen. Diefe Metamorpholen find in den verfchiedenen Ordnumgen verfchieden. Die noch nicht ausgebildeten Infekten, welche ihre letzte Bildung noch nicht erhalten haben, werden in ihrem erften Zuftande, wenn fie erft aus dem Eye gekommen find Raupen oder Larven 'genannt; in dom daraf folgenden $Z$ wifchenzudande aber heig Isen fie Pupper. 


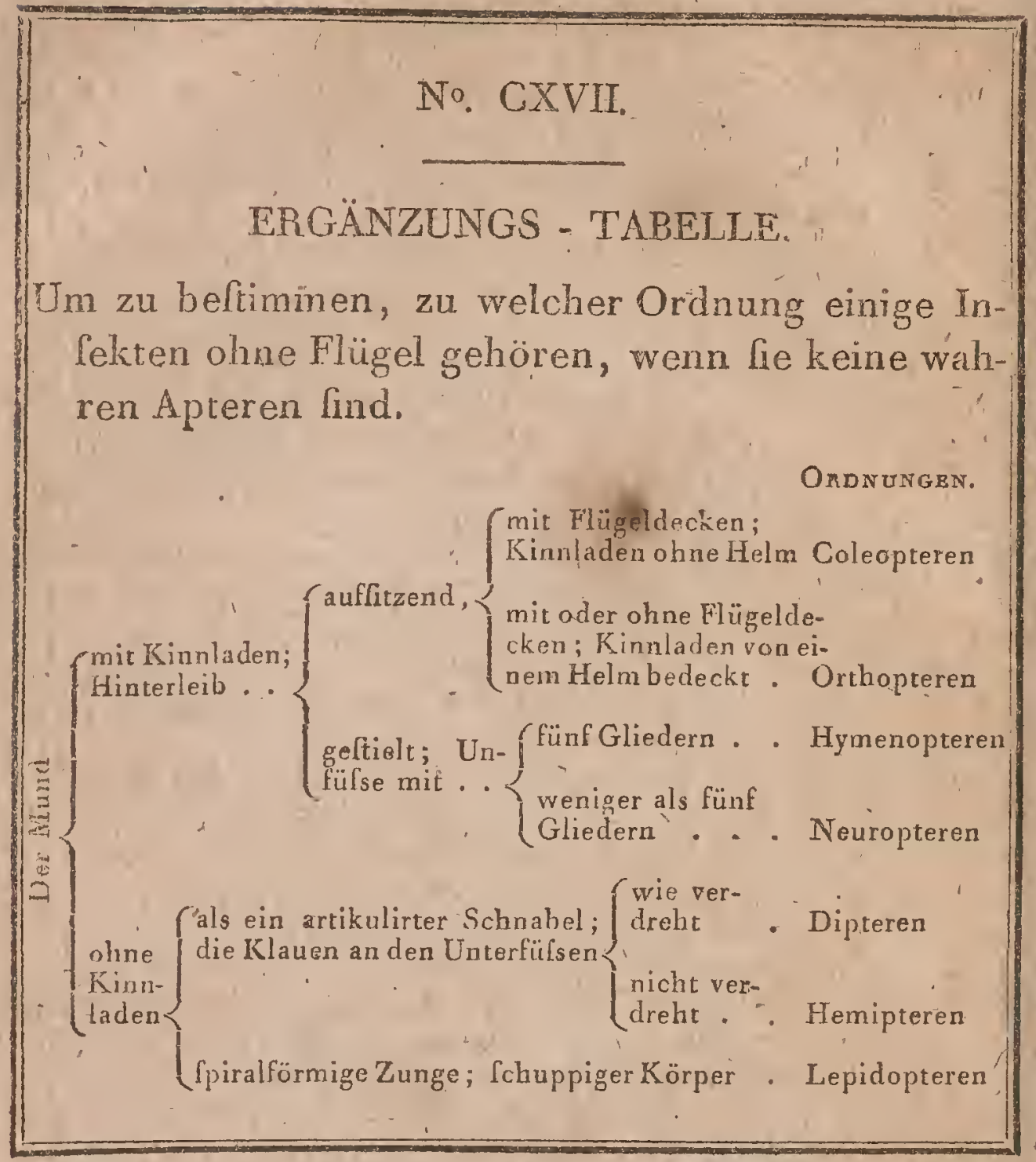

\section{BEMERKUNGEN ZUR GXVII. TABELLE.}

Obgleich die auf Gegenwart, Zahl und Form der Flïgel gegründete Klaffifikationsmethode, fehr genau, gerade die durch Bildung und Le. bensart am meiften verwaudten Arten vereinigt, lo kann man doch nicht läugnen, dals einige Arten, mit Unrecht, dem erften Anblick nach für Apteren gehalten werden könnten, wenn man blos aut diefen Theil der Bewegungswerkzeuge Rückficht nehmen wollte. Un folche Milsgriffe zu vermeiden, kann die hiè entworfene Ergänzungstabelle dienen, durch welrbe man auf, einem lehr verlchiedenen Wege zur Kenntnifs der Ordnungen g̈langt.

Die Kinnladen der Inleḱten, find artikulirte parweis an der Seite des Mundes fitzende-Stücke. Man unterfcheidet fie in Mandibeln oder 
Kinnbacken und in Kinnladen, felten find Yie hervorragend; find tie es, fo glcichen lie Haken, welche vor den Kopf vorltehen.

Der Hinterleib ift auffitzend, wenn feine Bafis ohne deutliche ZvriIchenräume dicht an dem Bruftitück anliegt. Im entgegengefetzlen Fall, oder wenn man zwifchen Hinterleib und Brufftück eine deutliche Zufammehfohnürnng wahrnimmt, ift er geficlt. Die Flügeldecken find lolide Fefte Flügel, welche lelten länger find als der Hinterleib, und denfelben bedecken lowie fie auch den häutigen Flügel als Putteral dienen. Crewöhnlich find die Flügeldecken bey den flügellofen Käfern mit einánł.r verwachlen und können fich nicht von einander entfernen. Die meifirn. Photophygen (15. Familie) einige Creophagen, Rhinoceren, Xylopbagen und Phytophagen. (Inlekten der 1. 15.20. und 2r. Familie) find in diefem Fall.1 Doch find bey den Oelkäférn die Flügeldecken von einander ftehęnd. Bey einigen Arten, z. B. einigen Leuchikäfern find auch gar keine Flügeldecken vorhandeu.

Der Helm (galea) ift ein auf der Wölbung der Kinnladen, noch aulser der dalelbft befindlichen Frefsfoitze, litzendes Anhänglel. Es giebt Arten olune Flïgel in faft allen Familien der Ordnung der Orthopteren z. B. die Schaben, Fangheufchrecken, Heulchrecken. Bey den Hymenopteren find die wichtiglten flügellolen Arten die Ameifen, und eivige Inlekten der 35 Familie.

In der Ordnung der Neuropteren haben wohl nur die Pfocke und die gefchlechtslofen Tarmiten keine Elügel.

Unter den Dipterèn kennt man nur die Schaaf-Lausfliege, als ein Infekt'ohne Flügel.

Die Ordnung der Hemipteren aber hat eine grolse Zabl ganz fügéllofer Arţn z. B. Wanzen, Blättäufe und.Schildläule. Anderé z. B. einige Langwanzen und Schnabelwanzen haben Refte von Flïgeldecken, aber immer einen artikulirten Schabel, der bey der Tabelle der Ordnung der Hemipteren helchrieben werden loll.

Endlich haben zwey oder drey Weibchen von Nacht-Schmetterlingen auch gar keine Flügel. Aber man kann fie leicht in ibre Ordnung bringen, wohin fie gehören, wenn man nur ihre lpiralartig gevundene Zunge nnd vorzüglich ihren mit leicht abgehenden Schuppenftaub bedecḱten Körper betrachtét.

Hat man aber einmal die Ordnung, wohin ein flügelloles Infekt gehört, beftimmt, lo ift es nicht Ichwer daflelbe" durch Vergleichung der Abtheilungen diefer Ordnung auch in die rechte. Familie und in leine Gattung zu bringen. 


\section{No. CXYIII.}

T. ORDNUng. KÄFER ODER KOLEOPTEREN. ,)

Kinnladen; vier Flïgel: die oberen find hart und heilsen Flügeldecken, die unteren häutig und in die Queere zulammengefaltet.

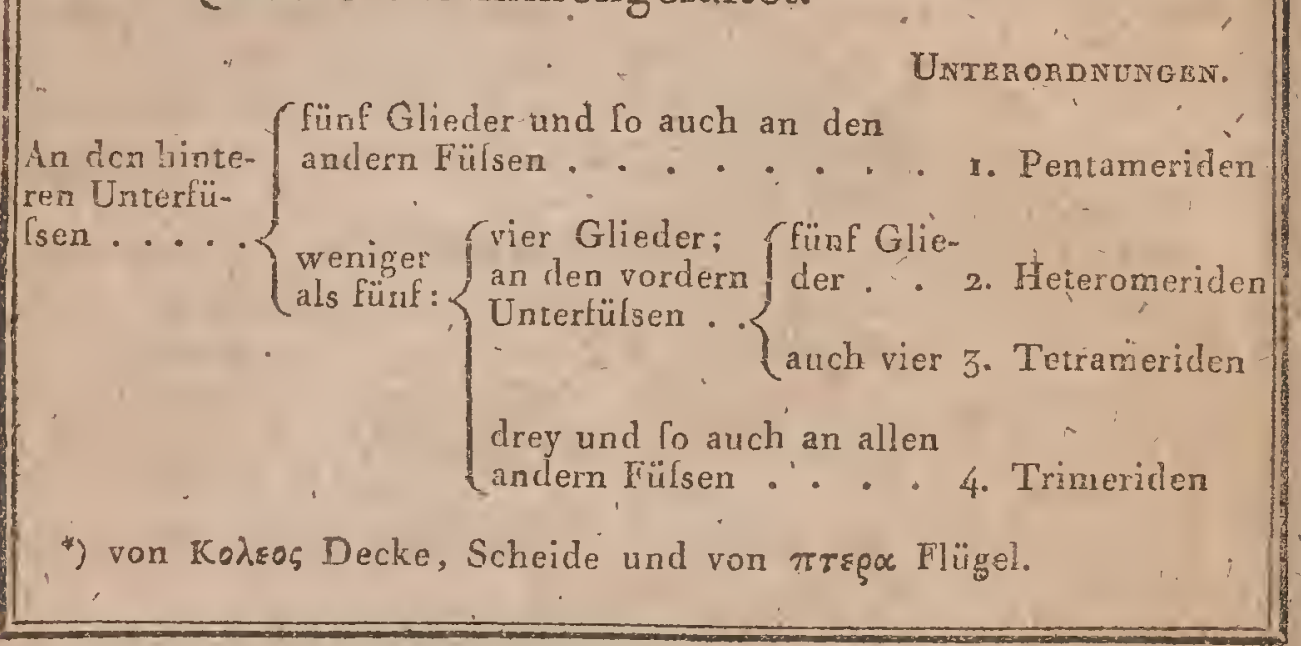

\section{BEMERKUNGEN ZUR CXVIII. TABELLE.}

Bey allen Kräfern (Coleoptera, Eleutheraca Fabr.) dienen die oberen Flügel nicht zum Fluge, fondern bedecken nur, als Futteral, die andern hautigen, längern und in die Queer gefalteten Flügel. Alle, ohne Aüsnahme künnen fich von felten thierifchen odèr vegerabilifchen Subfianzen nähren, denn ihr Mund ift mit Kinnbacken und Kinnladen verfehen. Sie entwickeln fich aus einer Larve mit lechs, mehr oder weniger langeu und nahe an dem Kopfe fitzenden, Fülsen, und mit wéicher und wie gefalteter Haut. Sie erleiden eine vollkomme Metamorphofe. Ihre Puppe ift unbeweglich und nimmt eine Zeitlang keine Nahrung wa fich obgleich dem Anfchéine nach lie die Bildung des vollkommner Infekts hát; aber alle Theile find in eine Oberhaut eingefchloffen, welche fich an fre dicht, anlegt ohne fie jedoch eigentlich zu vereinigen.

Die Koleopteren legen, wie die meiften andern Infekten, nur eimmal in ihrem Leben Eyer. Sie kommen alle in Eyern zur Welt. Dio Gefchlechter find getrennt." Die Weibchen find gewülnlich dicker als die Männchen. Man hat bis jetzt noch keine gelchlechtslolen oder Zwitter bey ilonen beobachtet. 
Es gehören in diele Ordnung die meiften der hekannten Inlekten. Da lie allein mehr als. zweyhundert Gatungen in fich fohliefst, lo war es nöthig fie in Abtheilungen und Unterabtheilungen zu bringen. Die Zahl det Glieder an dem Unterfulse giebr dazu ein lehr bequemes Hülfs. mittel $a b$, was von Geoffroy zuerlt angewendet ift.

Man neunt Unterfussglieder, diejenigen artikulirenden Stücke wo. mit die rexfchiedenen Fülse endigen; fo wie die Zehen und Finger der rückgrathigen Thiere aus mehreren Gliedern beltehen. Marn zälılt dabey die Haken", welche die Klaue bilden und deren Zahl, varïrt, niemals mit; und da man beobachtet hat, dals die mituleren Fülse immer liefelbe Zahl von Gliedern zeigen als die Vordern, lo betrachtet man diele richt anders als wenn die Vorderen fehlen.

Um die Zahl diefer Glieder zu finden, fängt man die Zählung bey den Hinterfürsen an. Sind da fünf Glieder vorhanden lo kann man lich darauf verlaffen, dafs fie fich auch an den andern Fülsen finden werden; eben fo wenn drey vorhanden find. Aber wenn ficlı vier Glieder an den Hinterfülsen finden, fo muls man nach der Zahl der Glieder an den Vorderfülsen oder an den mittern Fülsen lehen. Vermittals diefer Prnzedur gelangt man mit leichter Mühe zur Beftimmung der Unterordnungen, die durch andere in der Folge anzugebende Vergleichungen und Betrachicungen, bald zu den Familien tühren.

Die belondern Ausdrücke deren fich die Entomologen, orler diẹ Naturforlcher welche fich mit den Infekten befchäftigen, bedienen, follen allemal erläutert werden, wenn lie zum erftenmale in den Uuterordnungen und Familien varkommen; - und da. Lie curfiv gedruckt werden, fo werden fie aul der Seite, wo lie erklärt lind, leicht in die Aur gallen, wean daraut verwielen wird. 


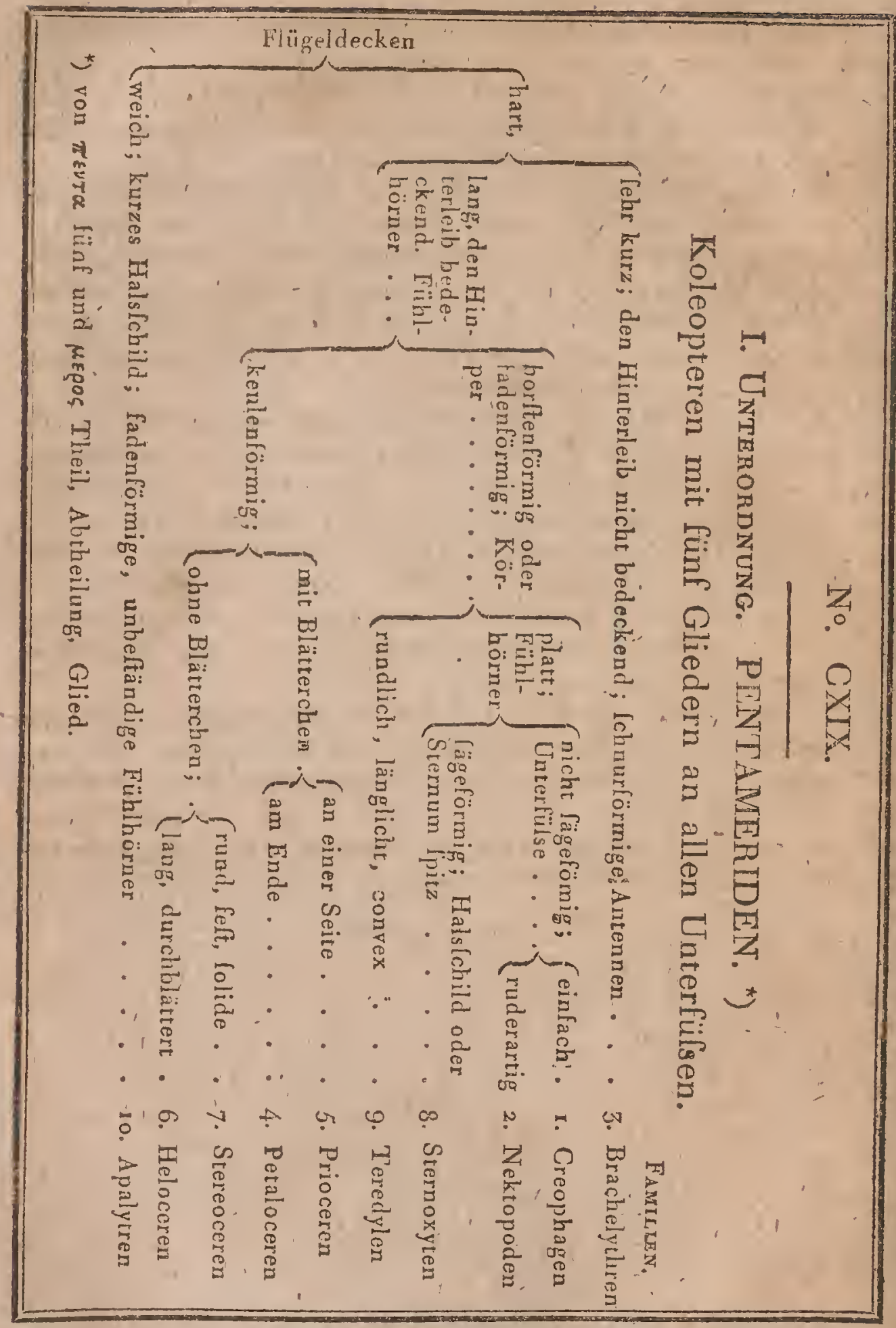

\section{BEMERKUNGEN ZUR CXIX. TABELLE.}

Der in der Unterordnung der Pentameriden begriffenen Käfer giebt es eine grolse Zăhl, die einé Cehr.verfchiedene Lebensart führen." Merk-

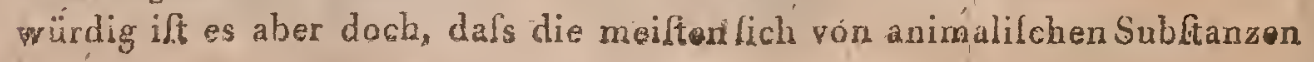


oder den allerbärteften vegetabilifchen Subftanzen nähren, fo lange fie Raupen und unvollkommne Infekten find.

Obgleich die in dief́er Untérordnung gebildeten Familien ziemlich natürlich genannt werden können, da lie, wie in der Folge fich zeigen wird, in vieler Hinficht unter fich übereinftimmen, fo kann man zu ihrer Kenntnifs doch nur durch lehr künftliche Hülfsmittel gelangen. Uebrigens mufs man ja nicht die Eigenthümlichkeiten dieler Familie allein nach den einzelnen auf der Takelle angegebenen Eigenheiten beurtheilen wollen; indem aut der Tabelle nur; a uf analytilchem Wege, die am meilten in die Augen fallenden Bildungen kennen gelehrt werden follen.

Die harten Flügeldecken, mit derci Betrachtung hier angefangen ift, find hier blos im Gegenfatze ron dem Charakter der einen (In) Familie gebraucht, in welcher alle Arten die obern Flügel bieglam und zur BeIchützung der von ihnen bedeckten häutigen Flügel wenig geeignêt haben.

Eben to ilt es mit der Kürze der Flügeldecken. Diefe Bildung ift auch nưr benutzt um gleich eine Familie, (wohin z. B. die Raubkäfer gehören, die damit verfehen ift,) wo mehr als die, Hälfte des Hinterlẹibes auf der Rückenleite unbedeckt ift und gegen den Kopf bewegt werden kann, von andern zu unterlcheiden.

Zwilchen einem borftenförmigen und fadenfürmigen Fühlhorn ift der Unterfchied. 'der, dals das letztere vom Anfang bis ans Ende immer gleich dick ift, bey dem erltern der Durchmefler aber von der Bafis bis zur Spitze kleiner wird wie bey einer Schweinsborfte.

Ein Fühlhorn heilst keulenförmif wenn es an feinem. Freyen Endo plötzlich aufgetrieben ift; es ift fchnurförmig, wenn leine Glieder rund wie die Kugeln eines Rolenkranzes find, auch nent man es wohl rofenkranzförmig oder paternofterförmig; es ift gëzähnelt oder fägeförmig wenn es auf der einen Seite. Einchnitte zeigt, find aber die Zähne tief eirgefahnitten, lo wird es Kammförmig genannt.

Die Fulshlätter oder Unterfülse nennt man ruderartig, zum Schwimmen tauglich, wenn die Glieder derfelben platt, hach, und meift an den Ränilern von Haaren eingefalst find, wodurch die Oberfäche'vergröfsert wird. Gewöhnlich find diele Fufsblätter mit lehr belchränkten Artikulationen verfehen und haben kéine Klauen, und können nur mit Schwierigkeit zum Gehen gebraucht werden.

Sternum heilst der unterfte Theil des Halsfchildes, der, welcher awilcben dem vorderften Fulspaare liegt; man giebt ihm aber nur dann dielen Namén.' wenn ex fehr beträchtlich hervorfteht oder lonft eine beJonder Bildung zeigt, 
Koleopteren.

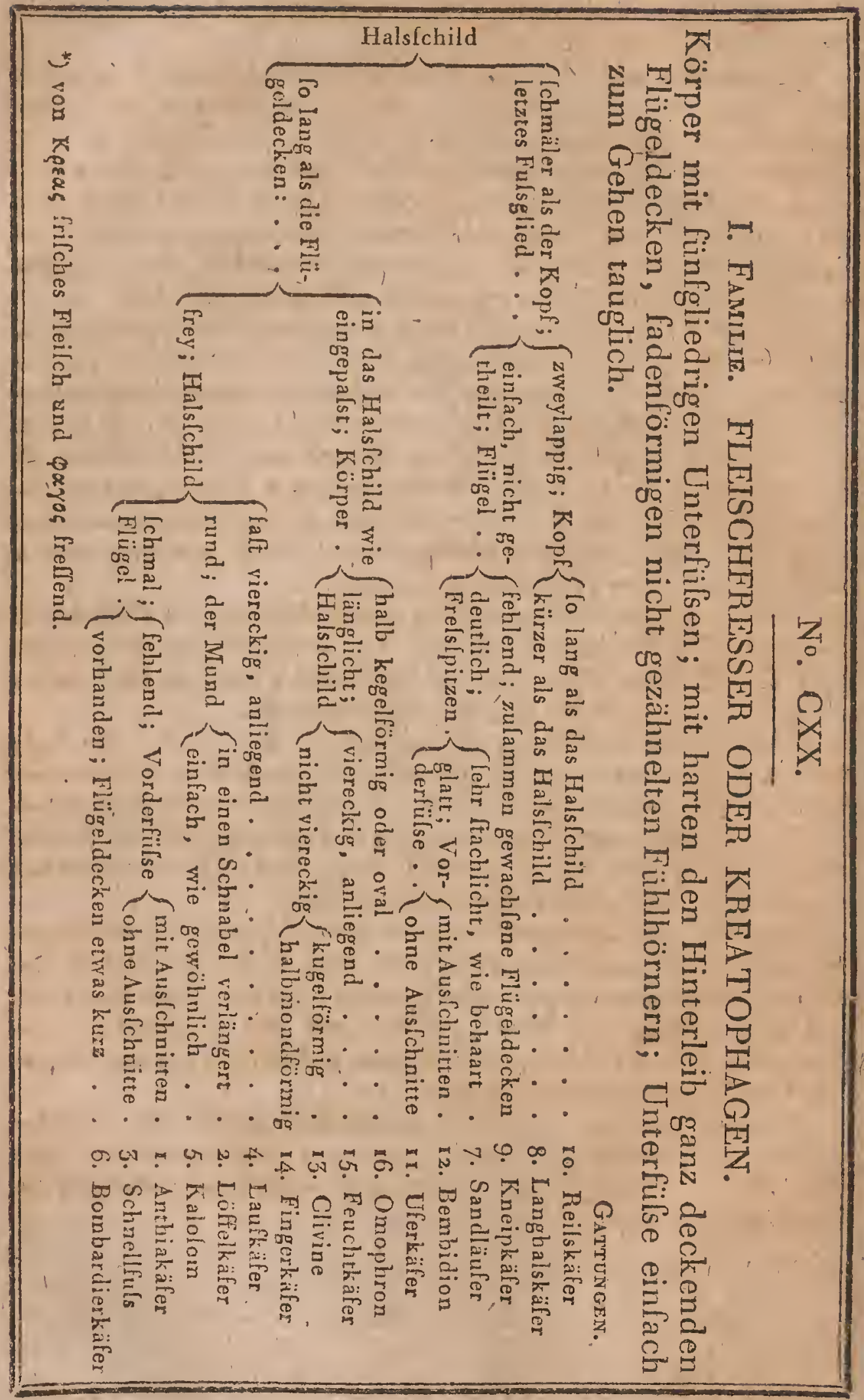




\section{BEMERKUNGEN ZUR CXX. TABELLE.}

Die Kreatophagen bilden die zablreichfte Familie in der Ordnung der Koleopteren, fie zerfallt in zwey grolse Abtheilungen nach der BeIchaffenheit des Halsfchildes. Die meilten Larven leben unter, der Erde unl uäluren fich von kleinen rückgrathlofen Thieren. r. Die Anthiakäfer (anthia, Weber) find Arten, welche fonft zu den Laufkäfern gezählt wurden. Z. B. carabus ro guttatus L. Die meiften finden fich in Afrika. 2. Die Lüffelkäfer (cychrus $F a b$.) haben, das Bruftchild und die Flügeldecken mit einen Saum eingefalst und die Frefsipitzen löffelförmig: Z. B. tenebrio roltratus. L. 3. Die Schnellyiufse (tachypus Weler) find die recht Ichnellantenclen! Laufkäfer.' Z. B. carabus hortenfis, auratus u. $\mathbb{f}_{\mathrm{w}}$. 4. Die Laufkäfor (carabus Linn.) begreifen nur die Arten, welche das Halsfchild nicht hinten zufammengefchnürt und an den Flügeldecken dichtanliegend haben. Z. B. Carab. cupreus, ferrugineus, rulgaris u. א. w. 5. Die Kalofomen (caloloma Weber) d. h. Schön-Leib, find fehr leicht an der runden Form ihres Halsfchildes zu erkennen. Z B. carab. lycophanfa, inquifitor L. 6. Die Bombardierkäfer (brachinus the ber) haben die Flügeldecken etwas kürzer wie den Leib und wie abgeftutzt. Z. B. carabus crepitans, fumans. 7. Die Sandläufer (cicindela L.) find nicht, wie der lateinifche Name vermuthen laffen Collte, in der Nacht leuchtende Käfer, londera folche, deren Körper mit Metallfarben geziert ift, wrozu oft auf den Flïgeldecken eine Art von Stickerey kommt. Man finder fie an trocknen Orten. Z. B. Cic. canpeltris L. 8. u. g. Der Langhalstïfer (colliurus de Geer) z. B. Collyris longicollis F abr. und die Kneipkäfer (mamicora $F a b r$.) z. B. mantic maxillaris find leicht zu unterScheidende afrikanilche Inlekten. Io. und Ir. Die Reifskäfer (drypte Fabr.z. B. dr. emarginata) und die Uferkäfer (elaphrus $F a b r . z . B$. cicindela riparia L.) gleichen den Sandläufern lehr; man findet fie aber an Ufern. 12, Die Bembidions (bembidion, L.atreille) fcheinen die Laufiäler den Saudkäfern zu nähern; fie gleichen den Bombardier. käfern, abor ihre Flügeldecken lind nicht abgeftutze und ihs Bruftlchild etwas ichmäler als der Kopf. Z. B. cicindela havipes L. 13. u. 14: Die

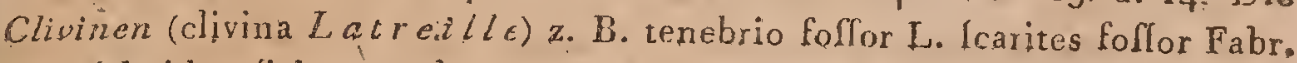
unterlcheidet lich yon den Fingerkäfern (Tcarites Fabr. z. B. Sc. gigas) nur durch das Hals fchild. Die in dielen $z$ wey Gattungen begriffenen Arten haben die Fühlhörner etwas fchnurförmig und die Vorderbeine gezäh. nelt oder mit lcharfen Spitzen, die zun in die Erde graben dienen, 15. Die Fruchtküfer (notiophilus) find eine, von den mit breitem viereckigen, platten Halsfchilde verfehenen Uferkäfern gebildete, Gattung, die den Uebergang zwilchen den zwey Abiheilungen der Creatophagen zu ma. chen fcheinen. 2, B. elaphrus aquaticus, femipunctatus $u, 1 . w, 16$. Die Gattung Omophron (omophron Lacreille) ift diefelbe, die yon Fabrio cius scolytes genannt ift. Z, B. Sc. limbalus, 


\section{No. CXXI.}

II. Famite, RUDERFÜSE ODER nECTOPO DEN. *)

Käfer, mit harten den ganzen Hinterleib bedeckenden Flïgeldecken, fadenförmigen nicht gezähnelten Fühlhörnern; die (fünfgliedrigen) Unterfüfse ruderförmig.

f fadenförmig, kürzer als der Kopf; vier Augen . 4. Drehkäfer

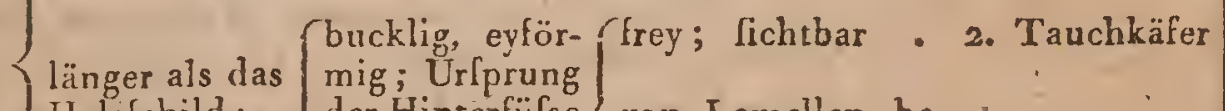
Halsichild; der Hinterfülse von Lamellen be- "

Körper... (deckt . . 3. Schiffkäter Lplatt; Sternum Ipitzig . . . 1. Wallerkäfer

*) von Nyxros zum fchwimmen tauglich und Todes Fülse.

\section{BEMERKUNGEN ZUR CXXI. TABELLE.}

Die Familie der Nektopoden ift eine natürliche Zufammenltellung; es gehören hieher alle im Wafler lebende fleifchfrelfende Käfer. Man kann fie fehr leicht an der ganzen Form ihres Körpers erkennen, der eyförmig und auf der Rückenfeite weniger convex ift. Im Ganzen find ihre Flügeldecken, wic auch die untere Fläche des Körpers, glatt aber mehzere Veibchen zeigen doch einige Furchen und die Mänuchen haben Torderfurse, Welche mit breiten (Saugnapf-oder Schildförmigen) Gliedern endigen oder aufserordentlich lang find. Alle diefe Gattungen, fo svie auch die in der vorigen Familie begriffenen, haben ein beträchtlirhes Anhängfel an der Balis der binteren Schenkel.

Die Infekten diefer Familie kommen aus Larven mit langem Körper, die auch im Wafler leben und fich von kleinen Thieren nähren; fie erleiden ihre Metamorphofe im Schlarnm oder inder Ufererde. Sebr wenige Infekten haben fo viele Mittel ihre Bedürtnifle zu befriedigen, ails die hiehergehörigen; fie können lich ins Wafler, an die Oberfläche delfelben, in die Luft rund auf den Erdboden begeben; denn Ge Ichwirmen 
tauchen, Aiegen und gehen; aber das Vermögen zu tauchen befitzen fie imböchften Grade. Die Geftalt ihrer Fülse kommit ihnen dabey auf eine bewunderungswürdige Weife zu ftatten. Alle, die Arten der vierten Gattung ausgenommen, haben dis Hinterfülse am langlten, bey allen find, fie in eine Art von Ruder verwandelt, und es Ichwitzt aus dem hintern Theil, ihres Körpers eine riechende, ölige Feuchtigkeit aus, welche fich auf der Oberlläche verbreitet, leltsige undurchdringlich macht, und fich der Ver. derbnils Ales Körpers wiederetzt. Der Körper ift beftändig wie geölt. wenn man ihn aus dem Wiaffer nimmt.

Die vier Gattungeñ, aus welchen diele Familie befteht, find fehr leieht zu unterfcheiden Sehr mit Unrecht haben einige Schriftteller hicher auch die Schwimmkäfer gezogen, deren Kürperform zwar, da diefe Infèkten gleichen Aufenthalt haben, dielelbe ift, die fich aber von vegetabilifchen Subltanzen nähren, deren Därme drey mahl lo lang lind, als der übrige Körper und deren Fühlhörner eine durchblätterte Keule bilden.

1. Deä Gattungsname der Wafferkïfer (dytiscus L.) bedeutet Taucher. Z. B. dytisc. margiralis L. Der Kürper diefer Infekten ift eval und unten mit einem Kiel verlehen; ihr Sternum, oder eine befondere Verlängerung des Halsfchildes, palst in eine entiprechende Vertiefung des Bruftfchildes. Die Vordern und mittleren Fürse fitzen einander wahe, während die hinterften Fülse entfernter fitzen. Die Männchen einer in,Lappland einheimifche Gattung haben den Antennen etwas aufgetrieben und gezähnelt. Z. B. Dytisc. clavatus Latreille.

2. Die Taucherkiaffer deren Name hyphydrus auf ibren Aufenthalt unter dem Wafler hinweilet, entiprechen der Gattung hydracna des. Fabricius, wovon aber der, Name Ichon einigen Infekten aus der Familie der Spinnen gegeben ilt. Zu der Gattung der Taucherkäfer gehören die Artenldytisc. Hermanni, ovalis, inaequalis u. I. 'w.

3. Die Schiffkäfer (Halyplus von Latreille genannt) leben nicht, wie ihr. Name es vermuthen laflen follte, im Meere. Die Geltalt ihres Körpers ift falt einem Bot ähnlich; es gehören dahin die kleinex Dyriscus Arten z. B. dytiscus obliquus, impreflus u. !. w:

4. Die Drehkä̈fer (gyrinus L.) find von den Waflerkäfern durch Form und Kürze der Fühlhörner verfchieden, fo auch durch die Kürze der Vorder und mittlern Fülse, in Proportion zu den Hinterfülspn, was fie beltän. dig drehen macht wenn fie an der Oberilache des Walfers Ichwimmen. Aulser dem haben fiẹ wirklich vier Augen, zwey oben, um in die Luft zu fehen, zwey unten, um im Waffer zu beobachten, eineBildung die der bey dem Vierauge, cinen Kuochenfich mit vollftändigen Kiemen aus der Pamilie der Zylindrofomea, angegebenen gleichkommt. Z. B. gyrinus natator. 


\section{No. CXXN.}

II. 'Famile. KURZDECKEN ODER BRACHELY TREN. *)

Käfér mit fünf Füssgliedern; mit haren kurzen, ' 'den Leib nicht bedeckenden Flügeldecken; rofenkranzlörmige Fuihlhörner.

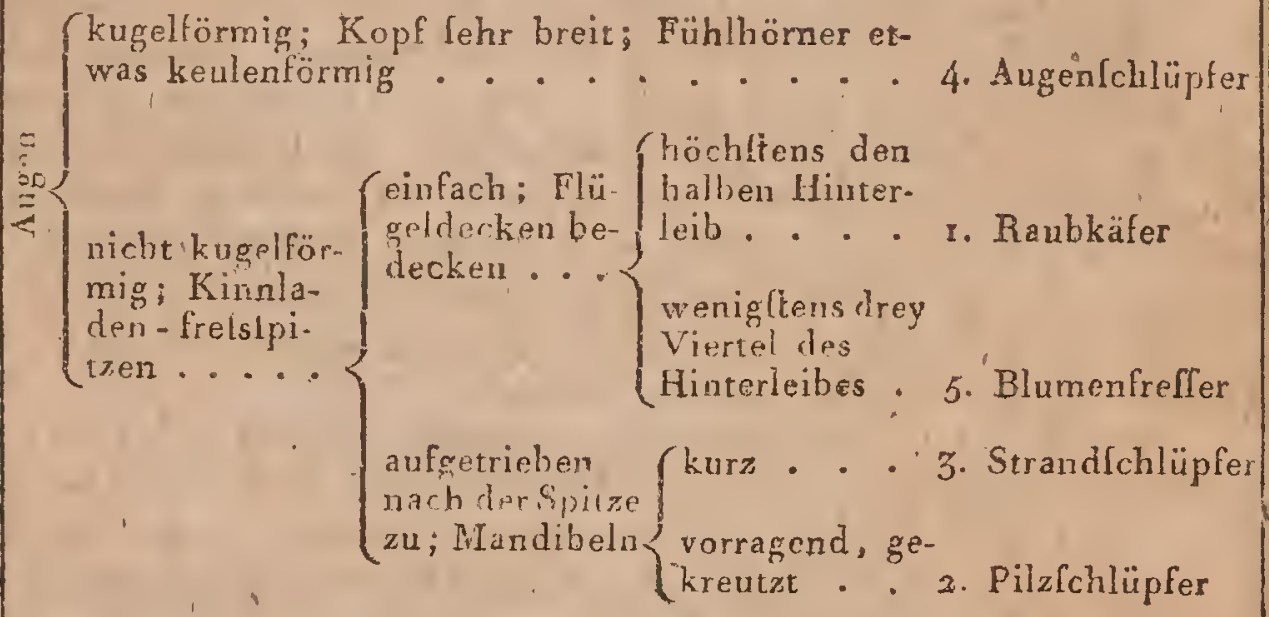

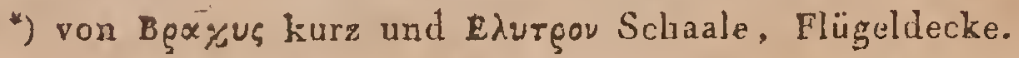

\section{BEMEPKUNGEN ZUR CXXIJ. TABELLE.}

Die Familie der Brachelytren ift eine fo natürliche Käferfamilie, dafs Schäffer aus ihnen eine befondere Klafle unter dem Namen micropıe. ra machen wollte. Wir haben zwey Monographien von dielen Infekten; die eine voh Paykull die andere von Gravenharst, und dera obngeachtet ift es eine Abtheilung, wo es fehr fchwer ift die Arten unter ihre Gattungen zu bringen; denn aufserdem dals die Abtheilung fo fehr zahlreich ilt, find die Individuen oft fehr klein und zeigen untereinander viele Uebreinftimmungen.

Man findet die Brachelytren an allen feuchten Orten, meilt unter todien Körpern, Mifthaufen, auf Pilzen und befonders da wo organifiche Körper verwelen. Nur eia:ge Arter findea ach in ibren letaten Zulan- 
de auf Blumen. Auch ihre Larver lieben feuchce Orte: fie fehen dem vollkommnen Infekt etwas ähnlich. Die Puppe gleicht, der der Küfer überhaupt.

Obgleich hier nur fïnf Gattungen in diefer Familie beftimmt find, Co Collen doch auch die Rïckfichten angegeben werden, wodurch einigg Entomologen veranlafst find, Unterabtheilungen dieler Gattungen mach weniger deutlichen Eigenheiten zu machen.

1. Die Paublä̈er (ítaphylinus L. z. B. ftaph. hirtus L.) haben Rolenkranzförmige Fühlhörner von runden Gliedern; ilir Halsfchild ift platt und breit; ihre Fühlhöroer fitzen entweder nahe an den Augen oder fie werden von den vorderen Rande des Kopfes getragen. Im erlten Falle ift der Kopf of fchmäler, als das convexe belonders hinten breite HalsIchild und dies findet fich bey den Gravenhorfichen Gattungen rachinus z. B. ftaphil. rufipes L. und tachyporus z. B. Staph. chrylomelinus L. oder der Kopf ift lo breit als das Halsfchild, wird aber von einer Verfchmälerung, wie von einem-Halle, getragen, lo ift es bey Gravenhorfit's Gattungen callicerus z. B. c. obfcurus, omalium z. B. Itaphylin. rivularis $P a^{\prime} y k$. oxyt los z. B. ftaph. piceus $F a b r$. Wenn die Fühlhörner weit von den Augen Litzen, lo endigen die Frefsfpitzen oft mit eiwem dicken Gliede (die Gattung aftrapaeus z. B. Staph. ulmi) oder wenn die Frelsipitzen ganz fadenförmig find; fo ift das Halsfchild entweder regelmälsig viereckig wie bey Pinophilus z. B. P. latipes und lachrobiumn 2. B. Itaph. elongatus oder es ift halbzirkelförmig, und der hintere Rand abgerundet, wie bey den übrigen Raubkäfern. Dies find die Merkmahle, wodurch Hr. Gravenhorft das Studium' diefer Käfer exleichtert zu haben glaubt.

2. Die Pilzfchlïpfer (oxyporus Fabr.) gleichen den, Raubkäfern, aber ihre Fühlhörner find aus kleinen, wie durch und durch gebohrten, Gliedern zufammengefetat; man nennt fie auch durchblätcert. Die meiSten leben in Schwämmen. Z. B. Itaphiliaus rufus.

3. Die Strandfchlüpfer (paederus $F a b r$.) find von allen Inlekten diefer Familie leicht zu unterfcheiden; ihr Halslchild ift lang; ihre Augen wenig-hervorragend; ihre Fühlhörner lang und fadenförmig. Z. B. ftapbylin. riparius.

4. Die Augenfohlitpfor (Stenus Latreille) haben felor grofse Augen wie die Sandläufer; ih: Halslchild if eylörmig, gewölbt, ihr Kopl dreyeckig; ihre Fühlhörner etwas keulförmig. Die meiften leben an Uferr vie die, Uferkäfer mit denen fie einen gleichez Geruch haben. Z. B. Staphylin. biguttatus.

5. Die Gatung Blumenfreffer (Leftesa, Latreille) entfpricht der Gattung Anthophagus von Gravenhorf. Es gehören hieher kleine Inlekten, welche diefe Familie mit den creatophagen durch die Bombardierkafer zn vereinigen lcheinen. Nan findet lie auf Elumen, befonders auf Weilsdorn. 2. B. carab. abbaviatug fabr. 


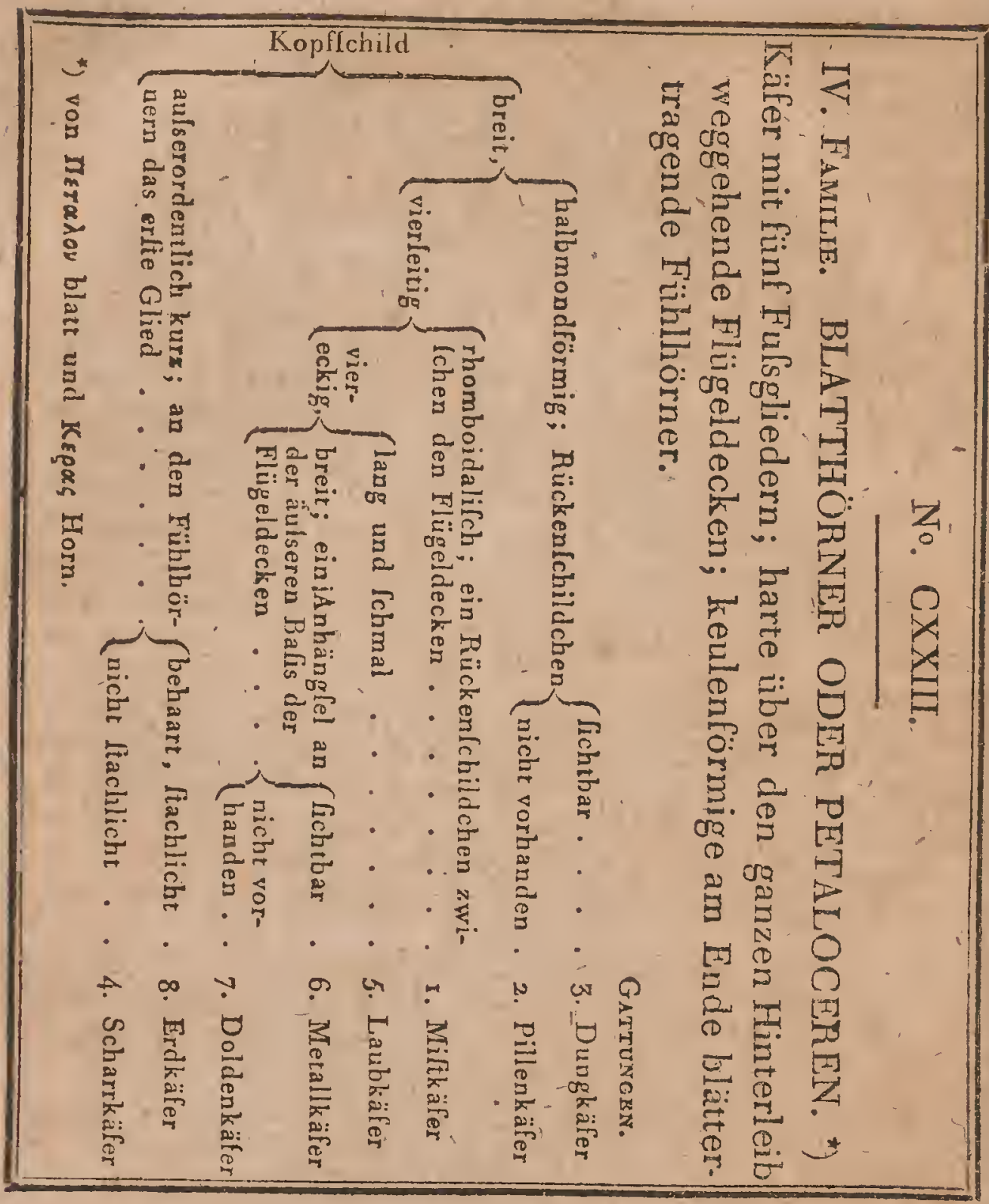

\section{BEMERKUNGEN ZUR LXXIII. TABELLE.}

Die Familie der Blaithürner entfpricht etwa der Linnéifchen Gat= tung Scarabaeus. Alle darin begriffenen Infekten leben während ibres erIten Zuftandes von Ueberbleiblela von Vegetabilien, dic fie unter der Erde oder in den Exkrementen der Thiere finden. Die meiften fiegen falt nur des Abends und des Nachts. Ihr Leben dauert in ihrem vollkomainen Zuftande nicht lange: einige nähren fich, aber nur in diefer Periode, von Phanzen oder Blumenblättern. Alle knmmen aus einér Larve, deron Körper weich und Bogenarig gekrümmt ift, deflen hinteres Ende gaz ftumpf ilt und den After unter fich'hat. Der Kopf ilt Ichaalig mit Warken Mandibeln und Kinnladen verlehen: die Tüsefind kurz, ualue 
an einanderltehend und Cchuppig. In dem erften Zultande bewegt fich wnd geht das Inlekt nur mit Mühe auf ebnen Boden. Die meifien lieben. Mifthaufen, Düngererde, und verlaulte Baumftämme. Wenn ihre Verwandluug vor fich gehen loll, bilden fie fich eine Art von Kokon, und um in ihren vollkommmen Zuftand zu gelangen, find fie gezwungen in einer feuchten Atmosphäre fich aufzuhalten.

I. Unter Miftkäfer (geotrupes Latreille) find hier einige Arten zufamméngeflellt, die lonft zu der Gattung Scarabaeus gezählt wurden. Z. B. Scarab. Itercorarius, fylvaticus, typhaeus, vernalis. Fabricius hat dea Namen geotrupes auf die eigentlichen Scharrkäfer übergetragen.

2. Die Pillenkäfer (copris Geoff.) find, zu der Linnéilchen Gattung Scarabaeus gehörige, Käfer ohne Rückenfchildchen und deren SıirnSchild (der vorderlte über den Mund vorragende Theil der Stirn) halbcirkelförmig ift. Neuerdings that Fabricius diele Gattung in drey andere Gattungen getheilt. Unter der erften Benenung hat er die Arten gelaflen. deren Stirnlchild nur einen einzigen Ausfchnitt hat und deren Bruffechild, wie der Kopf höckrig' oder gehörnt ift. Z. B. Lcarab. feftivus, lunaris L. : in die Gattung ateuchus hat er dio Arten gebracht, welche das Stirulchild gezähnelt, das Brufthlihild aber ohne Hörner oder Höker haben. Z. E. Icarab. lacer. Mit dem Namen onitis belegt er die Arten, deren Stirnfchild ungezähnelt und deren Bruftchild mit vier vertieften Purkten verfehen ift. Z. B. Scarab. bifon L.

3. Die Dungküfer (aphodius Illiger) bilden eine künltiche, den pillenkäfern durch die Form des Stirnlchildes verwandte, Gattung. die lich aber durch die Gegen wart des Rückenlchildchens, des kileinen Schup penftückchens zwilchen den Flügeldecken am Urfprunge der Nabt, unterIcheiden. Man kennt mehr als 80 Arten. Z. B. Scar. fimetarius.

4. Die Schurrkäfer (Scarabaeus $L$ in $n$ ) enthalten hier falt alle die von Fabricius unter dem Namen geotrupes aufgefuhhrten, meilt ausländifchen, Arten. Z. B. Scarab. hercules, actaeon.

5. Die Maikïf er (melolontha) find zu bekannt, als dafs fie hier nock charakterifirt zu werden brauchten. Z. B. mel. vulgaris.

6. und 7. Die Metallkäfer (cetonia Fabr.z. B. \{carab. auratus L.) und die Doldenkäfer (trichius $F a b$ r.) z. B. Scarab. eremita L. unterfchei den fich beym erften Anblick nur durch den Ausfchnitt, den man an der äulseren Balis der Flügeldecken, hinter dem Halsfchild, bey den Doldenkäfern wahnimmt; wo bey den Metallkäfern diefer Zwilchenraum durch eia kleines Stück ausgefüllt ift, das von dem Urfprung der Vorderfuilse ber zu kommen lcheint.

8. Die Erdkëfer (trox Fab r, z. B. Scarab. Cabulolus L.) kommen in cewas mit den Sandkäfern aus derFamilie (15) der Lygophilen überein, wn sericheiden fich aber đurch die Fühlhörner und durch die Z,ahl der'Unterfulsylieder. Die Arten diefer Gartung bringen, wenn man fie auffalst, durch ene plötzliche Bewequng ihres Hinterleibes gegen dip Flügthecken, ein Geräulch, wie daśAncinanderceiben harter liusper, hervor. 


\section{No. CXXIV.}

V. FAMILE. S̈̈GEHÖRNER ODER PRIONOCE REN. *)

Käfer mit fünf Fufsgliedern; harte über den ganzen Hinterleib weggehende Flügeldecken; keulförmige an der innern Seite geblätterte Fühlhörner.

Gatiungen.

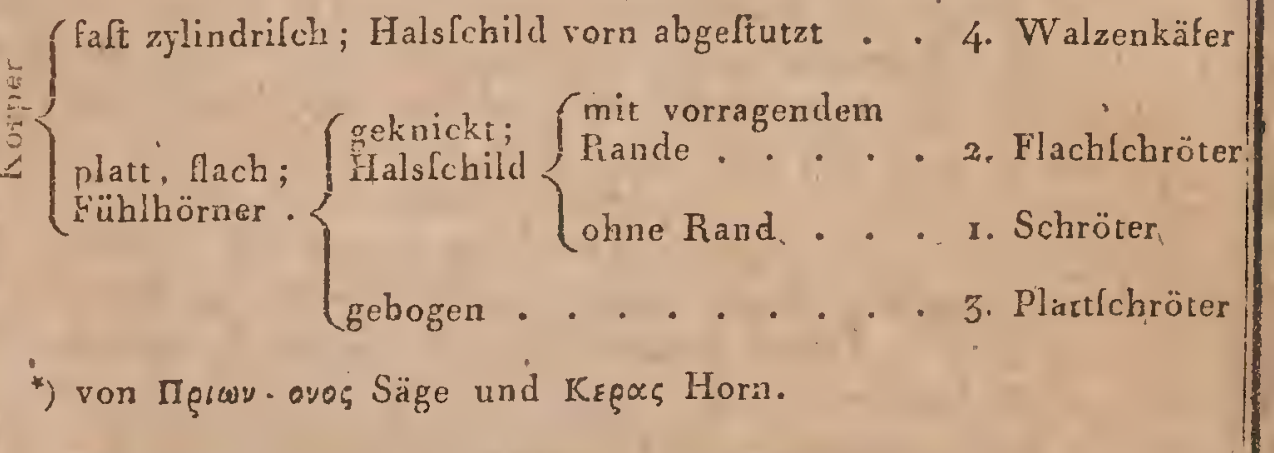

\section{BEMERKUNGEN ZUR CXXIV. TABELLE.}

Twifchen den Infekten der rorigen Familie und den jetzt zu betrachkenden Prioceren finden fich viele Uebercinfimmungen. Ihre Lebensweife ift fali diefelbe: ihre Larven entwickeln fich auch imerhalb vegetabiRifcher Körper, aber die Infekten der gegenwärtigen Familie gehen befonders noch nicht faulendes Holz an. Sie leben vorzüglich in den Stämmen, Stumpfen 'und Wụraeln fchon kranker Bäume. In ihrem letaten Juftande lieben fie den Saft der Bäume, den fie oft, vermittels einer beJondern Einrichtung ibrer Mundtheile, einlaugen. Sie liegen faft nur des Abends, oft find die Weibchen von den meiftens kleineren Mänchen in vieler Hinficht verfchieden.

1. Die Gattung Schröter oder Hirfchfchröter (lucsnus L.) z. B. lucanus cervus $I$. ift, fo zu lagen, der Typus dieler Familie, wo man eisige Arten herausgenommen hat, um die folgenden Gattungen zu biden. Thre Fühthörner find keulförmig, zulammengedrückt, gezähnelt und hineer dem erften Gliede, was allein fo lang ilt wié alle übrige, wie geknickt oder wie gebrochen. Ihr platter. Körper bildet falt ein länglichtes Viereck. Der Lehr breite Kopf endiget in der Mirte in ein fpitzes Stirnfchild, mater welchom nan die barige pinfelfömigen Kinnladen fieht. Die 
Mandibeh ader Kinnbacken find bey den Männchen of fehr lang, wahyIcheinlich um bey der Regattung zum fefthalten zu dienen.

2. Die Flachfchröter, Platthörner (platycerus Geoffroy) Find hies nur noch eine Abtheilung der Gattung, die Geoffroy in leiner Hifíoire abregée des infeccles des environs de Paris unter demfelben Namen aufleilte. Fabricius hat den Namen beybehalten, um die Infekten darinter zu laflen, die Geoffroy cheorettes nannte z. B. Lucan. caraboides. Diefe Iulekten haben keine in ein Haarbüfchel endigesde Kinnladen. Man findet fie oft auf den Blättern der Bäume, woron fie lich in iliren letzten Zuftande nähren. Ihr Stirnfchild ift ausgelchnitten; aber fie haben wie die Schröter vier Endklauen an allen Unterfülsen.

3. Die Plattfchröter haben ihren Namen (paflalus $F a b r$.) daher er. halten, weil die hiehergehörigen Käfer in ihrem Larvenftande die Baum* ftämme wie mit einen Nagel durchbohren. Es lind die Arten diefer Gattung in Amerika und Indien einheimifch and leicht zu unterfcheiden fowobl durch ihre Fühlhörner, deren erftes Glied nicht wie bey den beyden vorhergehenden Gattungen verlängert ift, als auch durch das mangelnde Rückenlchild. Z. B. Lucanus interruptus.

4. Die TWalsenküfer (finodendron $F a b r_{0}$ ) werden of in den durchfägren Baumfiämmen gefunden, machen aber nur eine kleine Zahl aus, die man fónlt zu den Skarabéen zählte. Sie gleichen den Platthörnern háben áber einen zylindrifchen Körper, "Die Männchen haben wis viele Gillenkäfer ein Horn auf dem Kopfe. Z. B. Scarab. cylindricus L. 


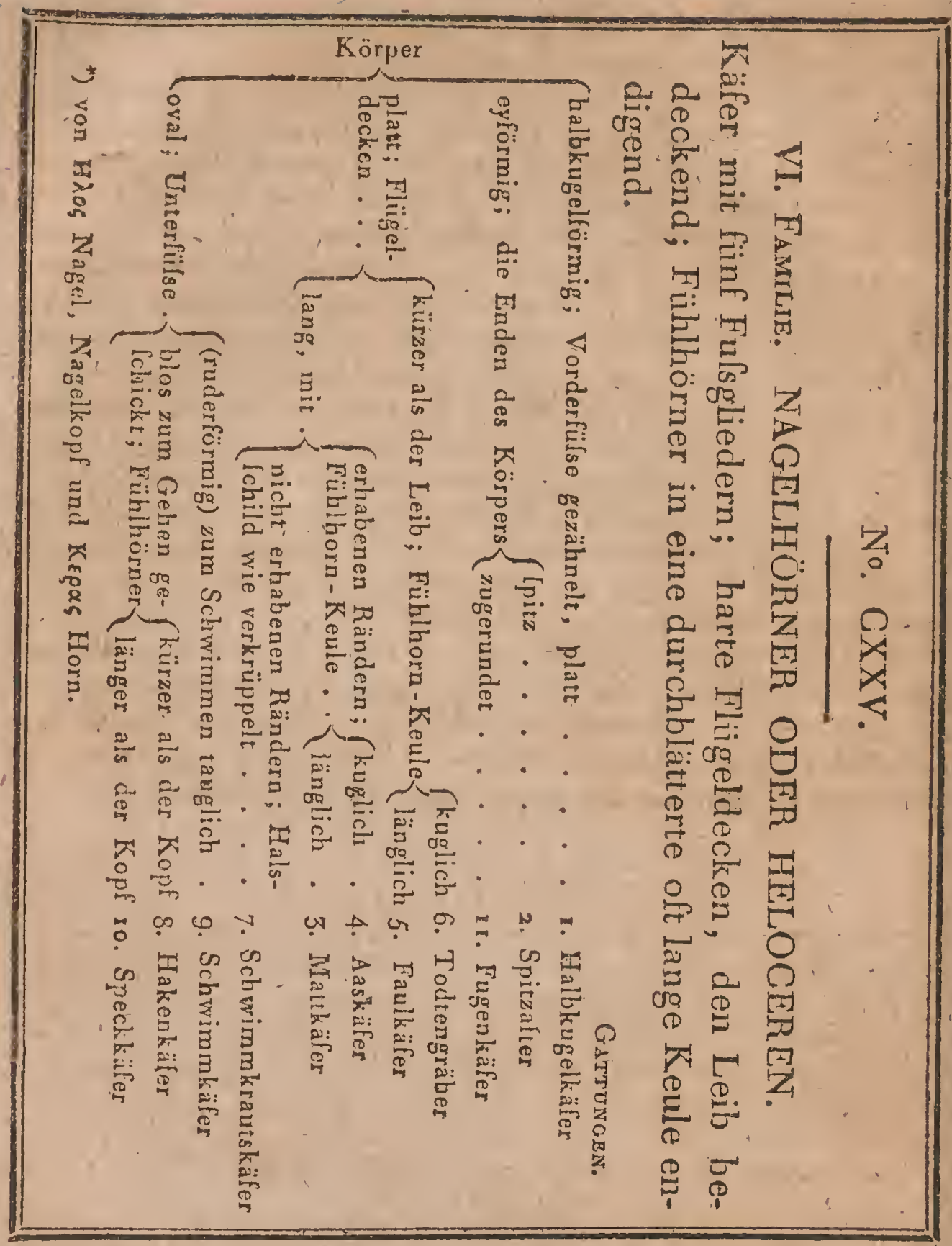

\section{BEMERKUNGEN ZUR CXXV. TABELLE.}

Die Infekten aus der zahlreichen Familie der Heloceren näbren fich alle ohne Ausnahme, von todten faulenden Körpern. Es Iclieint als wenn fie von der Natur beauftragt wären, alles verdorbene wegzufchaffen. Sie dringen allenthalben hin wo fich nur Dinge finden können; wovon fie fich nähren: ins Waffer, an die Ufer, an die trockendften unfruchtbarften Orte, tiaf nnter die Erde wie an ihier Oberläclie. Die meilten feheinta mir einem tehr vollkommnen Geruchsfin werfehen zu leyn. 
1. Die Halbkugelkäfer ('phaeridium Fabric.) z. B. dermeftes faraLaeoides L. leben im Kubmift, in den Gefchwülften der Bäume, unter der Rinde der in Feuchtigkeit vermodernden Bäume und einige in ver welkenden Blumen.

2. Die Spitzafter (lcaphidium Olivier z. B.flilpha agaricina L.) finden fich in den Schwämmen und vorzüglich in den in Verderbnils übergehenden Boletus Arten.

3. Die Matcküfer (nitidula Fabr.) führen dielelbe Lebensart wie die Spitzafter, z. B. filpha quadripultulata L.) gleichen aber, der Form nacl, mehr den Aaskäfern. Mehrere Arten leben auch auf ausgetrockneten Thierüberbleibleln.

4. Die Aaskäfer (Silpha Fabr. z. B. Silpha thoracica, L.) mit nich verkürzten Flügeldecken, halten fich in den Kadavern von rückgrathigen Thieren auf; nur einige nähren fich von Raupen.

5. und 6. Die Faulkäfer (peltis Geoffroy (Silph. 4 punctata L.) und der Todiengräber (necrophorus z. B. Silpha vespillo) fucben, befonders die der fünften Gattung die allerftinkenfter, faulendlten Kadaver. Die der fechsen Gattung machen fich an kleine todte Thiere, 2. B. Mäule, Maulwürfe, Frölche. Es kommen ilirer mehrere zufammen um ein lolches Kadaver, wohin lie ihre Eyer legen, einzuicharren.

7. und 8. Der Schwimmkrauckïfer (elophorus Fabr. Z. B. Silpha aquatica L. und die Hakenkïfer (parnus Falr. z, B. Parn. prolifericornis. Fabr, dryops auriculata Latr. leben im Waller. Man findet fie gewöhrlich auf faulenden Waferplanzen; ihre Lebensart kennt man nicht.

9. Die Schwimmkäfer (hydrophilus Geoffr. z. B. Hydr. piceus) die man lange als mit dem Waflerkäfer nah verwandt anfah, unterfcheiden fich doch durch ihre Lebensart fehr. In ibrem vollkommnen Zultande nähren fie fich vou Blättern die ins Wafterfallen und von andern faulenden Vegetabilien.

10. Die Speckkäfer (dermeftes I. z. B. Dermeft. lardarius, frellen gern, wie der Name ausdrückı, Häute. 'Sie bilden eine an Arten fehr zahlreiche Gatturg, man hat an zweyhundert bereits belchrieben.

I. Die Fugenküfer (Byrrhus Fabr.z. B. Byrrh. pilula L, entfernen fich durch die Körperform etwas von dan Infekten diefer Familie. Ihre Lebensart ilt gang unbekannt. 


\section{No. CXXVI.}

VII. Familie. FESTHÖRNER ODER STEREO CEREN. *)

Küfer mit fünf Fufsgliedern; harte den ganzen Hinterleib bedeckende Flügeldecken; Fühlhörner mit runder fefter Keule.

Gattuagen.

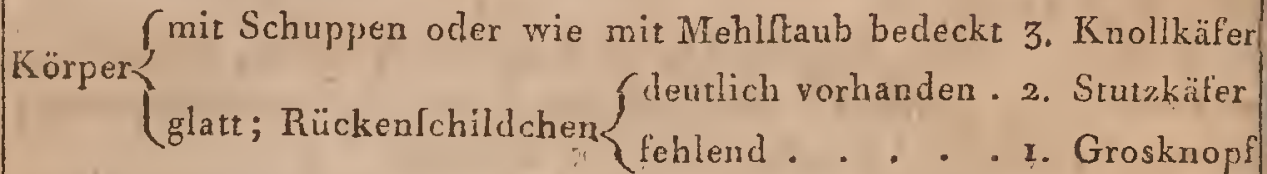

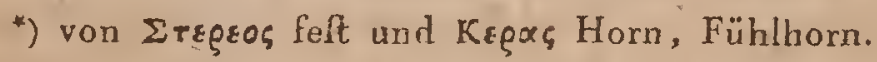

\section{No. CXXVII.}

VIII. FAMILIE. BRUSTSPITZEN ODER STERNO. XYTEN. *)

Käfer mit fünf Fufsgliedern; harte grofse Flügeldecken; langer platter Körper; fadenförmige oft gezïhnelte Fühlhörner; vorftehendes Sternum.

Gatruncien.

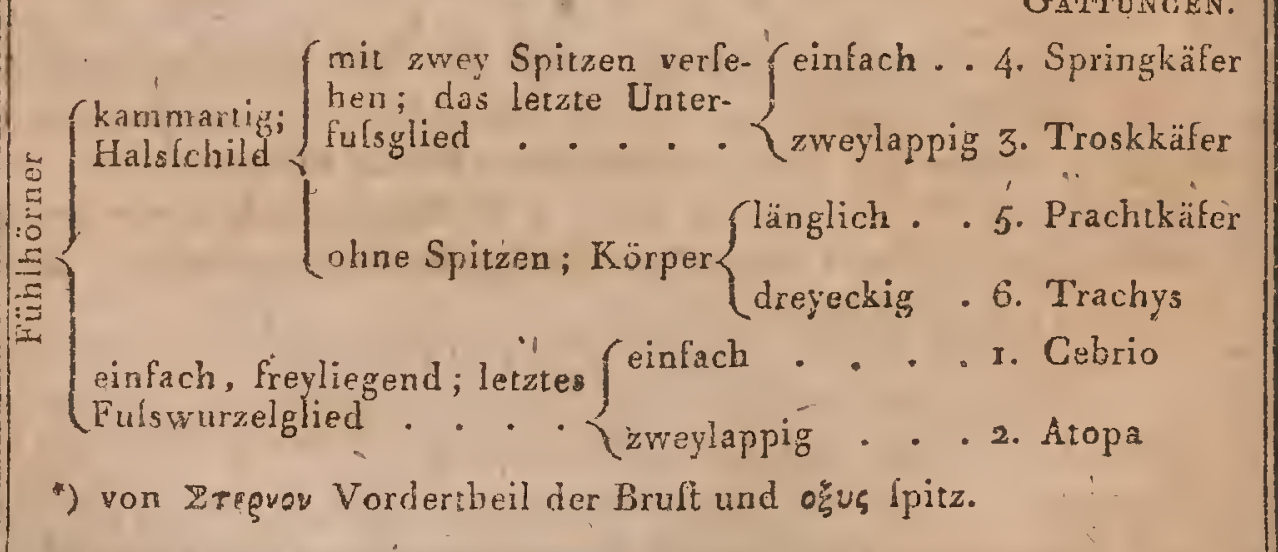

\section{BEMERKUNGEN ZUR CXXVI. TABELLE.}

Die Küfer mit felten Fühlhönern Stereoceren bilden eine an Arten nicht reichhaltige Gattung, dic, was die Lebensar anlang, den Heloce. ren rahe ru lommen lcheint. 
r. Die Gattung Grosknopf (lethrus Fabr. Bulbocerus Thunberg) die ton einigen bey die Miftkäfer geftellt wurden, veichen von iknen durch die Form der Fühlhörner ab. INan kennt nur eine Art genau; lethr. cephalotes, deren Flügeldecken verwachlen und deren Vorderfülse gozähnelt find.

2. Die Stutzkäfer (hifter L.) bilden eine fehr zahlreiche Gattung: alle Arten haben die Vorderfülse breit gebildet und bedienen fich derfel. ben um in die Erde zu graben. Die Flügeldecken find gewälnlich kürzer als der Leib und, der Kopf fitat in einer Vertiefung des Halsfchildes. Man findet fie im Koth. Z. B. hift. unicolor L.

3. Die Knollkäfer (anthrenus Fabr.) leben wirklich wie ihr Gattungsiname es angiebt auf Blumen, aber nur während ihres letzten Zuftandes; denn ihre Larven nähren fich von animalifchen Subftanzen. Diele Käfer find den Sammlungen über Zoologie befonders nachtheilig. Ihr Körper ift mit kleingefärbten Schüppchen, wie ein Schmetterlingskörper, bedeckt. Es lind fehr kleine Thiere z. B. Byrrhus lcrophulariae L.

\section{BEMERIKUNGEN ZUR CXXVII. TABELLE.}

Die Larven der Infekten dieler Familie, leben im Innern der Baumflämme, wo fie fich Gänge aushöhlen, wie die Infekten der folgenden Fa. milie, von der fie fich aber vorzüglich durch die Körperform unterfchei den.

1. und 2. Die beyden erften Gattungen Alopa (atopa Payliull z. B. chryfomela cervina L. und Cebrio (cebrio Olivier) z. B. ciftela gigas Roffi, enthalten nur wenige ausländifche Arten. Ihr Kopf lat eine andere Richtung als ihr Körper; ihre Fühlhörner liegen in keiner Furche. Thr Sternum ift mit keinem Stachel bewaffnet, wodurch lie fich von den andern vier Arten unterlcheiden.

3. und 4. Die Springkïfer (elater L. 2. B. elater ferrugineus) und die Trosken (Throscus Latr. z. B. elater dermeltoidos"L. ltimmen unter einander in mancher Hinficht überain. Ihr Sterntim ift in eine fteife elaftifche Spitze verlängert, welche die Stelle einer Feder verfieht, in dem fle in eine an der Bruft befindliche, entfprechende Vertiefung einfpringt. Dadurch find fie im Stande, fich wieder aufzurichten, wenn fie auf den Rücken zu liegen gekammen find, was fie fonlt zu thun nicht im Stande wären, da ibre Fülse zu kurz find. Deswegen hat mau lie Springkäfer. geuannt.

5. unfl 6. Die Prachtkäfer (bupreftis Linn. 2. B. B., chryloftigma) und die Gattung traclyys Fabr. z. B. bupreftis minuta L., verhalten fich zu einander ungefähr wie die beyden worigen Gattuxgen, mit denen lie einige Aehnlichkeit haben; aber fie haben nicht das Vermögea zu. Iprint. gen. Sie lind mit lehr fchönen Farben geziert. 


\section{No. CXXVIII.}

\section{Familie. HOLZBOHRER ODER TEREDY-} LEN. *)

Käfer mit fünf Unterfufsgliedern; harte grofse Flügeldecken; fadenförmige Fühlhörner; rundlicher, länglichter, convexer Körper.

Gattungen.
$\left\{\begin{array}{l}\text { am Ende dicker w } \\ \text { kammartig gezäh- } \\ \text { nelt; Halslchild }\end{array}\right.$
werdend .
5. Raulikäfer
$\left\{\begin{array}{l}\text { mit zwey Spitzen endigend } 4 \\ \text { ohne Spitze } . \cdot \cdot: 2\end{array}\right.$
4. Wedelkäfer
2. Federkammkäfer
einfach; $\left\{\begin{array}{l}\text { lebr lang geltreckt, in eine Spitze } \\ \text { endigend . . . . . . }\end{array}\right.$
6. Holzkäfer
Körper .
$\left\{\begin{array}{l}\text { kurz und dick ; } \\ \text { Halsfchild } .\end{array}\left\{\begin{array}{l}\text { Chmaler als der } \\ \text { Hinterleib. . } \\ \text { eben lo breit als } \\ \text { der Hinterleib -. }\end{array}\right.\right.$
3. Nagelkäfer
1. Bohrkäfer

*) von $\tau \varepsilon \rho y_{1} \delta \omega \nu$ Bohrer und $x \lambda y_{1}$ Holz.

\section{BEMERKUNGEN ZUR CXXVIII. TABELLE.}

Die zu der Familie der Holzholurer gehörigen Inlekten zerftören als Larven das Holz. Sie find an dex zylindrifchen langgeftreckten Form ih res Körpers fehr leicht zu erkennen und lo auch an ihren langgliedrigen, oft kammartig gezähnelten, Fühlhörnern. Die meiften nähren fich im vollkommen Zultande von asdern Inlekten und fcheinen den Uebergang zu der lolgenden Familie zu machen.

Die Gattung der Bohrkäfer (anobium Fabr. z. B. annob. pertinax) hat ihren deut [chen Namen von dèn Löchern welche die dahingehörigen Arten in das Holz bohren; der andere Name zeigt auf die fonderbare Eigenheit hin', dals diele Infekten im Stande find, nach dem fie fich meh rerc Stunden lang, lelbft während fie hefrig gequält werden, codt geftellt haben, wieder zu erwachen oder munter zu werden, Cobald fie die Gefahe für vorübergegangen anluluen. Lhr. Halslchild hat vorn die Gefkalt einer 
Kappe, worin der Kopf ganz verhorgen ilt'; die Fuhlhŏrner begen fich ganz unter den Körper und die Fülse bedecken diefelben. Oft laflen die Bohrkäfer in dem Holze, was lie zernagen, einen fchwingenden Ton hören, , weswegen fie von $S$ w a mmerd a $m$, Sonicephalus genannt worden find.

2. Die Federkanmkiifer (ptilinus Geoffr. Fabr.) haben ilire Benennung zuerft voh den Federn erhalten, womit bey einigen Arten die Fühlhörner verfehen find. $Z$. B. ptilinus pectinicornis." Sie find den Bohrkäfern fehr ähnlich.

3. Die Nağelkäfer (ptinus Lin.) weichen von den beyden vorigen Gattungen nur durch die Stellung der Fühllhörner ab, welche, flatt vor den Augen und von einander enternt zu fitzen, im Gegentheil zwifchen den Augen und dicht an einander fitzen. Das-Halsfchild hat bey ihnen auch eine belondere unterfcheidende Form. Z. B. ptinus fur.

4. Die Thedelkäfer (melatis $F a b r$.) haben das Halsichild hinten in zwey Spitzen éndigend, wie dic Springkäfer, aber fie haben ron diefen nicht das Sternum und die Körperform ift auch fehr verfchieden. Man kennt nur zwey Arten, von braunfr Farbe. Z B. elater bupreftoides L.

5. Die Rauhkäfer (tillus Olisier) z. B. chryfomela elongala'L. find lange Zeit unrecht befiimmt worden. So hat man wobl einige Arten mit den Immenkäfern verwechfelt, die cioch nur vier Glieder an dem Unterfufse haben, und deren Larven Infekten freflend find.

6. Die Holzkäfer (lymexylon) haben einen fchr langen und fchmalen Körper, fehr grofse Augen und weiche Flügeldegrién wie die Infekten der folgenden Familie. Diele Infekten richten in dem Bauholze grofse Verwüftungen an. Das Weibchen, was in leinem ausgebildeten Zuftande Inlekten frifst, tegt vermittels einer langen am Ende des Hinterleibes befindlichen Röhre, leine Eyer in die Ritzen, welche auf dem Anfchnitte gefällter, trockner Baumftümme entftehen. Dio aus diefen Eyern kommende Larve braucht zwey Jahre zu ihrer Entwicklung, fie höhlt im Innern des Holzes Kanäle aus, welche fie mit Spänen gefüllt lälst, wodurch die Feuchtigkeit der Luft angezegen nud, mit der Verminderung der. Feftigkeit qugleich auch, die Fäulnils hervorgebracht wird. Z. B، canțariș navale L. 


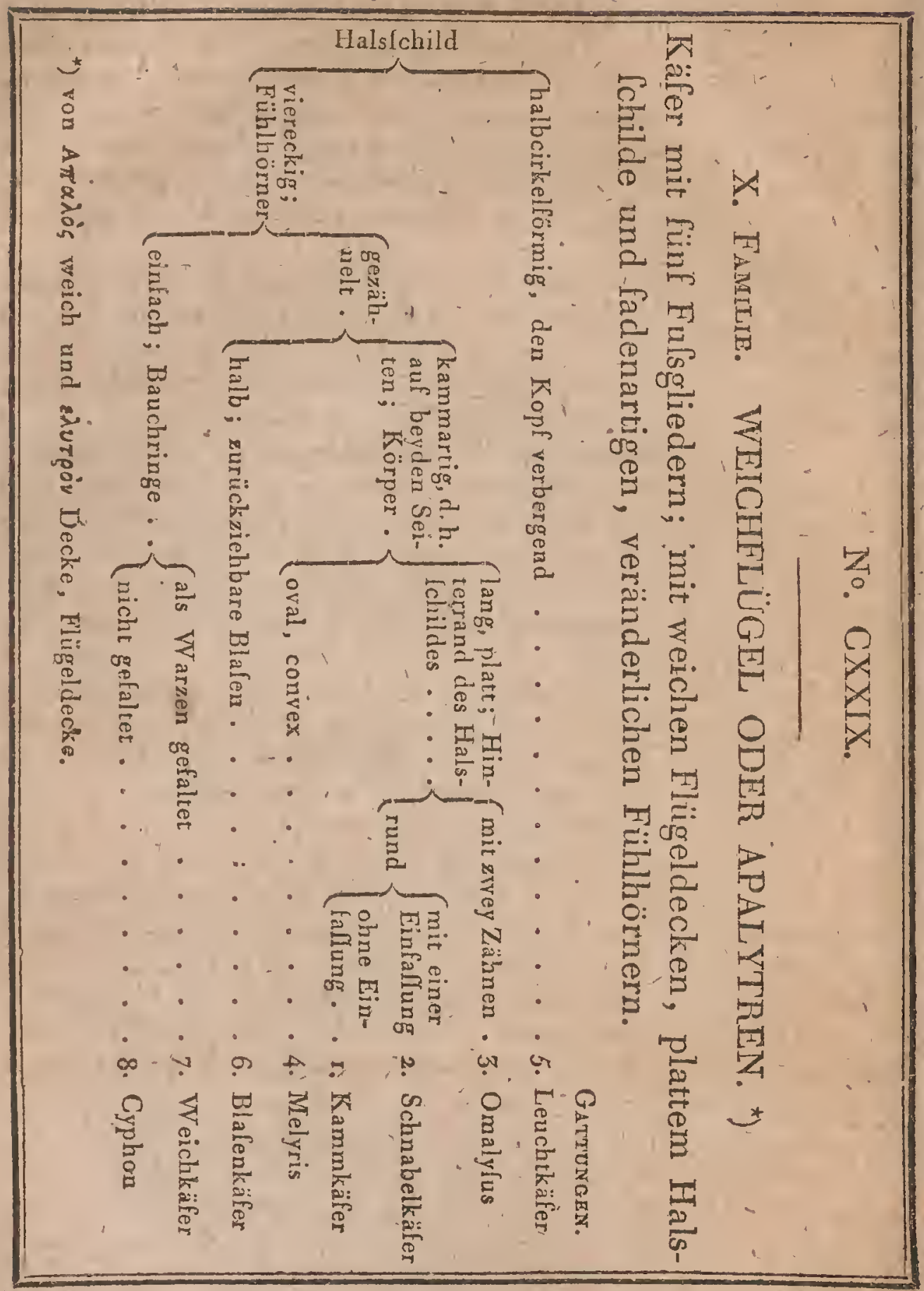

\section{BEMERKUNGEN ZUR CXXIX. TABELLE.}

Die Infekten aus der Familie der Apalytren machen, nicht weniger als die Creatophagen, Jagd auf kleine ihnen zur Nahrung dienende Thiere, die fie aber nur lebendig verzekren. Thre Flügeldecken find, vrie der Na- 
me lagt, weich und befchützen den Körper nur wenig. Die meiften laufen lehr fchnell; fie fliegen fehr gut, anbaltend und oft in berrächtich weite Entfernungen. Obgleich'die Gattungen dieler Familie zahlreich find und einige von ihnen fehr reich an eirsheimifchen Arten find, fo iff die Art ihrer Metamorphofe doch nicht bekannt.

I. Die Kammkïfer (drilus O livo) nähern Cich den Federkammkä. fern p: 2og.; aber der hieher gehörige Drilus flavescens Fabr. hat. weichere Flügeldecken und ift nicht auf Hölzern zu finden.

2. Die Schnabelkïfer (lycus Ifa $b$ r.). befonders die ausländifchen Arten, haben of die Flügelilecken, an ihrem freyen Ende, fehr ausgebreitet. Z. B. lampyris latifima Lin.

3. Der Name Omalyfus Ge offroy zeigt den beträchtlich platten Körper bey dem einzigen Infekt an, was hieker gehört. - Die Fühlhörner find fadenförmig und ftehen mit ihrer Bafis einander fehr nahe. Das Brufifchild ift viereckig und endigt fich, wie bey den Springkäfern, hinterwärts in żwey Spitzen. Z. B. O. luturalis.

4. Die Gattung Melyris, Olivier. beltelit nur aus zwey afrikani. Ichen Arter. Ihre Fühlhörner lind gezähnelt; ihr Kötper kurz, oval, und etwas convex. Ihr Kopt liegt vertikal, untex einem viereckigen Halsfchilde mit aufgebogenen Rändern. Z. B. melyr. viridis $F a b r$.

5. Die Gattung Lettchtküfer oder Leuchtzutrm (lampyris Lin.) unterfcheidet lich leicht durch die Form des Halsfchildes, was den Kopf Carnt den grolsen Augen bedeckt. Z. B. L. hespera L.

6. Die Blafcukäjer, auch von einigen Weichkrifer genannt, (malachius $F a b r$.) haben einen weichen Körper und find von Geoffroy als cicindeles a cocardes aufgeführt, weil lie aus ihrem Halsfchild und Bruftftück farbige Tentakeln liervorftrecken können. Z. B. cantharis a enea $L$.

7. Dio Weichkïfer haben von de Geer den Namen telephorus, d. h. von fern hergetragen, erlialten, weil man diele Inlekten nach einem ftarken Sturm, wie ein Pegen, aus der Luft hat fallen fehen. Z. B. Cantharis fusca $L$.

8. Die Cyphons (Cyphon, $P$ a $y k u l l$ ) bildon nur eine einftweilen aufgeftellte Gattung. Man rechnet dahin Käfer, die man auch zu den Farlenkäfern p. 2ig., Erdflohkülern p. 232 und Furchtkäfern gezählt hat. Latré $i$ l le hatte diele Gattung zuerlt aufgeftellt und ihr den Narnen elodes gegeben. Der'Körper ift halbkugelförmig und die meiften können fpringen. Z. B. C. haemisphaericus Fa $6 r$. 
Koleopteren.

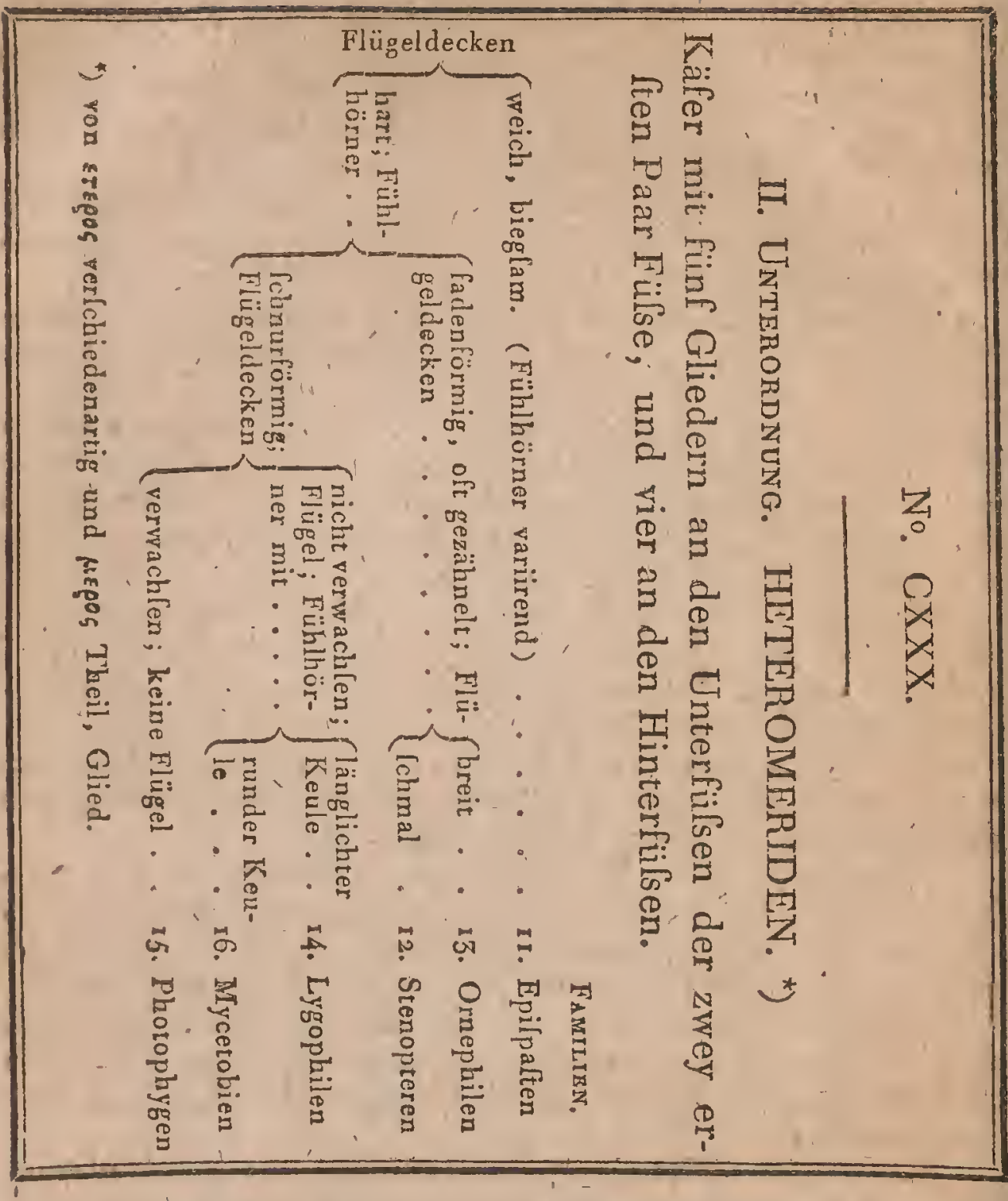

\section{BEMERKUNGEN ZUR CXXX. TABELLE.}

Obgleich man eigentlich nicht weils, in welchem Verhältnils die Zahl der Fufsglieder und die Lebensart der Infekten zu einander ftehen, und welchen Einfluls fie haben können, lo ift es doch darum nicht weniger merkwürdig, dals gewiffe Infektenordnungen immer dielelbe Zahl von Fulsgliedern in allen ihren Arten zeigen, während dafs man bey an= dern grolse Verfchiedenlieiten wahrnimmt. Die Unterordnung der Heteromeridên befonders zeigt èine fonft bey den andern Infekten nicht vorkommende Bildung und aile haben auch faft gleiche Lebensart. Im, Ganzen flieber alle das Helle, Giegen oder laufen nur des Abends herum 
und halten fich an dunkeln Orten auf. Alle bisjetzt bekannte Arter, ohne Ausnahme, nähren fich blos von vegetabilifchen Subftanzen; und vorzüg̣̣ lich lieben fie diefelben, wenn fie anfangen in Verderbnils überzugehen.

Obgleich die hier zur Bezeichnung der Familien gebrauchten Namen mehr eine Eigenheit der Lebensart als eine charakteriftilche Eigenthümlichkeit der,Bildung anzeigen, fo Icheinen fie doch nicht weniger zweckmärsign, um den Naturforfcher die dahin gezählten Infekten ins Gedächtnils zu bringen, weil doch alle diefe Infekten Verlchiedenheiten in der Form und Fefîtigkeit der Flügeldecken und verfchiedene Bildungen der Fühlhörner zeigen.

Die Flïgeldecken heilsen bey einer ( $x$ I) Familie weich, im Gegenlatze von den härteren der anderen Familie. Aber ihre Bieglamkeit if doch geringer als bey den Apalytren der vorigen Unterordnung. Uebrigens zähren fich die hiehergerechneten Inl'ekten nicht von kleinen Thieren ; man fiudet fie auf Blättern und Blumen und lie fliegen nur des Abends.

Blos die Stenopteren bilden eine Familie, deren Name von der Bil. dung gewifler Theile ihres Körpers hergenommen ift; auch ift die Verfchmälerung ihrer Flügeldecken fehr aulfallend und deutlich.

Die Ornephilen Icheinen faft diefelbe Lebensart zu führen als die Lygophilen, aber die erfteren fuchen weniger die Dunkelbeit. Man fieht fie bey Tage an fchattigen Orten unter Bäumen herumfliegen.

Die Photoplygen haben Flügeldecken, welche verwachfen find und den Hinterleib umgeben; gar keine häutige Flügel. Sie können nur gehen und felbft dies nur fchlecht und Ichleppend, da bey den meilten der Hinterleib grols und die Fürse Ichlecht artikulirt find: es find dies die Tar. digraden unter den Infekten, fie nähren fich nur von faulem Holz und Vegetabilien.

Die Mycetobien enthalten die kleinften Arten diefer Ordnung; fie Ccheinen fich blos von Schimmel, Moos und Champignons zu nähreu. Ihr Körper ift platt, fie halten lich unter Steinen oder unter Rindén und in den Vegetabilien auf, vor denen lie fich nähren. 
Koleopteren.

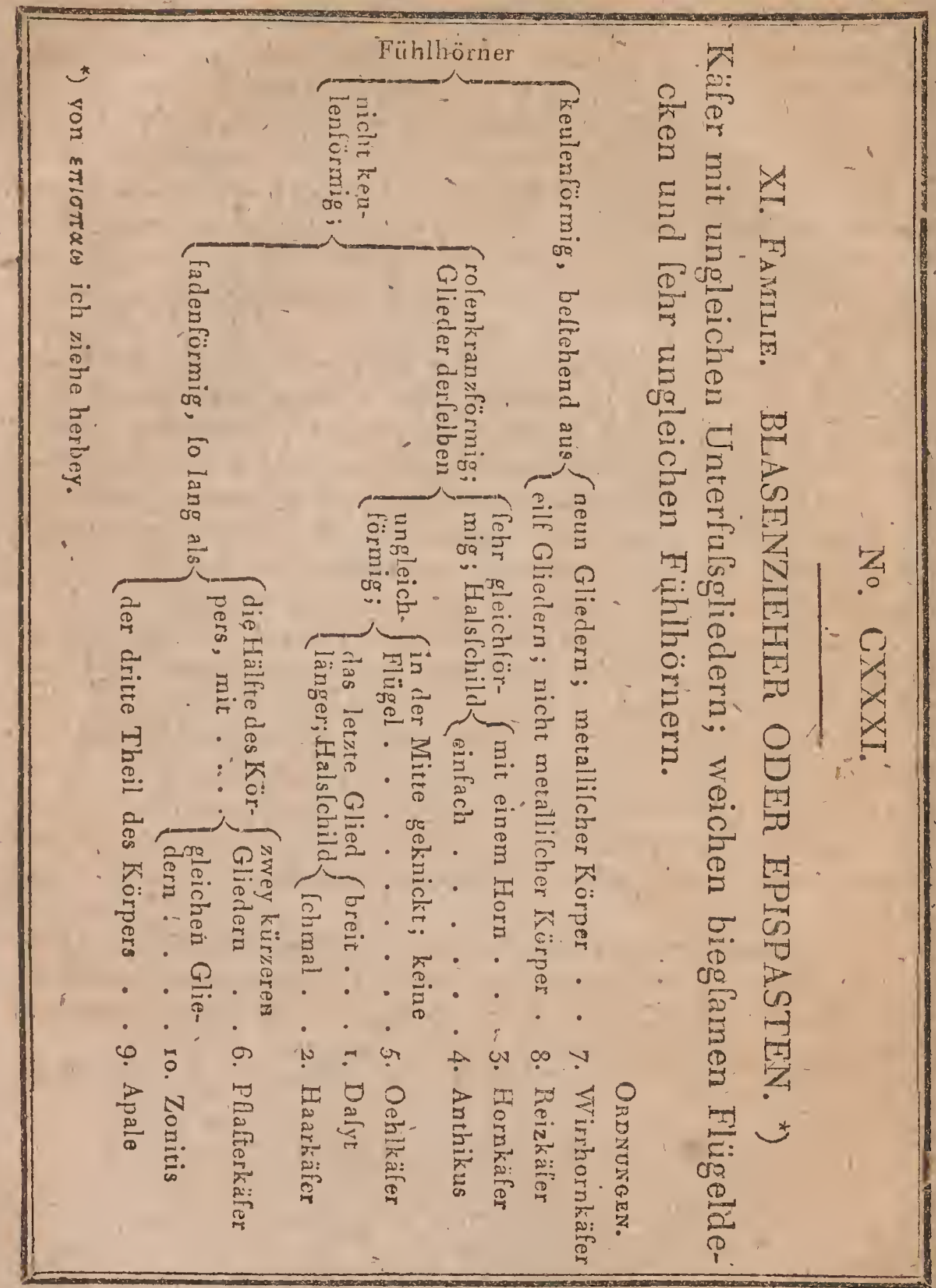

\section{BEMERKUNGEN ZUR CXXXI. TABELLE.}

Die Familie der Epifpaften, die fo nach an der Spitze derjenigen Ko. leopteren ftehen, welchefünf Glieder an den Vorderfüfsen und nur vier a dea Hinterfülsen haben, gränzen vollkommen an die Apalyeren der vorigen 
Unterordnung. Man kennt die Lehensart der Larven diefer Inlekten nur fehr. weuig; aber das was wir durch die Bøobachter (de Geer) bisjetzt dayon wiffen, muls die Neugierde fehr rege machen.. In ihrem vollkommnen Zuftande findet nan diele Infekten auf den Blumen und Blättern gewifler Bäume, wovon fie fich nähren. Man hat ihnen den Namen Blafenzieher gegeben, weil viele hieher gehörige Arten die Wirkung eiser leichten Verbrennung hervorbringen, wenn man fie auf die Haut leght. So ilt es wenigftens mit den Reizkäfern und Pfalterkäfern.

1. 1. 2. Die Gattung Dafyt (dafytes $P a y k u l b$ z. B. Dermeltes hirtus' L.) und 'Haarkäfer (lagria $F a b r$. ) z. B. Chryfomela hirta L. haben durch ibren Namen eine ihrer Haupteigenheiten ausyedrückt, nemlich die, dafs ihr Körper mit Haaren bedeckt ift. Durch dielen Umltand begreift man auch, dafs lich die Zahl ihrer Unterfufsglieder aicht gut unterfuchen lafle.

3. 11. 4. Die Hornkäfer (notoxus $S c h \ddot{a} f f e r z$. B. meloe monoceros L. und die Gattung anthicus Paykull z. B. meloe antherinus L. unterlcheiden fich blos durch die Form des Halsfchildes.' Man findet lie gewöhnlich auf Blumen und befonders auf Doldenblumen.

5. Die Oelkäfer (meloe L.) z. B. meloe profcarabaeus find als der Typus dicler Familie anzufehen. Es gehören jetzt hieber uur die Arten óhne häutige Flügel. De Geer hat ihre Larve als Schrnarotzerthier auf dem Körper einiger zweylügeligen Fliegenarten gelehen, aber ihre Verwandlung nicht verfolgen können.

6. Die Plafterkäfer (cantharis Geoffroy; lytta Fabricius) find die Inlekten, deren man fich am meiften in Europa bedient un Blalen zu ziehen. Sie leben, in Perfien, lehr gefellig auf den Efchen, Weiden und fpanifchen Flieder. Ihre Lebensart und Entwickelung kannt man noch nicht. Z. B. meloe veficatoria L.

7. Die Wirrhorikäfer (cerocoma Geoffr.) heilsen lo, weil-ihre Fühlhörner eine ganz helondere Form haben, und wie ein Haarwulf, durch die gezähnelton Zacken in der Mitte, ausfehen. Z. B. Gerocoma Schälferi fia b.r.

3. Die Reizkäfer (mylabris Fabr.) haben die Flïgeldecken etwas dachfömig, de Körper wie mit einem Buckel verfehen, das Halsfchild fchmäler als Kopf und Flügeldecken. Z. B. meloe cichorii L.' In China und Indien foll man Arten diefer Gattungen zu Blafonpflaftern anwenden.

9. Die Gattung Apale (apalus F a br. ) gleicht den Reizkäfern fehr; aber die Fühlhörner find hier nicht keulförmig. Von den Pfálterkäfern unterfcheiden fie fich durch das Rückenfchildchen. Z. B. meloe binaculatus $\mathrm{I}$.

10. Man kennt nuŕ cinige fremde Arten der Gattung Zonitis Fabr. fie gleichen denen der vorigen Gattung, aber ihre Füllhörner fiud viel kürzer. Z, B. Zon, vittata Fabro 


\section{No. CXXXII.}

XII. FAMLIE. SCHMALFLÜGEL ODER STENOP TEREN. *)

Käfer mit ungleichgliedrigen Unterfüsen; harte, Ichmale Flïgeldecken. Fadenförmige oft gezähnelte Fühlhörner.

GATTUNGEN.

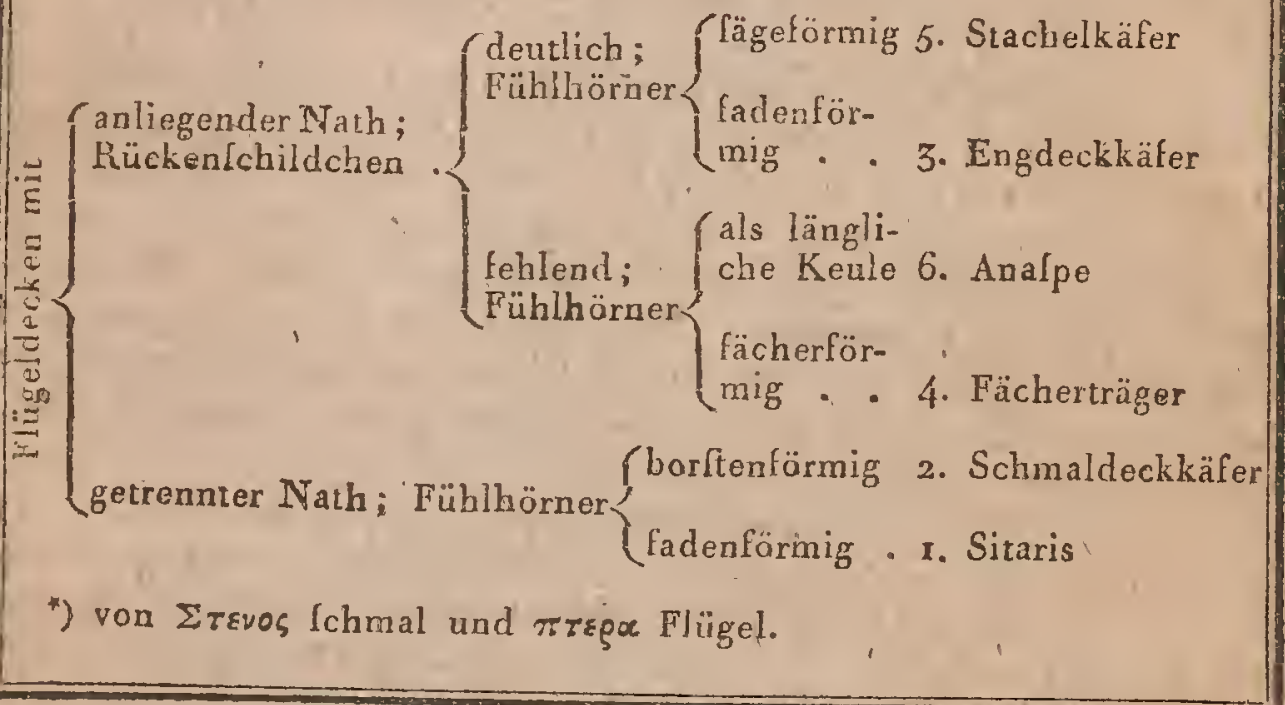

\section{BEMERKUNGEN ZUR CXXXII. TABELLE.}

Die Stenopieren haben fo londerhar gebildete Flügeldecken, dafs es leicht ift lie auf den erlien Blick zu unterfcheiden. Ihr freyes Eride il immer fchmäler als die Bafis, was den ganzen Körper ein fehr fonderbares Anfehn und Halcung giebt. Man kennt die Lebensart der Inlekten, die in dieler Familie vereinigt find, fehr wenig'; doch Icheint fie lehr verfchieden zu ́eyn, wenn man lie nach der Verfchiedenheit der Orte beurtheilen loll, wo man lie findet, da einige auf Blumen, andere im Lehm und wieder andere in Baumftämmen und Rinden gefunden werden.

1. Die Gattung Sitaris (Sitaris Latreille) enthält nur eine Art, die cantharide a bandes jaunes Geoffr. man findet fie in Herblt lehr häufig an Lehmwänden. Man glaubt, dals fie fich in ihrem erften Zuftande von dem Wachs oder den Larven dér Mauerbiene nähren.

2. Der Name Oedemera, Olivier, bedeutet aufgetriebener Scherkel. Diefe Eigenthümlichkeit wird zwar nicht an allen hierher gezählte 
Arten wathrgenomimen, auch nicht bey beyden Gelchlechtern gefunden. Aber auch aufser dem auf der Tabelle angegebenen Charakter kann man fie noch durch das in der Mitte wie zulammengefchnürte Halsfchild und durch ihren fehr vorltehenden Mund unterlcheiden, Z. B. necydalis coreut lea $F \backsim b r$.

3. Die eigentlichen Engdeckkäfer (necydalis Fabr.) haben vieles mic den Arten der vorigen Gattung gemein, mit der einige entomologifche Schriftlteller fie auch vereinigen. Ảber ihre Fühlhörner find fadenförmig, ihr Halsfchildchen nicht zulammengefchnürt, die inneren 'Ränder des Flügeldecken an der.Bafis vereinigt, am freyen Ende von einander ftehend, und ihr Mund nicht fo vorltehend. Man findet fie auf Blumen. Z. B. Nec. rufa.

4. Die Gattung Fächerträger oder Ripiphorus, Fabr. hat ilıren Namen von den, mit tiefen Einlchnitten verlëhenen, Fühlbörnern der Männchen. Die ganze Geftalt dieler Infekten ift höchft fonderbar., Der Kopf ift vorn abgeftutzt und wie mit einem verlängerten Scheitel verfehen. Das Halslchild fteht nach hinten mit einer Spitze vor und erletżt, am Anfange der Nath, das Rückenlchildchen. Der Körper ift keilförmig, glatt uyd hinter 'wie abgeftutzt.' Z. B. R. fubdipterus Fab.

5. Die Stachelkäfer (mordella L.) haben einen Ppitzigen Hinterleib, ein Rückenfchildchen an der Bafis und das Halsfchild vorn fehr zufama mengelchnürt. Diefe Infekten lében auf Baumftämmen oder Blumen. Z. B. M. fasciata.

6. Geoffroy hat' die Gattung anaspis aufgeftellt, weil er glaubte, dafs die Arten, die er dahin zählte, kein Rückenfchildchen hätten. Sie haben aber wirklich eins. Doch unterfcheiden fie fichtvon den Fächerträgern dadurch, dafs ihre Fühlhörner allrnählig gegen das Ende zu dicker werden und aus körnerförmigen nicht kammartigen oder fächer' förmigen Gliedern beftehen. Von den Stachelkäfern weichen fie dae durch $a b$, dafs ihr Hinterleib nicht in eine Art von Schwanz endiget und dals ihr Rückenlchildchen unmerklich und nur durch die Lupe wahrzunachmen ift. Z. B. mordella frontalis Lin. 


\section{No. CXXXII.}

XIII. Familie. WALDBEWOHNER ODER ORNEPHILEN. *)

Käfer mit ungleichgliedrigen Unterfüfsen; mit harten breiten Flügeldecken; fadenförmige oft gezähnelte Fühlhörner.

\section{Gattungen.}

falt viereckig: dervor- ausgelchnitten - . . I. Schattenkâfer dere Rand deflelben,. zugerundet . . . 2. Beilkäfer

$=$ vorne fchmäler hinten breit . . . . . . z. Fadenkäfer

in

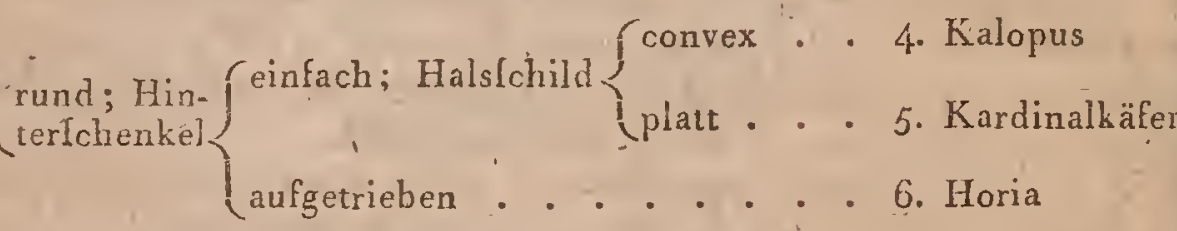

*) von ogin Holz, Wald und $\varphi$ idso ich liebe.

\section{No. CXXXIV.}

XIV. FAMiLIE. DUNKELWOHNER ODER LYGOPHILEN *)

Käfer mit ungleichgliedrigen Unterfüfsen; mit harten nicht verwachfenen Fliigeldecken; fchnurförmige Fühlhörner, keulenartig verlängert.

.Gattung Bn.

$\Xi$ zylindrifch, Ichmäler als die Flïgeldecken . . x. U.pis

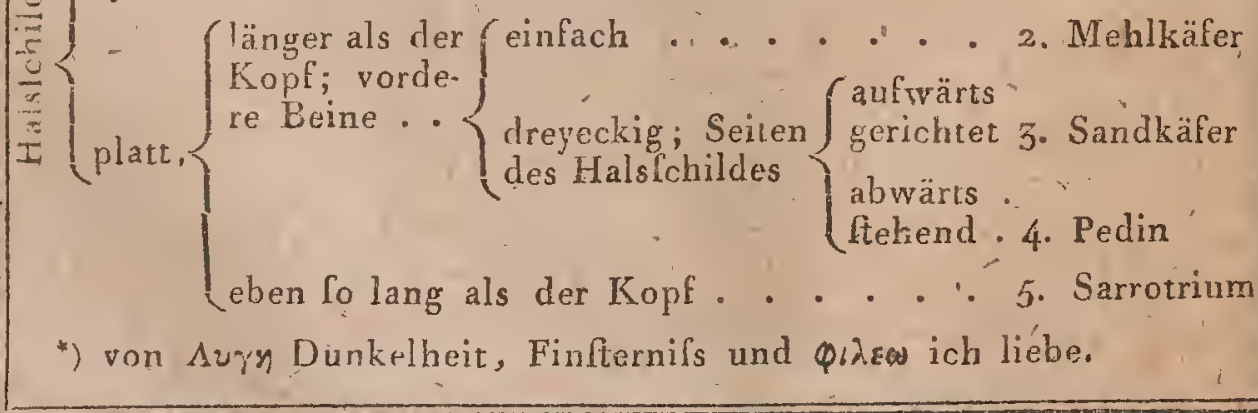




\section{BEMERKUNGEN ZUR CXXXIII. TABELLE.}

Die gegenwärige Familie hat den etwas unbeftimmten Namen Orne. philen oder. Walabewohner bekommen, weil lich kein ganz befimmter Charakter-für fie wollte finden'laffen. Man findet hier alle die Käfer mit ungleichgliedrigen Unterfülsen zufammengeltellt; 'welche in keine der fünf andern Familien pafsten. Und da inan diefe Inlekten meiftens in Wälderu triff, , (o hat das zu dem Namen die Veranlalfung gegeben. I. Die Schattenkäfer (belops $F a b r$. ) z. B. tenebrio lanipes, haben fadeńförmige Fühlbörner, deren untere Glieder zylindrifch, die andern aber konifch find. Das Halslchild endiget hinten mit zwey Spitzen. Sie habeñ ein Rückenfchildchen. Man findet fie únter Baurniuden: 2. Die Beilkïfer (ferropalpus Olivier) lind lehr leicht an den langen Frelslpizen zu erkennen, deren letztes Glied breit ilt. Man findet fie ebenfalls aul baum. ftämmen. 3. Die Fadenkäfer. (ciftela $F \& b r$.) haben lange, oft gezähnelte, Fühlhörner, einen kleinen vorwärtsgeneigrten Kopf und halbmondförmige Augen. Sie halten fich auf Blumen auf. Z. B. ciftela ceramboides. 4. Di Gattung. Calopus, $F a b r$, enthält nur eine einzige in Europa lehr leltne Art. Z. B.' ceramb. lerraticornis L. 5. Die Kardinalkäfer (pyrochroa, Geoffr.) haben den Gattungsnamen erhalten, weil bey den meiften die Flügeldecken feuerroth gefürbt find. Der Kopf ift wie abwärts genoigt, die Augen mit einem Auslchnitt und das Halslchild ruvdlich. Z. B. Pyr. coccinea $F a b r$. 6. Die Gattung Horia, Fabr. enthält nur ausländifche Arten. Z. B. Hor. maculata Fabr.

\section{BEMERKUNGEN ZUR CXXXIV. TABELLE.}

Dié Lygoplizilen werden von den übrigen Infekten der gegenwärtigen Unterordnung durch die Form ihrer Fühlhörner lëicht unterfchieden, leñ fie find die einzigen, welche lie als eine lange Kenle haben. Die Artenwomit lie noch die meifte Aehnlichkeit haben, find die der folgenden Tamilie, aber die haben dann die Flügeldecken verwachfen. I. Die Gattung Upis, Fabr. befteht aus einer einzigen Art, die auf Schwämmen lebt. Z. B. atte* lab. ceramboides L. 2. Die Melulkäfer (tenebrio $L$ in $n$.) haben ein viereckiges Halsfchild, was gleiche Breite mit den Flïgeldecken und die hintern Winkel verlängert hat. Die Vorderfchenkel find etwas aufgetrieben. Z. B. Tenebrio molitor L. 3. Die Sandkäfer (opatrum Fabr.) haben die Glieder der Fühlhörner mehr rundlich als die andern Arten. Ihr HalsCchild ift vorn.zulammengefchnürt und die vordern Beine zum Graben in die Erde geeignèt. Z. B. tenebrio labulolus L. 4. Die Pedinen (perinus La cr eille) lind den Sandkäfern Sehr ähnlich; aber ihre Fühlhörner find weniger keulenförmig, Z. B. Blaps glabra Fabr. 5. Die Gattung Srarrotrium Illiger. orthocerus La $L$ r. befteht aus einer einzigen Art; die fich im Sande aufhält; deren Fühlhörner apslehen als. wären Lie durchbläitert. Z. B. hispa murica $L$. 


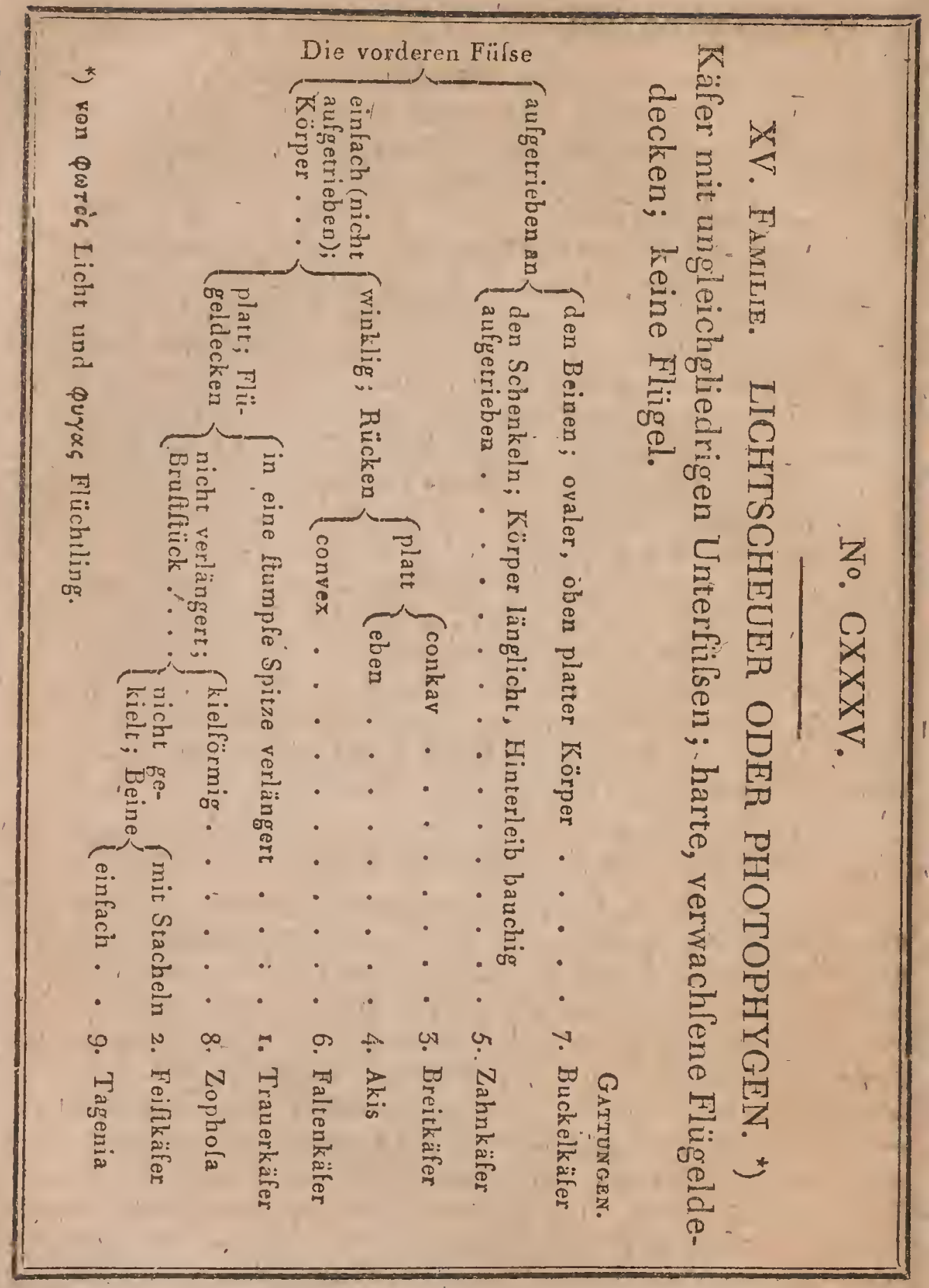

\section{BEMERKUNGEN ZUR LXXXV. TABELLE.}

Die Inlekten der (15ten) Familic der Photophygen entfprecken dẹr Linneifchen Gattung Tenebrio. Aber die Entomologie bat feit den letzton cwanzig Jahren folche Fortfchritte gemacht, dals'man durchaus neus. 
Gattungen, zu errichten genöthigt war, um diejenigen Infekten dahingzu ftellen; die, obgleich fie einige Aehnlichkeit zeigten, doch auch zu fehr fich unterfchieden, als dals man lie unter demfelben Namen und in derfelben Abtheilung hätte laflen können. Die meiften Inlekten dieler Familie fínd ausländifche. Man findet fie nur in warmen Ländern und auf den brennenden Sandwüften. Sie kommen nur des Nachts aus ihren düftern Winkeln hervor. Sie nähren fich von verderbenden vegetabiliCchen und feuchten animalilchen Körpern.

1. Die Tramerkäfer (blaps) haben von Fabricius ihren Gattungsnamen erhalten, um damit die Langlamkeit ihrer Bewegungen anzudeuren. Thre Flügeldecken erftrecken fich über den wie abgeftutzten Leib hinaus. Wenn man fie ergreift, lo verbreiten fie einen fehr unangenehmen Geruch.

Z. B. Tenebrio mortifaga L.

2. Die Friftiäfer (pimelia Fabr.) haben diefen Namen wegen der Rundung und Völle ihres Körpers. Die meiften Arten haben die Hinterfülse verlängert. Z. B. pimelia muricatus.

3. Die Gatrung Breitkäfer Eurychora Thunbérg untérlcheidet fich, von der Gattung akis. mind.platynotus des Fabricius, nú durch die londerbare Form ihres Halsfchildes und ibrer Flügeldecken, die denen einiger Randwanzen nahe kommen. Z. B. Pimelia ciliaris Olivier.

4. u. 5. Die Gattungen Akis, Fabr. z. B. Tenebrio Ipinofus L. und die Zahnkäfer (fcaurus $F a b r$.) z. B. Scaur. liriatus F. beltelien aus Infekten, diei in dem füdlichen Theile von Europa und Afrika zu Hanle find.

6. Die Faltenkäfer (fepidium Fab. z. B. Pimelia tricuspidata L.) find ebenfalls afrikanilche Infekten, deren Halsfchild oder Flügeldecken mit erhabenen Leiften uud oft mit. Furchen durch/chnitten find.

7. Buckelkäfer (erodius $F a b r$.) kommen auch nur in diefen Gegenden vor. Sie graben fich in den Sand, wo lie des Tags über verborgen bleiben. Z. B. Erod. gibbus Fabr.

8. Die Zophofen (Zophofis Latreille) gleichen den Buckelkäfern, unterfcheiden fich aber durch die Form der Fühlhörner, deren Glieder nicht ründe Körner lind. Z. B. Erodius teftudinarius $F a b r$,

9. Die Gattung Tagenia, Latreille befteht aus Inlekten von einer ganz belonderen Form. Der Kopf bildet ein lä̀nglichtes Viereck was von einem Halsfchilde von derfelben Form getragen wird. Der Hinterleib ift oval. Man hat fie nur an den barbarifchen Küften beobáchtet. Z.B. akis filiformis F $a b r$. 


\section{No. CXXXVI.}

XVI: FAMUIE. SCHWAMMFRESSER ODER MYCETOBIEN. *)

Küfer mit ungleichgliedrigen Unterfüfsen; harte nicht verwachfene Flügeldecken; fchnurförmige Fïhlhörner mit runder Keule.

(drey; Halsfchild breit und zugerundet; halbku-

Gattungen.

gelförmige Flïgeldecken . : . . . . .

4. Agathidie

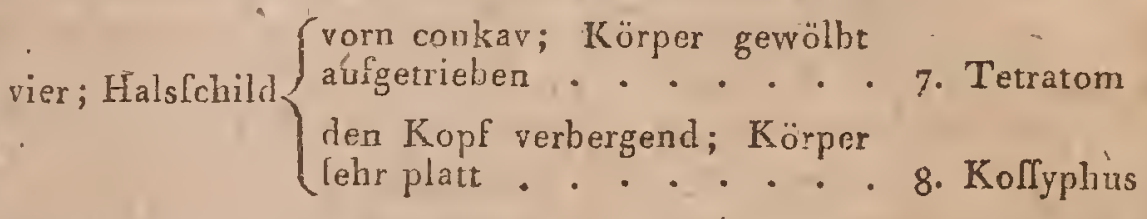

fïnf; Hals lchild mit umgefehlagenen Raride, un-

ten fchmäler werdend... . . . . .

3. Anifotom

Ceclis; Sternum als Tcharfe-Spitze vorftehend;

kleiner liopf... . . . . . . . .

6. Knodulon

fieben; Fühlhörner $\{$ wie geknickt . - . . 1. Pilztreller

fieben; Fühlhörner $\left\{\begin{array}{l}\text { gerade; Körper lang, fa* } \\ \text { denförmig . . . . . 2, Rindenkäfer }\end{array}\right.$

acht; Körper fehrinewülbt . . . . . . . 5. Pilzkäfer

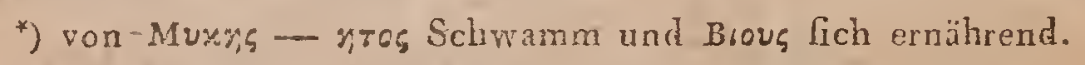

\section{BEMERKUNGEN =ZUR CXXXVI. TABELLE.}

Die Käfer die die Familie der Mycetobien bilden, nähren fich durchaus nur von verlerbenden vegetabililchen Subftanzen. Man hat fie vorzüglich an den Morgeln und Schwärmen gefunden, fo auch die meiften Larven. Aber ihre Eebensart ift noch nicht bekannt geworden:

I. Der Name Pilzfrefer (boletophagus Illiger) Eiedona Lacreille z. B. Silpha reticulata Le zeigt die Nabrung der Arten an, die diefen Namen tragen. Von den Pilzkäfern unterfcheiden fie fich durch ihre kürzere Fühlhornkeule und durch die Abwefenheit des Stirnfchildes; von den Anifotomen ebenfalls, da das Halsfchild der letztern, weniger breit als die Flïgeldecken und hinten zugerundet ilt; desgleichen von den. Rinden- 
käfern, deren Körper lang und fadenförmig ift und fo auch von den Agathidien d'eren Fühlhornkeule nur fünfgliedrig und deren Beine gezähnelt Cund:

2. Die'Rindenkäfer (hypophlaeus $P a y k u l l$ ) löben gewölunlich unter feuchten Rinden. Die Form ihres Körpers ift hinreichend um fie von den andern Arten diefer Familie zu unterlcheiden. Z. B.-Hyppophl. borus $F_{a} b r$.

3. Die Gartung Anifotoma $K n$ och, welche $K u g$ el a $n$ auch volvox und Herbfi Tetracoma, Lacreille Leiodes genanuthaben, die aber bey den meilten Entomologen für Halbkugelkäfer angelehen worden ift, hat ihren Namen von der londerbaren Form der Fühlhörner, deren dürchblätterte Keule nach dem Willen des Thieres vorlängert und verkürzt werden kann. Anifot. humeralis $F a b r$.

4. Die Agathidien. (agathidium Illiger) wurden auch lange mit den Halbkugelkäfern zufammen verwech[elt, mit denen fie wirklich gleiche Körperform haben. Man findet lie unter Baumrinden und auf Schwänı. men. Z. B. anifotoma feminulum $F a b r$.

5. Die Pilzküfer (diaperis Geoffroy) z. B. chrylomela boleti L. finden fich verzüglich auf den Pfifferlchwämmen (boletus) die fie, wie auch ihre Larve, von einem Ende zum andern durchbohren. Der Körper ilt ganz gewölbt, ungefähr wie bey den Blattlauskäfern.

6. Die Gattung Cnodulon Fabr. begreift nur Inlekten aus Afrika nund Südindien in fich. Man hat fie lange auch.mit dem Namen erotylus belegt, aber fie unterfcheiden lich von ihnen durch die Zahl der Fufsglieder: Z. B. cnod. viride.

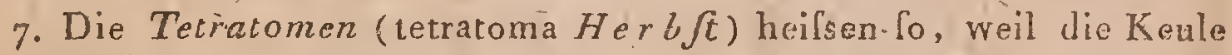
ihrer Fühlhörner aus vier Gliedern befteht. Das erfte ibrer Glieder der Unterfülse ift viel länger als die übrigen, die lo dicht an einander liegen, dafs fie fchwer zu unterfcheiden find. Man findet fie nur anf Schwämmen. Z. B. tetratoma fungorum:. $P$ a.nzer.

8. Die Gatútung Cofyphus O livi er enthält Infekten mit einem ovalen platten Körper, um welchen das Falsfchild und die Flügcldecken rundherum, eine breite, zarte und horizontale Einfaffung bilden. Sie gleichen 'etwas den Leuchtkäfern. Z. B. coflyph. depreflus $F$ a $b$ r. 


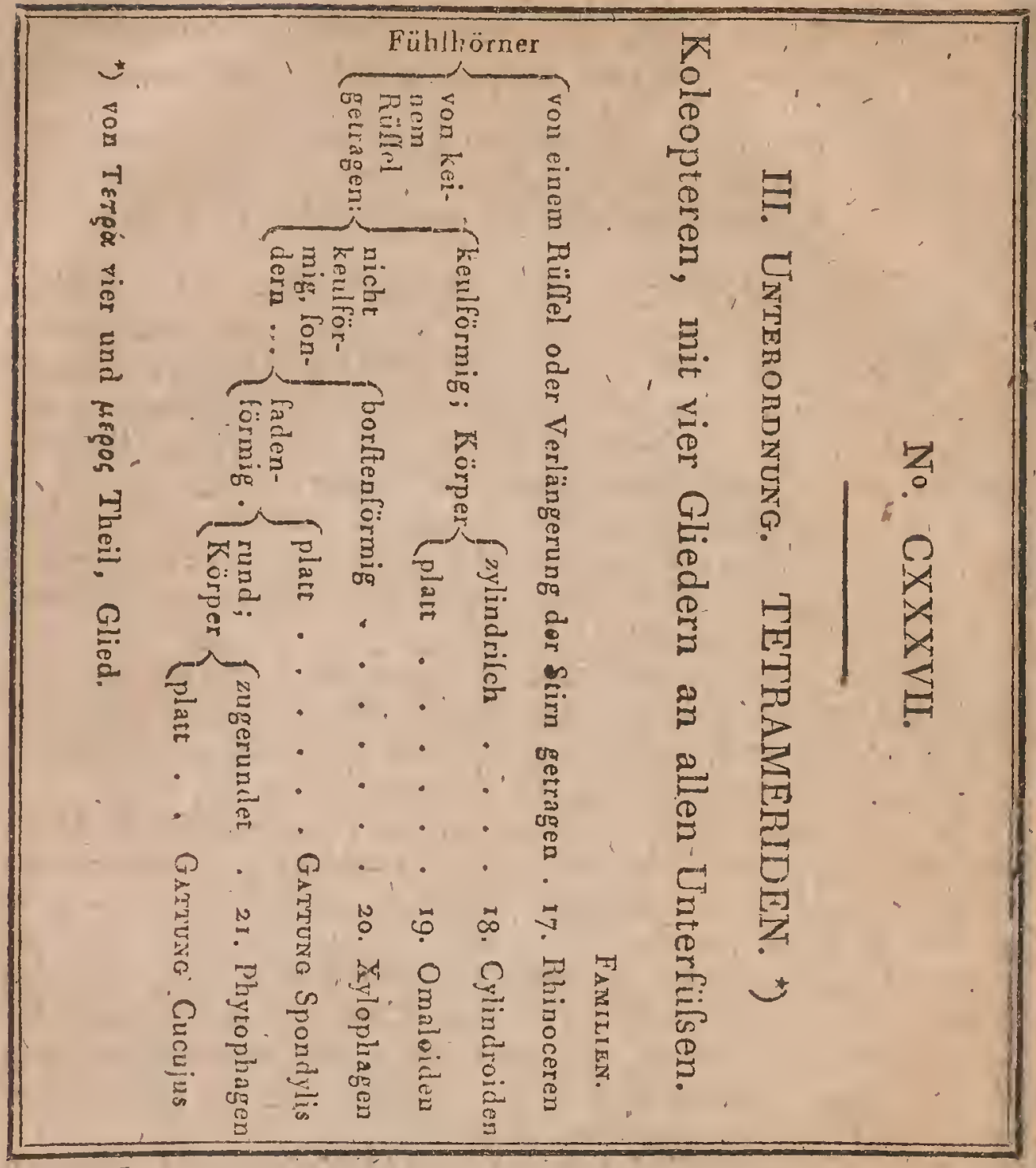

\section{BEMERKUNGEN ZUR CXXXVII. TABELLE.'}

Die Käfer mit vier Gliedern an allen Unterfülsen, oder die Tetra. meriden nähren fich alle von vegetabilifchen Subftanzen. Man findet bey ihnen drey lehr natürliche Familien, die eine grofse 'Zahl von Arten in fich enthalten. Sie entfprechen faft den, auch durch Lebensart fehr verfchiedenen, Gattungen curculio, chryfomela, und cerambyx der frühern Entomologen. Die Infekten der erften Familie nähren fich vorzüglich von Saamen; die der awevten von Blättern und die der dritten vors frifchiem oder faulendem Holz.

Die zwey andern Familien enthalten nur die Arten, worauf dis den drey erfien Hauptamilien beygelegten Charaktere nich pafsen. 
Nan hat ihren Namen von ihrer Bildung hergenommen und fie zeigen die. Eigenthümlichkeit, dafs ihre Fühlhörner immer keulenförmig find und von keiner Verlängerung der Stirn getragen werden, wie bey vielen Rhinoceren.

Zwey fehr abweichende Gattungen, die, einiger Dinge wegen, zugleich zu den Xylophagen und zu deh Omaloiden gezählt werden konnters, fich aber doch durch wefentliche Eigenheiten wieder davon entfernen, find hier belonders aufgeführt worden und follen auch gleich erläutert werden.

Die Gattung Spondylis Fabr. gleicht der Gattung cerambyx fehr, aber die Fühlhörner haben in ihrer ganzen Länge faft diefelben Dicke, beftehen aus rundlichen in einerley Richtung eiwas plattgedrückten Gliedern; fie find lüberdem kürzer als das Halsfchild, was kuglich ift, wie bey der Fabriciusfchen Gattung clytus. Man kennt nur eine Art, aus welcher Degeer einen Mehlkäfer, Linné einen Afterrüflelkäfer gemache hat; man giebt ihr den Beynamen aeramboides. Degeer hat fälfchlich fünf Fulsglieder an den Vorderfülsen abgebildet und belchrieben.

Dié zur Gattung Cucujus Fabr. gehörigen Käfer, nähern fich me'hr als alle andere Koleopteren, durch ihre platte Körperform, den Omaloiden; aber nur zwey Arten dieler Gattung baben die Fühlhörner etwas keulenförmig, bey den andern find fie fadenförmig mit deutlichen etwas körnerähnlichèn Gliédern. Man hat von dieler Gattung noch diejenigen Arten unter dem Namen bronte Fabr. oder ulleiotes Latr,eille getrerlnt, deren Fühlhörner bis an das Ende des Körpers gehen, während fie bey der Gattung cucujus etwas kürzer fiñd. Uebrigens ilt diele Gattung auch noch in 'der Familie der Omaloiden aufgeführt und $z$ war hat, die eine fpecies, welché in den Wäldern unter Baumrinden zuweilen angetroffen, wird, die Fühlhörner nach vorn allmählig dicker werdend. 


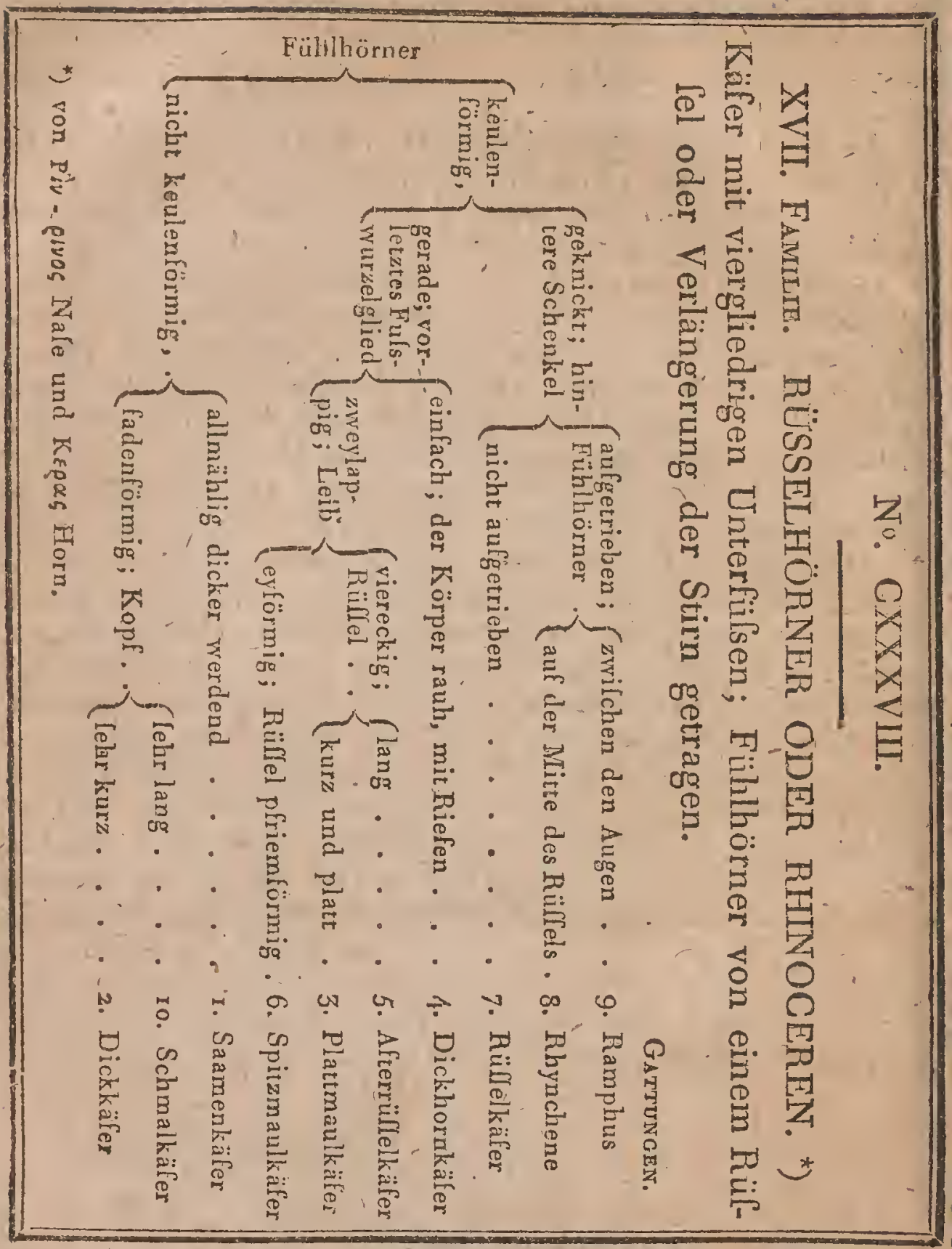

\section{BEMERKUNGEN ZUR CXXXVIII. TABELLE.}

Die Familie der Rhinoceren enthält Arten, die unter einander fo viele Aehnlichkeit zeigen, dafs die frühern Entomologen fie allé in eine Gattung brachten, die fie eben fo nannten als jetzt die Familie heifst. Da aber jetzt mehr als r 200 Arten bekannt find, fo mufste man durchaus Abtheilungen machen, die dazu noch nicht einmal genug vervielfältigt; find und aoch nicht hínreichen. Die meiften diefer Infekten entwickeln 
Gich aus weichen oft klebrigen Larve, die fich porzüglich von Pflanzenfaamen oder Blättern nähren und von welchen einige fich im Innern der Baumftämme und Wurzeln authalten und verwandeln.

I. Die Gattung Seamenkäfer (hruchus, Linné; Mylabris, Geoffr. 2. B. bruchus pifi) enthält diejenigen Käferarten, welche in den Saamen von Pflanzen und belónders in denen von den Gemüfepflanzen, Erblen, Linfen u. I. w. leben.

2. Die Dickkïfer (rhinomacer F $a b r_{0}$ ) find nicht -die, welche (f̧eoffroy als becmares auffïhrte, - die vielmehr zu der Gattung attelabus gehörten fondern kleine Käfer, mit kurzem Schnabel, fadenförmigen Fühlhörnern, viereckigem Halsfchilde und vorwärtsgeneigtem Kopfe, die fich auf Blumen finden. Z.B. rhinomac. curculinoides. Von Clairville ilt diefo Gattung mycterus genannt. Z. B. myct. grileus.

3. Mit den Plattmaulkäfern (anthribus $G$ eoffr.) ift es derfelbe Fall wie bey der vorigen Gattung. Der von Fabricius beybehaltene Name gilt nur nochi für die Arten, wovon Olivi er die Gattung macrocephalus gemacht hat. MIan findet fie auf Baumftümmen, kennt aber ibre Lebenșart nicht. Z. B. curcul. albinus L,

4. Die Dickhornkäfer (brachycertus Olivier) haben ganz kurze, nicht geknickte Fühlhörner; ihre Flügeldecken find verwachlen. Der Körper ift ungleich, rauh. Z. B. curculio barbarus L.

5. Diel Afterriüfelkäfer (attelabus L. z. B. attel. coryli L.) haben Kopf und Halstchild \{chmäler als die Flügeldecken, einen kurzen, wie zufammengefchnürten, Rüflel und Bogenförnaige Fühlhörner. Lie Larven haben keine Fülse; fie ziehen ihren Körper vermittels ihrer Mandibeln und einer klebrigen Feuchtigkeit, die aus etlichen Hervorragungen unter dem Leibe fchwitzt, fort.

6. Die Spitzmnulkäfer (oxyfioma) find kleine Arten Afterrülfelkäfes deren Körper birnförmig ift, fo dafs der Rüllel den Stiel bildet. Z. B. attelabus craccae $F$ a $b$ r.

7. Die Rüffelkäfer (curculio L.) bilden eine fehr zahlreiche Gattung, wohin man alle die Arten bringt, welche geknickte keulenförmige Fühlhörner, eineń ovalen Körper und rundlichen Rüffel haben. Man hat Untergàttungen gemacht, die man calendra z. B. curc. palmarum L., rhine z. B. lixus barbiroftris "Fabr., coffonas z. B. curc. ater L., lixcis z. curc。 paraplecticus L. u. I. w. genannt hat.

8. und 9. Die Gattung Ramphis, Clairville z. B ramph. clavicornis und Rhynckacnis, Clairville z. B. curc. alni, find auch von ders Rülfelkäfern, aber nach mehr hervorftechenden Eigenheiten, getrennt.

го. Die Schmalkäfer (Brentus $F a b r$.) haben eine lärghlichte, falt: fadenförmige Bildung. Der Kopf ift lehr lang geftreckt, nicht vorwärrsgeneigt, in der 'Gegend, der Augen etwas dicker. Man thealt lie in Arten mit gezähnelten und in Colchermit einfachen Schenkeln. Alle find in Amerika oder Afrika eimheimilch. Z. Ba. Breut, anehorago F a b r. 


\section{No. CXXXIX.}

XVIII. FAMILIE. WALZENFÜRMIGE ODER CY-

\section{LINDROIDEN. *)}

Käfer mit viergliedrigen Unterfüfsen; keulenförmige, von keinem Rüflel getragene Fühlhörner; wàlzenförmiger Körper.

Gattungen.

Shinten fchmüler werdend, $\{$ rundlich . . . 4. Immenkäfer

(faft würfelförmig; durchblätterte.

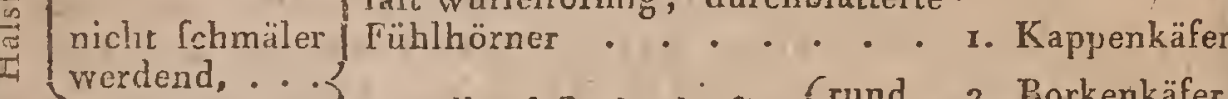
gewölbt; fefte, keulenför- rund . 2. Borkenkäfer mige Fühlhörner; Leib abge(ltutzt . 3. Rindenkäfer

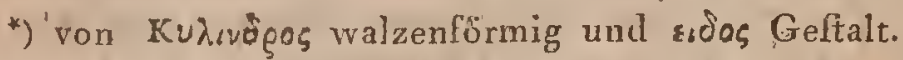

\section{No. CXL.}

XIX. FAMILIE, PLATTFÖRMIGE ODER OMALOIDEN. *)

Käfer mit viergliedrigen Unterfülsen; keulenförmige, auf keinem Piüllel fitzende Fühlhörner; platt gedrückter Körper.

\section{Gattuncen.}

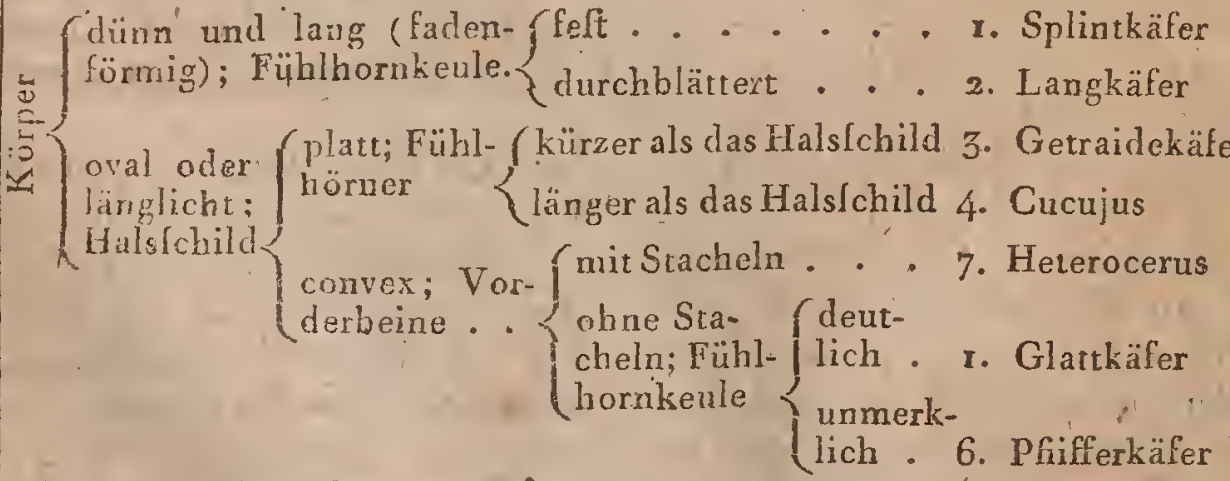

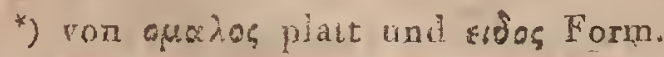




\section{BEMERKUNGEN ZUR CXXXIX. TABELLE.}

Dic Cylindroiden entfprechen durch Körpertorm und Lebensweife den Teredylen, unterlcheiden fich aber vou ihnen durch die Zahl Aler Unterfulsglieder. Alle, mit Ausnahme der zwey letzten' Gattungen, die wahrfcheinlich in der Folge eine Familie bilden werden, nähren und entwickelu fie fich in trocknem Holze, was fie verzehren und weswegen fie in Holzwerk und Meublen grofsen Schaden thun. r. Den Namen apate haben die Kappenkäfer von Fabricius deswegen erhalten, weil fie, wenu fie in Gefahr kommen, trügerilch fich todt ftellen können. Als Larven, leben lie zwey Jahre im Holze. Sie greifen vorzüglich gern abgefiorbene Vurzeln an. In ihrem, volltändigen Zuftande leben fie auf Bäumftänmen; fie fliegen nur des Abeuds. 2. und 3. Die Borkenkïfor (boftrichus F a br. z. B. bolt. typographus und die Rindenkäfer (Scolytus z. B. boft. ('colytus) leben in dem Splint der Bäume und in einigen holzjgen Schwäm. men. Ihre Larve ift der der Petaloceren ähnlich. Sie frellen unter den Rinden der Bäume labyrintbähnliche Gänge, die oft wie Buchftaber ausleben, daher der Beiıame typographus, calcographus u. Г. w. 14. Die Larven der Immenkäfer (clerus Lin. trichodes Herbf $\iota$, Fabr.)'lcheiuèn nach Swammerdams Beobachungen fich nur von Bienenlarven au nahren. Im ausgebildeten Zuftande leben fie auf Blüthen' belonders der Doldenblumen. Z. B. cler. apiarius. 5. Die Coryneten (corynetes $F a b r$ necrobia $L a t r$.) ermähren fich iu Gegentheil von animalifchen Subfan. zen, wie die Speckkafer. Z. B. c. rufipes

\section{BEMERKUNGEN ZUR CXL. TABELLE.}

Die Omaloiden heifsen fo im Gegenfatz zu den Inlekten der vórigen Familie, denen fie in der Form dèr Fühlhörner gleichen. Sie nähren lich von vegetabilifchen Sublianzen und haben einige Aehnlichkeit mit don Mycetobien. Meift find es kleine Arten. I. und 2. Die Splintkäfer (lyctus z. B. lyct. canaliculatus $P a y k$. F $a b r_{0}$ ) und die Langkäfer (colydium $P a y k$. z. B. ips fulcata $F a b r$.) unterfcheiden fich nur durch die Fühlhornkeule. Sie leben unter feuchten Rinden und in Holze, was in Verderbrils übergeht. 3. Die Getraidekäfer (trogolfita Oliv.) gleichen etwas der Gattung platycerus, mit dem fie Geoffroy zufammengefiellt hatt.e. Man finclet fie in feuchtem Brod oder unter Rinden. Z. B. Trog. coerulea $F a b r$. 4. und 5. Die Gattungen Cucujus z. B. cucuj. depreflus und ips Fabr. x. B. ips cellaris leben unter Rinden. Die erften find Sehr platt und ihre Fühlhörner haben körnerähnliche Glieder; bey den zweiten finden fich die allerkleiniten Käfer. 6. u. 7. Von den Pfiferkäfern (mycetophagus z. B. chryfomela 4 punctata S.) und HeLeroceren (heterocerus z. B. het. marginatus $B o s c$., Fabr.) die falt'gleiche Körpertorm bahen, leben die erftern ansfchliefslich aut Schwämmen, die zweyten finden fich an den Ründern litllfehender Gewälfer und fcheinen ihre Wohnung unter feuchien Sande zu haben. 


\section{No. CX́LI.}

XX. FAMILIE. HOLZFRESSER ODER XYLOPHA. GEN. *)

Bäfer mit viergliedrigen Unterfüfsen; borftenförmige, auf keinem Rüffel fitzende Fühlhörner.

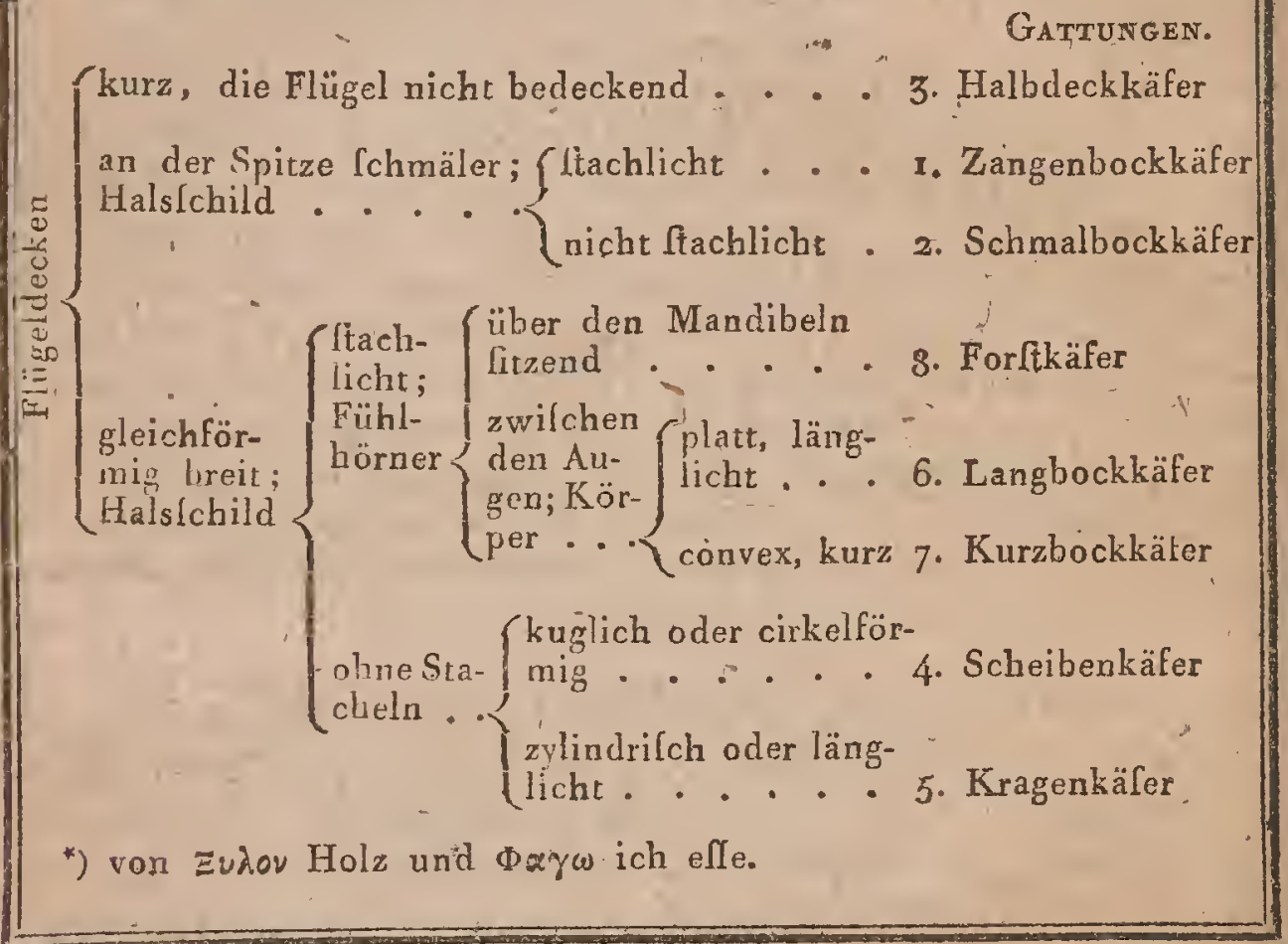

\section{BEMERKUNGEN ZUR CXLI. TABELLE.}

Die X Ylophagen entfprechen der fo lehr zahlreichen Linnéifchen Gattung cerambyx, von welcher man aber jetat alle die Arten weggenommen hat, dren Eigenthüralichkeiten eine lolche Trennung rechtlertigten. Uebrigens gleich n fich diele Infekten febr in der-Art fich zu bewegen und haben auch ganz gleiche Lebensart. Alle ohne Ausnahme leben als Larven im Inhern des Holzes. Sie haben dann die Geftalt eines langen, weichen, weilsen vierleitigen Wurmes, der auf dem Rücken und am Bauwhe mit Warzen beletzt ift. Das dem Kopfe entiprechende Ende iftetwas dicke und mit melireren Furchen verlehen. Unten fitzen lechs kurze, fchuppige Fuife. Einige leben in frifchen vollfafrigen Aeften, andere zieben die Stüme von abgeforbenen Bädmen vor. Sie bereiten fich daris 
lange Gänge, in welchen fie fich vermöge dẹr Warzen ihres Körpers mį einer unbegreiflichen Schnelligkeit bewegen. In ibrem ausgebildeten $Z \mathbf{Z}$ ftande find die meiften mit fchönen Farben geziert, baben lnage Borltenförmige Fühlbörter, mit grofsen, deutlichen rückwärtsgerichteten Gliedern. Durch das Reiben ihres Halsfchildes an der Bafis der Flügeldecken, bringen fie einen befondern Ton hervor. Die Weibchen find dicker als die Männchen, baben weniger glänzende Farben und kürzere Fühlbörner. Alle diele Inlekten leben in ihrem vollkommnen Zuftande nur kurze Zeit. 1. Die Zangenbockkiajer (rhagium Fabr.) hahen kurze Fühlhörner, in Proportion zu denen der übrigen Arten diefer Familie; fie litzen Jehr nahe an einander auf einem breiten hinten verfchmälerten Kopfe. Ihr Halsfchild ift fchmal, ftachlicht und die Flügeldecken gegen die Spitze zu fchmäler. Diefe Infekten haben eine londerbare:Haltung. VVenn fie ruhig find, find die Fühlhörner vorrvärtsgerichtet; Wenn ihnen Gefahr droht, bleiben fie ganz unbeweglich; ibre, mit rauben fantartigen Knöpfchen verfehenen, Fülse hailten felblt an den glatteften Körpern fehr feft. 2. Die Schmalhockkäfer (leptura L. z. B. Lept. melawura) gleichen der'Geftalt nach den Zangenbockkäfern; aber ihre Fühlhörner find länger und hinterwärtsgerichtet. Ihr Hals fchild ift nicht ftachlicht. Man findet? lie auf Blumen. 3. Die Halbdeckkäfer (molorchus Fab r. necydalis Geoffr.) z. B. necydalis major L. haben fehr lurze Flügeldecken, welche die, nicht in die Queere gefalteten, Flügel nicht ganz bedecken; fie fehen aus wie nicht vollftändig entwickelte Schmalbockkäfer. 4. Die Scheibenküfer haben, wie auch' der Name callidium Fabr. ausdrückt, lebhafte und angenehme Farben und find lebbaft in ihren Bewegungen. Z. B. cerambyx bajulus L. Neuerdings bat Fabricius diele Gattung in żwey getrennt. Die Arten mit kugelförmigem nicht plattem Halsfchilde, dreyeckigem nicht rundem RückenIchildchen, und zulammengedrückten nicht keulenartigen Hinterlchenkeln, belegt er mit dem Gattungsnamen clytus z. B. cerambyx arietis L. 5. Die Kragenküfer (Saperda Fabr. z. B. ceramb. linearis L. find die Arten der Bockkäfer, deren Halslchild rundlich, an den Seiten nicht ftachlicht und in Ganzen mehr lang als breit ift. Der Körper ift faft walzenförmig von einem Ende zum andern. 6. Die Bocḱkiëfer (cerambyx L. z. B: cer, mofchatus) haben die Fühlhörner zwilchen den Augen, den Körper hinten fchmäler, leicht platt gedrückt, die Augen rundlich, Halsfchild ftachlich und die hinteren Schenkel und Bein zufammengedrückt. 7. Die Kurzbockkäfer (lamia Fabr. z. B. ceramb. aedilis L) gleichen den Kragen - und den Bockkäfern. Ihr Kopf ift lehr abwärts geneigt; ihr Leib etwas aufgetrieben, die Schenkel rund und of find die Flügel zulammengewachfen. Die Larve lebt in Wurzelı. 8. Die-Forftkäfer (prionus Fabr. z. B. ceramb. coriarius L.) haben of lägeförmige Fühlhörner, den Körper immer etwas platt gedrückt, den Kopf gerade; die Fühlhörner fitzen über den Kinnladen und das Hásschild hat Ichneiclende, gezähnelte oder ftachlichte Ränrier. 


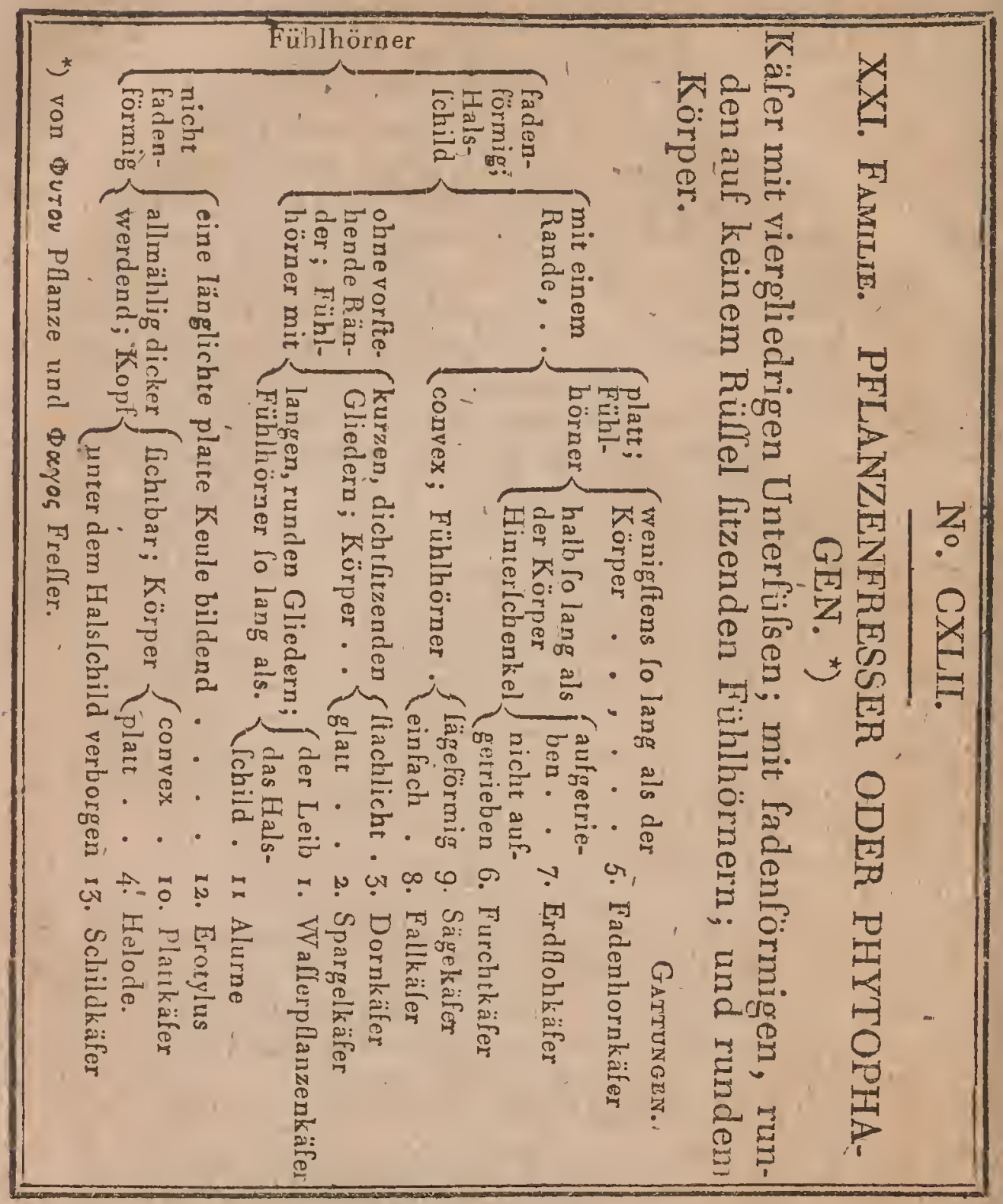

\section{BEMERKUNGEN ZUR CXLII. TABELLE.}

Man kann bey der Familie der Phytophagen die nämliché Bemerkung wie bey der vorigen Familie machen. Alle dazu gehörigen Arten wurden von Linué für. Blattkäfer angefehen. Diefe Inlekten kommen aus Larven, welche gewöhnlich gefellig auf Pflanzenblättern leben; ihr Körper ift oft gefärbt, kurz und dick und in die Queere gefurcht. Zuweilen laffen fie aus ibrer $O b \cdot r$ fläche oder aus ihren Gelenken gefürbte und riechende Feuchtigkeiten hervorfchwitzen. Ihre Füfse find lang und fie gehen mit Leichtigkeit. 1. Die Waljerpllanzenkäfer (Donacia Ifabr. z. B. Leptura 
aquatica De Geer) fcheinen die beyden Familien zu varbinden. Sie haben die Geftalt der Zangenbockküfer und die Lebensart und auch in etwas die Geltalt der Spargelkäfer. Ihre Larven nähren fich vou Wallerpllanzen. 2. Die Spargelkäfer (crioceris Geoffr., lema Fabr.z. B. Crioc: afparagi) können leicht an den nicht aufgetriebenen Hinterlchenkeln und an der Geltalt des Halsfchildes unterlchieden'werden, was Ichmal und zylindrilch ilt. 3. Die Dornkäfer (hilpa Fabr. z. B. hilpa atra) Find den Spargelkäfern fehr ähnlich, aber ibre Fühllı̈orner fitzen zwifchen und nicht vor den Augen; oft ilt der Körper ftachlicht. 4. Die Heloden (Helodes, Paykull; Pralocuris, Latreillez. B. Chrýlom. phellandrii L.) die lange für Spargelkäter gehalten worden find, haben die Fühlbörner nicht fo lang als das Halsfchild, letzteres aber ift breiter als der Kopf. 5. Die Fadenhornkäfer (luperus $G e$ off $r$.) haben Cehr lange, oft über den Körper hinausragende, Fühlhörner, den Kopf fo breit als das Halsfchild und den Leib breiter als beyde-genannte Theile. Z. B. Crioceris flavipes F $a b r$. 6. Bey den Furchtkäfern (galeruca Geoff $r$.) find die Fühlhörner etwa halb fo lang als der Körper und fitzen zwilchen den Augen. Der Körper ift oval und länglicht. Z. B. G. calmarienlis Fa br. 7. Die Erdfohkäfer (altica Creoffr.z. B. Chrylom. oleraceá L.) unterfcheider fich von den Fứchtkäfern nur durch die aufgetriebenen zum Springen tauglichen Schenkel. 8. Die Fallkïfer (cryptocephalus Fabr.) haben den Kopf unter dem convexen Halsfchilde verborgen und farlenförmige Fühlhörner, Z. B. Chrylom. Cericea L. 9. Die Sïgrekïfer (clychra Latr.) unterlcheiden fich von den Fallkäfern nur durch die lägeförmigen Fühlhörner. 'Z. B. Chryfom. quadripunctata L. ro. Die Blattküfer (chrylomela L. z. B. Chr. tencobrioides L.) haben einen ovalen an beyden Enden zugerundeten Körper. Ihr Halsfchild ift, platt, mit überftehendem Rande ail den Seiten rund, vorn ausgefchnitten. Ir. Die Alurnen (alurnus $F$ a $b r$.) gleichen einigermalsen den Dornkäfern, aber ihr Halsfchild ift etwas abgeplattet und der Körper nie mit Stacheln beletzt. Z. B. alurn. groffus Fabr. 12. Die Erotylen (erotylus Oliv. z. B. chrylom. gigantea L.) haben keulenförmige Fühlhörner. Sie gleichen den Blattkäfern und der Rand des Halslchildes zeigt vier deutiche Ecken. Die Flügeldecken find unter den Hinterleib umgelchlagen. 13. Die Schildkïfer (calfida 2. B. caffida viridis $I$, $i$ in.) kommen aus Larven, deren Schwanz gabelfürnig und oft von ihren Exkrementen bedeckt ift, wodurch fie bey Gefahr verborgen werden. Im vollfändigen Zuftande ift das Thier auch durch die Form feines Körpers gefchützt, der unten platt ift und über welchex die Flügeldecken und das Halsfchild überall hervorragen. 


\section{Nio. CXLIII.}

IV: UNTERORDIUNG

UND XXII. Famirie. RIDEN. *)

\section{Käfer mit drey Gliedern an allen Unterfülsen.}

Gatumingin.

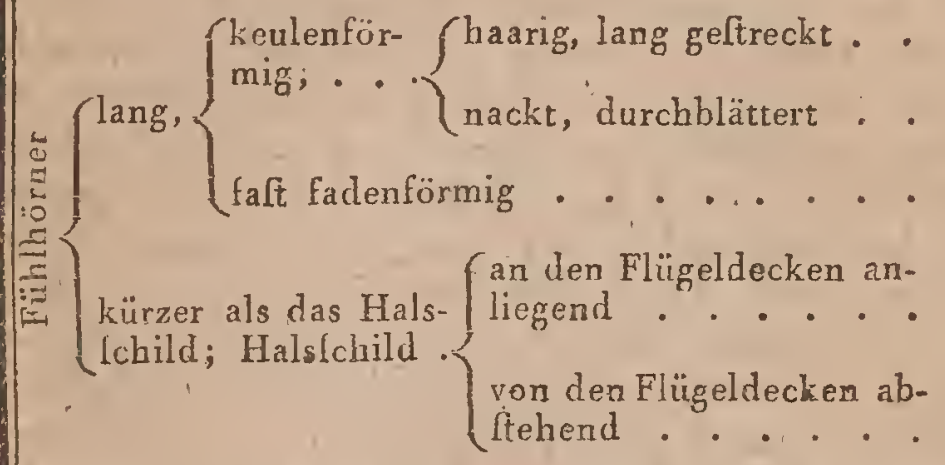

r. Haarhornkäfer

2. Eumorphe

3. Endomychus

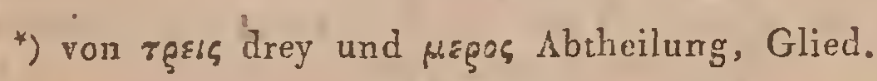

\section{Scymne}

4. Blattlauskäfer

\section{BEMERKUNGEN ZUR CXLIII. TABELLE.}

Die Unterordnung der dreygliedrigen Käfer enthält Arten, deren Lebensart fehr verlchieden ilt, und wovon die Gattungen vielleicht in der Folge den Stamm verfchiedener Familien abgeben werden! Hier find fie nur varläufig zufammengeftellt und da ihnen nur der einzige Charakter, die drey Unterfulsglieder, zugefchrieben lind, fo ilt es leicht die Arten. dahin zu beltimmen.

r. Die Gattung Haarhornkäfer (Dafycerus Brong niart) enthält nur eine einzige Art, welche auf ciner Boletusart gefunden worden ift. Der Name kommt dảber, weil die aus vier kugelichen Gliedern gebilde. ten Fühlhörner an ihren Enden mis Haaren befetzt find. Das Brultfchild hat fechs Seiten. Diele Käfer haben einige Áhnlichkeit mit den FaltenJäfern aus der Familie der Photophygen, aber die bekannt gewordene Art ift kaum zwey Linien lang. Z. B. dalyc. fulcatus (Bulletin des Scienees No. 39.)

2. Die Eumorphen (eumorphus Weber z. B. eum.'marginatus $\left.F a b r_{.}\right)$gleichen den Erotylen, mit welchen man fie auch anfangs zufrmmangefellt hatte; von denen fie fich aber durch die Fufsgliederzahl 
unterfcheiden. Auch den Endomychen find fie nahe verwandt, aber ihre Fühlhörner bilden eine zufammengedrückte durchblätterte Keule.

3. Die Endomychen (Endomychus Paykull z. B. Chryfomela coa cinea L.) haben einige Adhnlichkeit mit den Furchtkäfern und Erotylen. Ihr etwas plattes Halsichild ift fchmäler als der Hinterleib. Man findet fie unter feuchten Rinden in Schwämmen und Bofiften.

4. Die Blattlauskäfer (coccinella L. z. B. cocc. 7 maculata) haben einen halbkugelförmigen unten platten Körper, Halsfchild und Flügeldecken glatt, glänzend und mit überragendem Rande; ihre Fühlhörner find keulenförmig, wie abgeftutzt, und wenig länger als der Kopf, der in einen Ausfchnitt des Halsfchildes aufgenommen ift. Als Larven und als Küfer nähren', fie fich von Infekten vorzüglich von Blattläulen, von welchen fie eine grolse Menge vertilgen. Die Larven haben einen länglichten, kegelförmigen, aus zwölf Ringen beftehenden, Körper, wovon aber nur die drey erlten lange, überall gleichdicke, in einen Nagel endigende Fülse tragen. Diele Fülse dienen den Larven nur um die Blattläufe damit zum Munde zu führen. Sieverwandeln fich im Freyen, befeltigen fich, den Kopf nach unten gerichtet, mit dem Ende ibres Körpers an irgend eine felte Mafle. In dem Puppenzuftande bleiben fie nur einige Tage. - Was die Form anlangt, fo kommen die Arten der Blattlausküfer fehr mit einander überein; aber ihre Farben, zeigen die grölsten Verfchiedenheiten. Die meiften Arten können aus ihren Gelenken einen gelben unángenehm riechenden Saft auslchwitzen lallen, der den Zahnfchmerz oft befänfrigen kann.

5. Die Gattung Scymnus Her b $f$ (z. B. coceinella parvula Illiger) unterfcheidet fich voir den Blattlauskäfern nur durch die Art wie das Halsfchild an der Bafis der Flügeldecken anliegt, olne dals ein Zwilchenratam oder Auslchnitt übrig bliebe. Oft find auch die Flügeldecken wie mit einem feinen Flaum bedeckt und ihr Kopf ilt zugerundet, wie bey den Halbkugelkäfern, welchen fie auch vö einigen Entomologen beygefellt waren Ihre Larven hat man noch nicht beobachtet und ihre Lebensweife ift unbekannt. In ihrem vollftändigen Zuftande findet man fie gewöhnlich auf Baumrinden. 


\section{No. CXLIV.}

\section{Ordnung. ORTHOPTEREN. *)}

Infekten mit Flügeldecken; die häutigen Flügel, der Länge nach, gefaltet; Kinnladen.

Clehr viel länger, viel dicker und zum Springan

Famizien.

tauglich . . . . . . . . . 27. Grylloiden

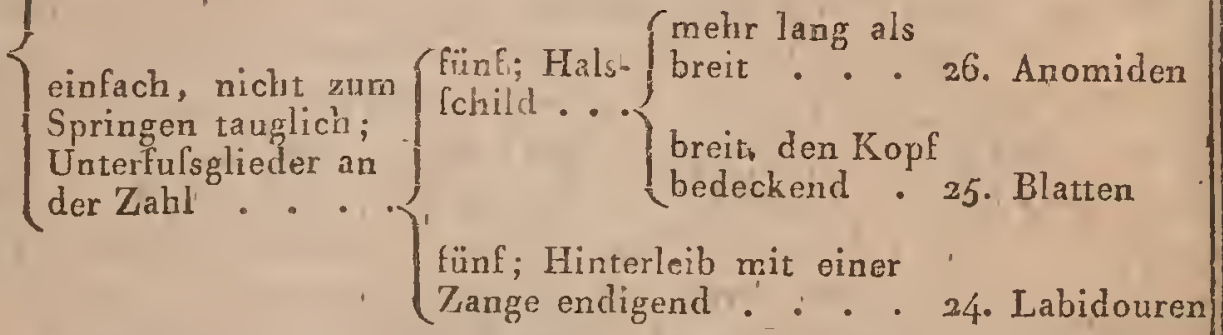

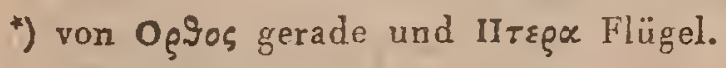

\section{No. CXLV.}

XXV. FAMrLIE. ZANGENSGHW ÄNZE ODER LABIDOUREN. *)

Orthopteren mit fadenförmigen Fühlhörnern, gleichen dreygliedrig endigenden Fülsen, und einem Żangenfchwanz.

\section{Zangenafter.}

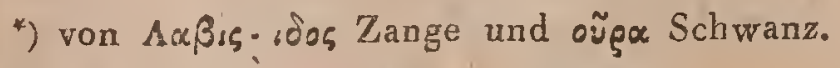

\section{BEMERKUNGEN ZUR CXLIV. TABELLE.}

Die Ordnung der Orthopterien, von Olivier aufgeflellt, entfpricht der Abcheiling, welche de Geer Dermapteren und Fabricius Ulonela genannt hat. Obgleich der von der Bildung der Flügel hergenom- 
mene Charakter hinreichend ift, um die hieher gehörigen Infekten zu unterfcheiden; fo lollen doch noch mehrere andere Eigenheiten hier aufgeführt werden, welche diefe Abtheilung rechtfertigen.

Die allerwichtigfte ilt die Art der Verwandlung. Bey den Käfern if die Larve total von dem ausgebildeten Inlekt verlchieden; die Plippe ift unbeweglicb, ruheind. Die Infekten der gegenwärtigen Ordnung dagegen, find in allen drey Zuftänden der B'ewegung fähig und nähren fich.von denfelben Sublianzen. Die Larve hat keine Flügel; die Puppe hat nur kleine Stumpfen, das ausgebildete Inlekt hat aber diefe Theile lehr grofs.

Óazu kommen noch andere Rückfichten die die Auffellung diefer Ordnung begründen helfen. Alle, mit Ausnahme der Zangenafter, haben weiche Flügeldecken, diefe durch keine Nath oder geraden Rand vereiniğt, und die Flïgel nicht, wie die Käfer, queer über die Länge zufafrimen géfaltet. Die meiften haber auf dem Kople, zwilchen oder vor den Fühlhörnern, hervorragende, glatte, glärzende Punkte, die man einfache Augen oder fícmmata nennt und dic fich bey durchaus keinem Käter finden. Bey den meilten find die Hinterbeine mit, in Längenreihen litzender, Stacheln bedeckt. Fafi alle nähren fich von vegetabilifchen Subftanzen, und haben-äuf der. convexen Seite ihrer Kinnladen eine ganz eigne Frelsfpitze, die man Helm (galea) nennt. Éinige Arten, belonders einige Weibchen, haben keine Flügel. Die Weibchen find gevöhnlich grölser als die Männchen und legen ihre Eyer auf einen Haufen. Die Männchen können in einigen Familien, durch.das Aneinanderreiben ihrer Flügeldecken und durcl die Bewegung derfelben, vermittelft der Hinterfüfse, einen befondern Ton hervorbringen.

\section{BEMERKUNGEN ZUR GXLV: TABELLE.}

Die Familie der Labidouren enthält nur eine Gattung, aber die Bildung derfelben ift auch lehr merkwürdig und auszeichnend. Man nennt fie Zangenafier oder Ohrwarm (forficula z: B. forf. auricularia L.) Ihre Flügeldecken find denen der Raubkäfer ähnlich; aber obgleich diele Decken fehr kurz find, fo bedecken fie doch die Flügel, die die Länge des Körpers haben, und zum fliegen tauglich find. Diefe häutigen Flïgel find dreymal in der Lünge zu lamnengefaltet und in der ganzen Breite durch einen bewundrungswürdigen Mechanismus zufammen gelchlagen : vermittels deln fen fiè äufserlt f́chnell entfaltet uind zulammen gefaltet werden können. Thr Leib endiget mit zwey Haken, welche, in die Queere, fich zangenartig gegen einander bewegen und deren Beftimmung man nicht kennt. Die Begattung gefchieht lo, dals beyde Gefchlechter mit den Enden des Körpers zufammen hängen. Das WVibchen bleibt gern in der INähe der Eyer und felbft der daraus hervorkommenden Jungen, die der Mutcer ähnlich aber Aügellos find. Nau findet fie gewöhnlich unter Rinden, Eine Art aber liebt vorzüglich trocknon, auf Landftråsen liegenden, Mift. Sie liegt nur des Abeuds. 


\section{No. CXLVI.}

\section{XXV; FAMILIE. BLATTEN.}

Orthopteren mit borftenförmigen, fehr langen Fühlhörnern; ovalein, pláttem Körper; mit breitem, fchildförmigem, den Kopf und den FlïgeldeckenAnfang bedeckendem Halsfchilde; Hinterleib in zwey kegelförmige. Spitzen ausgehend; platte Hüften; fünfgliedrige Unterfüifse.

\section{Schabe.}

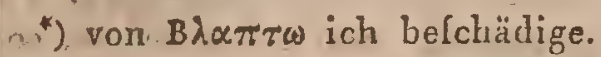

\section{No. CXLVII.}

XXVI. Familie. UNFÖRMIGE ODER ANOMIDEN. *)

Orthopteren mit länglichtem Körper und freyem $\mathrm{Ko}$ pfe; das Halsfchild mehr lang als breit, grolsentheils von dem Bruchftücke gebildet; Hinterfüfsé nicht zum Springen tauglich; alle-Unterfüfse mit fünf Gliedern.

Gattungen.

An den Vor- hakenförmig und eine Zange bilAn den Vor
derfüsen das dead. . . . . . . . . . I. Fangheufchrecke
Endglied.

$\left\{\begin{array}{l}\text { nicht haken- } \\ \text { förmig; Leib }\end{array}\left\{\begin{array}{l}\text { platt; flache Flügel- } \\ \text { decken ... . 2. Blatheulchrecke } \\ \text { rundlich.. . 3. Kahlheufchrecke }\end{array}\right.\right.$

*) von Avópsotos fonderbar, unähnlich und sidos Form. 


\section{BEMERKUNGEN ZUF CXLVI. TABELLE.}

Die Schaben (blatta L. z.B. Blatta orientalis) bilden auch eine natürliche und in der Familie einzige Gattung, deswegen ift hier auch der $\mathrm{Na}$ me der Familie unverändert geblieben. Die Weibchen diefer Gatturg legen ihre Eyer in Zwif chenräume eins hinter dem anderen. Dies Ey hat eine ganz belondere Form: es ift fehr dick, cylindrifch, an beyden Enden abgerundet und ift der Länge nach mit einer rorragenden Leifte oder Kièl verfeben: das Volumen deffelben ift faft eben fo grols als das des Leibes der Mutter. Diefe Inlekten fliehen càs Helle und laufen aufserordentlich fchnell. Mehrere Arten leben in Hölzern; andere haben fich in unlern Wohnungen niedergelaflen und richten da, durch Zerftörung von Kleidung und Zeug und Verzehrung von Elswaaren, grofsen Schaden an.

\section{BEMERKUNGEN ZUR CXLVII. TABELLE.}

Die Orthopteren Anomiden lind fleifchfreffende Infekten, weiche ihre Beute lebend verzehren. Ihre Haltung ift fehr fonderbar. Einige fehen aus wie trockne Blätter; andre ähneln einem langen Stabe von brauner oder röthlicher Farbe; mehrere können das Hálsfchild nach hinten aufwärts richten, um die Vorderfüfse zu erbeben, deren fie lich als Hände bedienen und die fie an den Mund führen könnerr. Alle legen ihre Eyer als eir Bünclel, von einer klebrigen blätterartig liegenden Hülle umgeben.

r. Die Fangheufchrecken (mantis L. z. B. mant. oratoria) haben eine eigne Haltung, woran fie leicht zu unterfcheiden find. Ihr Kopf fitzt fenkrecht auf dem Körper. ift dreyeckig und von einer Art von Hals getragen. Ihre Fühlhörner zeigen in den verfchiedenen Arten, 'in Beziehung auf Geftalt und Länge, manche Verfchiedenheiten, immer aber fitzen fie vorne auf dem Kopfe.

2. Die Blattheufchrecken (phyllium llliger) z. B. mantis ficcifolia L. haben ihren Namen von der fonderbaren Bildung ihrer Flügeldecken und ihres Leibes, welche Blättern ähnlich fehen. Auch hat man pine Art wandelndes Blatt genannt. Es find dies Inlekten der heilselten Qegenden.

3. Die Kahlheufchrecken Gelpenfter (Phasma $F a b r$.) haben oft keine Flügel. Ihr Körper ift fehr lang und fchmal. In diele Gattung gehören die gröfsten Infekten die es giebt. Man hat einige einen Fufs lang gefunden z. B. mantis gigas L. Die uneiften leben in Afien oder Afrika. 


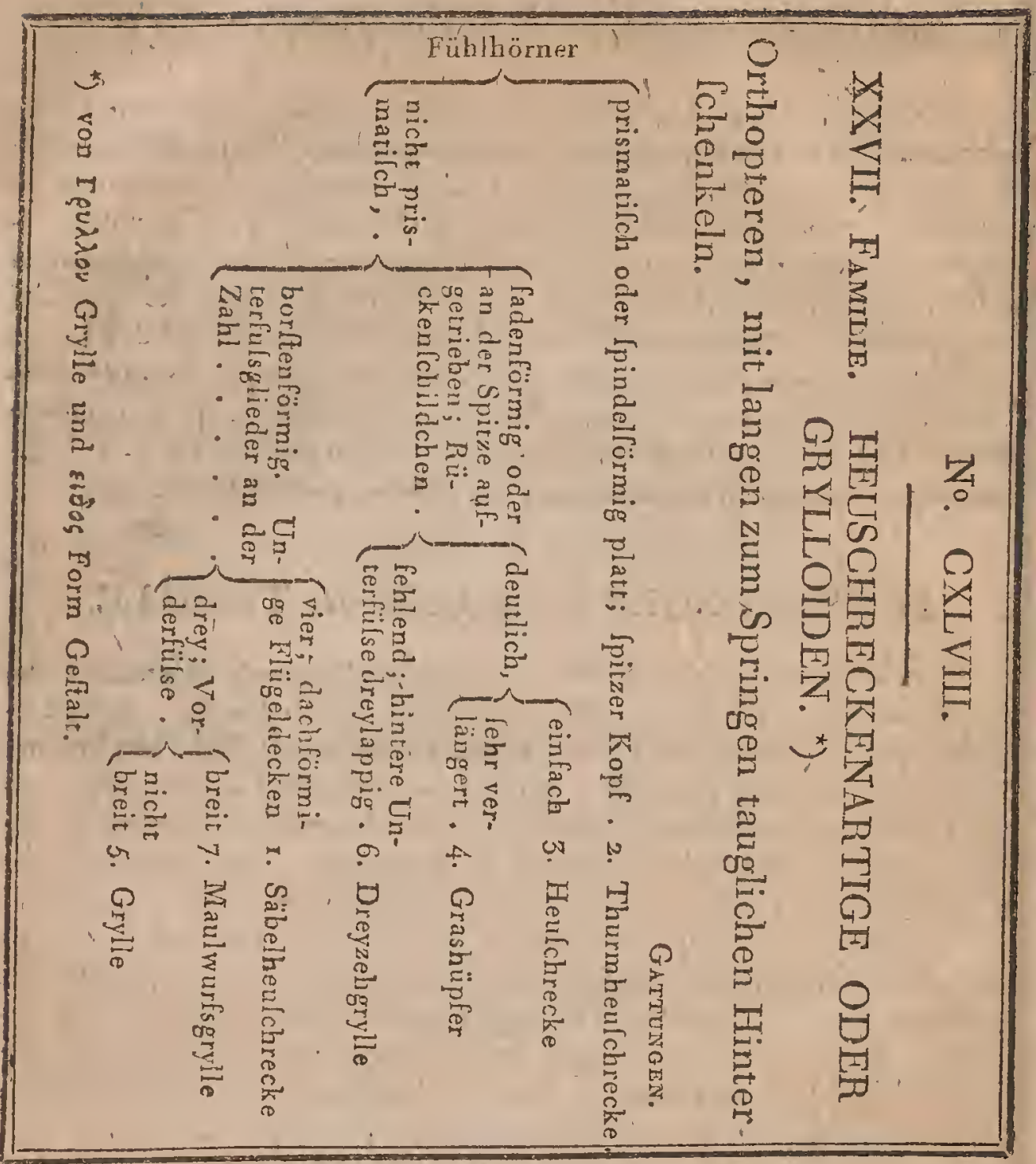

\section{BEMERKUNGEN ZUR CXLVIII. TABELLE.}

Die Grylloiden haben eine Familienähnlichkeit, wodurch fie auch lehr leicht zu unterfcbeiden find, und diefe liegt vorzüglich in der - Form dés Körpers, welcher Ichmal, faft zylindrifch und lang ift; dann in der Stellurng des Kopfes, die meiften vertikal, bey vorragenden Kinnladen, angetroffen wird; dann in der Länge der unteren Flügel, die der Länge nach gefaitet und gewöhnlich länger find als die oberen; _endlich in den langen. Hinterfüfsen und befonders in der Auftreibung der Hinterfchenkel, wodurch lie das Vermögen erhalten fich von der Erde in die Höke zu fchnellen, um nachlier davon zu fliegen.

Ihre Fühlhörner fo wie die Bildung anderer Körpertheile zeigt viele 
Verfchiedenheiten; wodurch es leicht wird fe in Gattungen abzutheilen. Die Weibchen lind gröönlich viel dicker als die Mänchen: fie legen ihre Eyer in einen aneinander kleberden Haufen. Die meifien Mänmchen bringen, auf die oben erwähnte Weile, eimen befondernílon hervor.

1. Die Säbclheufchrecken (loculta, Fabr.) haben borltenförmige Cehr lange Fithlhörner. Ihr Kopf ift von dem Halslchild, wie von-einer Kappe, bedeckt. Rückenlchildchen haben fie nicht. Ihr Leib ift hinten, wie der der Schaben, mit zwey Șpizen epdigend, Die Wibchen haben aulserdem zwey geráde oder gebogene läbelförmige Lamellen, awilchen welchen thre Eyer heraligleiten. Z: B. Gryll viridilimus L.

2. Die Thurmheiffhreckén (truxalis F $F^{\prime}$ r.) haben den Kopf pyramidenfönig verlängert und zufarnmengedrückt und, in Proportion zu den übrigen Gattungen, kurze Fühihörner, Jie über den Augen lilzen. Z. B. Gryll. nalutus L. Es find dies Infekten aus dem mittäglichen Europa und Afrika.

3. Die Heufchrecken (gryllus $I$, i $n$ n.) haben faft zylindrilche oft zufammengedrückte und logar woll auch Kenlenförnige Fihlhörner, lhr Halslchild verlängert fich nicht Rückenlchildartig zwifchen die Flügeldecken. Sie haben dreygliedrige Unterfülse. 2. B. Gryll Itridulus L.

4. Die Grashüpser (acridium $G$ e offr.) find den Heulchreclen fohr ähnlich, haben aber keine Flügeldecken und ihr Halsfchild verlängert fich über dew Leib in eine Art von Rückenlchild, welches oft über denlelbea binausraget. Z. B. Acr. bipunctatum.

5. Dié Gryllen (acheta L. Fabr) haben borftenförmige Fühlhörner wie die Säbelheulchrecken, aber hhr Kopf ilt kugelfömig und ihre Unterfüfse haben nur drey Glieder. Ilir Halslchild ift mehr breit als lang. Die Weibchen haben eine rundliche Legelcheide. Die meiften kommen nur 'des Abends hervor. Mehrere Arten bekonmen niemals Flügel: oft haben Ciè nùr Flügeldecken. Z $Z$. B. acheta domeftica.

6. Die Dreyzehgryllen (tridactylus, Olivier) haben fadenförnige Fühlhörner, fonft aber faft die Geftalt der Gryllen. Sie graben in die Erde. (Z. B. acheta digitata Cocqueb er illuftrat. iconograph. des InSectes Taf. 21 Fig 3.)

7. Die Mauliwurfsgryllen (grvllotalpa F.) unterlcheiden fich von den Gryllen nur durch die Lebensart und durch die Bildupg der Vorterfülse, worá die Beine breit, dreyeckig; gezähnelt und vorn lcheidend find und das erfte Unterfulsglied, medlerartig würkt. (Z. B. Gryllus gryllotalpa L.) 


\section{No. CXLIX.}

\section{Ordnung. NEUROPTEREN, *)}

Infekten mit vier náckten Flügeln, von gleicher Confiftenz, mit netzförmigen Aderftreifen; Kinnladen.

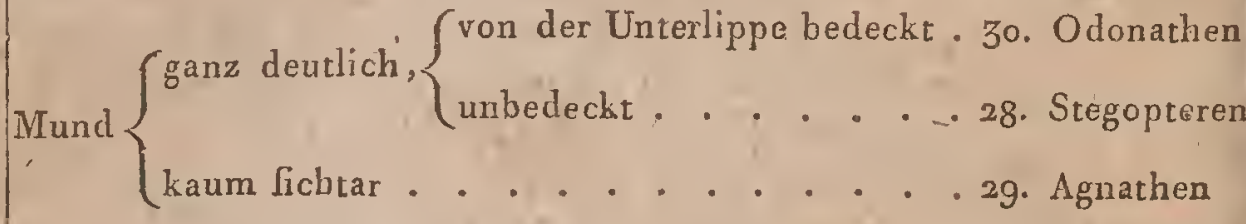

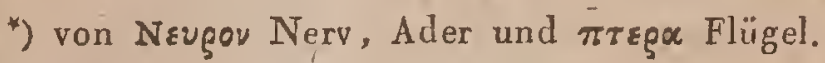

\section{BEMERKUNGEN ZUR CXLIX. TABELLE.}

Die Ordnung der Neuropteren oder Netzflïgler, begreift Inlekten. mit Kinnladen oder ohne Saugrüffel, welche nackte, netzlörmig geaderte Flügel haben. Eey den meiften entwickeln fich die Larven im VYalfer; bey andern unterm Sande und, von eíner kleinen Zahl, in freyer Luft. Es ift diefe Ordnung, obgleich auf die Geftalt der Flügel gegründet, 'doch keine natüliche, denn die in ibr vereinigten Inlekten find, was Lebensart und Metamorphofe anlangt, in den verfchiedenen Familien fehr verlchieden. Die Arten, welche als vollltändige Inlekten eine längere Zeit (mehrere Tage) leben, nähren fich blos von Inlekten; mehrere aber nehmen gar koine Nahrung zu fich.

Zur genauern Kenntnils der Infekten diefer Ordnung, foll hier das Allgemeine jeder Familie für fich betrachtét werden.

Die Lebensart der Stegopteren, welche im Rubezuftande ihre Flügel dachförmig liegen haben, ift nur wenig bekannt. Die meilten bis jetzt beobachteten Arten kommen aus fleilchfreflenden,Larven, welche den Infekten, wovon fie fich nähren, mit Lift gleichlam Fallen fțellen oder die langfam fich bewegenden oder die in Gelellfchaft lebenden angreifen. Sie Ipinnen fich unter der Erde, in einem Kokon, ein und verwandeln fich in eine unbewegliche Puppe, an der aber, wie bey den Käferpuppen, alle Theile fchon fichtbar find. Andere Larven bleiben im Holze verborgen. Einige entwickeln fich im Wafler. In ihrem vollkommnen Zuftande leben te nur wenige Tage: ihr Flug ift kurzund nicht bioch. Einige 
Individuen lcheinen zu einèr unbedingten Unfruchtbarkeit verdammt $z u$ reyn.

Die Agnathen entwickeln fich im Waffer.' Sie haben einige Aehnlichkeit mit den letzten Familien der Lepidopteren, - durch ihre Verwandlung, in ibrem Larvenzuftande. Die Meiften haben eine Art vori Kieme zur Refpiration im $\mathrm{W}^{\tau}$ afler. Bey Einigen ift die Puppe unbeweglich in einer Scheide fieckend; bey andern ift fie in alten Zuftänden beweglich. Im Ganzen leben diefe Infekten in ihrem vollkommnen Zuftande nur fehr: kurze Zeit, indem ihnen die Hülfsmittel mangeln, wodurch fie ihre Bedürfniffe, befriedigen können. Einige brauchen mehrere Jahre um lich zu entwickeln, endlich nehmen fie ihre letzle Geltalt an, werden zur Fortplanzung tüchtig und dann folgt oft in einem Tage Begattung, Eyerlegeu und der Tod aufeinander.

Die Odonachen haben alle Flügel faft von einer Grölse. Alle gle्ichen fich in Lebensart und Metamorphofe. Sie kommen aus Larven, die im Vaffer leben, wo fie fich yon kleinen Wafler-Thieren nähren, die fie mittels einer Zange ergreifen, womit ihre fehr vorfireckbare Únterlippe bewaffnet ift. Sie fchwimmen im Wafler auf eine ganz eigne Weife, die mit ihrer Relpirationsart zulammenhängt. Sie nehmen in das untere Ende ihres Darmkanals, durch die Afteröffung. Waller, worin fie beftändig lében, auf und einige Zeir nachher treiben fie es wieder wie mit einer Spritze hinaus. Das umgebende Walfer leiftet diefem heraussetriebenen Waffer Widerftand und dadurch wird das Infekt, in der entgegengeletzten Richtung, fortgetrieben. Alle Odonathen, ohne Ausnahme, haben eine bewegliche Puppe, die von der Larve nur durch die Flüg'elltumpfe abweicht, die man hinter dem Halslchilde wahrnimmt. Wenn fich diefe Inlekten, zum Uebergang in ihren letzten Zultand, verwandeln wollen, fo verlaffen fie das Wafler, durch trockenwerden fpaltet fich ihre Haut und das ausgebildete Inlekt fliegt in die Luft und verfolgt die kleinen Inlektenarten, von denen es fich nährt. Da die Generationsorgane bey den Männchen an dem Anfange des Hinterleibes, (dicht hinter der Brufty Sitzen, fo müffen fie durch ein Paar an ihrem Hinterleibsende befindliche Zangen, die fie den Weibchen an den Hals legen, diefé letzteren zwingen, dals fie ihre, wie gewöhnlich am Ende des Hinterleibes liegenden, Generationsorgane an jene des Männchens anlegen und zu diefem Behuf aine Lehr Sonderbare Biegung ihres Körpers vornehmen. 


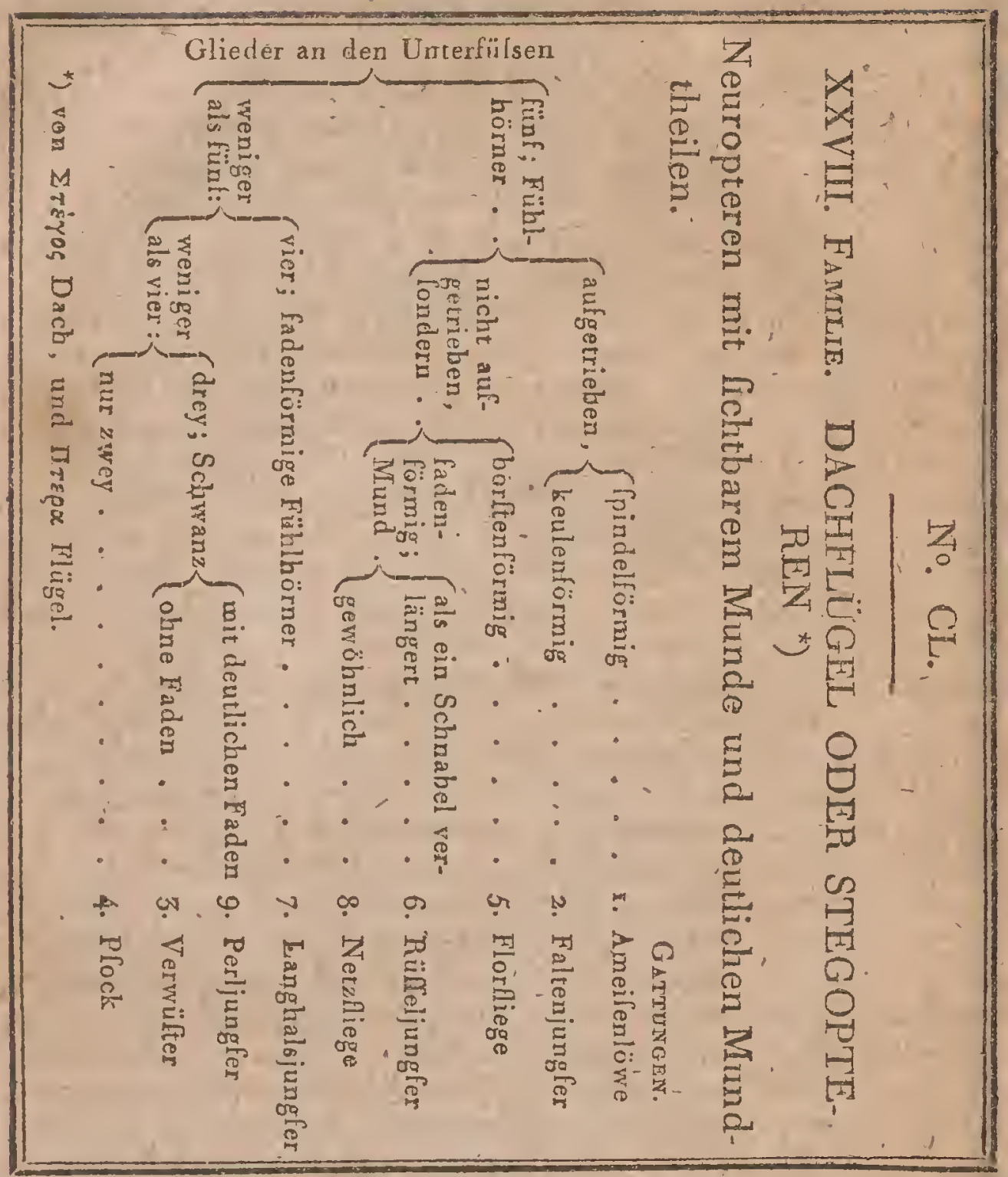

\section{BEMEPKUNGEN ZUP CL. TABELLE.}

Da auf der vorigen Tabelle das Allgemeine diefer Ordnung der Stegopteren angegeben ilt, fo können hier einge Details über die einzelnen Gattungen, deren liebensart fo fehr verfchieden ift, folgen. I. Die Ameifenlüwen (myrmeleon L. 2. B. M. formicaleo) find in ihrem ausgebildeten Zuftande fehr leicht an ibren kurzen, in der Mitte dickeren und etvas hạckenförmig gekrümmten, Füblhörnern zu erkennen. Thre Flügel find faft von gleicher Breite und nicht gefalcet. Ihre Larve, obgleich lie fich von fchnell beweglichen Infekten nähren muís, felbft nur im Stande, fich fehr langlam all beweren und zu rutchen. Aber das was fie 
nicht durch Schnelligkeit nnd Gewalt, erreichen und ausführen kann, be0. werkftelligt fie durch Lilt. Sie kann in lockerem Sande eine Art von breiten Trichter aushöhlen, auf delfen Boden fie auf der Lauer liegt, um mit ausgeftreckten Mandibeln die Infeḱten zu faffen und auszufaugen, die Aderä Rande diefer gefährlichen Grube zu nahe kommen. Gewöhnlich bleibt die Larve $z$ wey Jahre in dielem Zuftande, dagegen das Lehen int. dem letzten Zultande des entwickelten Infekts nur einige Tage dauert. 2. Die Falterjungfern (afcalaphus $F a b r$.) haben ganz die Füblhörner der Falter. Sie gleichen etwas den Ameifenlöwen, aber ihre Fühlhörner find verfchieden, fo auch die Flügel, welche gewöhnlich dunkelgefärbt find. Ihre Larven hat man noch nicht beobachtet. Z. B. Myrmeleon barbárus L. 3. Die Termiten oder Fersuiffter (termes L.) haberi fadenförmige Fühlhörner mit köłnerähnlichen Gliedern. Bey den Männchen und Weibchen bilden die Flügel ein plattes.Dach ; die Gefchlechtslofen haben keine Flügel. Die meiften diefer Infekten leben in zahlrei. chen Gefellfchaften, in Afrika und Indien. Sie bauen fich Wohnungen unter der Erde, nehmen truppweife, wie die Ameilen, grolse Wanderungen vor und richten da, wo fie hindringen, grofsen Schaden an dem Hausgeräth an. Z. B. termes,fatalis. 4. Die Pfocke (pícus L a Lr. z. B. Ploc. ăbdominalis $F a b r$.) haben einige Aehnlichkeit mit den Termiten, gewöhṭlich aber find lie nur fehr klein. Einige Arțen können fpringen. Diefe Infekter zerftören alte Meubeln und vorzïglich zartes Holz. 5. Die Florflegen (hemerobius) leben wohl länger als einen Tag obgleich ihr Gattungssname das Gegentheil anzudeuten Icheint. Die Weibclien legen Eyer, die mit einem langen Stiele verfehen find. Die daraus kommende Larve gleicht den Ameifenlöwen, ift aber länger; fie nähtr fich blös yon Blattläufen, die fie mittels ihrer an der Spitze mit einex Oeffnung verfehenen und, wie die der Spinnen, inwendig hohlen Mandibeln ausfaugen. Z. B. Hemerobius perla. 6. Man kennt die Lebensart der Riüfeljung fern (panorpa z. B. panorpa communis) noch nicht. Man weils blos dafs lie in ihrem vollftändigen Zuftande fich von Inlekten mähren, die fie im Fluge fangen und lebend verzehrein. Thre Flügel find fchmal und lang, faft horizontal; die meiften haben den Mund an der Spitze eines Rüffels; $L$ atreill $e$ hat die in Afrika und Aflien vorkommenden Arten, mit. langen fchmalen Flügeln, nemopter á ǵenannt. 7. Die Langhalsjundfern (raphidia L. z. B. R. ophiopfis) haben ein langes Halsfchild, den Kopł zund und frey beweglich oder auf einer Art von Halfe fitzend. Sie haben énige Aehnlichkeit mit den Fangheufclirecken. Ihre Larve und ihre fchnellbewégliche Nympfe, die fich in' Bauınritzen aufhält, "nähret.fich von Infekten. 8. Die Netzfliegen (Temblis Fabr. z. B. Lemblis: Lutaria) haben die Flügel als ein flaches Dach und den Kopé horizontal. 9. Die Perljungfern (perla Geoffr. femblis bicaudața Fabr.) gleichen den Netzfliegen aber ihre Flügel bilden um den Körper eine Art Scheide. Sie haben drey glatte Augen und nur drey Unterfufgglieder. Man vermuthet dafs ihre Larven fich im Wafleri entwickeln. 
No. CLI.

\section{Familie, AGNATHEN. *)}

Neuropteren mit fehr kleinem, blos durch die Frelsfpitzen merklichen, Munde.

Gatumangen.

Fühlhörner dié $\begin{aligned} & \left\{\begin{array}{l}\text { kürzer find als der Kopf . r. Tagfliegel } \\ \text { länger find als der Kopf . 2. Köcherjungfer }\end{array}\right.\end{aligned}$

*) von A privativo und Tvasos Kinnlade.

\section{No. CLII:}

XXX. Familie. LIBELLEN ODER ODONATHEN. *)

Neuropteren mit fehr deutlichem, von der. Unterlippe bedeckten, Munde; fehr kurze borftenförmige Fühlhörner.

Gattungen.

Kopf $\left\{\begin{array}{l}\text { kuglich́,' faft fo lang als breit . . 1. Wafferjungfer } \\ \text { breit, in die Queere grölser ... 2. Waflernympfe }\end{array}\right.$

*) von ofous Zahn und rvasos Kinnlade.

\section{BEMERKUNGEN ZUR CII. TABELLE.}

Die Agnathen haben keine hinlänglich entwickelten Käuorgane', um fefte Nahrungsmittel damit zu faflen und auch keine Saugorgane un Flüfo figkeiten aufzunehmen; áucls leben fie-im "vollkommnen Zultande nur fehr kuzze Zeit. 
I. Die Tagliegen (ephemera L. z. B. eph. vulggata) haben vier Flü. gel, wovon die obern fich perpendikulär ftellen und die untern kleiner find. Ihre Füllhörner find lehr kurz und endigen mit einer Borfte. Ihre Augen find of lehr grols. Ihr Leib endigt hinten mit zwey oder drey langen Borften und die Vorderfülse find fehr entwickelt. Thre Larven leben unterm Vafler odex im Flufsfchlamm; lie lind mit Kiemenartiger Or ganen verfehen. Ihre Puppe ift beyveglich. Das entwickelte Infekt häutet fich noch einmal in der Luft, ehe es fich begattet.

2. Die Köcherjungfern (phryganea L.z. B.'phr. ftriata) haben ihren Namen von der Gewohnheit ihrer Larven, fich, von kleinen Holnfückchei und andern fremden Subftanzen, einen Köcher oder Scheide zu verfertigen. Sie nähren fich vorzüglich von Wallerplanzen. Ihre Puppo bleibt nur eine Zeitlang in ihrer Scheide unbeweglich', 'wird aber hernach. ganz beweglich und lebt eine Zeitlang im VWaffer, bis fie Gelegenheit findet, fich felt zu hängen, aufser dem. Wafler fich der Luft auszufetzen, wo dann die Hant trocknet, fich Ipaltet und das vollftändige Infekt hervorkommen lälst, welches mit borftentörmigen Fühlhörnern verlehen ift, die oft langer find als der Körper und beftändig bewegt werden. Sie fliegen des Abends im zahllolen Trupps am Ufer des Wallers.

\section{BEMERKUNGEN ZUR CLIT. TABELLE.}

Die Odonathen bilden in dem Fabriciusfchen Syfteme nicht nur ein Familie fondern eine eigne Klafle. Die Charakteriftik derfelben ift Ichon bey der Betrachtung der Familien der gegenwärtigen Orcinung, pag. 240 , geliefert.

1. Die Wafferjungfern (libellula $L i n n$.) halten ibre Flügel im Ruhezuftande ganz horizontal. Ihre Larven find breit, und platt; ihr Leib endigt mit fünf Spitzen, die fich an einander legen und eine Art Warze bilden." Ihre Unterlippe hat eine ganz eigne Bildung, fie ift lang, dreymal in ihrer Länge gefaltet oder geknickt, und am Ende mit den fclion befchriebenen 'zwey 'Haken bewaffnet. Die Puppe ift beweglich wie die Larve. Z. B. Lib. depreffa $L$.

2. Die Waffernymphen (agrion Fabr. z. B. Libell. virgo L.) tragen in ihrem entwickelten Zuftande die.Flügel perpendikulär. Thre kugelförmigen Augen vergröfsern den Umfang des Kopfes vorzüglich in die Queere. Ihre Larven find weniger breit, weniger unförmlich dick und weniger langlam als die der vorigen Gattung. Sie fchwimmen fehr fchnell vermittelft', breiter blattförmiger Lamellen, die am Ende des Hinterleibes litzen und ibnen als Ruder dienen, Ihre Lebensart ift die der vorigen Gattung. 
Hymenopteren:

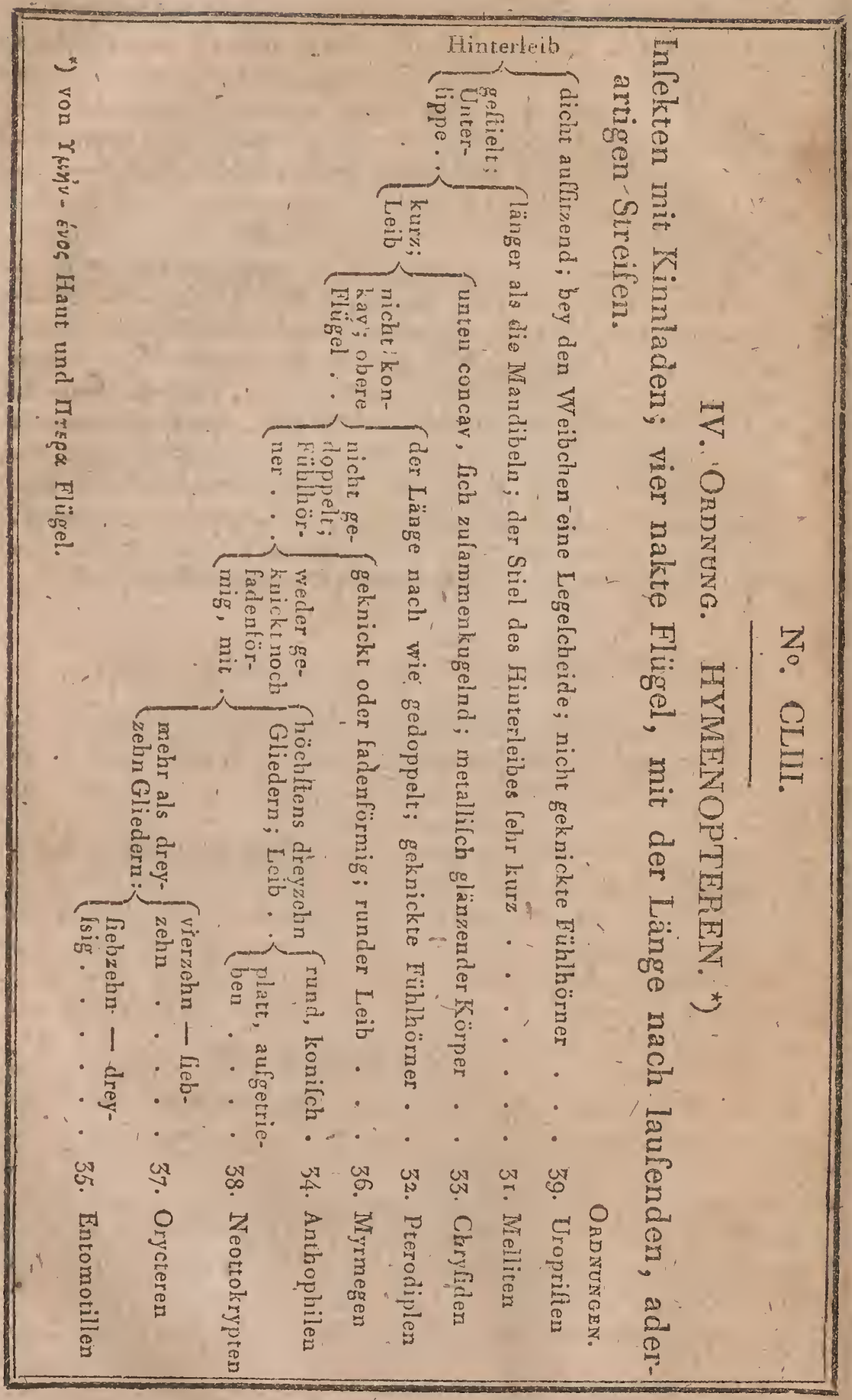




\section{BEMERKUNGEN ZUR CLIII. TABELLE'}

Die Ordnung der Hymenopieren entpricht der Klaffe Piezaia de Fabricius. Sie begreift alle die Infekten, die, neblt einem zur Zermalmnng felter Subftanzen belimmten Munde, vier häutige Flügel tragen, deren Streifen aderartig der Länge nach laufen. Ihre Unterflügel find immer fchmäler und kürzer als die obern, und alle zwey legen fich 'bey der Ausbreitung fo aneinander, dals fie nur eine Fläche bilden. Dia Hymenopteren haben fünf Unterfulsglieder. Bey den meilten endigt der Hinterleib der Weibchen mit einér Röhre, durch welche die Eyer gelegt werden. Andere, und vorzüglich die Männchen haben an diefer Stelle, einen zuräckziebbaren' Stachel, der in die damit gemachte Wunde eine Flüligkeit bringt, welche einen hoftigen Schmerz hervorbringt. Es kann diele Ordnung in zwoy grofse Abtheilmgen getheilt werden, "die den beyden erften auf der T'abelle entprectuen. Alle Uroprifien kommen aus einer Raupenähnlichen Larve, die nit Füfsen verfehen ilt und feiblt. für ihre Bedürfniffe forgen kann, uril ihre Aeltern nicht keqnt. Itu allen andern Familien haben die Laryen keine Fülse, gleichen, weichen Würmern und die Aeltern müllen fie meilt ernähren. In dieler Hinlicht zeigt die Ordnung der Hymenopteren die grölste Verlchiedenteit in den ver. fchiedenen Familien. So ernähren tie Melliten und Pterodipten ihre Larven mit dem Plumenltaub und Zucker der Pfanzen; es giebt bey ihnen Weibchen, die zu einer beftändigen Unfruchtbarkeit verdanmt lind, deren Gefchlechtscharakter fie aber zur Erziebung der, von einem osler einigen fruchibaren Paren kommenden, Jungen antreibt. Bey andern, z. B. den Myrmegen find die unfruchbaren Weibchen auch Flägellos und faugen, da fie nicht zu don Blumen kommen körnen, aus dem Leib́be der Blatuläufe die zuckerartige Materie und lammeln'auf den Boden, auf den Planzen auf die fie klettern, alle ihnen tauglich fcheinenden ernährenden Subftanzen und tragen fie in ihror Wohnung wo fie gemeinlchaftlich und nach gewillen Regierungsgefetzen leben. Die Orykteren und Anthophilen, greifen Infekten an, tauben ihnen durch einen Stich mit ihrem Stachel, das Vermögen fich zu bewergen, und begraben fie, fo gelähmt, neben das Ey wodurch lie ihre Gattumg fortpllane zen, und woraus die Larven gleich nachlem lie auskommen, in den Kör. perdieler nur halbgetölteten, aber eben dadurch vor fäulnils bewahrten, Infekton ohne Widerfiand einaringen. Andere z. B. die Neotiokrypten legen ihre Eyer unter die Oberhaut der Planzen oder in das Gewebe terfelben. Die dafelbftgemachten Wunden bewirken cinenZnfluts der Säfte, die rlalelbft ausfchwitzen und Gefchwïlfe billen, in deren Innern die kleinen Larven fich räbren und entwickeln. Endlich die Encomolillen zeigen noch auffallendere:Gewohnheiten. Die Weibchen legen ihre Eyer an die Oberfläche oder in llas Innère des Körpers, der Eyer, der Larven oder der Puppen anderer Infekten. Der kleine fuíslole Wum, der aus dénlelben auskriecht, nährt fich anfangs von der Fettmalle des Infekts, warhher greift er die edeliten Organe an und tödtet das Thier, in welchem or fcbmarotrend lebt. 


\section{No. CLIV.}

XXXI. Famile. BIENENARTIGE ODER MELLITEN. *)

Hymenopteren mit geftieltem Hinterleibe; Unterlippe länger als die Mandibeln; geknickte Fühlhörner.

flie Zunge bedeckend; gelber Körper mit

GatTunGen.

lchwarzen Flecken . . . . . .

6. Baftardbiene

die Zun- $\left(\begin{array}{l}\text { haarig' } \\ \text { oder }\end{array}\right.$ länger als Kopf und Bruft-

2. Langhornbiene

\begin{tabular}{l|l} 
se nicht & rauh; \\
bede- & Fühl- \\
\hline
\end{tabular}

ckend;

kürzer als Kopf und (platt

I. Biene

Kopf: hörner

Bruftichild; erftes

$\left\{\begin{array}{l}\text { Glied der hinteren } \\ \text { Unterfüfse cylin- }\end{array}\right.$

Unterfüfse * $\cdot\left\{\begin{array}{l}\text { cyli } \\ \text { drilch 4. Afterbiene }\end{array}\right.$

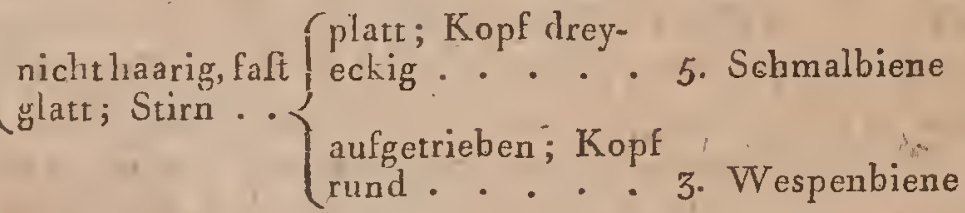

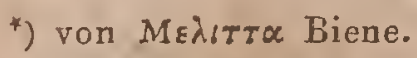

\section{No. CLV.}

XXXII. 'Familie: DOPPELFLÜGEL ODER PTERODIPLEN. *)

Hymenopteren mit geftieltem, unten nicht concavem, Hinterleibe; Unterlippe fo lang als die Mandibeln; obere Flügel wie gedoppelt; geknickte Fühlhörner, deren erftes und zweytes Glied lang find.

Gattungen.

Fühlhörner $\left\{\begin{array}{l}\text { lpindelförmig . . . . I. Wespe } \\ \text { keulenförmig . . . . 2. Kolbenwespe }\end{array}\right.$

*) von Mregov Flügèl und $\Delta$ rtriow ich verdopple. 


\section{BEMERKUNGEN ZUR CLIV. TABELLE.}

Die Fámilie der Mélliten unterfcheidet fich durch die Länge dér Unterlippe und der Kinnladen, wodurch diefe Inlekten das Vermögen erhalten, den Blumenfaft einzufaugen. Alle, ohne Ausnahme, emährea ihre Larven mit Blumenltaub und dem Zuckerftoff, den fie aus den Plinzen ausziehen. "Bey einigen Arten find die meiften Weibchen durchaus unfruchtbar. I. Die Gattung der Bienen (apis L.) ift die zahlreichlte an Arten. Man theilt lie ab in a) Maurerbienen, deren Hinterleib falt platt und ungeftielt ift und deren Flügel gefärbt find. Z. B. apis violacea $k a b$. b) Hummeln die den vorigen gleicben aber einen getrennten Hinterleib haben. Z.B. ap. terreftris. c) Tapezierbienen oder Blatlfchneidebienen, bey denen Halsfchild und Bafis des Hinterleibes geftutzt ift. Z. B. ap. centuncularis. d) Honigbienen z. B. apis mellifica L. das erfte Unterfulsglied der Hinterbeine ift löffelförnig auswehöhlt und oft mit Queerltreifen verfehen, bey den Arbeitsbienen und. Weibchen. e) Langzungbienen z. B. "apis dentata L. haben den Rüflel faft folang als der Körper, 2. Die Langhornbieneñ (eucera, Fabr.) find den Bienen fehr ähnlich, äber ihre Fühlhörner find nicht geknickt und find bey den Männchien aulserordentlich lang. Z. B. apis longicornis L. ' 3. Die Wespenbienen (nomada F a br. z. B ap. variegata L.) haben einen glänzenden Körper ohne Flaum; ihr Kopf ift etwas breiter als das Bruftchild, das Stimfchild etwas aufgetrieben und das Rückenfchildchen durch vorragende Spitzen erfetzt. 4. Die Aflerbienen (andrena $F a b r$. ) gleichen den Wespenbienen; aber ihr Körper ift rauhhaarig; fie haben kein Rückenfchildchen, das Stirnlchild ift platt. Z: B. ap. florum. 5. Die Schmalbienen (hylaeus $F a b r$.) fcheinen nur Männm chen der Afterbienen zu Seyn; wenigftens gilt das wohl von den meilten durch die Entomologen belchriebencn Arten. Z. B. ap.. glutinans-L. 6. Die Baftardbienen oder Baftardwcspen (bembex Fabr. z. B. bemb. roltrata $P$ a nz.). find lehr leicht an ihrer in einen Schnabel verlängerten Oberlippe zu unterfcheiden; auch ihre Augen, die drey Viertheile des Kopfes bilden und ihre meift ftachlichten Vorderfülse zeichnen fie aus.

\section{BEMERKUNGEN ZUR CLV. TABELLE.}

Die Lebensweife der Pterodiplen ift faft dielelbe, wie die der Bienen Ihre Unterlippe ilt lebr kurz; ihre Kinnladen find fehr lang; ihre Fïhllhörner wie geknickt und durch das erfte und zweite Glied ausgezeichnet. x. Die IT espen (vespaz. B. vespa vulgaris L.) haben Füllbörver, welche gegen die Spitze zu fich allmählich verdicken, nierenförmige Augen, vorragende lchmabelförmige, an der Spitze lich kreuzende Maudibeln. Einige haben einen kurzen Stiel vor dem Hinterleibe, andere haben ihn oft durch mehrereStïcke verlängert. 2. DieKolbenwespen "(malaris, $F a b r$.) haben, wie die Goldwespen, das Vermögen fich zufammenzurollen und find mit keulenförmigen Fühlhörnern verfehen. Sie fcheinen den natürlichen Uebergang zu der folgenden Familie zu machen. Z. B. mal. vespiformis Fabr. 


\section{No. GLVI.}

\section{Famlere. CHRYSTDEN *)}

Hymenopteren mit unten konkavem Hinterleibe; Unterlippe fo lang wie die Mandibeln; metal= lifch glänzender Körper.'

\section{Gattungen.}

Vordere Ringe des (von gleicher Grölse, . . . I. Rüffel wespe Hinterleibes

(von ,ungleicher GröIse . . 2. Goldwespe

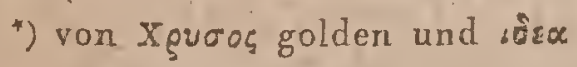

\section{No. CLVII.}

XXXIV. FAMILIE. BLUMENSUGHER ODFR AN-

\section{THOPHILEN. ${ }^{*}$ )}

Hymenopteren mit gefieltem, rundlichem, konifchem Hinterleibe; Unterlippe fo lang als die Frefsfpitzen; nicht geknickte, höchftens dreyzehngliedrige Fühlhörner.

Gattungen.

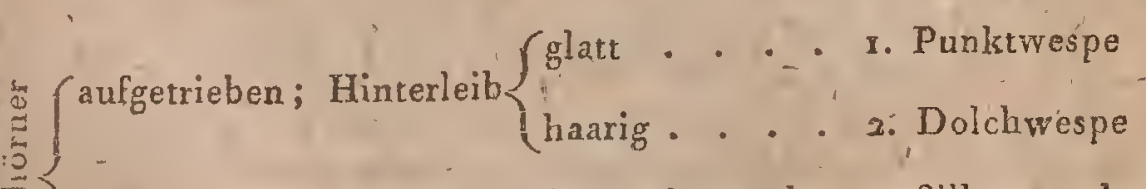

Ladenförmig; Stirnlchild $\{$ metallglänzend . 3. Silbermundwespe Znicht ló glänzend 4. Glattwespe

*) von AuSos Blumen und $\Phi / \lambda \varepsilon \omega$ ich liebe. 


\section{BEMERKUNGEN ZUR CLWT. TABELLE.}

Die:Chryfiden unterfcheiden fich von den Doppelfügeln durch ihre. fadenförmigen nicht keuleuförmigen $F u ̈ h$ h hörner, durch ihren unten konkaven Hinterleib; und durch die. Form des Halslchildes, was aus zwey an der Seite des Rüctens fichtbaren Stücken gebildet ift.

I, Dié Goldwespen.(chryfis Fa br. z. B. chr igrita) haben ihre votderften Hinterleibsringe von ungleicher Grölse, ihre Lebensart ift wenig bekamit. 2. Die Rïffclwespen (parnopes Latreille z. B. chryl. carnea $F a b r$.) unterfcheiden fich durch die Kinslade und Unterlefze, die eine Art von urterwärts gebogenen Rüfel bilden. Ihre vorderen Unterfüfse find, lehr gefranzt, und an der Batis, deś Flügels baben fie ein Lleines Schulterblattförmiges Schuppenfückchen.

\section{BEMERKUNGEN ZUR CLVI. TABELIE.}

Die Familio der Anthophilen kann von der Familie der Bienen oder Melliten fehr leicht an der Kürze der $Z$ ąe unterfchieden werden, die nicht weiter als die Mandibeln vorragt. as die übrigen Familien dieler Ordnung ańlangt, lo find auch diele hinläsglich abweichend. Die Chryfiden baben den unten concaven Hinterleib; die Myrmegen haben geknickte Fühlbörner; bey den Entomotillen und Oryteren finden fich mela als dreyzehn Fühlhornglieder; die Neottokrypten haben den Hinterleib zulammengedrückt und die Schenkel aufgetrieben; und die Uropriften haben den Hinterleib ganz diclit auffitzend. Die Anthophilen bilden alfo eine fehr natürliche Familie. Alle dazu gehörigen Infekten leben in ihrem letzren Zuftande aut Blumen; ihr Neft bereiten fie fich an der Erele; fie fammeln wẻder Hoaig noch Wachs, find vielmehr dem Anfchein nach fleifchfreffend, denn fie greiten andere Infekten an, tölten fie, fchléppen fie mit fich fort um ihre Larven damit zu füttern die fonftkein Mittel ha. ben um fle zu ergreifen. "x. Die Punkwwespen (philanthus Fabr. haben Spindelförmig aufgetriehene Fühlhörier, die Augen mit einem kleinan Ausfchnitt, den Kopf auf einer Verlängerung des Halsfchildes fitzen. Fufswurzel and Bein der Vorderfülse gefranzt. Z. B. phil. apivorus F a br. 2. Bey den Dolchwespen (fcolia $F a l$ r.) ift der Körper haarig, der Hinterleib lehr lang, die Augen mit einem Cehr grofsen Ausfchnitt; die Flügel oft dick und gefärbt; Unterfuls ünd Bein getranzt und zum Graben in die Erde gefchickt. Z. B. Sc. quadripunctata Fabr. 3. Silbermindwespen (crabo L. z. B. crabro cribrarius L.) Lind féhr leicht zu erkennen, an ihrem viereckigen Kopfe, der breiter ift als das Halsichild; an iliren vorn and unten einander genäherten Augen; an ihren zwilchen den Augex fitzenden Fühlhörnern und an ihrem of mit kurzen, atlasartigen filberoder gold -glänzenden Hàaren beletztem Stirnfchilde. Die Männchen einiger Arten haben die Vorderbeine mit einer fchildförmigen Ausbreitung: verfehen. 4. Die Glatcwespen (mellinus Fabr.) haben auch den Kopf breiter als das Halsfchild: Ibre Augen find von einagder ftehend und oh-we Auslchnit, z. B. mell, arvenl. Fabr. 


\section{No. GLVIII.}

XXXV. FAMILIE. INSEKTINERESSER ODER ENTOMOTLLEN. *)

Hymenopteren mit geftieltem unten nicht konkavem Hinterleibe; Unterlippe fo lang wie die Mandibeln; nicht geknickte. Fühlhörner von fiebzehn bis dreyfsig Gliedern.

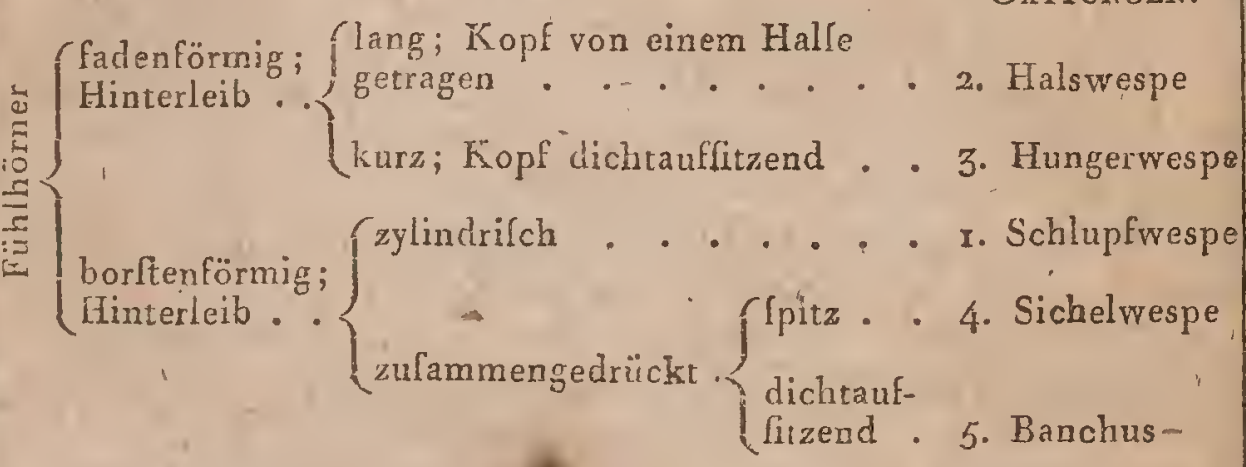

$\left.{ }^{*}\right)$ von Evropoy Infekt und $T$ t $\lambda \lambda \omega$ ich nage, ich verderbe.

\section{No. CLIX.}

XXXVI. FAMILIE. AMEISENARTIGE ODER MYRMEGEN. *)

Hymenopteren mit geftieltem, rundem Hinterleibe; Unterlippe fo lang als die Mandibeln; geknickte, fadenförmige Fühlhörner.

Gattungen.

$\frac{ \pm}{ \pm}$ faft dicht auffitzend . . . . . . .

¿ $\left\{\begin{array}{l}\text { langen, knotigem oder fchuppigen } \\ \text { Stiele. }\end{array}\right.$

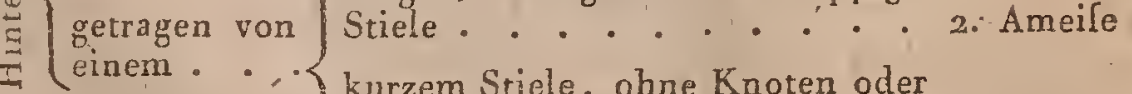

- $\{$ kurzem Stiele, ohne Knoten oder

Schuppen . . . . . 3. Bienenameife

${ }^{*}$ ), von Mugผяร Ameile. 


\section{BEMERKUNGEN ZUTR CLVIII. TABELLE.}

Die Larven der Entomotillen, entwickeln fich im Innern des Körpers anderer Infekten, welche fie anfreflen, wobey fie aber lorgtältig die Dige. ftionsorgane verfchonen, die die Süfte hergeben, von denca fie fich nähren. Nur'erft wenn fie im Begriff find fich zu verwandeln, oft aucs erlit wenn fie den Körper, worin fie bisher als Schmarotzer lebten, verlaflen, nur dann tödten lie diefe Raupen oder Puppen. Sie bieten alfo lehr fonderbare Eigenheiten in derLebensart dar. r. Die Schlupfwespen haben ihren Gaitungsnamen (ichneumon) von der Sorgfalt, womit lie die Infekten auffuchen, in welche fie ihre Eyer abletzen. Ihre langen Fühlhörner find in einer beftändigen Bewegung. Die Weibchen haben gewöhnlich eine Iange Legeröhre am Hinterleibe, die aus drey Fadenbefteht, zwilchén welchen ein feiner Kanal hleibt, der zum Durchgange der Eyer dient. Ihr Hinterleib ift zylindrifch und fitzt mit einem Stiel auf dem Untertheil des Hals - wand Bruftfückes. Z.B. ichneum, perfuaforius L.) 2. Die Halswespen (foenus Fa k r. z.'B. ichn. jaculator) haben die Fühlhörner vorwärts gerichtet, ihr Hinterleib if lang, fichelförmig zufámmengedrückt und litzt auf dem Rü. cken des Hals - und Brultifückes. Der Kopf wird von einer Art Hals getragen und an den Hinterfülsen find die Beine unten etwas keulenförmig. 3. Die Hungerwespen (evania Fa $b r_{\text {. }}$ ) gleichen den vorigen, aber ilır Hinterleib ift kurz, oval und dreyeckig; ihr Kopf ift auffitzend und ihre Hinterfülse ĺchr lang aber nicht keulenförmig, z. B. Sphex appendigafter. 4. Die Sicheluvespen (ophion Fabr.z. B. ichneumon luteus) haben borftenförmige Fühlhörner lo lang als der Körper; Hinterleib lang, geftielt, zulammengedrückt, fichelförmigr gekrümmt, keulenfürmig endigerid; die Legeröhre der Weibchen ift lebr kurz. 5. Bey der Gattung Banchis Fabr. find die Fühlhörner borltenförmig, der Leib zufammengedrückt, dichtauffitzend und Ifpitz. Z. B. ichneumon venator $L$.

\section{BEMERKUNGEN ZUP CLIX. TABELLE.}

Die Myrmegen bilden eine kleine Inlektenfamilie, in welcher gewille Individuen zur völligen Unfruchtbarkeit beftimmt find: unterdeflen baben liè die Sorge für die Erziehung der Nachkommenlchaft einiger Weibchen und die Ernährung dèr Larven von einer Menge Männchen, welchè nur einige Tage, lo lange als nothwendig if um die Weibchen zu befruchten, leben follen. I. Die Dorylen (dorylus Fabr. z. B. mutilla helvolus L.) find Afrikanifche, noch wenig bekannte Infekten. Ihr Hinterleib ilt platt, fichelförmig gekrümnt, und bewegt fich auf einem dreywinklichen Ringe. 2. Die Ameifen (formica L. z. B. formica fusca) haben mehrere Kroten oder eine Schuppe an der Bafis des Hinterleibes, an welchen fich kein Stachel findet. 3. Die Bienenaineifen oder Mutillen (mutilla z. B. m. europáea L.) gleichen den Ameilen, haben aber keine Schup. pe an der Bafis itures Körpers und ihr ganzer Körper ilt oft behaart. 


\section{No. CLX.}

XXXVII. FAMUE. GRABISSEKTEN ODER ORYKTEREN. *)

Hymenopteren mit gefieltem Hinterleibe; Unterlippe fo lang als die Mandibeln; nicht gènickte Fuhlhörner von vierzehn bis frebzehn Gliedern.

Gattungen.

f fadenförmig . . . . . . . . 1. Rauhwespen

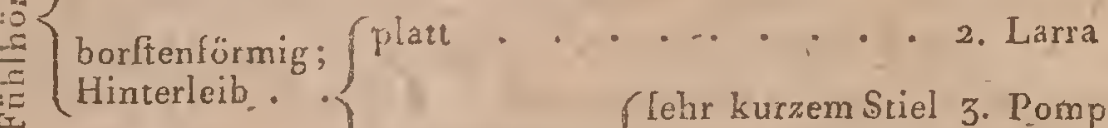

Hinterleib.. \{ rundlich, mit $\{$ lehr kurzem Stiel 3. Pompilus Sehr langem Stiel 4. Afterwespe

*) von O९jxryj in die Erde grabend.

\section{No. CLXI.}

XXXVIIT. FAMILE., GAILINSERTEN ODER NEOTTOCRYP'IEN. *)

Hymenopteren mit geftieltem, plattem oder aufgetriebenem Hinterleibe; Unterlippe fo larig als die Mandibeh; nicht geknickte Fühlhörner von höchftens dreyzehn Gliedern; Schenkel oft aufgetrieben.

Gattungen.

Gerade, fadenförmig; frund . . . . 2. Schenkelwespe Hinterleib . . Kzulammengedrückt . 3. Diplolepis an der Kopf dicht aulfitzend. 5. Gallwespe

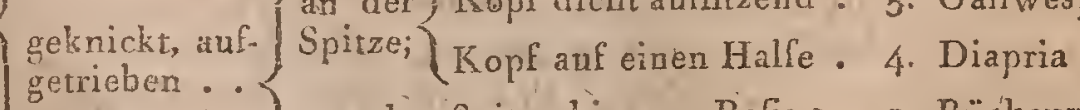

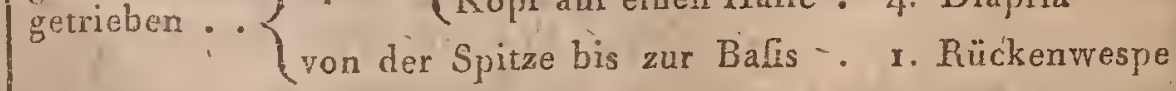
aftig odè kammartig . . . . . . . 6. Afthornwespe

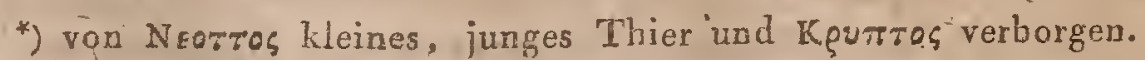




\section{BEMERIKUNGEN ZUR CLX. TABETLE.}

Obgleich die gegenwärtige Familie den Namen Orykteren irägt, fo find doch die hieher gehörigen Hymenopteren nicht die einaigen' w iche eh Loch in die Erde graben um ihre Eyer hinein zu legen. Die Baltardwespen unter den Melliten, alle Anthophilen, und die meilten Myrmegeu haben dielelbe Gewolnheit. I. Dir Raulswespen (tiphia Fabr:z.B. tiyh. femorara) fehen den Ameilen ähnlich, haben aber keine geknickten Fuhlhörner, anch keine Schuppe aul dem Sriel des ovalen Hiurerluibes, deffen erlter Ring conkav ift. 2. Die Larren (larra Fabr. z. B. Iphex niger L.) haben boritenförmige, an der Spitze fpiralartig gerollte, Fühlhörner. Ihr Kopf, der breiter ift als das Halslchild, hat oft ein mit Metallfarben glänzendes Stirnlchild. z. Die Gattung Pompilus, Fabr.) enthält diejenigen Arten von Afterwespen, deren Hinterleib einen lo kurzen Stiel bat, dals er Eaft dicht aufzufitzen fcheint. Z B. Iphex fusca. 4. Die Afcerwespen (fphex L. z. B. Iph. Cabulola) haben fadenförmige, zwilcben dèn Augen fitzende und, wie bey den Schlupfwespen, beliändig, lich bewegende Fübllı̈rner. - Ihre Flügel find kurz, in Proportion zu deın Hinterleibe und werden in der Ruhe immer etwas ausgebieitet gehahen. Ihre vier Hinterfüfse find lehr lang; die Stirn platt und der erlte Ring des Hinter!eibes rundlich.

\section{BEMERKUNGEN ZUR CLXI. TABELIE.}

Die Neoccokrypten haben einige Aehnlichkeit mit den Schlupfwespen in Beziehung auf Lehensart und Gewohnheiten; aber die neiften legen ihre Eyer in das, Gewebe lebender Pflanzen, ant welchen fie unförmlirhe Auswïchle hervorbringen. I. u. 2. Die Rückenwespen (leucopfis, Fa b r. z. B. L. dorfigera) und die Sohenkelruespen (chalcis Fal r. z. B. Ch. fispes) kommen in Form und Lebensart faff überein; aber bey den Weibchen der erften Gattung biegt firh die Legeröhre unter den Hinterleib. Ihre Larven entwickeln fich im Innern des Körpers anderer Inlekten, wie die Entomotillen. 3. Die Diplolepen (diplolepis Geoffr. 2. B. cynips glechomae) haben gerarle, faft fadenförmige Fühlhörner, einen runden dicht auffit»nden Kopf, und einen zulammengedrückı Hinterleib mit einer fpiraltörmige Legeröhre. 4. Die Gattung Diapria ( $L$ a tr.), haben körnerartige Glieder in den Fühlhörnern, den Kopf lang oder liuglich, und die Flügel faft ohne alle Adern. Z. B. D. conica. 5. Bey den Gallwespen (cynips Geoffr. z. B. ichneumon chryfis $F_{a} b r$.) find die Fühlhörner geknirkt und werden gegen das Ende zu allmählig dicker; der Körper ift kurz, aufgetrieben, glänzend und lie Hinterfülse meiltens zum Springen tauglich. 6. Die Afthornwespen (eulophus Geoffr.) unterlcheiden fich von der vorigen Gattung nurdurch die Befchaffenhoit der Fihi. hörner, die äfig, doppelkammartig lind. Z. B. ichnenmon ramicornic Fabr.

Dumeril Zool. 


\section{No. CLXII.}

\section{FAMILIE. SÄGESCHWÄNZE ODER} UROPRISTEN.

Hymenopteren mit dicht auffizendem Hinterleibe, bey dem Weibchen in einen Legeftachel endigend; nicht geknickte Fühlhörner.

Gattungert.

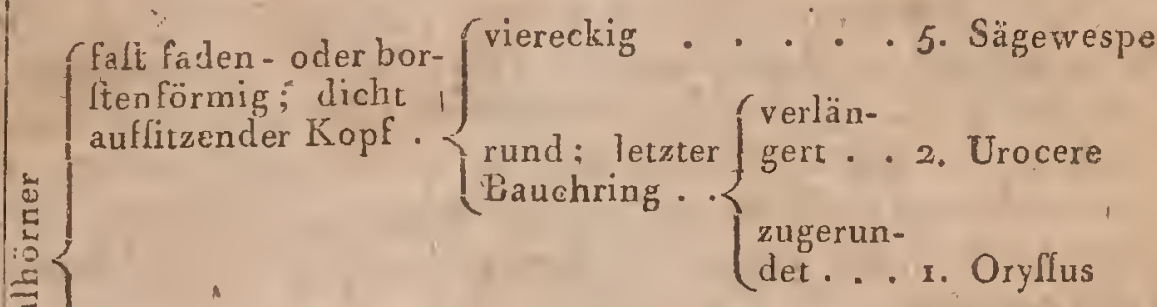

weder faden - Gegen das Ende zu dicker wer-

woch borften- deud; Kopf a uf einein Halle . 3. Holzwespe

-förmig,... eine runde Keule bildend; Kopf,

ohne Hals, dicht auffitzend . 4. Knopfhornwespe

\section{BEMERKUNGEN ZUR CLXII. TABELLE.}

Die Uroprifter, die man lange Zeit alle als Sägewespen anfah, bilden eine von allen übrigen Hymenopteren fo getrennte Familie, dafs man fie vielleicht in der Folge zu einer befonderen Ordnung erheben wird; ihr mit-einer breiten Bafis dicht an dem Halsfchilde auffitzender Hinterlëib, und die fägeförmige Legelcheide an dem Hinterleibe der Weibchen, bilden den fichtbaren Hauptcharakter. Ihre Larven find den Raupen ähnlich und haben weuigftens achtzehn, felten aber über zwey und zwanzig Fülse. Ihr Kopf ift dem der Schmetterlingsraupen fehr ähnlich. Wie die meiften Raupen haben lie an dem Munde Oeffnungen von Spinngefäl'sen, um fich eine doppelte Gefpinnft-Schale zu verfertigen, wovon die äulsere aus elaftifchen harten Fäden, die innere aber aus vielen zàrten dicht übereinander liegenden Lagen oder Häuten befteht.

Die Legefcheide, an dem Hinterleibe der Weibchen diefer Familie, ift dazu geeignet, einen kleinen Einfchnitt in die Rinden zu machen und gin Ey darumter zu legen. Wen diefes dahin gebracht ift, lo lafst das 
Infekt noch eine Feuchtigkeit in die Wunde fliefsen', welche die Verónigung und Verwachlung der Ränder hindert. Die kleine, aưs dem Eye kommende, Larve lorgt felblt für ihre Nahrung und frilst die Blätter der Bäume und Pflanzen, wobin die Mutter fie gebracht hat.

I. Die Gatturg OrgfJus, Latr. hat fadenförmige Füblhörner., einen, Grolsen, runden, dicht auffitzenden Kopf, und eineǹ am Ende zugerundeten Hinterléib ohne lichtbare Legelcheide; ilure Lebensart kennt man niclit. Z. B. O. coronatus.

2. Die Uroceren (urocerus $G$ e off $r$.) haben fadenförmige, an der Spizze aber etwas dünnere Fühlhörner, einen runden, fehr dicken Kopf。 und den Hinterleib bey den Weibchen mit einèr hornartigen Spitze endigend, welche einem vorragenden, hornartigen Legeftachel zur Scheildo dient. Z. B. Sirex gigas L.

3. Bey den Holzweespen (Sirex z. B. S. tabidus L.) werden die Fühi.. hörner gegen das Ende zu allmählich dichor, der Kopf fitzt auf einer Art Aals, der Hinterleib.ilt weich, zylindrifch oder zufammengedrückt und der letzte Ring ift nicht verlängert.

4. Die Knopfhornwespen (cymbex Oliy.z. B. tenthredo lutea) ha. ben keulenförmige Fühlhörner wie die Schmetterlinge; de' rundliche Hin: terleib ift weich, der Obertheil des Halsfchildes mit vertieften der Länge nach laufenden Linien verfehen und das Rückenlchildchen durch zwey Höcker erfetzt.

5. Die Sügewespen (tenthredo z. B. tenth. ruftica) zeigen in der Bildung der Fühlhörner grofse Eigenthümlichkeiten; der Kopf ift viereckig, das Halsfchild mit viereckigen Figuren und wie verkrüppelt. Der Hinterleib ift weich und zylindrilch. Einige Arten find, unter belonderen Namen, noch als ègne Gattungen aufgeführt. So ift der Name hylotoma den Arten beygelegt, welche, wie 'Tenthr. enodis, nur drey Füllhornglieder zu haben Icheinen; die Arten mit.kammartigen Fühlhörnern heifsen lophyris z. B. tenthr . pini; und megalodonta find die Arten genannt, die bey kammartigen Fühlhömern; noch lange an der Spitze gelpaltene Mandibeln haben. Z. B, tenth. cephalotes. 


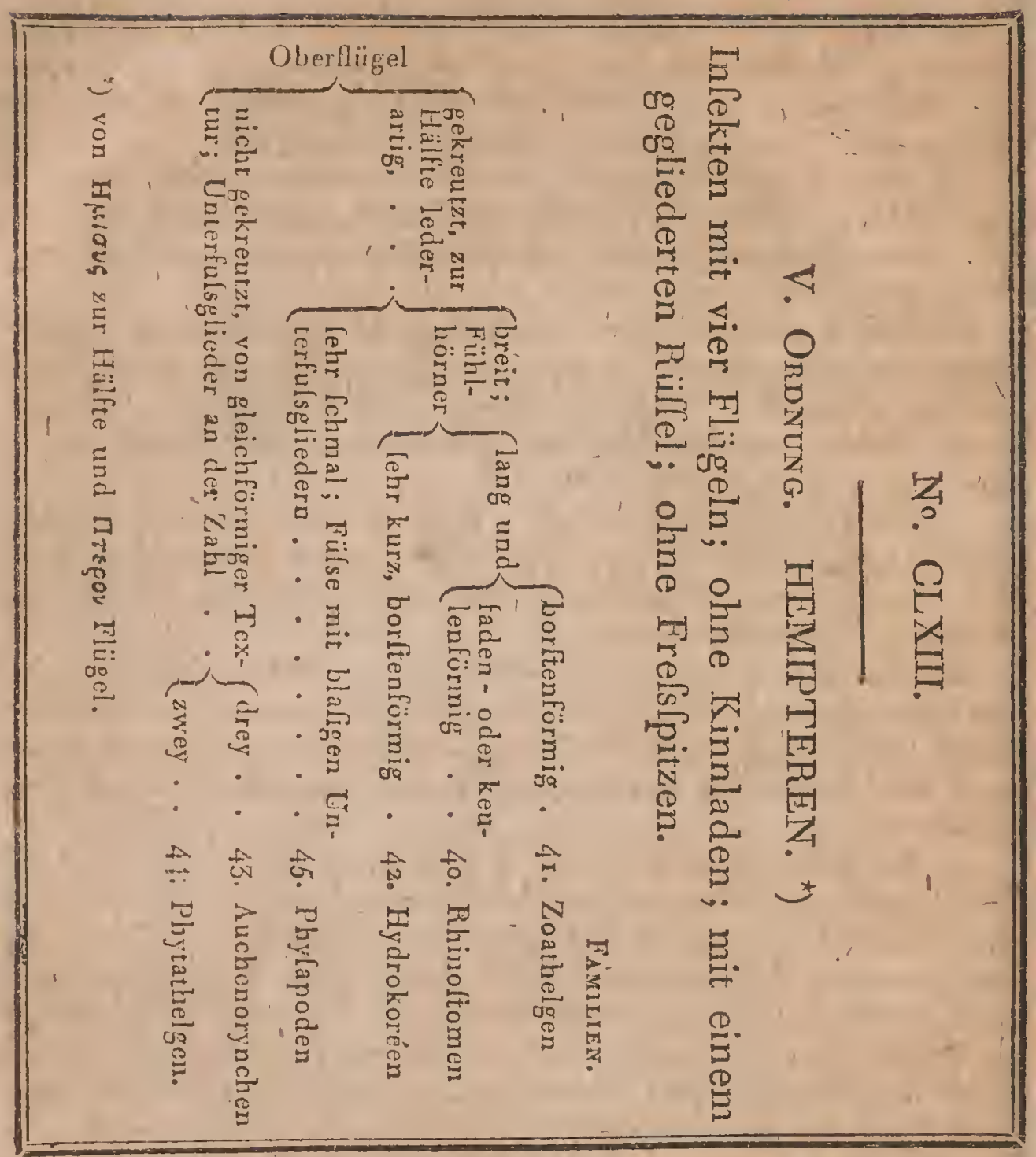

\section{BEMERKUNGEN ZUR CLXIII. TABELLE.}

Der Name Hemipteren giebt keine klare Vorftellung von den damit belegten Infekten, da zwey Familien diefer Ordnung keine Flügeldecken haben urid wirkliche Neuropteren feyn würden, wenn fie nicht einen gegliederten Rüßjel (roltrum) lätten. So nennt man nämlich den Mund, der den Hauptcharakter diefer Infekten ausmacht. Es ift dies eine aus mehreru Sï̈cken lieftehende Röhre, die von der Bafis nach der Spitze zu dünner werden und in deren Innerm feine fpitze Borften, meift drey, entllalten' lind. Frelsfpitzen find vier damit verbunden. Im Ruhezuftande ift diefer liüfel meift unter den Leib zwifchen die Beine gebogen, wenn aber das Inlekt laugen will, lo kann er falt lenkrecht erhoben werden. 
Diefés Inftrument vereinigt die Eigenlchaften einer Saugröhre und eines Haarröhrchens, Es ilt mit einer Spitze verlehen, welche wio eine Nadel oder Mellerchen gebraucht wird. Die Scheide worin diele Borften liegen, ift auf́ der Bauchfeite' nit einer Furche verlehen und da kann man fie aucb am beften Kehen. Beym erften Anblick, wenn man diele Borften aus der Furche hervortreten lält, follte man glauben es wäre nur eine vorhanden; aber fie liegen ganz dicht an einander. Zwey von ih山 Iten find gefurcht und bilden eine gleichlam innere Scheide für die zylin. drifche dritte, welche aufserordentlich fein ilt. Jede dieler Borften fuzt an einem Muskel, welcher die Bafis umgiebt und lie einzeln wirken la len kann. Die mittlere kann ain liärkften liervorgeftreckt werden und Icheint beftimmt, die erlte $\mathrm{W}$ unde hervorzubringen. Durch die Ichnelle (pumpende) Bewegnng in dem kleinen Kanale werden die Säfte der Mflanzen und Thiere, durch das Inlekt eingelogen und in die Speiféröhre gebracht.

Die Hemipteren erleiden faft dielelben Metamorphofen wie die Orthopteren. Sie find im allen drey Zuftänden, als Larve, Puppe und vollftändiges Infekt lehr flink beweglich. Oft unterlcheiden fich die Larven von dem letzteren nur durch die fehlenden (oder durcl die nicht entwichelten) Flügel; lo dấs die Hauptveränderungen eigentich nichts als Häutungent find, indem das Thier Bewegung und andere Verrichtungen nu fär einige Stunden unterläfst. - In dieler Ordnung kommen die meilten flü: gellofen, mit und ohne Flügeldecken, vor.

Die Lebensart ift in den verfchiedenen Familien nicht die nämliche. Esiff bemerkungswerth, dafs (von den Arten, deren obere Flügel, einer über den andern, gekreutzt und am Ende fehr dünne find,) die mit langen oder kurzen borltenförmigen Fühlhörnern fich von Thierläften nähren, Cie mögen nun im Wafler oder auf dem Lande leben; während die mit langen fadenförmigen oder keulenförmigen Fühihörnerı, alle ohne Ausnahme, Planzenläfte laugen.

Die Arten, welche keine gekreutzten Flügel haben, weichen in mancher Hinlicht, von den wahren Hemipteren ab. Auch hatue Degeer davon eine eigne Ordnung gebildet. Einige z. B. die Blattläule, bringen lebendige Junge. Oft reicht eine einzige Begatiung-anf mehrere Generationen hinaus. Die meiften leben in zahlreichen Gefellfchaften. Blos in diefer Abtheilung kommen Arten vor, welche fpringen. 


\section{No. CLXIV.}

XL. Familie. STIRNSCHNÄBEL ODER RHINO STOMEN. *)

Hemipteren mit halb lederartigen Flügeldecken; Rülfel yon der.Stirn entfpringend; lange, nicht borftenartige Fühlhörner; Fufsglieder zum Gehen tauglich.

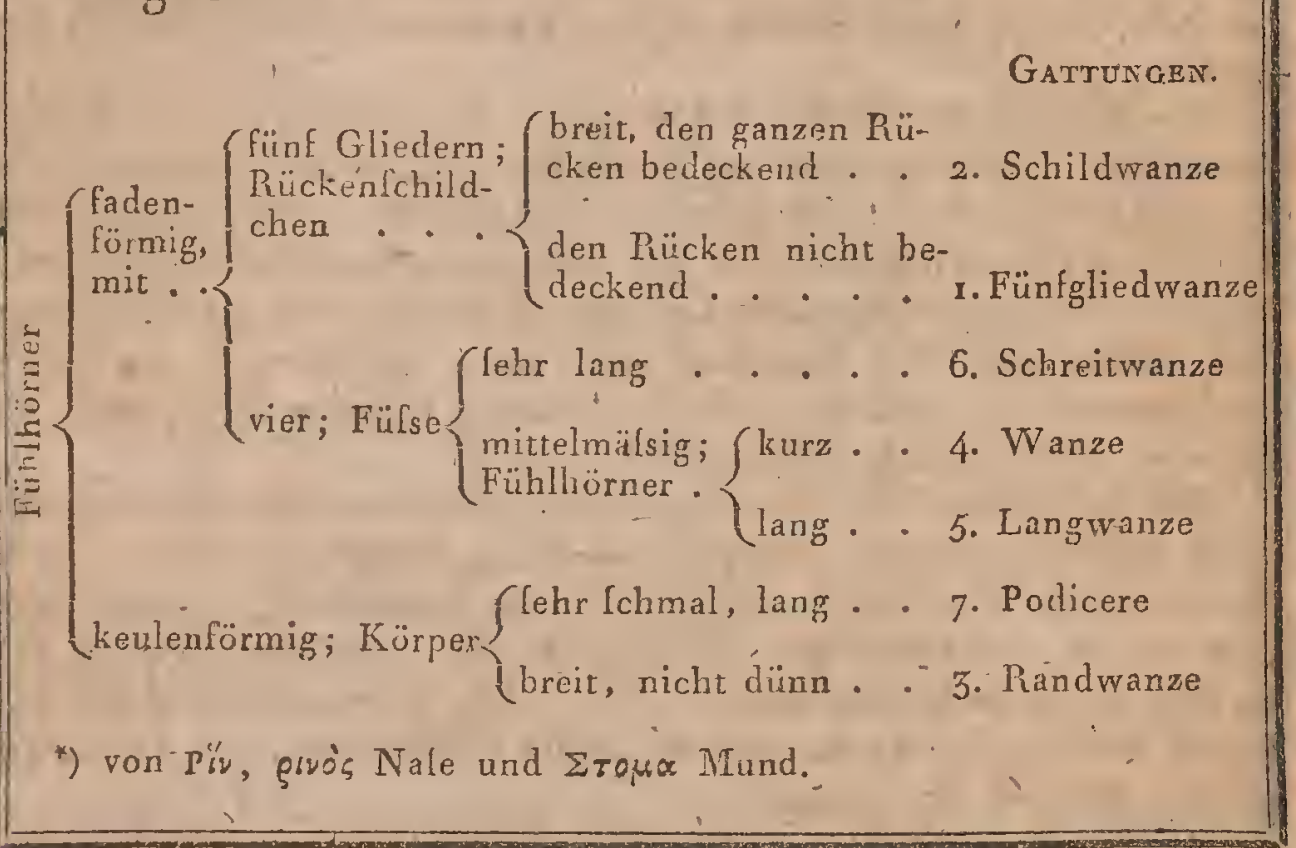

\section{BEMERKUNGEN ZUR CLXIV. TABELLE.}

Die Rhinoftomen laben zwar alle ihren Rüllel vorn an dem Kopfe; aber ihr welentlichlter Charakter liegt in der Bildung der Fühlhörner, welche nicht borftenförmig fird. Die hieher gehörigen Gattungen kommen in der Lehensart fehr überein. Man fundet fie gewöhnlich auf Bäumen, deren Saft fie laugen, fowohl im Laryen und Puppenzuftande, als auch als vollfü̈ndige lnfekten.

x. Die Pentatomen oder Fünfgliedwanzen' (pentaloma z. B. cimex rufipes L.) haben ihren Namen von dér Zahl der Gliedor' ihrer langen; auf einen befondern Höcker fitzenden, Fühlhörner. Ibr Rüllfel befteht aus vier 'Stückea von gleicher Länge, wovon das erfte lo gekuickt ilt, dals 
es fich unter das Halsfęhild léğt. Der Körper ift breit und platt und nie ganz von dem Tonlt deuilichen Rückeńfchildchen bedeckt. Sie leben auf Pflanzen. Ihr Flug dauert nicht lànge, ilt aber fchnell. Die meiften neh-: men gar keine Bewegung vor, wenn man fie anfalst, und verbreiten ieinen unangenehmen Geruch.

2. Die Schildwanzen (Fcutellera Lamark, thyreocoris Shrank) unterfcheiden fich von den Pentatomen nur durch die beträchtlichere Gröfse ihres Rückenfchildchens, was den ganzen Hinterleib bedeckt. Die Form des Körpers ift fehr verlchieden. Gewöhnlich iltider Rücken convex; Oft find fie mit den fchönften Farben gefchmückt. Z. B. cimex nobilis.

3. Die Randwanzen (coraeus Fabr. z. B. cim. marginatus) haben nur vierglieslrige Fühlhörner, wovon das letzte Glisd eine qvale, odé verdickte Keule bildet. Bey den meiften find die Ränder des Halsfchildes oder Hinterleibes erhaben, fo dafs der Rücken konkav ift, fonft konimen fie mit den Pentatomen fehr überein.

4. Die Wanzen (acanthia Fa br.z. B. cim. haemorrhoidalis) begreifen hier nur einige Arten der von Iabricius aufgeftellten Gattung, da diefer noch die Bettwanzen und einige Arten der vorigen Gattung zur gegenwärtigen zällte. - Einige leben an Ufern; lie haben einen etwas konvexen Körper, fehr grolse Augen, nuid das letzte Fühlhornglied etwas dick; andere haben fadenförrige, etwas platte aber nicht ftachliche Füblhörner und leben unter Baumrinden; einige endlich habex zugerundete Fühlhörner, mit liachligen oder haarigen Gliedern und meiltens findet manthervorragenrle Reifen auf dem Halsfchilde oder den Flügeldecken; diefe leben gewöhnlich auf Früchten.

5. Die Langwanzen (lygaeus Fabr.z. B. cimex equeftris L.) haben fadenförmige aus vier rundlichen Gliedern beftehende lühlhürner. Der Körper ift oben platt, unten gekielt lang und fchmal. Der Kopf fitzt auf einem Halle. Man kann fie eintheilen in Arten mit fachlichtem HalsIchilde und aufgetriebenen breiten Hinterbeinen; diefe finden fich meift in heifsen Ländern; die andern haben keine Stacheln am Palsichilde und einfache Füfse. Man kann auch noch nach der Farbe der Flügeldecken Unterabtheilnngen machen, die bey vielert roth gefleckt find.

6. Die Schreicwanzen (gerris $F$ a $b r$.) gleichen etwas den 'Langwanzen, haben aber äufserft lange und dürne Fülse und langen fchmalen Körper. Z. B. G. lacuftris F $a b r$.

7. Die Podiceren oder Fufshornwgnzen (podicerus) hiaben fehr lange keulenförmige, geknickte Fühilı̈̈rner, deren fich das Thier als Fülse mit' bedient. Sonft fehen fie den Schreitwanzen und den Plojeren der folgenden Familie ähnlich; zu welchen fie den Uebergang machen. 
No. CLXV.

XLI. Famile. BLUTSAUGER ODER ZOATHELGEN. *)

Hemipteren mit halb lederartigen Flügeln; Rür' lel wie an der Stirn entfpringend; lange, aber mit einem dünnen Gliede endende, Fühlhörner; Füfse zum Gehen tauglich.

Gattungen.

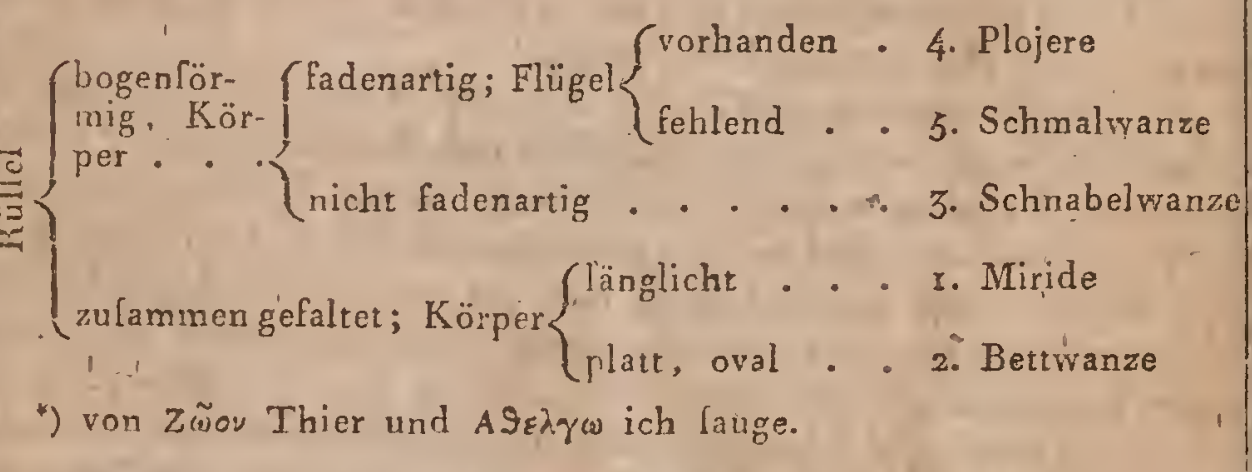

\section{No. CLXVI.}

XLII. Familte. SCHWIMMWANZEN ODER HYDROKOREEN. *)

Hemipteren mit harten, lederartigen Flügeldecken; Rüflel wie an der Stirn entfpringend; borftenCörmige, fehr kurze Fühlhömer; Hinterfüfse - Schwimmlüilse.

Gattungen.

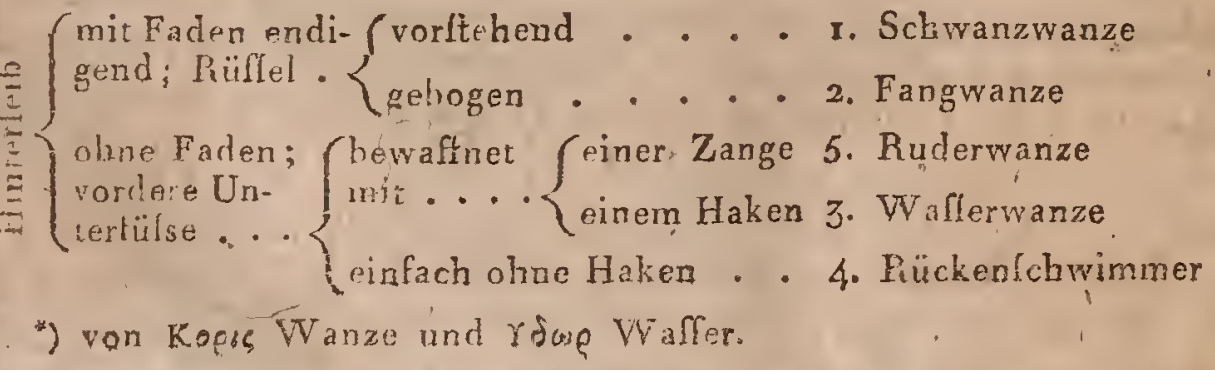




\section{BEMERKUNGEN ZUR CLXV. TABELLE.}

Die Zoathelgen find diejenigen Wanzenarten, welche fich ausfchlielslich von Blute nähren. Man kann fieleicht an ihren langen Fühlbörnernerkennen, die mit einer Borfte óder einem fehr feineu Gliede endigen. r. Die Miriden (miris $F a b r$.) find den Langwanzen durch die Körperform und Fühlhorngliederzahl etwas ahnlich. Ihre Augen find Cehr grols und ihre Fülse fehr lang und dünn. Sie laufen felır fchnell auf Pflanzen umher und man findet fie dalelbft oft belchäfriget, weiche Infekten auszufaugen. Z. B. mir. oder lygaeus campeftris. 2. Die Bettranzen (cimex L. acan4 thia $F a b r_{0}$ ) z. B. cim. lectularia) haben einen ovalen fehr platten Körper, fünt Fühlhornglieder; das halbmondtörmige Halsfchild fchliefst den Kopf etwas ein. Man kennt bisher nur eine Art; welche des Nachts die MenIcheu und einige Thiere, helonders die Schwalben angreift. 3. Die Schnabelwanzen haben den Crattuugsnamen reduvius ( $F$ a $b$ r.) erlialten, weil die Larven fich' mit Schmutz berlecken, um von:den Inlecken nicht gelehen zu werdeu, von denen fie fich nabren. Z. B. reduv. perfonatus. 4. Die plojeren, (plojera Scopoli) gleichen den Schreitwanzen und Podiceren in Hinficht der Körperform. Man findet fie an Mauern und feuchten Orten. Z. B. cimex vagabundus L: 5. Die Schmalwanzen (hydrometra Latr. aquarius Schelilenberg) find noch dünner und zarter als die vorige Gattung. Sie haben keine Flügel und laufen gewöhnlich unterm Wafler. Z. B. cimex ftagnorum L.

\section{BEMERKUNGEN ZUR CXLVI. TABELLE.}

Die Familie der Hydrokoreen oder Schwimmwanzen unterlcheidet fich von den andern durch die Kürze derFülılhörner, die borftenartig aber bey einigen Arten kaum fichrbar find, und lurch die platten zweygliedrigen Unterfüfse. r. Die Schwanzwanzen (Ranatra Fa $r_{0} z . B$. nepa linearis L.) haben einen langen fadenförmigen Körper, der hinten in eine aus langen vereinigten Fäden beftehende Legefcheide ausgeht. Die Füblhörner find kurz, gabelförmig und fitzen in dem Winkel des vorflehenden und dicken Auges. 2. Die Fangwanzen (nepa Geoffr.z. B. nep. cinerea) unterfcheiden fich von der vorigen Gattung nur durch die Form ihres plarten ovalen Körpers. 3. Die Wnfferwanzen (navcoris Geoffr. z. B. nepa cimicoides L.) haben keine Fäden am After. Die Bildung ihrer Füfse urd ihr Rückenfchild unterfcheiden fie von den folgenden Gattungen. 4. Die Rüickenfchwimmer (notonecta L.) z. B. noton. glanca, fchwimmen beftändig auf dem Rüchen, wie es auch ihr Name angiebt, ihr Körper ift länglicht, convex auf der Rückenfeite, und unters plat: 5. Die Ruderwnrzen (figara F a br. \%. B. notonecta ftriata L.) unterfcheiden fich von der Rückesśbwimmern nur durch die Form der Forkerfülse. 


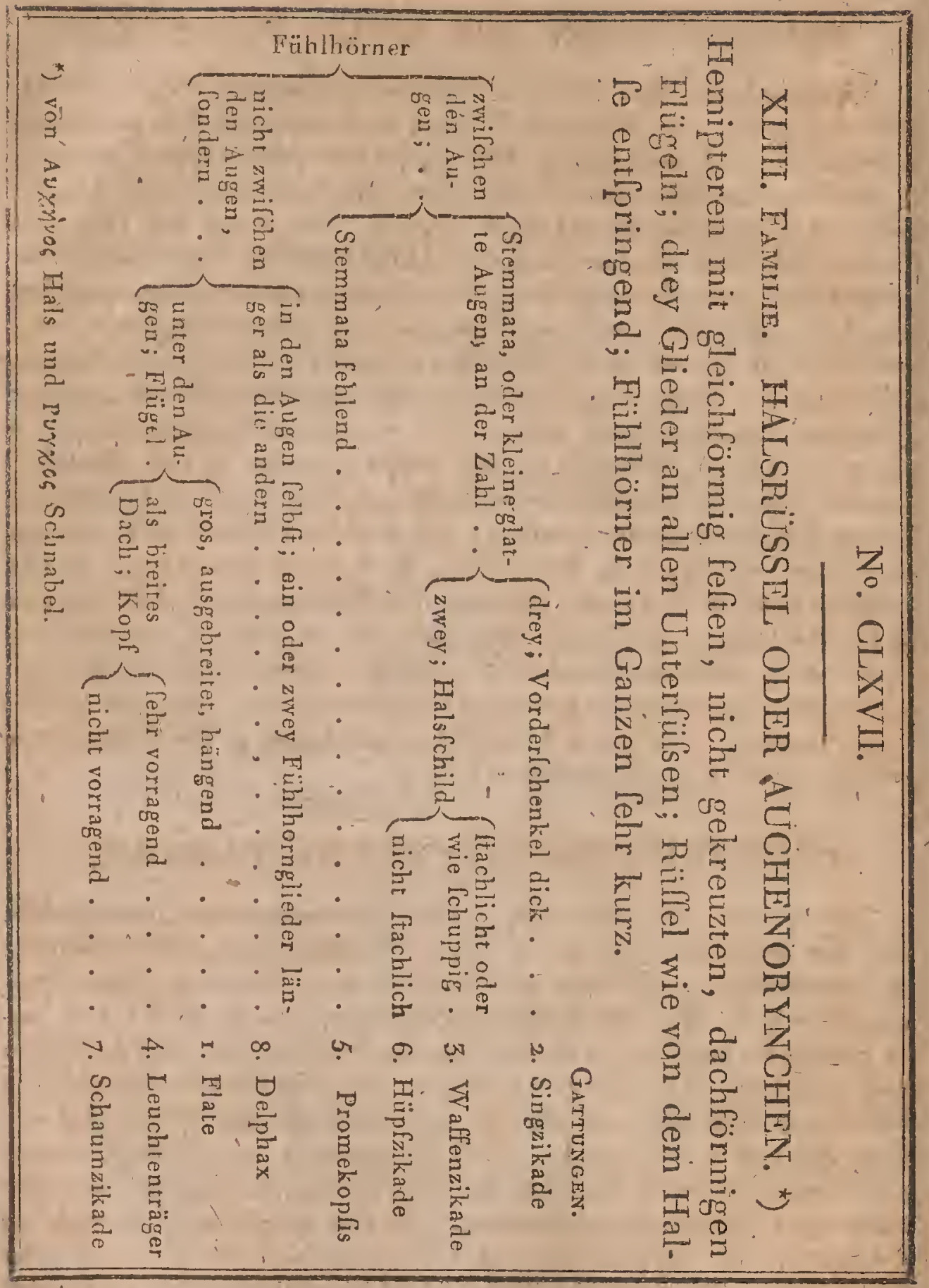

\section{BEMERKUNGEN ZUR CLXVII. TABELLE.}

Der Charakter, der an der Spitze der Tabelle angegeben ift, ift zur Unterfcbeidung der Auchenorhynchen von allen ïbrigen Hemipteren hinreichend. Ihre gleichförmigen Flügel unterlcheiden fie von den 
Phyfapoder, den Znathelgen, den Rhinoftomen und Schwimmwanzer, welche zur Hälfte lederartige und in dêr Rube gekreutzte Flügel haben; Eben fo deutlich unterfcheiden fich auch die Phytathelgen, welche zwey. Unterfufsglieder, ausgebreitete Flügel und Füblhörner haben, die länger find als "der Kopf. Die meilten Larven und Puppen diefer Fay milie bleiben in ihrem erften Zuftande unter der Erde, wo fie die WTurzeln oder Pflanzen und Bäume ausfaugen, bald halten fie :fich auf dem Stamne felbit auf und dann wenden fie befondere Kunftgriffe ar', um fich den Verfolgungenihrer Feinde zu entziehen. I. Die Flaten, (Flata Fabr. paccillopterus Látreille) haben kurze borftenfürmige, an dem inneren Ran. de der kleinen kugelförmigen Augen fitzende, Fühlhörner. Ihre 'lügel; die viel länger find als der Hinterleib, lind dachförmig, hangend und hintexz aus:gebreitet, oft gefärbt und ihr Kopl wie abgeftutzt; Z Z. B. cicada plaleaenoi des L. 2. Die Singzikaden (cicada $L i n n$; tettigonia $F a b r$.) enthalten die gröfsten Arten diefer Familie. Sie haben deutliche Augen faft lo lang als der Kopf, der méiftens breiter ift als das Halsfchild. Ihre Stirn ift vorragend, rund und mit Queerfurchen verfehen. Ihre oberen Flügel find gewöhnlich durchfichtig und mit netzartigen Streifen geadort. Die Weibchen haben wie die Sägewespen eine Legelcheide. Bey den Mănnchen finden fich an der Bafis des Leibes zwey breite gewölbte Schuppen, welche tönen, wenn das Infekt gewilfe mit Höckern verfehene hornarige Klöppel, die an der Hüfte fitzen, dágegen bewegt. Z. B. cic. orni. 3. Dio Waffenzikaden (membracis Fabr. Z. B. cicad. comuta,) baben einen platten Kopf. Das Hals Ichild was mit vorragenden Spitzen oder btätterartigen Schuppen verlehen ift, giebt ilıre Haupteigenheit ab. Sie haben nur zwey kleine glatte, Augen. Einige haben ein Rückenfchildchen andere nicht. 4. Die Leuchtenträger (Fulgoraz. B. Fulgora laternaria L.) haben die Fühlhörner Keulenförmig aber mit einer Seitengranne verlehien. Bey den-meiItem ift die Stirn in eine fpitze Schnautze oder in eine ftumpfe Blafe verlängert. 5. Die Promekopsiden (promecopfis) entfprechen den Hüpfpikaden die keine kleinen glatten Augen (liemmata) baben. Z. B. 6. Die Hüpfzikaden (cicadella, cicada $F a b r$.) haben den Kopf etwas breiter als das HalsIchild, die Stirn in die Queere gefurcht, die Augen ohne Ausfchnitt, kuglich, und fchrippentragende gefärbte Flügeldecken. Sie find mit Stemmaten verfehen z.B. Cic. vittata L. 7. Der Name Cercopis, den Fabr. den Schaumzikaden gegeben hat, Ipielt auf die Lift ader Gewohnheit ter Larven an, die fich mit dem Saft der Gewächle bedecken und unter dieler Art Schaum verborgen bleiben, wodurch lie gegen die Sornenhitze gefchützt, und dem Anblicke der auf fie lehr lïftemen Vügel entzogen werden Z. B. cerc. Ipumaria Fabr. 8, Die Gatung Delplacx (delphax Fab ro; afiraca $L a t r_{0}$ ) hat Fühlhörner von der Länge des Halsfchildes und etwas keulenförmïg. Darin lieğt auch ihre Hauptcharakter, Z. B. Delph,clavicornis 'F a b r. 


\section{No. CLXVIII.}

XLIV. Familie. PFlanzensaUger oder PHYTATHELGEN. *)

Hemipteren mit gleichen nicht gekreutzten, oft ausgebreiteten durchfichtigen Flïgehn; Rüflel wie am Halle entfpringend; Unterfufs mit zwey Gliedern.

mit mehligen Schmetterlingslek-uppen bedeckt . . I. Phalänzikade ylatt oder (dick, gleichfam einen, Theil der Stirn

bildend ......... 4. Kermes

fehlend;

Füblhör- faden- (mit zwey Warzen . . 3. Blattlaus

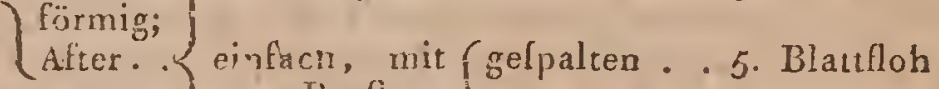
zwey Borften;

Stirn . $\left\{\begin{array}{l}\text { richt gelpal- } \\ \text { ten }\end{array}\right.$

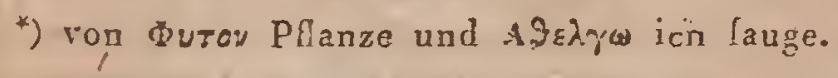

\section{"No. CLXIX.}

XLV. Familie. BLASENFUSS ODER PHYSAPODEN. *)

Hemipteren mit geraden, fchmalen, auf dem Rücken liegenden, Flïgeldecken; Unterfülse in eine kleine kleine Blafe endend.

\section{Blafenfiufse.}

*) von Dugry Blals, Beule und Bodx Fǘse. 


\section{BEMERKUNGEN ZUR CLXVII. TABELLE。}

Die Phythaihelgen find fehr langfame Infekten, die gewöhnlich auf den Pflanzen feltfitzen bleiben, wolin ihre Mutter lie gebracht hat. Meh- rere können lelbft gar nichr fliegen oder gehen; man hat fie aucls lange Zeit unter dem Namen Gallinfekten aufgeführt, weil Sie auf den Planzen feft litzende Erhabenbeiten bilden, die man für natürliche Auswüchle genommen hat.

I. Der Name Aleyrodes, Latreille, welchen die Phalänzikadere erhalten haben, beziebt fich auf die mehlartigen Schuppen, womit die vier Flügel bedeckt find und welche leicht heruntergelien. Z. B. Phalaena tinea, proletella L.

2. Die Kochenille (coccus L.) zeigt grofse Verlchiedenheit der Männchen und Weibchen. Jenï haben zwey Flügel, einen runden Kopf und lange Füblbörner. Die Weibchen aber find beltändig flïgellos und haben kurze Fülthörner. Nach der Befruchtung Ichwillt ihr Leib an, vertrocknet und dient nur noch als Bcklcidung und Schutz für die Eier. Die Männchen leben nur einige Tage unter ihrer letzten Geftalt. Eine Art diefer Gattung, welche fich auf der Nopalpfanze aufbält, giebt die fchönfte Scharlach und Karmin-Farbe. Im Handel und Wandel nennt man diefe Infekten auch Scharlachkörner und hat fie lange Zeit für Pflanzen Saamen gehalten. Z. B. coccus cacti coccinelliferi.

3. Die Blatulüufe (aphis z. B. aphis ulmi) find allgemein bekannt. Es find weiche Inlekten mit fadenförmigen oft langen Fühlhörnern, die ana Hintertheile ihres Leibes zwey Warzen haben, aus welchen beftändig ein zuckerartiger Saft ausfchwitzt, dem die Ameifen fehr nachffellen. Auch fagt Linné, dafs fie die Kühe der Ameifen wären. Die Gelchichte ihrer Generation zeigt ganz erftaunungswürdige Eigenheiten, die fich von allen andern über Generation bekannten [ehr entfernen.

4. und 5. Die Kermes (chermes L. z. B. Cla. ficus) und die Blattflöhe (plylla $L a t r . z$. B. cherm. ilicis) unterfcheiden fich nur durch das auf der Tabelle angegebene. Ihre Lebensart ift wenig bekannt.

\section{BEMERKUNGEN ZUR CLXIX. TABELLE.}

Die Phyfapoden begreifen nur eine einzige Gattung und die dahin gehörigea Arten find fo klein, dafs man fie bisher noch nicht hat beobachten können. Die. Blafenfiufse (thrips, z. B. th. phyfapus) leben, fo wie aluch ihre Larven, aut Blumen. Wenn fie fich in Gefahr glauben, fo erkeben lie, wie die Raubkäfer das Hintertheil des Körpers gegen den Kopfo Ihr Rüfel ift lo kurz, daßs die beften Beobachter geftehn, ihn nicht genau erkannt zu haben. Der ganze Körper ift lang geftreckt. Die'gröften Arten lind nicut über eine Linie lang. 


\section{No. CLXX.}

\section{Ordnung. LEPIDOPTEREN.}

Infekten mit vier Schuppentragenden Flügeln; Mund, ohne Kinnladen, mit einer zufarnmengerollten Zunge zwilchen den Frefsfpitzen.

Familien.

$\left\{\begin{array}{l}\text { aufgetricben Ende, oder keulenförmig }: \text { 46. Ropaloceren } \\ \text { in der Mitte oder Ipindelförmig 47. Klolteroceren }\end{array}\right.$

nicht aufgetrie- f fadenförmig oft kammartig . 48. Nematoceren
ben londern. ben londern. $\left\{\begin{array}{l}\text { borftenförmig . . . 49. Chetoceren } \\ \text {. . . }\end{array}\right.$

*) von $\Lambda \varepsilon \pi i \zeta-\delta_{0 \varsigma \zeta}$ Schuppe und II $\tau \varepsilon \rho \alpha$ Flügel.

\section{No: CLXXI.}

XLVI. Fá́nLIE. KUGELHÖRNER ODER ROPALOCEREN. *)

Lepidopteren, mit an.der Spitze keulenförmigen Fühlhörnern.

(Atande; Flügel flach oder vertikal, im Ruhezu-

GatTungen.

c hakenförmig; lchräg liegend und fich kreutzend,

Flügel : $\{$ im Ruhezuftande ... 3. Dickfiügel

flach oder vertikal in der Ruhe o. Dickkopffalter

*) von Potraher Keule und Kepas Horn.

BEMERKUNGEN ZUR CLXX. TABELLE.

Die Ordnung der Lepidopteren begreift Inlekten in fich, die von allen anderu durcb eiae grolse Menge Eigenbeiten Gich untorfcheiden. In 
ihrem vollkommnen Zultande ïhren fie fich von Flülfigkeiten, dio lie vermittels eines belondern Inftrumentes auslaugen, was aus zwey aneinander liegenden und einen kleinen Raum zwilchén fich laflenden Lamellen befteht, die gewöhnlich Ipiralförmig gerollt find und fich zwiIchen die mehr oder weniger langen Frefsfpitzen verbergen. Da dies die einzigen fo organilirten Infekten find, to hat Fabricius fie mit dem Namen Glaffata belegt. Nie haben, fie platte Augen (ftemmata); ihre Fühlbörner find immer lang, ihr Körper haarig, ihre Flügel mit kleinen, dachziegelartiğ übereinander liegenden, oft äulserft fchön gefärbten, Schüppchen bedeckt. - Ihre Larven find beweglich, lang, haben lechs gegliẹderte Fülse' an dem Kopfende, und mehrere hïutige fallche Fülse an den Ringen des Körpers, doch fteigt die Zahl der letztèren nie über fecluzehn. Ihr Kopf ift mit einem grolsen loornartigen Helm oder Schilde bedeckt, deflen Form nach den Arten verfchieden ift. Man nennt fie Raupen. Die meiften können Fäden fpinnen. Sie uähren fich gewöhnlich von Blättern, Früchten und einige von todten thierifclien Subftanzen. - Ihre Puppen fiad unbeweglich, und an dem Kopfende dicker; fie find gewiflermalsen durch eine äufsere Haut verglafet, in welcher alle Theile des eingefchloffenen Infekts abgedrückt find, Einige loängen fich mittels des Schwanzes feft und verwandeln fich in freyer Laft; andere leber beltändig in einer Scheide oder fchlielsen fich wenightens in der Verwandlungszeit darin ein. Die meiften bilden fich aber von feiner oder gröberer Seide ein Gehäufe oder Kockon, in welchem fie oft Jechs Monate lang in einen erftarrten fchlafenden Zuftande, bleiben ohne Nahrung zu fich zu nehmen. Da die Geltalt der Fühlhörner mit dèr Lebensart in Verbindung zu ftehen fcheint, fo hat man nach ihnen einigé ziemlich natürliche Abthéilungen gebildet.

\section{BEMERKUNGEN ZUR CLXXI. TABELLE.}

Die Ropaloceren entlprechen der Linneifchen Gattung papilio. Sie kommen von Raupen, mit meiftens is Füfsen, die niemals ein Seidengehäufe Ipinnen. Alle hängen fich zur Zeit der Verwandlung an dem Schwanze auf; einige bängen vertikal und frey, andere haben die Vorficht über ihre Körper und in die Queere einige Faden zu ziehen, wodurch fie an den Körper, auf denen fie liegen, ganz feltgehalten werden. Alle fliegen nur bey Tage; man hat unter ibnen norh kein Nachtinlekt gefunden. r.'Die Falter oder Papillions (papilio L.) enthalten allein an dreyhundert Arten, die man nach der Form der Flügel, nach ihrer Ausbreitung und Farbe in Untergattungen gebracht hat. Z. B. p. antiopa. 2. Die Dickkopffalter (hesperia L.) haben diefelbe Bildung wie die Falter, aber ihre Fühlhorn Keule ift länger und hakenfürmig gebogen $z$. B. papil, malvae. 3. Die Dickflizgel (heteropterus) haben eine von der der Falter ganz verfchiedene Haltung. Ihre Flügel lind dicker; die untern ragen in der Ruhe über die obern weg, lo dals einige Naturforlcher fie für Schnotterlinge mit verkrüppelten Flügeln angelehon haben. 


\section{No. CLXXII.}

XLVII. FAMILIE. SPINDELHÖRNER ODER KLO STEROCEREN. *)

Lepidopteren mit fpindelförmigen oder prismati〔chen Fühlhörnern.

Gattuncen.

Glach; After $\left\{\begin{array}{l}\text { lehr haarig . . . . 2. GlasIchwärmer } \\ \text { nicht haarig, Ipitz }\end{array}\right.$

। - . Schwärmer

ảachförmig: Haltung einer Phaläne . . 3. Kolbenlchwärmer

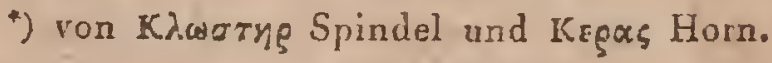

\section{IÑo. CLXXIII.}

XLVII. FamLIE. FADENHÖRNER ODER NEMATOCEREN. *)

Lepidopteren mit fadenförmigen Fühlhörnern.

Gatmunger.

¿ faft rolenkranzförmig, mịt rundlichen Abthei-

Jungen ............... Schmallpinner

$=\left\{\begin{array}{l}\text { eine Saugröhre . x. Spinner } \\ \text { keine Saugröhre 2. Holzlpinner }\end{array}\right.$

") von Nyga-aros Faden und Kepas Hom, Fühlhorn. 


\section{BEMERKUNGEN ZUR CLXXII. TABELLE.}

Die meiften Klofteroceren lind ebenfalls Tag-Schmetterlinge. Melirere fliegen nur am Abend in der erften Dämmerung, ihr BrultCchild ilt im Ganzen grölser und dicker, als bey den Ropaloceren und ihre Flügel haben eine andere Form, fie können nicht perpendikulär erhoben werden. Einige tragen fie dachförmig, andere horizontal. 'r. Die Schwürmer Icheinen ihren Namen Splinx, Lin $n$. von der Form ihrer lechzehnfülsigen dicken Raupe erhalten zn haben. Die Oberläche diefer Raupen ift bald glatt, bald rauh anzufililen. Die meifien tragen auf dem vorletzten Ringe eine Art von rückwärtsgakrümmien Horn und ibr zuweilen rundlicher Kopt ift meifters dreyeckig oder herzförmig. Wenn lie nicht kriechen, fützen fie lich auch nicht auf die lchuppigen Füfse; fie halten lich dann fill und unbeweglich wie die Spluinxe in der Fabel. Die meiften find mit Cchönen Farben geziert und graben fich gewöhnlich in die Erde um fich zu verwandeln. Z. B. Sphinx euphorbiae L. 2. Die Glasfchwärmer (felia z. B. S. Itellatarm) haben einen platten oder zylindrifchen Hinterleib, mit einem Haarbülchel endigend. Einige haben zum Theil durchfichtige Flïgel; von vielen gleichen die Raupen denen der Schvärmer; die ausgebildeten Infekten hiegen häufig, am Tage umber. 3- Die Kolben/chswärmer (Zygaena $F a b r$.) haben die Fühlhörner veränderlich : einfach oder kammartig, in der Mitte aufgetrieben, geltutat; die Flïgel find dachförmig und die ganze Haltung des Inlekts wie in der folgenden Familie. Z. B. Zyg. filipendulae.

\section{BEMERKUNGEN ZUR CLXXII. TABELLE.}

Die Nematoceren find Taft fämmtlich Nachtinfekten. Ihre Flïgel fiod dachförmig und meiftens zugerundet. Bey den meiften find die Tüllhörner nach dem Gelchlechte mehr oder weriger tief gezähnelt. Ihre Raupen find gevöhnlich behaart. Alle fpinnen ein Kockon; die Zahl ilırer Fülse ift variirend von ro zu r6. r. Die Spinner (bombyx L. z. B. Bomb. mori) machen allein eine Gattung von mehr als fünfhundert Arten, die man nach Eigenheiten, welche hier aus Mangel an Raum nicht angegeben werden, können, in Unterabtheilungen gebracht hat. 2. Die Schmallpinner (hepialus Fabr.z. B. phalaena humuli L.) habeǹ fehr kurze Fühlhörner'mit rundliclien Zähnen, fo dafs fie wie körnig auslehen; fie haben nur noch ein Ueberbleiblel von Zungenröhre; in ihrem erften Zuliande halten fie fich im Innern von frilchem Holze auf. 3. Die Holzfpinner (colfus Geoffr.z. B. coll. ligniperda) unterfcheiden fich nicht viel von den Schmalfpinnern, aber haben keine Zungenröhre, und an den Fühlhörnern fieht man deutliche zahnartige Einlchnitte. Die Raupe thut den Bäumen grolsen Schaden.

Dumeril Zool. 


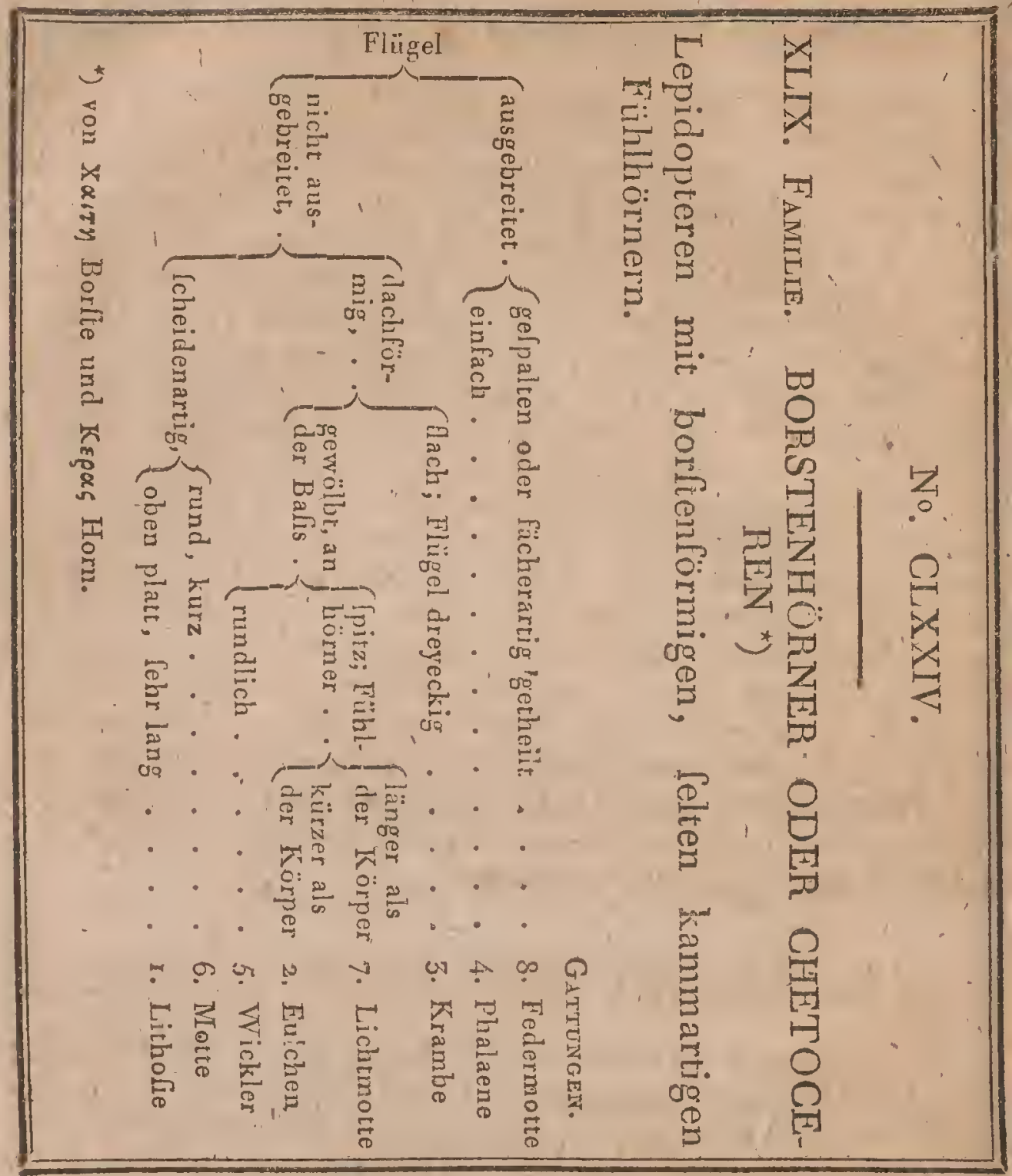

\section{BEMERKUNGEN ZUR CLXXIV. TABELLE.}

Die Familie der "Chetoceren begreift Inlekten, welche aufser der Fühlhoriform wenig Beziehungen unter einander haben; doch leben ihre Raupen meiftens in Scheiden oder Gängen, die fie fich in vegetabili[chen Subltanzen aushohlen. Die Geftalt ibrer Flïgel,ift fehr verfchieden und auf die darin beobachteten Eigenheiten hat man die Abtheilung in Gattungen begründet. I. Die Lithofien' (lithofia $F a b r$.) fcheinen den. Uebergang von diefer Familie zu der vorhergehenden zu machen, wenigftens in der Art und Weife wie fie ihre Fliigel tragen, welche viel länger find als der Leib. Ihre Frefsfpirzen find rückwärts gekrümmt. 'Thre Le- 


\section{No. CLXXV.}

\section{Ordnung. Dipteren *)}

Infekten mit zwey nakten Flügeln und einem Munde ohne Kinnladen.

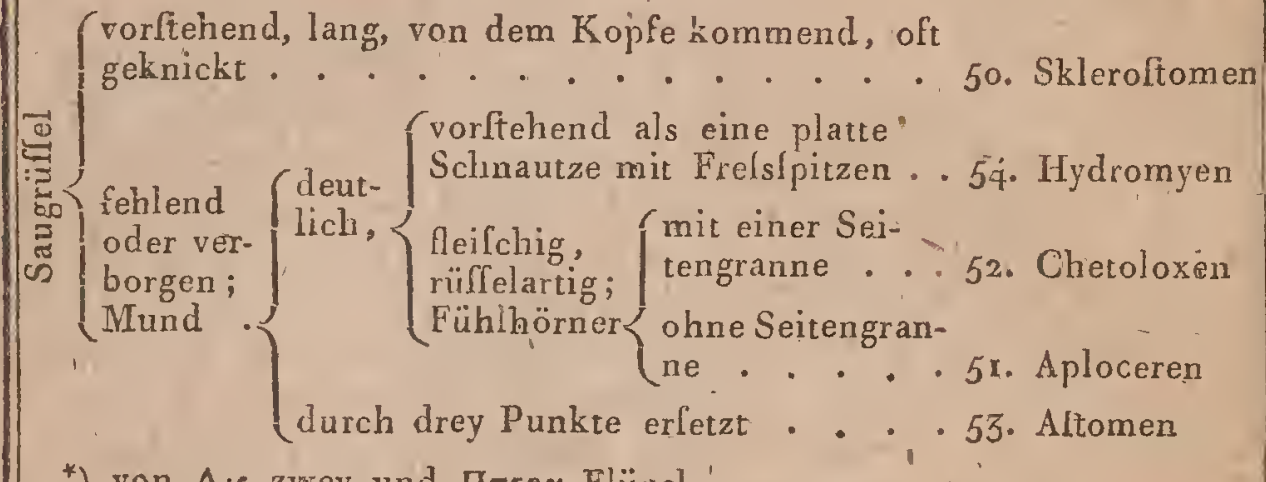

\section{BEMERKÚNGEN ZUR CLXXV. TABELLE.}

Schon der blorse Name Dipteren, (diptera) könnte hinreichend an den welentlichften Charakter dieler Inlekten-Ordnung erinnern; wenn nicht auch die Männchen der Kermes, einiger Blattläule und einiger Tagfliegen, wo die unteren Flügel lich nicht entwickeln, wenn diefe nicht auch nur zwey Flügel hätten. Die wahren Dipteren unterf'cleiden fich aber von allen Infekten durch die Metamorphofe, die in der ganzen Familie immer auf diefelbe Weife vor lich geht. Bey Fabricius heilst diele Ordnung anthliata. Die meiften kommen von Eiern, die von der Mutter an feuchte Orte gelegt find, zuweilen kommen die Eier fchon in Mutterleibe aus, und die Jarven werden lebendig gebohren. Einige z. B, die meiften Hydromyen, entwickeln fich im Waller; andere z. B.' die Chetoloxen; freflen frifche Planzen, aber die meiften nähren fich von faulenden Thier-und Planzenkörpern: Obgleich die Form der Larven Lehr verfchieden ift, fo haben doch alle weder Fülse noch Augen, ausgenommen die der Mücken und Schnaken. Wenn fie den Ort verändern, fo gefchieht dies durch fefthalten mit dem'Munde und allmähliges Auffiitzen mit den Ringen des Körpers, welche deutlich unterfchieden und mit, nach einerley Richtung Itehenden; Stacheln beletzt fund. Die Pupper find, dis-der Mü̈ken und Schnaken aüsgenommea, 
immer unberveglich. Bey òinigen Arten verhärtet und verdickt fich die Haut ler Larve und und umgiebt äufserlich den Körper des Infekts, deffen Geftalt ganz verwandelt aber noch lehr weich ilt. Bey andern entblölst lich im Gegentheil die Larve von ihrer Haut, und fcheint von einem glatten häutigen Gehäufe bekleidet zu werden, an deren Oberfäche man nichts von den Thcilen und Gliedern des Infekts unterfcheiden kann, die davon, wie das in den Eyern anderer Thiere der Fall ift, ganz bedeckt find. Fs ift dies eine' den Dipteren ganz eigenthünliche Verwandlung. Diele Gehäufe find gewöhnlich von runder Förm. Oft findet man lie in der letaten Haut der Larve felbft, die ihnen als Kokon dient. Das ausgebildete Infekt kommt gewöhnlich an dem einen Ende dieles Gehäufes hervor, fo dafs diefes fich in die Höhe hebt und nur an einem Ende, àls wie mit einem Chanier befeltiget, hangen bleibt. Die meiften diefer Infekten leben ziemlich lange in ihrem vollkommnen Zuftande. Ihre Lebensart ift nach den Familien lehr verlchieden, gewöhnlich aber haben fie unter einander grolse Aehn. lichkeit der Bildung. Im Ganzen ift der Kopf dick, fo auch die Augen die in manchen Arten bey den Männchen falt allein den ganzen Kopf bilden; die Augen find netzartig gefchliffen, wie die Augén der Falter. Die meiften haben auch noch drey klëine glatte Augen auf dem Scheitel oder Hintertheile des Kopfes. Ihre Fühlhörner zeigen, To wic auch die Form des Munces, grofse Verlchiedenheiten, wrorauf die Entornologen die Unterlcheidung der Arten gegründet haben. Sie haben lo zu fagen gar kein Halsfchild, wenn man mit dielen Namen den Theil belegt, der gleich auf den Kopf folgt, die zwey erlten Fufspaare trägt und bey den Käfern fo fichtbar ift; aber ihr Bruftfück ift lehr grofs, und trägt wie bey den übrigen Inlekten die Flügel und die vier Hinterfülse.' Ihr Leib zeigt viele Verfchiedenheiten der Form, gewöhan, lich ift er dicht auffitzend, bey einigen aber auch gefiélt. Die Flügel find lehr zart, "I immer ganz durchlichtig, zuweilen harig, meift lang und horizontal. Gewöhnlich find lie an der Bafis ausgelchnitten und man fielt dafelblt an jedem Flügel eine-gew ôlbte Schuppe, die die Bewegungen des Flügels theilt. Bey den meiften Dipteren fitzt unter dem Flügel noch ein befonderes Organ, ein mehr oder minder langer mit einem Knopf endigenden Faden, den man Schwingkolhe nennt, und deflen eigentliche Beltimmung mán nicht kennt. Es fcheint diếr Theil das Rù diment des Unterfïgels zu leyn; es ift beftändig in Bewegung wenn der Flügel fich bewwegt. Mit Uxireçt hat man es für eine Balanzierftange gehalten. 
Dipteren.

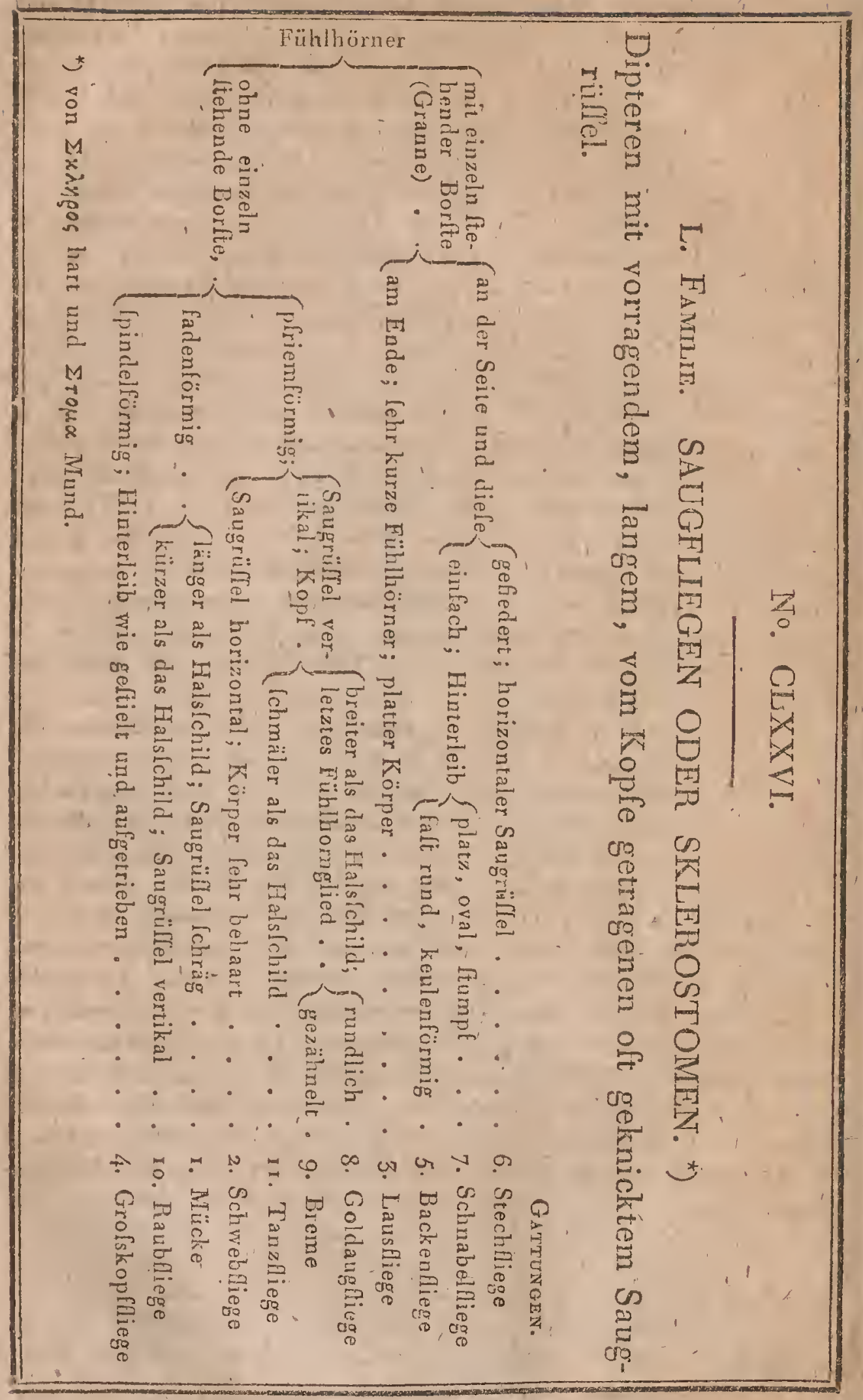




\section{BENERKUNGEN ZUR CLXXVI. TABELLE.}

Die Skleroftomen find leicht an der befonderm Form ihres Mundes zu erkennen; Conlt' aber in vieler Hinlicht von einander verlchieden. Einige laben Körper und Beine aufserordentlichlang; andere lind kurz und dick, und dabey niedrig auf den Beinen. Einige haben' einen vorwärts gerichteten nichtgeknickten Sauger; bey andern ift er kurz nnd liegt unter dem Kopfe: noch andere haben ihn in der Länge geknicktund Co eingericbtet. dals ervorwärts bewegt, und,zum Theil in den Kopf züückgezogen werden kenn. I. Die Mücken (culex L.z. B. c. pipiens) habenfadenförmige aber mit feinen Härchen befetzte, bey den Männchen oft ganz grefiederte, Fühlhörner; Körper únd Füfse find lehr lang. Der Saugrülfel ilt of län. ger als der halbe Körper. Sienähren fich von Blut und faugen wie die Wanzen (p. 26r.) 2. Dieschruebfliegen (bombylius L. z. B. Bumb. majơr luaben, einen runden, breiten, ovalen platten Kürper. Ihr Saugrültel ifit lang, dünn, [pitz und fieht horizontal.' 'Ihr Leib ift dicht auffitzend und kurz. Sie nälıren fick von Blumenltaub, licben fandige Gegenden und Miegen faft ohne Unterlals. 3. Die Lausfliegen (hippobosca L. z. B. H. equina) lind mit kurzem Rüflel verfehen. Sie find im Ganzen fehr platı; laufen fehr Ichncll und in jeder Richtung. Die Weibchen legen ein Ey was beynahe an. Grölse dem Körper gleich kommt; dies Ey ift eigentlich fclıon eine P'uppe. Eine dahin gehörige Art, H. ovina. hat niemals Flïgel. 4. u. 5. Die Grofs kopfficgen conops Fabr.z.B. con. macrocepliala und die Backenfliegen (myopa Fabr. \%. B. con. ferruginea) find nur nach ihrem vollkommen Zuftaude bekannt, wo man fie auf Blumen findet. 6. Die Stechfliegen. (llomoxys Geoffr.) gleichen den Stubentliegen aber ihr Saugrüllelift immer vorragend. Sie find im Herbftelir häufig und. faugen Blut. Z. B. conops calcitrans. 7. Die Sclinabelfliege (rhingia Scopoli) [cheinen in ihrem erften Zultande im Milte zu leben. "Ihre Sirn verlängert fich in eine Art von Schnabel, der dém. Sangrüflel zur Scheide dient, man findat fie auch auf Blumen. 2. B. rhing. roltrata fi a b $r$. 8. Die Goldaugen (chryfop/s) haben die grölste Aehulichkeit mit den Bremen, fowohl in Lebensart als Metamorphole. Ihre Fülliörner Cund" Pfriemenförmig, der vorragende Kopf hat fehr glänzende metallilçhe Augen Die Flügel find breit und halb ausgefpreitzt. Z. B. Taban caecutiens. 9. Die Bremen (tabanus I.) kommen vón in der Erde lebenden Larven. Die Puppen find hinlänglicher Bewe'gung fähig, um, wenn fie im Begrift find, fich zu verwandeln. aus der Erde hervor zu kriechen.' In ihrem letzten Zufande faugen fie Blut z. B. tab. bovinus 1. . jo. Die Raubfliegen (afilus $\mathrm{L}$. haben langen, haarigen Körpar, nackte Sclıwingkölbchen ohne Schüppchen. Ihre Larven leben im Sapde, und nahrèn fich, wie die vollkommen Inlekten, von Inlek. ten. Ihr Saugrüllel fteht fenkrecht. Z. B. af. crabriformis L. 11. Die Tanzfliegen (empis L. em. pennipes) haben diefelbe Lebensart wie die vorigen, von welchen fie fich nur durchdie Fühlhörner unterlcheiden. 
Dipteren.

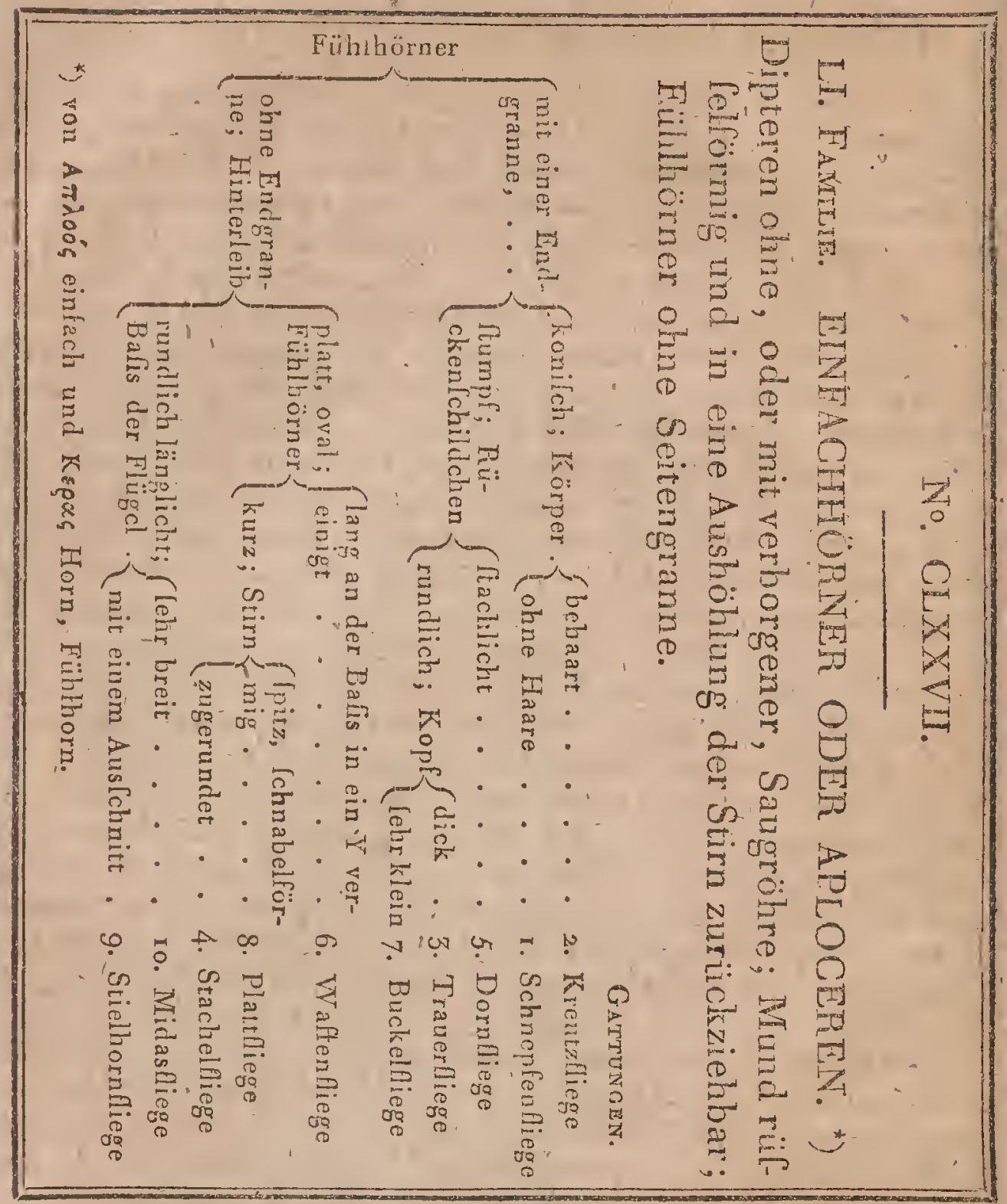

\section{BEMEPRUNGEN ZUR CLXXVII. TABELLE.}

Die Gefchichte der in die Familie der Aplocerén gehörigen Gattungen ift noch wenig bekannt, und diejenigen welche man beobachten konnte, haben bemerkenswerthe Verfchiedenheiten gezeigt. "

I. Die Schnepfenfliegén (rhagio Fabr.; nemotelus de Geer z.,B. müsca fcolopacea) fcheinen alle von fleifchfreflendem Larven zu kommen, welche fich, wie die Ameifenlöwen, Löcher in den Sand grabea. 'Auch hat man fje wohl vormilions genannt. In ihrem letzten Zuftande findet man fie auf Blumen. Sie haben fehr lange Fülso folche Schwingkölbchen. 
2. Die Kreuzfiegen (bibio Fabr. gleichen den vorigen, haben aber nur żvey Knöpfe an den Unterfülsen. Ihre Larven kennt, man nicht. Z. B. musca plebeja. L.

3. Die Trauerfliegen (anţhrax.Scopoli \%. B. musc. morio' L.) haben die Flïget gewöhnlich an der Balis Ichmal und an der Spitze breit, in der Ruhe ausgebreiter, ein Drittheil länger als der Körper und häufig, was by den Dipteren Celten ift, gefârbt. Sie find lehr beweglich, fchweben oft. ftundenlang an einer Stelle ohne lich zù ferzen: belonders gern halten fie-lich an fandigen trocknen Orten auf.

4. Die Gattung Stachelfliege (ficus Fabr. coenomia Latreillc) lat eine fleilchige gelappte Saugrohre, obgleich einige Entonológen fie zu den Bremen und Raubliegen gezäbl habèn. lhre Flügel find lang und kreuzen fích im Ruhezultande über den glatien, ovalen, Itumpfeu Hinterleib. Z. B. Sicus ferugiucus $F a b r$.

5. Die Dornfliegeñ (hypoleon z. B. ftratiom. hypoloon) baben viele Aehnlichkeit mit den Waffenhiggen, von denen lic lich durch die Kürze und eigenthïmliche Form der Fühlhömer unterfcheiden.

6. Die Waffenfliegen (ltrationys $G$ coffr.) find leicht an der Form ihrer Fühlhorner und ihres mit zwey Spitzen endigenden Rückenfchildchens zn erkennen, Ihre Fiugel find in der Rulie gekrentzt. Ihre Larven leben im. VVafler, haben eine fpindelahnliche aber dabey glatte-Form, man nimmt doutlich zwölf Ringe an ihr wahr. An ihrem Hintertheil findet fich eine Art ron wie eingeöhlten Feder- orter Haarbufch, der an der Oberfäche des Vaflers fich ausbreiter, fo dafs das Inlekt davon getragen wird. Im Mittelpunkt diefes Bufches, ilt die Oeffnung für die Refpirationsorgane. Die puppe behalt die Haut der Larve, aber die Theile des Körpers ziehen fich fo zurïck, dals vorn und hirten ein leerer Raum bleibt; Z. B. Str: chamaeleon.

7. Die Buckelfliegen (cyrtus l'abr.) haben ilren Namen von ihrem Anfehn; Ihr Halsfchild ift felur grofs, der Kopf fehr klein, der Hinterleib ift aufgetrieben, leer und ftumpf. Z. B. cyrt. acephalns.

8. Die Plattliegen (nemotelus Sch a effer) haben die Stirn lchnabelförwig verlängert wie die Schuabelliegen; ler Körper ilt glatt, glänzend, oval und plattgedrückt; das hückenfchildchen ift rundlich. Man finder lie auf Blumen, ihre Larve ift aber noch unbekannt. 'Z. B. nemot. uliginolus $F a b r$.

9. Dié Sticlhornfiegen (ceria Falr.z. B. musca conopsoillés. L.) haben an ihrer Bafis verwachlene. Fühthörner, die länger find als der Kopf, und woran das letzte Glied lpindelförnig ift. Der Kopf ift dreyeckig, depr Leib conifch, concav; thre Flügel find an der Bafis fchmal. Die meilten haben die Haltung der Sägewespen und Wespen.

ro. Bey den Midasjliegen (midas Fabr.) find die Fühlhörner auch rehr lang, vorwärts gerichtet, zufammengedruckt und nahe añ ginander fitzend. Der Korper if dick lang und "etwas platt; der Kopt breiter als das Halsfchild, die Flïgel von einanderftehend und an der Balis lehr breit. Z, B. mid. flata Fabr. 


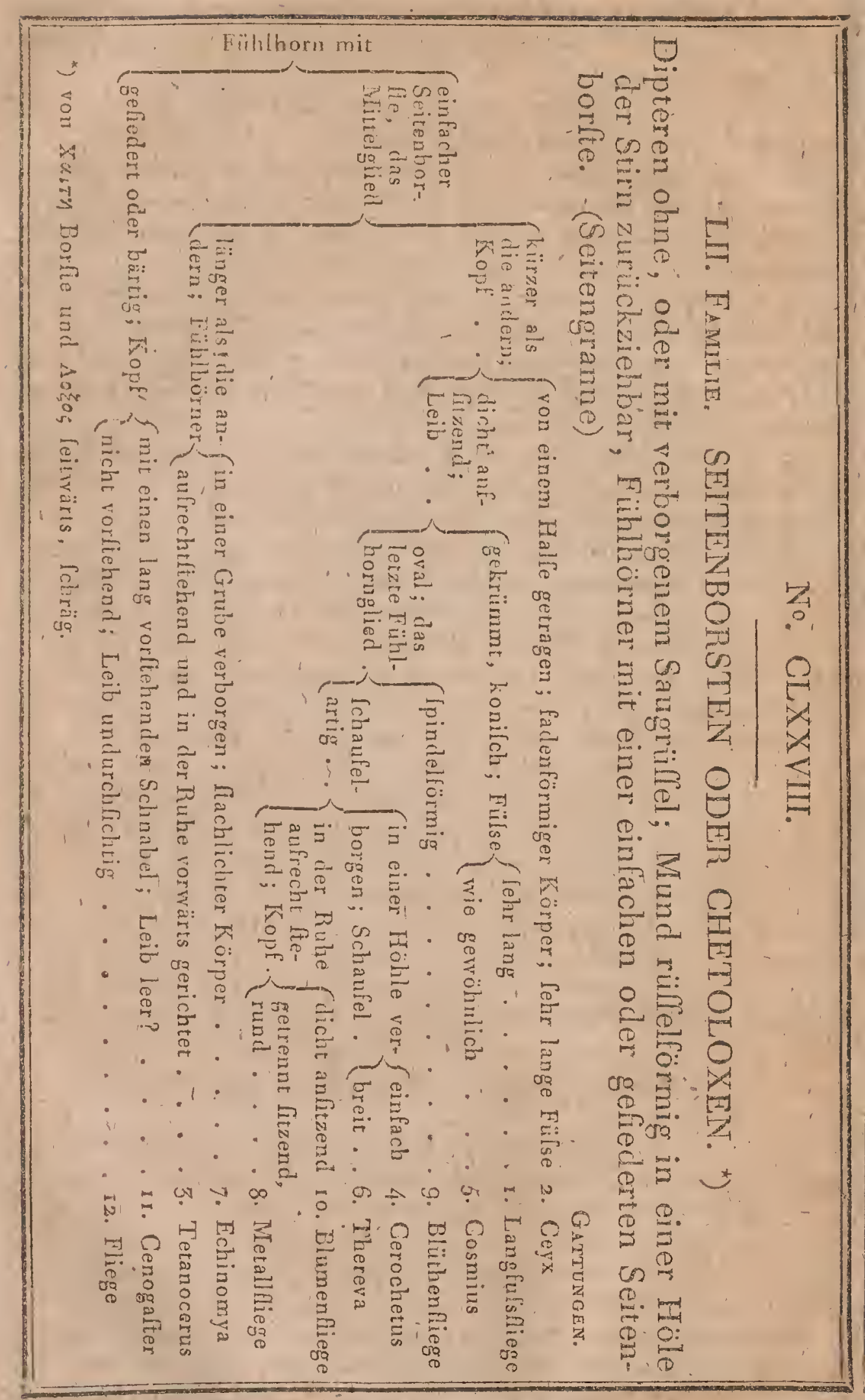




\section{BEMERKUNGEN ZUR CLXXVIII. TABELLE.}

Die in die Familie der Cheloloxen gehörigen-Infekten entprechen der Linuéilchen Gattung Hliege. Die hier anfgeführten Gatturngen zeigen fehr grolse Verfchiedenheit der Form und der Lebensart. 1. Die Langfuffliegen (dolichopus Latr. z. B. musc. ungulata L.) baben ihren Nas men von der Länge ihrer Fülse. Thr Körper ift meiftens von Metallfarben glänzend, zulammengedrückt, mit erhabenem Briftlchilde und fenkrechten, falt dreyeckigem Kopfe; der Leib ift konifch, und hey den Männchen vorwärts gekrümmt; die Flügel find fehr lang und die Fülse dünn. Sie laufén fehr fchnell und nähren fich von lebenden kleinen Inlekter. Lhre Larven halten fich in der Erde auf. An den Puppen kann man lchon die Geftalt des Inlekts erkenuen. 2. Die Cejx (ceyx \%. B. musca petrom nella L.) find kleiue Inlekten mit langem dïnnèn Körper, der bon ganz ausnehmend langen Fülsen getragen wird; der Fopf ilt rund und fitrt auf einer Art von Halfe. Die Fühlhörner find fehr kurz. Sielaufen aut dem Wafler. 3, Die Tetanoceren (tetanocerus) haben ihren Namen von der Geltalt ilırer ganz vorwärtsltehenden Fühlhöner. Der Kopl ift dick, halh kugelartig und hinten wie abgelintzt, der Mund aufgetrieben und blafig. Man findet fie auf faulenden thierifchen und regetabilifichen sublianzen, wo auch die Larven fich entwickelu. Z. B. musc. reticulata Fabr. 4. Die Cerocheten (cerochetus) haben vorwärtsgeneigte Fühlhörner, die in eine Vertiefung der Stirn aufgenommen werden. Ihr Körper ilt mit fparfamen und feinen Haaren bedeckt, und hat ein rundliches Rïckenfchild. Es ift eine an Arten zablreiche Gattung deren Lebensart mit der der vorigen übereinkornmt. 5. Die Gattum Cosmius, hat gewöhulich Ichön farbig-geltueifte oder gefeckte Ilügel; die hieher gehörigen Inlekten gleichen dem tetanoceren. Ihre Larven entwickeln fich in den Stämmen, Samen, Kapleln und Wurzeln der Pflanzen aus, der Fa_ milie Cruciferae. 6. Die Therevas (thereva Fa br. z. E. musc. plebeja L..) haben einen kurzen, ovalen Körper, breiten Kopl, platten abgerundeten Leib; dicke, oftundurchlichtige an der Balis breite Flügel. Die Schüppchen grofs und gefranzt. 7. Die laiuchhaarfliegen (echinomya z. B.musc. grof(a) heifsenlo; von ihren fteifen grolsen Haaren. Der Kopl ift lehr dick; die Flügel find lialb ausgebreitet; die dLärven entwickeln lich in den Raupen und Puppen der Schmetterlinge. 8. Die Metallfliegen (fargus Fabr. z. B. Sarg. cupraria) halten das Mittel zwilchen den Blumenflie. gen und Waftenfliegen. Ihre Verwandlung kennt man nicht. 9. Die Mulios (mulio Fabr. z. B. m. obfcura). haben lange mit der Bafis an einander fitzende Fühlhörner, gleichen übrigens den Blumenflegen. "Io Die Fliegen (musca L. z. B. m. vomitoria) find die einzigen Arten, wo das Seitenhaar der Fühlhörner, wie bey den Mücken, gefiedert ift und die arich fonft von den'übrigen Arten, abweichen. 'II. Die Cenogofter entlialten die Infekten, welche Geoffroyivolucelles gemannt hat, Z. Is, Syrphus pellucens, $F$ a $b$ r. 


\section{No. CLXXIX.}

LIII. Familie. BREMSEN ODER ASTÓMEN. *) Dipteren ohne Saugröhre und Rüffel; der Mund durch drey verticfte Punkte erfetżt.

\section{Bremfe.}

*) von A privativo und ETops Mund.

\section{No. CLXXX.}

LIV. FAMILE. WASSERFLIEGEN ODER HYDROMYEN. *)

Dipteren; ein, in eine platte und vorragende Schnautze verlängerter Mund, mit Frefslpitzen ohne Rüiflel und-Saugröhre.

GatTungen.

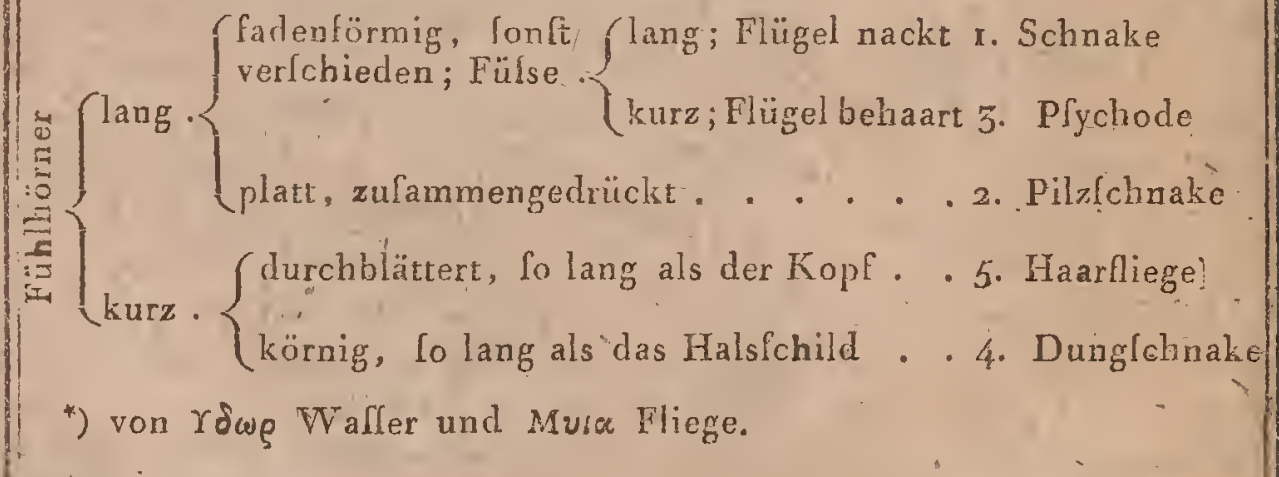

\section{BEMERKUNGEN ZUR CLXXIX. TABELLE.}

Die Bremfen haben, wie der Name Aftomen angiebt, keinen Mund. Sie kommen aus Larven, welche denen der Fliegen ähnlich find, deren । Körper länglicht; etwas platt und mit, nach einerley Richtung ftehen- 
den Spitzen ftachlicht beletzt ift, vermittels welcher fich das Thier fefthält und deñ Ort verändert. Alle bekannte Arıén entwickeln fich in Säugthieren: Wiederkäuern und Pferden. Einige dringen in den Darmkanal, andere in die Kinnlarler - und Stirnhöhlen, und einige unter die Haut, wo fre Eitergefchwülfte veranlaffen. Die Puppen oder vielmehr die Larven, wenn fie in Begriff find unbeweglich zu werden, gleiten yon ihrem bisherigen Aufenthaltsorte auf die Erde, wo fie fich, vergraben 'und in Koth i. $\int$. w. verborgen bleiben, bis fie ihre léate Geltalt angenommen haben. Die vollftändigen Infekten leben nur lo lange als nöthig ift, um fich $z u$ begatten und Eyer zu legen. Ihre Gefialt ift lebr verlchieder. Falt alle aber haben grol'se Augen.' Z. B. Oeftrus haemorhoidalis.

\section{BEMERKUNGEN ZUR CLXXX.-TABELLE.}

Diè Schnautze der Fydromyen ift in eine Art von Schnabel verläıgert, woran man nur noch gegliederte Fäden unterfcheidet. Oft find die Füh?hörner lehr lang, von verlchiedener Form, einfach oder kammartig. Der Konf ift klein, kugelförnig, mit zwey Augen, worauf man rundlich gefchliffere Felder wahrnimmt. Ihre Schwingkölbchen liegen blos, ohne Schüppo chen. Die Larven zeigen wenig Uebereinftimmendes in Lebensart und Geftalt. Oft fieht man fchon an der Puppe ganz deutlich äulserlich das in ihr verborgene vollftändige Inlekt abgedruckt.

I. Die Schnacken (tipula L, z. B. tip. pectinicornis) baben Körper and Füfse aulserordentlich lang. Die Larven entwickeln fich entweder in der Erde, wo lie fich von Pflanzenwurzeln nähren, oder im Mifte oder in Schwämmen; einige halten lich auch in Wafler oder Schlamm auf. Es ift dies eine Gattung, wo man die Arten nicht leicht autbewáhren kann.

2. Die Ceratoplaten, Pilyfchnacken (ceratoplatus Bosc. z. B. cer. tipuloides) gleichen den Schnacken aber ihre Füblhörner find znlarnmengedrückt und in der Mitte breiter. Sie entwickelin fich in Pilzen.

3. Die Pfychoden (Pfychoda La Lr. phalaenula Maig e.n z. B. tipula phalaenoides L.) haben fadenförmige Fühlbörner, die faft fo lang als der Körper find und aus haarigen Gliedern beftehen; ihr Kopf ift klein, ihre Flügel grols, behaart, gefranzt, und bilden auf dem Rücken ein Ichräges Dach. Sie lieben feuchre und dunkle Orte, laufen fchnell aber fliegen Ichlecht.

4. Die Dungfliegen (Icatople Geoffr. z.B. Sc. migra) finden fich in ihrem letaten Zuftande nur an den unreinlichlten Orten. Ifre Larven entwickeln fich in den Beulen mancher Pflanzen z. B. der Euphorbieu u. f. w.

5. 'Die Haarfliegen (hirtaea Fab̈r, bỉbio Geoffr.) haben Fühlhörnề (mit kurzen, platten, durchbätterten:Gliedern) die dicht neben dem. Rüflel fitzen. Zu gewiflen Jahrszeiten erfcheinen diefe Haarfliegen in groIser Meuge, daher' der Name mancher Arten z. B. hirtaca Joahnis, hirb. marci; die Larven entwickeln Gich im Mifte. 


\section{No. CLXXXI.}

\section{VHI. ORDNUNG. APTEREN.}

\section{Infekten immer ohne Flügel.}

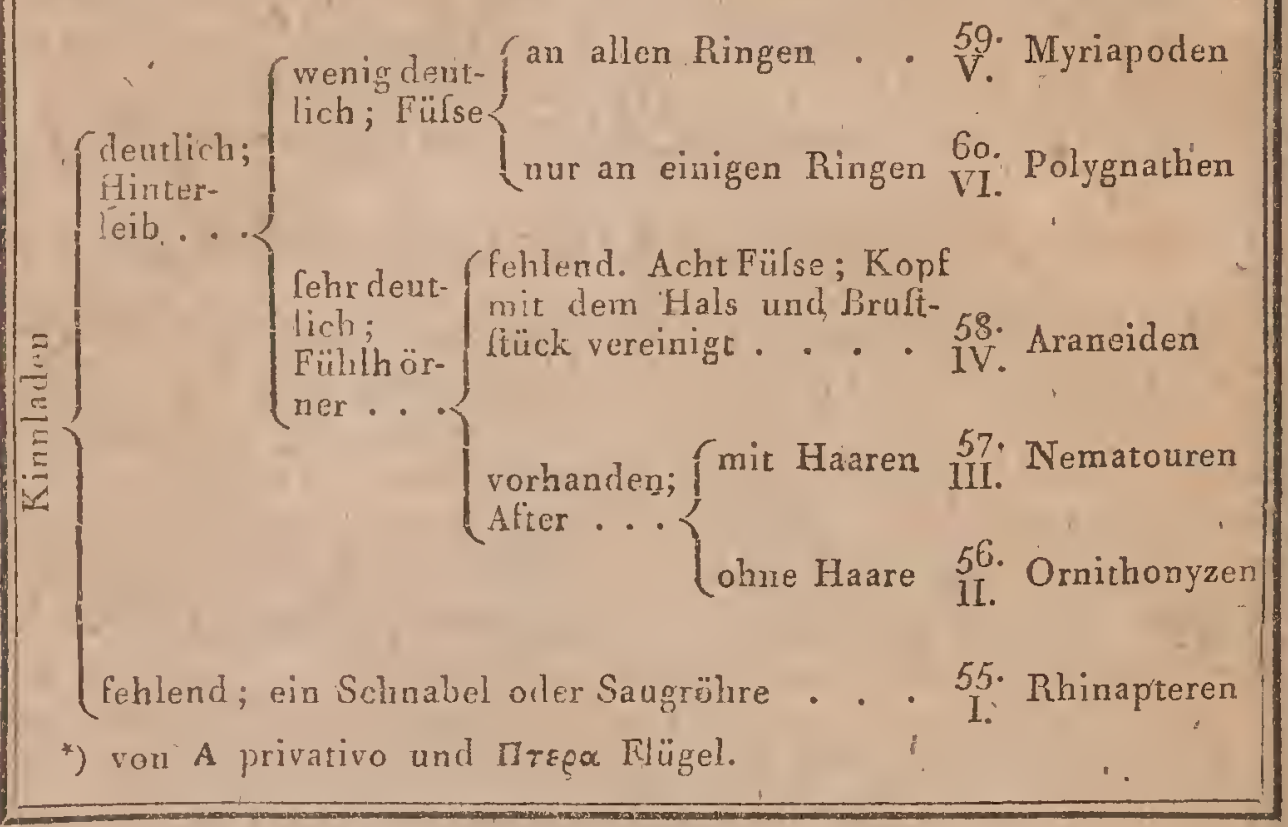

\section{BEMERKUNGEN ZUR CLXXXI. TABELLE.}

Die Ordnung der Apteren beruht auf weit weniger politiven Charakteren als die vorhergegangenen andern Ordnungen.- Doch find in ibr Infekten vereiniget, die untereinander in manchen Rücklichten überein. kommen, und zugleich durch Form, Organifation und Lebensart von denen, der übrigen lieben Ordnungen fehr abweichen.

Als Linné diele Ordnung auffiellte, brachte er alle Inlekten dahin, die mit denen der andern Orhuungen nicht zulammenpalsten, fo dals oft zwilchen'zwey Familien der gegenwärtigen Ordnung eine grölsere Kluft ift, als zwilchen zwey ganzen fehr verfchiedenen Ordnungen, wie z. B. zwilchen Koleopteren und Hemipteren. Auch haben mebrere Schriftfeller neuerdings verfucht, aus einigen Familien diefer Ordaung belondere Klallen zu machen (wie z. B. Lamark eiue eigne Klaffe: araneacea aufgefiihrt hat.)

Der Charakter der Ordnung' der Apteren, liegt, wie der Name lagt. in dem Mangel der Flügel. Aber diefer Unterlchied ift nicht hinreichend un Lich eine klare Vorltellung von den darunter begriffenen Inlekten zu 
machen. Man múfs daher oinen andern Weg einfchlagen, newlich fie mit den vorhergegangenen Ordnungen vergleichen und lie durch andere nugative Eigenfluaften beltimmen.

Die Koleopteren haben in ihrem vollkommnen Zultande immer nackte Kinnladen und Flügeldecken orler wenigltens Stumpten von Flügeldecken; das Weibchen des Leuchtwurmkäfers allein macht eine Ausnalume. Die Apteren haben nie Flügeldecken auchkeine Stumpten davon, und haben mehr als fechs Fülse.

Die Orthopteren haben immer einen Helm an den Kinnladen. Die Nematouren find faft, in demfelben Falle und könnten mit einigen Schaben verwechlelt werden.

Die Neuropteren können, da fie falt immer Flïgel haben, nicht mi: den Apteren verwechfelt werden. Doch fehlen dic Flügel einigen Pfocken und Termiten, aber diele haben einen runden Schwana, der fie von dein Nematouren unterfcheidet, die die einzigen Arten find wo lechs Fülse, Kinniladen und ein unteríchiedener Hinterleib vorkommen.

Da kein Inlekt aus der Ordnung der Apteren einery geftielten Hinterleib und weniger als acht Fülse hat, lo kann mit den Hymenopteren kei. ne Verwechfelung ftatt finden.

Was die Hemipteren, Lepidopteren und Dipteren anlangt, fo könnte`höchltens die Gattung pediculus und pulex vielleicht ibnen genähert werden, aber fie unterfcheiden fich clurch viele andere Eigenheiten.

Uebrigens lcheint die einfache Abtheilung auf der gegenwärtigen i 8 r Tabelle eine fehr vollftändige Idee der in diefe Ordnung gehörigen Inlekten zu geben, da man auf derlelben die Familien gut überlehen kank. Die Eigenthümlichkeiten und Lebensart der Unterabtheilungen, werden, bey den einzelnen Familien vorkommen."

Wenn übrigens über die Beftimmung eines ungeflïgelten Infekts einige'Schwierigkeit obwalten follte, Io mufs man denken, dafs die zu unterluchende Art in eine andere Ordnung gehöre und zur Ergänzungs-Tabelle No. 117 pag. I88 feine Zuflucht nehmen, wo über die Beltimmung def mit Unrecht Apteren genannten ungellïgelıé Infekteả ein leichır Weg vorgezeichnet ift. 


\section{No. CLXXXI.}

LV. FMIAIE. SCHMAROTZER ODER RHINAPTEREN. *)

Infekten ohne Kinnladen und ohne Flügel.

Fülse flecls; ' zufammengedrück't Hinterfülse länger . I. Floh

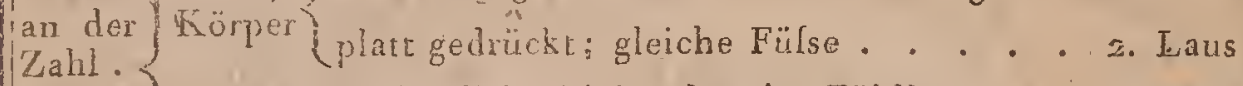
Zahl. acht; Kopf deutlich, klein; haarige Fühlhürner 3. Milfe *) von Piv Nafe und artze⿻ Flügellos.

\section{No. CLXXXII.}

LVI. Familie. ORNITHOMYZEN. *)

Infekten ohne Kinnladen mit deutlichem Kopfe; mit fechs Füfsen und ohne Haare an dem Schwanze.

\section{logellails.}

*) von ogusos Vogel und $\mu$ \%

\section{No. CLXXXIV.}

EVII. FAMILIE. BORSTENSCHWÄNZE ODER NEMATOUREN. *)

Apteren mit Kinnladen; mit deutlichem Hinterleibe; mit. Fühlhörnern; mit fechs Füfsen; der Hinterleib mit Borften endigend.

Gattungen.

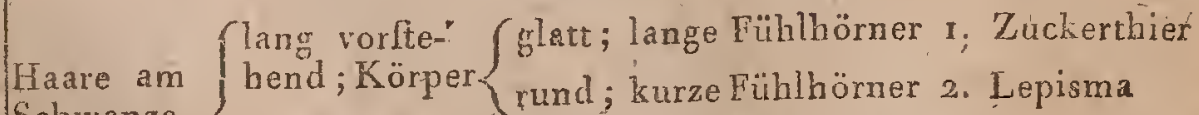
Schwanze . unter dem Leibe liegend, zum Springen dienend ........ 3. Springlchwanz

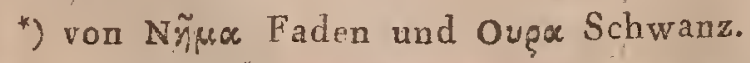




\section{BEMERKUNGEN ZUR CLXXXII. TABELLE.}

Die Familie der Rhinapieren enthält alle Flügel - und Kinnladenlole Infekten. x. Der Flok (pulex) 'erleidet eine vollitändige Metamorphole und nähert fich dadurch den Dipteren. Es ift das dies einzige BeyIpiel unter den Apteren. Ihre Larven haben keine Fülse, fie find mit k'einen Fühlizörnern verleben und fleifchfreflend: Zur Zeit ihrer Verwandlung !pinnen fie fich ein, Z. B. pulcx irritans L- 2 Die Jü̈ufe (pediculus) leben nur auf den Körpern der Säugthiere und auf Koften derfelben. Ihr ovaler platter Körper ift mit lechs gleich kurzen, und mit zwey Nügekn endigenden, Fül'sen verlehen. Der Kopf ift rund und fitzt in einer Vertiefung; der Saugrüllel ift lehr kurz. Z. B. ped. humanus I. 3. Die Millen (acarus:L.) gleichen den Läulen lehr, haben aber \& Füfse。 Ihre Geftalt ift fehriverfchieden; man hat fie nach der Form des Murides in 8 andere Unter-Gattungen, getheilt, Z. B. acarus firo L.

\section{BEMERKUNGEN ZUR CLXXXIII. TABELLE.}

Die kleine Familie der Ornithomyzen enthält die Vogellüufe (ricinus $F a b r$.) eine den Milben und Lüulen nah vervandte Gattung. Es find dies felur kleine Inlekten, die man nur auf den Körpern der Vögel gefunden hat: Ihr Mund ift mit zwey Hacken verfehen, womit lie die Federbärte bey den Vögeln faflen, ihre Antennen find lehr kurz, Z. B. ricinus pafferinus $L$.

\section{BEMERKUNGEN ZUR CLXXXIV. TABELLE.}

Die Nemaicouren bilden eine kleine, déutlich ahgefonderte Fàmilie. Es find lehr lebhafie Infekten, die fich von Ueberbleibleln vegetabilifsher und thierifcher Subltanzen nähren. Thr Kopf ift deutlich, ihre Fülse fitzen auf einer Art von Bruft. I. Die Zuckerchiere (forbicina Ge offr.) find durch ihre Lebhaftigkeit und Gewohnheit des Nachts zu laufen und organilche Subftanzen, wovon fie fich nähren, zu zerftören, den Schaben 'ännlich. Ihr Kopf if lehr fichtbar, mit zwey langen Antennen verlehen und ihr Śchwanz endiget mit drey langen Fäden. Z. B. Lepisma Cacharina L. 2. Die Lepisma (Lepisma L. Fabr.) haben den Körper bucklich, nicht platt. Ihre Antenuen find kurz und ihre Scliwanzfäden ungleich: Fie können fpringen, Z. B. Lepisma polypoda. 3. Die Spring (jchiö̈nze (podura L.) find fo genannt, weil ihr gabelförmiger unter den Schwanz in eine Art von Furche gebogener Schwanz, mittels einer elaftilchon liewegung daraus hexvorkommen und als Springluls dienen kanna 2. B. podura viridis. 


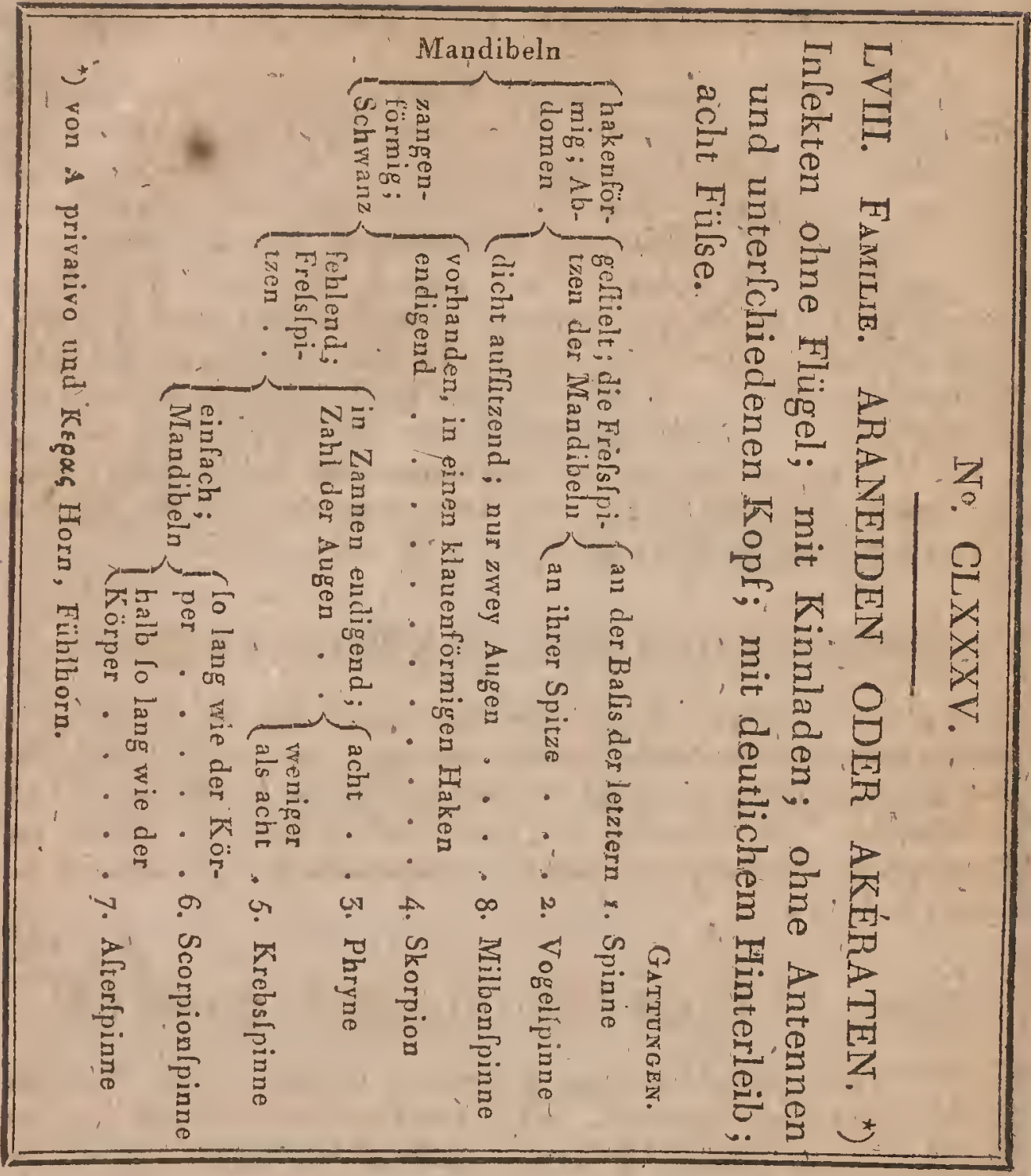

\section{BEMERKUNGEN ZUR CLXXXV. TABELLE.}

Die Araneiden, Spinnenartige untericheiden fich von allen andern vollkommnen Inlekıen dusch drey Haupteigenheiten. Erftens haben fie niemals Fühlhörnex, zweitens ift der Kopt mit dem HalsIchilde zulammen gelchmolzen und drittens planzen fie lich mehr als einmal in ihrem I,eben fort. Alle nähren fich von animalifchen Subftanzen, gewöhnlich von lebenden Thieren, denen fie ihre Feuchtigkeiten vermitteis der Oeffnung ausfaugen, die fich an, der Spitze ihrer Kinnladenhacken finden und durch zwey Kanäle in dielen Hacken in eime einfache Speileröhre führen. I. Die auf der Tabelle, gegebene analytilche Ueberficht ift hinreichend um die Spinnen (aranea $L_{\text {in }} \mathrm{T}_{\mathrm{n}}$ ) von allan übrigen Gattungen. 
der gegenwärtigen Familịe zu unterIcheiden, denn nach den Arbeiten dèr neuern Naturforfcher bleiben in der Gattung der eigentlichen Spinnen nur allein diejenigen, welche in den nach und nach gebildeten befonderen Gattungen richt haben untergebracht werden können. Die Spinneu háben wenigftens fechs, meiftens acht, glatte, fymmetrilch auf dem Scheitel fitzende Augen Die Generationsorgane der Männchen liegen in dè Nachbarlchaft des Mundes. Die meiften Spinnen können FadenIpinnen, entweder um ihrer Beute Schlingen zu fiellen oder um ihre Eyer mit einem für Feuchtigkeit undurchdringlichem Gewebe zu umgeben. Z. B. aran. diadema. 2. Die Vogelfpinnen (mygale Walkenaer) unterfcheiden fich von den ihnen fonft ganz ähnlichen Spinnen durch die Form der Frefsfpirzen, welche Fufsähnlich find und durch die einfachen nicht gezähnelten Fufoklauen. Man hat fie in zwey Abtheilungen gebracht, die eigentlichen Vogelfpinnen $z$. B. ar. avicularia L. die fehr grols und an den Fülsen mit einer Art von fteifen Haarbürfte verfehen find und wovon einige fich von kleinen Vögeln nähren, und die Minirfpinnen ohne BürIten, die fich in kleine unterirdilche Canäle zurücksiehen, die lie mit einem Deckel verfchliefsen. Z. B. ar. cementaria. 3. Die Phrynén (phrynus Oliw.) find noch wenig bekannt, man findet lie vorzïglich im lüdlichen Afrika; lie fehen den Scorpionen etwas ähnlich, da fie keiner Schwanz haben, z. B. Phalangium reniforme L. Es fcheint, dafs fie fpinnen können. 4. Die Scorpione (fcorpio L.) find an zwey Eigenbeiten leicht zu unterlcheiden. Die erfte ift der gegliederte Schwanz in' welchen der Hinterleib ausgeht und an deffen Ende fich ein 'Ipitziger Nagel findet; der mit kleinen Löchern durchbohrt ift, aus welchen eine giftige Feuchtigkeit bey'jedem Stich, der damit gefchieht hervorschwitzt; die zweyte Eigenthümlichkeit bilden die gefranzten kammartigen Blätter an der Bafis ' des finterleibes, die man für Kiemen halten könate. Die Eyer kommen Ichon im Leibé der Mutter aus und die Jungen kommen lebendig zur Welt. Z. B. Scorpio maurus. 5. Die Krebsfpinnen (chelifer. Geoffr. z. B. phaltangium cancroides, haben einen platten, fcorpionartigen Körper aber'keinen Schwanz. Sie laufen nach jeder' Richtung wie die Krabben; nähren fich von kleinen Infekten. 6. Die Scorpionfpinne (galeodes $O l i$ wier z. D. Solpuga araneoides $F a b r$ ) haben Aehnlichkeit mit der folgenden Gattung, aber ihr Körper ilt längẹ und ihre Mandibeln grölser. Ihr Vaterland ift Afrika. 7. Die Langheine oder Afterfpinnen (phalangium L.inn. z. B. ph. opilio) haben (ehr kurze Mandibeln der Körper ift platt rund oder viereckig. Ihre Fülse find fehr lang nnd endigen mit vieLen Gliedern. 8. Die Milbenfpinnen (trombidium $F a b r$.) fcheinen den Uebergang dieler Familie żu den Rhinapteren durch die Millben zu machen! Z. B. acar. tinctorius Linn. Die Arten, welche beftändig im WV afler leben und Schwimmfülse haben, hat Mïller unter dem Namen hy dractina in eine befondere Gattung gebraoht. Z. B. trombid. geograpihi cum Fabr. 


\section{No. CLXXXVI.}

LIX. FAMIJIE. TAUSENDFÜSSE ODER MYRIAPODEN. *)

Infekten ohne Fü̈gel, mit Kinnladen; Hinterleib wenig unterfchieden, mit Füfsen an allen Ringen des Körpers.

Gattungen.

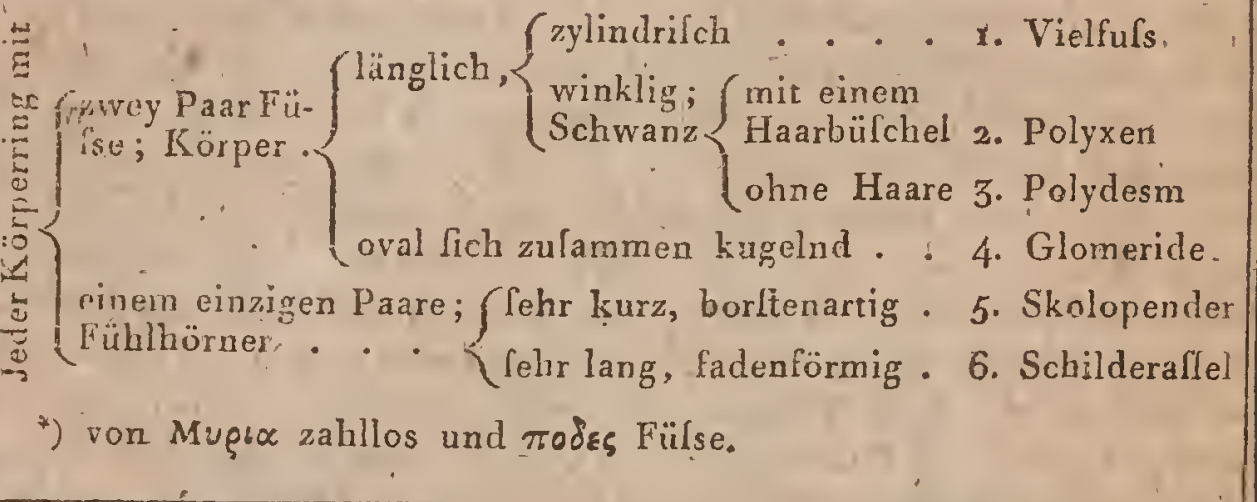

\section{No. CLXXXVII.}

LX. FAMILIE. VIERHÖRNER ODER POLYGNATHEN. *)

Infekten. ohne Flügel, mit Kinnladen; mit deutlichem Hinterleibe; mit $F$ ülsen unter einigen Körperringen.

Gattungen.

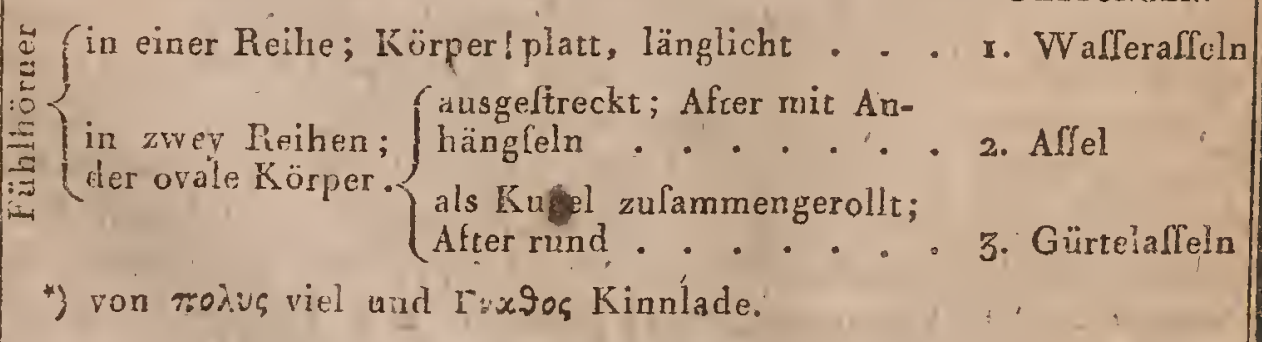




\section{BEMERKUNGEN ZUR CLXXXVI. TABELLE.}

Die Familie der Taufendfüfse oder Myriapoden entfpricht den Linmeifchen Gattungen julus und fcolopendra. Ihr Körper befteht ausfehr vieIen Ringen, unter welchen man keine belonderen Iür Bruft und Hinterlẹib anzunehmende wahrnehmen kann. Der Kopf ift immer deutlich getrennt, hat zwey Augen und zwey Fühlhörner. Fülse fivden fich an allen Ringen des Körpers und immer finden fich mehr als fieben Paar. "I. Die Tielfufse (julus Linı., z. B. jul. terreftris) thaben kurze keulenförmige Fühlhörner; ihr Körper ift zylindrilch und an jedem Ringe litzen zwey Paar Füfse. 2. Polyxenen (polyxenus Latreille z. B. Scolopendra lagura L.) find fehr kleine Iffekten mit etwas plattem, nicht harifcha-: ligem, kouifchem Körper, der hinten mit einemg länzenden Haarbüfchel endiget. 3. Die Polydesmen (polydesmus $L$ atr z. B. jul. complanatus L.) find Vielfülse mit plattem, winklichem Körper, die lich tweder Kegelförmig noch (pirałartig zufammen rolles. 4. Die Glomeden (ovomeris $L a \imath r .$, z. B. julus ovalis $L$ ) lind auch Vielfüfse, die aber den Affeln der folgendeı Familie ähnlich lehen. Ihr Kürper rollt fich zufammen. 5. Die Skolopender (ícolopendra L. z. B. Ic. morfitans) haben lange borlten - oder falenförmige Fühlhörner; ibrè Körperringe find nicht breit, liegen auch auf dem Rücken nicht fchuppenartig übereinander, 6. Die Schilderaffeln (Icutigera Lam. z. B. Icoloj) coleoptrata L) frid Skolopender nuit breiter Ringen, die auf dem Rücken Cchuppenartig übereinander werragen.

\section{BEMERKUNGEN ZUR CLXXXVII. TABELLE.}

Die Polygnathen Echeinen die Kruftazeen und. Infekten zu verbinfien, und unteffcheiden fich von eriteren nur durch die fehlenden Kiemen. Thr Kopf ift von dem ïbrigen Körper etwas gelchieden, und mit zw wey dicht auffitzenden, wie mit Facetten gelchliffenzn, Augen verlehen. Sie haben vierzeln Füfse. Die meiften tragen ihre Eyer unter dem Körper an Schwanze; wo auch die Jungen auskommen. r. Unter dem Namen Wafferlïufe (phylodes Fabr.) find hier diejenigen Infokten verltanlen. welche Latreille Afelloten genannt hat; es find dies meiftens im Waffer lebeñde Affeln, mit vier fichtbaren Füllbörnem und vorragenden Frelslpitzen; der letzte Körperring ift weit grülser als die andern. 2. und 3, Die Afjcln' (oniscus Linn, ż, B. onisc, alellus) und die Gürtelaffeln (armadillo z. B. onisc. 'armadillo L.) unterlcheiden fich nur durch die auf der. Tabelle angegebenen Eigenheiten. Zwey inref Fuhlhöner find verborgen und felir kurz; Der Ring am Ende des Körpers, ift nicht grüfser als alle übrigen." Sie lieben feuchte Orte und nühren fich vo: lauleuden vegerabilitchen Subftanzęn-

Fude der Clafe der Infekten. 


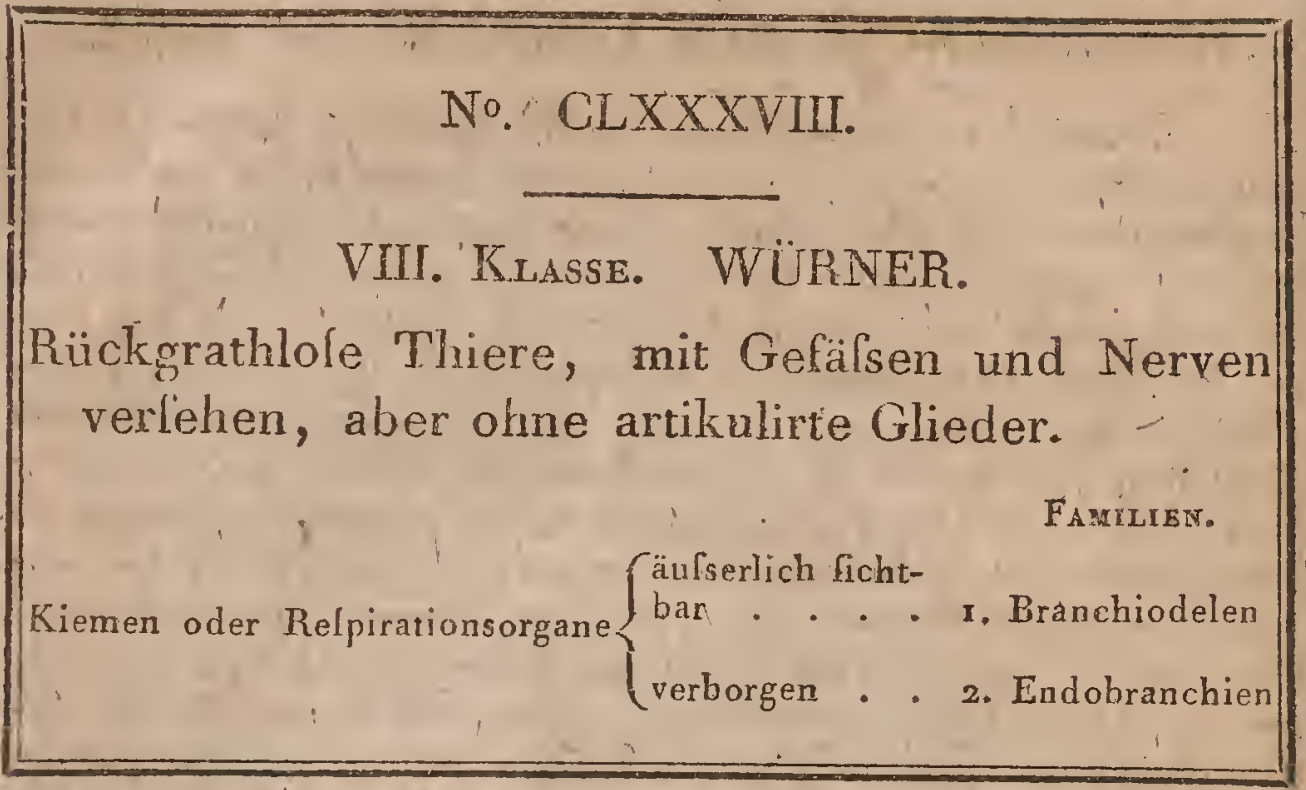

\section{BEMERKUNGEN ZUR CLXXXVIII. TABELLE.}

Die Claffe der Würmer fo wie fie hier nach Cuviers Unterfuchungen aufgeftellt ift, ilt unr eine Abrheilung der Klafle die Linne unter demlelben Namen gebildet hatte, und wohin er alle rückgratslofen Thiere, mit Ausnakme der Kruftazeen, Infekten und ihrer Larven, zäblte. Hier find als Würmer diejenigen rückgrathlofen Thiere angenómmen, welche einen Jänglichten, wie geringelten Körper haben, deren Kop€ nie deutlich von dem übrigen Körper getrennt ift, und die niemals gegliederte'Fülse haben. Man finder bey ihnen belondere zur Cirkulation der Ilüfligkeiten, des Blutes, befitimmte Kanale. Meiftens haben fie kiemenförmige Refpirationsorgane und Nerven, die denen der Infekten äbnlich find.

Der inneren Organilation zufolge, die bey den Würmern komplicirter ilt, als bey den lufekten, wo man noch keine Cirkulationsorgane entdeckt, hat, follte die gegenwärtige Clalfe in der natürlichen Stufenfolge gleich hinter die Kruftazeen geftellt werden, nnd: fo su den InIekten führen. Aber nach ilırer äulseren Form, nach der geringen Entwickelung ihrer Bewegungswerkzeuge, (und; wenn man die Refpirationsart der Inlekten, als den Blutumlauf erfetzeńd anfieht, indem die Luft in ihnen cirkulirt falt whie das Blut bey andern :Thieren,) hienach fcheinen docb die Würmer zwilchen Zoophyten und Infekten geftellt werden zu mïfien. Sie fchliefsen fich an die Zoophyten durck die Eingeweidewürmer an, und unterbrechen dann auch nicht die natürliche Kette, welche von den Kruftazeen zu den Irfekten, durch die Flohkreble und Affeln gebildet wird.

Die Würmer leben in Wafler oder in feuchter Erde; im letzten Falle, 
können fie meiftens lange Zeit auch in feuchter Luft laben und ihre ReIpirationsorgane find, bey denen, wo man lie überhaupt entdecken konnte, im Innern des Körpers befindlich. Die anderen aber, halten ifich beftändig im Waffer, und die meiften im Meere auf. Ihre Kiemen ifind immer äufserlich aın Körper, als Büfchel, Blätter oder Faden, befindlich.

Obgleich bey den Würmern der Kopf nicht vou dem übrigen Kör por merklich gefchieden ift, fo findet man ihn doch immer mit dena Munde an dem einen Ende. Der Mund ift bey einigen eine einfache Oeffnung, als ein konifcher Ipitzer Rüffel vorftreckbar, "mit oder ohne Traden, und ohne Kinnladen; bey andern ift der Mund in eine Scheibe a ausgebreitet, die als ein Saugnapf würkt und auch zur Fortbewegung ides Thieres dient; bey einigen aber ift der Mund auch mit feften, kalkartigen oder hornartigen, bey den verlchiedenen Gattungen verfchiedent. lich gebildeten, Kinnladen verlehen. Manchnal ift der ganze Mund vorz kouifchen, langen zahlreichen Frefsfpitzen umgeben.

Der Darmkanal geht meift gerade von dem Munde zum After, aber béy jedem Körperringe hat er eine Art von Einfchnürung, wodurch inwendig eben fo viel Falten hervorgebracht werden.

Die Bewegungswerkzeuge find fehr verfchieden; bald ift der Wurm in einer kalkartigen Röhre eingelchloflen, welche entweder aus der Oberfäche des Körpers auslchwitzt, oder von Schaalenftüicken, Sand und andere Subftanzen gebildet wird, die durch eine klebrige in Waffer nicht auflösliche Materie zulammen gehalten werden; bald ift der Körper nackt und dann bewegt er fich zuweilen mittelit leiner beiden wechfelsweile auf den Boder anhaltenden Körperenden ' oft ift der Körper auch mit fteifen in verlchiedener Richtung litzenden Borften bedackt, die lich auf den Boden fiützen, wenn das Thier vermittellt der Contraction leiner Körperringe kriecht.

Einige Arten haben noch Organe wie Augen; den meiften aber fehlen fie. Ihre anderen Sinnesorgane kennt man nicht, obgleich fie für Geräufch und Gerüche Sehr empfindlich find.

Die Generationsorgane find bey den Würmern fehr verfchieden. Einige find Hermophroditen wie die Schnecken, bedürfen aber einer wechfelfeitigen Begattung, z. B. die Endobranchien, welche Eyer lègen, oder deren Eyer in ihrem Körper auskommen. Andere find, 'wvie die Acephalen unter den Mollusken, Androgynen, fie fcheinen fich felbft befruchten zu können. 
Würmer.

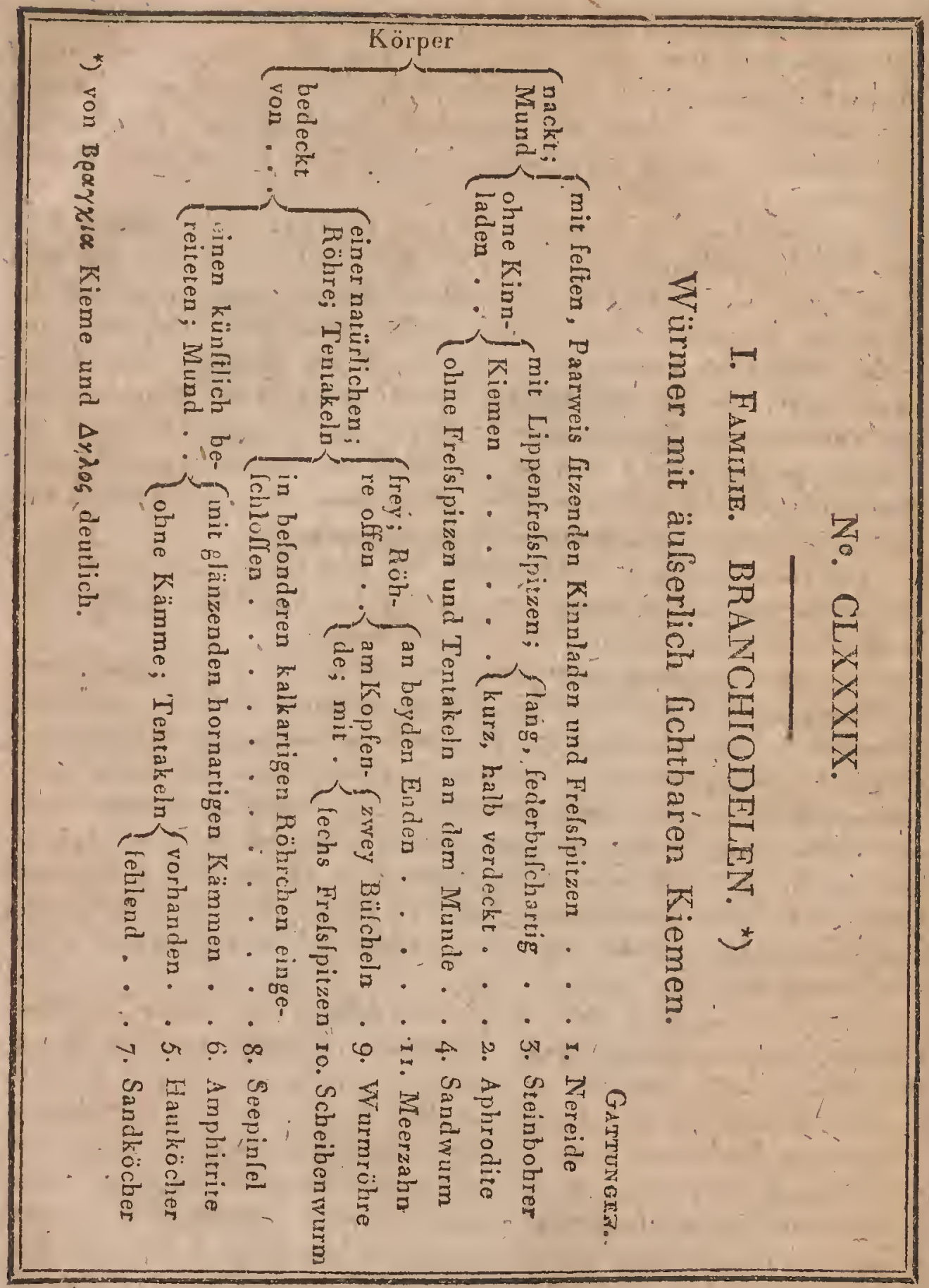

\section{BEMERIUNGEN' ZUR' CLXXXIX. 'TABELLE.}

Die Branchiodelen find von einander fehr verfchieden; die meiften leben im Merre. Einige lchwimmen frey und willkïrlich, oder verbergen fich in Löcher im. Trieblande; andere find in Robren eingelchlofen. Diele beyden Verichiedenheiten lcheiren grofen Einduls auf die Lebensañ 2 u baban. 
I. Die Nereiden (nereisi $L i n n$. z. B. ner. verficolor) Find auch of Seeskolopender genannt wordon, was auch ihre flache Form ausdrückt. Ihr Körper beftebt aus einer grolsen Zahl von Ringen die auf je ? r Seite mit Borltenbüfcheln beletzt find. Ihr Mund ift überdem mit Frelsfpitzen verfehen, deren Zahl nach den Árten verfchieden ilt.

2. Die Aphroditen oder Seeraupen (aphrodita L.z. B. aphrodic: aculeata) haben die Kiemen mit häutigen aber fchuppenförmigen Blättern bedeckt und überhaupt diefe Organe niclıt felir entwickelt. Obgleich diefe Thiere eigentlich keine Kinnladen haben, fo bemerkt man doch, dals fie oft den Anfang ihres Nahrungskanals umgeftülpt hervortreiben, welcher dann, wie der Magen der Kreble mit zahnartigen Organen befetzt ift.

3. Die Amplinomen oder Steinbohrer (amphinome Brugieres) unterfcheiden fich durch das auf der Tabelle, angegebene welentlich. Z. B. aphrodita roftrata $P$ a ll as.

4. Der Sandwurm, (arenicola $L a m a r k$ ) ift der Linneilche lumbricus marinus; diefer Wurm hat weder Kinnladen noch Fühlfäder und nur auf der Hälfte des Körpers ift er mit Kiemen beletzt. Die Ringel des Körpers lind lo, daf́s von fünt zu fünf allemal ein gröfserer folgt auf welchen Kiemen und Borften litzen. Die Cirkulation hat Cuvier im Bull. des fciences No. 64. Reils Archiv Bd. belchrieben.

5. Die Terebellen (terebella $L$ in $n$. $L a m$.) haben einen zylindrilchen Körper und leben in Röhren vonizulammengeklebten Sande. Man ift über die Charakteriftik der Gattung und die dahin gehörigen Arten noch nicht ganz einig. : Z. B. tereb. quinqueleta.

6. Die Amphitrilen (amphitrite $M$ ïll er) liaben den'Nund mit zwey kammartig gebildeten Hornblättern verfelıen, die oft wie Gold glänzen. Es ift dies der Hauptcharakter und der einzige, der lie von der vorigent Gattung unterfcheidet.

7. Die Sandkücher (Sabella Linn.) haben mit den beyden letatge* nanuten Gattungen grolse Aehnlichkeit. Linné hat den Namen blols auf die Scheiden' angewandt; er rechnet dabin die Arten ohne Frefslpitzen und Kämme. $Z$. B. amph. veutilabrum L.

8. Die Seepinfel (penicillus z. B. Cerpula penis L.) ift nur der Schazle nach bekannt; aber nuan kanu aus der Form derlelben auf die des 'I'hiers woll einen Schlufs macheu. (?)

9. u. 10. Die Darmröhren (lerpula L. z. B. Serp. contortuplicata) und die Schcibenwïrmer (fpirorbis $D a u d i n$ ) z. B. lerp. \{perorb. J. kommen fehr mit einander überein. Oft findot man lie an felten Seekör. pern, Schaalen, Madreporen u. dergl. fefiningend.

r. Die Gattung Meerzahn (dentalium Linn.z.B. D. elephantinum) hat ihren Namen von der Form der Röhre erhalten, woria dą Tlier eingelchloflen ift und welche nan mit einem Zahn verglich. Dite Röh Af ift nicht felt; das Thier fchleppt fie mit fich und foll fogar willk ührlich Ge verlallen kouner. 


\section{No. CLXC.}

\section{FAMILIE: ENDOBRANCHIEN. ${ }^{*}$}

\section{Würmer mit äufserlich nicht fichtbaren Refpira-} tionsorganen.

Gitrungen.

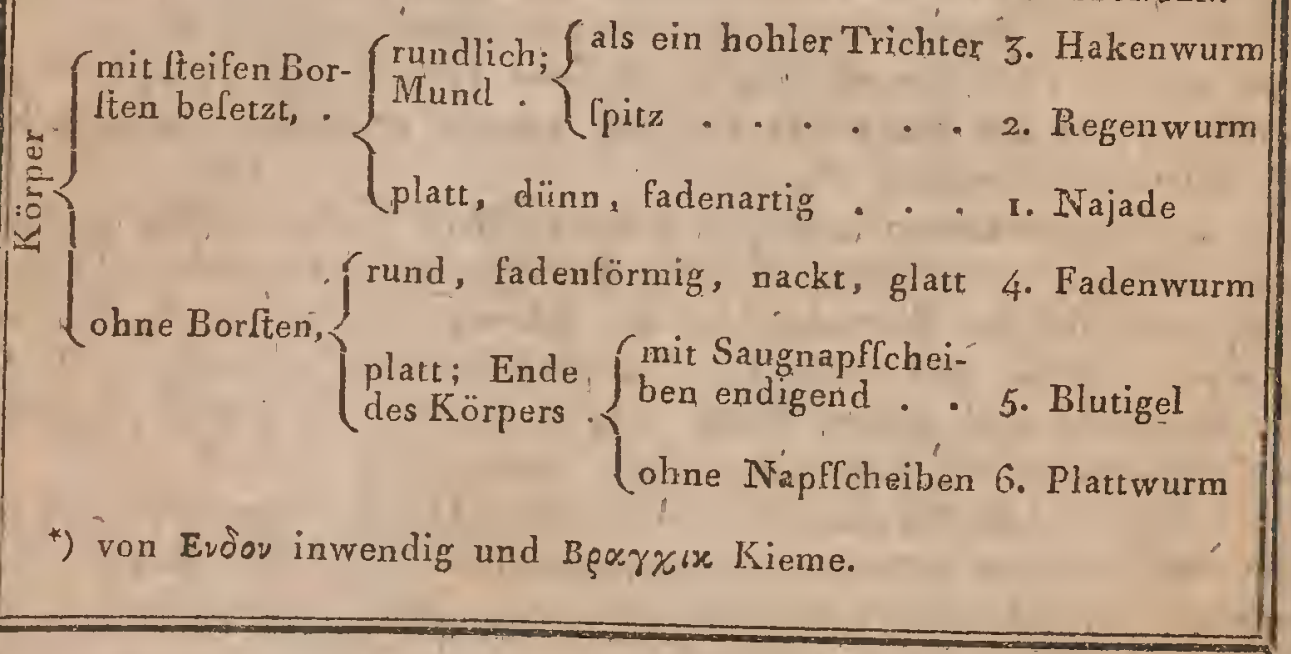

\section{BEMERKUNGEN ZUR CXC. TABELLE.}

Die Endobranchien kennt man weit weniger genau, als die Würmer der vorigen Familie mit fichtbaren Kiemen. 'Die meiften dieler Thiere leben wie lchon angegeben im Walfer oder in feuchter Erde. Keine einzige Art bildet fich Röhren. Man hat fie noch in zwey Unterabtheilun. gen gebracht, die mit der Lebensart der Thiere Uebereinftimmung zeigen.

r. Die Najaden (nais L. z. B. n. procoscidea) fcheinen den Uebergang von der einen Familie zur andern zu machen. Es find lehr kleine Thiere, die. man unter Steinen in Bächon findet. Ihr Körper ift lang, platt, dünn, durchfich!ig aber mit kleinen Büfcheln oder Seitenhaaren verlehen. Einige Arten haben in der Nähe des Kopfes ein Paar fchwarze Punkte, die man für Augen gehalten hat.

2. Die Regenwürmer (luinbricus L.) find zylindrilch lang, klebrig, von fleifhigen zulammenzichbaren Ringen gebildet. Das Kopfende ift fpitz und kegelförmig, das Afterende platt Itumpt. Die Haarbülchel, welche auf den Ringen fitzen, find lehr kurz und kaum merkbar. Sie haben beyderley Gefchlechtstheile in einem Individuo vereinigt und begatten fich meilt über der Erde; fie legen Eyer. Z. B. lumb. terreftris L. 
3. Die Hakenwiirmer (Thalaflema Cuvior z. B. Lumbr. thalaflema) unterlcheiden fich vorzïglich durch die Form des Mundes, der einem konilchen Trichter gleicht, durch die Form des Hintertheils des Körpers, was dicker als das Vordertheil'ift, und befonders durch zwey kleine ant Halfe fichtbare Haken, fie halten fich amUfer des Meers, wie unfere Regenwürmer in der Erde, auf.

4. Die Gattung Fadenwurm (gordius $L i n n . z . B$. gord. aquaticus) begreift kleine fehr lange im Wafler lebende, haarähuliche Würmer; fie haben die grölste Aehnlichkeit mit dem Zwirnwürmern die nur im ln. nern von Thieren vorkommen.

5. Die Blutigel (hirudo Linñ. z. B. hir. medicinalis) untenfcheiden fich von den bisher betrachteten Wurmgattungen durch die Tellerförmi. gen Enden ihres Körpers, womit das Thier fich wie mit einem Schröpfkopf auslaugt; ihre Haut ift ruuzlich und lederartig aber oft mit einem klebrigen Schleim überzogen, wodurch fie fanft anzufühlen ift. Der Mund ift dreywinklich, mit drey Ichneidenden, Cägeartig eingelchnittenem, Zäh* nen bewaffnet. Sie nähren fich von dem Blute der Thiere, in deren Haut fie einen dreyeckigen Einlchnitt gemacht haben, aus welcher das Bluc gleichlam hervorgelogen wird. Einige Arten find mit Augen verfehen, deren Zahl verlchieden ift. Sie haben beyderley Gelchlechtstheile wie die Schnecken. Sie bringen lebendige Junge.

6. Die Plactwürmer (planaria Linn. z. B. pl. rolea) fehen kleinen Blutigeln ähnlich; im Ruhezultande ift ihre Geftalt oval. Die meiften Arten find milchweiss oder durchlichtig. Das Vordertheil des Körpers ift zuweilen' mit einem Auslchnitt, zuweilen mit zwey.ohrförmigen Tentakeln verfehen. Sie legen Eyer. Man fieht unter ibrem Körper zwey Oeff. nungen, von denen man die eine für den Mund die andere für den After hält. Einige Arten haben'Augen orler fchwarze Punkte, die man für die Organe des Gefichtslinnes gehalten hat, deren Zahl nach Mïllers Beobachtungen von $z$ zu 8 , variirt.

Ende der Klaffe der Würmer. 


\section{No. CXCI.}

\section{Klasse. ZOOPHYTEN. \\ Rückgrathlofe Thiere, ohne Nerven, ohne Gefülse ohne artikulirte Glieder.}

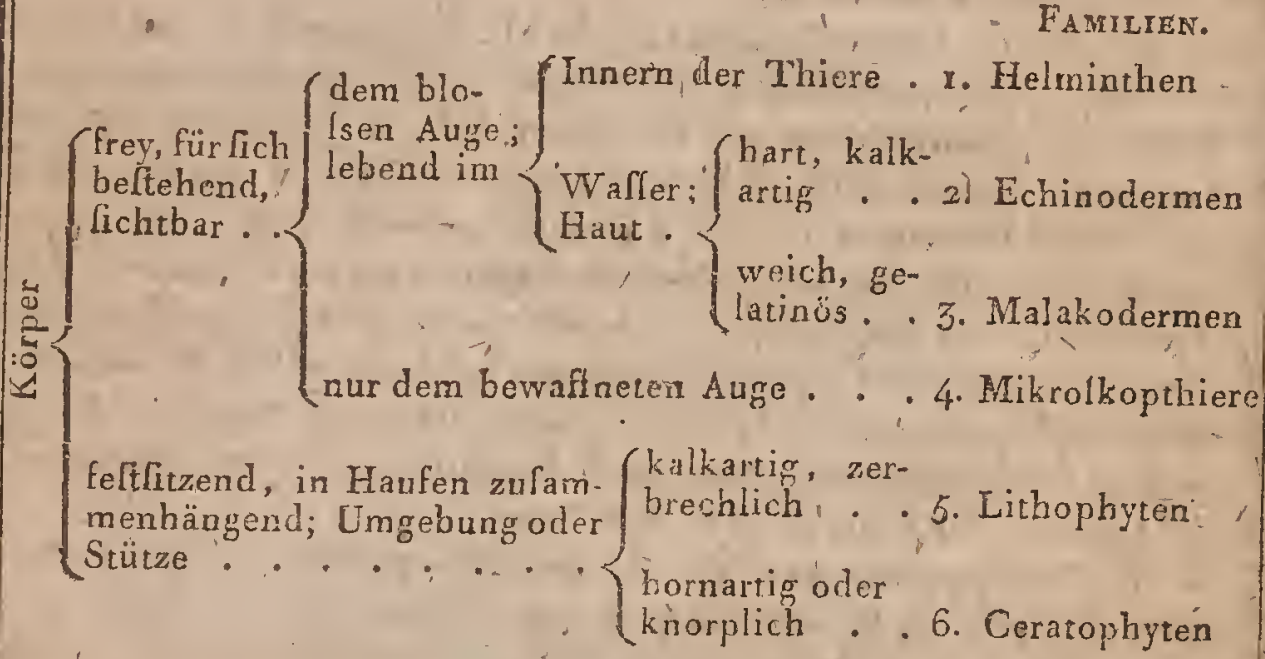

\section{BEMERKUNGEN ZUR CXCI. TABELLE.}

In der Clafle der Zoophyzen lind Thiere zulammengeltellt, die unter einander weit weniger Uebereinfimmung zeigen; als die der anderen Clallen. Es ift logar bey dem jetzigen Zultande der Zoologie noch ganz unmöglich, len Charakter eines Znophyten ganz beftimmt anzugeben. Sie merlcheiden fich von allen anderen organifirten Wefen durch zwey Eigenthümlichkeiten. Die erfțe ilt, mit ihrem ganzen Körper, oler wenigltens mit einem Theil deflelben den Ort verändern zu können, und ihre Nahrung in ihrem Innern mit fich zu nehmen, wodurch fie fich ron den Vegetabilier unterfcheiden; dio zweyte ift, dals fie aller Organe, die man bey andern Thieren findet, die der, Digeftion und Bewegung ausgenominen, beraubt zú Ceya fcheiren. Sie haben kein Rückgrath, und auch keine inneren feften Hölen zur Aufnaisme und Sicherumg von Eingeweiden. S:e haben weder Gefälse soch befondere und deutliche Refpirationswerkzeuge, noch Hirn, noch Dervan; nock anclere Sinnes-Werkżeuge als Gefillts orler Taftorgane. Sie haben knine artikulirten Glieder, und boice volldandig entwickelten Gonerubionsorgane. 
Alle diefe Thängel bilden noch keine Verwandtichaft für die hiex zulamméngeftellten Wefen die hier vielmehr durch ein blos künftliches Syltem vereinigt find.

Der Name Zoophyterz d. h. Thierpllanzen, war ins befondere den zwey letzten familien diefer Claffe beygelegt, weil fie wirklich wie die. Pflanzen feftitzen, und auch äufserlich ganz das Anlehn derfelben haben. Aber indem man diefe Idee auch auf die innere Organifation übertrug, wandte man den Namen in einer weiteren Ausdelinung an und belegte damit-alle diejenigen. Wefen, deren Leben aus einer Reilie von Erlcheinungen befteht, die ganz den in den Pflanzen vorkommenden ana$\log$ find.

Ihre Nahrung nehmen diele Thiere gewöhnlich durch Oeffnungen auf, deren Zahl oft auf mehrere Hunderte fteigt, und die die Stelle von. Rinden-poren vertreten. Einige find Hermaphroditen, die meiften zeigen gar kein belonderes Gefchlecht, pllanzen fich durch Ziveige, Sproflen, oder durch Trennung gewifler Theile, ihres Körpers fort. Llire Eyer, wenn fich deren finden, find äulserft zahlreich; und gewöhnlich lïirbt die Nutter nach dem Eyerlegen, oder die Theile, welche zur Entwicklung der Keime gedient haben, trennen fich wenigftens von dem lebenden Körper wie dieBlumen der Pflanzen ab. Sie athmen durch dié Oberfäche und haben kein befonderes Organ, wodurch Flüfligkeiten in ihrem Körper umhergetrieben' würden.

Alle diele Wefen leben und entwickeln fich an feuchten Orten. wo ihre Nahrungsmitttel ihren Bedürfniffe von felbft gleichfam entgegen kommen. Ihre Lebensart ift übrigens nach den Familien verfchiedell.

So finder man in der Familie der Eingeweidewürmer gewöhnlich melir oder weniger-faden - oder bandförmige Wefen, die im Innern anderer Körper und in gewiffen Stellen zu leben beftimmt find; aber ihre Organilation ift im Ganzen fehr komplizirt. Die meiften habeǹ nur einen einfachen Mund. Der Darmkanal ift ziemlich deutlich; einige Icheinen Nérven zu haben, fich den eigentlichen Würmern zu nähern, und fich von ihnen nur durch den Mangel der Cirkulations - und Refpirationsorgane zu unterfcheiden.

Die zrwey folgenden Fámilien hahen auch einen deutlichen Darmkanal , und obgleich man keine Cirkulations- und Relpirationsorgane wahrnimmt, fo find auch ihre Bewegungswerkzeuge lehr entwickelt und fie können leicht den Ort verändern.

Die Mikroskopifchen Thiere find noch zu wenig bekannt um ihnen den Platz anzuweilén, den fie vermöge ihrer Organilation in der Leiter der Welen einnehmen können. Die, zwey letzten Familien- Icheinen die drey Reiche der Natur mit einander zu verbinden. 


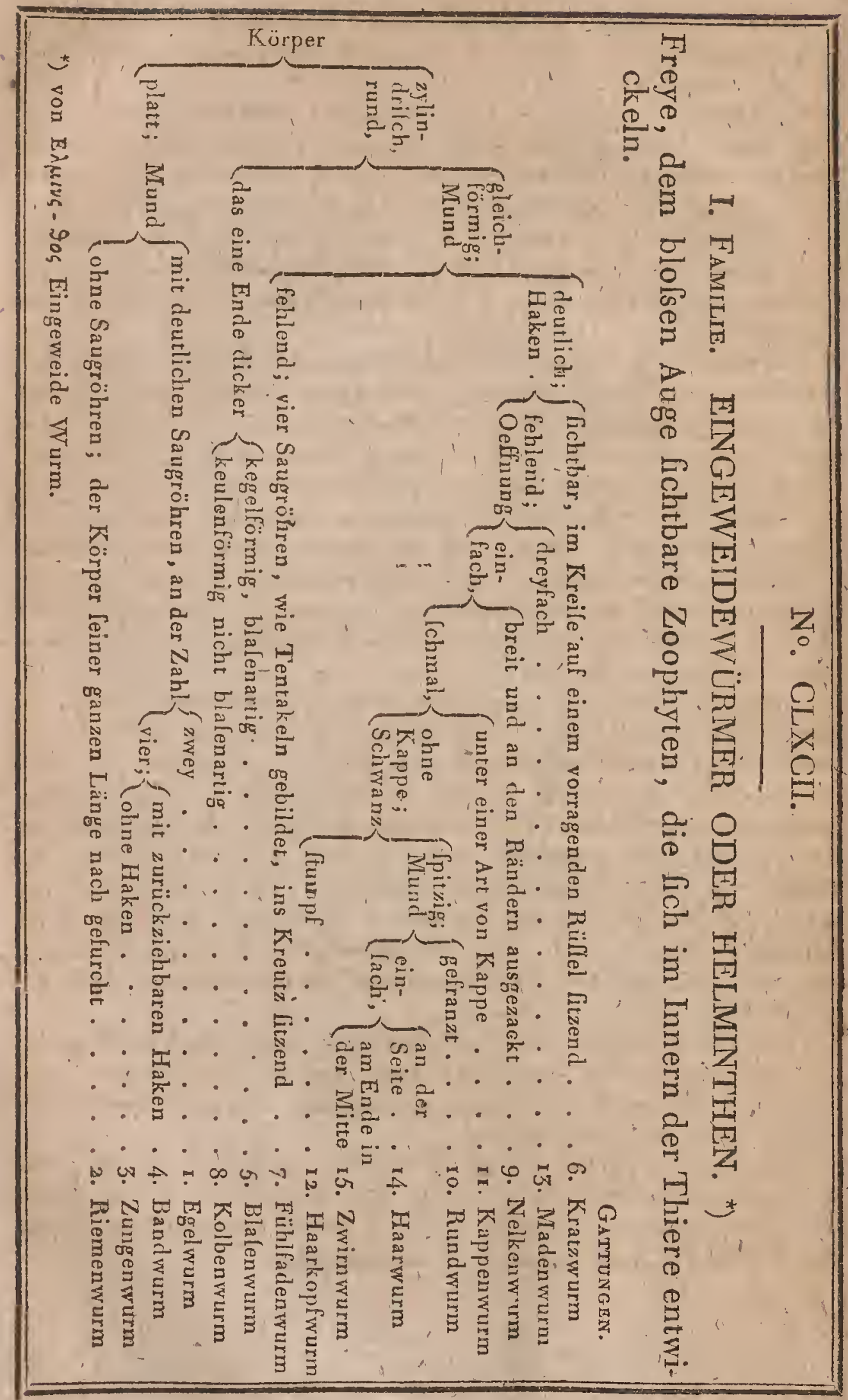




\section{BEMERIKUNGEN ZUR CLXCII, TABELLE.}

Die Eingeweidewïrmer find durch Form und Organifation fehr von einander unterfchieden. Dafs fie fich alle an einerley Orte, nemlich im Innern der Thiere entwỉckeln, ift das einzige ihnen allgemein eigne, worauf der Naturforfcher eine allgemeine Anficht gründen karin. I. Die Egelwürmer (fasciola L. z. B. f. bepatica) finden lich hauptIächlich in_der Leber der rückgratbigen Thiere. 2. Die Rimenwïrmer (ligula Bloch z- B. 1. avium Bl.) find bisjetzt nur in der Bauchhöhle der Wallervögel und Filche angetroffen. 3. Fröhlich ift der einzige (?) Schriftfeller, der den Zungenwurm (linguatula) belchrieben hat, den er in der Lunge eines Hafen fand. Z. B. Ling. ferrata. 4. Die Bandwïmer (taenia L.) haben ihren Namen von der Plattheit und auIserordentlichen Länge des Körpers erhalten, den man mit einem Bande verglichen hat. Z. B. taen. Soliunı. 5. Die Blafenwï̈rmer (Hydatis Lamark) gleichen kleinen mit Wafler gefüllten Blafen, bey denen man fehr genau nachluchcn muls, wenn man den Kopf entdecken will. Man findet fie nie im Darmkanale, aber in allen andern Hölen und felblt in der Subftanz des Hirns und der Muskeln. Sie verurfachen gefährliche und oft tödtiche Krankheit. Z.B. taenia hydatigena uhd cerebralis. 6. Die Kratzwïrmer erinnern fchon durch ihren Namen (ehinorynchus) $M$ ï ll.) an ihren. Hauptcharakter; fie finden fich in Menge in den Eingeweiden der Thiere. Z. B. E. gigas Bloch. 7. Bosc hat die Fühlfa: denwïrmer (tentacularia) nach Würmern belchrieben, die er in der Leber und an den Eingeweideñ eines Stutzkopfes fand. Tentac. coryphaena. 8. Die Kolbenwïrmer (lcolex Müller) find fehr kleine Wurmarten, die in den Därmen der Eingeweide der Fifche angetrofien werden. Z. B. Scolex pleuronectis M. 9. Die Nelkenwïrmer (caryofhyllaneus Gö́cze) begreifen nureine Art in fich, welche bey einigen Karpfenarten angetroffen lind. Z. B. car. piscium H. xo. Die Rundwürmer (ftrongylus Mülller) fcheinen blos in dem Darmkanale der Wiederkäuer und Pferde vorzukommen. Z. B. Strong, equinus. 1x. und 12. Die Bildung des Mundes hat den Kappenwürmern dielen Namen verfchafft (cucullanus Müller cuc. marinus;) lo wie die Haarkopfwïrmer (trichoceplualus, Trichuris, ) ihren Namen' erhalten haben, um damit die haaràrtige Verlängerung ibres einen Körperendes anzudeuten. Z. B. Tr. hominis. 3. Die Madenwiumer (ascaris Linn. leben in dem Darmkanal des Menlchen und anderer Thiere. Z. B. asc. lumbricalis und vermicularis $L$. 14. und 5. Die Haarwürmer (crino Lamark z. B, crino truncatus) und die Zwirnwürmer (flaria, MüL ll er z. S. flaria equi,) zeigen die grölste Uebereinltimmung, und unterlcheiden fich nur durcli die verfchiede. ne. Grölse die Lie erreichen, und belonders durch die Lage des Mundes. 


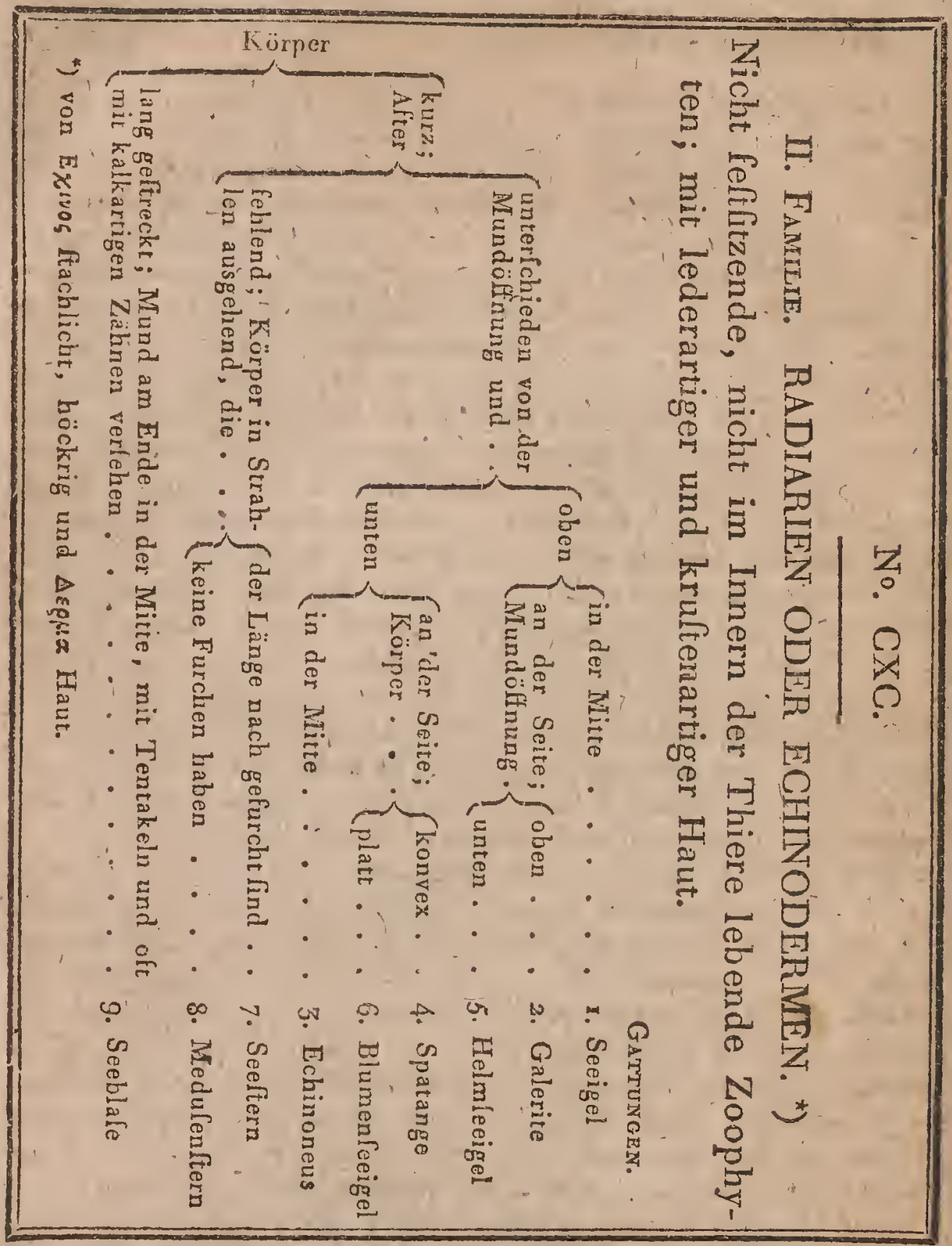

\section{BEMERKUNGEN ZUR CXCIH. TABELLE.}

Die zwcy Namen der gegenwärtigen' Familie drücken fo ziemlich die Eigenthümlichkeit der darunter begriffenen Thiere aus. Alle Echinodermen haben eine lederartige Haut, die von Löchern durchbohrt ift, we'che von einem Mittelpunkt aus in divergirenden Reihen, wie die Strahlen. eines Sterns, laufen. Aus diefen Löchern, derén Reihen man Günge (ambulacra) nennt, kommen zurückziehbare Tentakeln hervor, welche 


\section{Zoophyten.}

dazu dienen um den Ort zu verändern oder Gegenftände zu halten. Alle haben eine innere Höhle ungetähr in der Mitte des. Körpers, deren äulsere Oeffnung mit, meiftens fünf, kalkartigen, wie Kinnladen beweglichen Zähnen, befetzt ilt. Sie haben auch, blätrige Organe in dem Körper, die zur Relpiration beftimmt zu Ceyn fcheinen, und traubenarig fitzende Bläschen, die man für Generationsorgane gehalten tiat.

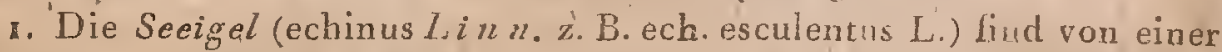
wahren kalkartigen Schaale umgeben, welche aus einer Menge kleiner, in einander greifeuder, nach den Arten verfchiedentich geformter Stückchen beftehen. Es find dies eyerlegende Thiere; ab lie aber Hermaphro. diten find weils man nicht.

2. Die Galericen (galerires, $L a m a r k$ ) ent Iprechen den Linnéilchen Seeigeln, deren After nicht in der Mitte der Schaale ift. Z. B: echinus vulgaris L.

3. Die Kuckenfeeigel (echinoneus Lamark) unterfcheiden fich von den andern Seeigeln curch die platre Form ihrer Schaale, und durch den falt im centro liegenden After. Z. B. echinus cycloftomus L.

4.-Die Spatangen (fpatangus Lamark) find auch Seeigel, deren Mund- und Afteröffung anders als bey den zwey vorhergehenden Gatsungen angebracht find. Z. B. echin. Cpasagus. (?)

5. Die Helmnfeeigel (calficlulu's $L$ a $m$.) kaben keine vollftändigen Gänge, und ihr Mund liegt wie bey den Galeriten. Z. B. E. caribaearum.

6. Eben fo verhält es fich mit der Gattung die $L, a m a r k$ unter dem Namen clypeafier,.. Blumenforigel aufgefübrt hat und welche fich den Seelternen fehr nähert. Z. B. Echin. rolaceus.

7. Als Li $n$ né die Gattung Seeftern (afterias) auffellte, begriff er darunter alle lederhäutigen Stralilenthiere, bey denen Mund und Afteröfnung in eins waren, Lamark hat den Namen Seeftern aber aul die Arten eingelchränkt, bey welchen die Itrahlenförmige Abtheilung des Körpers unten mit einem der Läuge nach laufende Kanale oder einer tiefen Furche verlëhen find. Ihre Lebensarı ift falt dielelbe wie die der Seeigel.' Z. B. A. rubens.

8. Die Medufenfeefterne (ophiura I a mark) haben die Abtheilungen des Körpers wieder in Abtheilungen gefpalten diefe wieder in feinere u. .. w. ; unteu find diele Abtheilungen platt, ohne Furche oder Kanal. Z. B. alterias caput medulae Li.

9. Die Zitterblafen oder Seeblafen (holothuria $L_{i} n_{n}$ ) z. B. holo. thuria tubulola, unterfcheiden lich von den bisher betrachteten Radiarièn darin, dals fio einem langen Cylinder ähnlich fehen, an deflen eineın Ende man den mit fternartig fitzenden Zähnen verfehenen Mund fieht, umgèben von zufammenziehbaren und oft uneàdlich zeräftelten Anhängfeln. Eins der hiehergehörigen Thiere bringt lebendige Junge, indem die Eyer im Innera des Körpers auskonimen. 
No. CXCIV.

III. FAMILIE: WEICHHÄUTER ODER MALACODERMEN. *)

Weiche, nicht im Innern von Thieren lebende, Zoophyten; mit gelatinö ${ }^{\circ}$ m nicht ftachlichtem Körper.

If Cinem Erdlchwamm; Mund-feinfach . . 1. Qualle,

rohre •. • • • • ' ingrolser Zabl. 2. Wurzelmaul

einer Blume . . . . . . . . 5. Aktinie

$\frac{2}{6}$ einer gerippten Melone . . . . . . . 3. Melonenqualle

( einem Stück Geld . . . . . . 4. Porpita

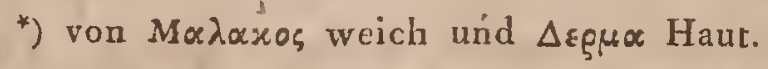

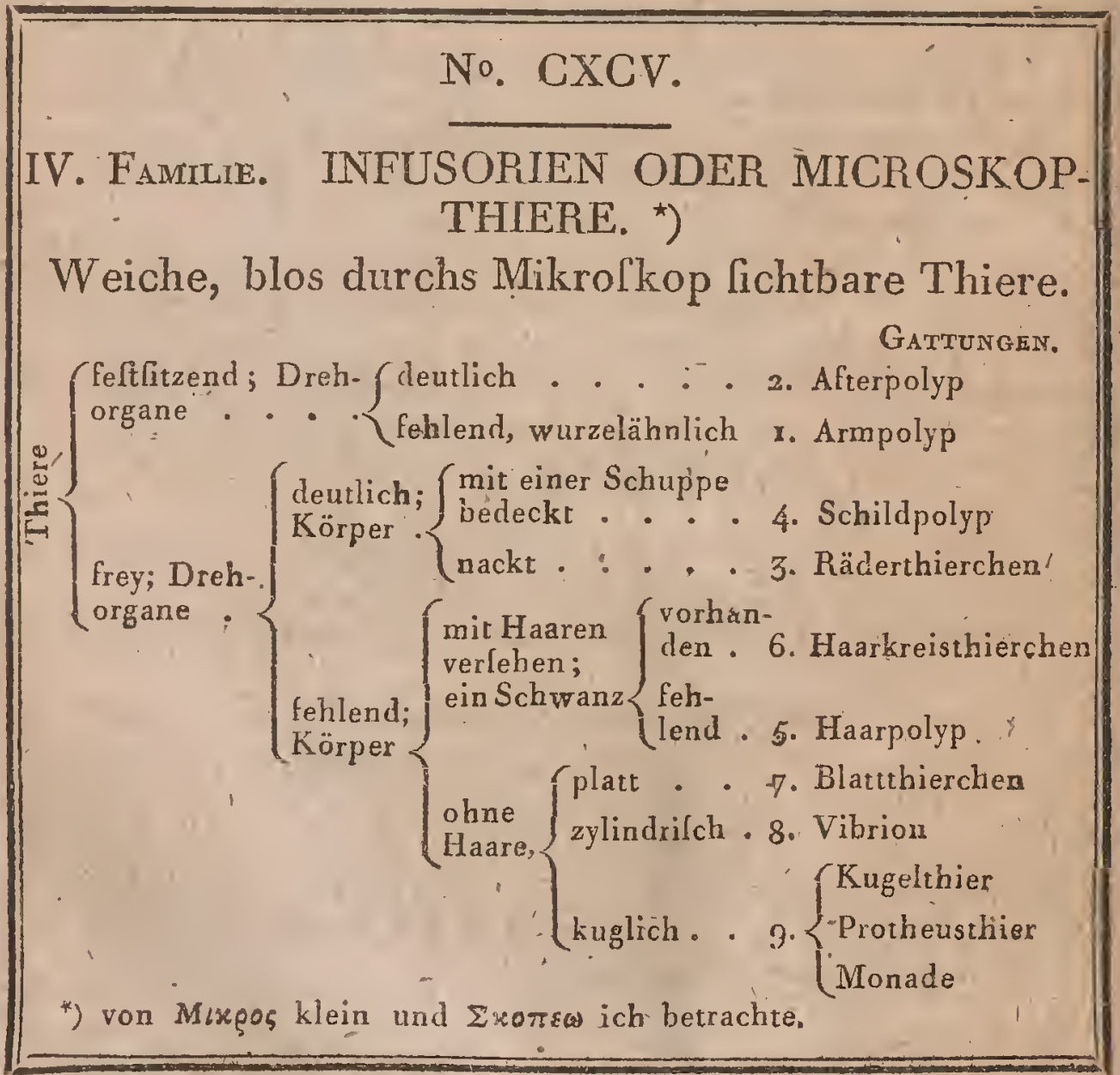




\section{BEMERKUNGEN ZUR CLXCIV。'TABELLE.}

Die Organifation der in der Familie der Malakodermen aufgeführten Zoophyten ift noch lo wenig behannt, dals man, um lie zu beltimmen, die äulsere Form des Körpers mit anderen bekannten Gegenltänden vergleichen mufs.

r. und2. Die Quallen oder Medufen (medufa $L i n n$. z. B. med. auria) und die Whrzelmäuler; (hhizoftoma, Cuvier) haben viel ähnliches in der Form. Es find Mallen, die wie Fleilchgallerte zittern, oft gefarbt und lehr grols find. Sie flottiren im Mcere, und lehen, durch ihre obere convexe! unten conkave oder platte Form, grofsen, unten mit wurzelartigen Ankängleln verlehenen Scluwämmen, Champignons ähnlich.

3. Melonenquallen (boroe Brugieres) find den Medulen verwandt, unterfcheiden fich aber durck die hervorragenden Ribben, die. längs der Haut laufen, und mit Haaren beletżt find, welche das Thier in feiner fchwimmenden Bewegung untediüzen; einige Arten haben FühlPaden. Z. B. Medula infundibulum, Müller (Zool. Dan.)

4. Die Gattung Porpica (porpita, $L a m a r k$ gleicht auch den Qual= len, hat aber nur lehr kurze und platte T'entakeln und einen lehr platten Körper. Man glaubt dals von ihnen'die unter dem Namen Nummulites bekannten Steinen kommen.

5. Die Aktinien oder Secanemonen (actinia Linn. z. B. act. rufa) find zwar gewöhnlich auf Fellen fitzend, 'künnen aber ihren Ort verändern. Lamark unterfcheidet noch unter dem Namen Zaantha die Arten die mit einer belonderen Röhre verfehen, und in grolser Menge vereinigt find. Z.B. Actin. lociata Ellis.

\section{BEMERKUNGEN ZUR CLXCV. TABELLE.}

Blols um keine Lücke in diefem Werke zu lallen, find hier auch die Infulorien aufgeführt, deren Formen man nicht mit andern zu gleicher Zeit zu vergleichen im Stande ift, zu deren Kenntnils man allo auch nicht, wohl einen analytifchen Weg cinlchlagen kann. Man muís über diele Welen durchaus die Werke von Mïller, Pallas, $B a L$ cker, Röfel, Trembley, Spalanzani und anderer geduldiger und gefchickter Beobachter, nachlclen; erft durch dalelbft aufrezeichnete genaue Details erbält man einigermalsen eine Vorltellung von dielen Welen, die fich nur in Flüfigkeiten entwickeln, und deren ungeheure Menge, fonderbare Bildungen, und Ichnelle Bewegungen, den Beobachter in ungewöhnliches Erftaunen letzea und erhalten. 


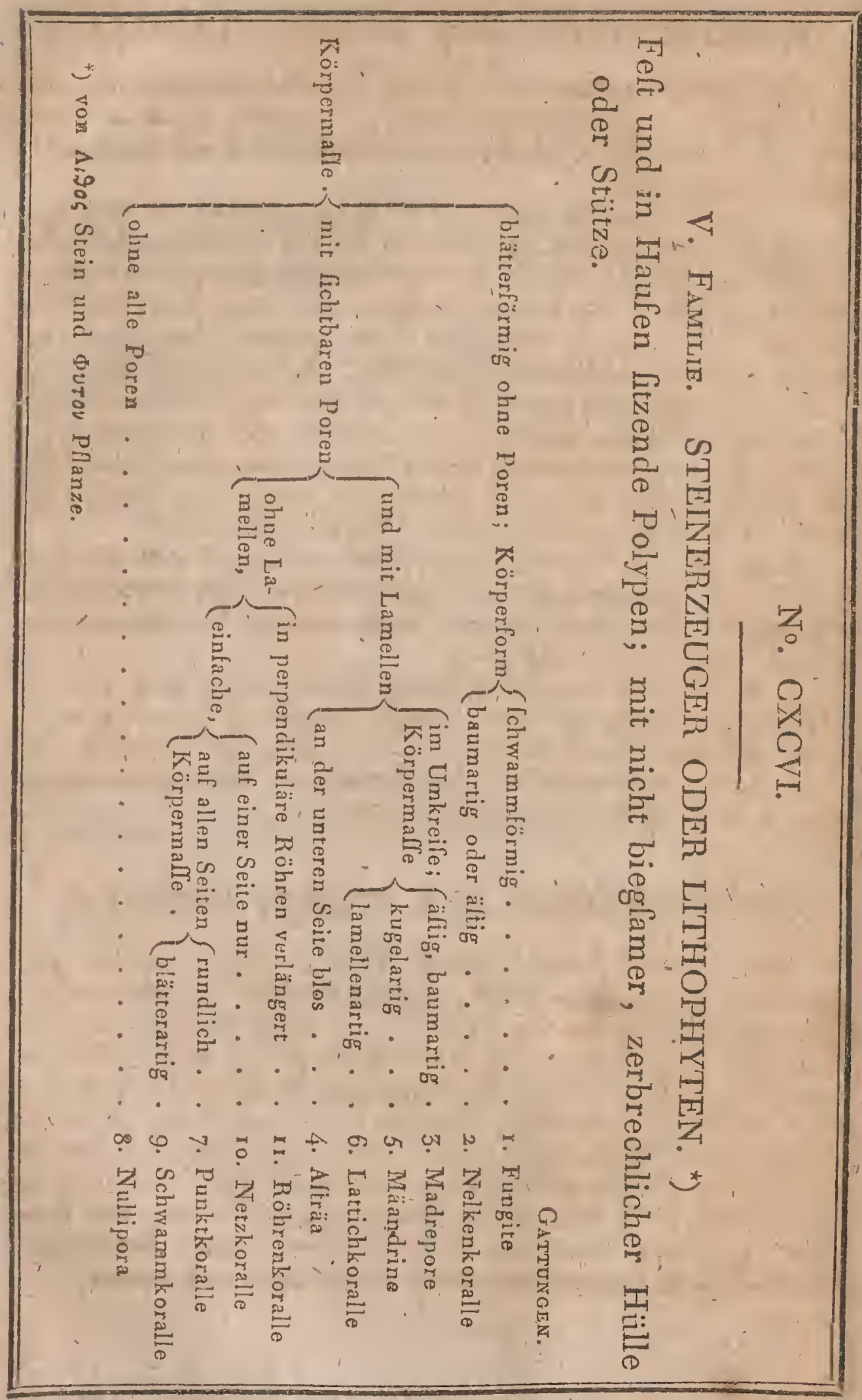




\section{BEMERIUNGEN ZUR CXCVI. TABELLE.}

Die Lithopiyten haben áuch den $\mathrm{N}$ amen Steincrzeriger bekommen, weil in den Meeren wo lie in Menge vorkommen, ihre Anhäufung an manchen Stellen Untiefen oder Fellenriffe unter der Oberfläche des Mceres veranlalst. Die kalkartige Materie, welche ilure Bafis bildet, ift von dem Körper der Thiere lelblt, welcher die Kalkmalse ablondert bedeckt. Dieler. Körper ift dem Anlchein nach eine gallertartige gleichförmige Mallè, die oft fich in'Poren oder Röhren der Bafis fich zurückziehen Kann: Die meiften dieler Steinbildungen find äftig und Cehen Gewächlen ähnlich, daher der Name Lithophyten. Man kennt die Wohnung, das Gehäufe, der Zoophyten beffer, als die Organifation der Thiere, wodurch erftere hervorgebracht wird, fo dals auch hier nnr von ihrer Hüle oder Stütze die Rede feyn kann.

I. Die-Gattung Fungile (fungia $L$ a $m$ ark) begrcifl diejenigen 'Linnéilchen Madreporen, die ifolirt unter der Form von Schwämmen mit Blättern auf der Oberfäche vorkommen. Z. B. Madrep. fungites L.

2.'Die Nelkenkorallen (caryophyllia $L a \mathrm{~m}$.) lind auch Madreporen; aber feftlitzende und Baumälten ähnliche, deren Zweige gerieft, abgeftutzt find und in einen Blätterftern endigen. Z. B. madrep. cyathus L.

3. Die Madreporen oder Sternkorallen (madrepora L.) bilden hier eine eingelchränktere Gattung; es gehören nach der gegenwärtigen $\mathrm{Ab}$ tbeilnng nur noch die pflanzenähnlichen Steinpolypen hieher, deren Zweige zugleich mit Poren und Blätterfternen verlehen find. Z, B. mad. muricata $L$.

4. u. 5. Die Afträen (aftrea 7. P. madrep. rotulola Ellis) und Meandrinen (meandrina $L$ am. z. B. madrep. meandrites. Ellis) find auch Linnéilche Madreporen, die fich durch die auf der Tabelle angegebenep̣ Eigenheiten unterlcheiden.

6. Die Lattickkorallen (pavona La m. z. B. madrep. lactuca El'lis) find platt und ibre Hauptblätter tragen wieder andere, unregelmälsige gefurchte.

7. Die Punktkorallen (millepora Linn. z. B. M. alcicornis) lind ganz porös und ohne Blätterfterne an ihrer Oberfläche.

8. Die Nullipóren (nullipora $L a m$.) haben keine fichtbare Poren-an der Oberfläche; ihre Form ilt lehr verlchieden. Z. B. Millep. polymorpha L.

9. u. Io. Die Schwammkorallen (efchara La m. z. B. millep. foliacea Ellis) und die Netzkorallen (retepora $L a m$. z. B. millep. reticulata L.) bilden ganz zarte Blätter. Die erften lind auf beyden Seiten porös und etwas bieglam; die letztern find ganz fteinig und haben nur auf einer Seite Poren.

II. Die Röhrenkorallen (tubipora $L$ inn. z. B. tub. mufica L.) heiIsen auch Orgelpfeifen, weil ihre Maffe aus deutlichen durch kleine' zwifchen, pfeifenähnlichen Lanellen verbundenen-Röhren zulammengefetzt ilt: 


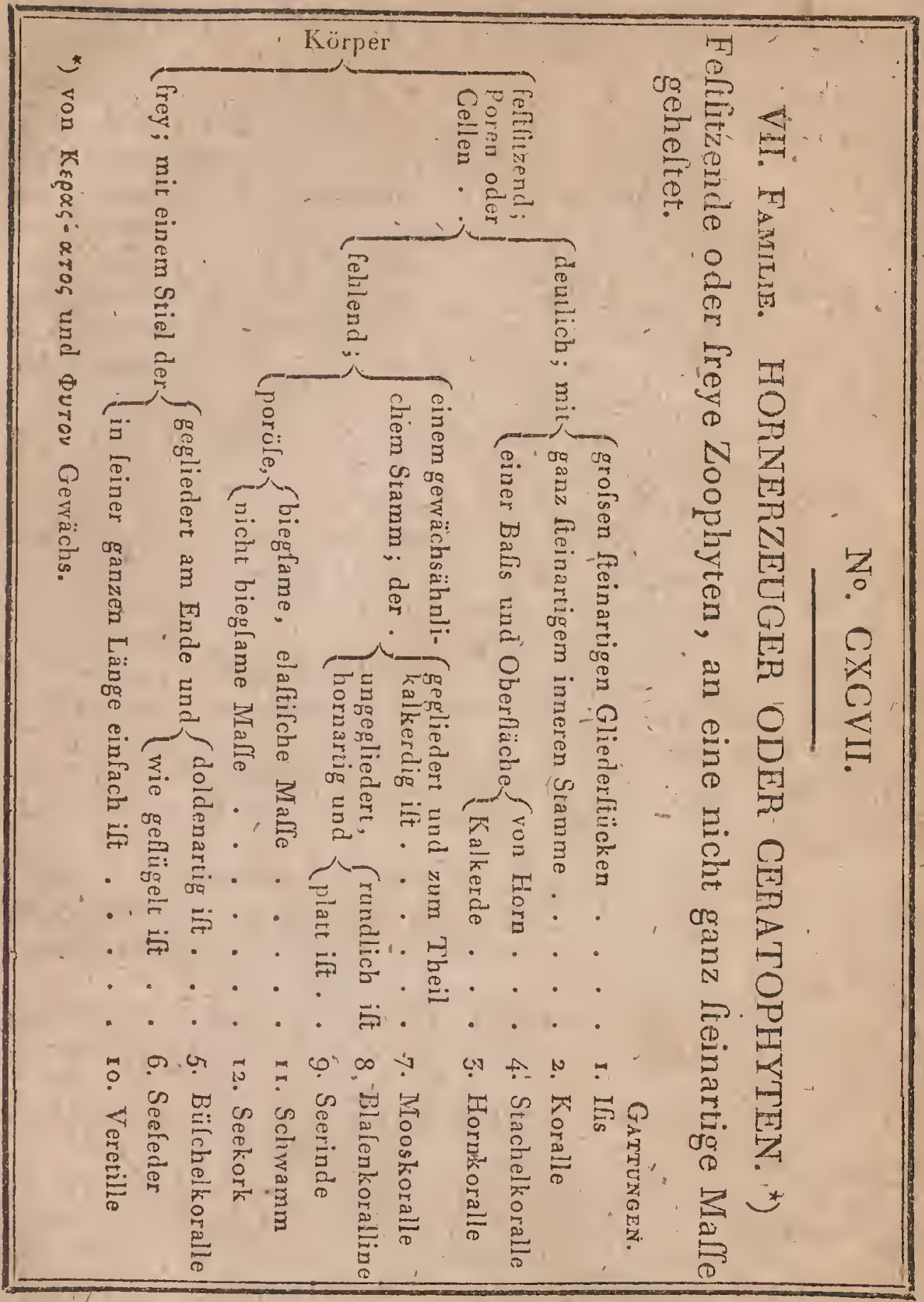

\section{BEMERKUNGEN ZUR, CXCVII. TABELLE.}

Die Ceratoplyzten fcheinen die unterften Thiere zu feyn, da fie rie die meiften Lithophytẹr, beftânảig an feften unter Waller befindlichen Körpern anhängen, und weil fie durch ihre äufsere Form die beyden Reiche organifirter Welen zu vereinigen fcheinen; auch fpielt der grie- 
chifche Namen d.h. Horupflauzen darauf an. Wirklich treten diele We: fen untér der Planzenform aul; bey den meiften find einige Theile von hornartiger Subftanz, bald die Bafis, bald der mittellte Kern ihres Stammes und ihrer Zweige, häufig fogar ihre ganze Ausbreitung. Man kennt nur die feften Theile der meiften dieler Thiere genau, und nach dieler. Art von Skelet, hat man die Gattungsmierkmale beftimmt.

r. Die Ifis oder edle Corallen '(ifis L. z. B. ifis hippuris' L.) fcheinen den. Uebergang zwifchen den Corallen und den zwey letzten Thierfarnilien zu' machen. Sie befteben aus kalkartigen, an der'Oberfläche geftreitten, ring, - oder röhrenförmigen Gliedern die in gewiffen Zwifchen= räumen durch eipen Stamm von hornartiger und fehr felter Subftanz zuLammenhängen.

2. Die Corallen corallium $L a m a r k$ ) haben nur an ihrer Balis und nur in der früheren Zeit ihres Wachsthums hornartige Subftanz. Z. B. ilis nobilis L.

3. ün 4. Die Gorgonien, Horncorallen, gorgonia L. Z. B. Gorg. ceràtophyta L.) und die Stachelcorallen (anthipates L. Z.B. A. myriophylla L.) Find von den übrigen Gattungen, vorzüglich durch das auf der Tabelle angegebene unterichieden.

5. und 6. Die zwey Gattungen Seefeder oder Federcoralle (pennata. 1a,z. B. Penn. phosphorea und Büfchelcorall (umbellularia Lam.-z. B. pennatula encrinus) unterfcheiden fich von allen andern Corallen-Gattungen dadurch, dafs ihr Körper frey ift, und an der Oberfläche des Meeres fchwimmen kann, wie die Medufen und Seefterne mit denen fie vielleicht gleiche Struktur haben.

7. Die Mooscorallen (corallina L. z. B. cor. officinalis J.) haben ein durchaus pllanzenartiges Anfehn; aber ihre Subftanz ift.kalkartig, und ift aus einer Menge kleiner Artikulation beltehend, ohne frehtbare Poren oder Zellen an der Oberflüche.

8. und 9. Die Blafencorallinen (fertularia L. z. B. fertul. tamarisca) und die-Seerinden (fluftra L. z. B. Aluft. foliacea) haben irn Gegentheil viele deutliche Zellen und ihre Sulftanz ilt durchaus horn - oder knorpelartig.

ro. Die Gattung veretillum (cuvier) hat einige Aehnlichkeit mit den Federcorallen und Bülchelcorallen, aber man bemerkt, bey den "hierher gehörigen Arten, Artikulationer.

II. und 12. Die Seefchwämme (Ipongia L. z. B. Pp.officinalis) und die Seekorke alcyonium L. z. B. alc. exos) find mit einer gallertartigen zitternden Maffe bedeckt, die mit den Thieren nichts gemein zu haben fcheinen, ałs die Nahrungsweile und die Beftandtheile, welche die Auflölung derlelben zeigt.

Ende der Claffe der Zoophyten und der analytifchen Zoologie. 

Deutfches Regifter.

Aal

Aalswels

Aaskäfer

Acanthophis

Acephalen

Achir

Achtfüfsler

Actinie

Adelobranchien

Adler

Aelfter

Aehrenfilch

Affen

Afterbiene

Afterpolyp

Afterrüfelkäfèr

Afterlpinne

Afterwespe

Agarna

Agathidie

Agnathere

Aguti

Akanthopomen

Akis

Albatrofs

Albunea

Alektriden

Aleyrode

Alipeden.

Alka

Allesfreffendo

Alpenhale

Alurne
A.

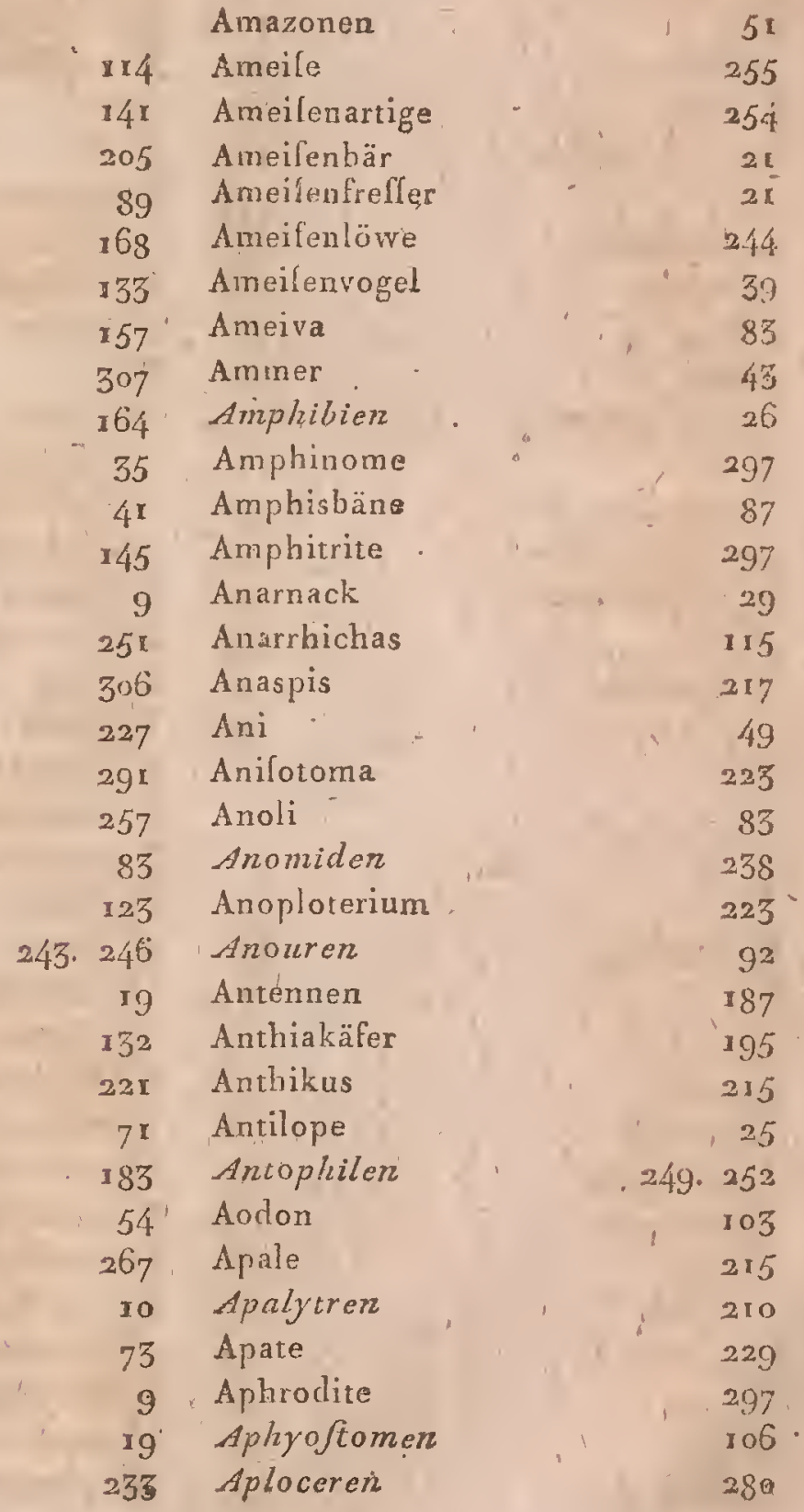


Aplyfia

Apteren

Apteronois

Ara

Araneiden

Argonaute.

Argulns

Armfinsler

Armpolyp.

Arthrocephalen

Alch

Aspidioten

Aspidophore

Aspidophoroide

Affel

Afthornwespe

Aftomen

Aftrea

Atopa

'Atraktofomen'

Atzel

Auclienopteren

Auchenoryuchen

Augenlchlüpfer

Aulter

Aufterfreffer

Aye - Aye

$B$.

Backentliege

Bär

Balänopter

Banchus

Bandfilch

Bandrücken

Bandwurm

Barlch

Bartfifch

Bartgeyer

Bartvogel

Bafilisk

Baftardbieno
165 Baltardwespe 251

286 Batrachicr

go

113 Batrachoide $\$ 17$

5t Bruchflofer , , 99

290 Bauchkieme Ior

157 Baumläufer \ 46

I77. Beilbauch $\mathbf{1 4 5}$

170 Beilkäfer . _ _ ' 229

306 Bembidion $\quad 195$

184 Bettwanze $\quad 265$

147 Beutélłachs I7

174 Beutelthier 16

$13 \mathbf{r}$ Biber $\quad$ r9

13r Biene 25 r.

293 Bienenameile. 255

257 Bienenarlige 250

284 Bienenfreller , 47

309 Bimanen 6

207 Bipede : 83

124 Birkhuhn 55

4 I Blafenfüfse $\quad 268$

r 6 Blalenkäfer 2r

$266^{\circ}$ Blalenkorallen 3Ix

199 Blalenwurm 303

169 Blafenzieher $\quad 254$

41. Blation 238

19 Blattloh $\quad 269$

Blattfuiskrabbe $\quad 79$

Blattheulchrecke - + $\quad 239$

Blatthörner. 200

Blattkäfer : 233

279 Blattlaus $\quad 269$

I5 Blattlauskäfer $\quad 235$

29 Blattlchnecke _ $\quad 163$

255 Blattchneidebienó - $25 \mathrm{I}$

I20 Blatthierchen $\quad 307$

129 Blindlchleiche : $\quad 87$

zo3 Blumenfliege 283

I33 Blumenfrefler 199

I27 Blumenleeigel $\quad 305$

35 Blumenfucher 252

5 B Blüthenfiege, , , 283

$8 \mathrm{I}$ Blutigel $\quad 299$

25I Blutfauger $\quad-264$ 
Boa

Bockkäfer

Bodianfilch

Bohrkäfer

Bombardierkäfer

Borkenkäfer-

Bor/tenkörner

Borftenfchwänze

Boltricht

Boltrichtoiden

Brachelytren

Brachiopoden

Brachvogel

Brachypteren

Branchiodelerz

Breitkäfer

Breitkrebs.

Breilfchnäbel

Breme

Bremfe

Brüllaffe

Brültie ।

Bruftioflen

Bruftspiczen

Buckelfilch

Buckellliege

Buckelkäfer

Büichelkorallen

Bufoniten

Bullee

Buro

Bufchreiher

$c_{a}$

Cálliomore

Calopus

Calyptrea

Caranx

Caranxomore

Carcinaider

Cüfio

Culiomore
89 Caloar

23r Cebrio

133. Cenogalier

209 . Centronodon

195 Centronote

229 Centropode

- 274 Centropome

288 Cephalopoder

r2r Cephalocen:-

121. Ceraiophyton

198 Ceratoplate

170 Cerochete

65 Cetaceen

56. Ceyx

$296^{\circ}$ Chalcide

22 I Cliamäleon

183 Chanos

64 Chätodipter.

279 Cheiline

284 Cheilodipter:

9 Chelonier

5 Chelys'.

99 Chetoceren

206 Chetoloxen

145 Chimäre

$28 \mathrm{r}$ Chiropteren

$22 \mathrm{I}$ Chismopnéen

31 Cleryfiden

113 Cirrhite

165 . Clio

$\checkmark 45$ Clivine

63 - Clupanodon

Cnodulon

Coendu

Columbella

Coralle

II Corallus

219 Corydoras

163 Corynet

125 Coryphänoide

125 Cosmius

380 Coffyphus

125 Crepidula

125. Crick
57

207 ,

283

$14 \mathrm{r}$

125

125

133

156

130

3 ro

285

285

28

283

83

83

145

135

127

127

76

77

274

282

105

10

104

252

143

159.

195

I. 45

223

19

167

3 II

89

I4

229

129

283

223

$\times 63$

$5 \pi$ 


\section{6}

Cucujus

Cytrloftomen

Ciyklop

Cylindroiden

Cylindrofomen.

Cypbon

Cypris

Gythere

D.

Dacliflügel

Dachs .

Dariyléen

D) aman

Daphnia

Darmrülirenwurm.

Daryt

J)alyure

Daumen

Deckfilch

Degentilch

Defphax

Delphin

Delphinapter

Dermobranchien

Dermopieren

Desman

Diapria

Dickflügel

Dickhornfalter

Dickhornkäler

Dịckkiffer .

Dickkopf

Digicigraden

Dimeriden

Diplolep

Dipieren

Dipteredón

Dolrhwelpe

Doldeukäfer

Donax

Doppelfiigel
Deutfches Regifter.

225 Doppelhalikieme $+\quad \$ 53$

ror Doppelreiher $\quad$ I69

177 Doras. 14

223 Doris : 162

138 Dornfliege $28 \mathbf{I}$

2 II Dornkäfer 233

177 Doryle $\quad 255$.

177 Drache 83.

Drachenkopf , 13 '

Dragone 80.

Drehkäfer $\quad \mathbf{1 9 7}$

Dreyzehgrille $\quad 24 \mathrm{I}$

244 Droute $\quad 57$

15 Droflel 39

130 Dügong : 27

23 Dünnfchnabel ' 64

177 Dungfliege $\quad 285$

297 Dungkäfer '20I

215 Dunkelwohner 218

17

5

I 15

113

267 Echidna 27

29 Echinodermen 304

29 Edelkoralle 312

162 Egelwurm 303

146 Eidechsfifch:- 148

15 Eichelmufchel ' i $\quad 17 \mathrm{r}$

257 Eichhörnchen $\quad$ rg

271. Einfachliorner $\quad 280$

27 Einfloflèr. . 113

227 Eingeweidewïrmer $\quad 302$

227 Einzahnlchnecke $\quad 165$

130 Eisvogel 47

12 Elephant 123

142 Elextheropomen 104

257 Eleutheropodion , 122

276 Emarginula . $\quad \mathbf{1 6 3}$

127 Endobranchicn! 298

253 Endomyche 235

201 Engdeckkäfer $\quad 2 x_{7}$

169 Enoplole 135

250 Ente 69 
Entenmufchel

Entomotillen

Entomoftrakinen

Eolide

Epifpalien

Erdflohkäfer

Erakäfer

Erotyle

Erpeton

Eryx

Eulchen

Eule

Eumorphe

Eydechle

Eyerfilch
17 Fingerfilch

249. 254 Fingerlieg

$174^{\circ}$ FingerflofJer

163 Fingerkäfer

214 Finke

233 Firole

233 Fische

233 Fifchlaus

85 Fil hotter

88 Fiflurelle

275 Flachfclinübel

35 Flachlchröter

234 Flamingo

83 Flate

rog Fledermáus

Fleifchfreffer

Fliege

Eliegenfänger

F'liegenvogel

217 Floh

272 Flohkrebs

253 Florfliege

2r9 Floflen

I 5 Flötenfifch

299 Flügeldecken

233 Flufsplerd

35 Flufsfchildkröte $76^{\circ}$

22 I Forltkäfer 23r

127 Fregattvogel 69

27 I Frolch 93

245 Frolchfilch 105

239 Frolchkrabbe $\quad 179$

265 Fruchekäfer $\quad 195$

55 Fühlfadenwnrm $\quad 303$

$\$ 05$ Fühlhorn - $\quad 187$

22. - - borftenförmiges , 193

34 - - fadenförmiges 193

209. ' - - gezähneltes $\mathbf{9 3}$

275 - kammförmiges , 193

225 - keulenförmiges 193

19 - - paternofterförmiges 193

5. $14.15-$ rolenkranaförmiges 193

206 - - Iägeförmiges 193

73 - - Icbunförmiges 193 
Deutfches Regifter.

Fünfgliedwamze

Fugenkäfer

Iingitcoralle

Furchtkäfer

Fuishoruwanze

$G$,

Galago

Galeode

Galeopitheken

Galerite

Gallinfekter

Gallwespe.

Gafteropodon

Gecko

GefäIse

Gelchwänzte (Batrachier)

Getraidekäfer

Geyer.

Giftlchlangen

Giraffe

Glaslchwärner.

Glatkïfer

Glattkiefer

Glattwespe"

Gliederköpfe

Glomeride

Glyphoramphen

Gobioide

Gobiomore -

Gobiomoroide

Goldauge

Goldfirch

Goldhäuter

Goldwespe.

Grabinfekten

Grashüpfer ,

Croppe

Grosauge

Grosknopf

Groskopf

Groskopfliege

262 Grylle

$20{ }^{-}$Grylloiden

309 Guenon

233 Gürtelaffel

263 Gürtelthier

Gymneter

Gymnomuräne

Gymnonecten

Gymnopomen

9

- Gyinnotus

29

II

305

256

257

160

85

3

94

229

33

85

25

373

229

128

253

184

293

38

32

$\times 23$

123

279

135

117

253

256

$\pi 4 \mathrm{~L}$

$13 \mathrm{t}$

149

207

$4 \mathrm{I}$

279

Haarfliegen

Haarhornkäter

Haarkäfer

Haarpolypen

Haarwurm

Habicht

Hahnfifch

Wakenkäfer

Haken wurm

Halbdeckkäfer

Halbkugelkäfer

Halskieme

Halsrüllel

Halsichild

Halsfück

Halswespe

Hamlter

Häring

Harnilchfilch

Hale

Halelhuhn

Haube

Hausvögel

Hayfilch

Hecht

Hechtgrundel

Helm $24^{\prime \prime}$

240

293

2 I

I2.

152

776

144

113

H.

Haarknopfwurm

Haarkreilsthierchen

Haarlchwanzwurm
285

234

213

303

306

306

303

503

35

I35

205

299

23 r

205

153

$266^{\circ}$

187

187

255

19

$\times 45$

45

19

55

24

54

203

149

13 I

89. 237 
Deutfches Regifter.

Helmfilch

Helminthen

Helmieeigel

Helóceren

Helode

Hemipteren

Hemipteromote.

Hepate

Heterocere

Tecerodermen

Heteromeriden

Heterofomen

Heulchrecke

Henfchreckenartige

Heufchreckenkrebs

Hiatula

Hinterleib

Hippa

Hippopotarn

Hirlch

Hirlchlchröter

Hochrücken

Hocko

Hoblfchnabel

Holobranchien

- Bauchflolfer

- Bruftioller

- Kahlbäuche

- Kehlfoller

Holakanth

Hologymnus

Holothurie

Holzbolerer

Holzfreder

Holzkäfer

HolzSpinner

Holzwespe

Homodermen

Honigbiene

Horia

Hornfifch

Hornkäfer

Horncoralle

Hornyogel.
127 Hünerarlige

302 Hïpfrikade

305 "Hufe

204 Hummel

233

260

129

181

229

85. 88

212

132

241

240

183

I 27

I 89

I 83

23

25

202

I 17

55

65

II 0

136

118

II 0

II 7

135

127 ,

305

208

230

209

273

259

84.86

$25 \mathrm{r}$

219

105

215

311

$4 \mathrm{r}$

Iabiru

Iakamar

Ibis

Igel

Igelfifch

Immenkäfer

Indri

Infuforien

Infekten

Käfer

'Kahlbïuche

Kahlrücken '

Kakatu

Kalmar

Kaloftom

Kameel

Kammkäfer

Kampagnol
52

267

5

$25 \mathrm{I}$

13

9

255

89

159

13

264

284

19

248

29

141

I.

Inlektenfrelfer

63

49

63

I5

109

229

9

306

I 86

254

$K$.

Käferlchnecke

Kahlbeufchrecke
190

163

99

239

Ir3

5 I

157

1,95

25

$2 \mathrm{II}$

I9 
Deutfches Regifter.

Kä̀guruh

Kappenkäfer

Kappenwurm

Karrlinalkäfer .

Karpfen

Kalchelot

Katzen

Kazike

Kegelfchnäbel

Kehilloffer

Kehllappenvogel

Keilfchuäbel

Kenoramphen

Kermes

Kernbeifser

Kieferfuls

Kiemen

Kiemendeckel

Kiemenfuls

Kiemenhaut

Kinkaju

Kinkhorn [chnecke

Kinnladen

Klaffunufchel

Klaffrchnäbel

Klapper\{clilange

Kleinkopf

Klettervögel

Kluppifch

Klofteroceren

Kneipkäfer

Knochenfifche

Knochenfchnabel

Knollkäfex

Knopfhornwespe

Knorpelfifche

Knurrfilch !

Koati

Kochenille

Köcherjungfer

Kofferfifch

Kolben chwärmer

Kolbenwespe

Kolbenwurm
I9 Koleopteren

$22 \dot{9}$. Kolibri

303 Konoramphen

219 Kopfauge

145 Kopffich

29 Krábbe

13 Krabbenühnliche

43 Krabbenkrebs

42 Kräufelfchnecke

99 Kragenkäfer

41.43

43. 4.9

50

269

43

177

3. 97

97

175

79

15

165

i 89

169

63

85

I13

$3 \mathrm{r} .49$

135

272

195

97. 99 . Kumal

129 Kuruku

207 Kurzbockkäfer

259 Kurzdecken

97. 99 Kurzflttige

139 Kuraflïgel

I5 Kuskus

269

.247

109

273

$25 \mathrm{r}$

305

$L$.

Laabmagen
Igo

46

42.43

17.7

109

$18 \mathrm{x}$

180

183

165

$23 \mathrm{t}$

275

63

303

192

183

29 I

$28 \mathrm{r}$

43

170

93

80

172

172

32

I50

305

49

$\log$

270

306

103

$5 \mathrm{r}$.

$23 \mathrm{I}$

198

72

56

17

24

236 
Deutfches Regifter.

Iachs

Lachsbrafleme

Lachsforelle

Lama

Lamprete.

Landfchildkröte

Landfchnecké

Langarmkrebs

Langbein

Langfulsfliege

Lang/ügel

Langhalsjungfer

Langhalskäter

Langhornbiene

Langkäfer

Langrïllel

Lang fckwänze

Langwanze

Langzungbiene

Larre

Larve

Latuchkoralle

Laubiro[cls

Laufkäfer

Laufkrabbe

Laus

Lausfliege

Leguan

Leichtfchnäb,el.

Leiopomen

Lepidopomen

Lepidopteren

Lepisma.

Leptorampher

Leptofomen

Lerche

Leuchtenträger

Leuchtkäfer

Leuchtwurm

Libellen

Lichtmotte

Lichtfcheuer

Ligularie

Linfenkrabbe

Dumeril Zool. $147^{\circ}$ Lippenfinger

143

147 Lippfirch

147 Lipphänger

127

127

25 Liftkrabbe

10 Litholia

77 Lithopleyter

165 Löffelkäfer

183 Löffellichnabel

29. Lophionoter

$283^{\prime}$ Lophys

70 Lori

245 Loris

195 Lungen

251 Lutian

229 Lygophilen

107 Lynzea.

182

263

25 I

257.

18: Madenwurm

$3 \circ 9$ Madrepore

93 Maikäfer.

195. Maki

18 Makrele

289 Makrelenhecht

${ }^{279}$ Makropteren

83 Makroramphole

50 Makrouren

I26 Malakodermen

142 Mattkäfer

270 - Mammarie

289 . Manati

46 Manakin

134 Mandibeln

.45 Mangulte

267 Marder

2II Marginella

2 II Maflala

246 Mauérbiene

275 Maulwurf

220 Maulwurfgryll

170 Maus

178 Meandrine
179

274

308

195

65

128

$8 \mathrm{c}$

9

$5 \mathrm{r}$

3

133

218

577.

N2.

303

$3 \circ 9$

$20 x$

9

124

149

70

142

182

306

205

169

27

45

188

13

13

167

103

251

I 6

$24 \mathrm{I}$

19

$3 \circ 9$ 


Medule
Merle
Meerafch
Meerbarbe
Meerbraflern
Meerengel
Merrgrundel
Meerbuhn
Meerpferd
Mrerlchildkröte
Meerlchralbe
Meerwachtel
Meerzahn
Mublkäfer
Meife
Mellicen
Melonenđqulle
Melyris
Mene
Menfch
Mefferfifch
Metallfiege
Metallkäfer
Midasfliege
Miesmulchel
Mikropter
Mikropteren
Mikroskopthier
Milbe
Miride
Miftkäfer
Möve
Mollisken
Monade
Mondlchnecke
Mooskoralle
Molchus
Molchushirfch
Motte
Mücke
Mugiloide
Mugilomore
Muräne

\begin{tabular}{|c|c|c|c|c|}
\hline $3 c 7$ & Muränoblenna & & & 153 \\
\hline 39 & Muränoide & & & 117 \\
\hline 143 & Murmelfifch & & & $15 \mathrm{I}$ \\
\hline 27 & Murmelthier & & & I9 \\
\hline 27 & Mulafreller & & & 5 \\
\hline 03. & Mutille & & & 255 \\
\hline 23 & Mycetobien & & & 22 \\
\hline 60 & Myriapoden & & & 29 \\
\hline 105 & Myrmegen & & 249. & 254 \\
\hline 77 & Myfis & & & 18 \\
\hline 71 & Myltus & & & $x 45$ \\
\hline & & & & $\checkmark$ \\
\hline & & V. & & \\
\hline 4 & NabellchwimmIch & hnecke & & 56 \\
\hline 50 & Nachtiöwen & & . & If \\
\hline 07 & Nachtlchwalbe & & & 45 \\
\hline I $\mathbf{I}$ & Nachtvögel & 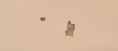 & $r^{-}$ & 34 \\
\hline 45 & Nackthälse & & & 3. \\
\hline 6 & Nackefchwimmor & & & 176 \\
\hline 107 & Nadelfifch & & & 109 \\
\hline 3 & Nägel & & & \\
\hline $\mathbf{I}$ & Nagelfilch & & & 127 \\
\hline & Nagelkäfer & - & & 209 \\
\hline 169 & Nagethiere & & & 18 \\
\hline 5 & Najade & & & 299 \\
\hline & Neuropieren & & & 342 \\
\hline 6 & Napffchnecke & & & 163 \\
\hline 289 & Narbwal & 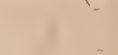 & 1 & 29 \\
\hline if & Nashorn & & T & 23 \\
\hline 201 & Nallalchnecke & & & 167 \\
\hline I & Natter & & & 89 \\
\hline 154 & Nattéfilch & $=$ & & 139 \\
\hline 307 & Nautilus & ' & r & 157 \\
\hline in & Nektopoden & & $\star$ & 196 \\
\hline 312 & Nelkenkoralle & & & $3 \circ 9$ \\
\hline 25 & Nelkenwurm & & & 303 \\
\hline 25 & Nematoceren & & 7 & 272 \\
\hline 75 & Nematouren & & & 288 \\
\hline 0 & Neotiokrypten & & 2.49 & 256 \\
\hline & Nereide & & & 297 \\
\hline & Nerite & & & 165 \\
\hline & Nerve & & & 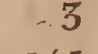 \\
\hline & Netzllioge & 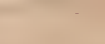 & & 245 \\
\hline
\end{tabular}


Netzkoralle Neuropteŕen Noctilion Notopter

o.

Ochs

Ochlenhacker

Odonathen

Odontoramphen-

Oedemera

Delkäfer

Ohnflofler

Obreule

Oligopode

Olivenlchn'ecke

Ornaloider

Omalorampfen

Omalyfus

Dmophron

Ompock

Ondatra

Oplichthyen

Ophidier

Op hilaure

Oplophoren

Orang.

Ornephilen.

Ornithomyzen

Orthopteren

Orykierer

Orykterop

Oryffus

Osphronemus

ofteodermen

oftrakinen

ofieoftomen

Oxyrynches:

Orole

\section{Pantopteren}

242 Pauren

Ir Panzerfifch

IIz Papazey.

Papageyfifch

Papillon

Paradiesvogel

25

43

$243 \cdot 246$

Patella

Pavian

Pedimanen

40

216

215

102

35

$1 \times 7$

167

228

35

$21 \pi$

195

$+39$

I9

152

84

87

140

9

213. 218

284

236

249. 256

2 I

259

I. 27

108

176

I 28

176. 178

Pedine

Pelikan

Penelope

Pencameriden

Pentatum.

Periftedion

Perifierien

Perlhuhn

Perljungfer

Peropteren

Petaloceren

Pecalofomen

Petermännchen

Pfahlbohrer

Pfau

Pfeiffenfich

Pferd

Pfifferkäfer

Pflanzenbeilser

Pflanzenfrefjer

Planzenfauger

Plafterkäfer

Pfriemfchnübel

Phaläne

Phalanger:

Phälanzikade

Phaskolome

Phatagin

Pholade

I75

Photophygen

Phronime

Phryne

23 Phylloltom

23 Phyralus
I 4

24

If $\mathrm{x}$

5 I

I 29

$27 \mathrm{x}$

4 .

$\times 63$

9

$\times 6$

$\$ 19$

69

55

192

$262^{\circ}$

135

52

55

245

112

200

120

I 7

169

55

$+39$

20

229

$4 x$

232

268

215

44

275

$x 7$.

269

19

2 I.

169

213. 220

I 85

$29 \mathrm{x}$

it.

29 
Deutlches Fegifter.

Plyfapoden

Phyleter

Phytathelgen

Phylophagen

Pillcnkäfer

Pilafrefler

Pilkkäfer

Pilzlchlüples

Pilzlchnacke

pimelode

Pinguin

Pinnipeder

Piunothere

Pipa

Pirol

Plagioftomer

Plantigradent

Plattaal

Plattliege

Platyformige (Käfer)

Platthorn

Plattmauikäfer

Plattfchuabel

Plattlchröter

Plattchwänze

Plattwels

Plattwurm

Plature

Plekopoden

Plekopieren

Plereorampfen

Pleurotomalchneck

Plojere

Pneumoderen

Podicere

Podopteren,

Pogonathen

Polydesme

Polyurion

Polygnathen

Polyxen

P'omacenter

Ponadafis

Pomakauth

$\begin{aligned} 268 & \text { Pomatom } \\ 29 & \text { Pompilus } \\ 268 & \text { Pongo } \\ 232 & \text { Porpita } \\ 201 & \text { Porzellana } \\ 222 & \text { Porzellanfchnecke } \\ 223 & \text { Prachtkäfer } \\ 199 & \text { Prionoceren } \\ 285 & \text { Prionoramplen } \\ 141 & \text { Promekopliden } \\ 73 & \text { Proteus } \\ 68 & \text { Plalter } \\ 181 & \text { Plok } \\ 93 & \text { Plychode } \\ 43 & \text { Pierodiplen } \\ 102 & \text { Picropoden }\end{aligned}$

I4 " Punktkoralle 309

28 i 'Punktwespe . 253

228 Puppen 187

202 Purpurichnecke $\quad 167$

227 Python 89

203

80

$14 \mathrm{I}$

299

89

122

108

40

$\mathrm{I} 67$

265

159

263

68

Quadrumanè

$Q$

Quallo

Queckfilberfifch

Queermïuler

145

102

Rabe

Hacen

r/I Racke

293 Radiarien

ro5 Räderthierchen

$R$.

292 Ralle

293 Ramphokopien

135 Rampholiten

135 Ramploftenen

135 Ramphus 
Randwanze

Raphiorampher

Raubfiege

Raubkäter

Raubvögel

Rauchhaarfliege

Raubkäfer

Rauhwespe

Raupen

Rebhubn

Regenpfeiffer

Regenwurm

Reiher

Reilskäfer

Reizkäfer

Reptiliez

Rhinapleren

Rhinobate

Rhinoceren

Rhinolophe

Rhinoftomen

Rhinozeros

Rhombus

'Riemenwurm

Rindenkäfer

Ringellchlange

Ritter

Rochen

Röhrenkoralles

Röhrenmundfifch

Ropaloceren

Rückenfchwimmer

Rückgrath

Rückenwespe

Ruderfedern

Ruderfufse

Ruderkrabbe

Ruderwanze"

Rïllel

Rüffelhürner

Rüfleljungfer

Rüflelkäfer

Rüfelwespe

Rund folwänze

Ruxdvrurm
263

44

279

199

52

283

209

257

187. $27 \mathrm{I}$

55

65

299

62

195

215

74

288

105

226

Ix

262

23

I 5

302

223. 229

87

129

In 3

$3 \circ 9$

1.07

270

265

3

257

5 I

196

$18 x$

265

260

226

245

227

253

82

303 s.

Samenkäfer 227

Säbelheufchrecke $24 \mathrm{r}$

Säbellchuäbler " $65.1 \%$

Sägeluörner

202

$23 \%$

183

$13 x$

68

2.58

259

45

95

115

219

307

195

$\$ 97$

9

अ 7

33

$2: 9$

278

Saugefliegen

Säugthiere

Saurier

Savia

Schaaf

Schaalbauch

Schabe

Scharrkäfer

Scharrmaus

Schattenkäfer

Schaufelkrebs

Schaumzikade

Scheibenkäfer

Scheibenfchnecke

Scheibenwurm

Scheidenmulchel

Schellfilch

Schenkelwespe

Schiffshalter

Schiffkäfer

Schilderaflel

Schiddfifch 


\section{Dentfches Regifter}

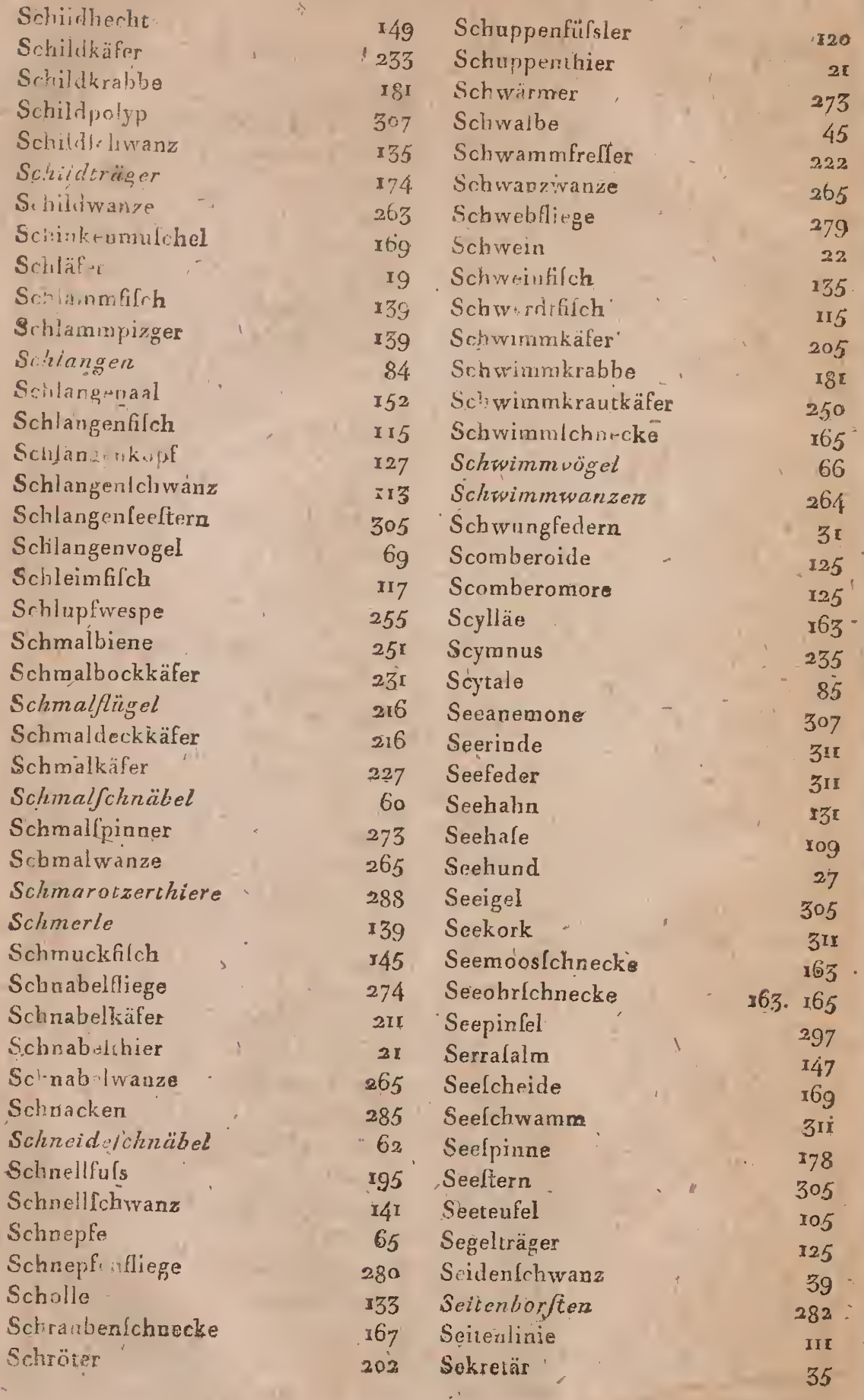




\section{Selene}

Sepie

Seps

Siagonober

Sichelwespe

Sigaret

Silberfich

Silbermund wespe

Singuägel

Singzikade

Siphonobranchien

Siphonoftomen

\section{Siren}

Sitaris

Skalataria

Skleroftomen

Skolopendex

Skorpion:

Sogofifch

Solenoftom

Solipeden

Spanner

Spargelkäfer

Spatange

Spatelreiher

Specht

Spechtmeile

Speckkäfer

Sperbereule

Sphenaramphen

Spiegelfilch

Spindelhürner

Spinne

Spinnenfifch

Spinner

Spirularier

Spitzàfter

Spitzmaulkäfer

Spitzmaus

Spitzfohnautzen

SpitzIchwariz

Splintkäfer

Spondylis

Sporntlügel
55 Springkäfer

2007

156 Springlchwan

289

.83 Squatine -

148 Staar

255 Stachelbauch

265 Stachelliege

145 Stachelfuls

253 Stachelkäfer

36. Stachelkamm

267. Stachelkopf

x65. Stachelkoralle

I38 Stachelkrebs

95 Stachelnacken

216 Stachelrücken

$\times 65$ Stacbelfchnecté

278 Stachellchwanz

293 Stachellchwein

29I 'Stechfiege

132 - Stegopteren

- r07. 139 Steinbohrer

26. Steinerzeuger

275 Steilsfuls

233 Steinkoralls

305 Stellio

65 Stemmaten

49 Stenopteren

46 Stereoceren

205 Sternkoralle

35 Sternoptygen

48 Sternoxyter

135 Sternfeher

272 Sternum

29 Steuerfeder

IIy Stichling

2,273 Stielauge

I57 Stielhornfliege

205 Srielíchwanz

227 Stielträger

35 Stink

178 Stinktbier

113 Stint ' ... 147

229 Sirnfchnäbel $\quad 262$

225 Stür $\quad 105$

Storch $\ldots 63$ 
Deutfches Regifter.

Strahlenthiere

Strandläufer

Strandilchlüpfer

Strauls

Sturmvogel

Stutzkäfer

Stutzkopf

Sumpfoügel

Synodus

T.

Tachydrom

Tagenia

Tagfliege

Tanagra

Tänioide

Tantalus

Tanzfliege

Tapir

Tapezierbiene

Tardigraden

Tarfer

Taulienartige

Tauchente

Taucherhuhn

Taucherkäfer

Taufendfiifse

Teleobranchier

Termit

Tenreck

Terebratel

Teredylén

Tetanocerus

Tietratom

Tetrameriden

Thaliter

Thereve

'Thier'

Thurmheulchrecken

Thurmfchwalbe

Todtengräbion

Tölpel
304 Trachéen.

63 Trachinot

I99 Trachy's

57 Trappe

7 Trauerfliege!

207 Trauerkäfer

129 Trematopnćers

58 Trimeriden

549 Tripteronor

Triton

Tritonie

Tropikvogel

Trolk

83 Trupial

221 Truthahn

247 Tuckan

173. 184

125

207

55

281

$22 \mathrm{I}$

100.

234.

$\checkmark 39$

95

163

69

307

43

55

$5 \mathrm{r}$

39 Tuju . 57

$12 \mathrm{r}$ Tupinambis. $8 \mathrm{r}$

63 , Turako 5 I

279 Turbinellalchnecke $\quad \mathbf{6 7}$

23 Tuten[chnecke 167

$25 \mathrm{r}$

22

9

53

69

73

197

292

106

245

$\times 5$

$x_{7} \mathbf{r}$

208

283

223

224

185

283

2

740

45

205
U.

Uferkäfer

Uferuögel

Umberfich

Untörmige

Ungefchwänzte "(Batrachier)

Unterfulsglieder.

Upis

Urocere

Urodelen

Uroplate

Uropodere

Uroprifter

195

58

133

238

$9^{2}$

igr

$2 \times 9$

$2: 59$

94.

$8 \mathrm{r}$

72

72

$\mathbf{6 5}$

Vampyr, I , II

Venusmulchel 
Veretille

Verkehrt\{chnäb

Verwüfter

Vibrio

Vielfinger

Vielllolier

Vielfuls

Vierauge -

Vierhöner

Viper

Vögè

Vogellaus

Vogelfpinne

Vollschnäbel
Wachtel

Waffenfliege

Waffenzikade

Waldbewohner

Waldhuhn

Wallerfich

Wallfilch

Wallrors

Walzenförmige

Walzenkäfer

Walzénfchnecke

Wandelthier

Wanderkrabbe

Wandervägel

Wanze

Warzenichlange

Wafferaflel

Wadferfliegen

Wafferhuhn

Wafferjungfer

Wallerkäfer

Wafferlaus

Waflernymphe

Wallerphanzenkäfer

Wallerlalamandef
3II Wafferfçhlange

$7^{\mathrm{T}}$ Walferfpinne $29 \mathrm{r}$

245 Wallerwanze $\quad 265$

307 Wedelkäfer 209

143 Weglchnecke $\quad 165$

\$49 Weichflïgel 210

293 Weichkäfer, 2 Ir

I39 Weichlchwanzkrebs $\quad 183$

292 W.eihe 35

89 Wels 4 I I

30 Wendehals, , 49

289 Wespe '25I

29I Wespenbiene $35 \mathrm{I}$

40 Wickler 375

Wiedehopf 47

Wiederküuer

Wirrhornkäfer $\quad 215$

Wombat 1 i

Würger 38

55 IVïrmer 294

28r' 'Wurmfich ir3

267 Wurmfchlange $\quad .86$

218 Wurzelmaul 307

55

139

29

27

228

203 Xylophagen .

167 Xyfter 230

145

$18 i$

36

263

$x$

87

293 Zähne

284

Zackenzahn

247 Zahrilose

${ }_{97}$ Zahnfchnübel

293 Zangenafter

247 Zangenbockkäfer 237

332 , 23r

$95 \cdot$ Zibenfowanze. 236

9 
330

Zibeththier

Ziege

Ziegenmelker

Zitteraal

Zitterblale

Zitterroclien

Zitterwels

Zoathelger

Zoe
Deutfches Regifter.

$\begin{array}{rlr}13 & \text { Zonitis } & 215 \\ 25 & \text { Zoophytat } & 300 \\ 45 & \text { Zophofe } & 221 \\ 113 & \text { Zuckerthier } & 269 \\ 305 & \text { Zungenwurm } & 303 \\ 102 & \text { Zweyauge } & 175 \\ 14 \mathrm{n} \text { Zweyfchaalen } & 176 \\ 264 & \text { Zwergfell } & 5 \\ 177 & \text { Zwirnwurm } & 303\end{array}$




\section{Lateinifches Regifter.}

Acanthia

Acanthínion

Acanthopodus

Acanthurus

Acarus

Accipitres

Acephala

Acbeta

Achirus.

Acipenfer

Acrochordus

Acridium

Actinia

Adelobranchiasa

Agama

Agathidium

Ageneios

Agrion

Akis

Alauda

Albunaea

Alça

Alcedo

Alcyonium

Alectrides

Alipedes

Altica

Alucita

Alurnus

Amia

Ammodytés

Ampelis

Amphibia

$A$

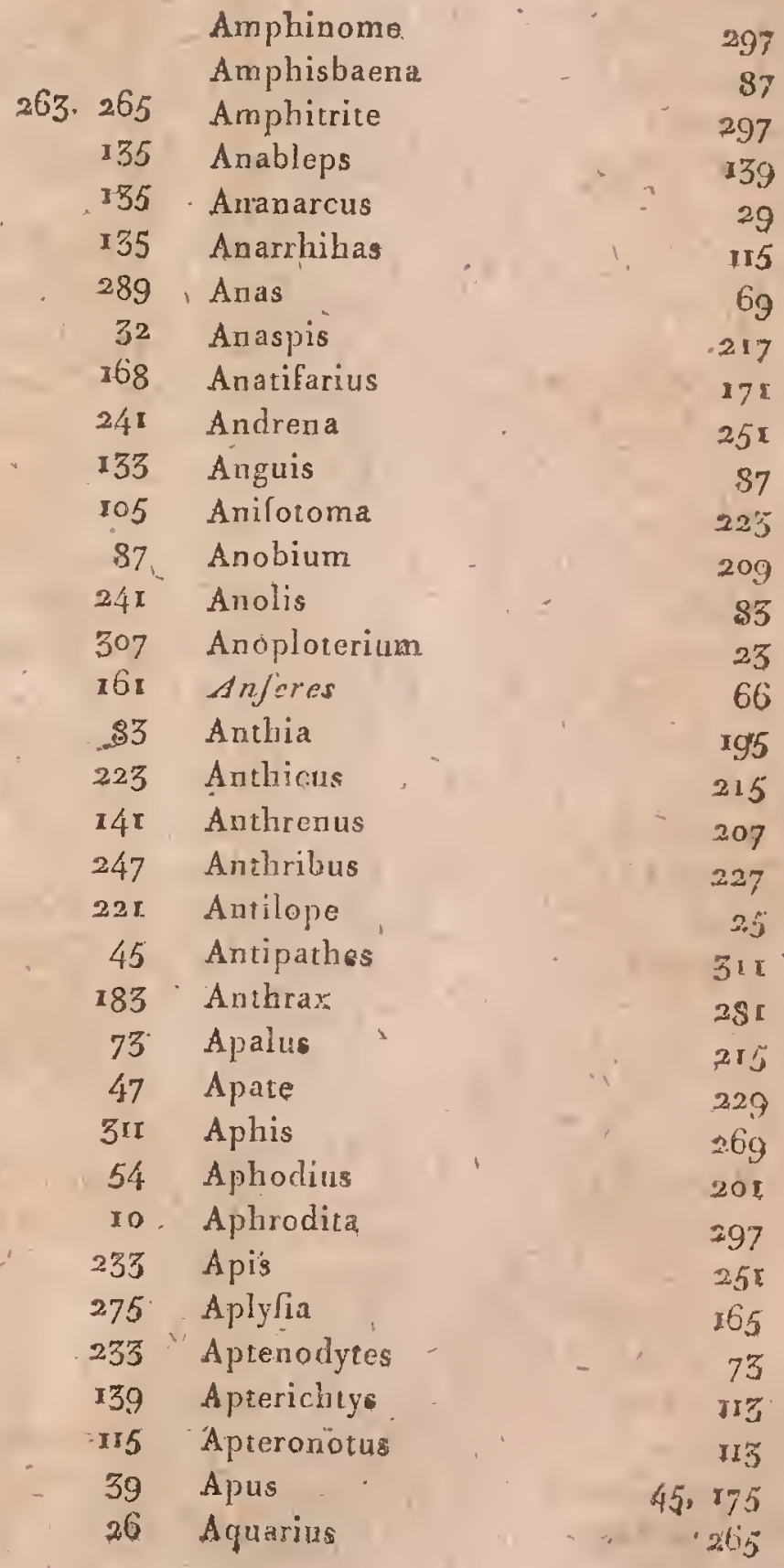

Amphinome.

97

87

97

39

29

$\mathrm{I} 5$

69

217

78

87

225

09

83

23

66

195

215

207

227

2.5

I

S I

215

229

69

$25 \mathrm{r}$

$-65$

73

$1 \%$

113

265 
Lateinilches Regifter.

Aquila
Ara
Aranea
Arctomys
Ardea
Arenicola
Argentina
Argonautarius
Argulus
Argyreiofus
Armadillo
Arvicola
Ascalaphus
Ascaris
Ascidia
Afilus
Afraca
Aspidophoroidos
Aspilurus
Afiacoidea
Aftacus
Afterias
Aftea
Aftur
Ateuchus
Atherina
Atopa
Attelabus
Auloftoma
Aves
Avocetta

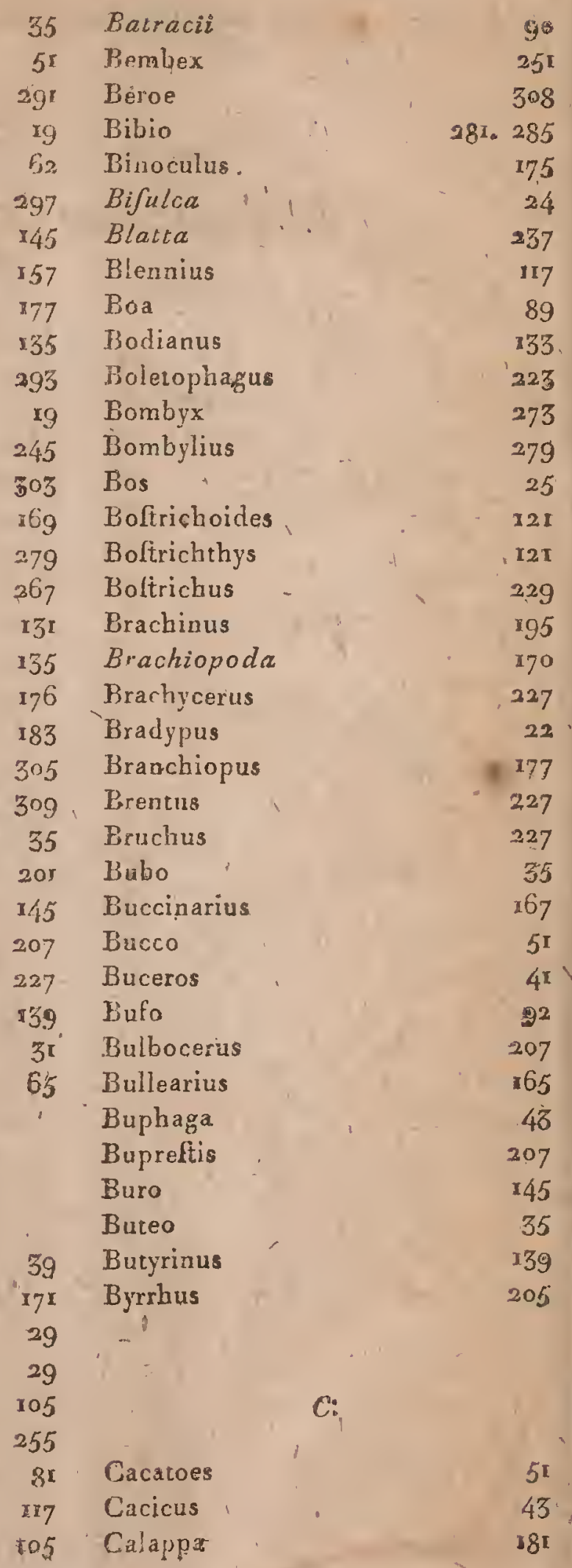


Callidium

Calliomorus.

Callionymus

Callitrix.

Callaeas

Callorhincus

Calopus

Caloloma

Calygus

Camaeleo

Camelo-pardalis

Camelus

Cancer

Canceriformes

Cancroma.

Canis

Cantharis

Capra

Caprimulgus

Capros

Carábus

Caranx

Caranxomerus

Cardiarius

Cariophyllia

Caryophyllaneus

Callida

Calfidulus

Caluarius

Cataphractus

Catodon

Caudati

Caudivolvulus

Cavia

Cebrio

Cebus

Cenogalter

Centranodor

Centriscus

- Centrolophus

Centronotus

Centropodus

Centropoma

CSephalacanthú
23 Cephalopoda

I 7 Cephalus

17 Cepola

9 Cerambyx

43 - Ceratoplatus

I05 Cercopis

219 Cercopithecus

195 Ceria

175 Cerochetus

83 Cerocoma

25 Cervus

25 Certhia

179. 18I Cete, Ceti

180 Cetonia

65 Ceyx

13 Chalcides

215 Chalcis

25 Chauos'

45 Characinus

135. Charadrius

195 Chelifer

I25 Cheiliuus

125 Chelio

6 G Cheilodactylus

309 Cheilodipterus

303

233

305

57

I4I

, 29

94.

15

19

207

9

283

$\mathrm{r} 4 \mathrm{r}$

107

129

125

125

133

825
156

109

I2I

$.23 \mathrm{i}$

285

267

9

281

283

215

25

47

28

20 I

283

83

257

143

147

65

$29 x$

127

$\times 27$

143

137

76

$7^{6}$

76

269

135

135

$\times 63$

105

19

233

279

135

II 7

267

267

195

63

265

143 
Lateinifches Regifter.

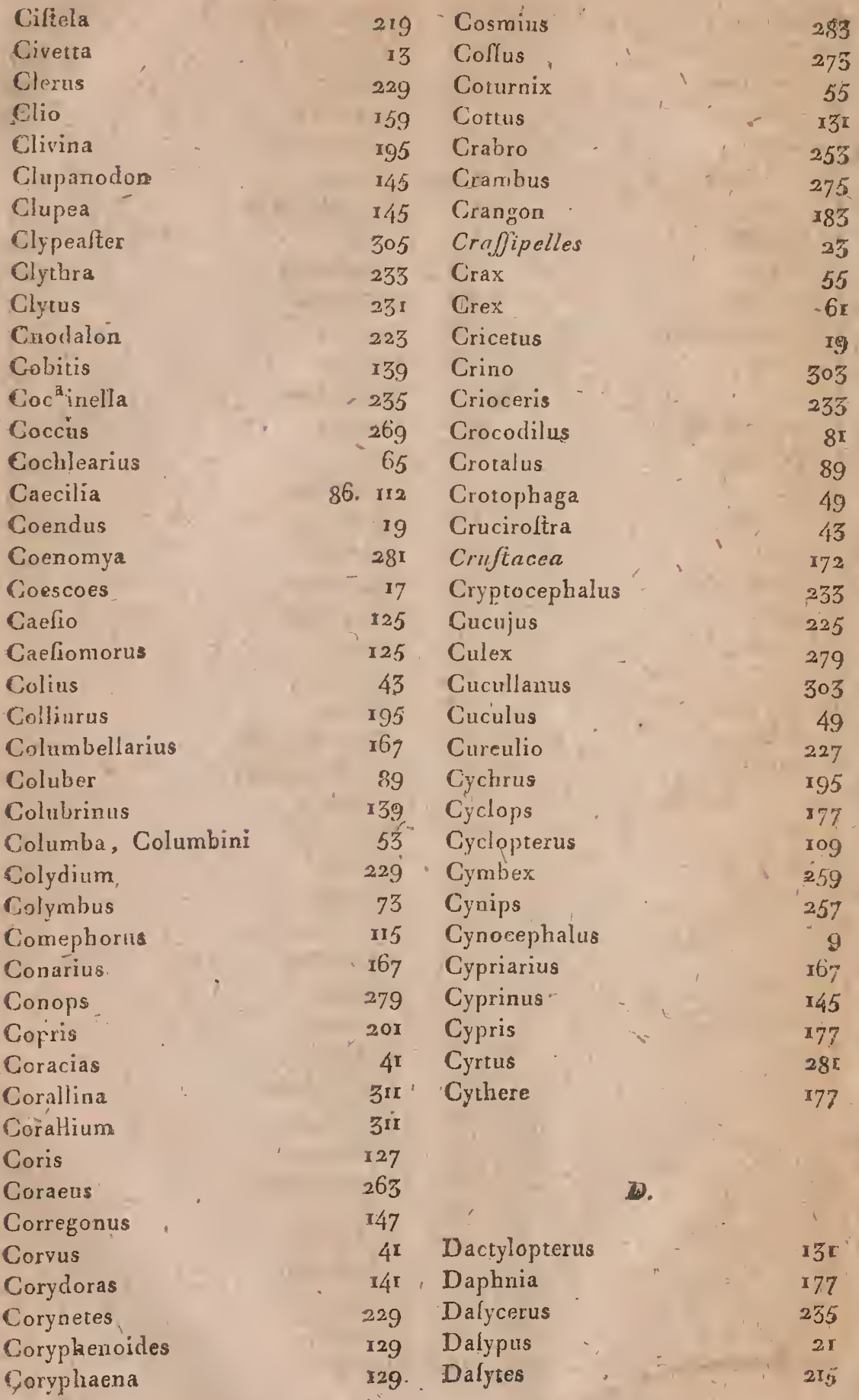


Lateinifches Regifter.

Dalyurus:

Delphax

Delphinapterws

Delphinus

Dentálium

Dermobranchiata

Diaperis

Diapria

Didelphis

Didus

Diodon

Diomedea

Diplolepis

Dipterodon

Dolichopus

Donacia"

Donaciarius

Doras

Dorippe

Doris

Derfuarius

Dorylus

Draco

Dracoena

Drilus

Dromia

Drypta.

Dugong

Dytiscus

$E$

\section{Ecaudati}

Echeneis

Echidna

Echingmya

Echinoneus

Echinorinchus

Echinus

Edentati, Edentuli

Elater

Elephantus

Elephas

17 Elophorus

267 Elops

29 Emarginatiroftres

29 Enberiza

296 Empis

161 Emys

223 Endomychus

257 'Enoplofis

17 Entomoftraca

rag Eques

7I" Equus

257 Erinaceus

127 Erix

283 Erodius

233 Erotylus

169 Efchara.

r4x Elox

I79 Eucera

163 Eulophus

145 Eumorphus

255 Eurychora

83 - Evania

81 Exocoetus

211

$18 \mathrm{I}$

195

27

97

II
57 Ephemera

205

149

39

45

279

77.

235

135

172

247

129

27

15

89

225

233

509

149

255

257

235

$22 x$

255

145

\section{5}

303

Falciola

Felis

Fiber

Filaria

92 Firola

123 Fiftularia

21 Flata

283 Fluftra

305 Foenus

303 Fondulus

305 Forbicina

20 Forficula

207 Formica

23 Formicivori

23 . Fregata 
Lateinilches Regifter.

Fringiila

Fulgora

Fulica

Fungia

$\begin{aligned} 42 & \text { Gymnomuroena } \\ 267 & \text { Gymnota } \\ 60 & \text { Gymnothorax } \\ 309 & \text { Gymnotus } \\ & \text { Gypoetus } \\ & \text { Gyrinus }\end{aligned}$

$\times 55$

I77

$\times 53$

113

35

197.

G.

Gadus

Galago

II7

Galatoea

Galbula

Galeodes

Galerites

Galeruca

Gallus

Gallinae

Gallinacac

Gummarus

Gafteropleucus

Gafterofteus

Gaftrobranchus

Gaftropoda

Gecko

9

183 Haliotidarius

II.

49

$29 \mathrm{r}$

- 305

233

135

52

54

185

145

125

ror

16 I

Haliotis

165

Haliplus

Helix

Helodes

Hemerobius

Hemipteronotus

163

з 97

$\times 65$

233

245

129

$18 x$

275

Hepialus

27 I

Hefperia

89

Hecerodermi

$27 \mathrm{t}$

83

Geotrupes

Gerris

Glaucopis

Gliphyfodon

Glomeris

Gobiefox

Gobio

Gobioides

Gobiomoroides

Gobiomorus.

Gompholus

Gorgonia.

Gordius

Graculal

Grallae

Graplus

Grus

Gryllo-taipa

Gryllus

Gymnetrus

20

263

43

Heteropterus

127

183

279

23

285

135 . Hirudo 299

293 Hirundo , 45

$33^{1}$ Hilpa . . 233

323 Hifter . . 207

123 Hoematopus 6r

123 Holacanthus + 135

123 Holocentrus $\quad 133$

127 Hologymnos 127

3r Holothuria 305

299 Homo *. 6

$4 \pi$ Horia $12 \times$

58 Hyalaea " $\quad$ I59

Ig: Hyans - 63

63 Hydatis 303

$24 \mathrm{r}$ Hydrachna , 197

24 Hydrochoerus .' I9

I.2 Hydrometra 265 
Lateinifches Regifter.

Eydrargyrus

Hydroinys

Hydrophilus

Hydrophis

Hyla

Iylaeus

Hysena

Hyperodon

Hyplyydrus

Hypoleon

Hyponkloeus

Hypoftomus

Hyrax

Hyltrix

I.

Ichxยาน

Iguana

Indri

Infecta

Ifis

1fiophorus

Iulus

$\widetilde{K}$

Kangurus

Kurtus

L.

Labrus

Lacerta

Lagomys

Lagria"

Lamia

Lampyris .

Lanius

Larra

Larus

Laticauda

- Dumeril Zool.
145 Leiognatbus - $\quad$ \$99

19 Lema , 233

205 Lemur 9

87 Lepadogafterus $\quad$ Iog

93 Lepidopus - " 12 ז

25 L Lepilacanthus 1, $\quad 225$

13 Lepisma. " 289

29 Lepifolieus , $\quad \mathbf{4 9}$

897 Leptoceplialus , $\mathbf{x}$

28 r Leptura, - $23 \pi$

223 Lepus i -19

\$4r Lefieva 99

23 Lethrus 207

19 Lencoplis $257^{\prime}$

Leucolia , $\quad 178$

Libellula 247

Ligula - $30 \%$

Ligularius . $17 \%$

x.. 255 Limax , , 165

83 Limulus - 175

9 Linguatula 87 . 303

3ni Litholia, ' 275

125 Loculta $24 \pi$

293 , Loligo $\$ 57$

293 Lophius 105

Lophyrus 35

Lori 9

Loricaria _ $\quad 44 \pi$

Ig Luxia 45

II 7 Lucanus, 205

Lumbricus $\quad 2.93$

I.uperus : $\quad 233$

Lutjanus, . $\$ 33$

Lutris

$\$ 27$ Lyctus

13

229

21

263

177

$23 \mathrm{r}$ Lytta 215

2 II

$39+M$

257

7I Macrognatus $\quad$ I5

89 Macropteronotus I/4 
Lateinifches Regifter.

Macroramphosits

Nacrorhycus

Madrepora

Maja

Malachius

Malapterurus. Ma nu alia

Mammaria

Maminata

'Manatus

Manis

Manticora

Mantis

Marginellarius

Marfupiati

Malaris

Matuta

Meandrina

Medula

Megalops

Meleagris

Mellinus

Melolontha

Melyris

Membracis

Mené

Mephitis

Meretrix

Mergus

Merops

Merula

Micropterus

Midas

Millepora

Miris

Misgurnus

Mol asca

MoLorcnus

Momotus

Monodactylus

Monodontarius

Monopterus

Mordella

Mormyrus

\begin{tabular}{|c|c|c|}
\hline$\pi 4 x$ & Molchus & \\
\hline 107 & Motacilla & \\
\hline 309 & - Mugil & \\
\hline 179 & Mugiloides & \\
\hline 2 II & Mugilomorus & \\
\hline 141 & Mulio & \\
\hline 5 & Mílus & \\
\hline+69 & Muraena & \\
\hline .5 & Muraenoblenniu & \\
\hline 27 & Muraenoïdes & \\
\hline $2 x$ & Muraenophis & \\
\hline 195 & Muriciarius & \\
\hline 239 & Mlus & \\
\hline 167 & Musca & \\
\hline 17 & Muscicapa & \\
\hline $25 \mathrm{I}$ & Mulophaga & \\
\hline ISI & Muffela & \\
\hline 309 & Mutilla & \\
\hline 307 & Myarius & \\
\hline$\$ 49$ & Mycteria & \\
\hline 55 & Mygale & \\
\hline .253 & Mylabris & \\
\hline $20 I$ & Myopa & \\
\hline $21 \mathrm{I}$ & Myoxus & \\
\hline 267 & Myrrnecopbaga & \\
\hline 145 & Myrmeleon & \\
\hline 13 & Myjis & \\
\hline $\mathbf{1 6 9}$ & Myftus & \\
\hline 69 & $\because$ & \\
\hline 47 & t & \\
\hline 39 & & \\
\hline 133 & & \\
\hline$-28 \mathrm{I}$ & Nais & s \\
\hline $3 \circ 9$ & Narwhalus & \\
\hline 265 & Naflarius & \\
\hline 139 & Nafua & \\
\hline 155 & Natarius & \\
\hline $23 I$ & Naticarius & \\
\hline $4 \mathbf{r}$ & Naucoris & \\
\hline$\$ 27$ & Necrobia & . \\
\hline 165 & Necrophorus & \\
\hline 113 & Necyrlalis & \\
\hline 277 & Nemotelus & \\
\hline 51 & Nepa & 。 \\
\hline
\end{tabular}

25

45

143

143

143

283

127

115

152

I 7

153

167

' 9

283

39

5 工

13

255

169

63

29 I

214. 227

279

19

2 I

245

185

145

IN.

299.

29

167

15

157

165

265

229

205

$216,23 \mathrm{r}$

$28 \mathrm{I}$

265 
Lateinifches Regifter.

Nereis

Neritarius

Nitidula

Noctilio

Noctua

Nociurni

Nomada

Nothiophilus

Notonecta.

Notopterus

Notoxus

Nullipora

Numenius

- Numida

$\begin{array}{rlr}297 & \text { Osphronemus } & 127 \\ 165 & \text { Oftorbincus } & 129 \\ 205 & \text { Oftracarius _ } & 169 \\ 11 & \text { Oftracion } & 109 \\ 275 & \text { Oftracoda } & 177 \\ 35, & \text { Otis } & 55 \\ 251 & \text { Oris } & 25 \\ 195 & \text { Oroides } & 109 \\ 265 & \text { Oxiporus } & 199 \\ 115- & \text { Oxyltoma } & 227 \\ 215 & \text { Ozolus } & 175 \\ 309 & & \\ 65 & & \end{array}$

o.

Octopus

Oedemera

Oeolidia

Oligopodus

Olivarius

Omalylus

-Ombellularia

Ompólk

Oncotion

Ondatra-

Onilcus.

Opatrum

Ophicephalus

Ophidium

Ophion

Ophifaurus

Ophifurus

Opliurus

Orbicularius

Oriolus

Orithya

Ornilionincus

Ortherincus

Orjcteropus

Oryffus

Osmerus

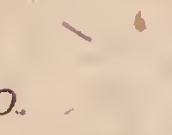

Pagurus

185

Palemori

183

Palinurus

183

157 Paloeotherium $\quad 23$

217 Panorpa

2.15

rb5 Papilio

$27 . \mathrm{I}$

17 Papio'

I67 Paradifea

9

2i Parnopea ' ' 253

3 I Parrus

139 Parra

2.05

$60 \mathrm{r}$

109 - Parus

45

19 Pallalus

203 Paferes

203

137

219 Patellarius $\quad 165$

127 Pavo

15 Pavona

255 Pecora

87 I'ediculus

rr3 Pedinus

305. Pegalus

17r Pelecanus

43 Pélits

179 Peneus

21 Penelope

55

309

34

289

219

105

69

205

183

55

47 Penicillus

297

2I. Penmatula

- 3 i

259 Pentatoma 263

147 Peramele

17 
Perca

Periltedion

Perla

Petromizon

Phaeton

Phalacrocorax

Phalaena

Phalánula

Phalangilta,

Phalangium

Phascolomys

Phafianus

Phasma

Philanthus

Phoca

Phoenicopterus

Pholadiarius

Phronima

Jhryganea

Phryous

Phyllidiá

Phyllium

Phylloltome

Plyylalus

Phyleterus

Phylodes

Phytotoma

Picae

Picus

Pimelia.

Pimelodes

Pinnarius

Pinnata

Pinnotheres

Pipa

Pipre

Pifces

Pitbecus

Planaria

Planicaudate

P]anorbarius

Platalea

Platurus

Platycerus

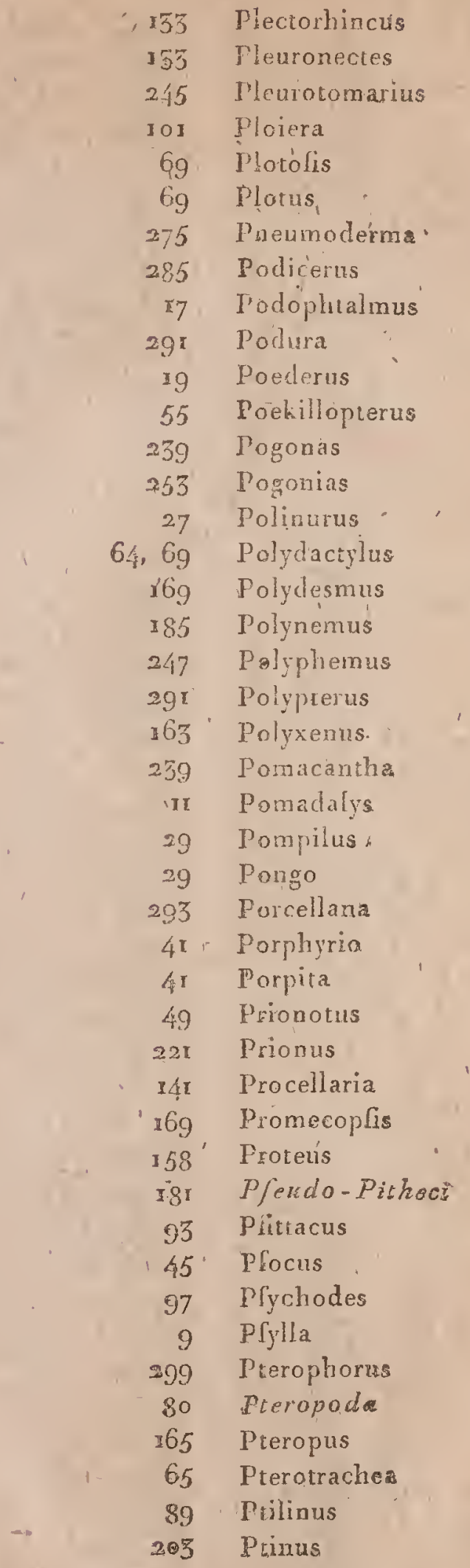

127

133

$+67$

265

$14 \mathrm{I}$

69

I 59

263

$18 \mathrm{I}$

289

199

269

Iq I

127

I 83

I4́3

293

$\times 43$

177

149

393

135

135

257

9

I $\mathrm{S}$

6 I

307

13 t

$23 \mathrm{I}$

$7 x$

267

95

8

$5 \mathrm{I}$

245

285

269

275

159

I I

159

209

209 
Lateinifches Regifter.

341

Pulex

Purpurarius

Pyralis

Pyrochroa

$\begin{aligned} 299 & \text { Salmo } \\ 167 & \text { Salpa } \\ 275 & \text { Saperda } \\ 219 & \text { Sarcoramphus } \\ & \text { Sargus } \\ & \text { Sarrotrium } \\ & \text { Saurii } \\ 8 & \text { Scalatarius } \\ & \text { Scanfores } \\ & \text { Scaphidium } \\ & \text { Scarabaeus } \\ 103 & \text { Scarites } \\ 6 \mathrm{r} & \text { Scarus } \\ 51 & \text { Scathople } \\ 227 & \text { Scaurus } \\ 93 & \text { Sciuena } \\ 265 & \text { Scincus } \\ 179 & \text { Sciurus } \\ 245 & \text { Scolex }\end{aligned}$

147

169

$23 \mathrm{I}$

33

283

$Q$.

219

178

165

48

205

201

195

129

285

$22 x$

133

83

19

303

65. 71. Scolia, 253

, 265 Scolopax .. . 65

74 Scolopendrar 293

308 Scolytus 229

280 Scomber $\quad 125$

230 Scomberoides 125

57 Scomberomorus $\quad 125$

279 Scombrefox 149

103. Scorpio 298

23 Scorpaena 131

xI Scutellera $\quad 265$

227 Scutigera • 293

7 Scyllarus:, 183

307 Scyllaea : 163

II5 Scymnus $\quad 235$

227 Scytale $\quad 89$

289 Secretarius " 55.

217 Selene $\mathbf{1 3 5}$

I9 Semblis " $\quad 245$

25 Sepidium $22 \mathrm{I}$

Serpentarime $\quad 35$

Serpentes * $\$ 4$

Serpita $\quad 297$

297 Serrafalmo $\quad 347$

95 Sorratirofires 40

Sabella

Salamandra

\& 
Lateinifches Regifter.

Serropalpus

Sertularia

Selia

Sicus

Sigara

Sigaretarius

Silpha

Silurus

Simiae

Siren

Sirex

Sitaris

Sitta

Sepia

Solenarius

Solenoftoma

Solipedes

Solpuga

Sorex

Spalax

Sparus

Spatangus

Spatularia

Sphneridium

Sphagehranchus

spheroides

Sphex

Sphirix

Spliyraena

Spirorbis

Spirularius

Spondylis

Sponyia

Squalus

Squatina

Squilla

Staphylinus

Stellio

Stenus

Sterma

Sternoptyx

Stolephorus

Stomoxys

Stratiomy'

219 Sirix

3r Stromateus

I 5

273 Sitrongylus

503

$28 \mathrm{I}$, Srruthio.

57

26, Sturnus

45

165 Sula

69

205 Surnia

35

23

4I Sus

$\times 5 \mathrm{r}$

8 Stylephorus

$\log$

95 Syngnathus

203

259 Synodendron

149.

217 Synodus

47

157

169

107. 139

26

Tabanus

279

29 Tachypus -

195

14 L

15 Tachyfurus

503

19 Taenia

T.

127 Taenianotus

129. 133

305 Taenioides

12 I

105 Tagenia

$22 \mathrm{r}$

205 Talpa . . 5

153 Tanagra 39

Iog Tantalus 63

257 Tapirus $\quad 23$

273 Tardigradi 23

149 Tarlius 9

297 Taxus. 15

157 Telephorus 211

235 Tellinarius _ $\quad 169$

3 II Tenebrio $2 \times 9$

103 Tentacularia -... 303

103 Tenthredo 259

185 , Terebella $\quad 297$

rg9 Terebrarius $\quad \mathbf{6 7}$

83 Terebratularius I7

199 Teredarius $\quad \mathbf{1 6 9}$

7 Tereticaudaii 33

15 I T'ermes 245

145 Teftudo $\therefore, \ldots 7$

279 Tetanocerus 1 283

28 I Tetrao 55 
Tetraodou

Tetratoma

Tettigonia

Thalaflema

Thalia.

Thalitrus

Thereva

Throscus

'Thyreocoris

Tillus

Tinea

Tiphia

Tipula

Todus

Torda

Torpedo

Turaco

'Trachinotus

Trarhinus

Trachys

Trichecus

rrichocephalus

Trichodes

Tridactylus

Trichurus

'Trichius'

Tricopodus.

Trigla

Tringa

Tripteronotus

Triton

Tritonia

Trochiarius

Trochilus

Trogon

Trogoflita

Trombidium

Truxalis =

Tubioora

Tupinambis

Turbinarius.

Turbinellarius

Tubilpirantia

Turdus
$U$.

109

223

267 Unibranchaperturus

299 Upis

- 69 Upupa

185 Uranoscopue

283 Uria

207. Urocerus

263 Uroplatus

209 Urfus.

553

$2 \times 9$

47

117

73

259

$8 \mathbf{I}$

15

165

169

$31 \mathrm{I}$

251

$1 \mathrm{r}$

89

$\times 67$

33

W.

Wombaius

I 7

127

$13 \mathrm{r}$

65

139

95

163

I 65

47

$5 \mathrm{I}$

229

$29 \mathrm{I}$

$24 \mathrm{r}$

309

8 r. Zeus

165 Zoe

I67. Zonitis

$16 i$ Zophofis

39 Zygaena
X.

$\times 15$

145

$\boldsymbol{Y}$

49

2.

135

177

215

225

273 
- Verbelferungen einiger Druckfehler.

Seite 8 fehlt auf der VIr. Tabell folgende Ueberfchif : Säugthiere mic Nïgeln, ohne Ecksühne.

- r2g, Zeile 2 von oben, ftatt Ofteofomen, lefe man Qfieofiomen.

- 133. Zeile 7 von unten, muls liat des Wortes - find geleizt werden: haben die Kiemendeckel.

- 154. Zeile 14 von unten ftatt an der Spicze, 1. an die Spitze.

- i57, Zeile 9 und 13 von oben, muls es ftatt diefer Kürper heilsen diefer.Tnochen.

- 157, Zéile 23,ven oben, Liatt 8 Fïjse: lele man 8 als Fil fse dieneride Tentakelu.

- 173 bis 150 . muls es in der Ueberlchrift fint, Entomoftrakinen, heifsen Alinkoiklex.

- r94, Tabollé 120 , muls es bey der erfen Abtheilung, flatt fo lang als die Fligraldecken: heilsen fo breit als dic Flügeldrcken: Kopf.

- 229. Zeile 8 von untan fetze man vor ips noch den deutfolen Namen Glactkiifer. 


QL Duméril, André Marie
$351 \quad$ Constant, 1774-1860.
D88 C. Dumeril's
Rept. Analytische Zoologie. 
SMITHSONIAN INSTITUTION LIBRARIES

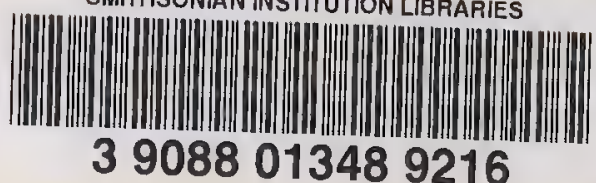

